\title{
Fluorogenic Enzyme-Triggered Domino Reactions Producing Quinoxalin-2(1H)-one-based Heterocycles
}

Garance Dejouy, ${ }^{\dagger}, \dagger$ Kévin Renault, ${ }^{*}, \dagger$ Quentin Bonnin, ${ }^{\dagger}$ Arnaud Chevalier, Cédric Michaudet, ${ }^{\dagger}$ Michel Picquet,$\dagger$ Ibai E. Valverde, ${ }^{\dagger}$ and Anthony Romieu ${ }^{*}, \dagger$

†Institut de Chimie Moléculaire de l'Université de Bourgogne, UMR 6302, CNRS, Univ. Bourgogne Franche-Comté, 9, Avenue Alain Savary, 21000, Dijon, France

IInstitut de Chimie des Substances Naturelles, CNRS UPR 2301, Université Paris-Saclay, 1, Avenue de la Terrasse, 91198 Gif-sur-Yvette, France

E-mail: kevin.renault@u-bourgogne.fror anthony.romieu@u-bourgogne.fr

$¥$ These authors contributed equally to this work 


\section{Table of Contents}

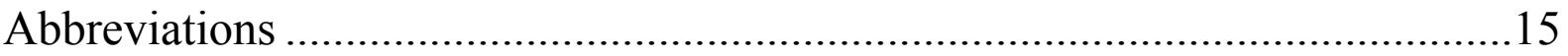

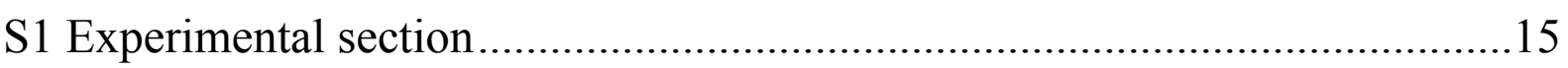

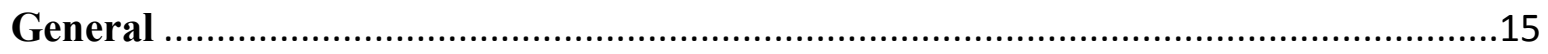

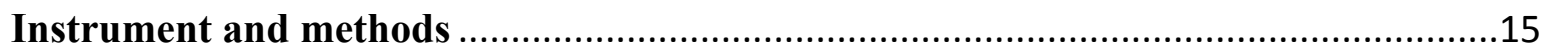

High-performance liquid chromatography separations .......................................18

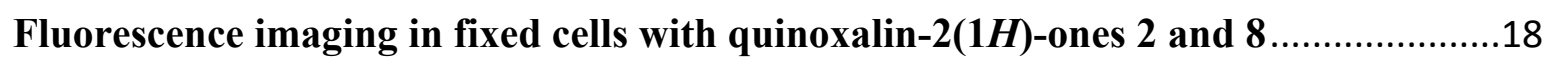

In vitro activation of "covalent-assembly" type probes 12-18 by PGA - experimental

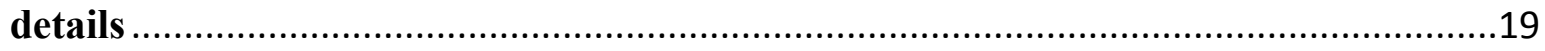

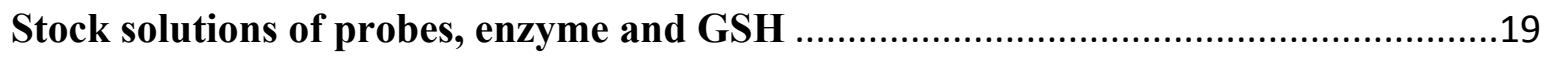

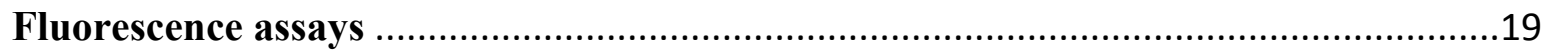

RP-HPLC-fluorescence and RP-HPLC-MS (full scan and SIM modes) analyses .......19

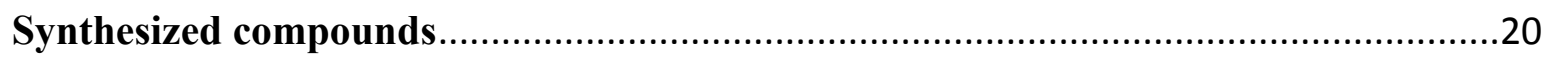

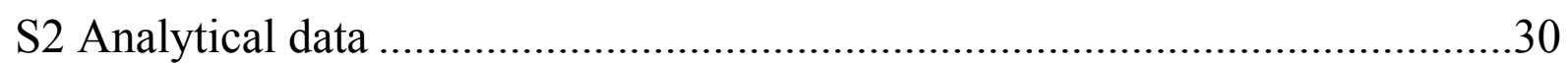

Fig. S1 - ${ }^{77}$ Se NMR spectrum of 2-acetylselenophene in $\mathrm{CDCl}_{3}(114.5 \mathrm{MHz})$.....................30

Fig. S2 - ESI- mass spectrum (high resolution) of $\alpha$-oxo-2-selenopheneacetic acid ............30

Fig. S3 - RP-HPLC elution profile of $\alpha$-oxo-2-selenopheneacetic acid (system $C$, detection at

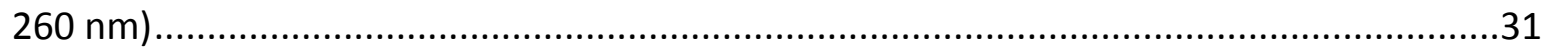

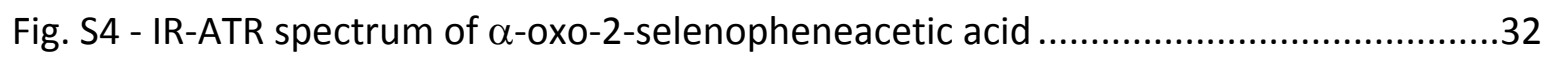

Fig. S5 - ${ }^{1} \mathrm{H}$ NMR spectrum of $\alpha$-oxo-2-selenopheneacetic acid in DMSO- $d_{6}(500 \mathrm{MHz}) \ldots . .32$

Fig. S6 - ${ }^{13} \mathrm{C}$ NMR spectrum of $\alpha$-oxo-2-selenopheneacetic acid in $\mathrm{CDCl}_{3}(126 \mathrm{MHz}) \ldots \ldots . . . .33$

Fig. S7 - ${ }^{77}$ Se NMR spectrum of $\alpha$-oxo-2-selenopheneacetic acid in DMSO- $d_{6}(114.5 \mathrm{MHz})$

Fig. S8 - ESI+ mass spectrum (high resolution) of quinoxalin-2(1H)-one 1 ...........................34

Fig. S9 - ESI+ (left) / ESI- (right) mass spectra (low resolution) of quinoxalin-2(1H)-one 1..34

Fig. S10 - RP-HPLC elution profile of quinoxalin-2(1H)-one 1 (system A, detection at $260 \mathrm{~nm}$ )

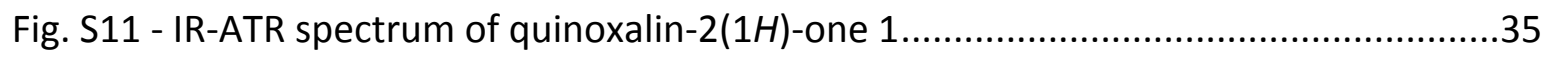

Fig. S12 - ${ }^{1} \mathrm{H}$ NMR spectrum of quinoxalin-2(1H)-one 1 in DMSO- $d_{6}(400 \mathrm{MHz}) \ldots \ldots \ldots \ldots \ldots . . . . .35$

Fig. S13 $-{ }^{13} \mathrm{C}$ NMR spectrum of quinoxalin-2(1H)-one 1 in DMSO- $d_{6}(101 \mathrm{MHz}) \ldots \ldots \ldots \ldots . . . . .36$

Fig. S14 - ESI+ mass spectrum (high resolution) of quinoxalin-2(1H)-one 2 .......................36

Fig. S15 - ESI+ (left) / ESI- (right) mass spectra (low resolution) of quinoxalin-2(1H)-one 237

Fig. S16 - RP-HPLC elution profile quinoxalin-2(1H)-one 2 (system A, detection at $260 \mathrm{~nm}$ )

Fig. S17 - RP-HPLC elution profile of quinoxalin-2(1H)-one 2 (system A, detection at $450 \mathrm{~nm}$ ) 
Fig. S18 - IR-ATR spectrum of quinoxalin-2(1H)-one 2.

Fig. S19 - ${ }^{1} \mathrm{H}$ NMR spectrum of quinoxalin-2(1H)-one 2 in $\mathrm{CDCl}_{3}\left(+10 \%\right.$ TFA- $\left.d_{1}\right)(500 \mathrm{MHz}) 39$

Fig. S20 $-{ }^{13} \mathrm{C}$ NMR spectrum of quinoxalin-2(1H)-one 2 in $\mathrm{CDCl}_{3}\left(+10 \% \mathrm{TFA}^{-\mathrm{d}_{1}}\right)(126 \mathrm{MHz})$

Fig. S21 - TFA determination by IC - results for sample of quinoxalin-2(1H)-one 2 $2 \ldots \ldots \ldots . . . . .40$

Fig. S22 - ESI+ mass spectrum (high resolution) of quinoxalin-2(1H)-one 3

Fig. S23 - ESI+ (left) / ESI- (right) mass spectra (low resolution) of quinoxalin-2(1H)-one 341 Fig. S24 - RP-HPLC elution profile of quinoxalin-2(1H)-one 3 (system A, detection at $260 \mathrm{~nm}$ )

Fig. S25 - RP-HPLC elution profile of quinoxalin-2(1H)-one 3 (system A, detection at $450 \mathrm{~nm}$ )

Fig. S26 - IR-ATR spectrum of quinoxalin-2(1H)-one 3.

Fig. S27 - ${ }^{1} \mathrm{H}$ NMR spectrum of quinoxalin-2(1H)-one 3 in DMSO- $d_{6}(400 \mathrm{MHz})$ .43

Fig. S28 $-{ }^{13} \mathrm{C}$ NMR spectrum of quinoxalin-2(1H)-one 3 in DMSO-d $d_{6}(101 \mathrm{MHz})$ .44

Fig. S29 - ESI+ mass spectrum (high resolution) of quinoxalin-2(1H)-one 4 . .44

Fig. S30 - ESI+ (left) / ESI- (right) mass spectra (low resolution) of quinoxalin-2(1H)-one 445 Fig. S31 - RP-HPLC elution profile of quinoxalin-2(1H)-one 4 (system A, detection at $260 \mathrm{~nm}$ ) . .45

Fig. S32 - RP-HPLC elution profile of quinoxalin-2(1H)-one 4 (system A, detection at $450 \mathrm{~nm}$ ) .46

Fig. S33 - IR-ATR spectrum of quinoxalin-2(1H)-one 4. .46

Fig. S34 - ${ }^{1} \mathrm{H}$ NMR spectrum of quinoxalin-2(1H)-one 4 in DMSO- $d_{6}(400 \mathrm{MHz})$ .47

Fig. S35 $-{ }^{13} \mathrm{C}$ NMR spectrum of quinoxalin-2(1H)-one 4 in DMSO- $d_{6}(151 \mathrm{MHz})$ .47

Fig. S36 - ${ }^{19} \mathrm{~F}$ NMR spectrum of quinoxalin-2(1H)-one 4 in DMSO- $d_{6}(470 \mathrm{MHz})$ . .48

Fig. S37 - ESI+ mass spectrum (high resolution) of quinoxalin-2(1H)-one 5 .48

Fig. S38 - ESI+ (left) / ESI- (right) mass spectra (low resolution) of quinoxalin-2(1H)-one 549 Fig. S39 - RP-HPLC elution profile of quinoxalin-2(1H)-one 5 (system A, detection at $260 \mathrm{~nm}$ ) . .49

Fig. S40 - RP-HPLC elution profile of quinoxalin-2(1H)-one 5 (system A, detection at $450 \mathrm{~nm}$ ) .50

Fig. S41 - IR-ATR spectrum of quinoxalin-2(1H)-one 5. .50

Fig. S42 - ${ }^{1} \mathrm{H}$ NMR spectrum of quinoxalin-2(1H)-one 5 in DMSO- $d_{6}(400 \mathrm{MHz})$ .51

Fig. S43 $-{ }^{13} \mathrm{C}$ NMR spectrum of quinoxalin-2(1H)-one 5 in DMSO- $d_{6}(101 \mathrm{MHz})$ .51

Fig. S44 - ESI+ mass spectrum (high resolution) of quinoxalin-2(1H)-one 6

Fig. S45 - ESI+ (left) / ESI- (right) mass spectra (low resolution) of quinoxalin-2(1H)-one 652 Fig. S46 - RP-HPLC elution profile of quinoxalin-2(1H)-one 6 (system A, detection at $260 \mathrm{~nm}$ ) 
Fig. S47 - RP-HPLC elution profile of quinoxalin-2(1H)-one 6 (system A, detection at $450 \mathrm{~nm}$ )

Fig. S48 - IR-ATR spectrum of quinoxalin-2(1H)-one 6. .54

Fig. S49 - ${ }^{1} \mathrm{H}$ NMR spectrum of quinoxalin-2(1H)-one 6 in DMSO- $d_{6}(400 \mathrm{MHz})$ . .54

Fig. S50 - ${ }^{13} \mathrm{C}$ NMR spectrum of quinoxalin-2(1H)-one 6 in DMSO- $d_{6}(101 \mathrm{MHz})$..... .55

Fig. S51 - ESI+ mass spectrum (high resolution) of quinoxalin-2(1H)-one 7 .55

Fig. S52 - ESI+ (left) / ESI- (right) mass spectra (low resolution) of quinoxalin-2(1H)-one 756 Fig. S53 - RP-HPLC elution profile of quinoxalin-2(1H)-one 7 (system A, detection at $260 \mathrm{~nm}$ )

Fig. S54 - RP-HPLC elution profile of quinoxalin-2(1H)-one 7 (system A, detection at $450 \mathrm{~nm}$ )

Fig. S55 - ${ }^{1} \mathrm{H}$ NMR spectrum of quinoxalin-2(1H)-one 7 (TFA salt) in DMSO- $d_{6}(600 \mathrm{MHz}) .58$ Fig. S56 - ${ }^{13} \mathrm{C}$ NMR spectrum of quinoxalin-2(1H)-one 7 (TFA salt) in DMSO-d $d_{6}(151 \mathrm{MHz}) 58$ Fig. S57 - ${ }^{19} \mathrm{~F}$ NMR spectrum of quinoxalin-2(1H)-one 7 (TFA salt) in DMSO- $d_{6}$ (565 MHz).59 Fig. S58 - ${ }^{77}$ Se NMR spectrum of quinoxalin-2(1H)-one 7 (TFA salt) in DMSO- $d_{6}(114.5 \mathrm{MHz})$ .59

Fig. S59 - TFA determination by IC - results for sample of quinoxalin-2(1H)-one $7 \ldots \ldots \ldots \ldots . . .60$

Fig. S60 - ESI+ mass spectrum (high resolution) of quinoxalin-2(1H)-one $8 \ldots \ldots \ldots \ldots \ldots \ldots \ldots . . . . .60$

Fig. S61 - ESI- mass spectrum (high resolution) of quinoxalin-2(1H)-one 8 61

Fig. S62 - ESI+ (left) / ESI- (right) mass spectra (low resolution) of quinoxalin-2(1H)-one 861 Fig. S63 - RP-HPLC elution profile of quinoxalin-2(1H)-one 8 (system A, detection at $260 \mathrm{~nm}$ )

Fig. S64 - RP-HPLC elution profile of quinoxalin-2(1H)-one 8 (system A, detection at $450 \mathrm{~nm}$ )

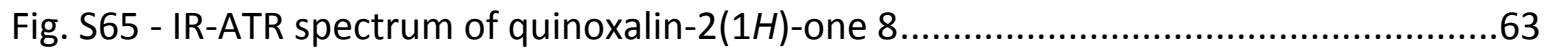

Fig. S66 - ${ }^{1} \mathrm{H}$ NMR spectrum of quinoxalin-2(1H)-one 8 in DMSO- $d_{6}(500 \mathrm{MHz}) \ldots \ldots \ldots \ldots \ldots . . . . . .63$

Fig. S67 - ${ }^{13} \mathrm{C}$ NMR spectrum of quinoxalin-2(1H)-one 8 in DMSO- $d_{6}(126 \mathrm{MHz})$ .64

Fig. S68 - Confocal fluorescence images (left for full image and right for zoom) of fixed A549 cells incubated with quinoxalin-2(1H)-one 8 (concentration: $5.0 \mu \mathrm{M}$ ) for $2 \mathrm{~h}$. Ex. $405 \mathrm{~nm} /$ Em. 430-600 nm.

Fig. S69 - Confocal fluorescence image of fixed A549 cells incubated with quinoxalin-2(1H)one 2 (concentration: $5.0 \mu \mathrm{M}$ ) for 2 h. Ex. $405 \mathrm{~nm} /$ Em. 430-600 nm .65

Fig. S70 - ESI+ mass spectrum (high resolution) of mono- $N$-acyl 1,2-phenylenediamine 11

Fig. S71 - ESI+ (left) / ESI- (right) mass spectra (low resolution) of mono- $N$-acyl 1,2phenylenediamine 11

Fig. S72 - RP-HPLC elution profile of mono- $N$-acyl 1,2-phenylenediamine 11 (system A, detection at $260 \mathrm{~nm}$ ) .66 
Fig. S73 - IR-ATR spectrum of mono- $N$-acyl 1,2-phenylenediamine 11.

Fig. S74 - ${ }^{1} \mathrm{H}$ NMR spectrum of mono- $N$-acyl 1,2-phenylenediamine 11 in DMSO- $d_{6}$ (500 $\mathrm{MHz})$

Fig. S75 $-{ }^{13} \mathrm{C}$ NMR spectrum of mono-N-acyl 1,2-phenylenediamine 11 in DMSO- $d_{6}$ (126 $\mathrm{MHz})$

Fig. S76 - ESI+ mass spectrum (high resolution) of probe 12 .68

Fig. S77 - ESI- mass spectrum (low resolution) of probe 12 .69

Fig. S78 - RP-HPLC elution profile of probe 12 (system A, detection at $260 \mathrm{~nm}$ ). .69

Fig. S79 - IR-ATR spectrum of probe 12 .70

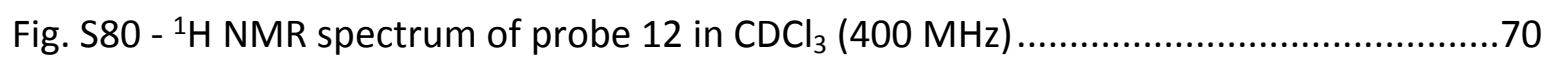

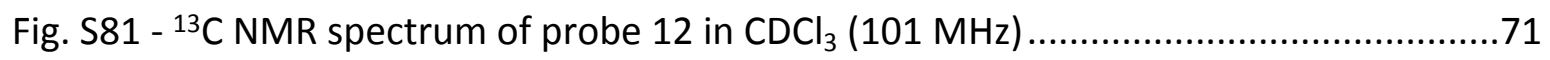

Fig. S82 - ESI+ mass spectrum (high resolution) of probe 13.............................................71

Fig. S83 - ESI+ (left) / ESI- (right) mass spectra (low resolution) of probe 13 .....................72

Fig. S84 - RP-HPLC elution profile of probe 13 (system A, detection at $260 \mathrm{~nm}$ ) ...............72

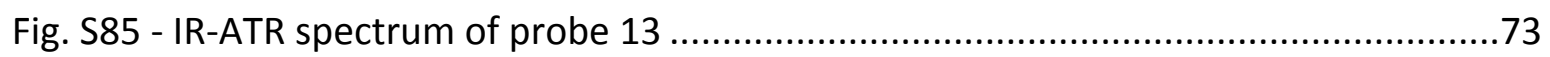

Fig. S86 - ${ }^{1} \mathrm{H}$ NMR spectrum of probe 13 in $\mathrm{CDCl}_{3}(600 \mathrm{MHz})$.........................................73

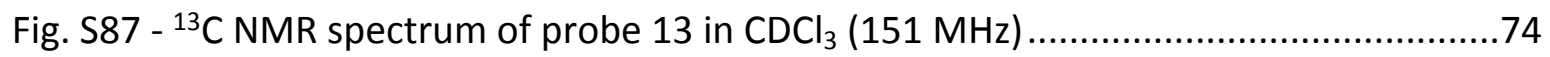

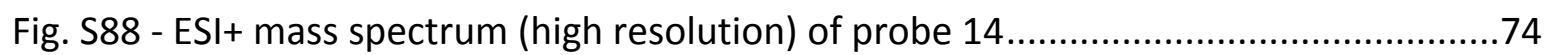

Fig. S89 - ESI+ (left) / ESI- (right) mass spectra (low resolution) of probe 14 ......................75

Fig. S90 - RP-HPLC elution profile of probe 14 (system A, detection at $260 \mathrm{~nm}$ ) ................75

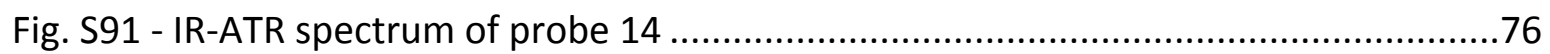

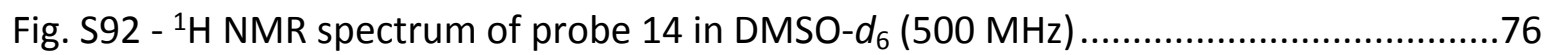

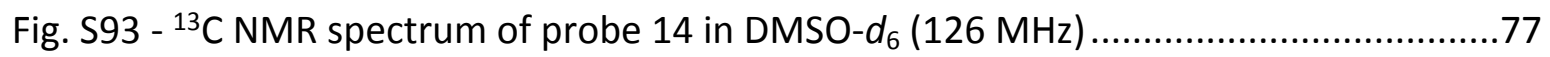

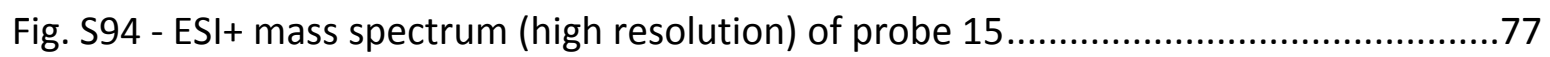

Fig. S95 - ESI+ (left) / ESI- (right) mass spectra (low resolution) of probe 15 .....................78

Fig. S96 - RP-HPLC elution profile of probe 15 (system A, detection at $260 \mathrm{~nm}$ ) ...............78

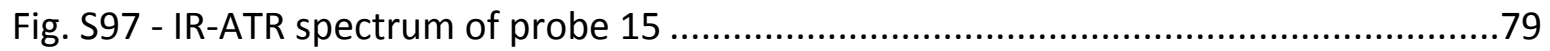

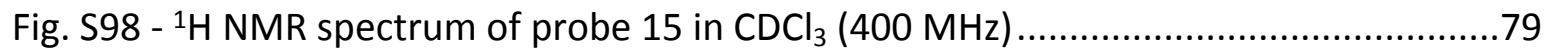

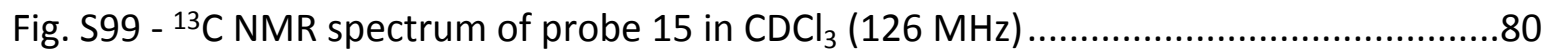

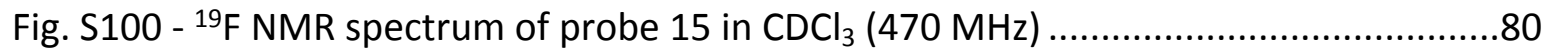

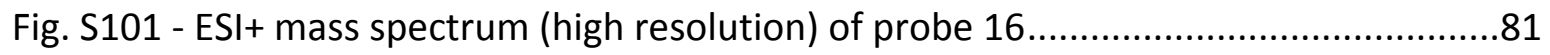

Fig. S102 - ESI+ (left) / ESI- (right) mass spectra (low resolution) of probe 16 ....................81

Fig. S103 - RP-HPLC elution profile of probe 16 (system A, detection at $260 \mathrm{~nm}$ ) ..............82

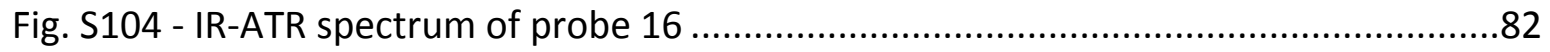

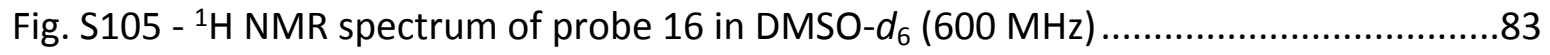

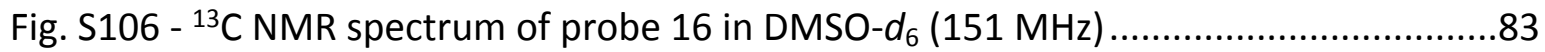


Fig. S107 - ESI+ mass spectrum (high resolution) of probe 17 .84

Fig. S108 - ESI- mass spectrum (low resolution) of probe 17..........................................84

Fig. S109 - RP-HPLC elution profile of probe 17 (system A, detection at $260 \mathrm{~nm}$ ) ..............85

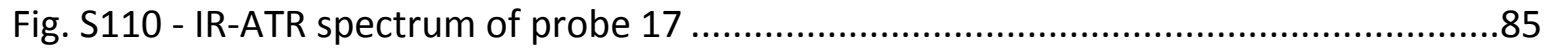

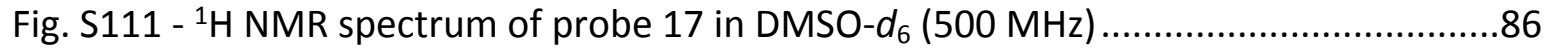

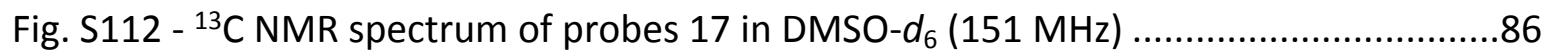

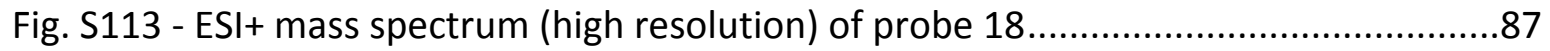

Fig. S114 - ESI+ (left) / ESI- (right) mass spectra (low resolution) of probe 18 ....................88

Fig. S115 - RP-HPLC elution profile of probe 18 (system A, detection at $260 \mathrm{~nm}$ ) .............88

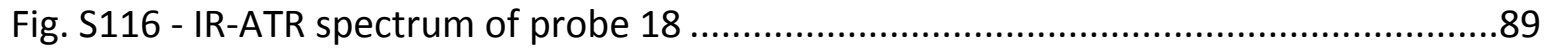

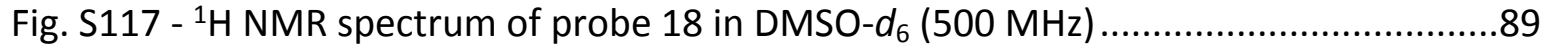

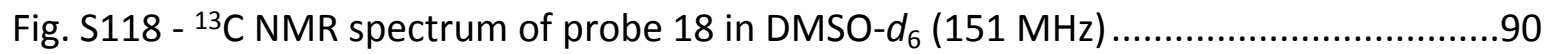

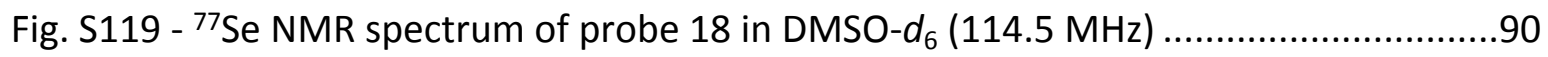

Fig. S120 - Normalized UV-vis absorption, excitation (Em. 500 nm, slit 5 nm), emission (Ex.

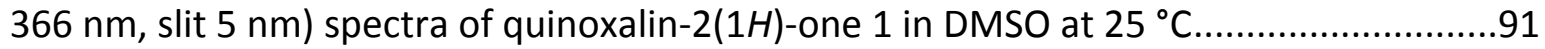

Fig. S121 - Normalized UV-vis absorption, excitation (Em. 500 nm, slit 5 nm), emission (Ex. $366 \mathrm{~nm}$, slit $5 \mathrm{~nm}$ ) spectra of quinoxalin-2(1H)-one 1 in PB at $25^{\circ} \mathrm{C}$.

Fig. S122 - Normalized UV-vis absorption, excitation (Em. 500 nm, slit 5 nm), emission (Ex. $366 \mathrm{~nm}$, slit $5 \mathrm{~nm}$ ) spectra of quinoxalin-2(1H)-one 2 in DMSO at $25^{\circ} \mathrm{C}$.

Fig. S123 - Normalized UV-vis absorption, excitation (Em. $500 \mathrm{~nm}$, slit $5 \mathrm{~nm}$ ), emission (Ex. $366 \mathrm{~nm}$, slit $5 \mathrm{~nm}$ ) spectra of quinoxalin-2(1H)-one 2 in PB at $25^{\circ} \mathrm{C}$.

Fig. S124 - Normalized UV-vis absorption, excitation (Em. $500 \mathrm{~nm}$, slit $5 \mathrm{~nm}$ ), emission (Ex. $366 \mathrm{~nm}$, slit $5 \mathrm{~nm}$ ) spectra of quinoxalin-2(1H)-one 3 in DMSO at $25^{\circ} \mathrm{C}$.

Fig. S125 - Normalized UV-vis absorption, excitation (Em. 500 nm, slit 5 nm), emission (Ex. $366 \mathrm{~nm}$, slit $5 \mathrm{~nm}$ ) spectra of quinoxalin-2(1H)-one 3 in PB at $25^{\circ} \mathrm{C}$

Fig. S126 - Normalized UV-vis absorption, excitation (Em. 500 nm, slit 5 nm), emission (Ex. $421 \mathrm{~nm}$, slit $5 \mathrm{~nm}$ ) spectra of quinoxalin-2(1H)-one 4 in DMSO at $25^{\circ} \mathrm{C}$.

Fig. S127 - Normalized UV-vis absorption, excitation (Em. $500 \mathrm{~nm}$, slit $5 \mathrm{~nm}$ ), emission (Ex. $366 \mathrm{~nm}$, slit $5 \mathrm{~nm}$ ) spectra of quinoxalin-2(1H)-one 4 in PB at $25^{\circ} \mathrm{C}$. .94

Fig. S128 - Normalized UV-vis absorption, excitation (Em. 500 nm, slit 5 nm), emission (Ex. $366 \mathrm{~nm}$, slit $5 \mathrm{~nm}$ ) spectra of quinoxalin-2(1H)-one 5 in DMSO at $25^{\circ} \mathrm{C}$. . .95

Fig. S129 - Normalized UV-vis absorption, excitation (Em. $500 \mathrm{~nm}$, slit $5 \mathrm{~nm}$ ), emission (Ex. $366 \mathrm{~nm}$, slit $5 \mathrm{~nm}$ ) spectra of quinoxalin-2(1H)-one 5 in PB at $25^{\circ} \mathrm{C}$ .95

Fig. S130 - Normalized UV-vis absorption, excitation (Em. $500 \mathrm{~nm}$, slit $5 \mathrm{~nm}$ ), emission (Ex. $421 \mathrm{~nm}$, slit $5 \mathrm{~nm}$ ) spectra of quinoxalin-2(1H)-one 6 in DMSO at $25^{\circ} \mathrm{C}$.

Fig. S131 - Normalized UV-vis absorption, excitation (Em. $500 \mathrm{~nm}$, slit $5 \mathrm{~nm}$ ), emission (Ex. $366 \mathrm{~nm}$, slit $5 \mathrm{~nm}$ ) spectra of quinoxalin-2(1H)-one 6 in PB at $25^{\circ} \mathrm{C}$

Fig. S132 - Normalized UV-vis absorption, excitation (Em. 500 nm, slit 5 nm), emission (Ex. $366 \mathrm{~nm}$, slit $5 \mathrm{~nm}$ ) spectra of quinoxalin-2(1H)-one 7 in DMSO at $25^{\circ} \mathrm{C}$. 
Fig. S133 - Normalized UV-vis absorption, excitation (Em. 500 nm, slit 5 nm), emission (Ex. $366 \mathrm{~nm}$, slit $5 \mathrm{~nm}$ ) spectra of quinoxalin-2(1H)-one 7 in PB at $25^{\circ} \mathrm{C}$

Fig. S134 - Normalized UV-vis absorption, excitation (Em. $500 \mathrm{~nm}$, slit $5 \mathrm{~nm}$ ), emission (Ex. $366 \mathrm{~nm}$, slit $5 \mathrm{~nm}$ ) spectra of quinoxalin-2(1H)-one 8 in DMSO at $25^{\circ} \mathrm{C}$.

Fig. S135 - Normalized UV-vis absorption, excitation (Em. $500 \mathrm{~nm}$, slit $5 \mathrm{~nm}$ ), emission (Ex.

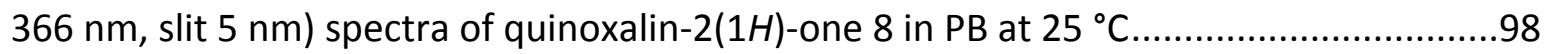

Fig. S136 - UV-vis spectrum of probe 12 (recorded during RP-HPLC analysis) ...................99

Fig. S137 - UV-vis spectrum of probe 13 (recorded during RP-HPLC analysis) ...................99

Fig. S138 - UV-vis spectrum of probe 14 (recorded during RP-HPLC analysis) ...................99

Fig. S139 - UV-vis spectrum of probe 15 (recorded during RP-HPLC analysis) ..................100

Fig. S140 - UV-vis spectrum of probe 16 (recorded during RP-HPLC analysis) .................100

Fig. S141 - UV-vis spectrum of probe 17 (recorded during RP-HPLC analysis) .................100

Fig. S142 - UV-vis spectrum of probe 18 (recorded during RP-HPLC analysis) .................101

Fig. S143 - Time-dependent changes in the blue-cyan fluorescence intensity (Ex./Em. $365 / 455 \mathrm{~nm}$, slit $2 \mathrm{~nm}$ ) of fluorogenic probe 12 (concentration: $1.0 \mu \mathrm{M}$ ) in the presence of PGA (1 U) in PB at $37^{\circ} \mathrm{C}$.

Fig. S144 - Over-layed fluorescence emission spectra (Ex. $365 \mathrm{~nm}$, slit $5 \mathrm{~nm}$ ) of fluorogenic probe 12 before and after incubation with PGA

Fig. S145 - Time-dependent changes in the blue-cyan fluorescence intensity (Ex./Em. $380 / 480 \mathrm{~nm}$, slit $2 \mathrm{~nm}$ ) of fluorogenic probe 13 (concentration: $1.0 \mu \mathrm{M}$ ) in the presence of PGA (1 U) in PB at $37^{\circ} \mathrm{C}$ 102

Fig. S146 - Over-layed fluorescence emission spectra (Ex. $380 \mathrm{~nm}$, slit $5 \mathrm{~nm}$ ) of fluorogenic probe 13 before and after incubation with PGA .103

Fig. S147 - Time-dependent changes in the blue-cyan fluorescence intensity (Ex./Em. $390 / 475 \mathrm{~nm}$, slit $2 \mathrm{~nm}$ ) of fluorogenic probe 14 (concentration: $1.0 \mu \mathrm{M}$ ) in the presence of PGA (1 U) in PB at $37^{\circ} \mathrm{C}$ 103

Fig. S148 - Over-layed fluorescence emission spectra (Ex. $390 \mathrm{~nm}$, slit $5 \mathrm{~nm}$ ) of fluorogenic probe 14 before and after incubation with PGA 104

Fig. S149 - Time-dependent changes in the blue-cyan fluorescence intensity (Ex./Em. $385 / 490 \mathrm{~nm}$, slit $2 \mathrm{~nm}$ ) of fluorogenic probe 15 (concentration: $1.0 \mu \mathrm{M}$ ) in the presence of PGA (1 U) in PB at $37^{\circ} \mathrm{C}$ 104

Fig. S150 - Over-layed fluorescence emission spectra (Ex. $385 \mathrm{~nm}$, slit $5 \mathrm{~nm}$ ) of fluorogenic probe 15 before and after incubation with PGA 105

Fig. S151 - Time-dependent changes in the blue-cyan fluorescence intensity (Ex./Em. 405/480 nm, slit $2 \mathrm{~nm}$ ) of fluorogenic probe 16 (concentration: $1.0 \mu \mathrm{M}$ ) in the presence of PGA (1 U) in PB at $37^{\circ} \mathrm{C}$. 105

Fig. S152 - Over-layed fluorescence emission spectra (Ex. $405 \mathrm{~nm}$, slit $5 \mathrm{~nm}$ ) of fluorogenic probe 16 before and after incubation with PGA 106 
Fig. S153 - Time-dependent changes in the blue-cyan fluorescence intensity (Ex./Em. $390 / 480 \mathrm{~nm}$, slit $2 \mathrm{~nm}$ ) of fluorogenic probe 17 (concentration: $1.0 \mu \mathrm{M}$ ) in the presence of PGA (1 U) in PB at $37^{\circ} \mathrm{C}$ 106

Fig. S154 - Over-layed fluorescence emission spectra (Ex. $390 \mathrm{~nm}$, slit $5 \mathrm{~nm}$ ) of fluorogenic probe 17 before and after incubation with PGA 107

Fig. S155 - Time-dependent changes in the blue-cyan fluorescence intensity (Ex./Em. $380 / 490 \mathrm{~nm}$, slit $2 \mathrm{~nm}$ ) of fluorogenic probe 18 (concentration: $1.0 \mu \mathrm{M}$ ) in the presence of PGA (1 U) in PB at $37^{\circ} \mathrm{C}$

Fig. S156 - Over-layed fluorescence emission spectra (Ex. $380 \mathrm{~nm}$, slit $5 \mathrm{~nm}$ ) of fluorogenic probe 18 before and after incubation with PGA 108

Fig. S157 - Time-dependent changes in the blue-cyan fluorescence intensity (Ex./Em. $365 / 455 \mathrm{~nm}$, slit $2 \mathrm{~nm}$ ) of fluorogenic probe 12 (concentration: $1.0 \mu \mathrm{M}$ ) in the presence of PGA ( 1 U) with or without GSH (50 equiv.), in PB at $37^{\circ} \mathrm{C}$ 108

Fig. S158 - Time-dependent changes in the blue-cyan fluorescence intensity (Ex./Em. $380 / 480 \mathrm{~nm}$, slit $2 \mathrm{~nm}$ ) of fluorogenic probe 13 (concentration: $1.0 \mu \mathrm{M}$ ) in the presence of PGA (1 U) with or without GSH (50 equiv.), in PB at $37^{\circ} \mathrm{C}$ 109

Fig. S159 - Time-dependent changes in the blue-cyan fluorescence intensity (Ex./Em. $390 / 475 \mathrm{~nm}$, slit $2 \mathrm{~nm}$ ) of fluorogenic probe 14 (concentration: $1.0 \mu \mathrm{M}$ ) in the presence of PGA (1 U) with or without GSH (50 equiv.), in PB at $37^{\circ} \mathrm{C}$ 109

Fig. S160 - Time-dependent changes in the blue-cyan fluorescence intensity (Ex./Em. $385 / 490 \mathrm{~nm}$, slit $2 \mathrm{~nm}$ ) of fluorogenic probe 15 (concentration: $1.0 \mu \mathrm{M}$ ) in the presence of PGA (1 U) with or without GSH (50 equiv.), in PB at $37^{\circ} \mathrm{C}$

Fig. S161 - Time-dependent changes in the blue-cyan fluorescence intensity (Ex./Em. 405/480 nm, slit $2 \mathrm{~nm}$ ) of fluorogenic probe 16 (concentration: $1.0 \mu \mathrm{M}$ ) in the presence of PGA (1 U) with or without GSH (50 equiv.), in PB at $37^{\circ} \mathrm{C}$ .110

Fig. S162 - Time-dependent changes in the blue-cyan fluorescence intensity (Ex./Em. $390 / 480 \mathrm{~nm}$, slit $2 \mathrm{~nm}$ ) of fluorogenic probe 17 (concentration: $1.0 \mu \mathrm{M}$ ) in the presence of PGA (1 U) with or without GSH (50 equiv.), in PB at $37^{\circ} \mathrm{C}$

Fig. S163 - Time-dependent changes in the blue-cyan fluorescence intensity (Ex./Em. $380 / 490 \mathrm{~nm}$, slit $2 \mathrm{~nm}$ ) of fluorogenic probe 18 (concentration: $1.0 \mu \mathrm{M}$ ) in the presence of PGA (1 U) with or without GSH (50 equiv.), in PB at $37^{\circ} \mathrm{C}$

Fig. S164 - RP-HPLC elution profile (system E, fluorescence detection Ex./Em. 365/455 nm) of $\mathrm{PB}$.

Fig. S165 - RP-HPLC elution profile (system E, fluorescence detection Ex./Em. 365/455 nm) of quinoxalin-2(1H)-one 1 (concentration: $1.0 \mu \mathrm{M}$ in $\mathrm{PB}$ )

Fig. S166 - RP-HPLC elution profile (system E, fluorescence detection Ex./Em. 365/455 nm) of fluorogenic probe 12 without PGA (concentration: $1.0 \mu \mathrm{M}$ in $\mathrm{PB}, 30 \mathrm{~min}, 37^{\circ} \mathrm{C}$ ) .......113

Fig. S167 - RP-HPLC elution profile (system E, fluorescence detection Ex./Em. 365/455 nm) of fluorogenic probe 12 (concentration: $1.0 \mu \mathrm{M}$ in PB) with PGA $\left(1 \mathrm{U}, 30 \mathrm{~min}, 37^{\circ} \mathrm{C}\right.$ ) .....113

Fig. S168 - RP-HPLC elution profile (system E, fluorescence detection Ex./Em. 365/455 nm) of co-injection of fluorogenic probe 12 (concentration: $0.5 \mu \mathrm{M}$ in PB) with PGA (1 U, $30 \mathrm{~min}$, $37^{\circ} \mathrm{C}$ ) and quinoxalin-2(1H)-one 1 (concentration: $0.5 \mu \mathrm{M}$ in $\mathrm{PB}$ ) 114 
Fig. S169 - RP-HPLC elution profile (system E, fluorescence detection Ex./Em. 365/455 nm) of fluorogenic probe 12 (concentration: $1.0 \mu \mathrm{M}$ in PB) with PGA $\left(1 \mathrm{U}, 30 \mathrm{~min}, 37^{\circ} \mathrm{C}\right.$ ) and GSH (50 equiv.) 114

Fig. S170 - RP-HPLC elution profile (system E, fluorescence detection Ex./Em. 365/455 nm) of co-injection of fluorogenic probe 12 (concentration: $0.5 \mu \mathrm{M}$ in PB) with PGA ( $1 \mathrm{U}, 30 \mathrm{~min}$, $37^{\circ} \mathrm{C}$ ) and GSH (50 equiv.), and quinoxalin-2(1H)-one 1 (concentration: $0.5 \mu \mathrm{M}$ in PB) ..115 Fig. S171 - RP-HPLC elution profile (system E, fluorescence detection Ex./Em. 380/480 nm) of PB.

Fig. S172 - RP-HPLC elution profile (system E, fluorescence detection Ex./Em. 380/480 nm) of quinoxalin-2(1H)-one 2 (concentration: $1.0 \mu \mathrm{M}$ in $\mathrm{PB}$ ) 116

Fig. S173 - RP-HPLC elution profile (system E, fluorescence detection Ex./Em. 380/480 nm) of fluorogenic probe 13 without PGA (concentration: $1.0 \mu \mathrm{M}$ in $\mathrm{PB}, 30 \mathrm{~min}, 37^{\circ} \mathrm{C}$ ) .......116

Fig. S174 - RP-HPLC elution profile (system E, fluorescence detection Ex./Em. 380/480 nm) of fluorogenic probe 13 (concentration: $1.0 \mu \mathrm{M}$ in PB) with PGA $\left(1 \mathrm{U}, 30 \mathrm{~min}, 37^{\circ} \mathrm{C}\right) \ldots . .117$

Fig. S175 - RP-HPLC elution profile (system E, fluorescence detection Ex./Em. 380/480 nm) of co-injection of fluorogenic probe 13 (concentration: $0.5 \mu \mathrm{M}$ in PB) with PGA $(1 \mathrm{U}, 30 \mathrm{~min}$, $37^{\circ} \mathrm{C}$ ) and quinoxalin-2(1H)-one 2 (concentration: $0.5 \mu \mathrm{M}$ in $\mathrm{PB}$ )

Fig. S176 - RP-HPLC elution profile (system E, fluorescence detection Ex./Em. 380/480 nm) of fluorogenic probe 13 (concentration: $1.0 \mu \mathrm{M}$ in PB) with PGA $\left(1 \mathrm{U}, 30 \mathrm{~min}, 37^{\circ} \mathrm{C}\right.$ ) and GSH (50 equiv.)

Fig. S177 - RP-HPLC elution profile (system E, fluorescence detection Ex./Em. 380/480 nm) of co-injection of fluorogenic probe 13 (concentration: $0.5 \mu \mathrm{M}$ in PB) with PGA (1 U, $30 \mathrm{~min}$, $37^{\circ} \mathrm{C}$ ) and GSH (50 equiv.), and quinoxalin-2(1H)-one 2 (concentration: $0.5 \mu \mathrm{M}$ in PB). .118 Fig. S178 - RP-HPLC elution profile (system E, fluorescence detection Ex./Em. 390/475 nm) of PB.

Fig. S179 - RP-HPLC elution profile (system E, fluorescence detection Ex./Em. 390/475 nm) of quinoxalin-2(1H)-one 3 (concentration: $1.0 \mu \mathrm{M}$ in $\mathrm{PB}$ )

Fig. S180 - RP-HPLC elution profile (system E, fluorescence detection Ex./Em. 390/475 nm) of fluorogenic probe 14 without PGA (concentration: $1.0 \mu \mathrm{M}$ in PB, $30 \mathrm{~min}, 37^{\circ} \mathrm{C}$ ) .......120

Fig. S181 - RP-HPLC elution profile (system E, fluorescence detection Ex./Em. 390/475 nm) of fluorogenic probe 14 (concentration: $1.0 \mu \mathrm{M}$ in PB) with PGA $\left(1 \mathrm{U}, 30 \mathrm{~min}, 37^{\circ} \mathrm{C}\right) \ldots . .120$ Fig. S182 - RP-HPLC elution profile (system E, fluorescence detection Ex./Em. 390/475 nm) of co-injection of fluorogenic probe 14 (concentration: $0.5 \mu \mathrm{M}$ in PB) with PGA (1 U, $30 \mathrm{~min}$, $37^{\circ} \mathrm{C}$ ) and quinoxalin-2(1H)-one 3 (concentration: $0.5 \mu \mathrm{M}$ in $\mathrm{PB}$ )

Fig. S183 - RP-HPLC elution profile (system E, fluorescence detection Ex./Em. 390/475 nm) of fluorogenic probe 14 (concentration: $1.0 \mu \mathrm{M}$ in PB) with PGA (1 U, 30 min, $37^{\circ} \mathrm{C}$ ) and GSH (50 equiv.)

Fig. S184 - RP-HPLC elution profile (system E, fluorescence detection Ex./Em. 390/475 nm) of co-injection of fluorogenic probe 14 (concentration: $0.5 \mu \mathrm{M}$ in PB) with PGA (1 U, $30 \mathrm{~min}$, $37^{\circ} \mathrm{C}$ ) and GSH (50 equiv.), and quinoxalin-2(1H)-one 3 (concentration: $0.5 \mu \mathrm{M}$ in PB) ..122 
Fig. S185 - RP-HPLC elution profile (system E, fluorescence detection Ex./Em. 385/490 nm) of PB.

Fig. S186 - RP-HPLC elution profile (system E, fluorescence detection Ex./Em. 385/490 nm) of quinoxalin-2(1H)-one 4 (concentration: $1.0 \mu \mathrm{M}$ in $\mathrm{PB}$ )

Fig. S187 - RP-HPLC elution profile (system E, fluorescence detection Ex./Em. 385/490 nm) of fluorogenic probe 15 without PGA (concentration: $1.0 \mu \mathrm{M}$ in $\mathrm{PB}, 90 \mathrm{~min}, 37^{\circ} \mathrm{C}$ ) .......123

Fig. S188 - RP-HPLC elution profile (system E, fluorescence detection Ex./Em. 385/490 nm) of fluorogenic probe 15 (concentration: $1.0 \mu \mathrm{M}$ in PB) with PGA $\left(1 \mathrm{U}, 90 \mathrm{~min}, 37^{\circ} \mathrm{C}\right) \ldots . .124$

Fig. S189 - RP-HPLC elution profile (system E, fluorescence detection Ex./Em. 385/490 nm) of co-injection of fluorogenic probe 15 (concentration: $0.5 \mu \mathrm{M}$ in PB) with PGA (1 U, $90 \mathrm{~min}$, $37^{\circ} \mathrm{C}$ ) and quinoxalin-2(1H)-one 4 (concentration: $0.5 \mu \mathrm{M}$ in $\mathrm{PB}$ )

Fig. S190 - RP-HPLC elution profile (system E, fluorescence detection Ex./Em. 385/490 nm) of fluorogenic probe 15 (concentration: $1.0 \mu \mathrm{M}$ in PB) with PGA $\left(1 \mathrm{U}, 90 \mathrm{~min}, 37^{\circ} \mathrm{C}\right.$ ) and GSH (50 equiv.)

Fig. S191 - RP-HPLC elution profile (system E, fluorescence detection Ex./Em. 385/490 nm) of co-injection of fluorogenic probe 15 (concentration: $0.5 \mu \mathrm{M}$ in PB) with PGA (1 U, $90 \mathrm{~min}$, $37^{\circ} \mathrm{C}$ ) and GSH (50 equiv.), and quinoxalin-2(1H)-one 4 (concentration: $0.5 \mu \mathrm{M}$ in PB) ..125 Fig. S192 - RP-HPLC elution profile (system E, fluorescence detection Ex./Em. 405/480 nm) of PB.

Fig. S193 - RP-HPLC elution profile (system E, fluorescence detection Ex./Em. 405/480 nm) of quinoxalin-2(1H)-one 5 (concentration: $1.0 \mu \mathrm{M}$ in $\mathrm{PB}$ )

Fig. S194 - RP-HPLC elution profile (system E, fluorescence detection Ex./Em. 405/480 nm) of fluorogenic probe 16 without PGA (concentration: $1.0 \mu \mathrm{M}$ in $\mathrm{PB}, 30 \mathrm{~min}, 37^{\circ} \mathrm{C}$ )

Fig. S195 - RP-HPLC elution profile (system E, fluorescence detection Ex./Em. 405/480 nm) of fluorogenic probe 16 (concentration: $1.0 \mu \mathrm{M}$ in PB) with PGA $\left(1 \mathrm{U}, 30 \mathrm{~min}, 37^{\circ} \mathrm{C}\right) \ldots . .127$

Fig. S196 - RP-HPLC elution profile (system E, fluorescence detection Ex./Em. 405/480 nm) of co-injection of fluorogenic probe 16 (concentration: $0.5 \mu \mathrm{M}$ in PB) with PGA (1 U, $30 \mathrm{~min}$, $37^{\circ} \mathrm{C}$ ) and quinoxalin-2(1H)-one 5 (concentration: $0.5 \mu \mathrm{M}$ in $\mathrm{PB}$ ).

Fig. S197 - RP-HPLC elution profile (system E, fluorescence detection Ex./Em. 405/480 nm) of fluorogenic probe 16 (concentration: $1.0 \mu \mathrm{M}$ in PB) with PGA $\left(1 \mathrm{U}, 30 \mathrm{~min}, 37^{\circ} \mathrm{C}\right.$ ) and GSH (50 equiv.)

Fig. S198 - RP-HPLC elution profile (system E, fluorescence detection Ex./Em. 405/480 nm) of co-injection of fluorogenic probe 16 (concentration: $0.5 \mu \mathrm{M}$ in PB) with PGA (1 U, $30 \mathrm{~min}$, $37^{\circ} \mathrm{C}$ ) and GSH (50 equiv.), and quinoxalin-2(1H)-one 5 (concentration: $0.5 \mu \mathrm{M}$ in PB) ..129 Fig. S199 - RP-HPLC elution profile (system E, fluorescence detection Ex./Em. 390/480 nm) of $\mathrm{PB}(0.1 \mathrm{M}, \mathrm{pH} 7.6)$

Fig. S200 - RP-HPLC elution profile (system E, fluorescence detection Ex./Em. 390/480 nm) of quinoxalin-2(1H)-one 6 (concentration: $1.0 \mu \mathrm{M}$ in $\mathrm{PB}$ )

Fig. S201 - RP-HPLC elution profile (system E, fluorescence detection Ex./Em. 390/480 nm) of fluorogenic probe 17 without PGA (concentration: $1.0 \mu \mathrm{M}$ in $\mathrm{PB}, 30 \mathrm{~min}, 37^{\circ} \mathrm{C}$ ) ........130 
Fig. S202 - RP-HPLC elution profile (system E, fluorescence detection Ex./Em. 390/480 nm) of fluorogenic probe 17 (concentration: $1.0 \mu \mathrm{M}$ in PB) with PGA $\left(1 \mathrm{U}, 30 \mathrm{~min}, 37^{\circ} \mathrm{C}\right) \ldots . .131$ Fig. S203 - RP-HPLC elution profile (system E, fluorescence detection Ex./Em. 390/480 nm) of co-injection of fluorogenic probe 17 (concentration: $0.5 \mu \mathrm{M}$ in PB) with PGA $(1 \mathrm{U}, 30 \mathrm{~min}$, $37^{\circ} \mathrm{C}$ ) and quinoxalin-2(1H)-one 6 (concentration: $0.5 \mu \mathrm{M}$ in PB) 131

Fig. S204 - RP-HPLC elution profile (system E, fluorescence detection Ex./Em. 390/480 nm) of fluorogenic probe 17 (concentration: $1.0 \mu \mathrm{M}$ in PB) with PGA $\left(1 \mathrm{U}, 30 \mathrm{~min}, 37^{\circ} \mathrm{C}\right.$ ) and GSH (50 equiv.)

Fig. S205 - RP-HPLC elution profile (system E, fluorescence detection Ex./Em. 390/480 nm) of co-injection of fluorogenic probe 17 (concentration: $0.5 \mu \mathrm{M}$ in PB) with PGA (1 U, $30 \mathrm{~min}$, $37^{\circ} \mathrm{C}$ ) and GSH (50 equiv.), and quinoxalin-2(1H)-one 6 (concentration: $0.5 \mu \mathrm{M}$ in PB) ..132 Fig. S206 - RP-HPLC elution profile (system E, fluorescence detection Ex./Em. 380/490 nm) of PB.

Fig. S207 - RP-HPLC elution profile (system E, fluorescence detection Ex./Em. 380/490 nm) of quinoxalin-2(1H)-one 7 (concentration: $1.0 \mu \mathrm{M}$ in PB)

Fig. S208 - RP-HPLC elution profile (system E, fluorescence detection Ex./Em. 380/490 nm) of fluorogenic probe 18 without PGA (concentration: $1.0 \mu \mathrm{M}$ in $\mathrm{PB}, 30 \mathrm{~min}, 37^{\circ} \mathrm{C}$ ) .......134

Fig. S209 - RP-HPLC elution profile (system E, fluorescence detection Ex./Em. 380/490 nm) of fluorogenic probe 18 (concentration: $1.0 \mu \mathrm{M}$ in PB) with PGA $\left(1 \mathrm{U}, 30 \mathrm{~min}, 37^{\circ} \mathrm{C}\right.$ ) .....134 Fig. S210 - RP-HPLC elution profile (system E, fluorescence detection Ex./Em. 380/490 nm) of co-injection of fluorogenic probe 18 (concentration: $0.5 \mu \mathrm{M}$ in PB) with PGA (1 U, $30 \mathrm{~min}$, $37^{\circ} \mathrm{C}$ ) and quinoxalin-2(1H)-one 7 (concentration: $0.5 \mu \mathrm{M}$ in PB) 135

Fig. S211 - RP-HPLC elution profile (system E, fluorescence detection Ex./Em. 380/490 nm) of fluorogenic probe 18 (concentration: $1.0 \mu \mathrm{M}$ in PB) with PGA $\left(1 \mathrm{U}, 30 \mathrm{~min}, 37^{\circ} \mathrm{C}\right.$ ) and GSH (50 equiv.)

Fig. S212 - RP-HPLC elution profile (system E, fluorescence detection Ex./Em. 380/490 nm) of co-injection of fluorogenic probe 18 (concentration: $0.5 \mu \mathrm{M}$ in PB) with PGA (1 U, $30 \mathrm{~min}$, $37^{\circ} \mathrm{C}$ ) and GSH (50 equiv.), and quinoxalin-2(1H)-one 7 (concentration: $0.5 \mu \mathrm{M}$ in PB) ..136

Fig. S213 - RP-HPLC elution profile (system B) of blank (injection of PB alone). UV detection at $260 \mathrm{~nm}$; UV detection at $365 \mathrm{~nm}$; ESI+ mass detection (SIM mode at $\mathrm{m} / \mathrm{z} 221.1 \pm 0.5$ ); ESI+/ESI- mass detection (SIM mode at $m / z 506.2 \pm 0.5$ and $504.2 \pm 0.5$ ) (top-down) .....136

Fig. S214 - RP-HPLC elution profile (system B) of probe 12 without PGA (concentration: 1.0 $\mu \mathrm{M}$ in $\left.\mathrm{PB}, 30 \mathrm{~min}, 37^{\circ} \mathrm{C}\right)$. UV detection at $260 \mathrm{~nm}$; UV detection at $365 \mathrm{~nm}$; ESI+ mass detection (SIM mode at $\mathrm{m} / \mathrm{z} 221.1 \pm 0.5$ ); ESI+/ESI- mass detection (SIM mode at $m / z 506.2$ \pm 0.5 and $504.2 \pm 0.5$ ) (top-down)

Fig. S215 - RP-HPLC elution profile (system B) of probe 12 (concentration: $1.0 \mu \mathrm{M}$ in PB) with PGA ( $\left.1 \mathrm{U}, 30 \mathrm{~min}, 37^{\circ} \mathrm{C}\right)$. UV detection at $260 \mathrm{~nm}$; UV detection at $365 \mathrm{~nm}$; ESI+ mass detection (SIM mode at $\mathrm{m} / \mathrm{z} 221.1 \pm 0.5$ ); ESI+/ESI- mass detection (SIM mode at $\mathrm{m} / \mathrm{z} 506.2$ \pm 0.5 and $504.2 \pm 0.5$ ) (top-down)

Fig. S216 - RP-HPLC elution profile (system B) of probe 12 (concentration: $1.0 \mu \mathrm{M}$ in PB) with PGA ( $1 \mathrm{U}, 30 \mathrm{~min}, 37^{\circ} \mathrm{C}$ ) and GSH (50 equiv.). UV detection at $260 \mathrm{~nm}$; UV detection at 
$365 \mathrm{~nm}$; ESI+ mass detection (SIM mode at $\mathrm{m} / \mathrm{z} 221.1 \pm 0.5$ ); ESI+/ESI- mass detection (SIM mode at $m / z 506.2 \pm 0.5$ and 504.2 \pm 0.5 ) (top-down)

Fig. S217 - RP-HPLC elution profile (system B) of blank (injection of PB alone). UV detection at $260 \mathrm{~nm}$; UV detection at $400 \mathrm{~nm}$; ESI+ mass detection (SIM mode at $\mathrm{m} / z 283.1 \pm 0.5$ ); ESI+/ESI- mass detection (SIM mode at $m / z 568.2 \pm 0.5$ and $566.2 \pm 0.5$ ) (top-down) .....142

Fig. S218 - RP-HPLC elution profile (system B) of probe 13 without PGA (concentration: 1.0 $\mu \mathrm{M}$ in $\mathrm{PB}, 30 \mathrm{~min}, 37^{\circ} \mathrm{C}$ ). UV detection at $260 \mathrm{~nm}$; UV detection at $400 \mathrm{~nm}$; ESI+ mass detection (SIM mode at $m / z 283.1 \pm 0.5$ ); ESI+/ESI- mass detection (SIM mode at $m / z 568.2$ \pm 0.5 and $566.2 \pm 0.5$ ) (top-down).

Fig. S219 - RP-HPLC elution profile (system B) of probe 13 (concentration: $1.0 \mu \mathrm{M}$ in PB) with PGA ( $\left.1 \mathrm{U}, 30 \mathrm{~min}, 37^{\circ} \mathrm{C}\right)$. UV detection at $260 \mathrm{~nm}$; UV detection at $400 \mathrm{~nm}$; ESI+ mass detection (SIM mode at $m / z 283.1 \pm 0.5$ ); ESI+/ESI- mass detection (SIM mode at $m / z 568.2$ \pm 0.5 and $566.2 \pm 0.5$ ) (top-down)

Fig. S220 - RP-HPLC elution profile (system B) of probe 13 (concentration: $1.0 \mu \mathrm{M}$ in PB) with PGA ( $1 \mathrm{U}, 30 \mathrm{~min}, 37^{\circ} \mathrm{C}$ ) and GSH (50 equiv.). UV detection at $260 \mathrm{~nm}$; UV detection at $400 \mathrm{~nm}$; $\mathrm{ESI}+$ mass detection (SIM mode at $\mathrm{m} / \mathrm{z} 283.1 \pm 0.5$ ); ESI+/ESI- mass detection (SIM mode at $m / z 568.2 \pm 0.5$ and $566.2 \pm 0.5$ ) (top-down) 146

Fig. S221 - RP-HPLC elution profile (system B) of blank (injection of PB alone). UV detection at $260 \mathrm{~nm}$; UV detection at $400 \mathrm{~nm}$; ESI+ mass detection (SIM mode at $\mathrm{m} / \mathrm{z} 313.1 \pm 0.5$ ); $\mathrm{ESI}+$ /ESI- mass detection (SIM mode at $m / z 598.2 \pm 0.5$ and $596.2 \pm 0.5$ ) (top-down).....147

Fig. S222 - RP-HPLC elution profile (system B) of probe 14 without PGA (concentration: 1.0 $\mu \mathrm{M}$ in $\mathrm{PB}, 30 \mathrm{~min}, 37^{\circ} \mathrm{C}$ ). UV detection at $260 \mathrm{~nm}$; UV detection at $400 \mathrm{~nm}$; ESI+ mass detection (SIM mode at $\mathrm{m} / \mathrm{z} 313.1 \pm 0.5$ ); ESI+/ESI- mass detection (SIM mode at $\mathrm{m} / \mathrm{z} 598.2$ \pm 0.5 and $596.2 \pm 0.5$ ) (top-down)

Fig. S223 - RP-HPLC elution profile (system B) of probe 14 (concentration: $1.0 \mu \mathrm{M}$ in PB) with PGA ( $\left.1 \mathrm{U}, 30 \mathrm{~min}, 37^{\circ} \mathrm{C}\right)$. UV detection at $260 \mathrm{~nm}$; UV detection at $400 \mathrm{~nm}$; ESI+ mass detection (SIM mode at $\mathrm{m} / \mathrm{z} 313.1 \pm 0.5$ ); ESI+/ESI- mass detection (SIM mode at $\mathrm{m} / \mathrm{z} 598.2$ \pm 0.5 and $596.2 \pm 0.5$ ) (top-down)

Fig. S224 - RP-HPLC elution profile (system B) of probe 14 (concentration: $1.0 \mu \mathrm{M}$ in PB) with PGA ( $1 \mathrm{U}, 30 \mathrm{~min}, 37^{\circ} \mathrm{C}$ ) and GSH (50 equiv.). UV detection at $260 \mathrm{~nm}$; UV detection at $400 \mathrm{~nm}$; ESI+ mass detection (SIM mode at $\mathrm{m} / \mathrm{z} 313.1 \pm 0.5$ ); ESI+/ESI- mass detection (SIM mode at $m / z 598.2 \pm 0.5$ and $596.2 \pm 0.5$ ) (top-down).

Fig. S225 - RP-HPLC elution profile (system B) of blank (injection of PB alone). UV detection at $260 \mathrm{~nm}$; UV detection at $400 \mathrm{~nm}$; ESI+ mass detection (SIM mode at $\mathrm{m} / z 351.1 \pm 0.5$ ); ESI+/ESI- mass detection (SIM mode at $m / z \quad 636.2 \pm 0.5$ and $634.2 \pm 0.5$ ) (top-down) .....152

Fig. S226 - RP-HPLC elution profile (system B) of probe 15 without PGA (concentration: 1.0 $\mu \mathrm{M}$ in $\mathrm{PB}, 90 \mathrm{~min}, 37^{\circ} \mathrm{C}$ ). UV detection at $260 \mathrm{~nm}$; UV detection at $400 \mathrm{~nm}$; ESI+ mass detection (SIM mode at $\mathrm{m} / \mathrm{z} 351.1 \pm 0.5$ ); $\mathrm{ESI}+\mathrm{ESI}$ - mass detection (SIM mode at $\mathrm{m} / \mathrm{z} 636.2$ \pm 0.5 and $634.2 \pm 0.5$ ) (top-down)

Fig. S227 - RP-HPLC elution profile (system B) of probe 15 (concentration: $1.0 \mu \mathrm{M}$ in PB) with PGA ( $\left.1 \mathrm{U}, 90 \mathrm{~min}, 37^{\circ} \mathrm{C}\right)$. UV detection at $260 \mathrm{~nm}$; UV detection at $400 \mathrm{~nm}$; ESI+ mass detection (SIM mode at $\mathrm{m} / \mathrm{z} 351.1 \pm 0.5$ ); ESI+/ESI- mass detection (SIM mode at $\mathrm{m} / \mathrm{z} 636.2$ \pm 0.5 and $634.2 \pm 0.5$ ) (top-down) 
Fig. S228 - RP-HPLC elution profile (system B) of probe 15 (concentration: $1.0 \mu \mathrm{M}$ in PB) with PGA ( $1 \mathrm{U}, 90 \mathrm{~min}, 37^{\circ} \mathrm{C}$ ) and GSH (50 equiv.). UV detection at $260 \mathrm{~nm}$; UV detection at $400 \mathrm{~nm} ; \mathrm{ESI}+$ mass detection (SIM mode at $\mathrm{m} / \mathrm{z} 351.1 \pm 0.5$ ); ESI+/ESI- mass detection (SIM mode at $m / z 636.2 \pm 0.5$ and $634.2 \pm 0.5$ ) (top-down). 156

Fig. S229 - RP-HPLC elution profile (system B) of blank (injection of PB alone). UV detection at $260 \mathrm{~nm}$; UV detection at $400 \mathrm{~nm}$; ESI+ mass detection (SIM mode at $\mathrm{m} / z 273.1 \pm 0.5$ ); ESI+/ESI- mass detection (SIM mode at $m / z 558.2 \pm 0.5$ and $556.2 \pm 0.5$ ) (top-down) .....158

Fig. S230 - RP-HPLC elution profile (system B) of probe 16 without PGA (concentration: 1.0 $\mu \mathrm{M}$ in $\mathrm{PB}, 30 \mathrm{~min}, 37^{\circ} \mathrm{C}$ ). UV detection at $260 \mathrm{~nm}$; UV detection at $400 \mathrm{~nm}$; ESI+ mass detection (SIM mode at $\mathrm{m} / \mathrm{z} 273.1 \pm 0.5$ ); ESI+/ESI- mass detection (SIM mode at $\mathrm{m} / \mathrm{z} 558.2$ \pm 0.5 and $556.2 \pm 0.5$ ) (top-down)

Fig. S231 - RP-HPLC elution profile (system B) of probe 16 (concentration: $1.0 \mu \mathrm{M}$ in PB) with PGA ( $\left.1 \mathrm{U}, 30 \mathrm{~min}, 37^{\circ} \mathrm{C}\right)$. UV detection at $260 \mathrm{~nm}$; UV detection at $400 \mathrm{~nm}$; ESI+ mass detection (SIM mode at $\mathrm{m} / \mathrm{z} 273.1 \pm 0.5$ ); ESI+/ESI- mass detection (SIM mode at $\mathrm{m} / \mathrm{z} 558.2$ \pm 0.5 and $556.2 \pm 0.5$ ) (top-down) 160

Fig. S232 - RP-HPLC elution profile (system B) of probe 16 (concentration: $1.0 \mu \mathrm{M}$ in PB) with PGA ( $\left.1 \mathrm{U}, 30 \mathrm{~min}, 37^{\circ} \mathrm{C}\right)$ and GSH (50 equiv.). UV detection at $260 \mathrm{~nm}$; UV detection at $400 \mathrm{~nm}$; ESI+ mass detection (SIM mode at $\mathrm{m} / z 273.1 \pm 0.5$ ); ESI+/ESI- mass detection (SIM mode at $m / z 558.2 \pm 0.5$ and $556.2 \pm 0.5$ ) (top-down)

Fig. S233 - RP-HPLC elution profile (system B) of blank (injection of PB alone). UV detection at $260 \mathrm{~nm}$; UV detection at $400 \mathrm{~nm}$; ESI+ mass detection (SIM mode at m/z $289.1 \pm 0.5$ ); ESI+/ESI- mass detection (SIM mode at $\mathrm{m} / \mathrm{z} 574.2 \pm 0.5$ and $572.2 \pm 0.5$ ) (top-down) .....163

Fig. S234 - RP-HPLC elution profile (system B) of probe 17 without PGA (concentration: 1.0 $\mu \mathrm{M}$ in $\mathrm{PB}, 30 \mathrm{~min}, 37^{\circ} \mathrm{C}$ ). UV detection at $260 \mathrm{~nm}$; UV detection at $400 \mathrm{~nm} ; \mathrm{ESI}+$ mass detection (SIM mode at $\mathrm{m} / \mathrm{z} 289.1 \pm 0.5$ ); ESI+/ESI- mass detection (SIM mode at $\mathrm{m} / \mathrm{z} 574.2$ \pm 0.5 and $572.2 \pm 0.5$ ) (top-down)

Fig. S235 - RP-HPLC elution profile (system B) of probe 17 (concentration: $1.0 \mu \mathrm{M}$ in PB) with PGA ( $\left.1 \mathrm{U}, 30 \mathrm{~min}, 37^{\circ} \mathrm{C}\right)$. UV detection at $260 \mathrm{~nm}$; UV detection at $400 \mathrm{~nm}$; ESI+ mass detection (SIM mode at $\mathrm{m} / \mathrm{z} 289.1 \pm 0.5$ ); ESI+/ESI- mass detection (SIM mode at $\mathrm{m} / \mathrm{z} 574.2$ \pm 0.5 and $572.2 \pm 0.5)$ (top-down) 166

Fig. S236 - RP-HPLC elution profile (system B) of probe 17 (concentration: $1.0 \mu \mathrm{M}$ in PB) with PGA ( $1 \mathrm{U}, 30 \mathrm{~min}, 37^{\circ} \mathrm{C}$ ) and GSH (50 equiv.). UV detection at $260 \mathrm{~nm}$; UV detection at $400 \mathrm{~nm} ; \mathrm{ESI}+$ mass detection (SIM mode at $\mathrm{m} / \mathrm{z} 289.1 \pm 0.5$ ); ESI+/ESI- mass detection (SIM mode at $m / z 574.2 \pm 0.5$ and $572.2 \pm 0.5$ ) (top-down)

Fig. S237 - RP-HPLC elution profile (system B) of blank (injection of PB alone). UV detection at $260 \mathrm{~nm}$; UV detection at $400 \mathrm{~nm}$; ESI+ mass detection (SIM mode at $\mathrm{m} / \mathrm{z} 337.0 \pm 0.5$ ); $\mathrm{ESI}+/ \mathrm{ESI}$ - mass detection (SIM mode at $\mathrm{m} / \mathrm{z} 622.1 \pm 0.5$ and $620.1 \pm 0.5$ ) (top-down) .....168

Fig. S238 - RP-HPLC elution profile (system B) of probe 18 without PGA (concentration: 1.0 $\mu \mathrm{M}$ in $\mathrm{PB}, 30 \mathrm{~min}, 37^{\circ} \mathrm{C}$ ). UV detection at $260 \mathrm{~nm}$; UV detection at $400 \mathrm{~nm}$; ESI+ mass detection (SIM mode at $m / z 337.0 \pm 0.5$ ); ESI+/ESI- mass detection (SIM mode at $m / z 622.1$ \pm 0.5 and $620.1 \pm 0.5$ ) (top-down)

Fig. S239 - RP-HPLC elution profile (system B) of probe 18 (concentration: $1.0 \mu \mathrm{M}$ in PB) with PGA ( $\left.1 \mathrm{U}, 30 \mathrm{~min}, 37^{\circ} \mathrm{C}\right)$. UV detection at $260 \mathrm{~nm}$; UV detection at $400 \mathrm{~nm}$; ESI+ mass 
detection (SIM mode at $\mathrm{m} / \mathrm{z} 337.0 \pm 0.5$ ); ESI+/ESI- mass detection (SIM mode at $\mathrm{m} / \mathrm{z} 622.1$ \pm 0.5 and $620.1 \pm 0.5$ ) (top-down)

Fig. S240 - RP-HPLC elution profile (system B) of probe 18 (concentration: $1.0 \mu \mathrm{M}$ in PB) with PGA ( $1 \mathrm{U}, 30 \mathrm{~min}, 37^{\circ} \mathrm{C}$ ) and GSH (50 equiv.). UV detection at $260 \mathrm{~nm}$; UV detection at $400 \mathrm{~nm}$; ESI+ mass detection (SIM mode at $\mathrm{m} / z 337.0 \pm 0.5$ ); ESI+/ESI- mass detection (SIM mode at $m / z 622.1 \pm 0.5$ and $620.1 \pm 0.5$ ) (top-down) ................................................172

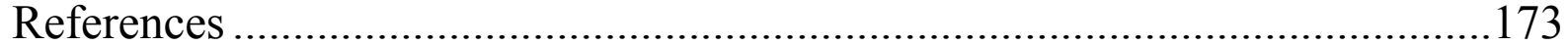




\section{Abbreviations}

The following abbreviations are used throughout the text of the ESI file: Abs, absorption; aq., aqueous; Ar, argon; ATR, attenuated total reflectance; BBOF, double resonance broadband observe; C153, coumarin 153 or 2,3,6,7-tetrahydro-9-(trifluoromethyl)- $1 \mathrm{H}, 5 \mathrm{H}, 11 \mathrm{H}$ [1]benzopyrano[6,7,8-ij]quinolizin-11-one; DAD, diode array detector/detection; DCM, dichloromethane; DMF, $N, N$-dimethylformamide; DMSO, dimethylsulfoxide; EDC.HCl, 1ethyl-3-(3-dimethylaminopropyl)carbodiimide hydrochloride; Em., emission; ESI, electrospray ionization; EtOAc, ethyl acetate; Ex., excitation; FA, formic acid; FCS, fetal calf serum; FLD, fluorescence detector; FT, Fourier transform; $\mathrm{H}_{2} \mathrm{O}$, water; HOBt, 1hydroxybenzotriazole; HPLC, high-pressure liquid chromatography; HRMS, high-resolution mass spectrum; IR, infrared; LRMS, low-resolution mass spectrum; MeCN, acetonitrile; $\mathrm{MeOH}$, methanol; min, minutes; NMR, nuclear magnetic resonance; PACSMUB, plateforme d'analyse chimique et de synthèse moléculaire de l'université de bourgogne; $\mathrm{PB}$, phosphate buffer; PBS, phosphate buffered saline; PFA, paraformaldehyde; PGA, penicillin G acylase; PhAc-PABA, para-( $N$-phenylacetamido)benzyl alcohol; MS, mass spectrometry; PLC, preparative layer plate; PMT, photomultiplier tube; RP, reversed-phase; rpm, revolution per minute; RPMI, Roswell park memorial institute medium; RS, rapid separation; rt, room temperature; SIM, selected ion monitoring; SR, saturation recovery; TBO, triple resonance broadband; TFA, trifluoroacetic acid; TMS, tetramethylsilane; $t_{\mathrm{R}}$, retention time; UV, ultraviolet; vis, visible.

\section{S1 Experimental section}

\section{General}

Unless otherwise noted, all commercially available reagents and solvents were used without further purification. TLC were carried out on Merck Millipore DC Kieselgel 60 F-254 aluminum sheets. The spots were directly visualized or through illumination with UV lamp ( $\lambda$ $=254 / 365 \mathrm{~nm}$ ). Flash-column chromatography purifications were performed on silica gel (40$63 \mu \mathrm{m})$ from VWR. DMF was purchased from Carlo Erba and dried through storage over $3 \AA$ molecular sieves and Ar atmosphere. TFA and PGA (from Escherichia coli, \#EZ50150, 841 $\mathrm{U} / \mathrm{mL}$ ) were provided by Iris Biotech GmbH. DMSO (for spectrophotometry, \#D5293) and glutathione (reduced form, GSH, 98\%) were provided by TCI Europe and Acros Organics respectively. Absolute EtOH and n-pentane (for analysis, RPE) were provided by Carlo Erba. The HPLC-gradient grade MeCN used for RP-HPLC analyses was obtained from Carlo Erba or VWR. Formic acid (FA, puriss p.a., ACS reagent, reag. Ph. Eur., $\geq 98 \%$ ) was provided by Merck-Millipore (brand Sigma-Aldrich). All aq. buffers used in this work and aq. mobilephases for HPLC were prepared using water purified with a PURELAB Ultra system from ELGA (purified to $18.2 \mathrm{M} \Omega . \mathrm{cm}$ ).

\section{Instrument and methods}

${ }^{1} \mathrm{H}-,{ }^{13} \mathrm{C}$-, ${ }^{19} \mathrm{~F}$ - and ${ }^{77} \mathrm{Se}-\mathrm{NMR}$ spectra were recorded either on a Bruker Avance NEO $400 \mathrm{MHz}$ (equipped with a $5 \mathrm{~mm}$ TBO probe) or $500 \mathrm{MHz}$ (equipped with a $5 \mathrm{~mm}$ BBOF iProbe), or on a Bruker Avance III HD $600 \mathrm{MHz}$ spectrometer (equipped with a BBOF $\mathrm{N}_{2}$ cryoprobe). NMR spectroscopy chemical shifts are quoted in parts per million $(\delta)$ relative to TMS (for ${ }^{1} \mathrm{H}$, and ${ }^{13} \mathrm{C}$ ), $\mathrm{CFCl}_{3}$ (for ${ }^{19} \mathrm{~F}$ ) or $\mathrm{Me}_{2} \mathrm{Se}$ (for ${ }^{77} \mathrm{Se}$ ). For ${ }^{1} \mathrm{H}$ and ${ }^{13} \mathrm{C}$ spectra, calibration was made by using residual signals of partially deuterated solvent summarized in 2010 by Fulmer et al. ${ }^{1}$ For all other nuclei, SR value obtained after zero-calibration of the corresponding reference was applied. $J$ values are expressed in Hz. IR spectra were recorded with a Bruker Alpha FT-IR spectrometer equipped with a universal ATR sampling accessory. The bond vibration 
frequencies are expressed in reciprocal centimeters $\left(\mathrm{cm}^{-1}\right)$ and rounded to the nearest $\mathrm{cm}^{-1}$ (no decimal). HPLC-MS analyses were performed on a Thermo-Dionex Ultimate 3000 instrument (pump + autosampler at $20^{\circ} \mathrm{C}+$ column oven at $25^{\circ} \mathrm{C}$ ) equipped with a diode array detector (Thermo-Dionex DAD 3000-RS) and MSQ Plus single quadrupole mass spectrometer. Purifications by semi-preparative HPLC were performed on a Thermo-Dionex Ultimate 3000 instrument (semi-preparative pump HPG-3200BX) equipped with a RS Variable Detector (VWD-3400RS, four distinct wavelengths within the range 190-800 $\mathrm{nm}$ ). Lyophilization operations were performed with a Christ Alpha 2-4 LD plus. Centrifugation operations were performed with a Thermo Scientific Espresso Personal Microcentrifuge instrument. TFA mass content of samples purified by semi-preparative was determined by ion chromatography according to a method developed by the PACMSUB staff. ${ }^{2}$ Such analyses were performed with an ion chromatograph Thermo Scientific Dionex ICS 5000 equipped with a conductivity detector CD (Thermo Scientific Dionex) and a conductivity suppressor ASRS-ultra II $4 \mathrm{~mm}$ (Thermo Scientific Dionex). Low-resolution mass spectra (LRMS) were recorded on a Thermo Scientific MSQ Plus single quadrupole equipped with an electrospray (ESI) source (LC-MS coupling mode). High-resolution mass spectra (HRMS) were recorded on a Thermo Scientific LTQ Orbitrap XL apparatus equipped with an ESI source.

UV-vis absorption measurements (scan mode) were conducted on a Varian Cary 50 Scan spectrophotometer using rectangular quartz cells (Hellma, 100-QS, $45 \times 12.5 \times 12.5 \mathrm{~mm}$, pathlength: $10 \mathrm{~mm}$, chamber volume: $3.5 \mathrm{~mL}$ ), at $25{ }^{\circ} \mathrm{C}$ (using a temperature control system combined with water circulation). Fluorescence spectroscopic studies (scan and kinetics modes) were performed with an HORIBA Jobin Yvon Fluorolog spectrofluorimeter (software FluorEssence) at $25{ }^{\circ} \mathrm{C}$ or $37{ }^{\circ} \mathrm{C}$ (using a temperature control system combined with water circulation), with a standard fluorometer cell (Labbox, LB Q, light path: $10 \mathrm{~mm}$, width: $10 \mathrm{~mm}$, chamber volume: $3.5 \mathrm{~mL}$ ). The absorption spectra of quinoxalin-2 $(1 H)$-one fluorophores 1-8 were recorded in phosphate buffer $(\mathrm{PB}, 100 \mathrm{mM}, \mathrm{pH} 7.5)$ with concentrations in the range 5$25 \mu \mathrm{M}$ (total volume $=3.0 \mathrm{~mL}$, three distinct dilutions for the accurate determination of molar extinction coefficients). Ex./Em. spectra were recorded after emission/excitation at the suitable wavelength (set of parameters for Fluorolog: shutter: Auto Open, excitation slit $=5 \mathrm{~nm}(2 \mathrm{~nm}$ for measurements in kinetics mode) and emission slit $=5 \mathrm{~nm}(2 \mathrm{~nm}$ for measurements in kinetics mode), integration time $=0.1 \mathrm{~s}, 1 \mathrm{~nm}$ step, $\mathrm{HV}(\mathrm{S} 1)=950 \mathrm{~V})$. All fluorescence spectra were corrected. Relative fluorescence quantum yields were measured in the corresponding buffer at $25^{\circ} \mathrm{C}$ by a relative method using the suitable standard (see Tables S1 and S2). The following equation was used to determine the relative fluorescence quantum yield:

$$
\Phi_{\mathrm{F}}(\mathrm{x})=\left(\mathrm{A}_{\mathrm{S}} / \mathrm{A}_{\mathrm{X}}\right)\left(\mathrm{F}_{\mathrm{X}} / \mathrm{F}_{\mathrm{S}}\right)\left(\mathrm{n}_{\mathrm{X}} / \mathrm{n}_{\mathrm{S}}\right)^{2} \Phi_{\mathrm{F}}(\mathrm{s})
$$

where $\mathrm{A}$ is the absorbance (in the range of 0.01-0.1 A.U.), $\mathrm{F}$ is the area under the emission curve, $\mathrm{n}$ is the refractive index of the solvents (at $25^{\circ} \mathrm{C}$ ) used in measurements, and the subscripts $\mathrm{s}$ and $\mathrm{x}$ represent standard and unknown, respectively. 
Table S1. Photophysical properties of quinoxalin-2(1H)-ones studied in this work, determined in $\mathrm{PB}(\mathrm{pH} 7.5)$ at $25{ }^{\circ} \mathrm{C}$.

\begin{tabular}{cccccc}
\hline Fluorophore $^{a}$ & $\lambda$ Abs $(\mathrm{nm})$ & $\begin{array}{c}\lambda \mathrm{Em} . \\
(\mathrm{nm})\end{array}$ & $\varepsilon\left(\mathrm{M}^{-1} \mathrm{~cm}^{-1}\right)$ & $\begin{array}{c}\text { Stokes shift } \\
\left(\mathrm{cm}^{-1}\right)^{b}\end{array}$ & $\Phi_{\mathrm{F}}{ }^{c}$ \\
\hline $\mathbf{1}$ & 361 & 454 & 10600 & 5674 & 0.47 \\
$\mathbf{2}$ & $310 / 387$ & 476 & $4200 / 12000$ & 4831 & 0.60 \\
$\mathbf{3}$ & $319 / 391$ & 474 & $5700 / 15400$ & 4478 & 0.59 \\
$\mathbf{4}$ & $236 / 273 /$ & 492 & $13700 / 7700$ & 5514 & 0.19 \\
& 387 & & $/ 11600$ & & \\
$\mathbf{5}$ & $258 / 345 /$ & 481 & $6000 / 8300 /$ & 3901 & 0.37 \\
$\mathbf{6}$ & 405 & 18600 & 5373 & 0.20 \\
$\mathbf{7}$ & $277 / 386$ & 487 & $8600 / 12900$ & 5921 & 0.06 \\
$\mathbf{8}$ & 381 & 492 & 8700 & 5921 & $<0.01$
\end{tabular}

${ }^{a}$ stock solutions $(1.0 \mathrm{mg} / \mathrm{mL})$ of fluorophores were prepared in spectroscopic grade DMSO.

${ }^{b}$ for fluorophores showing several distinct absorption maxima, Stokes shift was calculated using the red-shift absorption maximum value.

${ }^{c}$ mean between the two close values determined using quinine sulfate $\left(\Phi_{F}=54 \% \text { in } 0.05 \mathrm{M} \mathrm{H}_{2} \mathrm{SO} \text {, Ex at } 366 \mathrm{~nm}\right)^{3}$ and 7-hydroxycoumarin $\left(\Phi_{F}=76 \% \text { in } P B \mathrm{pH} 7.5, \text { Ex at } 366 \mathrm{~nm}\right)^{4}$ as standards respectively. The following refractive indexes have been used: 1.333 for $0.05 \mathrm{M} \mathrm{H}_{2} \mathrm{SO}_{4}$ and 1.337 for $\mathrm{PB}$.

Table S2. Photophysical properties of quinoxalin-2 $(1 H)$-ones studied in this work, determined in DMSO at $25^{\circ} \mathrm{C}$.

\begin{tabular}{|c|c|c|c|c|c|}
\hline Fluorophore $^{a}$ & $\lambda$ Abs $(\mathrm{nm})$ & $\begin{array}{l}\lambda \mathrm{Em} . \\
(\mathrm{nm})\end{array}$ & $\varepsilon\left(\mathrm{M}^{-1} \mathrm{~cm}^{-1}\right)$ & $\begin{array}{l}\text { Stokes shift } \\
\left(\mathrm{cm}^{-1}\right)^{b}\end{array}$ & $\Phi_{\mathrm{F}}^{c}$ \\
\hline 1 & $298 / 363$ & 435 & $2500 / 9700$ & 4560 & 0.57 \\
\hline 2 & $316 / 400$ & 475 & $6000 / 13900$ & 3947 & 0.83 \\
\hline 3 & $326 / 403$ & 473 & $6300 / 16700$ & 3672 & $-d$ \\
\hline 4 & $322 / 412$ & 494 & $8500 / 18800$ & 4023 & $0.62^{e}$ \\
\hline 5 & $\begin{array}{c}328 / 407 / \\
428\end{array}$ & 473 & $\begin{array}{c}7200 / 17800 \\
/ 15400\end{array}$ & 3428 & 0.62 \\
\hline 6 & $\begin{array}{c}335 / 416 / \\
436\end{array}$ & 485 & $\begin{array}{c}8700 / 27400 \\
/ 24100\end{array}$ & 3420 & $0.54^{e}$ \\
\hline 7 & $412 / 433$ & 442 & $\begin{array}{c}14200 / \\
12800\end{array}$ & 1647 & 0.25 \\
\hline 8 & $\begin{array}{c}385 / 402 / \\
424\end{array}$ & 462 & $\begin{array}{c}21600 / 32 \\
100 / 27900\end{array}$ & 3230 & $-d$ \\
\hline \multicolumn{6}{|c|}{$\begin{array}{l}\text { a stock solutions }(1.0 \mathrm{mg} / \mathrm{mL}) \text { of fluorophores were prepared in spectroscopic grade DMSO. } \\
\text { b for fluorophores showing several distinct absorption maxima, Stokes shift was calculated using the red-shift } \\
\text { absorption maximum value, except for } 5(407 \mathrm{~nm} \text {, characterized by the highest value of } \varepsilon), 6(416 \mathrm{~nm} \text {, } \\
\text { characterized by the highest value of } \varepsilon), 7(412 \mathrm{~nm} \text {, characterized by the highest value of } \varepsilon) \text { and } 8(402 \mathrm{~nm} \text {, } \\
\text { characterized by the highest value of } \varepsilon) \text {. }\end{array}$} \\
\hline
\end{tabular}


${ }^{c}$ mean between the two close values determined using quinine sulfate $\left(\Phi_{F}=54 \%\right.$ in $0.05 \mathrm{M} \mathrm{H}_{2} \mathrm{SO}_{4}$, Ex. at 366 $\mathrm{nm})^{3}$ and 7-hydroxycoumarin $\left(\Phi_{F}=76 \% \text { in } \mathrm{PB} \mathrm{pH} \mathrm{7.5,} \mathrm{Ex.} \mathrm{at} 366 \mathrm{~nm}\right)^{4}$ as standards respectively. The following refractive indexes have been used: 1.333 for $0.05 \mathrm{M} \mathrm{H}_{2} \mathrm{SO}_{4}, 1.337$ for $\mathrm{PB}$, and 1.478 for DMSO.

${ }^{d}$ a non-linear relationship between Abs at $366 \mathrm{~nm}$ and fluorescence emission intensity (area under the emission curve, within the range 380-700 $\mathrm{nm}$ ) was obtained.

e relative fluorescence quantum yield was determined using C153 as standard ( $\Phi_{F}=38 \%$ in EtOH, Ex. at 421 $n m)^{3}$, refractive index for $\mathrm{EtOH}=1.362$.

\section{High-performance liquid chromatography separations}

Several chromatographic systems were used for the analytical experiments (HPLC-MS or HPLC-fluorescence) and the purification steps:

System A: RP-HPLC-MS (Phenomenex Kinetex $\mathrm{C}_{18}$ column, $2.6 \mu \mathrm{m}, 2.1 \times 50 \mathrm{~mm}$ ) with $\mathrm{MeCN}$ $(+0.1 \% \mathrm{FA})$ and $0.1 \%$ aq. formic acid (aq. FA, $\mathrm{pH} 2.5)$ as eluents [5\% $\mathrm{MeCN}(0.1 \mathrm{~min})$ followed by a linear gradient from $5 \%$ to $100 \%$ ( $5 \mathrm{~min}$ ) of $\mathrm{MeCN}$, then $100 \% \mathrm{MeCN}$ (3 min)] at a flow rate of $0.5 \mathrm{~mL} / \mathrm{min}$. UV-visible detection was achieved at 220, 260, 450 and $500 \mathrm{~nm}(+\mathrm{DAD}$ in the range 220-700 nm). Low resolution ESI-MS detection in the positive/negative mode (full scan, $100-1000$ a.m.u., data type: centroid, needle voltage: $3.0 \mathrm{kV}$, probe temperature: $350^{\circ} \mathrm{C}$, cone voltage: $75 \mathrm{~V}$ and scan time: $1 \mathrm{~s}$ ). System B: system A with UV-visible detection at 220, 260, 365 and $400 \mathrm{~nm}$ (+ DAD in the range 220-800 nm). Low resolution ESI-MS detection in the positive/negative mode (full scan, 100-1000 a.m.u. and SIM mode (ESI+ and/or ESI- at the corresponding $\mathrm{m} / \mathrm{z}$ value, specific to each probe or fluorophore, vide infra). System C: RPHPLC-MS (Phenomenex Kinetex $\mathrm{C}_{18}$ column, $\left.2.6 \mu \mathrm{m}, 2.1 \times 50 \mathrm{~mm}\right)$ with $\mathrm{MeCN}(+0.1 \% \mathrm{FA})$ and $0.1 \%$ aq. $\mathrm{FA},(\mathrm{pH} 2.5)$ as eluents $[0 \% \mathrm{MeCN}(3 \mathrm{~min})$ followed by linear gradient from $0 \%$ to $100 \%$ ( $5 \mathrm{~min}$ ) of $\mathrm{MeCN}$ ] at a flow rate of $0.5 \mathrm{~mL} / \mathrm{min}$. UV-visible detection was achieved at 220, 230, 260 and $300 \mathrm{~nm}$ (+ DAD in the range 220-700 nm). Low resolution ESI-MS detection in the positive/negative mode (full scan, 100-1000 a.m.u., data type: centroid, needle voltage: $3.0 \mathrm{kV}$, probe temperature: $350{ }^{\circ} \mathrm{C}$, cone voltage: $75 \mathrm{~V}$ and scan time: $1 \mathrm{~s}$ ). System D: semipreparative RP-HPLC (SiliCycle SiliaChrom $\mathrm{C}_{18}$ column, $10 \mu \mathrm{m}, 20 \times 250 \mathrm{~mm}$ ) with $\mathrm{MeCN}$ and aq. $0.1 \%$ TFA ( $\mathrm{pH} 2.0)$ as eluents [ $10 \% \mathrm{MeCN}$ ( $5 \mathrm{~min})$, followed by a linear gradient from $10 \%$ to $25 \% \mathrm{MeCN}(7.5 \mathrm{~min})$, then $25 \%$ to $100 \% \mathrm{MeCN}(87.5 \mathrm{~min})]$ at a flow rate of 20.0 $\mathrm{mL} / \mathrm{min}$. Quadruple UV-vis detection was achieved at 220, 270, 415 and $440 \mathrm{~nm}$. System E: RP-HPLC-fluorescence (Phenomenex Kinetex $\mathrm{C}_{18}$ column, $2.6 \mu \mathrm{m}, 2.1 \times 50 \mathrm{~mm}$ ) with same eluents and gradient as system A. Fluorescence detection was achieved at $45^{\circ} \mathrm{C}$ at the following Ex./Em. channels: 365/455 nm, 380/480 nm, 390/475 nm, 385/490 nm, 405/480 nm, 390/480 $\mathrm{nm}$ and 380/490 nm (sensitivity: 1, PMT 1, filter wheel: auto).

\section{Fluorescence imaging in fixed cells with quinoxalin-2(1H)-ones 2 and 8}

\section{Cell culture}

Cancer cell lines were obtained from the American type Culture Collection (Rockville, USA) and were cultured according to the supplier's instructions. A459 cells were grown in Lab-Teck ${ }^{\circledR}$ plates using RPMI 1640 containing 10\% FCS and $1 \%$ glutamine. They were maintained at 37 ${ }^{\circ} \mathrm{C}$ in a humidified atmosphere containing $5 \% \mathrm{CO}_{2}$. After enough confluence was obtained, the medium was removed and replaced by a solution of fluorophore $(5.0 \mu \mathrm{M}$ in RPMI medium, prepared from a stock solution of fluorophore in DMSO, final concentration in DMSO $=0.5 \%$, please note: no problem of solubility was noted). The cells were incubated for $2 \mathrm{~h}$ at $37{ }^{\circ} \mathrm{C}$ in a humidified atmosphere containing $5 \% \mathrm{CO}_{2}$. The fluorophore solution was then removed and the cells were washed thrice with PBS (1X) at rt. A 4\% solution of PFA in PBS was then added and the cells were incubated at $\mathrm{rt}$ for 15 min until fixation. After removing the PFA solution, cells were washed thrice with PBS (1X) then prepared for microscopy. 


\section{Fluorescence microscopy}

Once cell fixation is made, the culture chambers were removed and the microscope slide was prepared using Neo-Mount mounting medium. Fluorescence images were acquired using a Leica SP8-X inverted confocal microscope with a $40 \times$ oil immersion objective (HC PL APO CS2 Leica). Excitation was performed using a pulsed Diode $405 \mathrm{~nm}$ (Leica, $50 \mathrm{~mW}$ ). Detection was performed by using PMT detector (Hamamatsu 6357) collecting photons from $430 \mathrm{~nm}$ to $600 \mathrm{~nm}$.

\section{In vitro activation of "covalent-assembly" type probes 12-18 by PGA - experimental details}

\section{Stock solutions of probes, enzyme and GSH}

- Solutions Ax (x=12-18): a stock solution $(1.0 \mathrm{mg} / \mathrm{mL})$ of probe in DMSO (spectrophotometry grade),

- Solution B: Commercial PGA solution $(841 \mathrm{U} / \mathrm{mL})$ directly used without dilution,

- Solution C: a stock solution $(1.0 \mathrm{mg} / \mathrm{mL}, 3.25 \mathrm{mM})$ of GSH in DMSO (spectrophotometry grade).

\section{Fluorescence assays}

All assays were performed at $37{ }^{\circ} \mathrm{C}$ (using a temperature control system combined with water circulation and conducted with magnetic stirring). For all probes 12-18 (final concentration in $3.5 \mathrm{~mL}$ fluorescence quartz cell: $1 \mu \mathrm{M}$, volume: $3.0 \mathrm{~mL}$ of $\mathrm{PB}, \mathrm{pH} 7.6)$, the fluorescence emission of the released corresponding quinoxalin-2(1H)-one was monitored at $\lambda(\mathrm{Ex} . / \mathrm{Em})=$. $365 / 455 \mathrm{~nm}$ (for 12), 380/480 nm (for 13), 390/475 nm (for 14), 385/490 nm (for 15), 405/480 $\mathrm{nm}$ (for 16), 390/480 $\mathrm{nm}$ (for 17) and 380/490 nm (for 18), slit $=2 \mathrm{~nm}$, over time with measurements recorded every $5 \mathrm{~s} .1 \mathrm{U}$ of PGA $(1.2 \mu \mathrm{L}$ of solution B) was added after 5 min of incubation of the probe in PB. Blank experiments to assess the stability of the probes in PB, were achieved in the same way but without adding the enzyme.

For the kinetics performed in the presence of GSH (50 equiv.) with PGA, $46.0 \mu \mathrm{L}$ of solution $\mathrm{C}$ was added after 5 min of incubation of the probe in PB, and $1 \mathrm{U}$ of PGA (1.2 $\mu \mathrm{L}$ of solution B) was added after 5 min of incubation of the probe with GSH (50 equiv.).

\section{RP-HPLC-fluorescence and RP-HPLC-MS (full scan and SIM modes) analyses}

Enzymatic reaction mixtures from fluorescence-based in vitro assays were directly analyzed by RP-HPLC-fluorescence after an incubation time of 30 min (injected volume: $20 \mu \mathrm{L}$, system E). Thereafter, each enzymatic reaction mixture (ca. $3 \mathrm{~mL}$ ) was freeze-dried; the resulting white amorphous powder was dissolved in a $1: 1(\mathrm{v} / \mathrm{v})$ mixture of ultrapure $\mathrm{H}_{2} \mathrm{O}$ and $\mathrm{MeCN}$ (total volume $=400 \mu \mathrm{L})$. The solution was vortexed followed by centrifugation (9000 rpm, $1 \mathrm{~min})$. $20 \mu \mathrm{L}$ of supernatant was injected into the HPLC-MS apparatus (system B).

Please note: injection of $P B$ was also achieved immediately prior to this latter analysis, especially to confirm the lack of residual contaminants within the C18 column or ESI probe at the corresponding $\mathrm{m} / \mathrm{z}$ value selected for the SIM detection mode and then avoid misinterpretations

For RP-HPLC (fluorescence or MS detection) analyses of pure quinoxalin-2(1H)-one samples, $1.0 \mu \mathrm{M}$ solution in PB was prepared and $20 \mu \mathrm{L}$ was injected into the HPLC-fluorescence/MS apparatus (systems B and E). 
For "co-injection" analysis, $250 \mu \mathrm{L}$ of sample from enzymatic activation (vide supra) combined to $250 \mu \mathrm{L}$ of $1.0 \mu \mathrm{M}$ solution of quinoxalin-2(1H)-one. $20 \mu \mathrm{L}$ was injected into the

HPLC-fluorescence/MS apparatus (system E).

\section{Synthesized compounds}

Pyruvic acid (Acros Organics), benzoylformic acid (Acros Organics), 4'-hydroxyacetophenone (Acros Organics), 4'-(trifluoromethyl)acetophenone (Acros Organics), $\alpha$-oxo-2-furanacetic acid (Merck-Millipore, Sigma-Aldrich), 2-acetylthiophene (Merck-Millipore, Sigma-Aldrich), selenophene (Acros Organics) and indole-3-glyoxylyl chloride (Alfa Aesar) were commercially available. Other $\alpha$-oxocarboxylic acids were prepared by $\mathrm{SeO}_{2}$-mediated oxidation of the corresponding $\alpha$-methylketones (4'-methoxyacetophenone, 4'(trifluoromethyl)-acetophenone, 2-acetylthiophene), according to literature procedures. ${ }^{5}$ 4'-Methoxyacetophenone [100-06-1] was synthesized through $O$-methylation of 4'-hydroxyacetophenone. ${ }^{6}$ 4,5-Dimethoxy-1,2phenylenediamine 9 [27841-33-4] and para-nitrophenyl para-( $N$-phenylacetamido)benzyl carbonate 10 [701913-55-5] were prepared according to literatures procedures. ${ }^{7}$

Please note: 4,5-dimethoxy-1,2-phenylenediamine 9 was found to be partially unstable over prolonged storage (degradation was observed after less than 2 months at $-20{ }^{\circ} \mathrm{C}$ and under argon atmosphere), it was prepared immediately prior to use by hydrogenation over $\mathrm{Pd} / \mathrm{C}$ catalyst of commercial, stable 4,5-dinitroveratrole.

Please note: selenophene and its derivatives are highly hazardous substances (danger of cumulative effects, toxic by inhalation and if swallowed, highly flammable, very toxic for (aquatic) environment). For handling these chemicals, please work under a well-ventilated fume hood, wear protective gloves (two pairs) and goggles. Please oxidize all residual/trace amounts of selenophene derivatives (assumed to be present in syringues, needles, aq. phases after extraction, on the outer surface of the gloves, ...) by overnight incubation with bleach, $\mathrm{H}_{2} \mathrm{O}_{2}$ and EtOH. The resulting solutions will be next transferred into a special tank devoted to the storage of heavy metal wastes. Thereafter, this tank will be collected and treated by a specialist firm.

\section{2-Acetylselenophene [149066-23-9]}

This $\alpha$-methylketone was prepared from selenophene and acetyl chloride under Friedel-Crafts conditions. ${ }^{8}{ }^{77} \mathrm{Se}\left(114.5 \mathrm{MHz}, \mathrm{DMSO}-d_{6}\right): \delta=630.6$ (s, 1Se). All other spectroscopic data are identical to those reported by Trofimov et al.

$\alpha$-Oxo-2-selenopheneacetic acid [87787-77-7]

SMILES $=\mathrm{OC}(\mathrm{C}(\mathrm{C} 1=\mathrm{CC}=\mathrm{C}[\mathrm{Se}] 1)=\mathrm{O})=\mathrm{O}$

$\mathrm{InChI}=1 \mathrm{~S} / \mathrm{C} 6 \mathrm{H} 4 \mathrm{O} 3 \mathrm{Se} / \mathrm{c} 7-5(6(8) 9) 4-2-1-3-10-4 / \mathrm{h} 1-3 \mathrm{H},(\mathrm{H}, 8,9)$

InChIKey $=$ XCDCTDKIUDROAM-UHFFFAOYSA-N

2-Acetylselenophene (350 mg, $2.01 \mathrm{mmol}, 1$ equiv.) was solubilized in pyridine $(8 \mathrm{~mL})$ and $\mathrm{SeO}_{2}$ (268 mg, $2.41 \mathrm{mmol}, 1.2$ equiv.) was added. The resulting reaction mixture was stirred at $110{ }^{\circ} \mathrm{C}$ for $1 \mathrm{~h}$ and at $90{ }^{\circ} \mathrm{C}$ for $5 \mathrm{~h}$ (heath source: oil bath). The reaction was checked for completion by TLC (EtOAc-MeOH, 7:3, v/v). Then, the mixture was filtered and the filtrate was acidified to $\mathrm{pH} 1$ with $1.0 \mathrm{M}$ aq. $\mathrm{HCl}$. The aqueous phase was extracted thrice with EtOAc, 
dried over anhydrous $\mathrm{MgSO}_{4}$, filtered and concentrated under reduced pressure. The resulting residue was purified by flash-column chromatography over silica gel (eluent: step gradient of $\mathrm{MeOH}$ in EtOAc from $0 \%$ to $30 \%$ ) to give $\alpha$-oxo-2-selenopheneacetic acid as white amorphous powder (321 mg, $1.66 \mathrm{mmol}$, yield 79\%). $\mathrm{R}_{\mathrm{f}}($ EtOAc-MeOH, 7:3, v/v) $=0.51$; IR (ATR, neat): $v=3318,3096,2959,2926,2855,1729,1616,1513,1464,1413,1394$, $1379,1333,1241,1195,1081,1042,964,868,808,781,756,718,694{ }^{1} \mathrm{H}$ NMR $(500$ MHz, DMSO- $\left.d_{6}\right): \delta=8.62(\mathrm{~s}, 1 \mathrm{H}), 8.04(\mathrm{~s}, 1 \mathrm{H}), 7.54-7.34(\mathrm{~m}, 1 \mathrm{H}) ;{ }^{13} \mathrm{C}$ NMR $(126 \mathrm{MHz}$, $\left.\mathrm{CDCl}_{3}\right): \delta 176.8,160.4,147.8,142.4,140.2,131.84 ;{ }^{77} \mathrm{Se}\left(114.5 \mathrm{MHz}, \mathrm{DMSO}-d_{6}\right): \delta=640.0$ (s, 1Se), please note: surprisingly, despite a satisfying concentration (ca. $5 \mathrm{mg}$ in $0.6 \mathrm{~mL}$ of DMSO- $d_{6}$ ) in NMR tube and a very long acquisition duration (4096 scans), it was impossible to obtain a good quality spectrum (too slow relaxation?). HPLC (system C): $t_{\mathrm{R}}=1.7 \mathrm{~min}$ (purity $91 \%$ at $260 \mathrm{~nm}$ ); HRMS (ESI-): $\mathrm{m} / z$ [M - H] $]^{-}$Calcd for $\mathrm{C}_{6} \mathrm{H}_{3} \mathrm{O}_{3} \mathrm{Se}^{-}$202.9252; Found 202.9245.

\section{General procedure for the synthesis of quinoxalin-2(1 H)-one fluorophores (1-7)}

4,5-Dimethoxy-1,2-phenylenediamine 9 [27841-33-4] (100 mg, $0.60 \mathrm{mmol}, 1$ equiv.) and water-soluble carbodiimide coupling reagent EDC.HCl (114 mg, $0.60 \mathrm{mmol}, 1$ equiv.) were mixed together and solubilized in dry DMF $(3 \mathrm{~mL})$ at $\mathrm{rt}$ for $5 \mathrm{~min}$. The corresponding $\alpha-$ ketoacid ( $0.60 \mathrm{mmol}, 1$ equiv.) pre-solubilized in $2 \mathrm{~mL}$ of dry DMF, was added dropwise to the previous solution. The resulting reaction mixture was stirred at $\mathrm{rt}$ for $1 \mathrm{~h}$. The reaction was checked for completion by TLC. Thereafter, the mixture was diluted with EtOAc, washed twice with $5 \%$ aq. $\mathrm{NaHCO}_{3}$ and brine, dried over anhydrous $\mathrm{MgSO}_{4}$, filtered and concentrated under reduced pressure. The resulting residue was purified by flash-column chromatography over silica gel (except for compound $\mathbf{2}$, vide infra) to give the corresponding pure quinoxalin-2(1H)one. Please note: for this reaction, the use of a base (i.e., tertiary amine such as NEt $t_{3}$ or DIEA) is prohibited because leading to rapid decarboxylation of $\alpha$-ketoacid and hence formation of benzimidazole instead of quinoxalin-2(1H)-one aza-heterocycle.

6,7-Dimethoxy-3-methylquinoxalin-2(1H)-one (1).

SMILES $=\mathrm{COC} 1=\mathrm{C}(\mathrm{OC}) \mathrm{C}=\mathrm{C}(\mathrm{N}=\mathrm{C} 2 \mathrm{C}) \mathrm{C}(\mathrm{NC} 2=\mathrm{O})=\mathrm{C} 1$

$\mathrm{InChI}=1 \mathrm{~S} / \mathrm{C} 11 \mathrm{H} 12 \mathrm{~N} 2 \mathrm{O} 3 / \mathrm{c} 1-6-11(14) 13-8-5-10(16-3) 9(15-2) 4-7(8) 12-6 / \mathrm{h} 4-5 \mathrm{H}, 1-$

$3 \mathrm{H} 3,(\mathrm{H}, 13,14)$

InChIKey $=$ AIWLGDWWEZIPIB-UHFFFAOYSA-N

Pyruvic acid [127-17-3] (52.4 mg, $41.4 \mu \mathrm{L}, \mathrm{d}=1.267)$ was used as $\alpha$-ketoacid. The compound was purified using the following eluent (step gradient of EtOAc in heptane from $30 \%$ to $100 \%)$ to give quinoxalin-2(1H)-one 1 as brown amorphous powder ( $7 \mathrm{mg}, 0.03 \mathrm{mmol}$, yield $5 \%$ ). $\mathrm{R}_{\mathrm{f}}$ (heptane-EtOAc, 1:1, v/v) $=0.07$; IR (ATR, neat): $v=3000,2953,2917,2850$, 2830, 1659, 1623, 1551, 1504, 1470, 1444, 1394, 1365, 1283, 1250, 1218, 1204, 1152, 1081, 993, 903, 865, 848, 821, 766, 728; ${ }^{1} \mathrm{H}$ NMR (400 MHz, DMSO- $\left.d_{6}\right): \delta=12.14(\mathrm{~s}, 1 \mathrm{H}), 7.21$ (s, $1 \mathrm{H}), 6.76(\mathrm{~s}, 1 \mathrm{H}), 3.81(\mathrm{~s}, 3 \mathrm{H}), 3.80(\mathrm{~s}, 3 \mathrm{H}), 2.34(\mathrm{~s}, 3 \mathrm{H}) ;{ }^{13} \mathrm{C}$ NMR $\left(101 \mathrm{MHz}, \mathrm{DMSO}-d_{6}\right): \delta$ $=155.4,154.8,150.7,145.6,126.7,125.9,109.3,97.0,55.8,55.7,20.2 ;$ HPLC (system A): $t_{\mathrm{R}}$ $=3.2 \mathrm{~min}$ (purity $97 \%$ at $260 \mathrm{~nm}$ ); LRMS (ESI+, recorded during RP-HPLC analysis): $\mathrm{m} / \mathrm{z}$ $221.4[\mathrm{M}+\mathrm{H}]^{+}(100)$ and $441.4[2 \mathrm{M}+\mathrm{H}]^{+}$(4), calcd for $\mathrm{C}_{11} \mathrm{H}_{13} \mathrm{~N}_{2} \mathrm{O}_{3}{ }^{+}$221.1; LRMS (ESI-, recorded during RP-HPLC analysis): $m / z 219.2$ [M - H] $]^{-}(100), 439.2[2 \mathrm{M}-\mathrm{H}]^{-}(39)$ and 659.2 $[3 \mathrm{M}-\mathrm{H}]^{-}(61)$, calcd for $\mathrm{C}_{11} \mathrm{H}_{11} \mathrm{~N}_{2} \mathrm{O}_{3}^{-}$219.1; HRMS (ESI+): $m / z[\mathrm{M}+\mathrm{H}]^{+}$Calcd for $\mathrm{C}_{11} \mathrm{H}_{13} \mathrm{~N}_{2} \mathrm{O}_{3}{ }^{+}$221.0920; Found 221.0923.

6,7-Dimethoxy-3-phenylquinoxalin-2(1H)-one (2).

$\mathrm{SMILES}=\mathrm{COC} 1=\mathrm{C}(\mathrm{OC}) \mathrm{C}=\mathrm{C}(\mathrm{N}=\mathrm{C} 2 \mathrm{C} 3=\mathrm{CC}=\mathrm{CC}=\mathrm{C} 3) \mathrm{C}(\mathrm{NC} 2=\mathrm{O})=\mathrm{C} 1$

$\mathrm{InChI}=1 \mathrm{~S} / \mathrm{C} 16 \mathrm{H} 14 \mathrm{~N} 2 \mathrm{O} 3 / \mathrm{c} 1-20-13-8-11-12(9-14(13) 21-2) 18-16(19) 15(17-11) 10-6-4-3-5-7-$

10/h3-9H,1-2H3,(H,18,19) 
InChIKey $=$ JHDFVCADDXAART-UHFFFAOYSA-N

Benzoylformic acid [611-73-4] (89 mg) was used as $\alpha$-ketoacid. The compound was purified by preparative TLC (Merck-Millipore PLC, silica gel $60, \mathrm{~F}_{254}, 1 \mathrm{~mm}, 20 \times 20$; eluent: $\mathrm{DCM} / \mathrm{MeOH} 100: 5+1 \%$ of TFA, v/v, two successive migrations) to give quinoxalin$2(1 H)$-one 2 as yellow amorphous powder $(25 \mathrm{mg}, 0.09 \mathrm{mmol}$, yield $15 \%$ based on TFA mass $=5.8 \%$ determined by ionic chromatography). $\mathrm{R}_{\mathrm{f}}(\mathrm{DCM}-\mathrm{MeOH}, 100: 5+1 \%$ of TFA, v/v) $=0.45$; IR (ATR): $v=3056,3002,2918,2827,2772,1648,1624,1534,1503,1461,1439$, 1389, 1269, 1236, 1214, 1147, 1075, 1027, 1007, 916, 900, 847, 828, 815, 799, 752, 738, 716, 690; ${ }^{1} \mathrm{H} \mathrm{NMR}\left(500 \mathrm{MHz}, \mathrm{CDCl}_{3}+10 \%\right.$ TFA- $\left.d_{1}\right): \delta=10.31$ (s) peak assigned to residual nondeuterated $\mathrm{TFA}\left(\mathrm{CF}_{3} \mathrm{CO}_{2} \underline{\mathrm{H}}\right), \mathrm{N} \underline{\mathrm{H}}$ of quinoxalin-2(1H)-one heterocycle was not observed, probably due to exchange with TFA. 8.19 (dd, $J=7.5 \mathrm{~Hz}, J=1.8 \mathrm{~Hz}, 2 \mathrm{H}), 7.56-7.48(\mathrm{~m}, 3 \mathrm{H})$, $7.46(\mathrm{~s}, 1 \mathrm{H}), 6.80(\mathrm{~s}, 1 \mathrm{H}), 4.06(\mathrm{~s}, 3 \mathrm{H}), 4.01(\mathrm{~s}, 3 \mathrm{H}) ;{ }^{13} \mathrm{C} \mathrm{NMR}\left(126 \mathrm{MHz}, \mathrm{CDCl}_{3}+10 \% \mathrm{TFA}-\right.$ $\left.d_{1}\right): \delta=160.6(\mathrm{q}, J=42.4 \mathrm{~Hz})$ peaks assigned to residual non-deuterated $T F A, 156.3,154.5$, 149.6, 149.5, 132.5, 131.9, 130.6, 129.7, 128.9, 128.8, 127.5, 126.3, 118.4-110.9 (m) peaks assigned to residual non-deuterated TFA, 107.2, 96.9, 57.1, 56.7; HPLC (system A): $t_{\mathrm{R}}=4.4$ min (purity $98 \%$ at $260 \mathrm{~nm}$ and $>99 \%$ at $450 \mathrm{~nm}$ ); LRMS (ESI+, recorded during RP-HPLC analysis): $m / z 283.3[\mathrm{M}+\mathrm{H}]^{+}(100), 565.4[2 \mathrm{M}+\mathrm{H}]^{+}(8)$ and $847.5[3 \mathrm{M}+\mathrm{H}]^{+}(4)$, calcd for $\mathrm{C}_{16} \mathrm{H}_{15} \mathrm{~N}_{2} \mathrm{O}_{3}{ }^{+}$283.1; LRMS (ESI-, recorded during RP-HPLC analysis): $m / z 281.1[\mathrm{M}-\mathrm{H}]^{-}$ (100), 562.9 [2M - H] $]^{-}(29)$ and 845.3 [3M - H] $]^{-}$(35), calcd for $\mathrm{C}_{16} \mathrm{H}_{13} \mathrm{~N}_{2} \mathrm{O}_{3}{ }^{-}$281.1; HRMS (ESI+): $m / z[\mathrm{M}+\mathrm{H}]^{+}$Calcd for $\mathrm{C}_{16} \mathrm{H}_{15} \mathrm{~N}_{2} \mathrm{O}_{3}{ }^{+}$283.1077; Found 283.1075; HRMS (ESI+): $\mathrm{m} / z$ $[\mathrm{M}+\mathrm{Na}]^{+}$Calcd for $\mathrm{C}_{16} \mathrm{H}_{14} \mathrm{~N}_{2} \mathrm{O}_{3} \mathrm{Na}^{+}$305.0896; Found 305.0892.

\section{6,7-Dimethoxy-3-(4-methoxyphenyl)quinoxalin-2(1H)-one (3).}

SMILES $=\mathrm{COC} 1=\mathrm{C}(\mathrm{OC}) \mathrm{C}=\mathrm{C}(\mathrm{N}=\mathrm{C} 2 \mathrm{C} 3=\mathrm{CC}=\mathrm{C}(\mathrm{OC}) \mathrm{C}=\mathrm{C} 3) \mathrm{C}(\mathrm{NC} 2=\mathrm{O})=\mathrm{C} 1$

$\mathrm{InChI}=1 \mathrm{~S} / \mathrm{C} 17 \mathrm{H} 16 \mathrm{~N} 2 \mathrm{O} 4 / \mathrm{c} 1-21-11-6-4-10(5-7-11) 16-17(20) 19-13-9-15(23-3) 14(22-2) 8-$ 12(13)18-16/h4-9H,1-3H3,(H,19,20)

InChIKey $=$ PALPFPHVXCIRAS-UHFFFAOYSA-N

(4-Methoxyphenyl)glyoxylic acid [7099-91-4] (107 mg) was used as a-ketoacid. The compound was purified using the following eluent (step gradient of $\mathrm{MeOH}$ in DCM from $0 \%$ to $2 \%$ ) to give quinoxalin-2(1H)-one 3 as yellow amorphous powder ( $9 \mathrm{mg}, 0.03 \mathrm{mmol}$, yield 5\%). $\mathrm{R}_{\mathrm{f}}(\mathrm{DCM}-\mathrm{MeOH}, 98: 2, \mathrm{v} / \mathrm{v})=0.44$; IR (ATR, neat): $v=2923,2824,2766$, 2034, 1658, 1624, 1601, 1573, 1507, 1459, 1439, 1413, 1242, 1215, 1172, 1143, 1031, 1009, 923, 836, 796, 753, 675; ${ }^{1} \mathrm{H}$ NMR (400 MHz, DMSO- $\left.d_{6}\right): \delta=12.38(\mathrm{~s}, 1 \mathrm{H}), 8.40(\mathrm{~d}, J=8.9$ $\mathrm{Hz}, 2 \mathrm{H}), 7.30(\mathrm{~s}, 1 \mathrm{H}), 7.02(\mathrm{~d}, J=8.9 \mathrm{~Hz}, 2 \mathrm{H}), 6.82(\mathrm{~s}, 1 \mathrm{H}), 3.85(\mathrm{~m}, 6 \mathrm{H}), 3.83(\mathrm{~s}, 3 \mathrm{H}) ;{ }^{13} \mathrm{C}$ $\operatorname{NMR}\left(101 \mathrm{MHz}, \mathrm{DMSO}-d_{6}\right): \delta=160.5,154.6,151.4,149.4,146.0,130.4,128.6,126.9,126.5$, $113.2,109.4,96.6,55.8,55.8,55.2 ;$ HPLC (system A): $t_{\mathrm{R}}=4.5 \mathrm{~min}$ (purity $96 \%$ at $260 \mathrm{~nm}$ and $>99 \%$ at $450 \mathrm{~nm}$ ); LRMS (ESI+, recorded during RP-HPLC analysis): $\mathrm{m} / z 313.2[\mathrm{M}+\mathrm{H}]^{+}$ (100) and $625.4[2 \mathrm{M}+\mathrm{H}]^{+}(8)$, calcd for $\mathrm{C}_{17} \mathrm{H}_{17} \mathrm{~N}_{2} \mathrm{O}_{4}{ }^{+}$313.1; LRMS (ESI-, recorded during

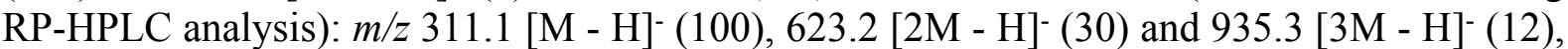
calcd for $\mathrm{C}_{17} \mathrm{H}_{15} \mathrm{~N}_{2} \mathrm{O}_{4}{ }^{-} 311.1$; HRMS (ESI+): $m / z[\mathrm{M}+\mathrm{H}]^{+}$Calcd for $\mathrm{C}_{17} \mathrm{H}_{17} \mathrm{~N}_{2} \mathrm{O}_{4}{ }^{+} 313.1182$; Found 313.1177; HRMS (ESI+): $m / z[\mathrm{M}+\mathrm{Na}]^{+}$Calcd for $\mathrm{C}_{17} \mathrm{H}_{16} \mathrm{~N}_{2} \mathrm{O}_{4} \mathrm{Na}^{+}$335.1002; Found 335.0993.

\section{6,7-Dimethoxy-3-(4-(trifluoromethyl)phenyl)quinoxalin-2(1H)-one (4).}

$\mathrm{SMILES}=\mathrm{COC} 1=\mathrm{C}(\mathrm{OC}) \mathrm{C}=\mathrm{C}(\mathrm{N}=\mathrm{C} 2 \mathrm{C} 3=\mathrm{CC}=\mathrm{C}(\mathrm{C}(\mathrm{F})(\mathrm{F}) \mathrm{F}) \mathrm{C}=\mathrm{C} 3) \mathrm{C}(\mathrm{NC} 2=\mathrm{O})=\mathrm{C} 1$

$\mathrm{InChI}=1 \mathrm{~S} / \mathrm{C} 17 \mathrm{H} 13 \mathrm{~F} 3 \mathrm{~N} 2 \mathrm{O} 3 / \mathrm{c} 1-24-13-7-11-12(8-14(13) 25-2) 22-16(23) 15(21-11) 9-3-5-10(6-$ 4-9)17(18,19)20/h3-8H,1-2H3,(H,22,23)

InChIKey = RJUVRZNYOPTMMA-UHFFFAOYSA-N

(4-Trifluoromethylphenyl)glyoxylic acid [79478-02-7] (107 mg) was used as $\alpha$-ketoacid. The compound was purified using the following eluent (step gradient of EtOAc in heptane from 
$60 \%$ to $90 \%$ ). The powder obtained was triturated and washed with absolute EtOH, recovered by centrifugation, dried under vacuum to give quinoxalin-2(1H)-one $\mathbf{4}$ as yellow amorphous powder $\left(23 \mathrm{mg}, 0.065 \mathrm{mmol}\right.$, yield 11\%). $\mathrm{R}_{\mathrm{f}}$ (heptane-EtOAc, $\left.1: 1, \mathrm{v} / \mathrm{v}\right)=0.17$; IR (ATR, neat): $v=3001,2936,2900,2833,2775,1649,1623,1614,1503,1467,1447,1410,1393$, $1325,1269,1249,1235,1216,1168,1149,1107,1070,1033,1007,927,856,847,820,754$, 690; ${ }^{1} \mathrm{H}$ NMR $\left(400 \mathrm{MHz}, \mathrm{DMSO}-d_{6}\right): \delta=12.60(\mathrm{~s}, 1 \mathrm{H}), 8.56(\mathrm{~d}, J=8.3 \mathrm{~Hz}, 2 \mathrm{H}), 7.83(\mathrm{~d}, J=$ $8.3 \mathrm{~Hz}, 2 \mathrm{H}), 7.35(\mathrm{~s}, 1 \mathrm{H}), 6.83(\mathrm{~s}, 1 \mathrm{H}), 3.86(\mathrm{~s}, 6 \mathrm{H}) ;{ }^{13} \mathrm{C}$ NMR $\left(151 \mathrm{MHz}, \mathrm{DMSO}-d_{6}\right): \delta=154.0$, 152.0, 147.8, 145.8, 139.3, 128.8, 127.3, 126.0, 124.7, 124.6 (q, 1C, $\left.\underline{C} \mathrm{~F}_{3}\right), 122.8,109.1,95.9$, $55.4\left(1 \mathrm{C}, \mathrm{O}_{\underline{C}} \mathrm{H}_{3}\right), 55.3\left(1 \mathrm{C}, \mathrm{O}_{\underline{C}} \mathrm{H}_{3}\right) ;{ }^{19} \mathrm{~F} \mathrm{NMR}\left(470 \mathrm{MHz}, \mathrm{DMSO}-d_{6}\right) \delta=-61.11(\mathrm{~s}, 3 \mathrm{~F}, \mathrm{C} \underline{F})$; HPLC (system A): $t_{\mathrm{R}}=4.5 \mathrm{~min}$ (purity $96 \%$ at $260 \mathrm{~nm}$ and $>99 \%$ at $450 \mathrm{~nm}$ ); LRMS (ESI+, recorded during RP-HPLC analysis): $m / z 351.1[\mathrm{M}+\mathrm{H}]^{+}(100)$ and $701.2[2 \mathrm{M}+\mathrm{H}]^{+}(10)$, calcd for $\mathrm{C}_{17} \mathrm{H}_{14} \mathrm{~N}_{2} \mathrm{O}_{3} \mathrm{~F}_{3}{ }^{+}$351.1; LRMS (ESI-, recorded during RP-HPLC analysis): $\mathrm{m} / z 349.0$ [M $\mathrm{H}]^{-}(100)$ and 699.0 [2M - H] $]^{-}(28)$, calcd for $\mathrm{C}_{17} \mathrm{H}_{12} \mathrm{~N}_{2} \mathrm{O}_{3} \mathrm{~F}_{3}{ }^{-} 349.1$; HRMS (ESI+): $\mathrm{m} / z$ [M + $\mathrm{H}]^{+}$Calcd for $\mathrm{C}_{17} \mathrm{H}_{14} \mathrm{~N}_{2} \mathrm{O}_{3} \mathrm{~F}_{3}{ }^{+} 351.0951$; Found 351.0948; HRMS (ESI+): $\mathrm{m} / z$ [M $\left.+\mathrm{Na}\right]^{+} \mathrm{Calcd}$ for $\mathrm{C}_{17} \mathrm{H}_{13} \mathrm{~N}_{2} \mathrm{O}_{3} \mathrm{~F}_{3} \mathrm{Na}^{+}$373.0770; Found 373.0766.

\section{3-(Furan-2-yl)-6,7-dimethoxyquinoxalin-2(1H)-one (5). \\ $\mathrm{SMILES}=\mathrm{COC} 1=\mathrm{C}(\mathrm{OC}) \mathrm{C}=\mathrm{C}(\mathrm{N}=\mathrm{C} 2 \mathrm{C} 3=\mathrm{CC}=\mathrm{CO} 3) \mathrm{C}(\mathrm{NC} 2=\mathrm{O})=\mathrm{C} 1$ \\ $\mathrm{InChI}=1 \mathrm{~S} / \mathrm{C} 14 \mathrm{H} 12 \mathrm{~N} 2 \mathrm{O} 4 / \mathrm{c} 1-18-11-6-8-9(7-12(11) 19-2) 16-14(17) 13(15-8) 10-4-3-5-20-$ 10/h3-7H,1-2H3,(H,16,17) \\ InChIKey $=$ DBFIPQUIXNEUSZ-UHFFFAOYSA-N}

$\alpha$-Oxo-2-furanacetic acid [1467-70-5] (83 mg) was used as $\alpha$-ketoacid. The compound was purified using the following eluent (step gradient of EtOAc in heptane from $20 \%$ to $100 \%$ ) to give quinoxalin-2(1H)-one 5 as orange amorphous powder $(12.5 \mathrm{mg}, 0.05 \mathrm{mmol}$, yield $8 \%$ ). $\mathrm{R}_{\mathrm{f}}($ heptane-EtOAc, $1: 1, \mathrm{v} / \mathrm{v})=0.11$; IR (ATR, neat): $\mathrm{v}=3140,3113,2996,2919,2850$, 2826, 1649, 1623, 1569, 1505, 1453, 1412, 1385, 1287, 1263, 1244, 1216, 1183, 1144, 1048, $1011,1000,906,882,841,830,812,744,695 ;{ }^{1} \mathrm{H}$ NMR $\left(400 \mathrm{MHz}, \mathrm{DMSO}-d_{6}\right): \delta=12.51(\mathrm{~s}$, 1H), 7.93 (d, $J=0.8 \mathrm{~Hz}, 1 \mathrm{H}), 7.67$ (d, $J=3.3 \mathrm{~Hz}, 1 \mathrm{H}), 7.33$ (s, 1H), 6.83 (s, 1H), 6.69 (dd, $J=$ $3.3 \mathrm{~Hz}, J=1.7 \mathrm{~Hz}, 1 \mathrm{H}), 3.85(\mathrm{~m}, 6 \mathrm{H}) ;{ }^{13} \mathrm{C} \mathrm{NMR}\left(101 \mathrm{MHz}, \mathrm{DMSO}-d_{6}\right): \delta=153.2,152.0,149.9$, $146.8,145.6,142.2,127.0,116.9,112.7,109.8,97.3,56.3,56.3$; HPLC (system A): $t_{\mathrm{R}}=3.6$ min (purity $>99 \%$ at $260 \mathrm{~nm}$ and $>99 \%$ at $450 \mathrm{~nm}$ ); LRMS (ESI+, recorded during RP-HPLC analysis): $m / z 273.3[\mathrm{M}+\mathrm{H}]^{+}(100)$, calcd for $\mathrm{C}_{14} \mathrm{H}_{13} \mathrm{~N}_{2} \mathrm{O}_{4}{ }^{+}$273.1; LRMS (ESI-, recorded during RP-HPLC analysis): $m / z 271.1\left[^{\left[\mathrm{M}-\mathrm{H}^{-}\right.}(100), 543.2\left[2 \mathrm{M}-\mathrm{H}^{-}(22)\right.\right.$ and $815.2\left[3 \mathrm{M}-\mathrm{H}^{-}\right.$ (17), calcd for $\mathrm{C}_{14} \mathrm{H}_{11} \mathrm{~N}_{2} \mathrm{O}_{4}-271.1$; HRMS (ESI+): $m / z$ [M $\left.+\mathrm{H}\right]^{+}$Calcd for $\mathrm{C}_{14} \mathrm{H}_{13} \mathrm{~N}_{2} \mathrm{O}_{4}{ }^{+}$ 273.0869; Found 273.0869; HRMS (ESI+): $m / z[\mathrm{M}+\mathrm{Na}]^{+}$Calcd for $\mathrm{C}_{14} \mathrm{H}_{12} \mathrm{~N}_{2} \mathrm{O}_{4} \mathrm{Na}^{+} 295.0689$; Found 295.0687.

\section{6,7-Dimethoxy-3-(thien-2-yl)quinoxalin-2(1H)-one (6).}

$\mathrm{SMILES}=\mathrm{COC} 1=\mathrm{C}(\mathrm{OC}) \mathrm{C}=\mathrm{C}(\mathrm{N}=\mathrm{C} 2 \mathrm{C} 3=\mathrm{CC}=\mathrm{CS} 3) \mathrm{C}(\mathrm{NC} 2=\mathrm{O})=\mathrm{C} 1$

$\mathrm{InChI}=1 \mathrm{~S} / \mathrm{C} 14 \mathrm{H} 12 \mathrm{~N} 2 \mathrm{O} 3 \mathrm{~S} / \mathrm{c} 1-18-10-6-8-9(7-11(10) 19-2) 16-14(17) 13(15-8) 12-4-3-5-20-$ 12/h3-7H,1-2H3,(H,16,17)

InChIKey = DQCLBYNGXRPPOD-UHFFFAOYSA-N

2-Thiopheneglyoxylic acid [4075-59-6] (92 mg) was used as $\alpha$-ketoacid. The compound was purified using the following eluent (step gradient of EtOAc in heptane from 20\% to 80\%) to give quinoxalin-2(1H)-one 6 as orange amorphous powder $(20 \mathrm{mg}, 0.07 \mathrm{mmol}$, yield 12\%). $\mathrm{R}_{\mathrm{f}}($ heptane-EtOAc, $1: 1, \mathrm{v} / \mathrm{v})=0.17$; IR (ATR, neat): $v=3067,3020,2887,2823,2763$, 1655, 1624, 1529, 1504, 1463, 1449, 1429, 1394, 1368, 1287, 1264, 1147, 1079, 1048, 1028, $1007,964,918,889,842,821,808,756,686 ;{ }^{1} \mathrm{H}$ NMR $\left(400 \mathrm{MHz}, \mathrm{DMSO}-d_{6}\right): \delta=12.58(\mathrm{~s}$, $1 \mathrm{H}), 8.32(\mathrm{dd}, J=3.7 \mathrm{~Hz}, J=1.1 \mathrm{~Hz}, 1 \mathrm{H}), 7.74(\mathrm{dd}, J=5.1 \mathrm{~Hz}, J=1.1 \mathrm{~Hz}, 1 \mathrm{H}), 7.25(\mathrm{~s}, 1 \mathrm{H})$, $7.20(\mathrm{dd}, J=5.0 \mathrm{~Hz}, J=3.7 \mathrm{~Hz}, 1 \mathrm{H}), 6.84(\mathrm{~s}, 1 \mathrm{H}), 3.86(\mathrm{~s}, 6 \mathrm{H}) ;{ }^{13} \mathrm{C}$ NMR $(101 \mathrm{MHz}, \mathrm{DMSO}-$ 
$\left.d_{6}\right): \delta=153.2,151.5,146.4,145.6,139.6,130.6,129.9,127.8,126.7,126.3,108.9,96.8,55.3$, 55.3; HPLC (system A): $t_{\mathrm{R}}=4.2$ min (purity $97 \%$ at $260 \mathrm{~nm}$ and $>99 \%$ at $450 \mathrm{~nm}$ ); LRMS (ESI+, recorded during RP-HPLC analysis): $\mathrm{m} / z 289.3[\mathrm{M}+\mathrm{H}]^{+}(100)$, calcd for $\mathrm{C}_{14} \mathrm{H}_{13} \mathrm{~N}_{2} \mathrm{O}_{3} \mathrm{~S}^{+}$ 289.1; LRMS (ESI-, recorded during RP-HPLC analysis): $m / z$ 287.1 [M - H] ${ }^{-}(100)$ and 575.0 [2M - H] $]^{-}$(13), calcd for $\mathrm{C}_{14} \mathrm{H}_{11} \mathrm{~N}_{2} \mathrm{O}_{3} \mathrm{~S}^{-}$287.1; HRMS (ESI+): $m / z[\mathrm{M}+\mathrm{H}]^{+}$Calcd for $\mathrm{C}_{14} \mathrm{H}_{13} \mathrm{~N}_{2} \mathrm{O}_{3} \mathrm{~S}^{+}$289.0641; Found 289.0639; HRMS (ESI+): $m / z[\mathrm{M}+\mathrm{Na}]^{+}$Calcd for $\mathrm{C}_{14} \mathrm{H}_{12} \mathrm{~N}_{2} \mathrm{O}_{3} \mathrm{SNa}^{+}$311.0460; Found 311.0459.

\section{6,7-Dimethoxy-3-(selenothien-2-yl)quinoxalin-2(1H)-one - TFA salt (7).} $\mathrm{SMILES}=\mathrm{O}=\mathrm{C} 1 \mathrm{C}(\mathrm{C} 2=\mathrm{CC}=\mathrm{C}[\mathrm{Se}] 2)=\mathrm{NC}(\mathrm{C}=\mathrm{C}(\mathrm{OC}) \mathrm{C}(\mathrm{OC})=\mathrm{C} 3)=\mathrm{C} 3 \mathrm{~N} 1$

$\mathrm{InChI}=1 \mathrm{~S} / \mathrm{C} 14 \mathrm{H} 12 \mathrm{~N} 2 \mathrm{O} 3 \mathrm{Se} / \mathrm{c} 1-18-10-6-8-9(7-11(10) 19-2) 16-14(17) 13(15-8) 12-4-3-5-20-$ 12/h3-7H,1-2H3,(H,16,17)

InChIKey = VWSPLRDXMKPEMM-UHFFFAOYSA-N

$\alpha$-Oxo-2-selenopheneacetic acid [87787-77-7] (121 mg) was used as $\alpha$-ketoacid. The compound was purified using the following eluent (step gradient of EtOAc in heptane from $20 \%$ to $40 \%$ ). The desired compound was not recovered in a pure form and a further purification by semi-preparative RP-HPLC (system D) was required to provide a pure sample of quinoxalin-2(1H)-one 7 as orange amorphous powder (TFA salt, $2 \mathrm{mg}, 6 \mu \mathrm{mol}$, yield $<1 \%$, TFA content $=17.3 \%$ determined by ionic chromatography). $\mathrm{R}_{\mathrm{f}}$ (heptane-EtOAc, $1: 1$, $\mathrm{v} / \mathrm{v})=0.17 ;{ }^{1} \mathrm{H}$ NMR $\left(600 \mathrm{MHz}, \mathrm{DMSO}-d_{6}\right): \delta=12.67(\mathrm{~s}, 1 \mathrm{H}), 8.49(\mathrm{~d}, J=3.7 \mathrm{~Hz}, 1 \mathrm{H}), 8.39$ $(\mathrm{d}, J=5.6 \mathrm{~Hz}, 1 \mathrm{H}), 7.48-7.37(\mathrm{~m}, 1 \mathrm{H}), 7.27(\mathrm{~s}, 1 \mathrm{H}), 6.86(\mathrm{~s}, 1 \mathrm{H}), 3.86(\mathrm{~s}, 6 \mathrm{H}) ;{ }^{13} \mathrm{C} \mathrm{NMR}(151$ MHz, DMSO- $\left.d_{6}\right): \delta=153.3,151.6,146.8,146.5,143.1,137.4,131.1,130.2,126.6,109.0,96.9$, $55.8,55.8 ;{ }^{19} \mathrm{~F}$ NMR $\left(565 \mathrm{MHz}, \mathrm{DMSO}-d_{6}\right) \delta=-73.4$ (s, 3F, C $\underline{F}_{3}$-TFA); ${ }^{77} \mathrm{Se} \mathrm{NMR}(115 \mathrm{MHz}$, DMSO- $d_{6}$ ): $\delta=643.0\left(\mathrm{~s}, 1 \mathrm{Se}\right.$ ); HPLC (system A): $t_{\mathrm{R}}=4.2 \mathrm{~min}$ (purity $97 \%$ at $260 \mathrm{~nm}$ and $>99 \%$ at $450 \mathrm{~nm}$ ); LRMS (ESI+, recorded during RP-HPLC analysis): $\mathrm{m} / z 337.1[\mathrm{M}+\mathrm{H}]^{+}$ (100) and $673.2[2 \mathrm{M}+\mathrm{H}]^{+}(3)$, calcd for $\mathrm{C}_{14} \mathrm{H}_{13} \mathrm{~N}_{2} \mathrm{O}_{3} \mathrm{Se}^{+}$337.0; LRMS (ESI-, recorded during RP-HPLC analysis): $m / z 335.0$ [M - H] $]^{-}(100)$, calcd for $\mathrm{C}_{14} \mathrm{H}_{11} \mathrm{~N}_{2} \mathrm{O}_{3} \mathrm{Se}^{-} 335.0$; HRMS (ESI+): $m / z[\mathrm{M}+\mathrm{H}]^{+}$Calcd for $\mathrm{C}_{14} \mathrm{H}_{13} \mathrm{~N}_{2} \mathrm{O}_{3} \mathrm{Se}^{+}$337.0085; Found 337.0077.

\section{3-(1H-Indol-2-yl)-6,7-dimethoxyquinoxalin-2(1H)-one (8)}

\section{$\mathrm{SMILES}=\mathrm{COC} 1=\mathrm{C}(\mathrm{OC}) \mathrm{C}=\mathrm{C}(\mathrm{N}=\mathrm{C} 2 \mathrm{C} 3=\mathrm{CC}(\mathrm{C}=\mathrm{CC}=\mathrm{C} 4)=\mathrm{C} 4 \mathrm{~N} 3) \mathrm{C}(\mathrm{NC} 2=\mathrm{O})=\mathrm{C} 1$}

$\mathrm{InChI}=1 \mathrm{~S} / \mathrm{C} 18 \mathrm{H} 15 \mathrm{~N} 3 \mathrm{O} 3 / \mathrm{c} 1-23-15-8-12-13(9-16(15) 24-2) 21-18(22) 17(20-12) 14-7-10-5-3-$ 4-6-11(10)19-14/h3-9,19H,1-2H3,(H,21,22)

\section{InChIKey $=$ SLGOHCSAEPTFNE-UHFFFAOYSA-N}

4,5-Dimethoxy-1,2-phenylenediamine 9 [27841-33-4] (100 mg, $0.60 \mathrm{mmol}, 1$ equiv.) and $\mathrm{NEt}_{3}$ (80 $\mu \mathrm{L}, 0.06 \mathrm{mmol}, 1$ equiv.) were solubilized in dry DMF $(3 \mathrm{~mL})$ at $\mathrm{rt}$. Then, commercial indole-3-glyoxylyl chloride (123 mg, $0.60 \mathrm{mmol}, 1$ equiv.) was pre-solubilized in $2 \mathrm{~mL}$ of dry DMF and added dropwise to the previous solution. The resulting reaction mixture was stirred at $\mathrm{rt}$ for $1 \mathrm{~h}$. The reaction was checked for completion by TLC. Thereafter, the reaction mixture was diluted with EtOAc and washed twice with $5 \%$ aq. $\mathrm{NaHCO}_{3}$ and brine, dried over anhydrous $\mathrm{MgSO}_{4}$, filtered through cotton and concentrated under reduced pressure. The resulting residue was purified by flash-column chromatography over silica gel (eluent: step gradient of EtOAc in DCM from $0 \%$ to $50 \%$ ). The powder obtained was triturated and washed with pentane, recovered by centrifugation, dried under vacuum to give quinoxalin$2(1 H)$-one 8 as yellow amorphous powder $\left(69 \mathrm{mg}, 0.21 \mathrm{mmol}\right.$, yield $36 \%$ ). $\mathrm{R}_{\mathrm{f}}$ (heptaneEtOAc, $1: 1, \mathrm{v} / \mathrm{v})=0.27$; IR (ATR, neat): $v=3336,3053,2956,2925,2850,2833,1735$, $1648,1625,1603,1531,1503,1463,1456,1436,1425,1386,1356,1305,1276,1261,1241$, 1216, 1206, 1187, 1144, 1112, 1093, 1043, 1012, 1002,9 64, 941, 918, 897, 878, 840, 803, 772, $764,753,701 ;{ }^{1} \mathrm{H}$ NMR $\left(500 \mathrm{MHz}, \mathrm{DMSO}-d_{6}\right): \delta=12.25(\mathrm{~s}, 1 \mathrm{H}), 11.63(\mathrm{~s}, 1 \mathrm{H}), 9.04-8.71(\mathrm{~m}$, $2 \mathrm{H}), 7.49(\mathrm{dd}, J=6.0 \mathrm{~Hz}, J=2.9 \mathrm{~Hz}, 1 \mathrm{H}), 7.38(\mathrm{~s}, 1 \mathrm{H}), 7.26-7.05(\mathrm{~m}, 2 \mathrm{H}), 6.84(\mathrm{~s}, 1 \mathrm{H}), 3.90$ 
(s, 3H), $3.84(\mathrm{~s}, 3 \mathrm{H}) ;{ }^{13} \mathrm{C}$ NMR $\left(126 \mathrm{MHz}, \mathrm{DMSO}-d_{6}\right): \delta=154.2,150.0,149.2,145.9,136.2$, $131.8,126.8,126.1,124.8,123.0,122.3,120.6,111.7,111.5,109.1,96.9,55.8,55.7$; HPLC (system A): $t_{\mathrm{R}}=4.5 \mathrm{~min}$ (purity $97 \%$ at $260 \mathrm{~nm}$ and $93 \%$ at $450 \mathrm{~nm}$ ); LRMS (ESI+, recorded during RP-HPLC analysis): $m / z 322.1[\mathrm{M}+\mathrm{H}]^{+}(100)$, calcd for $\mathrm{C}_{18} \mathrm{H}_{16} \mathrm{~N}_{3} \mathrm{O}_{3}{ }^{+} 322.1$; LRMS (ESI-, recorded during RP-HPLC analysis): $m / z$ 320.1 [M - H] $]^{-}(100)$, calcd for $\mathrm{C}_{18} \mathrm{H}_{14} \mathrm{~N}_{3} \mathrm{O}_{3}{ }^{-}$ 320.1; HRMS (ESI+): $m / z 322.1175[\mathrm{M}+\mathrm{H}]^{+}$(69), calcd for $\mathrm{C}_{18} \mathrm{H}_{16} \mathrm{~N}_{3} \mathrm{O}_{3}{ }^{+}$322.1186; HRMS (ESI+): $m / z \quad[\mathrm{M}+\mathrm{Na}]^{+}$Calcd for $\mathrm{C}_{18} \mathrm{H}_{15} \mathrm{~N}_{3} \mathrm{O}_{3} \mathrm{Na}^{+}$344.1005; Found 344.0995; HRMS (ESI-): $m / z[\mathrm{M}-\mathrm{H}]^{-}$Calcd for $\mathrm{C}_{18} \mathrm{H}_{14} \mathrm{~N}_{3} \mathrm{O}_{3}{ }^{-} 320.1041$; Found 320.1033.

\section{4-(2-Phenylacetamido)benzyl (2-amino-4,5-dimethoxyphenyl)carbamate (11) SMILES \\ $\mathrm{COC} 1=\mathrm{C}(\mathrm{OC}) \mathrm{C}=\mathrm{C}(\mathrm{N}) \mathrm{C}(\mathrm{NC}(\mathrm{OCC} 2=\mathrm{CC}=\mathrm{C}(\mathrm{NC}(\mathrm{CC} 3=\mathrm{CC}=\mathrm{CC}=\mathrm{C} 3)=\mathrm{O}) \mathrm{C}=\mathrm{C} 2)=\mathrm{O})=\mathrm{C} 1$ \\ $\mathrm{InChI}=1 \mathrm{~S} / \mathrm{C} 24 \mathrm{H} 25 \mathrm{~N} 3 \mathrm{O} / \mathrm{c} 1-30-21-13-19(25) 20(14-22(21) 31-2) 27-24(29) 32-15-17-8-10-$ 18(11-9-17)26-23(28)12-16-6-4-3-5-7-16/h3-11,13-14H,12,15,25H2,1- \\ $2 \mathrm{H} 3,(\mathrm{H}, 26,28)(\mathrm{H}, 27,29)$ \\ InChIKey $=$ GBGSFOOWHWPTKD-UHFFFAOYSA-N}

PhAc-PABA 10 (145 mg, 0.37 mmol, 1 equiv.) and $\mathrm{NEt}_{3}(62 \mu \mathrm{L}, 0.89 \mathrm{mmol}, 2.75$ equiv.) were solubilized in dry DMF (6 mL) at rt. 4,5-Dimethoxy-1,2-phenylenediamine 9 [27841-33-4] (150 mg, $0.89 \mathrm{mmol}, 2.75$ equiv.) was pre-solubilized in $3 \mathrm{~mL}$ of dry DMF and added dropwise to the previous solution. Finally, HOBt (50 $\mathrm{mg}, 0.37 \mathrm{mmol}, 1$ equiv.) was added to the reaction mixture which was stirred at rt overnight. The reaction was checked for completion by TLC (eluent: EtOAc 100\%). Thereafter, the mixture was diluted with EtOAc and washed with 5\% aq. $\mathrm{NaHCO}_{3}$ and brine (thrice), dried over anhydrous $\mathrm{MgSO}_{4}$, filtered through cotton and concentrated under reduced pressure. The resulting residue was purified by flash-column chromatography over silica gel (eluent: step gradient of EtOAc in heptane from $50 \%$ to $100 \%)$ to give carbamate 11 as brown amorphous powder (122 mg, $0.28 \mathrm{mmol}$, yield $76 \%)$. $\mathrm{R}_{\mathrm{f}}$ (heptane-EtOAc, 2:8, v/v) = 0.29; IR (ATR, neat): $v=3392,3259,3117,3051,3002$, $1715,1684,1602,1533,1518,1468,1452,1413,1367,1319,1300,1243,1211,1197$, $1177,1145,1114,1059,1041,1009,990,970,943,862,811,775,755,731,695 ;{ }^{1} \mathrm{H}$ NMR (500 MHz, DMSO- $\left.d_{6}\right): \delta=10.21(\mathrm{~s}, 1 \mathrm{H}), 8.55(\mathrm{~s}, 1 \mathrm{H}), 7.61(\mathrm{~d}, J=8.0 \mathrm{~Hz}, 2 \mathrm{H}), 7.39-$ $7.29(\mathrm{~m}, 6 \mathrm{H}), 7.28-7.21(\mathrm{~m}, 1 \mathrm{H}), 6.81(\mathrm{~s}, 1 \mathrm{H}), 6.38(\mathrm{~s}, 1 \mathrm{H}), 5.03(\mathrm{~s}, 2 \mathrm{H}), 4.51(\mathrm{~s}, 2 \mathrm{H}), 3.66(\mathrm{~s}$, $3 \mathrm{H}), 3.64(\mathrm{~s}, 2 \mathrm{H}), 3.59$ (s, 3H); ${ }^{13} \mathrm{C}$ NMR $\left(126 \mathrm{MHz}, \mathrm{DMSO}-d_{6}\right): \delta=169.6,155.0,147.7,140.2$, 139.4, 136.4, 132.0, 129.6, 129.2, 128.8, 127.0, 126.7, 119.4, 116.3, 112.0, 101.5, 65.9, 57.0, 55.9, 43.8; HPLC (system A): $t_{\mathrm{R}}=3.8 \mathrm{~min}$ (purity $97 \%$ at $260 \mathrm{~nm}$ ); LRMS (ESI+, recorded during RP-HPLC analysis): $m / z 436.3[\mathrm{M}+\mathrm{H}]^{+}(25)$ and $m / z 871.5[2 \mathrm{M}+\mathrm{H}]^{+}(21)$, calcd for for $\mathrm{C}_{24} \mathrm{H}_{26} \mathrm{~N}_{3} \mathrm{O}_{5}{ }^{+} 436.2$; LRMS (ESI-, recorded during RP-HPLC analysis): $m / z 434.3$ [M - H] ${ }^{-}$ (38), 480.2 [M + FA - H] $]^{-}(100)$ and $915.3[2 \mathrm{M}+\mathrm{FA}-\mathrm{H}]^{-}(60)$, calcd for $\mathrm{C}_{24} \mathrm{H}_{24} \mathrm{~N}_{3} \mathrm{O}_{5}-436.2$; HRMS (ESI+): $m / z[\mathrm{M}+\mathrm{Na}]^{+}$Calcd for $\mathrm{C}_{24} \mathrm{H}_{25} \mathrm{~N}_{3} \mathrm{O}_{5} \mathrm{Na}^{+}$458.1686; Found 458.1684.

\section{General procedure for the synthesis of PGA-responsive "covalent-assembly" fluorogenic probes (12-18)}

Step 1 - preparation of acyl chloride: The corresponding $\alpha$-ketoacid ( $0.71 \mathrm{mmol}, 1$ equiv.) was solubilized in 1,1-dichlorodimethylether $(516 \mu \mathrm{L}, 5.68 \mathrm{mmol}, 8$ equiv.) and the mixture was stirred at $50{ }^{\circ} \mathrm{C}$ for $40 \mathrm{~min}$ (heath source: oil bath). Thereafter, the reaction mixture was evaporated to give the corresponding crude acyl chloride which was used in the next step without further purification. Please note: an alternative protocol was required for preparing acyl chloride of $\alpha$-oxo-2-selenopheneacetic acid due to complete degradation of this latter selenophene derivative in the presence of 1,1-dichlorodimethylether. $\alpha$-Oxo-2selenopheneacetic acid (100 $\mathrm{mg}, 0.5 \mathrm{mmol}, 1$ equiv.) was dissolved in dry DMF $(1.5 \mathrm{~mL})$. $\mathrm{SOCl}_{2}(54 \mu \mathrm{L}, 0.74 \mathrm{mmol}, 1.5$ equiv. $)$ was added at $0{ }^{\circ} \mathrm{C}$ and the resulting reaction mixture was 
stirred at $\mathrm{rt}$ for $1 \mathrm{~h}$. Thereafter, the mixture was evaporated to give the corresponding crude acyl chloride which was used in next step without further purification.

Step 2: N-acylation of aniline 11: Compound 11 (50 mg, $0.12 \mathrm{mmol}, 1$ equiv.) and $\mathrm{NEt}_{3}$ (32 $\mu \mathrm{L}, 0.23 \mathrm{mmol}, 2$ equiv.) were dissolved in dry DMF $(2 \mathrm{~mL})$ at $\mathrm{rt}$. Then, the freshly prepared acyl chloride ( $0.14 \mathrm{mmol}, 1.2$ equiv.) pre-dissolved in $0.5 \mathrm{~mL}$ of dry DMF, was added dropwise to the previous solution. The resulting reaction mixture was stirred at $\mathrm{rt}$ for $2 \mathrm{~h}$. The reaction was checked for completion by TLC and the mixture was diluted with EtOAc, washed three times with brine, dried over anhydrous $\mathrm{MgSO}_{4}$, filtered through cotton and concentrated under reduced pressure. The resulting residue was purified by flash-column chromatography over silica gel. The powder obtained was triturated and washed with pentane, recovered by centrifugation, dried under vacuum to give the corresponding PGA probe in a pure form.

4-(2-Phenylacetamido)benzyl (4,5-dimethoxy-2-(2-oxopropanamido)phenyl)carbamate (12). SMILES

$\mathrm{COC} 1=\mathrm{C}(\mathrm{OC}) \mathrm{C}=\mathrm{C}(\mathrm{NC}(\mathrm{C}(\mathrm{C})=\mathrm{O})=\mathrm{O}) \mathrm{C}(\mathrm{NC}(\mathrm{OCC} 2=\mathrm{CC}=\mathrm{C}(\mathrm{NC}(\mathrm{CC} 3=\mathrm{CC}=\mathrm{CC}=\mathrm{C} 3)=\mathrm{O}) \mathrm{C}=\mathrm{C} 2)$ $=\mathrm{O})=\mathrm{C} 1$

$\mathrm{InChI}=1 \mathrm{~S} / \mathrm{C} 27 \mathrm{H} 27 \mathrm{~N} 3 \mathrm{O} 7 / \mathrm{c} 1-17(31) 26(33) 29-21-14-23(35-2) 24(36-3) 15-22(21) 30-27(34) 37-$ 16-19-9-11-20(12-10-19)28-25(32)13-18-7-5-4-6-8-18/h4-12,14-15H,13,16H2,1-

$3 \mathrm{H} 3,(\mathrm{H}, 28,32)(\mathrm{H}, 29,33)(\mathrm{H}, 30,34)$

InChIKey = PIVCDZQFMKVNKC-UHFFFAOYSA-N

Pyruvic acid (62 mg) and the corresponding acyl chloride $(15 \mathrm{mg})$ were used for this 2-step synthesis. Chromatographic purification was achieved using the following eluent (step gradient of EtOAc in heptane from $60 \%$ to $80 \%)$ to give $12(45 \mathrm{mg}, 0.05 \mathrm{mmol}$, yield $46 \%)$. $\mathrm{R}_{\mathrm{f}}$ (heptane-EtOAc, 2:8, v/v) = 0.54; IR (ATR, neat): $v=3297,3135,2947,1723,1686$, $1656,1610,1525,1495,1463,1451,1411,1353,1307,1250,1214,1182,1156,1118$, $1064,1033,1006,984,920,867,844,820,773,760,729,697 ;{ }^{1} \mathrm{H}$ NMR $(400 \mathrm{MHz}$, $\left.\mathrm{CDCl}_{3}\right): \delta=8.96(\mathrm{~s}, 1 \mathrm{H}), 7.41(\mathrm{t}, J=7.1 \mathrm{~Hz}, 4 \mathrm{H}), 7.34(\mathrm{t}, J=7.1 \mathrm{~Hz}, 5 \mathrm{H}), 7.23(\mathrm{~s}, 1 \mathrm{H}), 7.09$ $(\mathrm{s}, 1 \mathrm{H}), 6.97(\mathrm{~s}, 1 \mathrm{H}), 6.79(\mathrm{~s}, 1 \mathrm{H}), 5.13(\mathrm{~s}, 2 \mathrm{H}), 3.87(\mathrm{~s}, 3 \mathrm{H}), 3.84(\mathrm{~s}, 3 \mathrm{H}), 3.74(\mathrm{~s}, 2 \mathrm{H}), 2.53(\mathrm{~s}$, $3 \mathrm{H}) ;{ }^{13} \mathrm{C} \mathrm{NMR}\left(101 \mathrm{MHz}, \mathrm{CDCl}_{3}\right): \delta=196.5,169.1,158.1,154.6,147.4,147.1,137.8,134.3$, $131.9,129.5,129.4,129.3,127.8,119.8,67.1,56.2,44.9,24.3$; HPLC (system A): $t_{\mathrm{R}}=3.8 \mathrm{~min}$ (purity 97\% at $260 \mathrm{~nm}$ ); UV (recorded during RP-HPLC analysis): $\lambda_{\max }=245 \mathrm{~nm}$; LRMS (ESI-, recorded during RP-HPLC analysis): $m / z 504.3[\mathrm{M}-\mathrm{H}]^{-}$(46), calcd for $\mathrm{C}_{27} \mathrm{H}_{26} \mathrm{~N}_{3} \mathrm{O}_{7}{ }^{-}$ 504.2; HRMS (ESI+): $m / z[\mathrm{M}+\mathrm{Na}]^{+}$Calcd for $\mathrm{C}_{27} \mathrm{H}_{27} \mathrm{~N}_{3} \mathrm{O}_{7} \mathrm{Na}^{+}$528.1741; Found 528.1742.

4-(2-Phenylacetamido)benzyl (4,5-dimethoxy-2-(2-oxo-2-phenylacetamido)phenyl)carb-
amate (13).
SMILES
$\mathrm{COC} 1=\mathrm{C}(\mathrm{OC}) \mathrm{C}=\mathrm{C}(\mathrm{NC}(\mathrm{C}(\mathrm{C} 2=\mathrm{CC}=\mathrm{CC}=\mathrm{C} 2)=\mathrm{O})=\mathrm{O}) \mathrm{C}(\mathrm{NC}(\mathrm{OCC} 3=\mathrm{CC}=\mathrm{C}(\mathrm{NC}(\mathrm{CC} 4=\mathrm{CC}=\mathrm{CC}=$
$\mathrm{C} 4)=\mathrm{O}) \mathrm{C}=\mathrm{C} 3)=\mathrm{O})=\mathrm{C} 1$ $\mathrm{InChI}=1 \mathrm{~S} / \mathrm{C} 32 \mathrm{H} 29 \mathrm{~N} 3 \mathrm{O} 7 / \mathrm{c} 1-40-27-18-25(34-31(38) 30(37) 23-11-7-4-8-12-23) 26(19-$ 28(27)41-2)35-32(39)42-20-22-13-15-24(16-14-22)33-29(36)17-21-9-5-3-6-10-21/h3-16,18$19 \mathrm{H}, 17,20 \mathrm{H} 2,1-2 \mathrm{H} 3,(\mathrm{H}, 33,36)(\mathrm{H}, 34,38)(\mathrm{H}, 35,39)$

InChIKey $=$ POUHPXQFCPQAFB-UHFFFAOYSA-N

Benzoylformic acid (107 mg) and the corresponding acyl chloride $(23 \mathrm{mg})$ were used for this 2-step synthesis. Chromatographic purification was achieved using the following eluent (step gradient of EtOAc in DCM from 0\% to 20\%) to give $13(28 \mathrm{mg}, 0.05 \mathrm{mmol}$, yield 43\%). $\mathrm{R}_{\mathrm{f}}(\mathrm{DCM}-\mathrm{EtOAc}, 8: 2, \mathrm{v} / \mathrm{v})=0.27$; IR (ATR, neat): $v=3276,3030,2955,2837,1692$, $1656,1607,1519,1448,1441,1355,1305,1245,1211,1178,1129,1060,1041,1009$, $917,861,826,762,738,717,679 ;{ }^{1} \mathrm{H} \mathrm{NMR}\left(400 \mathrm{MHz}, \mathrm{CDCl}_{3}\right): \delta=9.16(\mathrm{~s}, 1 \mathrm{H}), 8.39-8.33$ (m, 2H), 7.65 (t, $J=7.4 \mathrm{~Hz}, 1 \mathrm{H}), 7.49$ (t, $J=7.8 \mathrm{~Hz}, 2 \mathrm{H}), 7.44-7.27$ (m, 10H), 7.05 (s, 1H), 
$7.01(\mathrm{~s}, 1 \mathrm{H}), 6.84(\mathrm{~s}, 1 \mathrm{H}), 5.13(\mathrm{~s}, 2 \mathrm{H}), 3.89(\mathrm{~s}, 3 \mathrm{H}), 3.86(\mathrm{~s}, 3 \mathrm{H}), 3.73(\mathrm{~s}, 2 \mathrm{H}) ;{ }^{13} \mathrm{C}$ NMR $(151$ $\left.\mathrm{MHz}, \mathrm{CDCl}_{3}\right): \delta=187.1,169.2,159.8,154.8,147.6,147.2,137.8,134.8,134.4,133.2,132.1$, $131.5,129.6,129.4,128.7,127.9,123.0,122.4,120.0,108.7,107.3,67.2,56.4,56.3(2 \mathrm{C}$, $\mathrm{OCH}_{3}$ ), 45.0; HPLC (system A): $t_{\mathrm{R}}=5.0 \mathrm{~min}$ (purity $98 \%$ at $260 \mathrm{~nm}$ ); UV (recorded during RP-HPLC analysis): $\lambda_{\max }=248 \mathrm{~nm}$; LRMS (ESI+, recorded during RP-HPLC analysis): $\mathrm{m} / z$ $568.4[\mathrm{M}+\mathrm{H}]^{+}$(34), calcd for $\mathrm{C}_{32} \mathrm{H}_{30} \mathrm{~N}_{3} \mathrm{O}_{7}{ }^{+}$568.2; LRMS (ESI-, recorded during RP-HPLC analysis): $m / z$ 566.2 [M - H] $]^{-}(88)$, calcd for $\mathrm{C}_{32} \mathrm{H}_{28} \mathrm{~N}_{3} \mathrm{O}_{7}{ }^{-}$566.2; HRMS (ESI+): $m / z$ [M $\left.+\mathrm{Na}\right]^{+}$ Calcd for $\mathrm{C}_{32} \mathrm{H}_{29} \mathrm{~N}_{3} \mathrm{O}_{7} \mathrm{Na}^{+}$590.1897; Found 590.1898.

4-(2-Phenylacetamido)benzyl

(4,5-dimethoxy-2-(2-(4-methoxyphenyl)-2oxoacetamido)phenyl)carbamate (14).

SMILES

$\mathrm{COC} 1=\mathrm{C}(\mathrm{OC}) \mathrm{C}=\mathrm{C}(\mathrm{NC}(\mathrm{C}(\mathrm{C} 2=\mathrm{CC}=\mathrm{C}(\mathrm{OC}) \mathrm{C}=\mathrm{C} 2)=\mathrm{O})=\mathrm{O}) \mathrm{C}(\mathrm{NC}(\mathrm{OCC} 3=\mathrm{CC}=\mathrm{C}(\mathrm{NC}(\mathrm{CC} 4=\mathrm{CC}$ $=\mathrm{CC}=\mathrm{C} 4)=\mathrm{O}) \mathrm{C}=\mathrm{C} 3)=\mathrm{O})=\mathrm{C} 1$

$\mathrm{InChI}=1 \mathrm{~S} / \mathrm{C} 33 \mathrm{H} 31 \mathrm{~N} 3 \mathrm{O} 8 / \mathrm{c} 1-41-25-15-11-23(12-16-25) 31(38) 32(39) 35-26-18-28(42-$ 2)29(43-3)19-27(26)36-33(40)44-20-22-9-13-24(14-10-22)34-30(37)17-21-7-5-4-6-8-21/h4-

$16,18-19 \mathrm{H}, 17,20 \mathrm{H} 2,1-3 \mathrm{H} 3,(\mathrm{H}, 34,37)(\mathrm{H}, 35,39)(\mathrm{H}, 36,40)$

InChIKey = QYKPLSPMQJTXGQ-UHFFFAOYSA-N

(4-Methoxyphenyl)glyoxylic acid (128 mg) and the corresponding acyl chloride (28 $\mathrm{mg}$ ) were used for this 2-step synthesis. Chromatographic purification was achieved using the following eluent (step gradient of EtOAc in DCM from 0\% to 20\%) to give 14 (47 mg, $0.08 \mathrm{mmol}$, yield 69\%). $\mathrm{R}_{\mathrm{f}}(\mathrm{DCM}-\mathrm{EtOAc}, 8: 2, \mathrm{v} / \mathrm{v})=0.48$; IR (ATR, neat): $v=3286,2936,2837$, $1687,1656,1598,1570,1523,1452,1411,1352,1254,1212,1166,1129,1059,1028$, $1009,913,848,797,761,702 ;{ }^{1} \mathrm{H}$ NMR $\left(500 \mathrm{MHz}, \mathrm{DMSO}-d_{6}\right): \delta=10.21(\mathrm{~s}, 1 \mathrm{H}), 10.09(\mathrm{~s}$, $1 \mathrm{H}), 8.90(\mathrm{~s}, 1 \mathrm{H}), 8.13(\mathrm{~d}, J=8.9 \mathrm{~Hz}, 2 \mathrm{H}), 7.59$ (d, $J=8.4 \mathrm{~Hz}, 2 \mathrm{H}), 7.36-7.30(\mathrm{~m}, 6 \mathrm{H}), 7.29-$ $7.19(\mathrm{~m}, 2 \mathrm{H}), 7.12(\mathrm{~s}, 1 \mathrm{H}), 7.06(\mathrm{t}, J=9.6 \mathrm{~Hz}, 2 \mathrm{H}), 5.06(\mathrm{~s}, 2 \mathrm{H}), 3.85(\mathrm{~s}, 3 \mathrm{H}), 3.79-3.72(\mathrm{~m}$, $6 \mathrm{H}), 3.63(\mathrm{~d}, J=7.0 \mathrm{~Hz}, 2 \mathrm{H}) ;{ }^{13} \mathrm{C}$ NMR $\left(151 \mathrm{MHz}, \mathrm{DMSO}-d_{6}\right): \delta=187.2,169.1,164.3,162.7$, 154.3, 146.5, 145.6, 139.1, 135.9, 132.9, 131.1, 129.1, 128.8, 128.3, 126.5, 125.7, 118.9, 114.1, $109.0,65.8,55.8,55.7,55.7,43.3$; HPLC (system A): $t_{\mathrm{R}}=5.1 \mathrm{~min}$ (purity $97 \%$ at $260 \mathrm{~nm}$ ); UV (recorded during RP-HPLC analysis): $\lambda_{\max }=245$ and $299 \mathrm{~nm}$; LRMS (ESI+, recorded during RP-HPLC analysis): $m / z 598.5[\mathrm{M}+\mathrm{H}]^{+}(16)$, calcd for for $\mathrm{C}_{33} \mathrm{H}_{33} \mathrm{~N}_{3} \mathrm{O}_{8}{ }^{+}$598.2; LRMS (ESI-, recorded during RP-HPLC analysis): $m / z 596.2[\mathrm{M}-\mathrm{H}]^{-}$(39), calcd for $\mathrm{C}_{33} \mathrm{H}_{30} \mathrm{~N}_{3} \mathrm{O}_{8}{ }^{-} 596.2$; HRMS (ESI+): $m / z$ [M + Na $]^{+}$Calcd for $\mathrm{C}_{33} \mathrm{H}_{31} \mathrm{~N}_{3} \mathrm{O}_{8} \mathrm{Na}^{+}$620.2003; Found 620.2001.

4-(2-Phenylacetamido)benzyl acetamido)phenyl)carbamate (15).

SMILES

(4,5-dimethoxy-2-(2-oxo-2-(4-(trifluoromethyl)phenyl)

$\mathrm{COC} 1=\mathrm{C}(\mathrm{OC}) \mathrm{C}=\mathrm{C}(\mathrm{NC}(\mathrm{C}(\mathrm{C} 2=\mathrm{CC}=\mathrm{C}(\mathrm{C}(\mathrm{F})(\mathrm{F}) \mathrm{F}) \mathrm{C}=\mathrm{C} 2)=\mathrm{O})=\mathrm{O}) \mathrm{C}(\mathrm{NC}(\mathrm{OCC} 3=\mathrm{CC}=\mathrm{C}(\mathrm{NC}(\mathrm{CC} 4$ $=\mathrm{CC}=\mathrm{CC}=\mathrm{C} 4)=\mathrm{O}) \mathrm{C}=\mathrm{C} 3)=\mathrm{O})=\mathrm{C} 1$

$\mathrm{InChI}=1 \mathrm{~S} / \mathrm{C} 33 \mathrm{H} 28 \mathrm{~F} 3 \mathrm{~N} 3 \mathrm{O} / \mathrm{c} 1-44-27-17-25(38-31(42) 30(41) 22-10-12-23(13-11-$ 22)33(34,35)36)26(18-28(27)45-2)39-32(43)46-19-21-8-14-24(15-9-21)37-29(40)16-20-6-43-5-7-20/h3-15,17-18H,16,19H2,1-2H3,(H,37,40)(H,38,42)(H,39,43)

InChIKey = FEQKRASWNLHQRC-UHFFFAOYSA-N

(4-Trifluoromethylphenyl)glyoxylic acid (155 mg) and the corresponding acyl chloride (33 mg) were used for this 2-step synthesis. Chromatographic purification was achieved using the following eluent (step gradient of EtOAc in heptane from 20\% to 40\%) to give $15(17 \mathrm{mg}$, $0.03 \mathrm{mmol}$, yield 23\%). $\mathrm{R}_{\mathrm{f}}$ (heptane-EtOAc, 2:8, v/v) $=0.71$; IR (ATR, neat): $v=3290$, 2938, 2057, 1674, 1600, 1525, 1454, 1409, 1353, 1325, 1255, 1213, 1167, 1125, 1067 , $1035,1005,918,860,826,797,757,705 ;{ }^{1} \mathrm{H} \mathrm{NMR}\left(400 \mathrm{MHz}, \mathrm{CDCl}_{3}\right): \delta=9.26(\mathrm{~s}, 1 \mathrm{H})$, $8.49(\mathrm{~d}, J=8.3 \mathrm{~Hz}, 2 \mathrm{H}), 7.75(\mathrm{~d}, J=8.3 \mathrm{~Hz}, 2 \mathrm{H}), 7.45-7.38(\mathrm{~m}, 4 \mathrm{H}), 7.34(\mathrm{dd}, J=11.0 \mathrm{~Hz}, J$ 
$=7.0 \mathrm{~Hz}, 6 \mathrm{H}), 7.03(\mathrm{~s}, 1 \mathrm{H}), 6.96(\mathrm{~s}, 1 \mathrm{H}), 6.72(\mathrm{~s}, 1 \mathrm{H}), 5.15(\mathrm{~s}, 2 \mathrm{H}), 3.90(\mathrm{~s}, 3 \mathrm{H}), 3.87(\mathrm{~s}, 3 \mathrm{H})$, $3.74(\mathrm{~s}, 2 \mathrm{H}) ;{ }^{13} \mathrm{C}$ NMR $\left(126 \mathrm{MHz}, \mathrm{CDCl}_{3}\right): \delta=186.3,169.2,158.9,154.9,147.7,137.9,136.0$, $135.8,135.5,134.4,132.0,131.8,129.7,129.6,129.5,128.0,125.7$ (2C), 124.7, 122.5, 120.0, 108.8, 107.3, 67.4, 56.4, 56.3, 45.0; ${ }^{19} \mathrm{~F}$ NMR (470 $\left.\mathrm{MHz} \mathrm{CDCl}_{3}\right): \delta=-63.35\left(\mathrm{~s}, 3 \mathrm{~F}, \mathrm{C}_{3}\right)$; HPLC (system A): $t_{\mathrm{R}}=5.3 \mathrm{~min}$ (purity $97 \%$ at $260 \mathrm{~nm}$ ); UV (recorded during RP-HPLC analysis): $\lambda_{\max }=248$ and $342 \mathrm{~nm}$; LRMS (ESI+, recorded during RP-HPLC analysis): $\mathrm{m} / z$ $636.5[\mathrm{M}+\mathrm{H}]^{+}(6)$, calcd for $\mathrm{C}_{33} \mathrm{H}_{29} \mathrm{~N}_{3} \mathrm{O}_{7} \mathrm{~F}_{3}{ }^{+}$636.2; LRMS (ESI-, recorded during RP-HPLC analysis): $m / z$ 634.1 [M - H] $]^{-}$(44), calcd for $\mathrm{C}_{33} \mathrm{H}_{28} \mathrm{~N}_{3} \mathrm{O}_{7} \mathrm{~F}_{3}{ }^{-}$634.2; HRMS (ESI+): $m / z$ [M + $\mathrm{Na}]^{+}$Calcd for $\mathrm{C}_{33} \mathrm{H}_{28} \mathrm{~N}_{3} \mathrm{O}_{7} \mathrm{~F}_{3} \mathrm{Na}^{+}$658.1771; Found 658.1782.

\section{4-(2-Phenylacetamido)benzyl (2-(2-(furan-2-yl)-2-oxoacetamido)-4,5-dimethoxyphenyl) carbamate (16). \\ SMILES}

$\mathrm{COC} 1=\mathrm{C}(\mathrm{OC}) \mathrm{C}=\mathrm{C}(\mathrm{NC}(\mathrm{C}(\mathrm{C} 2=\mathrm{CC}=\mathrm{CO} 2)=\mathrm{O})=\mathrm{O}) \mathrm{C}(\mathrm{NC}(\mathrm{OCC} 3=\mathrm{CC}=\mathrm{C}(\mathrm{NC}(\mathrm{CC} 4=\mathrm{CC}=\mathrm{CC}=\mathrm{C} 4$ )$=\mathrm{O}) \mathrm{C}=\mathrm{C} 3)=\mathrm{O})=\mathrm{C} 1$

$\mathrm{InChI}=1 \mathrm{~S} / \mathrm{C} 30 \mathrm{H} 27 \mathrm{~N} 3 \mathrm{O} 8 / \mathrm{c} 1-38-25-16-22(32-29(36) 28(35) 24-9-6-14-40-24) 23(17-26(25) 39$ 2)33-30(37)41-18-20-10-12-21(13-11-20)31-27(34)15-19-7-4-3-5-8-19/h3-14,16-

$17 \mathrm{H}, 15,18 \mathrm{H} 2,1-2 \mathrm{H} 3,(\mathrm{H}, 31,34)(\mathrm{H}, 32,36)(\mathrm{H}, 33,37)$

InChIKey = AGZBAGVQMYKWSM-UHFFFAOYSA-N

$\alpha$-Oxo-2-furanacetic acid (100 mg) and the corresponding acyl chloride (22 $\mathrm{mg}$ ) were used for this 2-step synthesis. Chromatographic purification was achieved using the following eluent (step gradient of EtOAc in DCM from $0 \%$ to 20\%) to give 16 (34 mg, $0.06 \mathrm{mmol}$, yield $53 \%) . \mathrm{R}_{\mathrm{f}}(\mathrm{DCM}-\mathrm{EtOAc}, 8: 2, \mathrm{v} / \mathrm{v})=0.44$; IR (ATR, neat): $v=3340,3263,3121,2955$, $2835,1690,1665,1608,1521,1462,1414,1392,1353,1304,1268,1244,1214,1160$, $1135,1082,1056,1027,990,969,926,907,883,886,816,770,735,694 ;{ }^{1} \mathrm{H}$ NMR (600 MHz, DMSO- $\left.d_{6}\right): \delta=10.21(\mathrm{~s}, 1 \mathrm{H}), 10.00(\mathrm{~s}, 1 \mathrm{H}), 9.07(\mathrm{~s}, 1 \mathrm{H}), 8.19(\mathrm{~s}, 1 \mathrm{H}), 7.95(\mathrm{~d}, J=3.3$ $\mathrm{Hz}, 1 \mathrm{H}), 7.59(\mathrm{~d}, J=7.9 \mathrm{~Hz}, 2 \mathrm{H}), 7.37-7.30(\mathrm{~m}, 6 \mathrm{H}), 7.27-7.21(\mathrm{~m}, 2 \mathrm{H}), 7.15(\mathrm{~s}, 1 \mathrm{H}), 6.81(\mathrm{~s}$, $1 \mathrm{H}), 5.07(\mathrm{~s}, 2 \mathrm{H}), 3.73(\mathrm{~s}, 6 \mathrm{H}), 3.63(\mathrm{~s}, 2 \mathrm{H}) ;{ }^{13} \mathrm{C}$ NMR $\left(151 \mathrm{MHz}, \mathrm{DMSO}-d_{6}\right): \delta=174.1,169.1$, 159.4, 154.3, 150.3, 149.0, 146.6, 145.4, 139.1, 135.9, 131.1, 129.1, 128.9, 128.3, 126.5, 125.7, 118.9, 113.3, 65.8, 55.8, 55.7, 43.3; HPLC (system A): $t_{\mathrm{R}}=5.1 \mathrm{~min}$ (purity $>99 \%$ at $260 \mathrm{~nm}$ ); UV (recorded during RP-HPLC analysis): $\lambda_{\max }=246$ and $301 \mathrm{~nm}$; LRMS (ESI+, recorded during RP-HPLC analysis): $m / z 558.4[\mathrm{M}+\mathrm{H}]^{+}$(11), calcd for $\mathrm{C}_{33} \mathrm{H}_{28} \mathrm{~N}_{3} \mathrm{O}_{8}{ }^{+}$558.2; LRMS (ESI-, recorded during RP-HPLC analysis): $m / z 556.2[\mathrm{M} \mathrm{-} \mathrm{H}]^{-}$(88), calcd for $\mathrm{C}_{33} \mathrm{H}_{26} \mathrm{~N}_{3} \mathrm{O}_{8}{ }^{-}$ 556.2; HRMS (ESI+): $m / z[\mathrm{M}+\mathrm{Na}]^{+}$Calcd for $\mathrm{C}_{30} \mathrm{H}_{27} \mathrm{~N}_{3} \mathrm{O}_{8} \mathrm{Na}^{+}$580.1690; Found 580.1684.

\section{4-(2-Phenylacetamido)benzyl (4,5-dimethoxy-2-(2-oxo-2-(thien-2-yl)acetamido)phenyl) carbamate (17). \\ SMILES \\ $\mathrm{COC} 1=\mathrm{C}(\mathrm{OC}) \mathrm{C}=\mathrm{C}(\mathrm{NC}(\mathrm{C}(\mathrm{C} 2=\mathrm{CC}=\mathrm{CS} 2)=\mathrm{O})=\mathrm{O}) \mathrm{C}(\mathrm{NC}(\mathrm{OCC} 3=\mathrm{CC}=\mathrm{C}(\mathrm{NC}(\mathrm{CC} 4=\mathrm{CC}=\mathrm{CC}=\mathrm{C} 4$ $=\mathrm{O}) \mathrm{C}=\mathrm{C} 3)=\mathrm{O})=\mathrm{C} 1$ \\ $\mathrm{InChI}=1 \mathrm{~S} / \mathrm{C} 30 \mathrm{H} 27 \mathrm{~N} 3 \mathrm{O} 7 \mathrm{~S} / \mathrm{c} 1-38-24-16-22(32-29(36) 28(35) 26-9-6-14-41-26) 23(17-$ 25(24)39-2)33-30(37)40-18-20-10-12-21(13-11-20)31-27(34)15-19-7-4-3-5-8-19/h3-14,16- \\ $17 \mathrm{H}, 15,18 \mathrm{H} 2,1-2 \mathrm{H} 3,(\mathrm{H}, 31,34)(\mathrm{H}, 32,36)(\mathrm{H}, 33,37)$ \\ InChIKey = BZGOYYLPZMXGHV-UHFFFAOYSA-N}

2-Thiopheneglyoxylic acid (111 mg) and the corresponding acyl chloride $(24 \mathrm{mg})$ were used for this 2-step synthesis. Chromatographic purification was achieved using the following eluent (step gradient of EtOAc in DCM from 0\% to 20\%) to give 17 (19 $\mathrm{mg}, 0.03 \mathrm{mmol}$, yield $29 \%) . \mathrm{R}_{\mathrm{f}}(\mathrm{DCM}-\mathrm{EtOAc}, 8: 2, \mathrm{v} / \mathrm{v})=0.44$; IR (ATR, neat): $v=3296,3029,2960,1689$, $1654,1610,1529,1493,1453,1407,1354,1293,1269,1245,1213,1175,1131,1075$, $1048,1006,969,911,864,851,818,793,774,739,704 ;{ }^{1} \mathrm{H}$ NMR (500 MHz, DMSO- $\left.d_{6}\right)$ : 
$\delta=10.21(\mathrm{~s}, 1 \mathrm{H}), 10.04(\mathrm{~s}, 1 \mathrm{H}), 9.09(\mathrm{~s}, 1 \mathrm{H}), 8.27(\mathrm{dd}, J=3.9 \mathrm{~Hz}, J=1.1 \mathrm{~Hz}, 1 \mathrm{H}), 8.20(\mathrm{dd}, J$ $=4.9 \mathrm{~Hz}, J=1.1 \mathrm{~Hz}, 1 \mathrm{H}), 7.59(\mathrm{~d}, J=8.4 \mathrm{~Hz}, 2 \mathrm{H}), 7.37-7.28(\mathrm{~m}, 7 \mathrm{H}), 7.27-7.20(\mathrm{~m}, 2 \mathrm{H}), 7.15$ $(\mathrm{s}, 1 \mathrm{H}), 5.07(\mathrm{~s}, 2 \mathrm{H}), 3.74(\mathrm{~m}, 6 \mathrm{H}), 3.63(\mathrm{~s}, 2 \mathrm{H}) ;{ }^{13} \mathrm{C}$ NMR $\left(151 \mathrm{MHz}, \mathrm{DMSO}-d_{6}\right): \delta=178.8$, 169.1, 159.8, 154.3, 146.7, 145.4, 139.2, 139.1, 137.6, 136.9, 135.9, 131.10 (s), 129.1, 128.9, $128.6,128.3,126.5,118.9,65.8,55.8,55.7,43.3 ;$ HPLC (system A): $t_{\mathrm{R}}=5.0$ min (purity $>99 \%$ at $260 \mathrm{~nm}$ ); UV (recorded during RP-HPLC analysis): $\lambda_{\max }=247$ and $315 \mathrm{~nm}$; LRMS (ESI-, recorded during RP-HPLC analysis): $m / z 572.2[\mathrm{M}-\mathrm{H}]^{-}(100)$, calcd for $\mathrm{C}_{33} \mathrm{H}_{26} \mathrm{~N}_{3} \mathrm{O}_{7} \mathrm{~S}^{-} 572.2$; HRMS (ESI+): $m / z$ [M + Na] $]^{+}$Calcd for $\mathrm{C}_{30} \mathrm{H}_{27} \mathrm{~N}_{3} \mathrm{O}_{7} \mathrm{SNa}^{+}$596.1461; Found 596.1458.

4-(2-Phenylacetamido)benzyl

(4,5-dimethoxy-2-(2-oxo-2-(selenothien-2-yl)acetamido) phenyl)carbamate (18).

SMILES

$\mathrm{COC} 1=\mathrm{C}(\mathrm{OC}) \mathrm{C}=\mathrm{C}(\mathrm{NC}(\mathrm{C}(\mathrm{C} 2=\mathrm{CC}=\mathrm{C}[\mathrm{Se}] 2)=\mathrm{O})=\mathrm{O}) \mathrm{C}(\mathrm{NC}(\mathrm{OCC} 3=\mathrm{CC}=\mathrm{C}(\mathrm{NC}(\mathrm{CC} 4=\mathrm{CC}=\mathrm{CC}=$ $\mathrm{C} 4)=\mathrm{O}) \mathrm{C}=\mathrm{C} 3)=\mathrm{O})=\mathrm{C} 1$

$\mathrm{InChI}=1 \mathrm{~S} / \mathrm{C} 30 \mathrm{H} 27 \mathrm{~N} 3 \mathrm{O} 7 \mathrm{Se} / \mathrm{c} 1-38-24-16-22(32-29(36) 28(35) 26-9-6-14-41-26) 23(17-$ 25(24)39-2)33-30(37)40-18-20-10-12-21(13-11-20)31-27(34)15-19-7-4-3-5-8-19/h3-14,16-

$17 \mathrm{H}, 15,18 \mathrm{H} 2,1-2 \mathrm{H} 3,(\mathrm{H}, 31,34)(\mathrm{H}, 32,36)(\mathrm{H}, 33,37)$

InChIKey $=$ GWAFQRHTSSRVRR-UHFFFAOYSA-N

$\alpha$-Oxo-2-selenopheneacetyl chloride $(31 \mathrm{mg}$ ) was used for this synthesis. Chromatographic purification was achieved using the following eluent (step gradient of EtOAc in DCM from $0 \%$ to $20 \%)$ to give $18\left(48 \mathrm{mg}, 0.08 \mathrm{mmol}\right.$, yield 67\%). $\mathrm{R}_{\mathrm{f}}(\mathrm{DCM}-\mathrm{EtOAc}, 8: 2, \mathrm{v} / \mathrm{v})=0.48$; IR (ATR, neat): $v=3341,3267,2954,1683,1650,1611,1520,1468,1450,1442,1339$, $1265,1246,1211,1168,1130,1070,1057,1040,1008,977,911,859,824,798,777$, 760, 713; ${ }^{1} \mathrm{H}$ NMR $\left(500 \mathrm{MHz}, \mathrm{DMSO}-d_{6}\right): \delta=10.21(\mathrm{~s}, 1 \mathrm{H}), 10.09(\mathrm{~s}, 1 \mathrm{H}), 9.13(\mathrm{~s}, 1 \mathrm{H}), 8.97-$ $8.75(\mathrm{~m}, 1 \mathrm{H}), 8.49(\mathrm{dd}, J=4.1 \mathrm{~Hz}, J=1.1 \mathrm{~Hz}, 1 \mathrm{H}), 7.60(\mathrm{~d}, J=8.4 \mathrm{~Hz}, 2 \mathrm{H}), 7.53(\mathrm{dd}, J=5.4$ $\mathrm{Hz}, J=4.1 \mathrm{~Hz}, 1 \mathrm{H}), 7.39-7.29(\mathrm{~m}, 6 \mathrm{H}), 7.28-7.20(\mathrm{~m}, 2 \mathrm{H}), 7.15(\mathrm{~s}, 1 \mathrm{H}), 5.08(\mathrm{~s}, 2 \mathrm{H}), 3.74(\mathrm{~m}$, $6 \mathrm{H}), 3.64(\mathrm{~s}, 2 \mathrm{H}) ;{ }^{13} \mathrm{C}$ NMR $\left(151 \mathrm{MHz}, \mathrm{DMSO}-d_{6}\right): \delta=179.3,169.1,159.9,154.3,147.5$, 146.7, 145.5, 139.8, 139.6, 139.1, 135.9, 131.1, 130.7, 129.1, 128.9, 128.3, 126.5, 119.0, 109.2, 108.1, 65.9, 55.8, 55.7, 43,3; ${ }^{77} \mathrm{Se}$ NMR $\left(114.5 \mathrm{MHz}, \mathrm{DMSO}-d_{6}\right): \delta=675.3(\mathrm{~s}, 1 \mathrm{Se})$; HPLC (system A): $t_{\mathrm{R}}=5.0 \mathrm{~min}$ (purity $99 \%$ at $260 \mathrm{~nm}$ ); UV (recorded during RP-HPLC analysis): $\lambda_{\max }=247$ and $315 \mathrm{~nm}$; LRMS (ESI-, recorded during RP-HPLC analysis): $m / z 620.3[\mathrm{M}-\mathrm{H}]^{-}$ (37), calcd for $\mathrm{C}_{33} \mathrm{H}_{26} \mathrm{~N}_{3} \mathrm{O}_{7} \mathrm{Se}^{-}$620.1; HRMS (ESI+): $m / z[\mathrm{M}+\mathrm{Na}]^{+} \mathrm{Calcd}$ for $\mathrm{C}_{30} \mathrm{H}_{27} \mathrm{~N}_{3} \mathrm{O}_{7} \mathrm{SeNa}^{+}$644.0906; Found 644.0905. 


\section{S2 Analytical data}

Fig. S1 - ${ }^{77} \mathrm{Se} \mathrm{NMR}$ spectrum of 2-acetylselenophene in $\mathrm{CDCl}_{3}(114.5 \mathrm{MHz})$

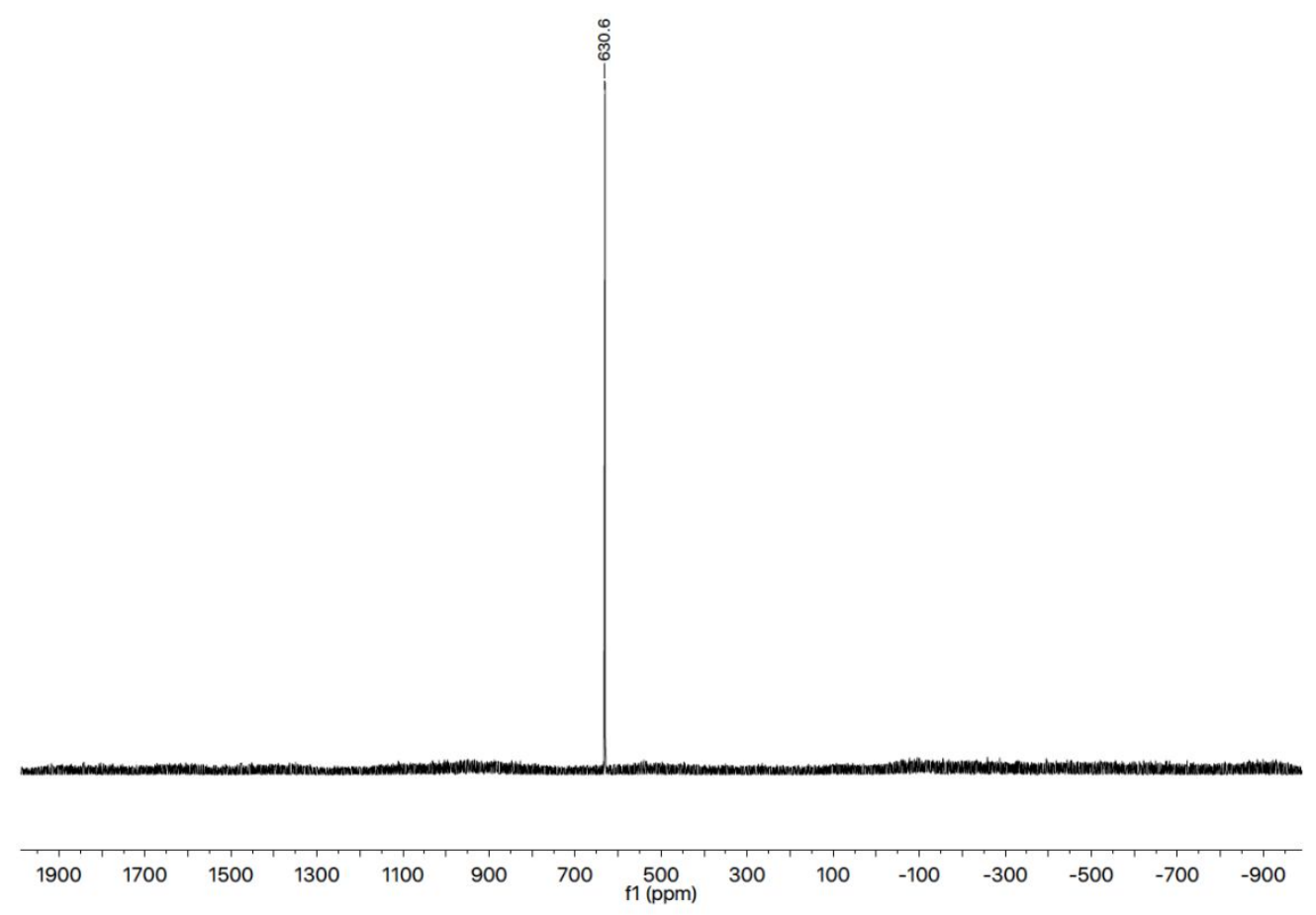

Fig. S2 - ESI- mass spectrum (high resolution) of $\alpha-0 x 0-2-$ selenopheneacetic acid

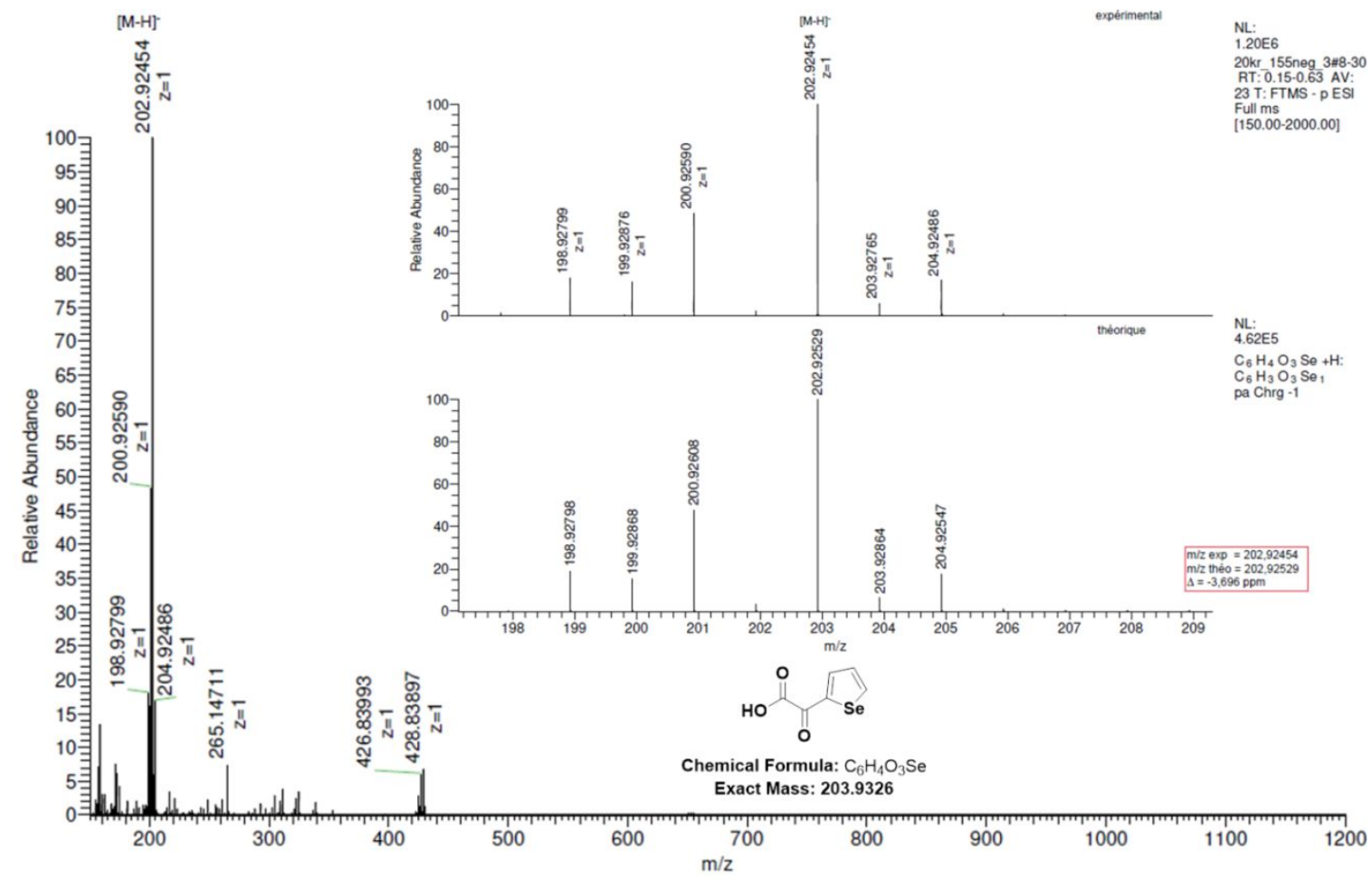




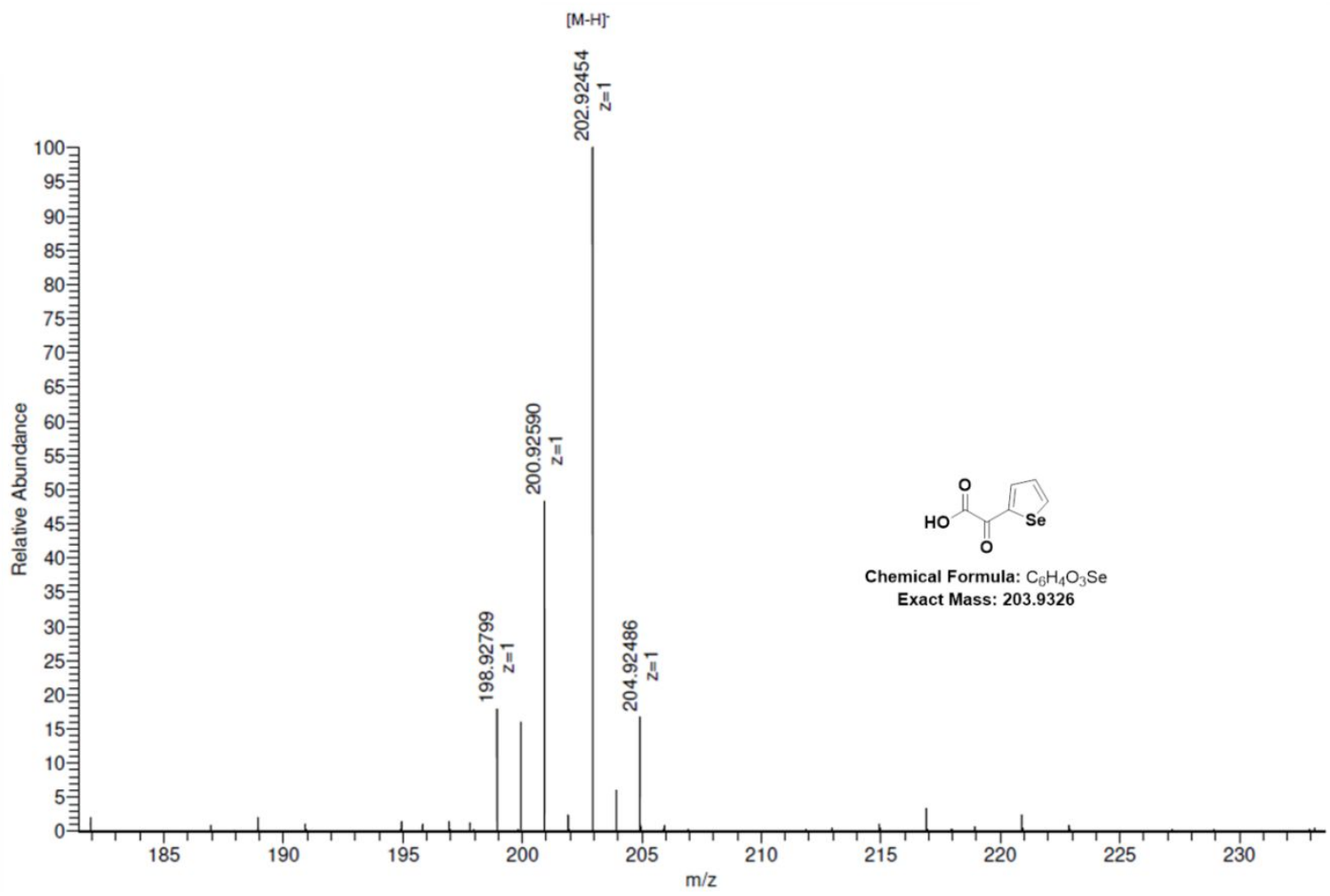

Fig. S3 - RP-HPLC elution profile of $\alpha$-oxo-2-selenopheneacetic acid (system C, detection at $260 \mathrm{~nm}$ )

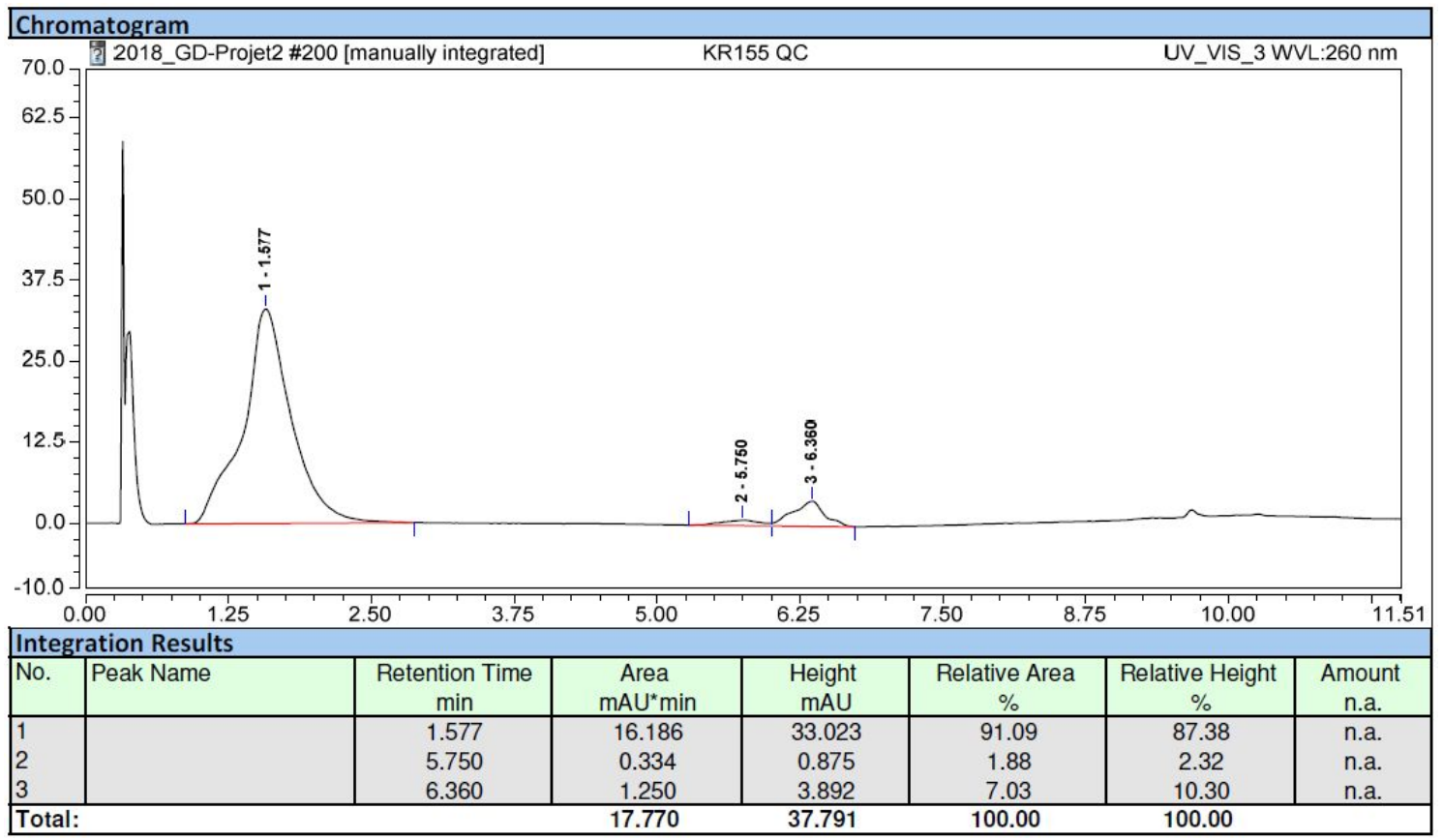


Fig. S4 - IR-ATR spectrum of $\alpha$-oxo-2-selenopheneacetic acid

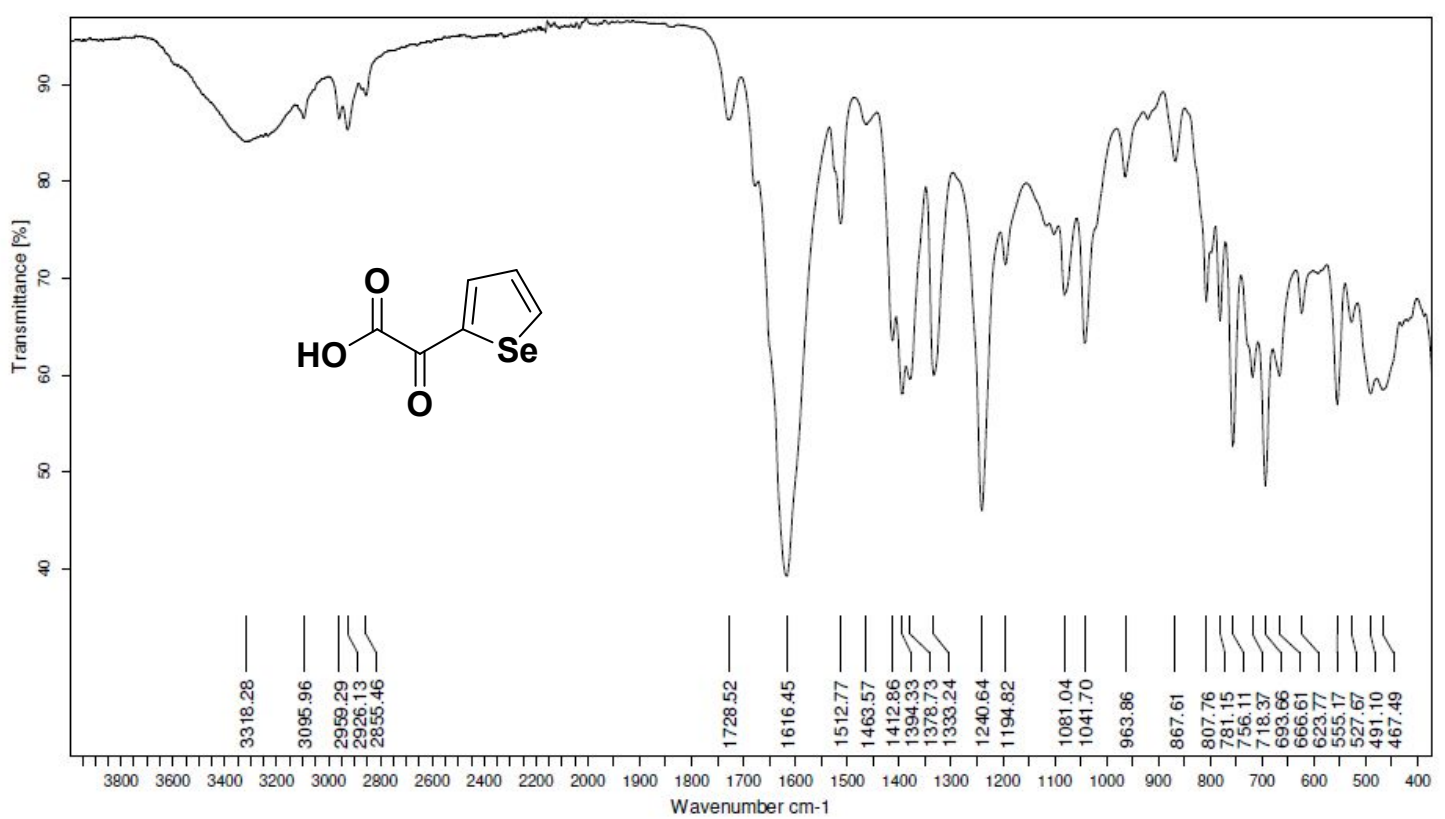

Fig. S5 - ${ }^{1} \mathrm{H}$ NMR spectrum of $\alpha-0 \times 0-2-$-selenopheneacetic acid in DMSO- $d_{6}(500$ MHz)

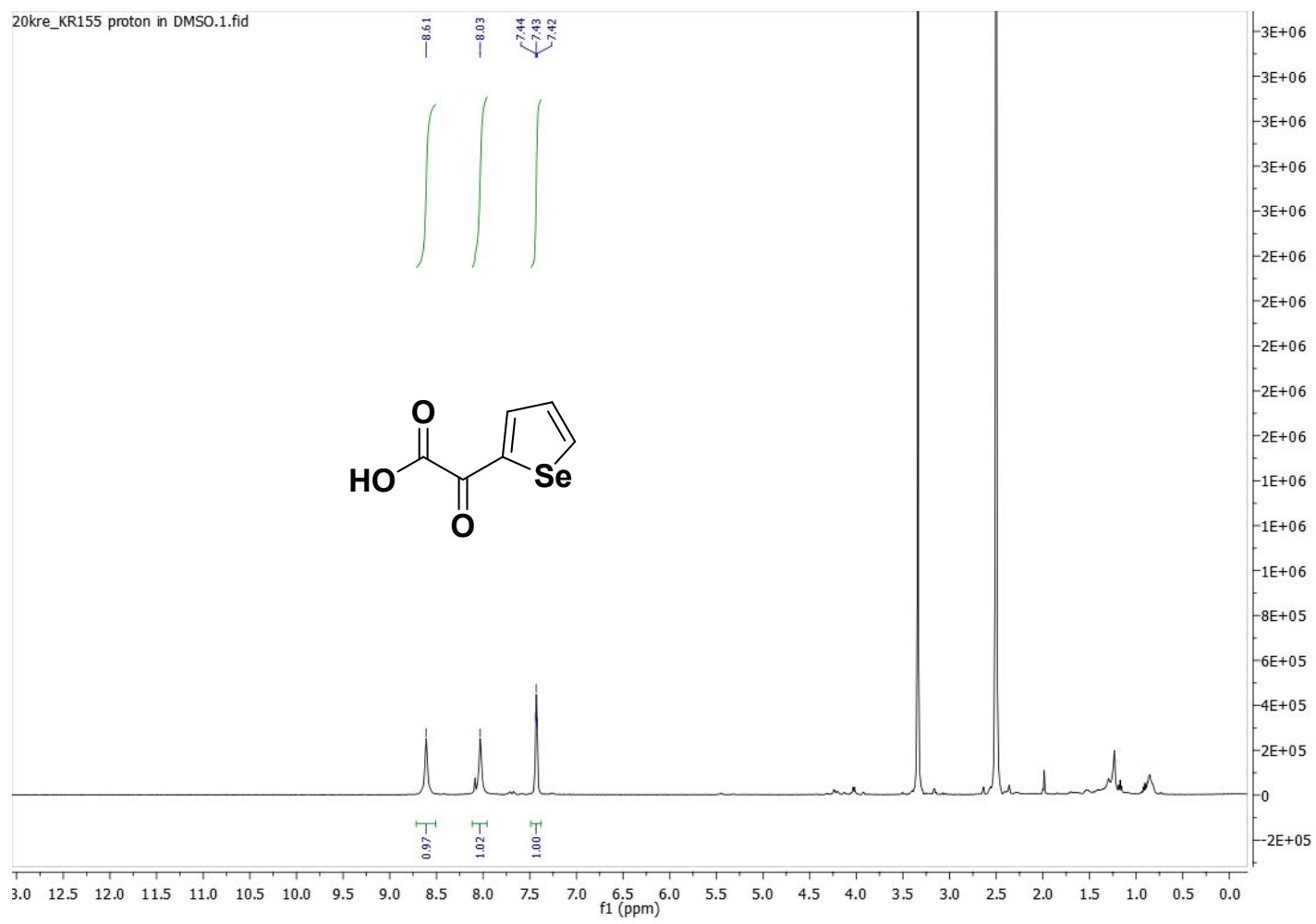


Fig. S6 - ${ }^{13} \mathrm{C}$ NMR spectrum of $\alpha-0 x 0-2$-selenopheneacetic acid in $\mathrm{CDCl}_{3}(126 \mathrm{MHz})$

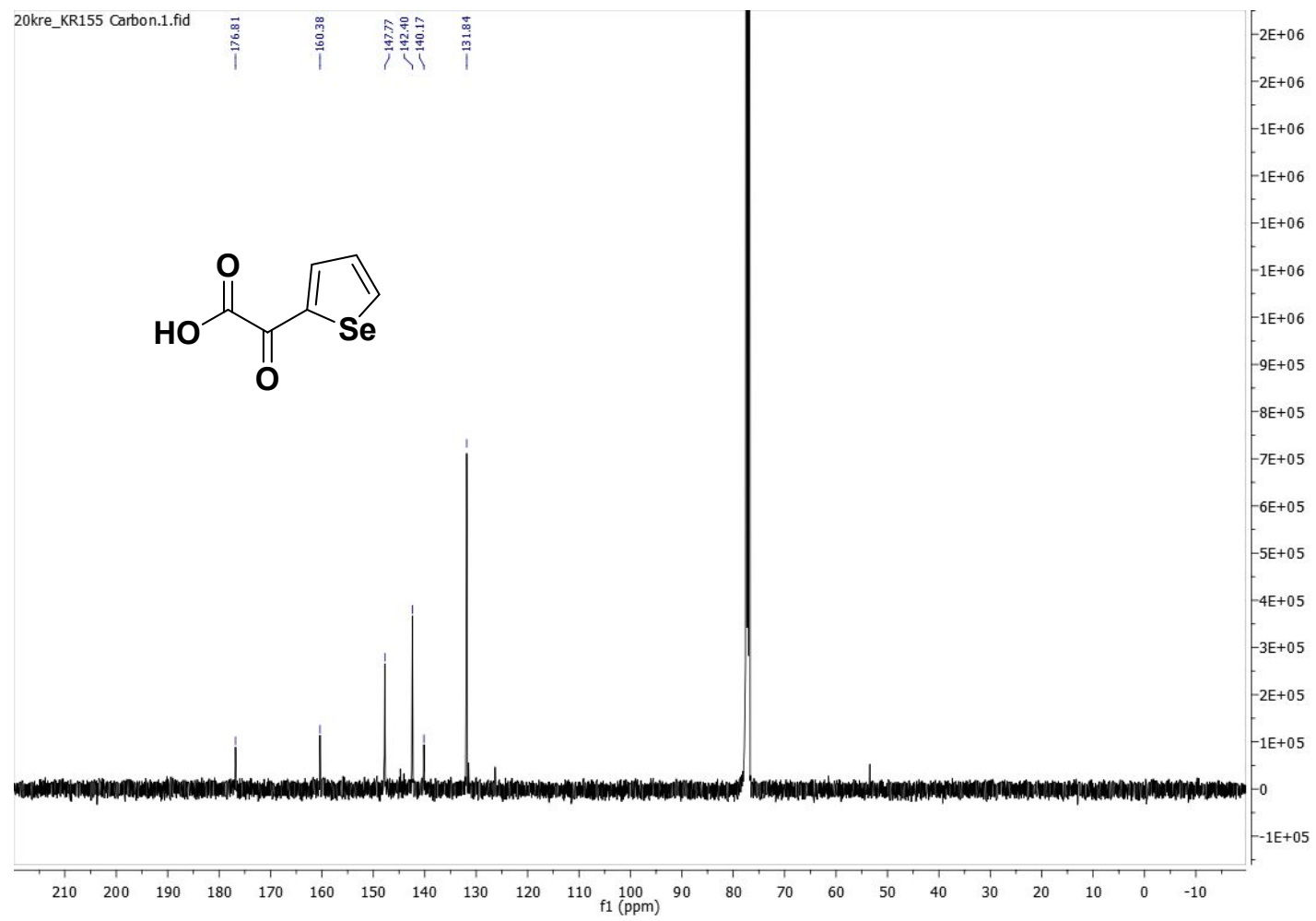

Fig. S7 - ${ }^{77}$ Se NMR spectrum of $\alpha-0 x 0-2-$ selenopheneacetic acid in DMSO- $d_{6}(114.5$ MHz)

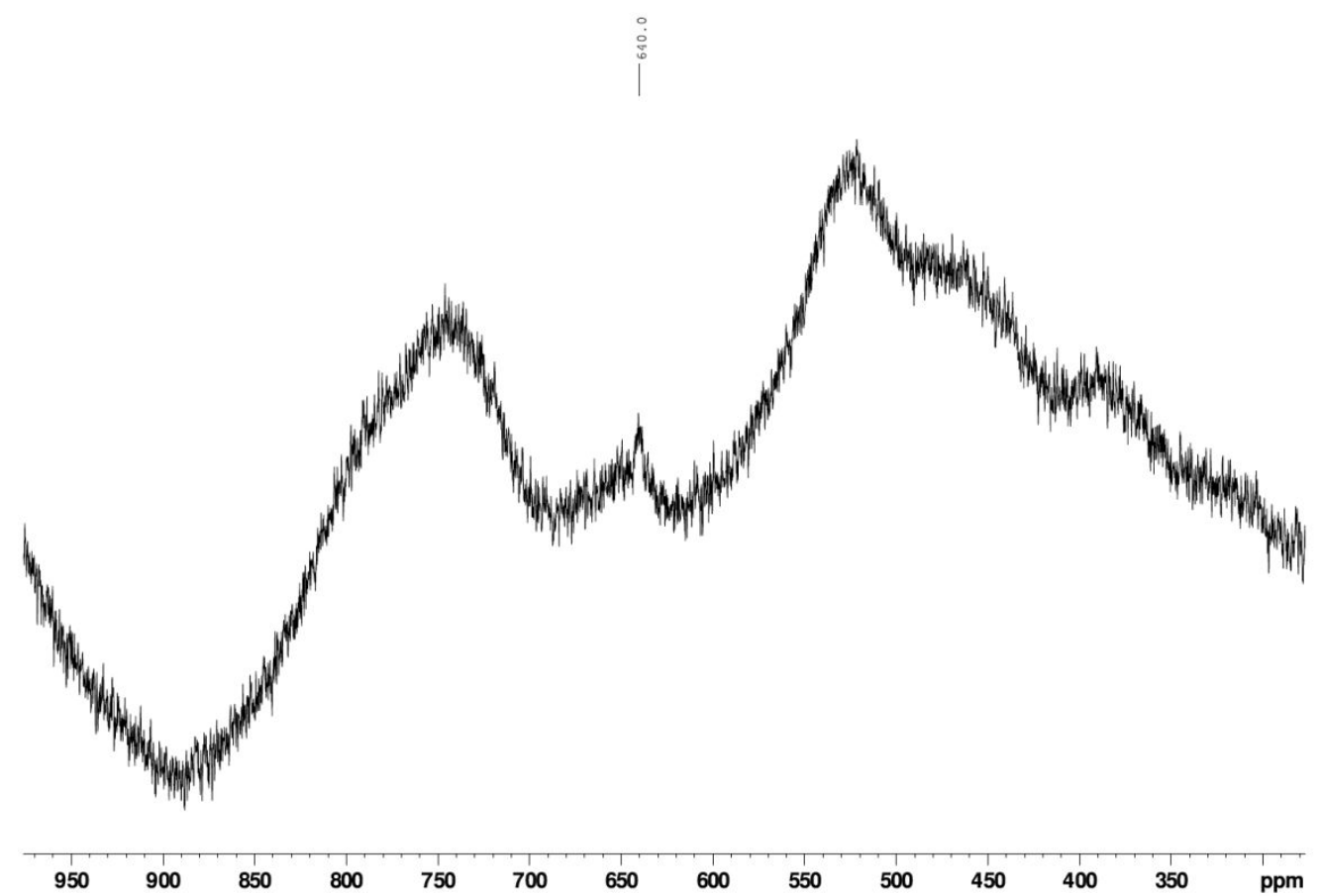


Fig. S8 - ESI+ mass spectrum (high resolution) of quinoxalin-2(1H)-one 1

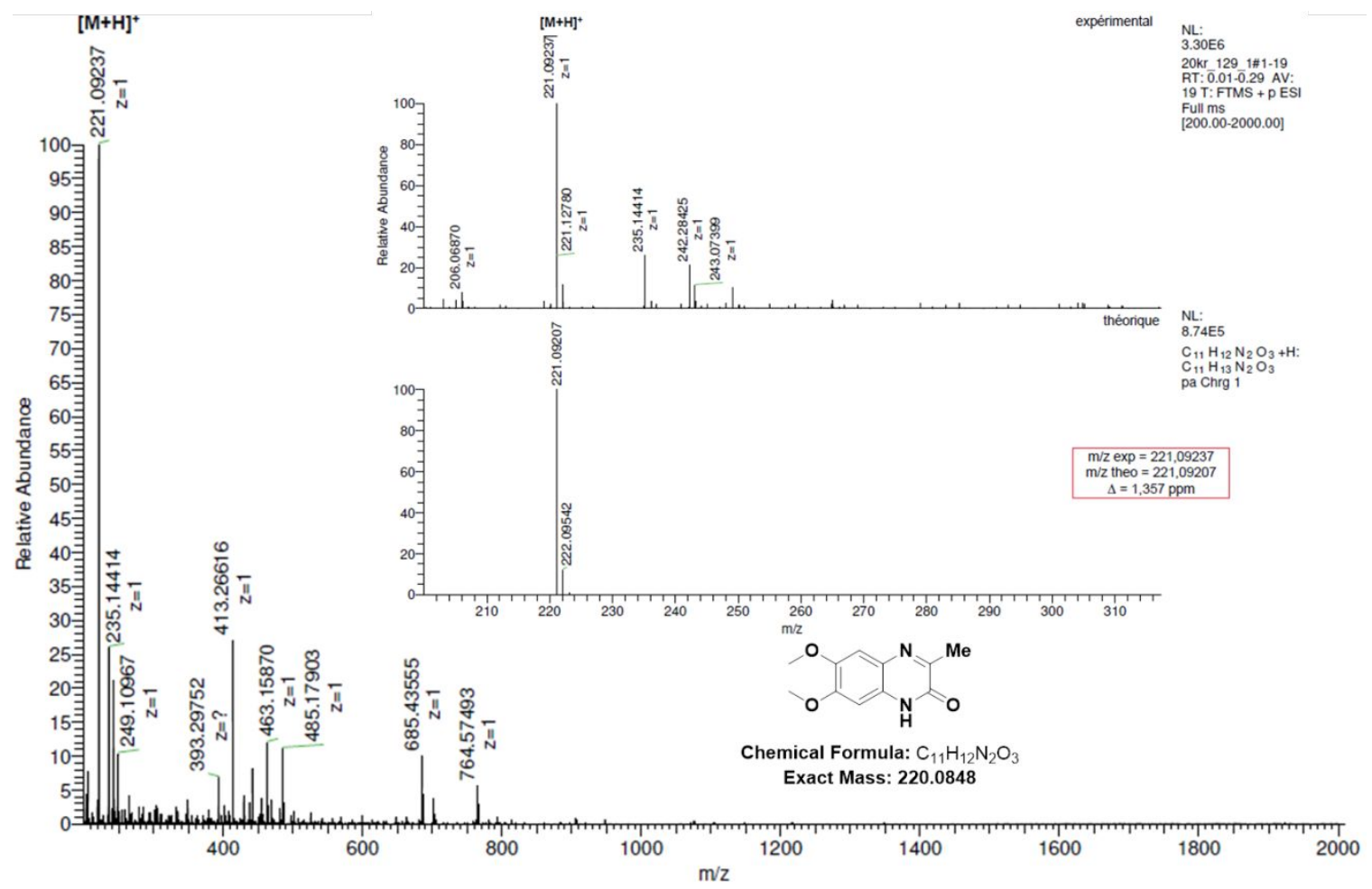

Fig. S9 - ESI+ (left) / ESI- (right) mass spectra (low resolution) of quinoxalin-2(1H)one 1
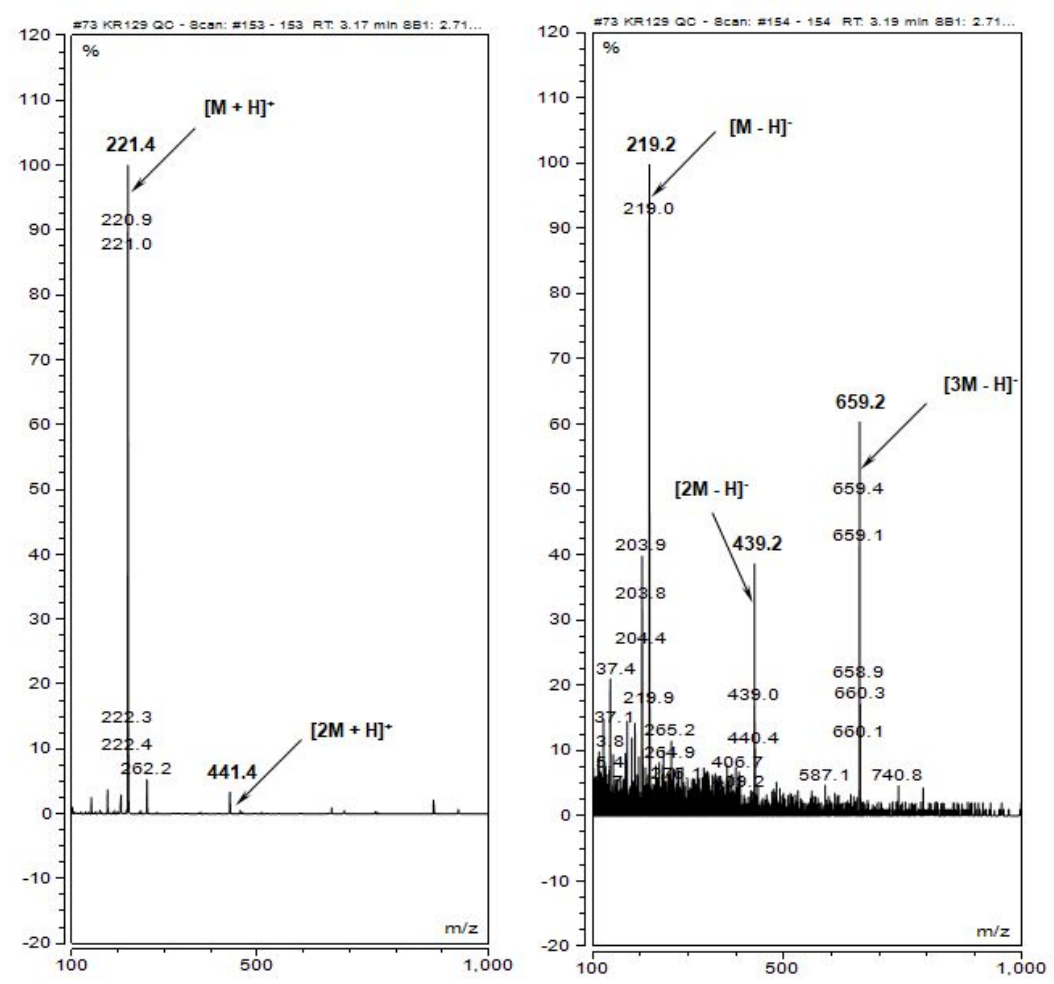
Fig. S10 - RP-HPLC elution profile of quinoxalin-2(1H)-one 1 (system A, detection at $260 \mathrm{~nm}$ )

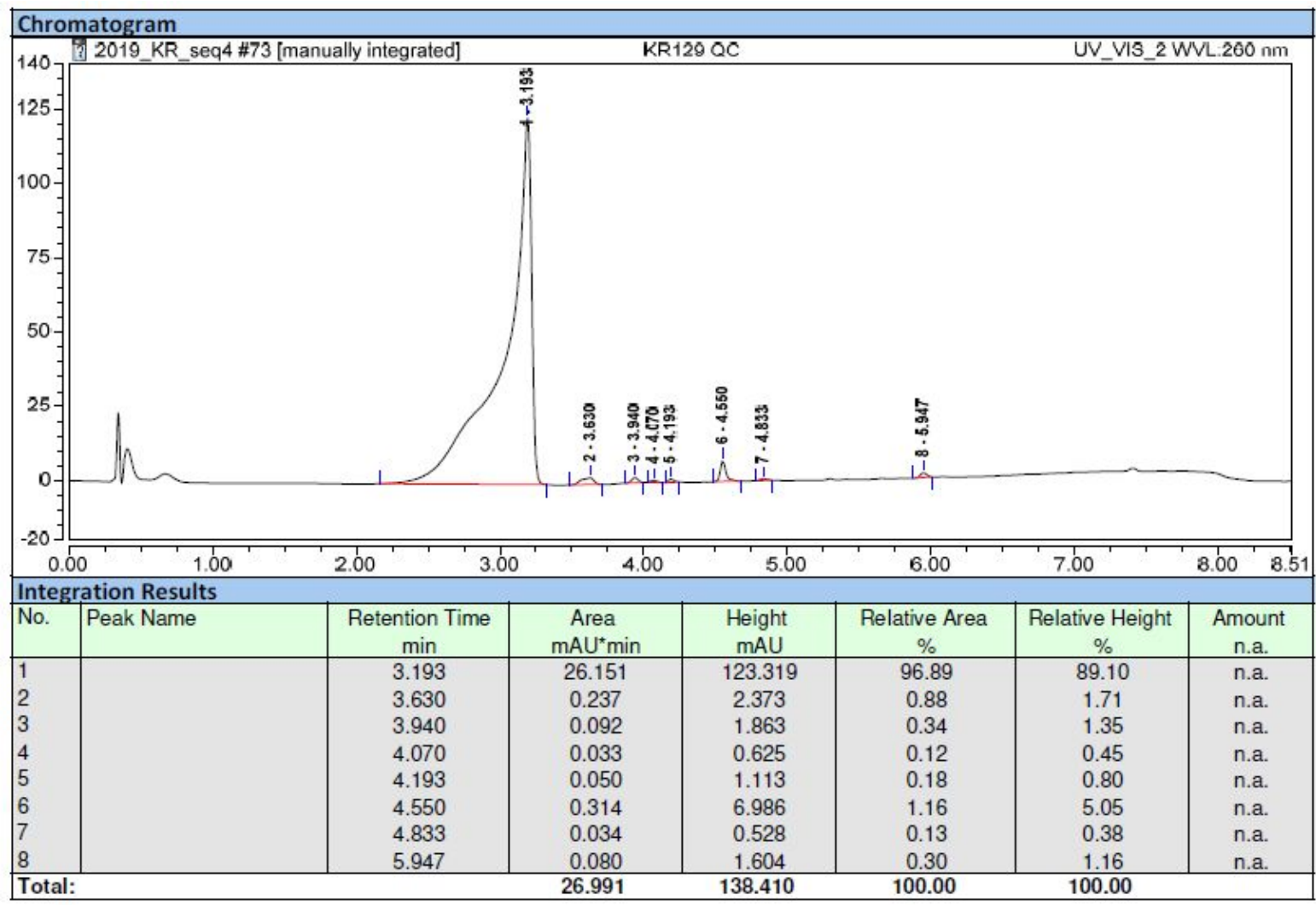

please note: the pure compound was found to be eluted as a broad asymmetric peak whatever the solvent mixture used for sample preparation.

Fig. S11 - IR-ATR spectrum of quinoxalin-2(1H)-one 1

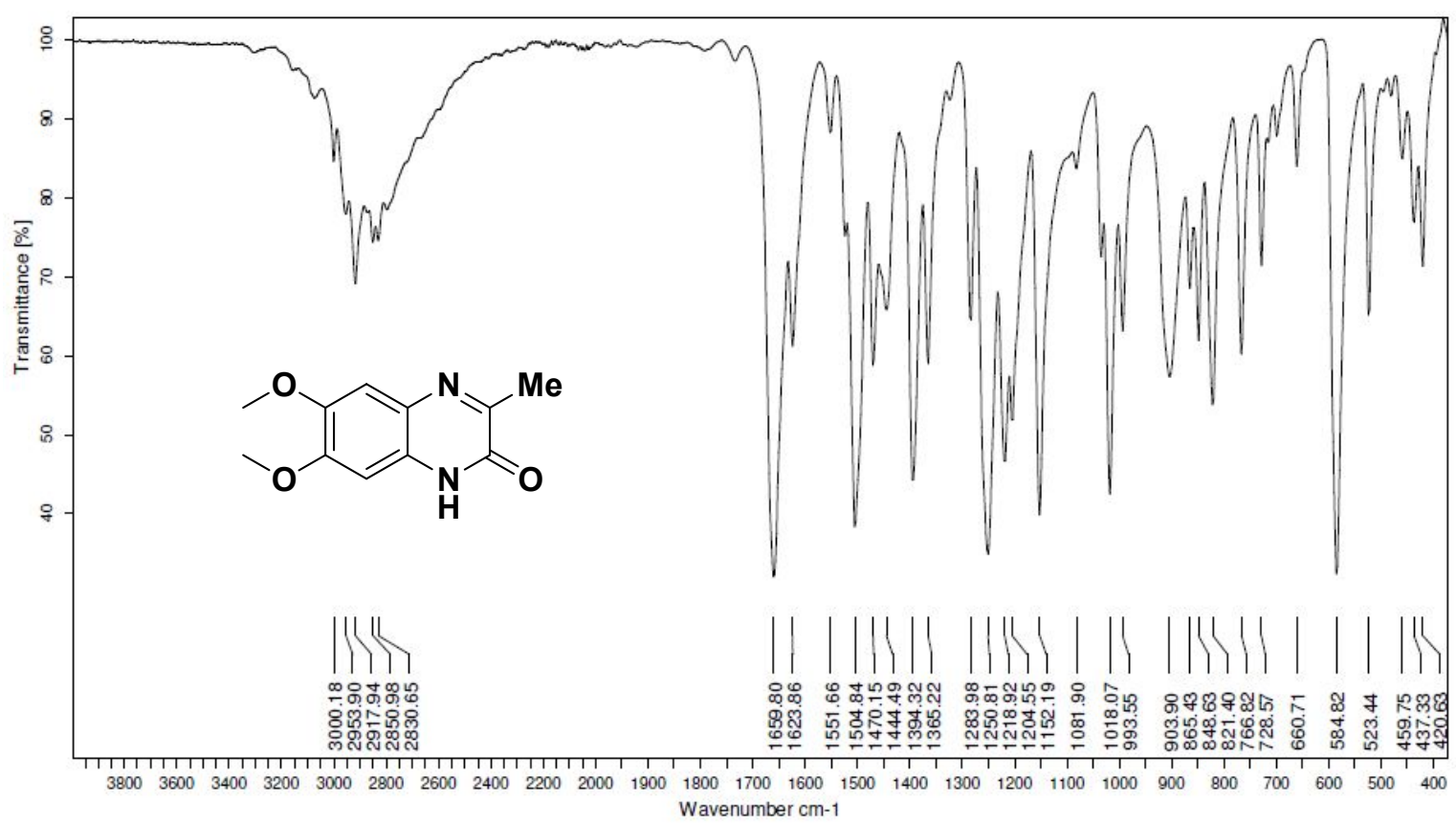

Fig. S12 - ${ }^{1} \mathrm{H}$ NMR spectrum of quinoxalin-2(1H)-one 1 in DMSO- $d_{6}(400 \mathrm{MHz})$ 


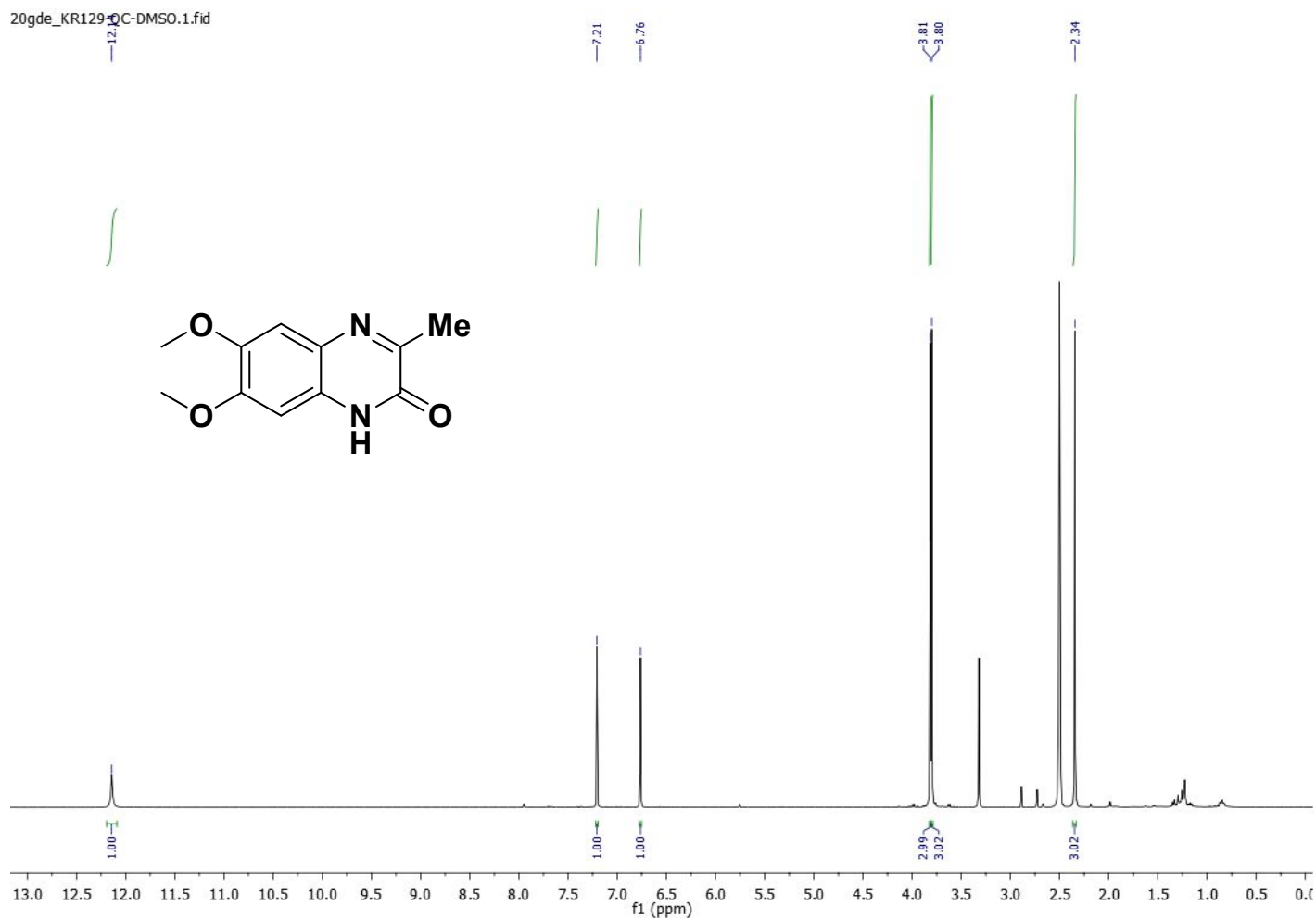

Fig. S13 $-{ }^{13} \mathrm{C}$ NMR spectrum of quinoxalin-2(1H)-one 1 in DMSO- $d_{6}(101 \mathrm{MHz})$ 20gde_KR129-QC-DMSO.2.fid<smiles>COc1cc2nc(C)c(=O)[nH]c2cc1OC</smiles>

$\begin{array}{llllllllllll}210 & 200 & 190 & 180 & 170 & 160 & 150 & 140 & 130 & 120 & 110 & 100\end{array}$

Fig. S14 - ESI+ mass spectrum (high resolution) of quinoxalin-2(1H)-one 2 


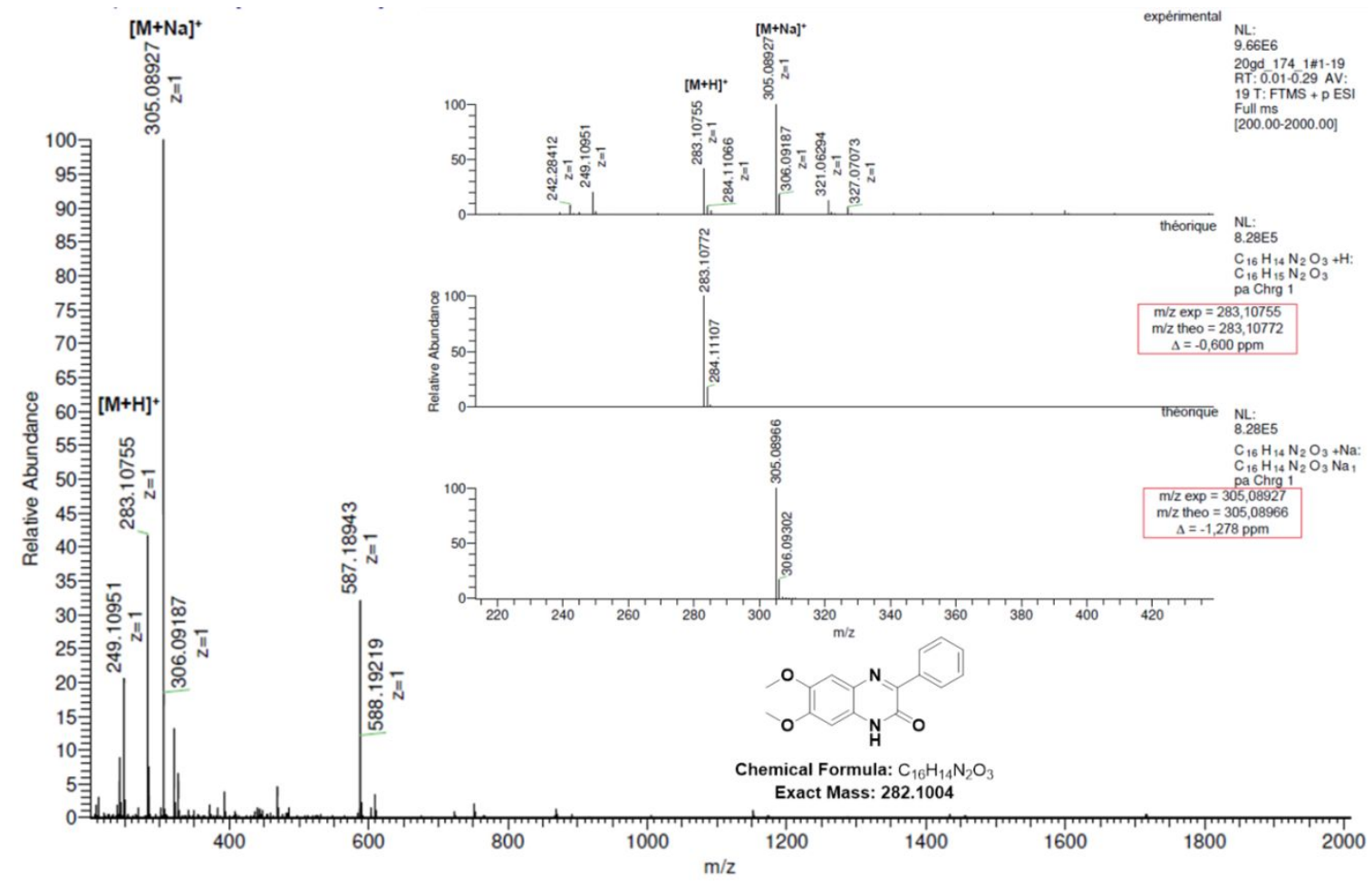

Fig. S15 - ESI+ (left) / ESI- (right) mass spectra (low resolution) of quinoxalin2(1H)-one 2
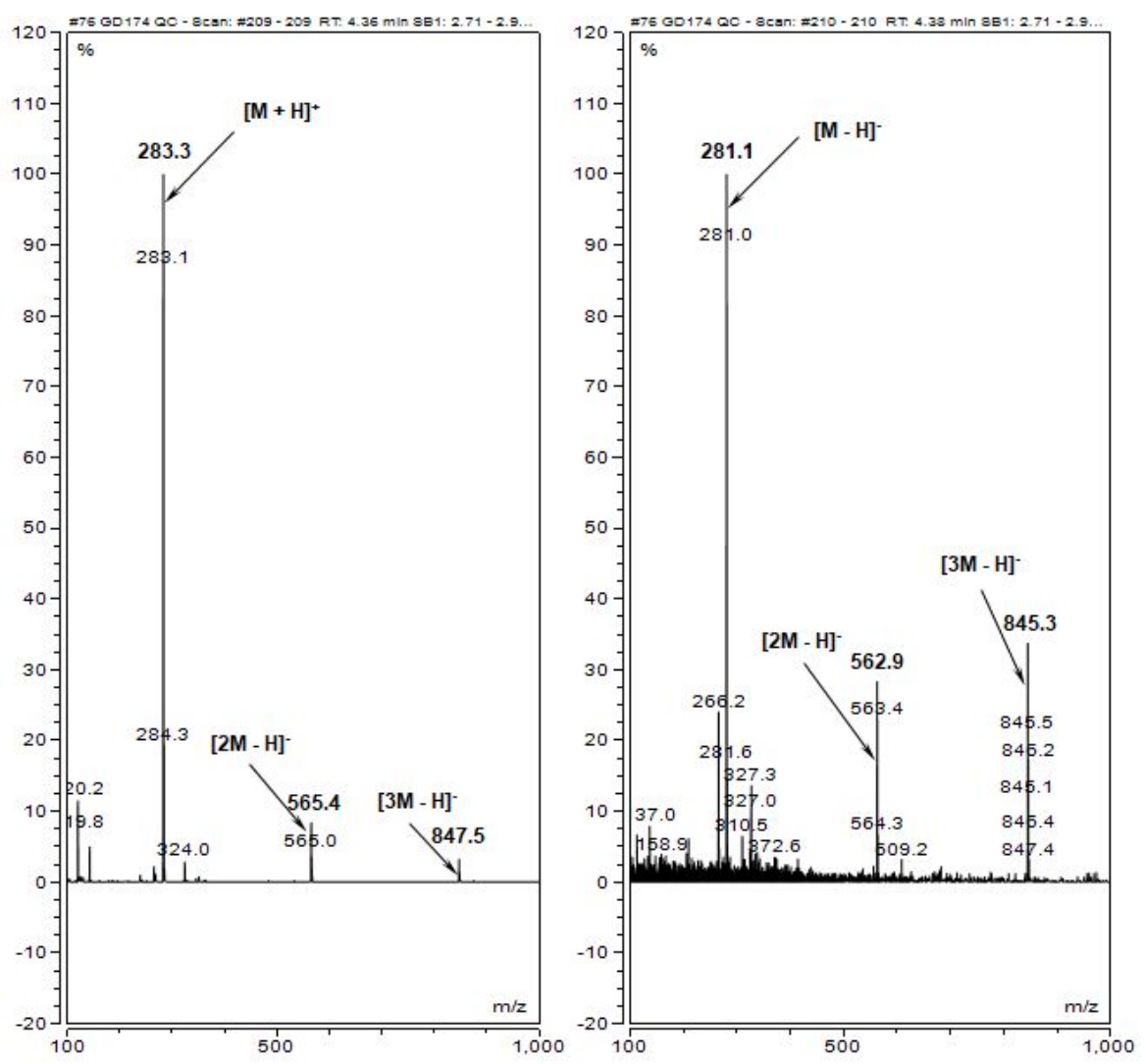
Fig. S16 - RP-HPLC elution profile quinoxalin-2(1H)-one 2 (system A, detection at $260 \mathrm{~nm})$

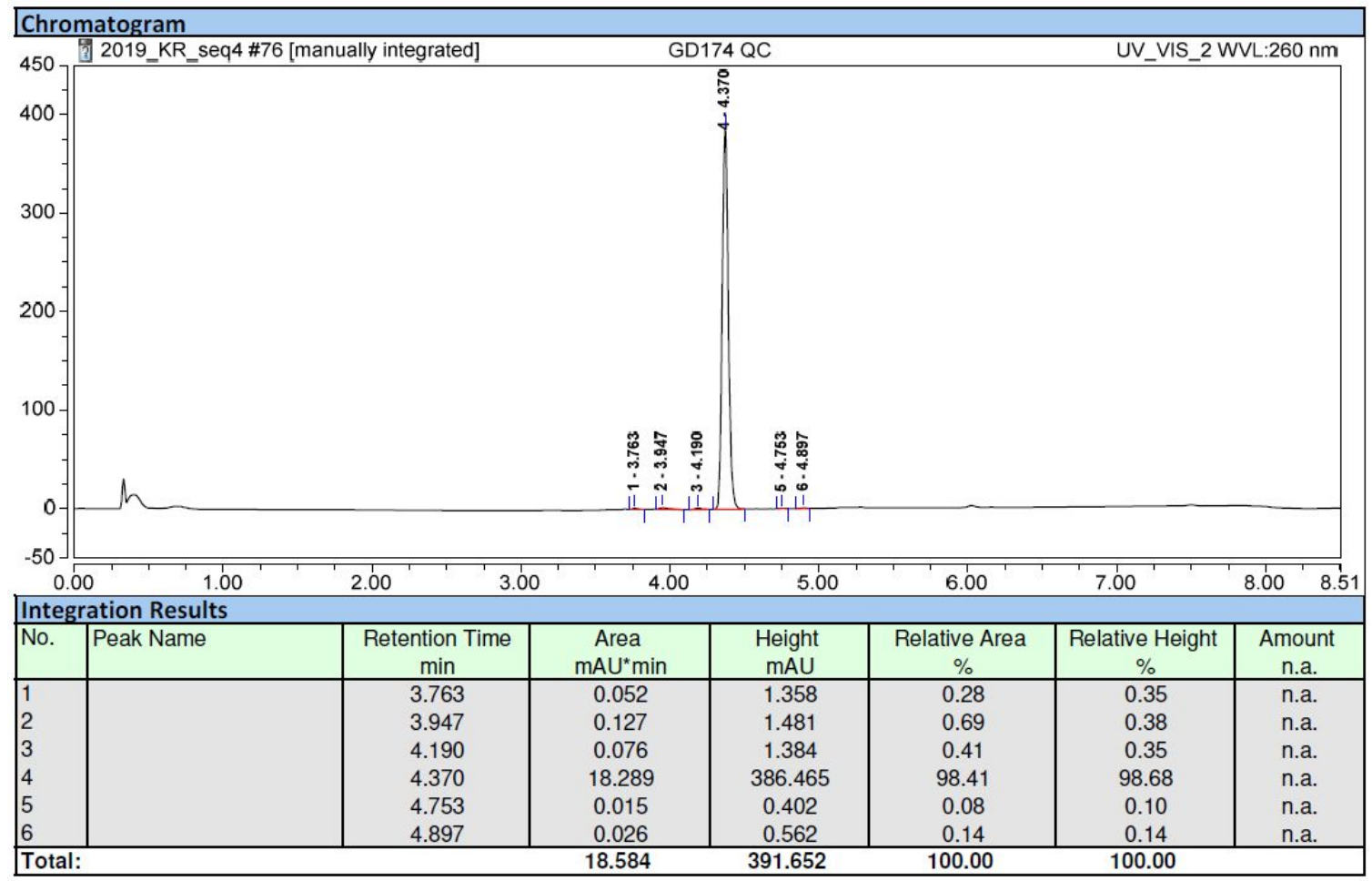

Fig. S17 - RP-HPLC elution profile of quinoxalin-2(1H)-one 2 (system A, detection at $450 \mathrm{~nm}$ )

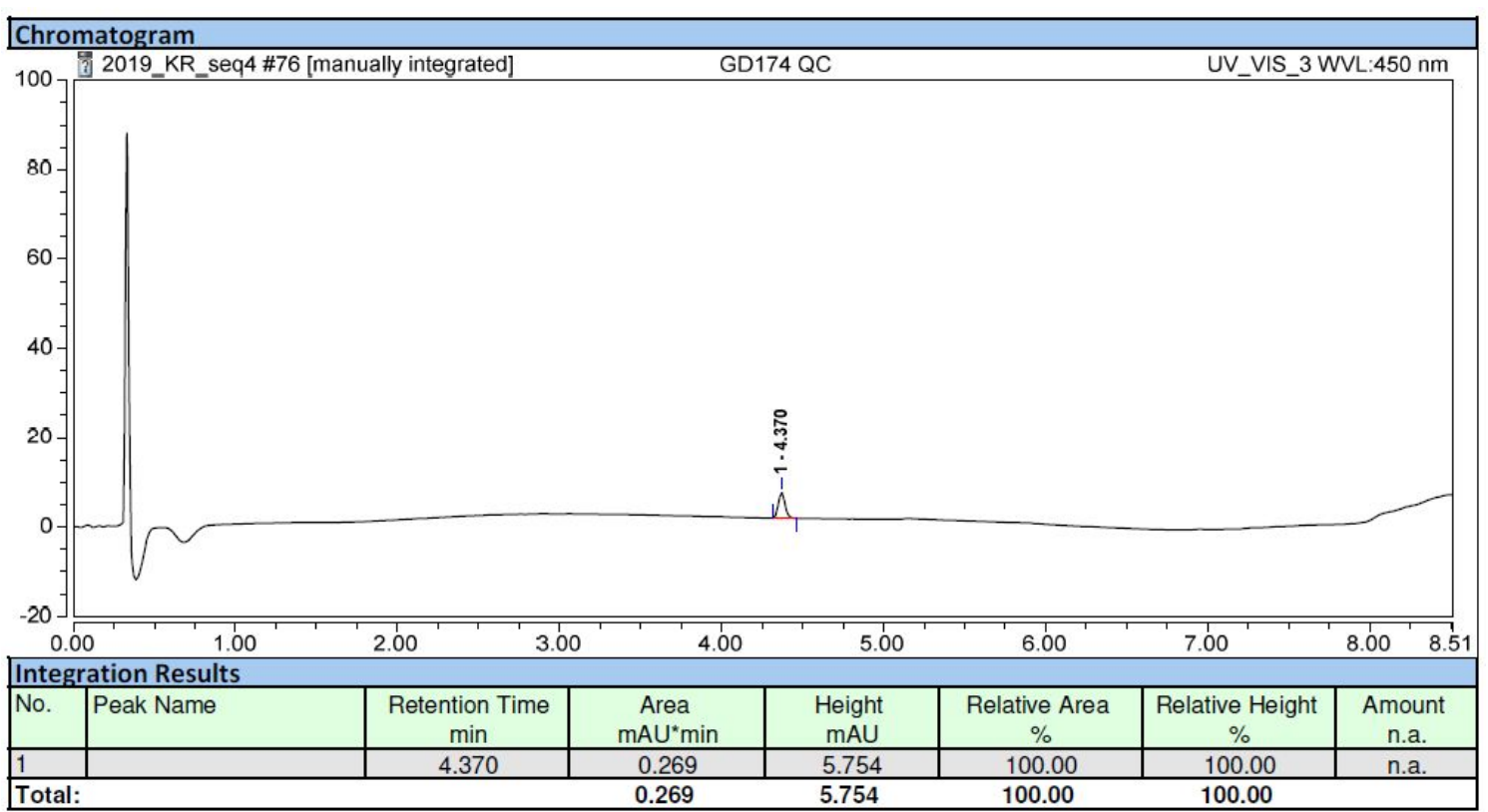


Fig. S18 - IR-ATR spectrum of quinoxalin-2(1H)-one 2

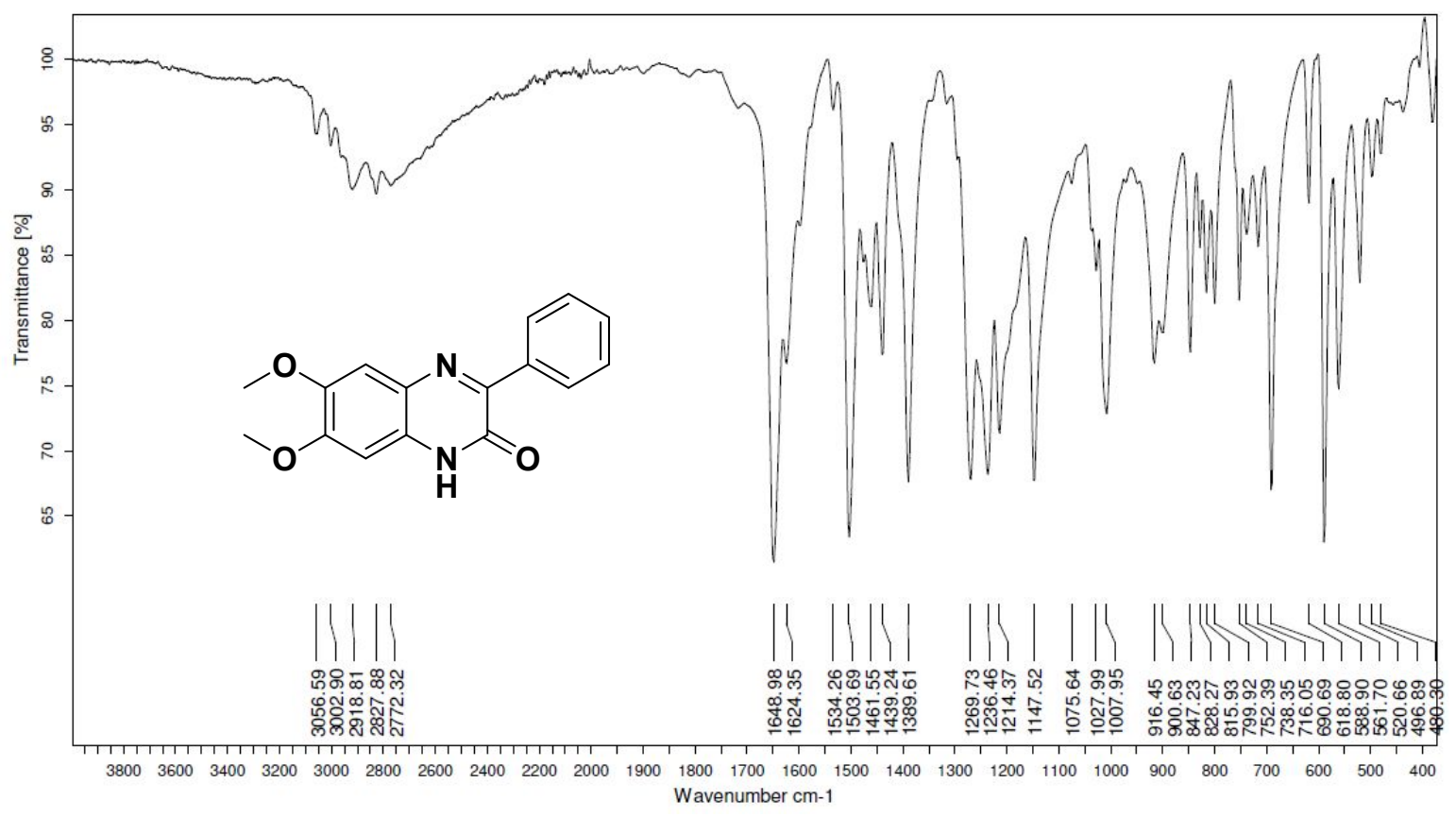

Fig. S19 - ${ }^{1} \mathrm{H}$ NMR spectrum of quinoxalin-2(1H)-one 2 in $\mathrm{CDCl}_{3}\left(+10 \%\right.$ TFA-d $\left.{ }_{1}\right)$ (500 MHz)

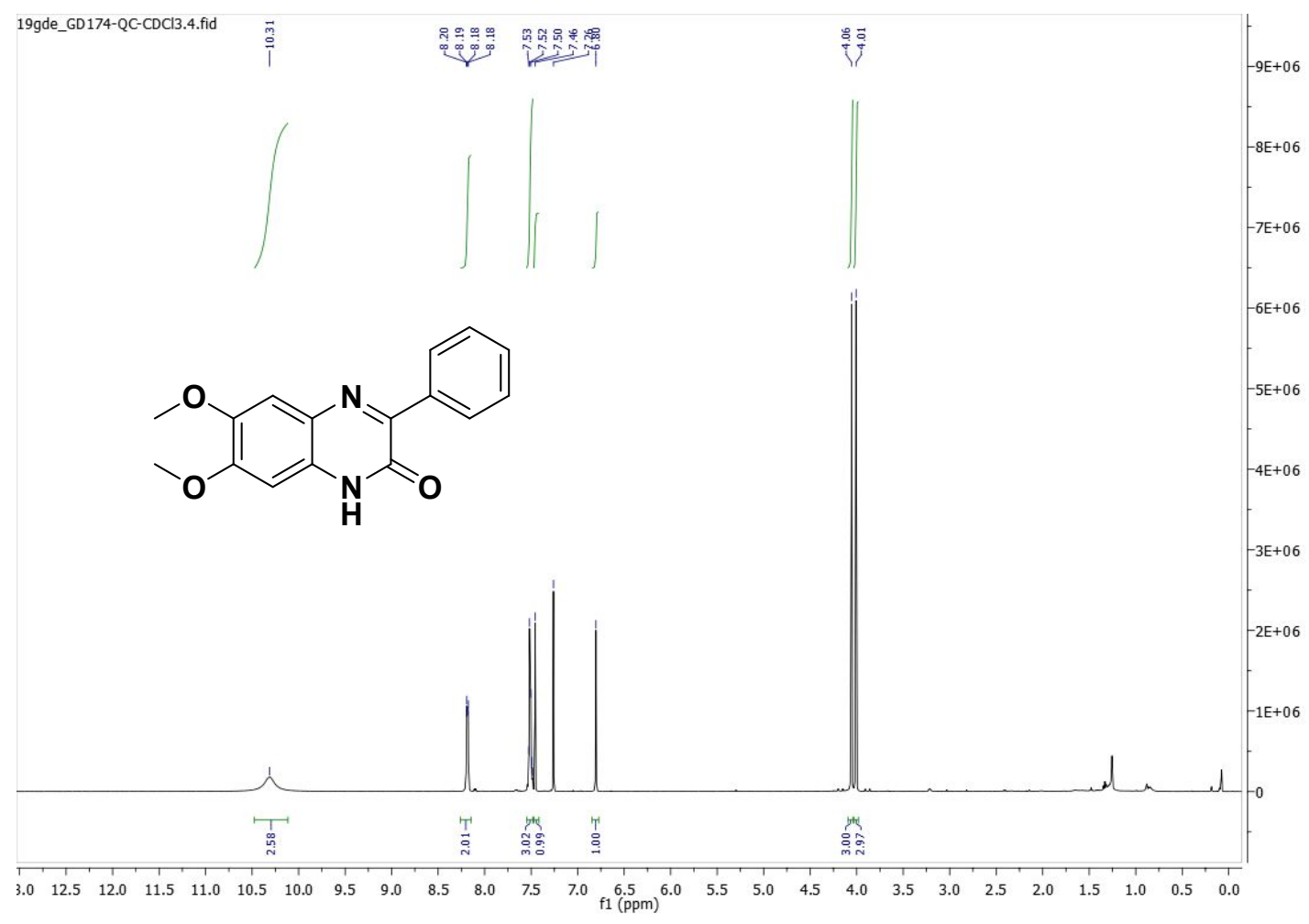


Fig. S20 - ${ }^{13} \mathrm{C}$ NMR spectrum of quinoxalin-2(1H)-one 2 in $\mathrm{CDCl}_{3}(+10 \%$ TFA-d 1$)$ (126 MHz)

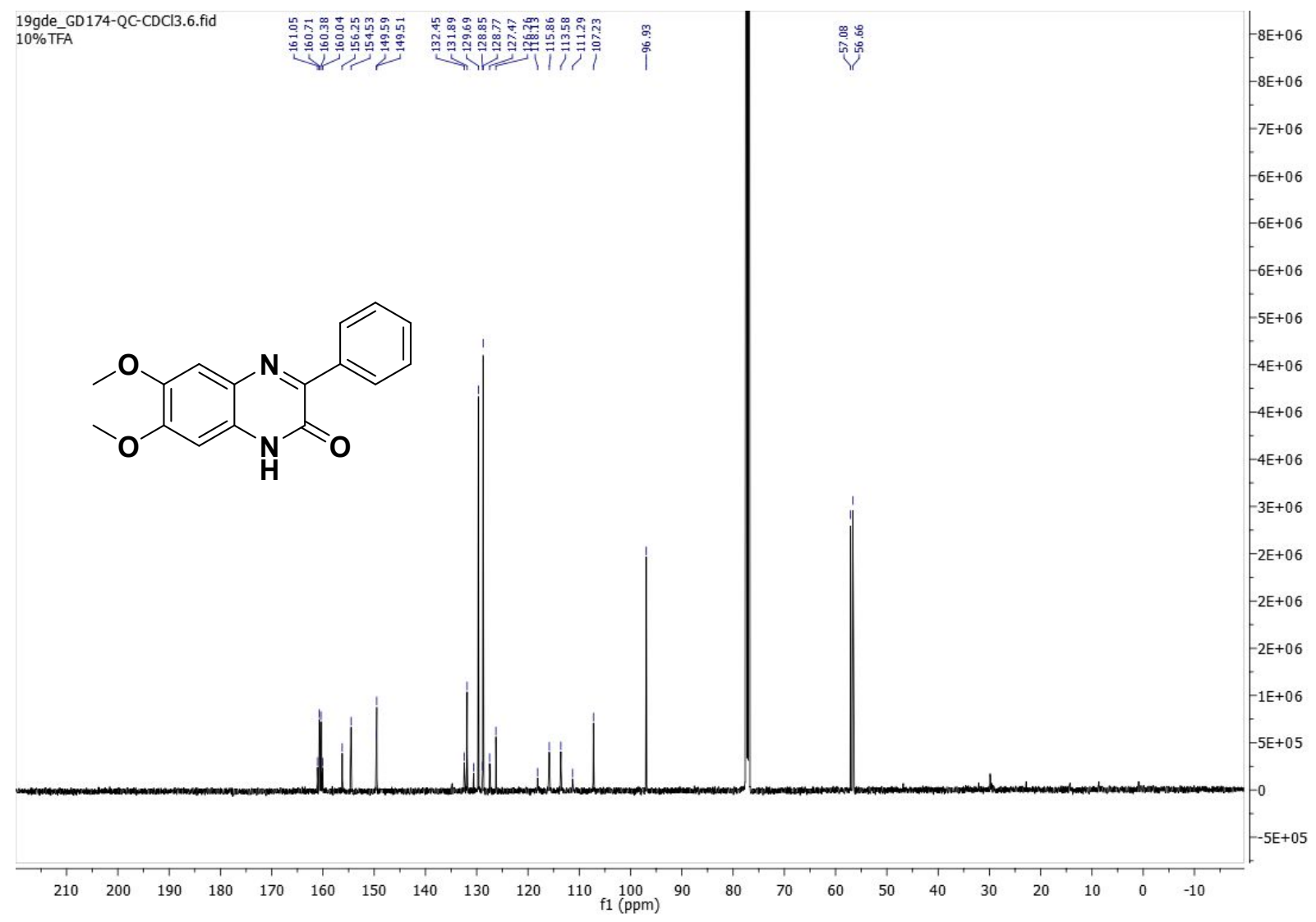

please note: the two quartets centered at 160.5 and 114.7 are assigned to TFA-d . $_{\text {. }}$

Fig. S21 - TFA determination by IC - results for sample of quinoxalin-2(1H)-one 2

\begin{tabular}{|c|c|c|}
\hline Concentration & 100 & $1.0 \mathrm{mg} / \mathrm{mL}$ in DMSO \\
\hline Sample dilution factor & 0.565 & 5.866 \\
\hline Raw data ppm & 5.65 & 5.87 \\
\hline Content in wt \% & \multicolumn{2}{|c|}{5.76} \\
\hline Average content in wt \% & \\
\hline
\end{tabular}


Fig. S22 - ESI+ mass spectrum (high resolution) of quinoxalin-2(1H)-one 3

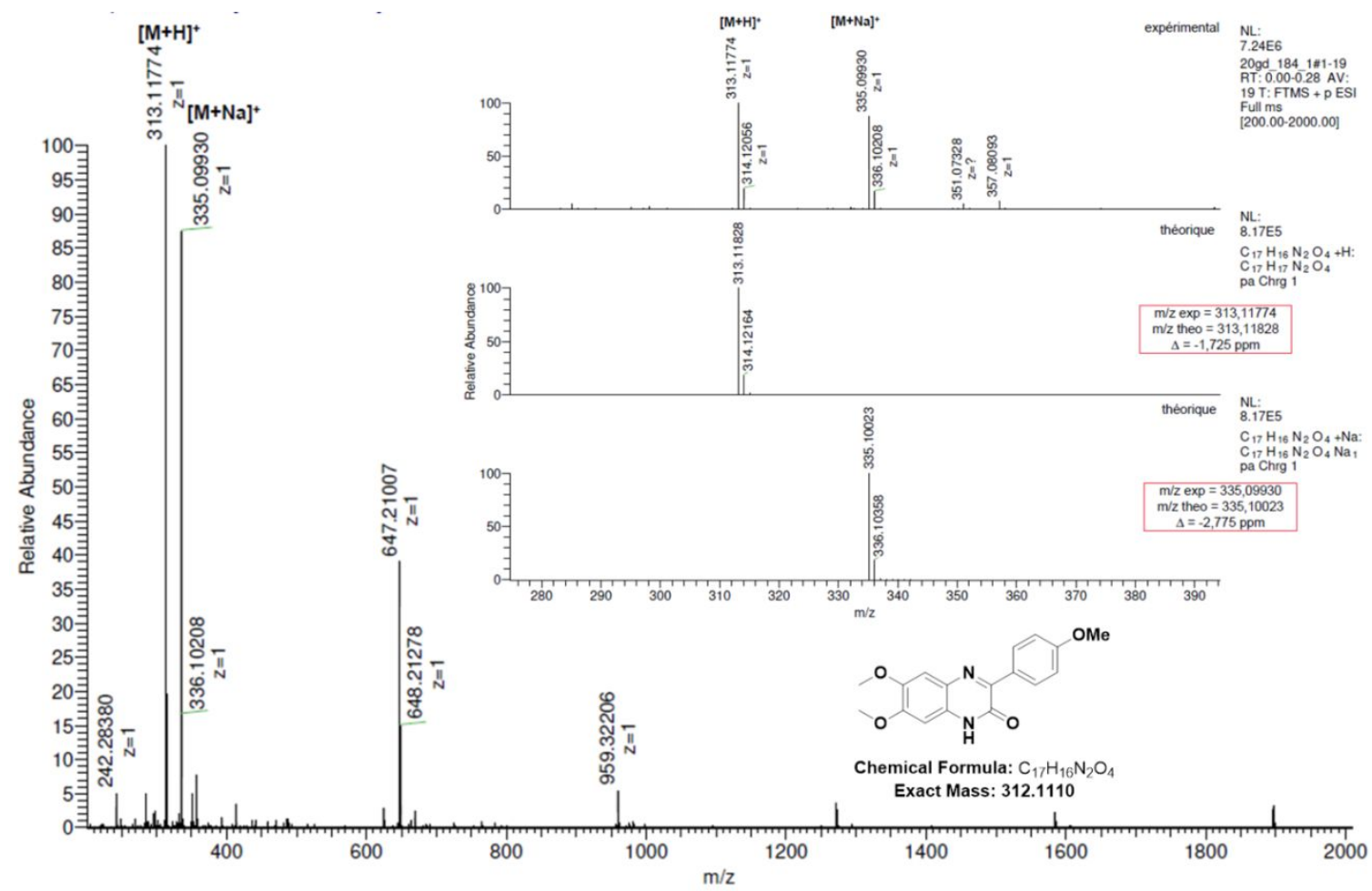

Fig. S23 - ESI+ (left) / ESI- (right) mass spectra (low resolution) of quinoxalin2(1H)-one 3

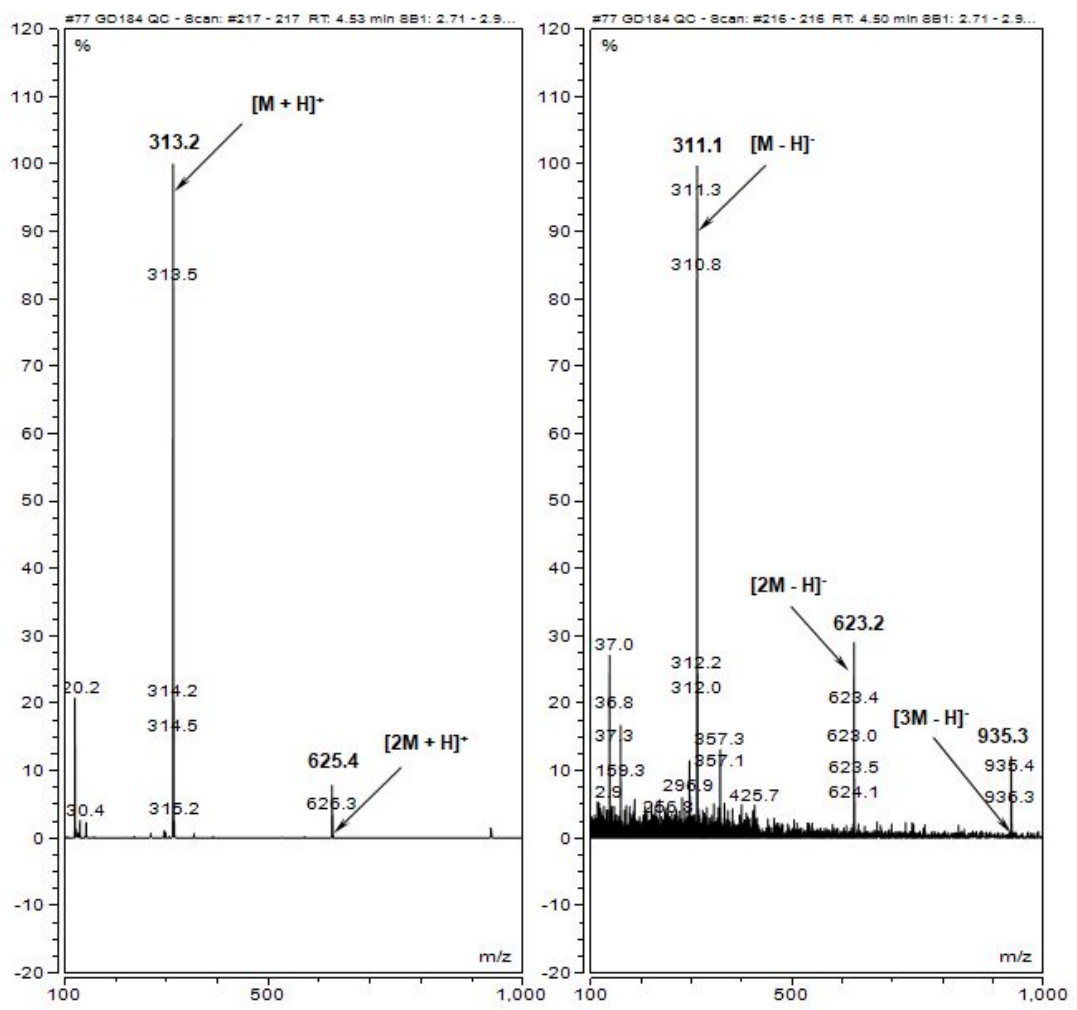


Fig. S24 - RP-HPLC elution profile of quinoxalin-2(1H)-one 3 (system A, detection at $260 \mathrm{~nm}$ )

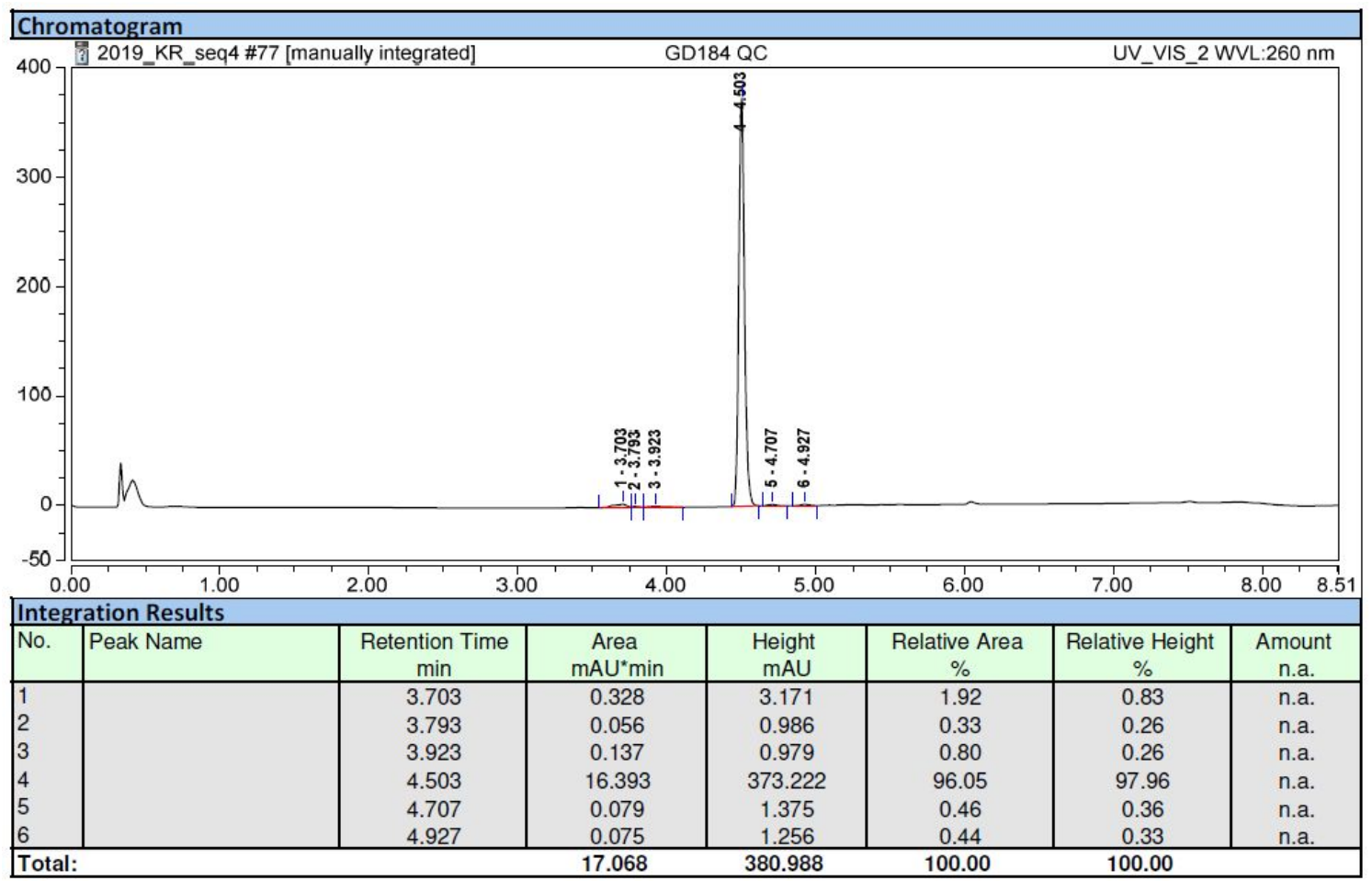

Fig. S25 - RP-HPLC elution profile of quinoxalin-2(1H)-one 3 (system A, detection at $450 \mathrm{~nm}$ )

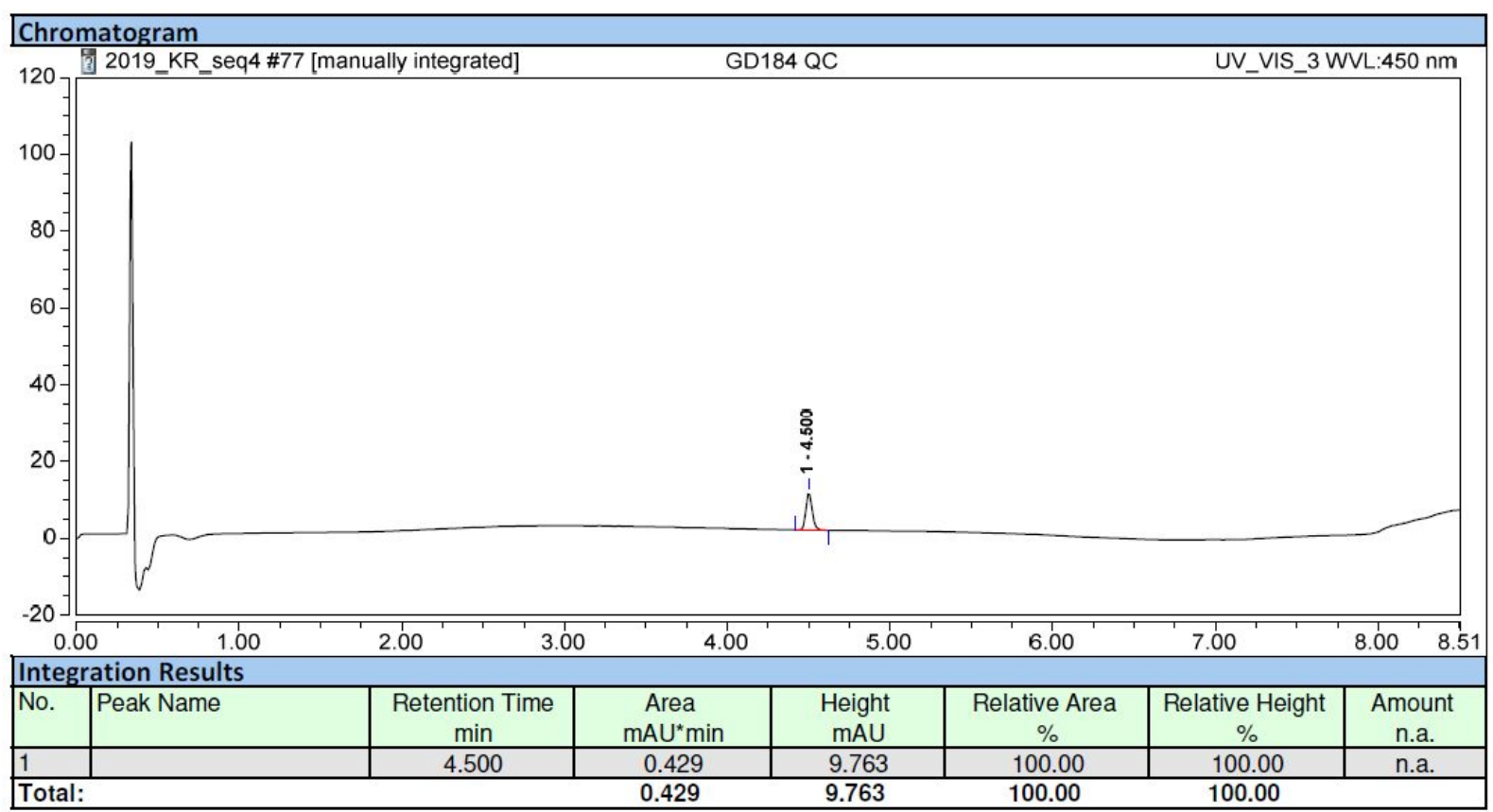


Fig. S26 - IR-ATR spectrum of quinoxalin-2(1H)-one 3

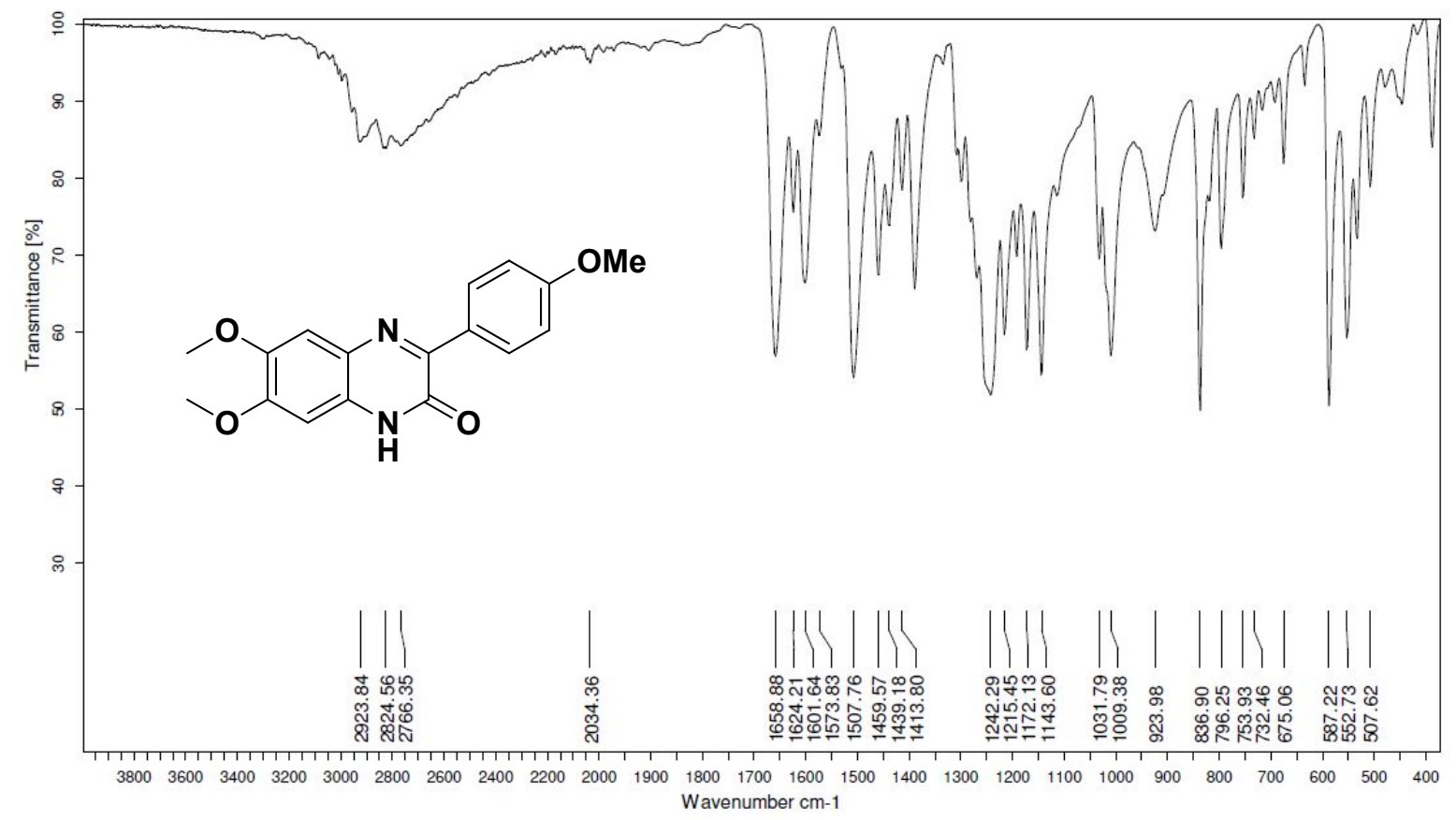

Fig. S27 - ${ }^{1} \mathrm{H}$ NMR spectrum of quinoxalin-2(1H)-one 3 in DMSO- $d_{6}(400 \mathrm{MHz})$

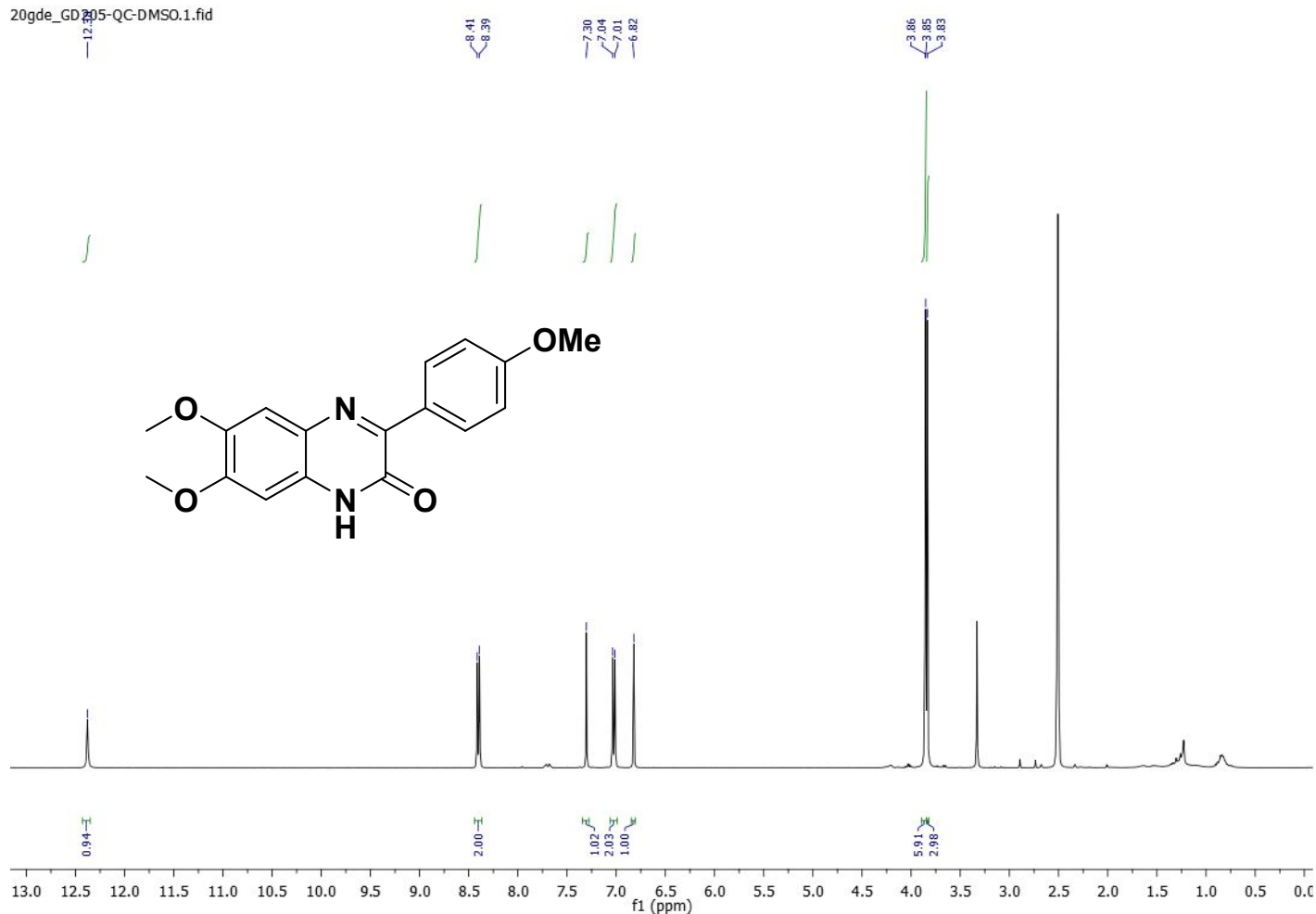


Fig. S28 $-{ }^{13} \mathrm{C}$ NMR spectrum of quinoxalin-2(1H)-one 3 in DMSO- $d_{6}(101 \mathrm{MHz})$

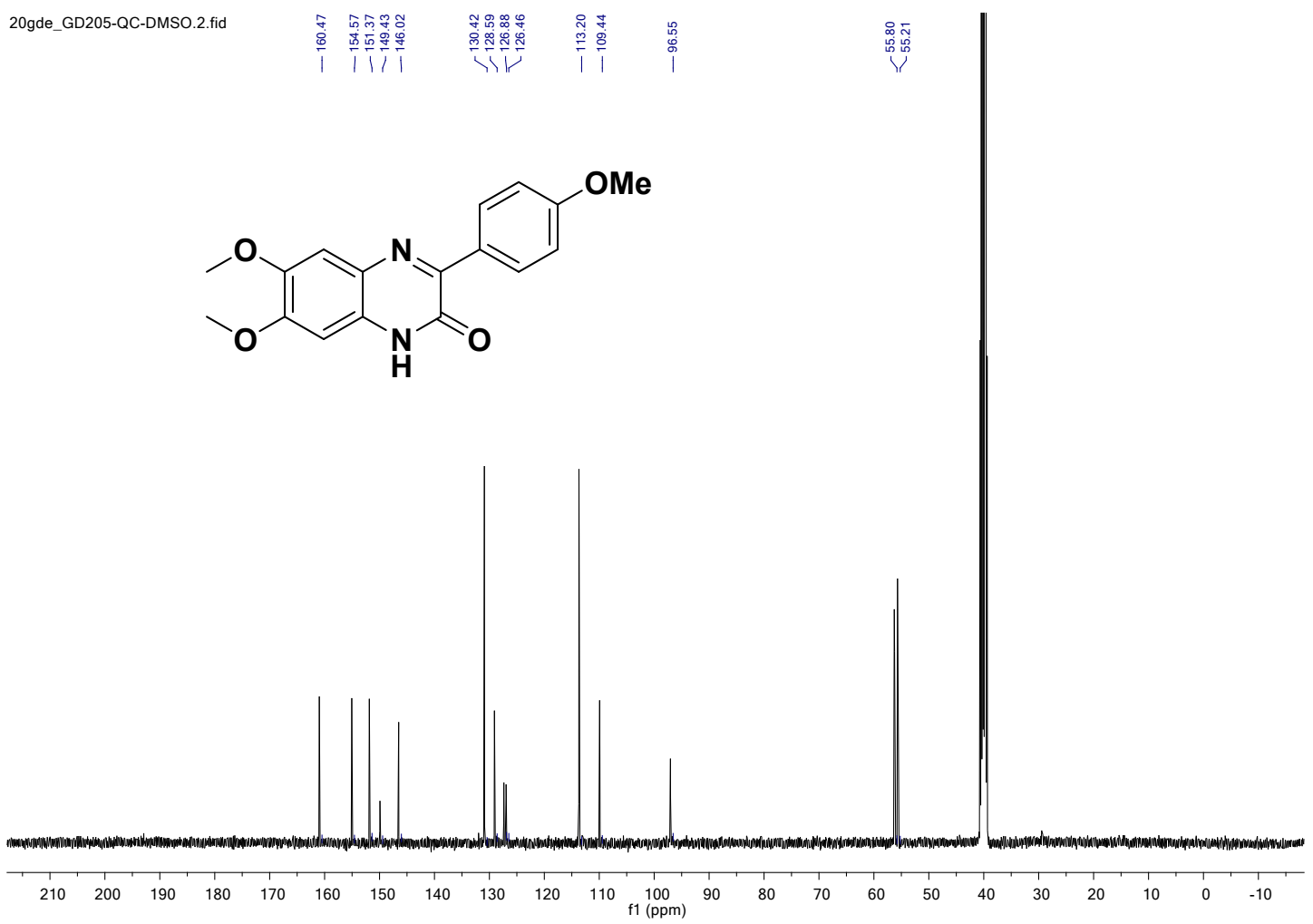

Fig. S29 - ESI+ mass spectrum (high resolution) of quinoxalin-2(1H)-one 4

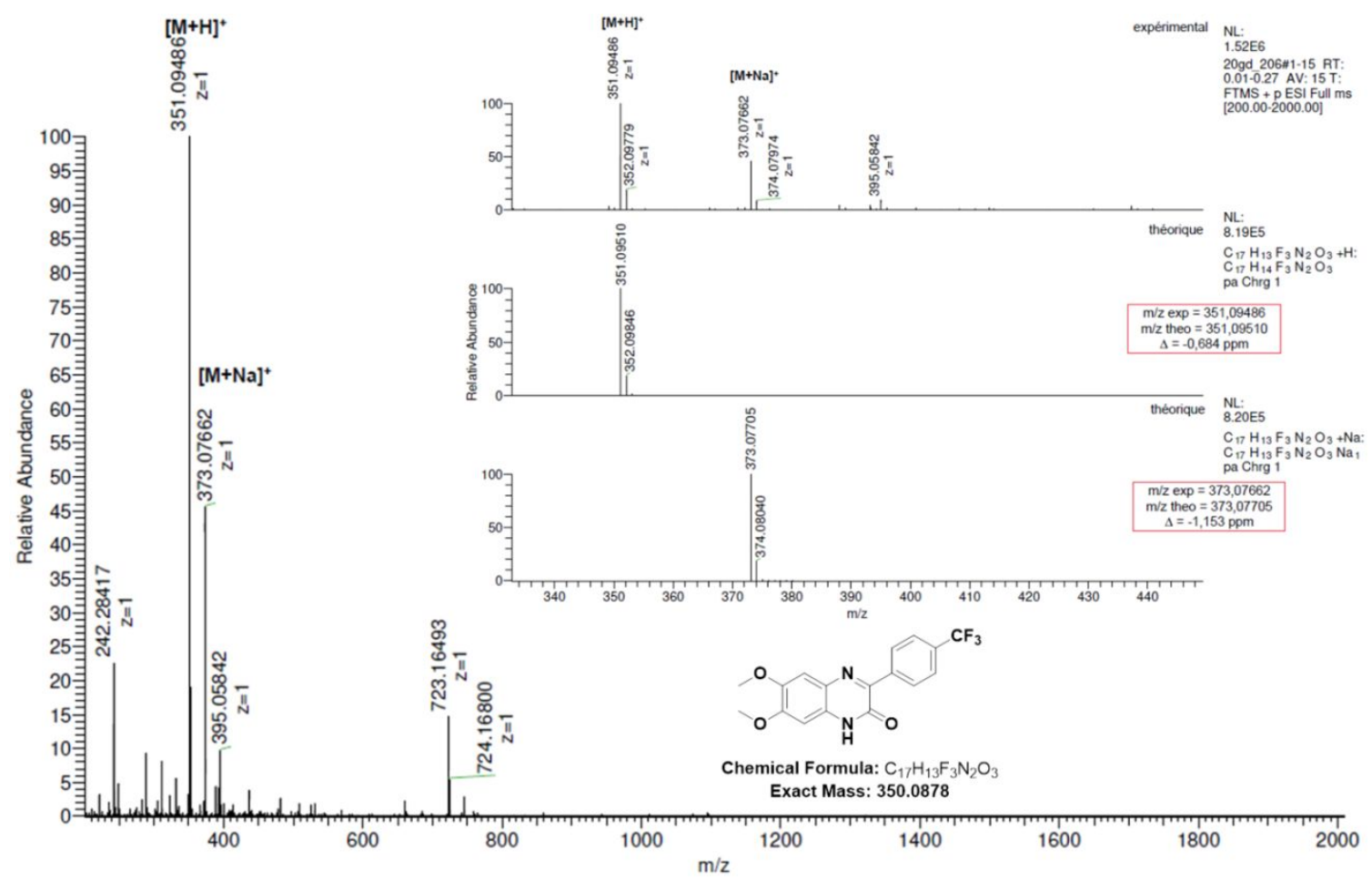


Fig. S30 - ESI+ (left) / ESI- (right) mass spectra (low resolution) of quinoxalin2(1H)-one 4

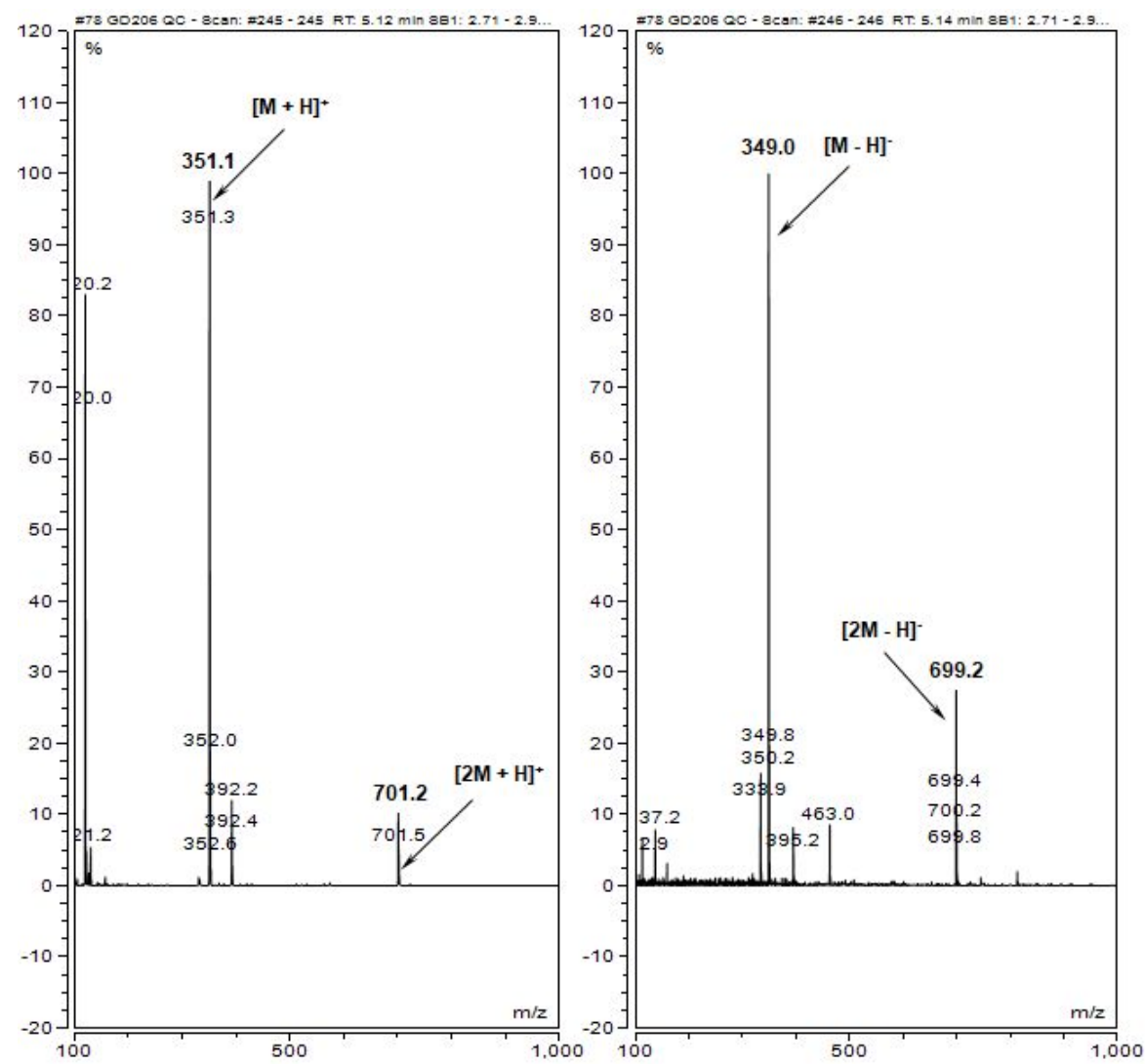

Fig. S31 - RP-HPLC elution profile of quinoxalin-2(1H)-one 4 (system A, detection at $260 \mathrm{~nm}$ )

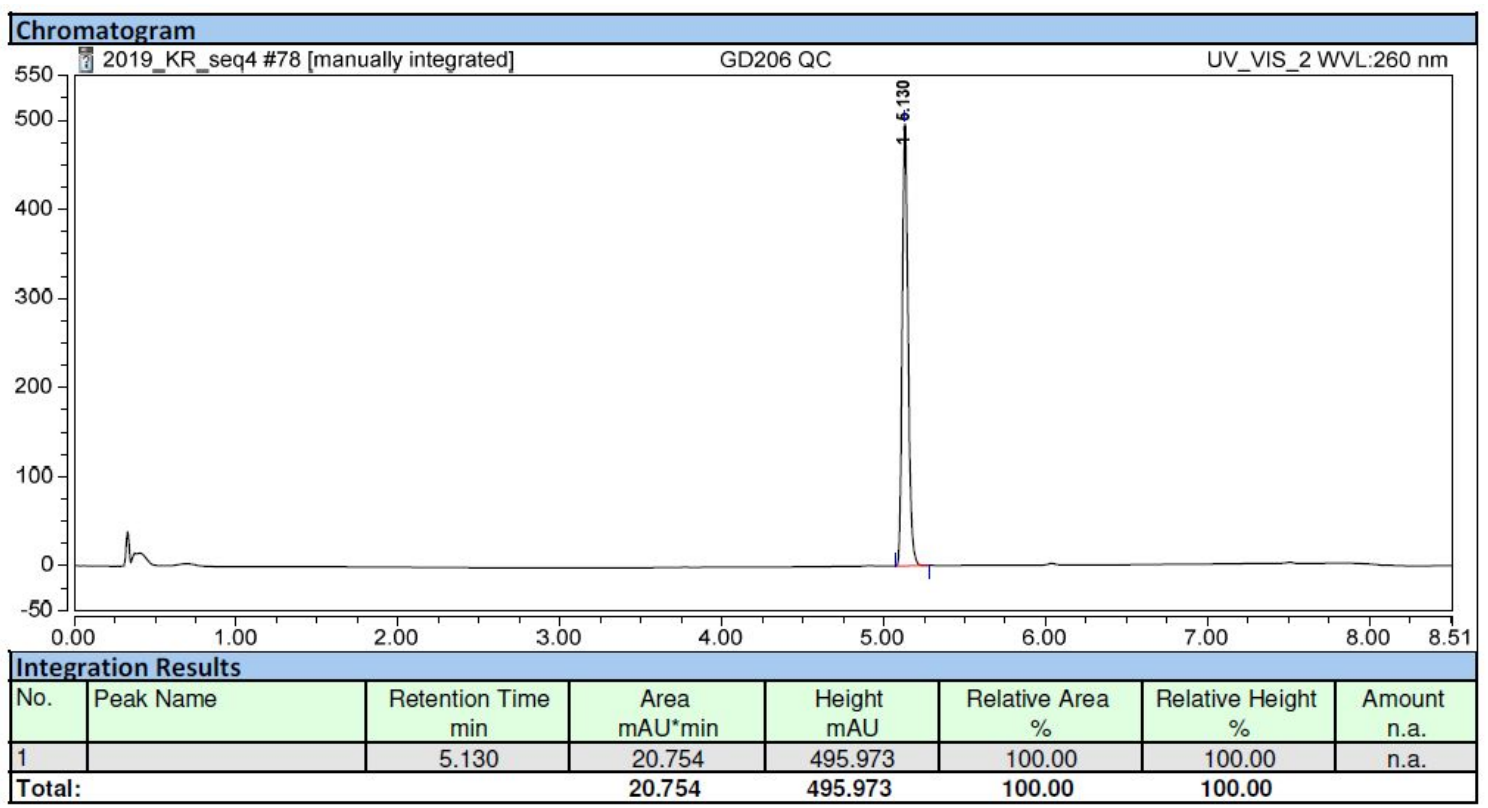


Fig. S32 - RP-HPLC elution profile of quinoxalin-2(1H)-one 4 (system A, detection at $450 \mathrm{~nm}$ )

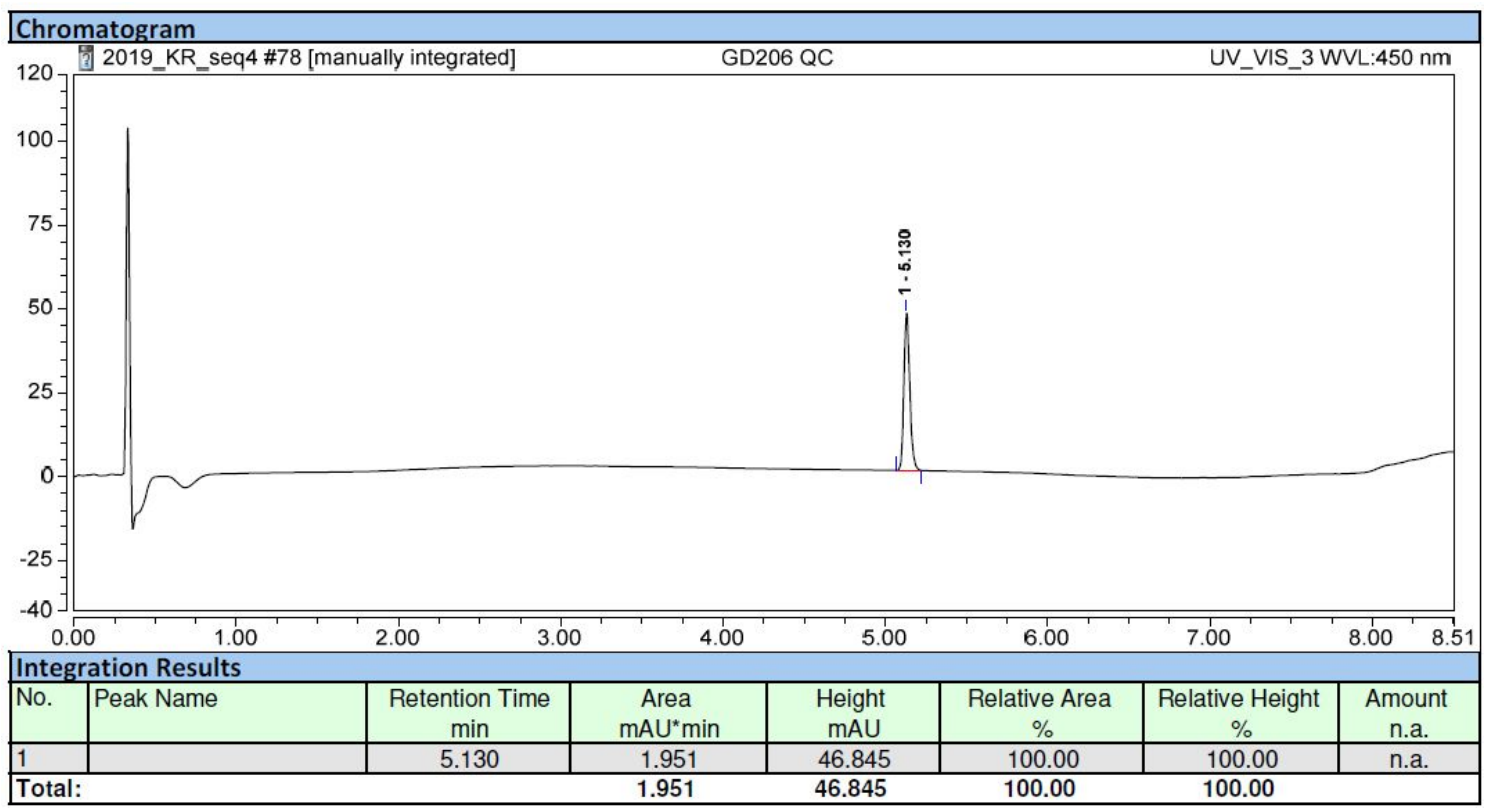

Fig. S33 - IR-ATR spectrum of quinoxalin-2(1H)-one 4

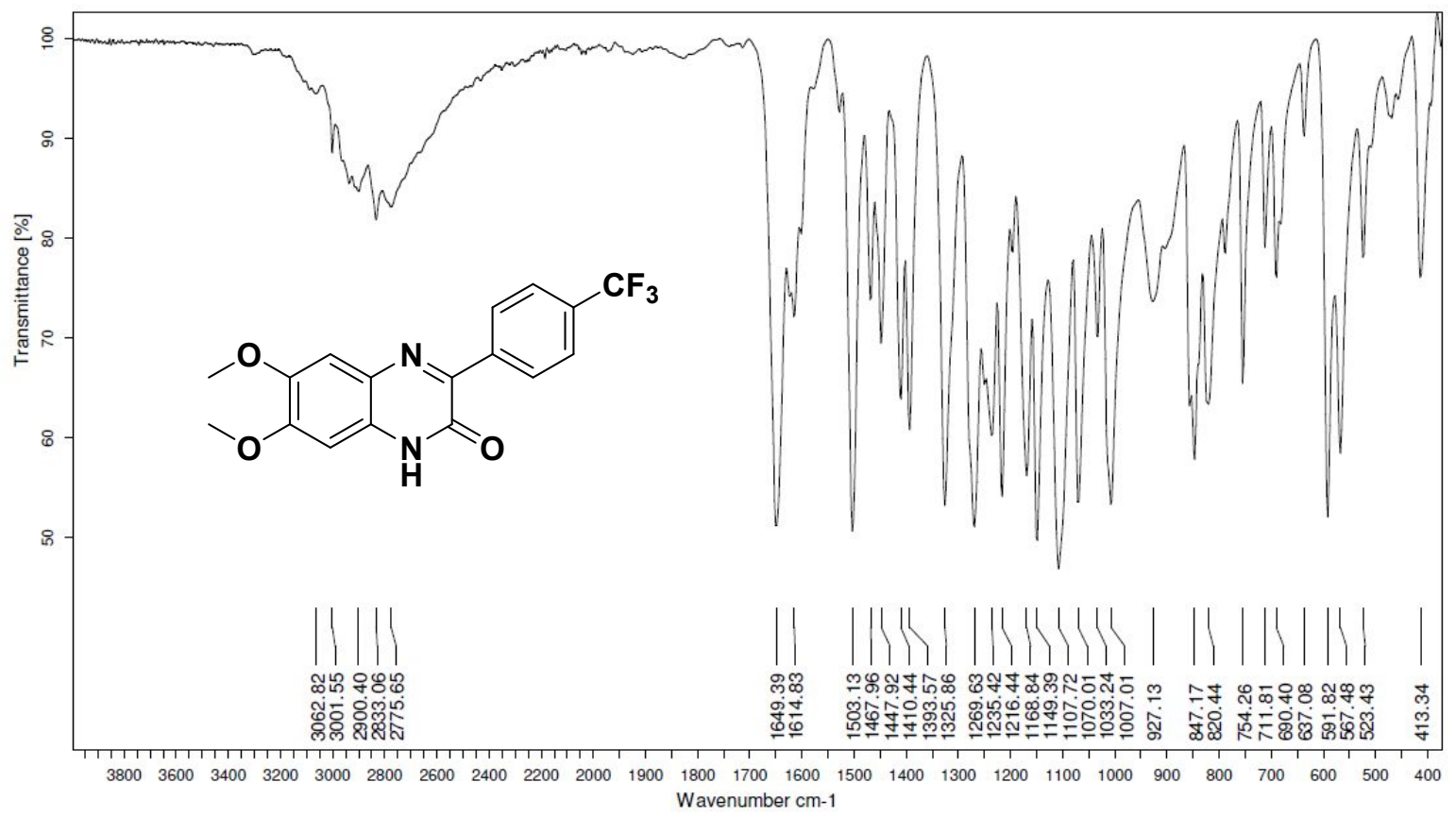


Fig. S34 - ${ }^{1} \mathrm{H}$ NMR spectrum of quinoxalin-2(1H)-one 4 in DMSO- $d_{6}(400 \mathrm{MHz})$

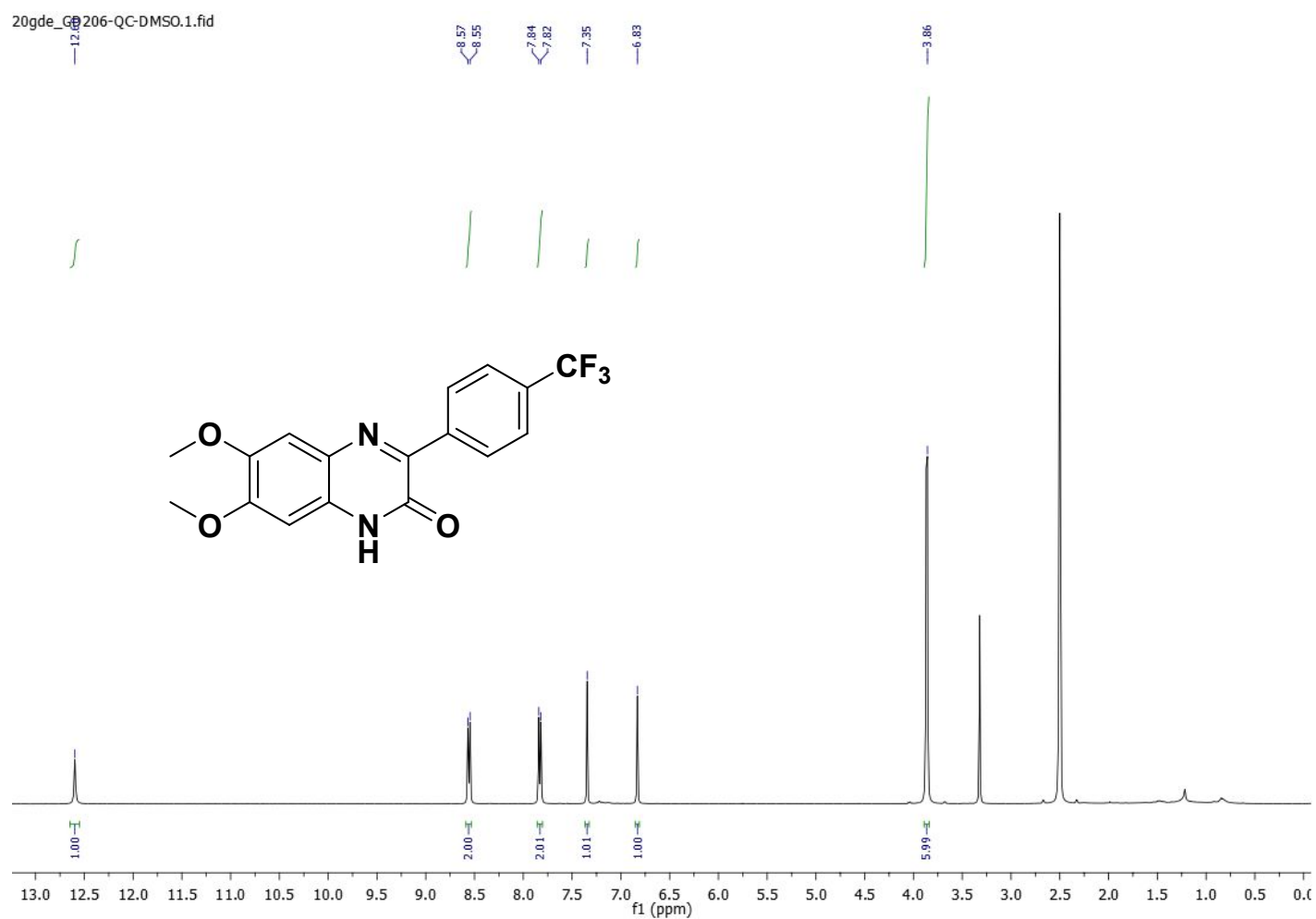

Fig. S35 $-{ }^{13} \mathrm{C}$ NMR spectrum of quinoxalin-2(1H)-one 4 in DMSO- $d_{6}(151 \mathrm{MHz})$

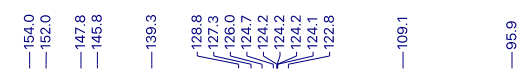<smiles>COc1cc2nc(-c3ccc(C(F)(F)F)cc3)c(=O)[nH]c2cc1OC</smiles>
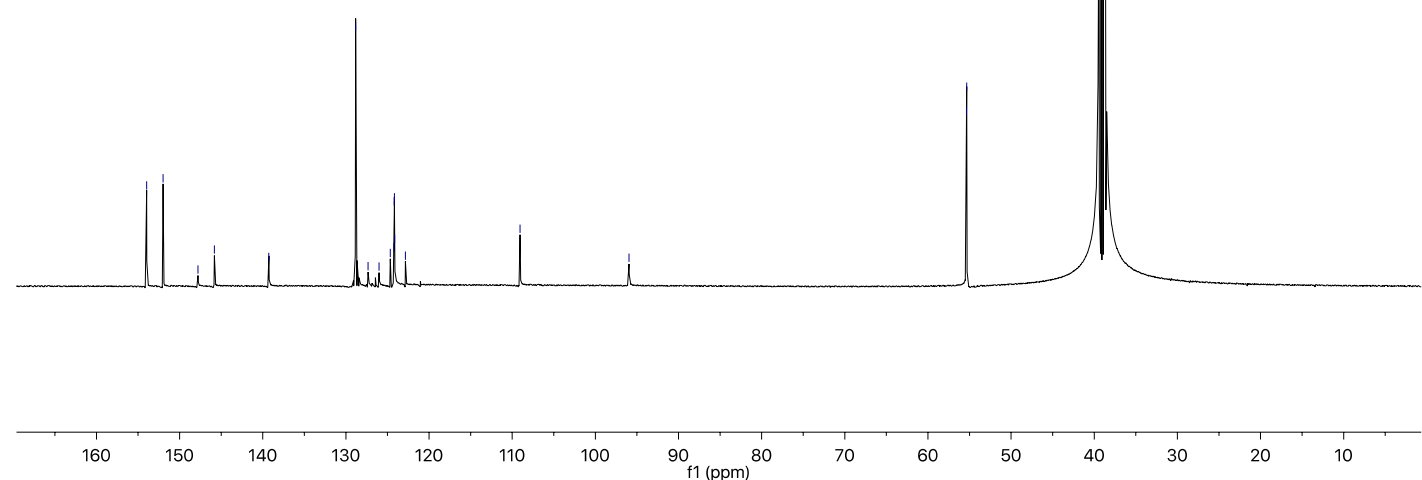

Please note: some difficulties were encountered in phase correction of this ${ }^{13} \mathrm{C} N \mathrm{~N}$ spectrum, even in manual mode. 
Fig. S36 - ${ }^{19} \mathrm{~F}$ NMR spectrum of quinoxalin-2(1H)-one 4 in DMSO- $d_{6}(470 \mathrm{MHz})$

20gde_GD 206-QC-DMSO.2.fid<smiles>COc1cc2nc(-c3ccc(C(F)(F)F)cc3)c(=O)[nH]c2cc1OC</smiles>

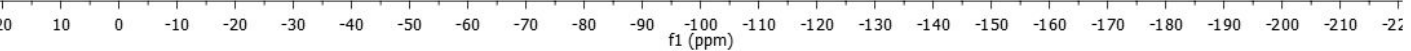

Fig. S37 - ESI+ mass spectrum (high resolution) of quinoxalin-2(1H)-one 5

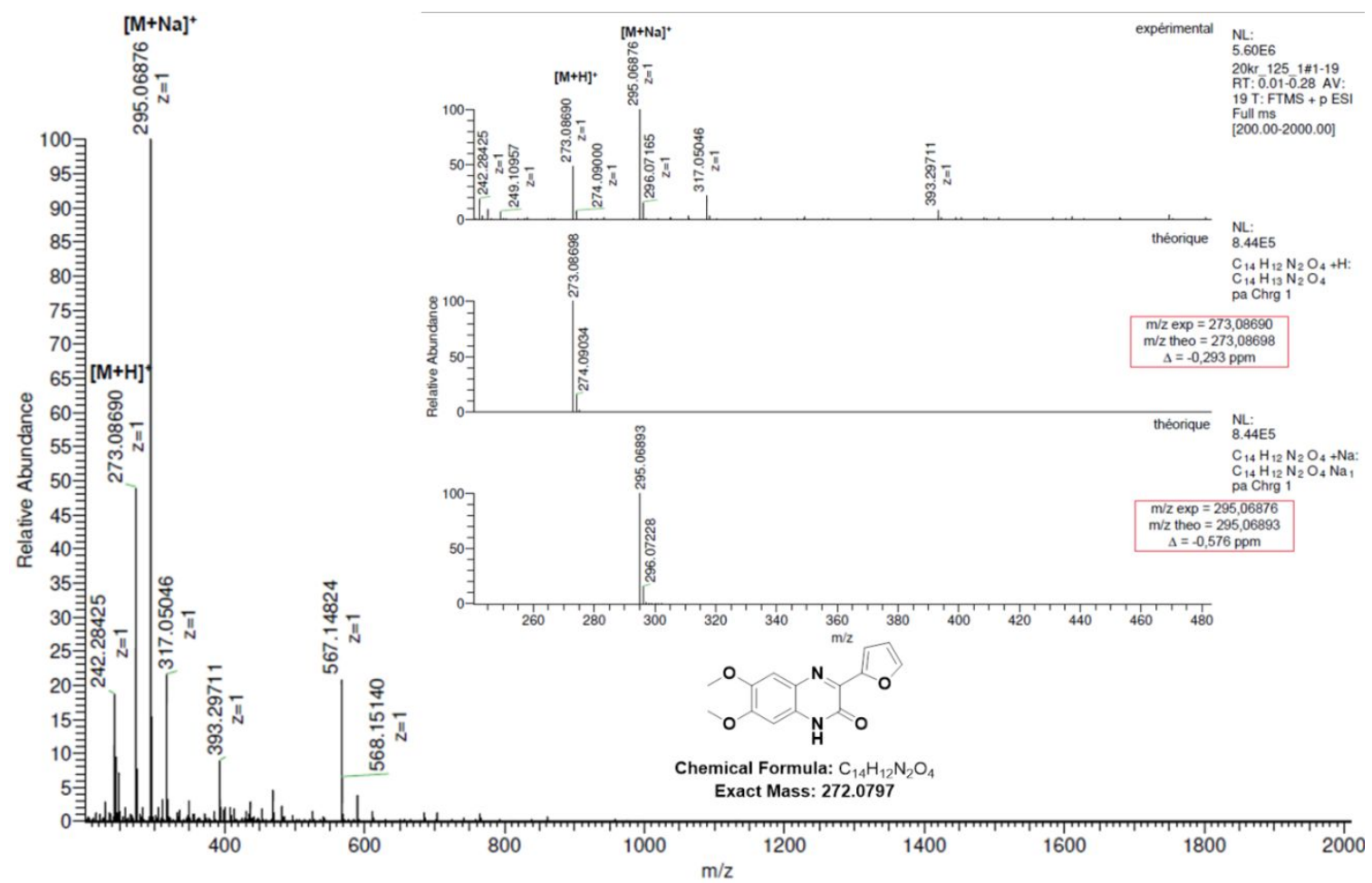


Fig. S38 - ESI+ (left) / ESI- (right) mass spectra (low resolution) of quinoxalin2(1H)-one 5
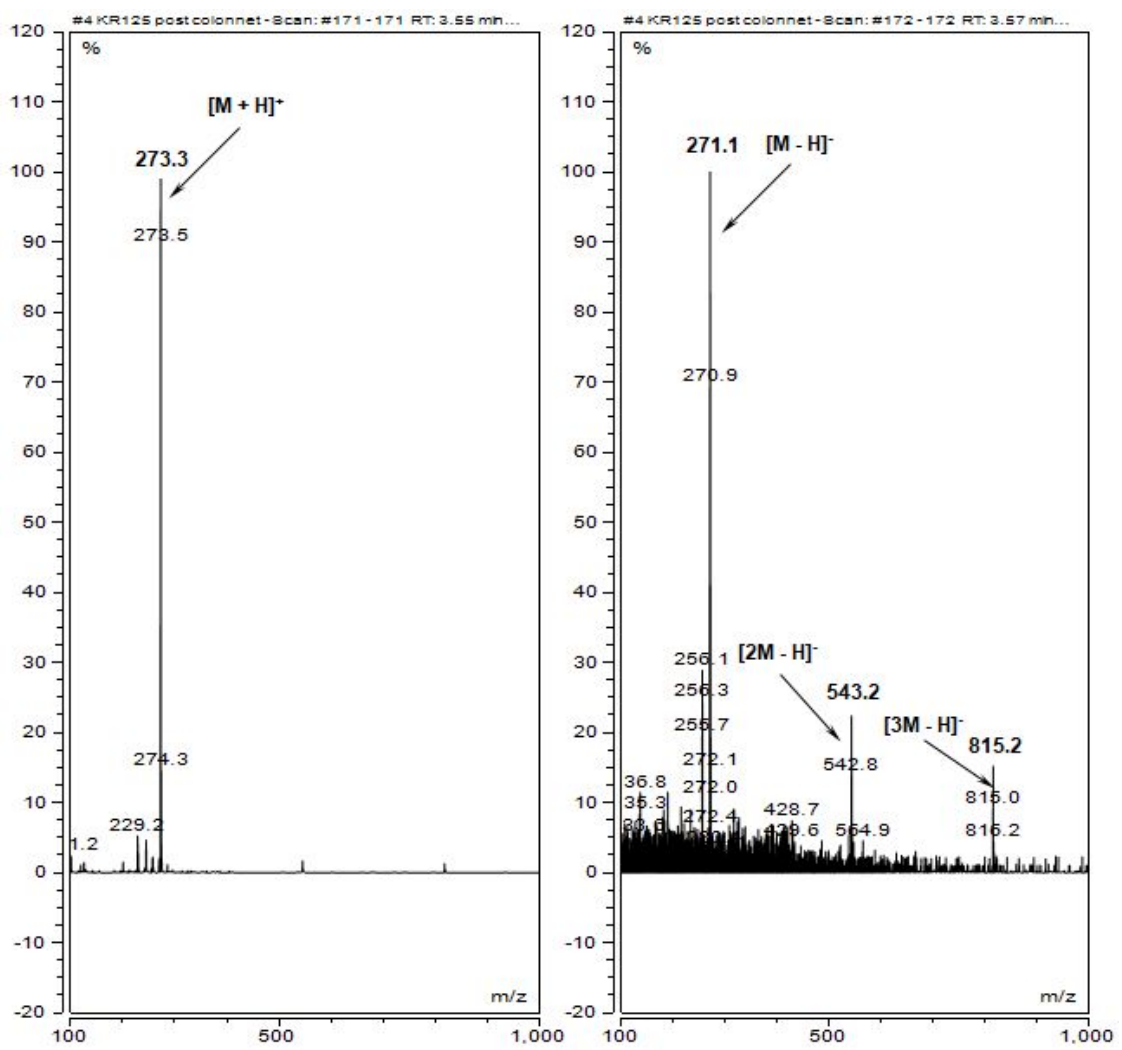

Fig. S39 - RP-HPLC elution profile of quinoxalin-2(1H)-one 5 (system A, detection at $260 \mathrm{~nm}$ )

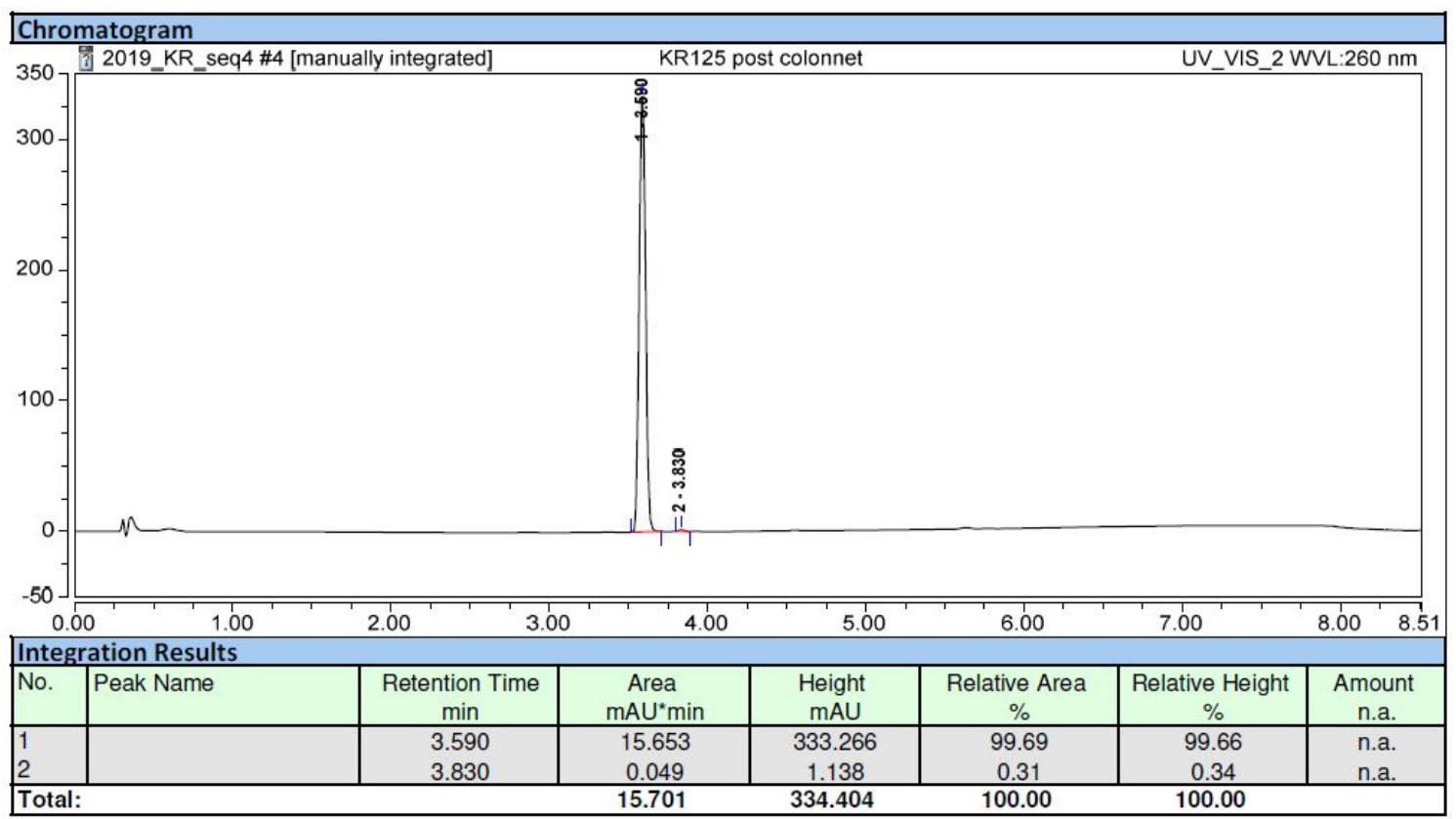


Fig. S40 - RP-HPLC elution profile of quinoxalin-2(1H)-one 5 (system A, detection at $450 \mathrm{~nm}$ )

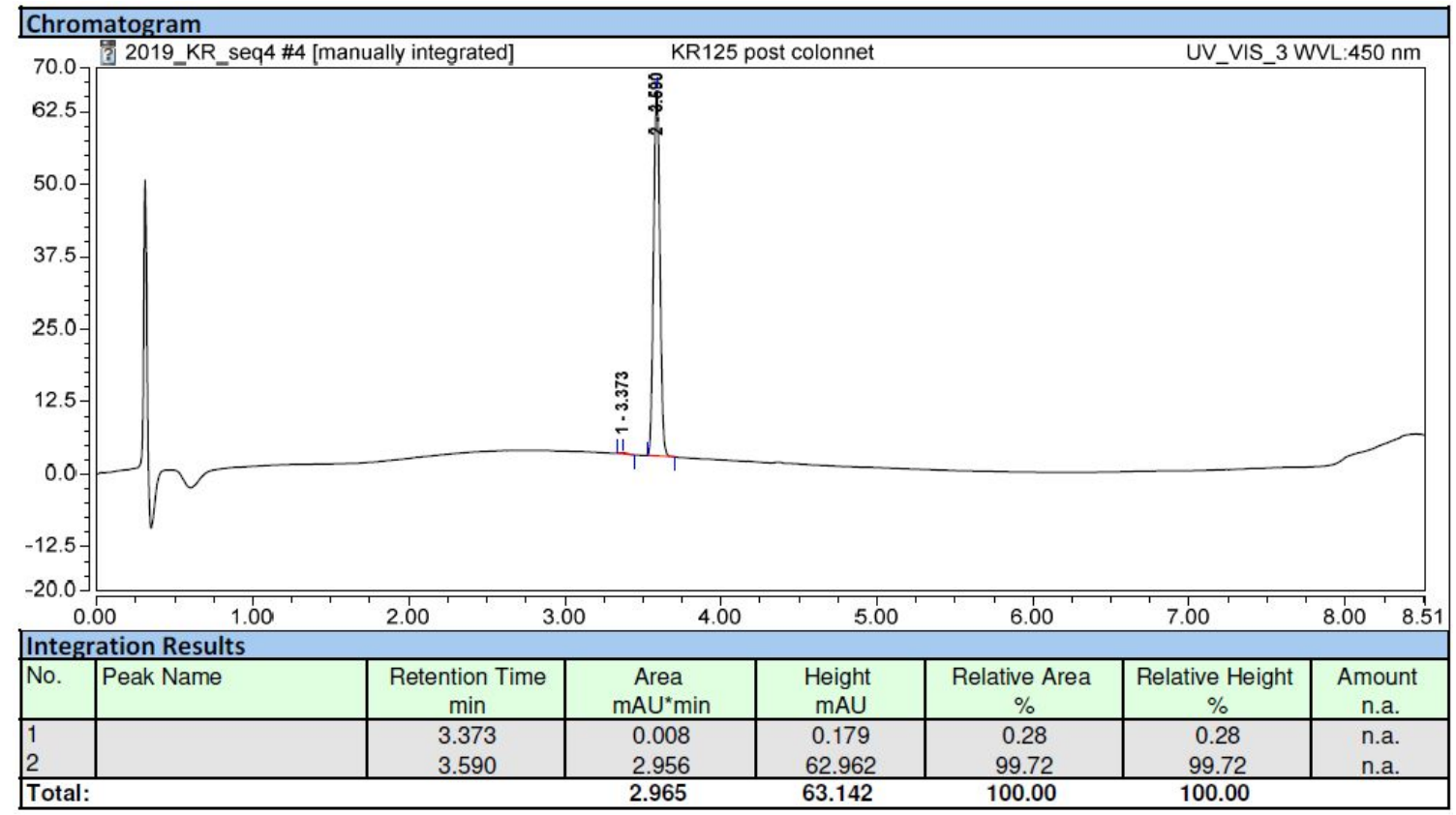

Fig. S41 - IR-ATR spectrum of quinoxalin-2(1H)-one 5

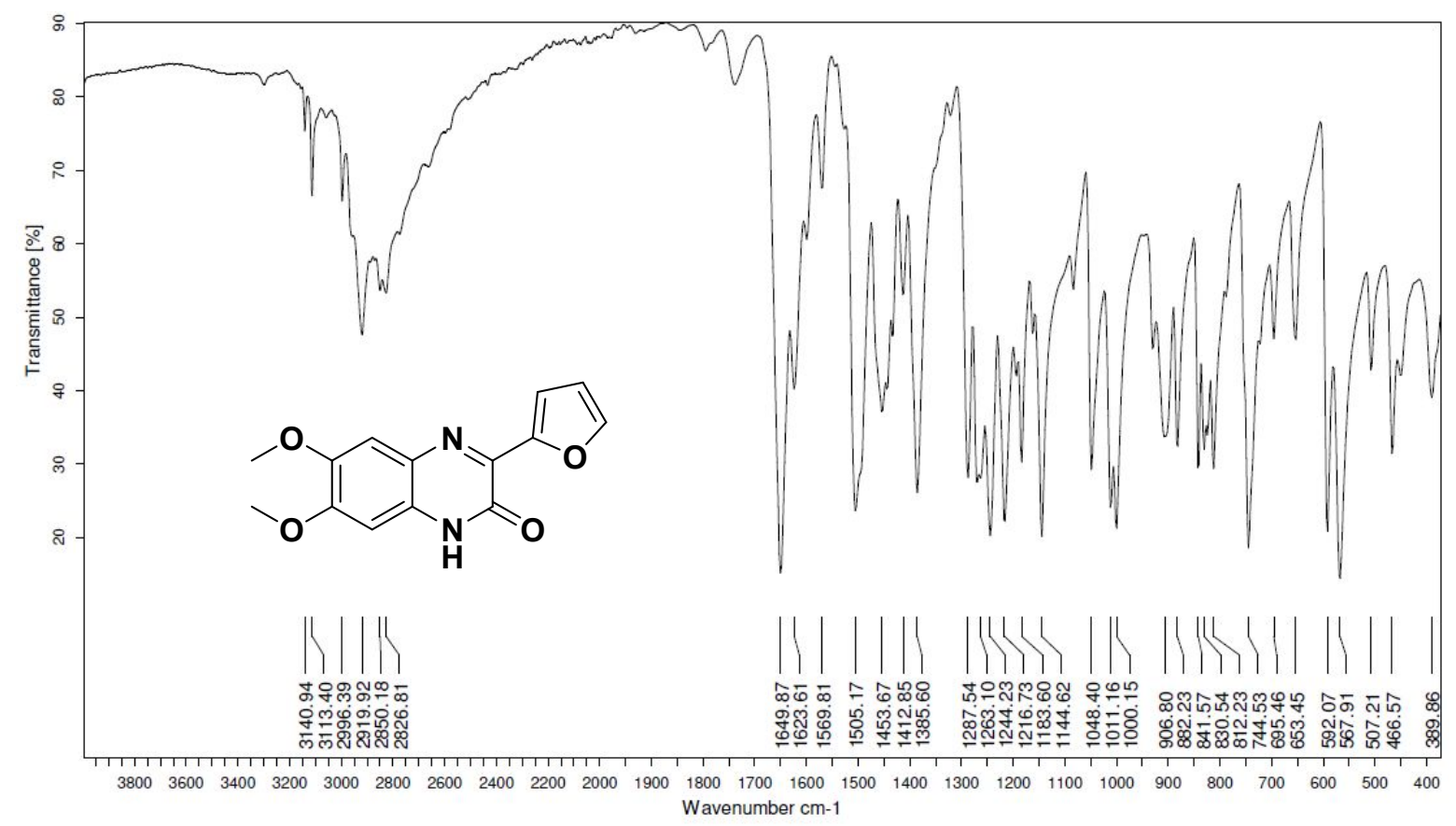


Fig. S42 - ${ }^{1} \mathrm{H}$ NMR spectrum of quinoxalin-2(1H)-one 5 in DMSO- $d_{6}(400 \mathrm{MHz})$

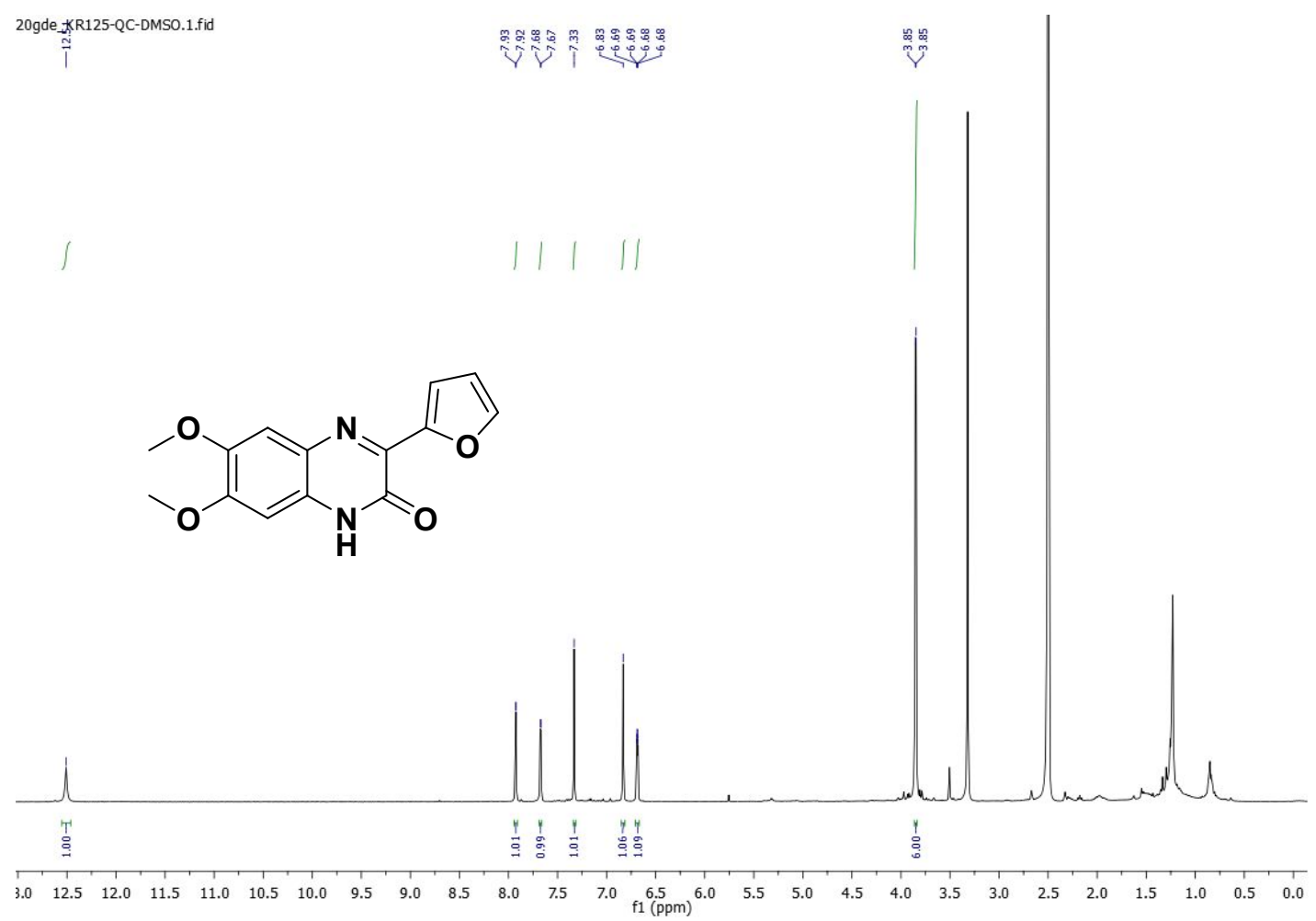

Fig. S43 - ${ }^{13} \mathrm{C}$ NMR spectrum of quinoxalin-2(1H)-one 5 in DMSO- $d_{6}(101 \mathrm{MHz})$

20gde_KR125-QC-DMSO.2.fid

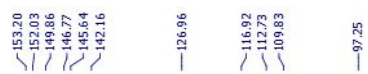

พที่<smiles>COc1cc2nc(-c3ccco3)c(=O)[nH]c2cc1OC</smiles>

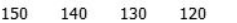

$10 \stackrel{100}{\mathrm{f} 1(\mathrm{ppm})}$

please note: signal of one quaternary carbon is missing (probably, the carbon carrying 2-furanyl substituent) even after an extended acquisition time. 
Fig. S44 - ESI+ mass spectrum (high resolution) of quinoxalin-2(1H)-one 6

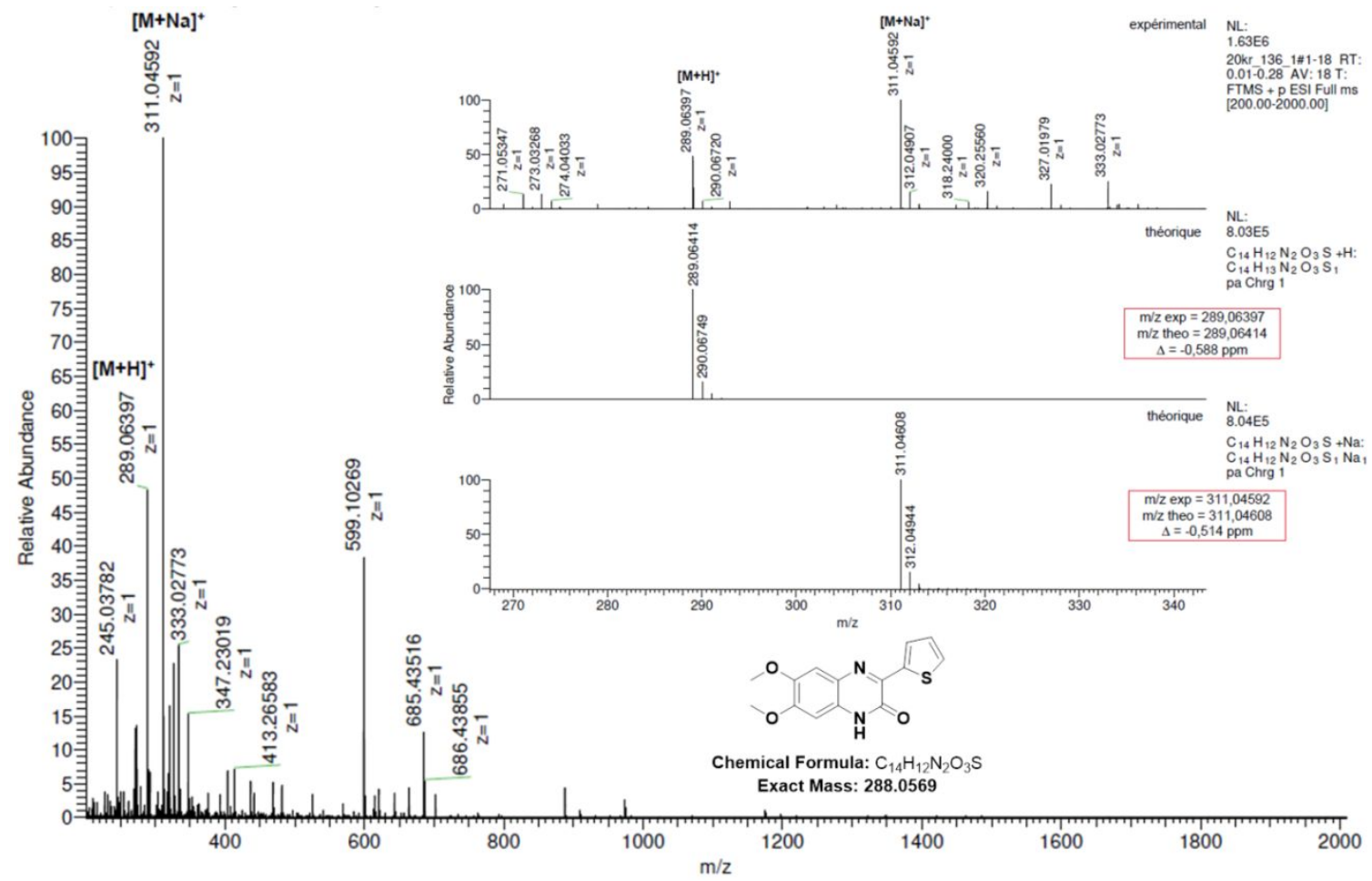

Fig. S45 - ESI+ (left) / ESI- (right) mass spectra (low resolution) of quinoxalin2(1H)-one 6

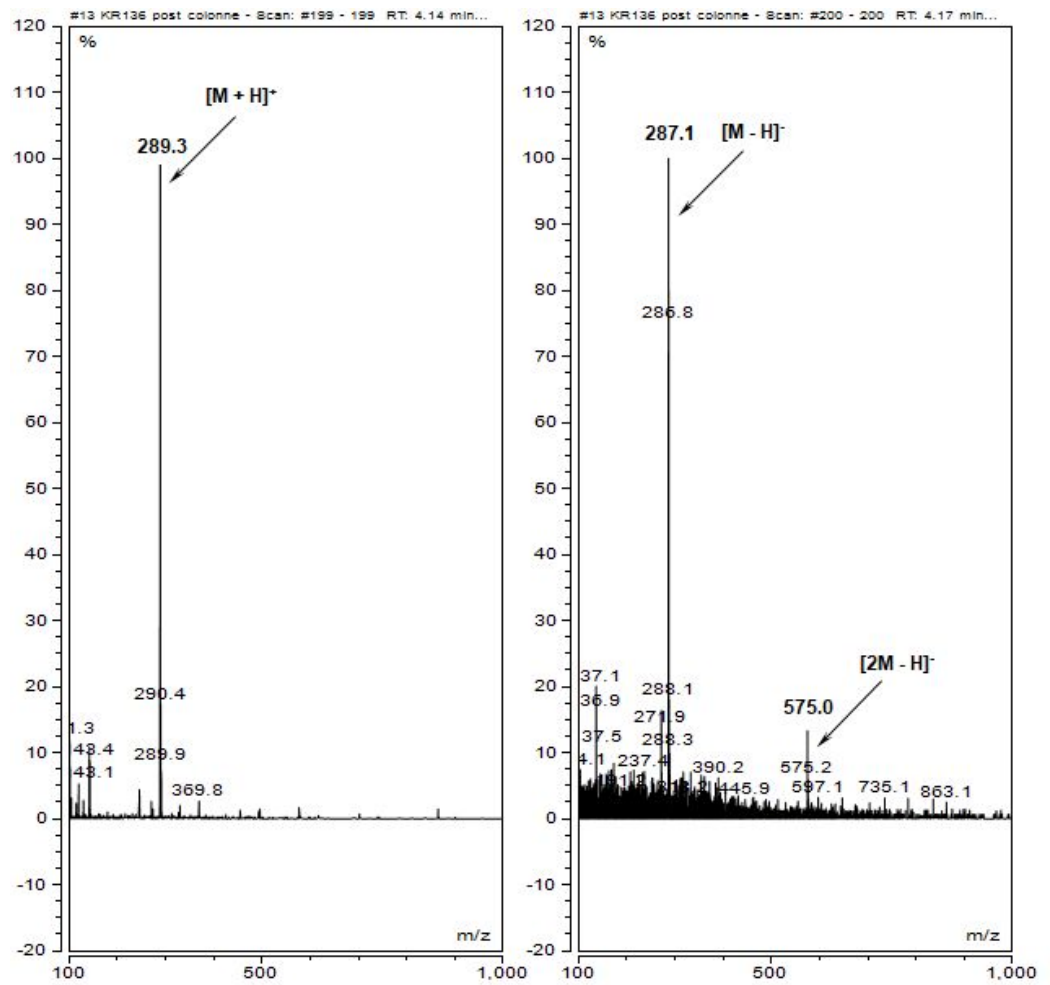


Fig. S46 - RP-HPLC elution profile of quinoxalin-2(1H)-one 6 (system A, detection at $260 \mathrm{~nm}$ )

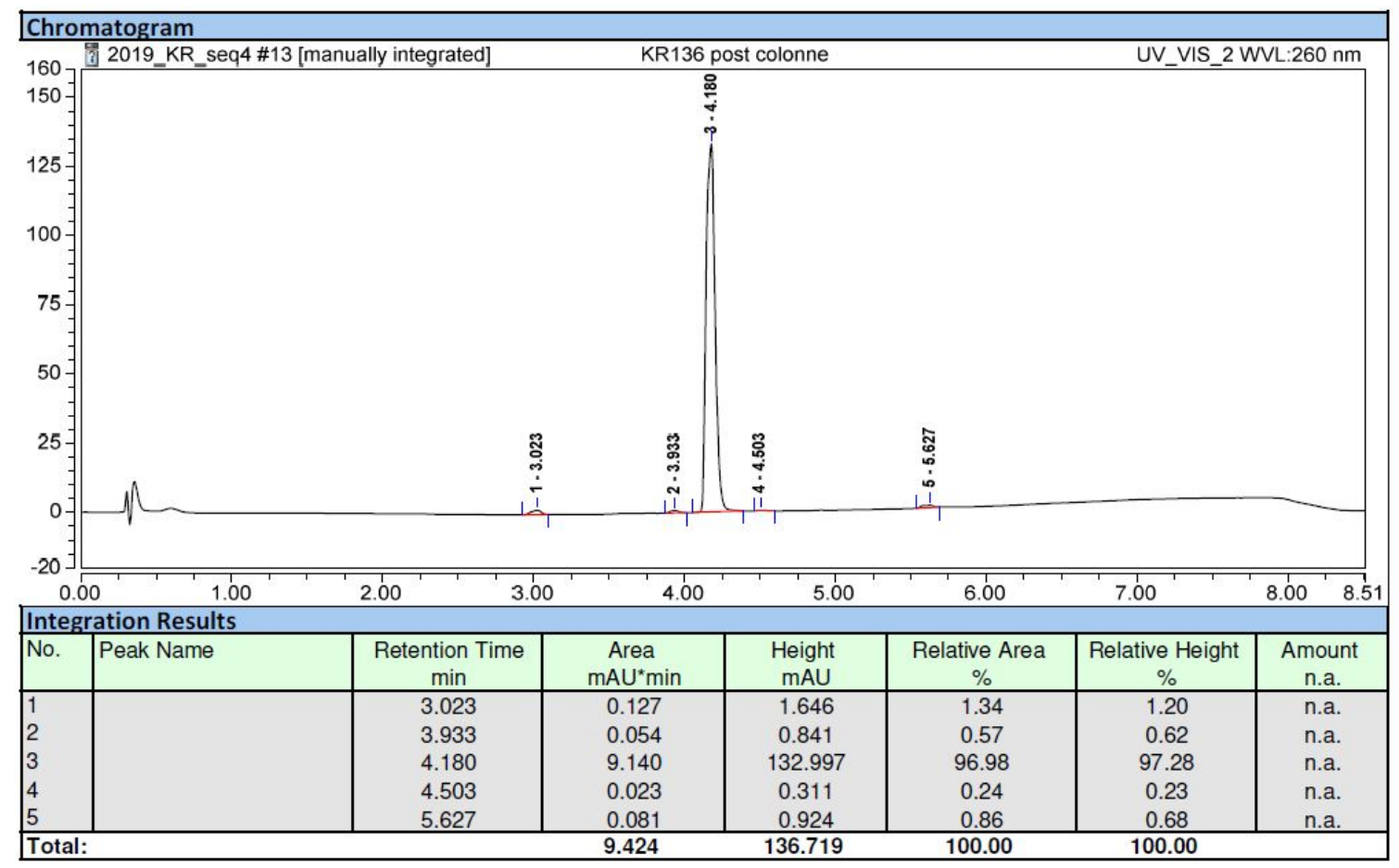

Fig. S47 - RP-HPLC elution profile of quinoxalin-2(1H)-one 6 (system A, detection at $450 \mathrm{~nm}$ )

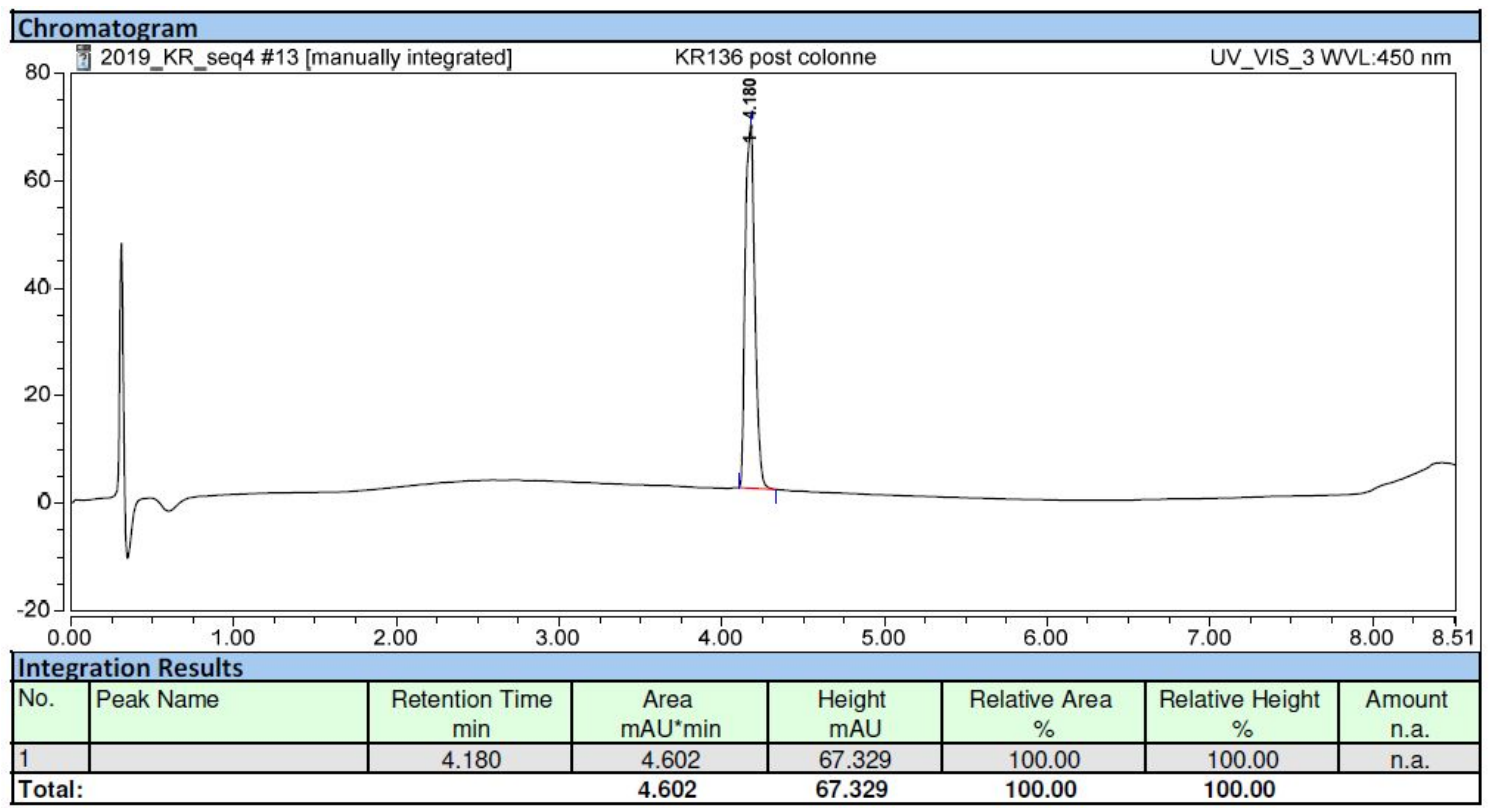


Fig. S48 - IR-ATR spectrum of quinoxalin-2(1H)-one 6

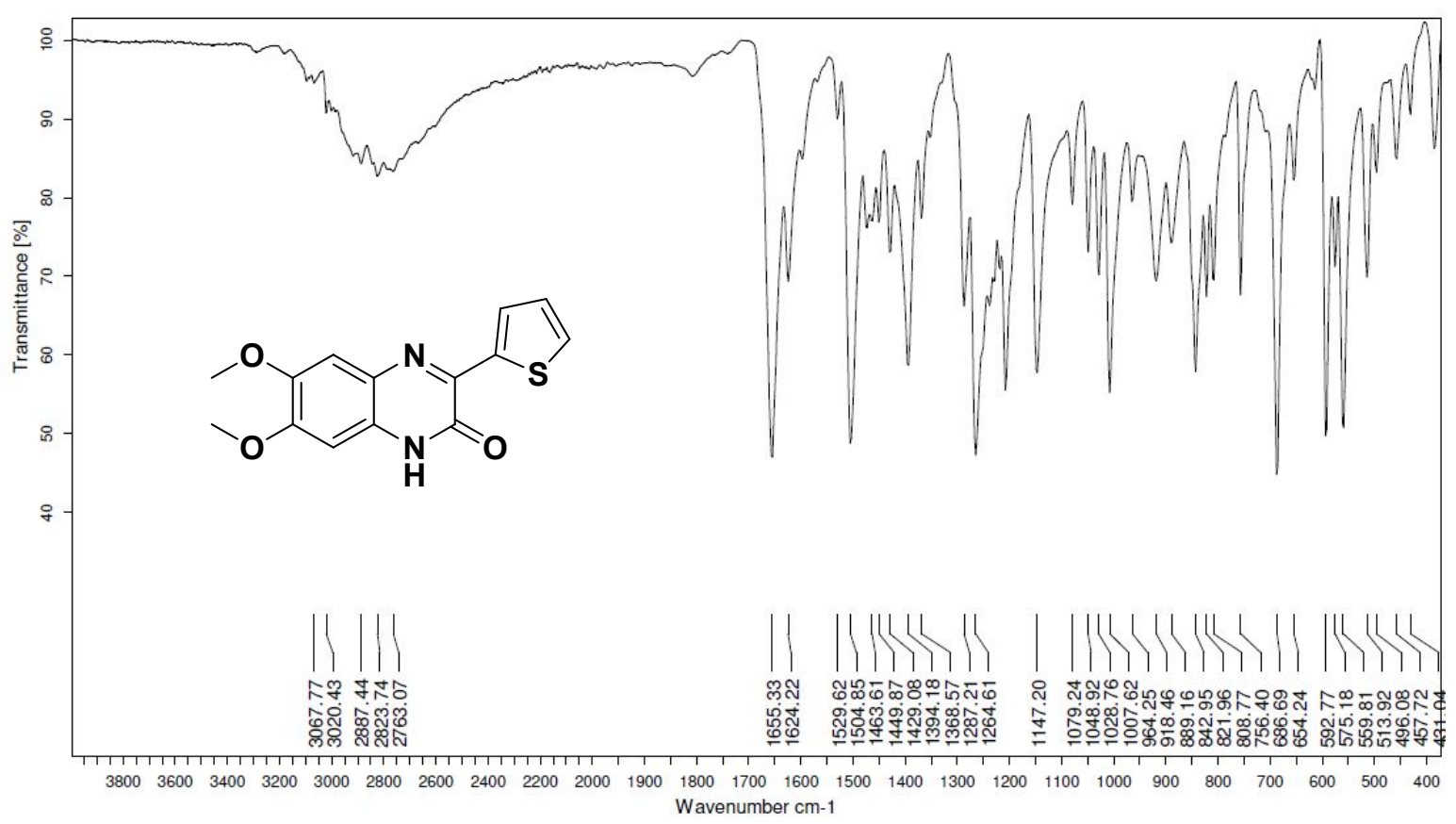

Fig. S49 - ${ }^{1} \mathrm{H}$ NMR spectrum of quinoxalin-2(1H)-one 6 in DMSO- $d_{6}(400 \mathrm{MHz})$

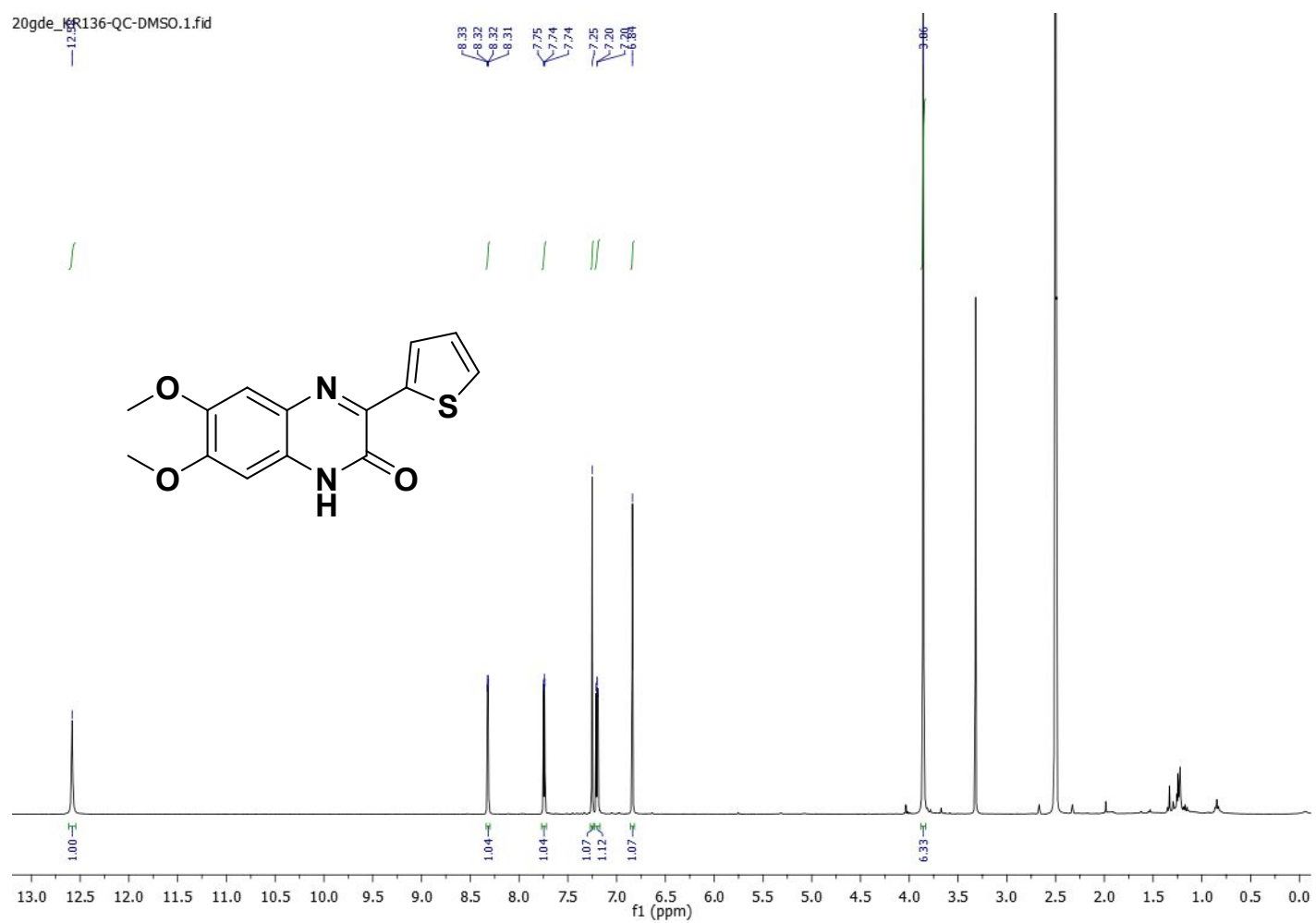


Fig. S50 - ${ }^{13} \mathrm{C}$ NMR spectrum of quinoxalin-2(1H)-one 6 in DMSO- $d_{6}(101 \mathrm{MHz})$ 20gde_KR136-QC-DMSO.2.fid

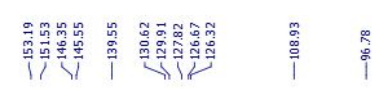<smiles>COc1cc2nc(-c3cccs3)c(=O)[nH]c2cc1OC</smiles>

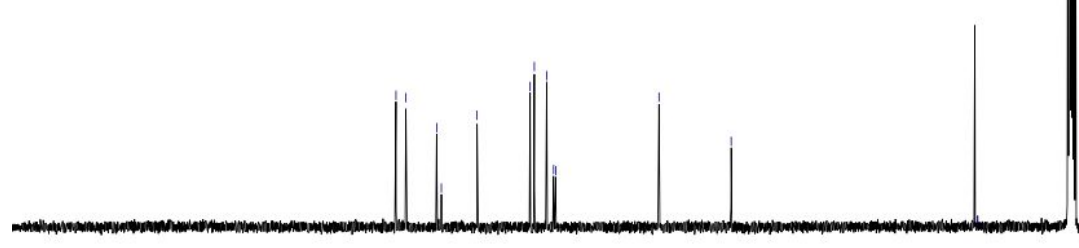

$\begin{array}{llllllllllll}210 & 200 & 190 & 180 & 170 & 160 & 150 & 140 & 130 & 120 & 110 & \begin{array}{l}100 \\ \mathrm{f} 1(\mathrm{ppm})\end{array}\end{array}$

Fig. S51 - ESI+ mass spectrum (high resolution) of quinoxalin-2(1H)-one 7

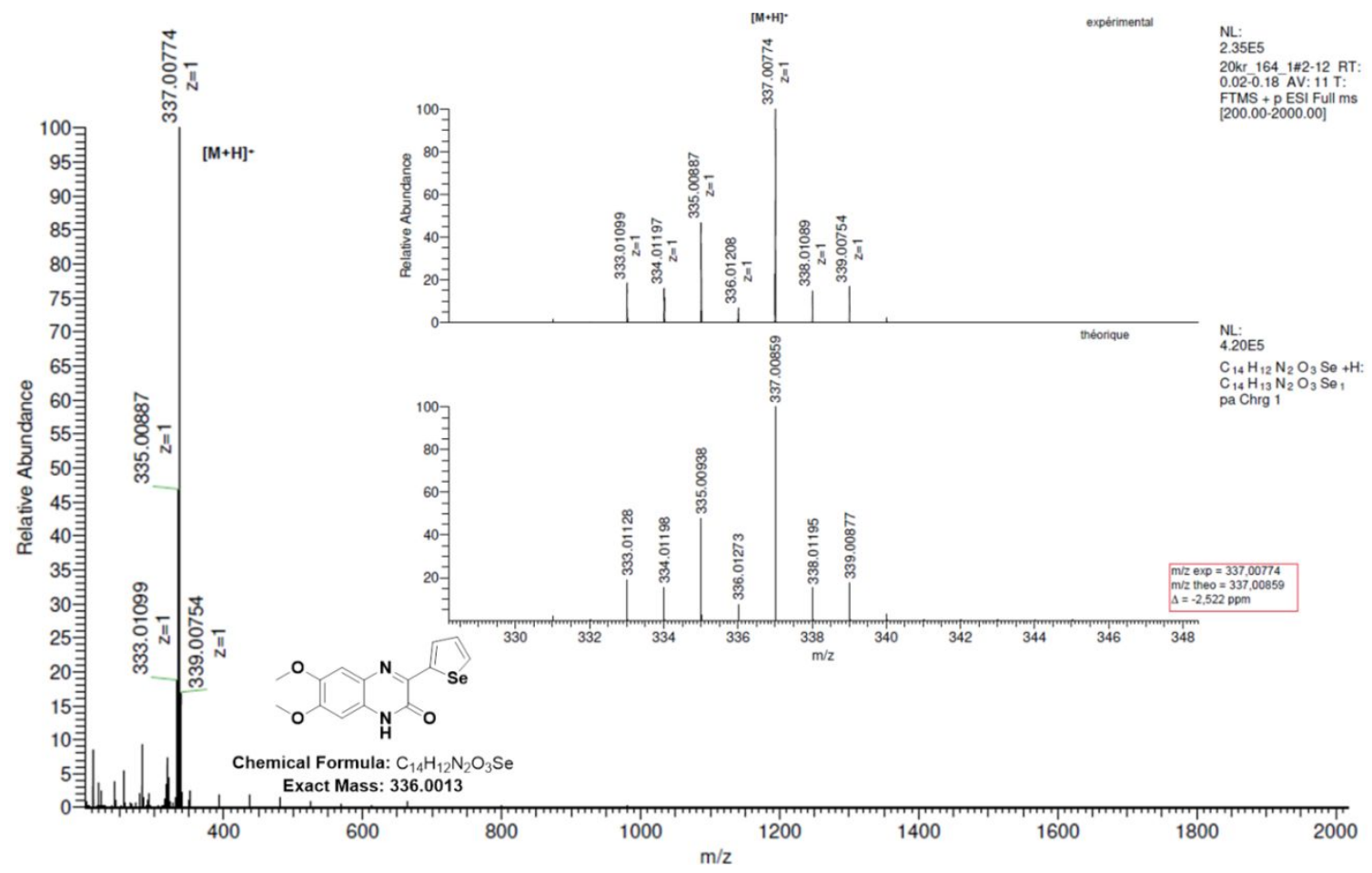




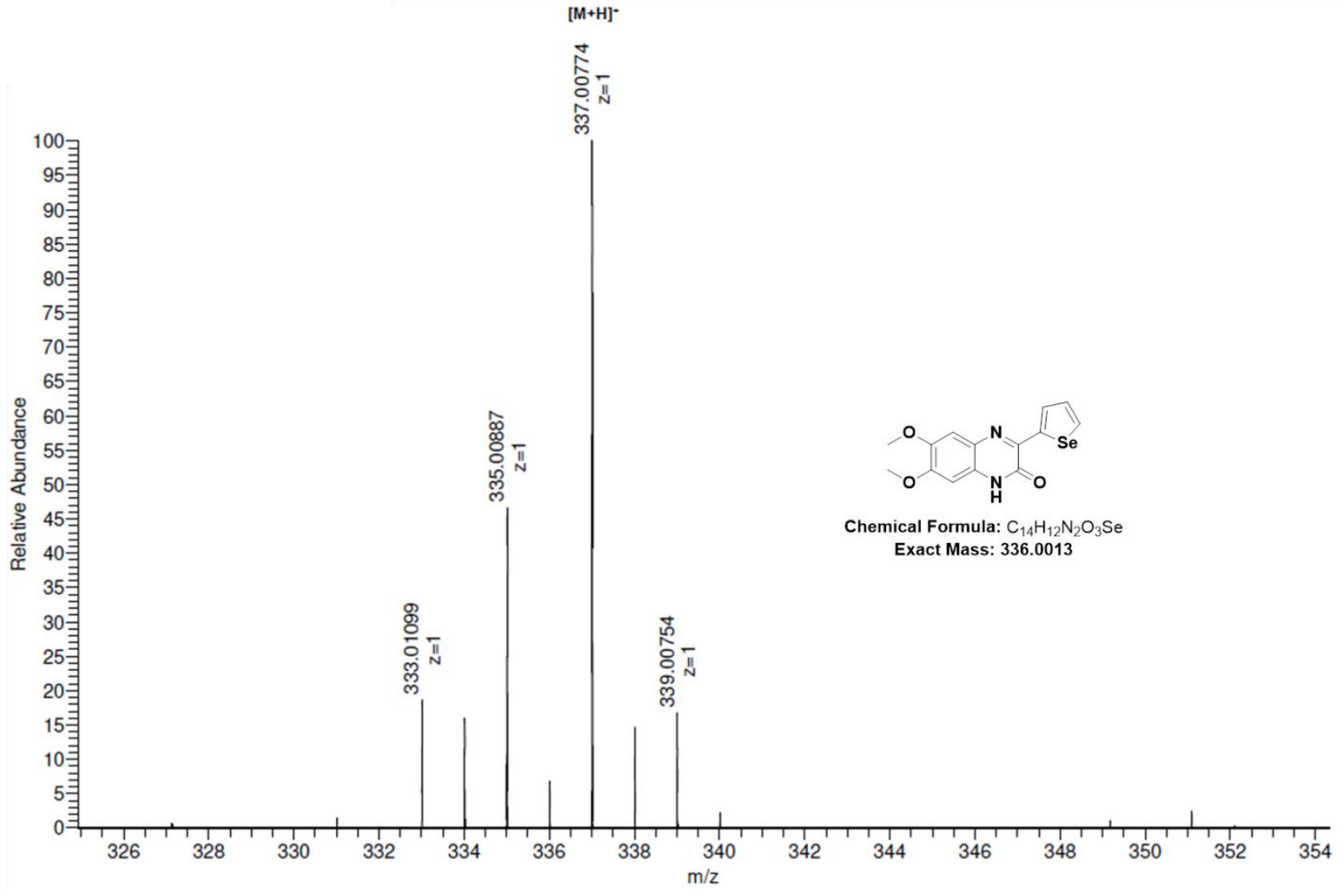

Fig. S52 - ESI+ (left) / ESI- (right) mass spectra (low resolution) of quinoxalin2(1H)-one 7

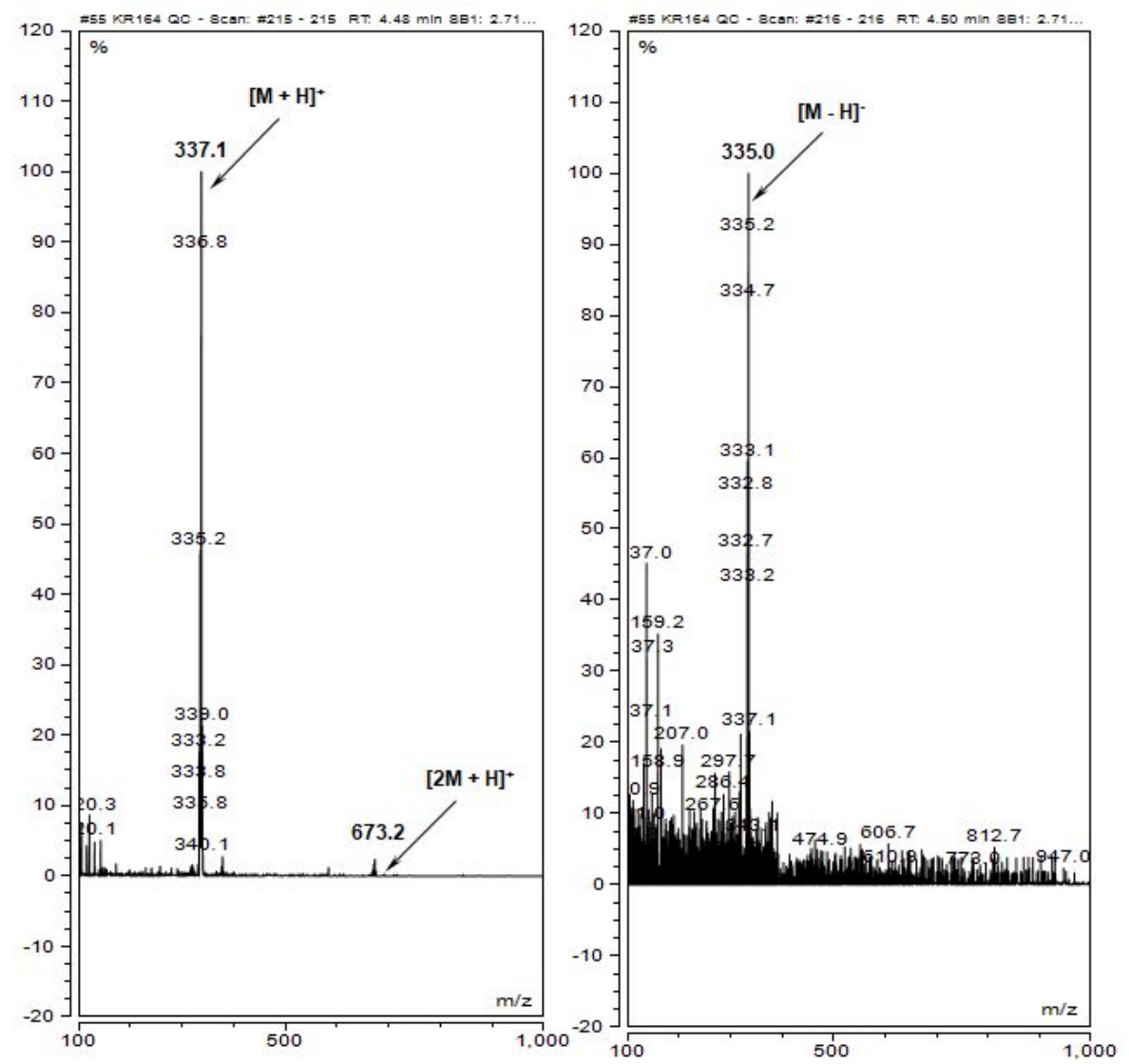


Fig. S53 - RP-HPLC elution profile of quinoxalin-2(1H)-one 7 (system A, detection at $260 \mathrm{~nm}$ )

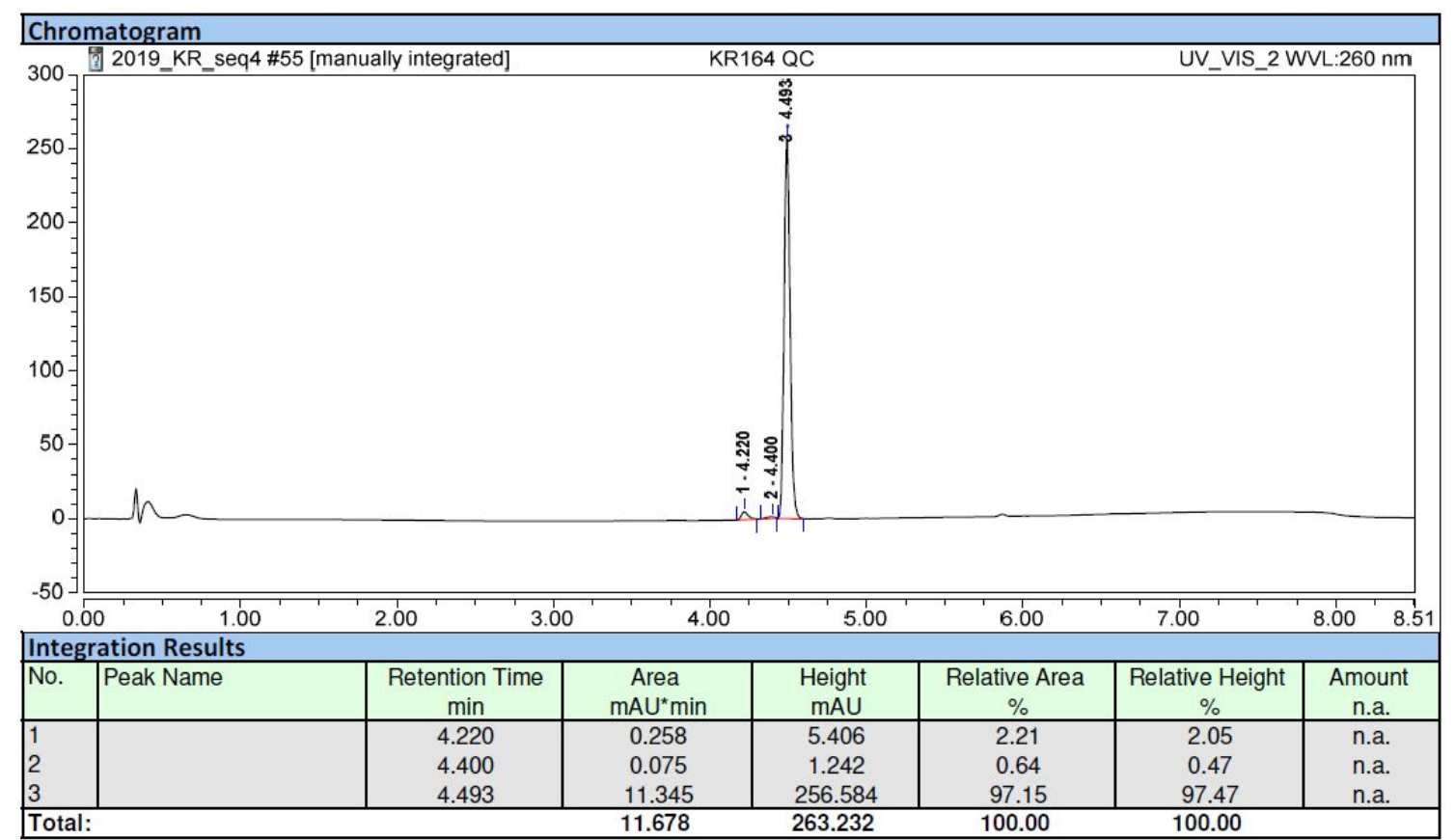

Fig. S54 - RP-HPLC elution profile of quinoxalin-2(1H)-one 7 (system A, detection at $450 \mathrm{~nm}$ )

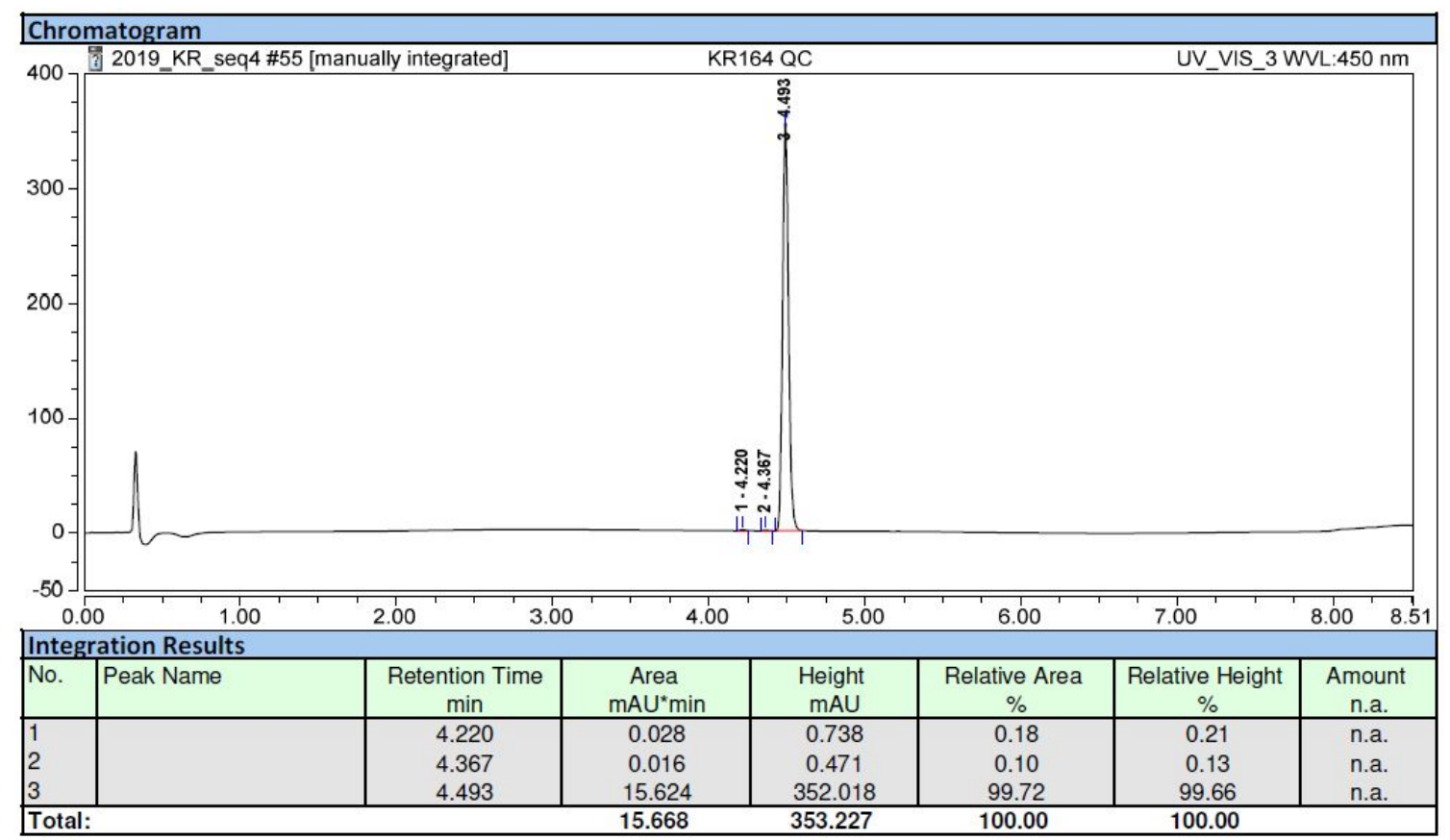


Fig. S55 - ${ }^{1} \mathrm{H}$ NMR spectrum of quinoxalin-2(1H)-one 7 (TFA salt) in DMSO- $d_{6}$ (600 MHz)

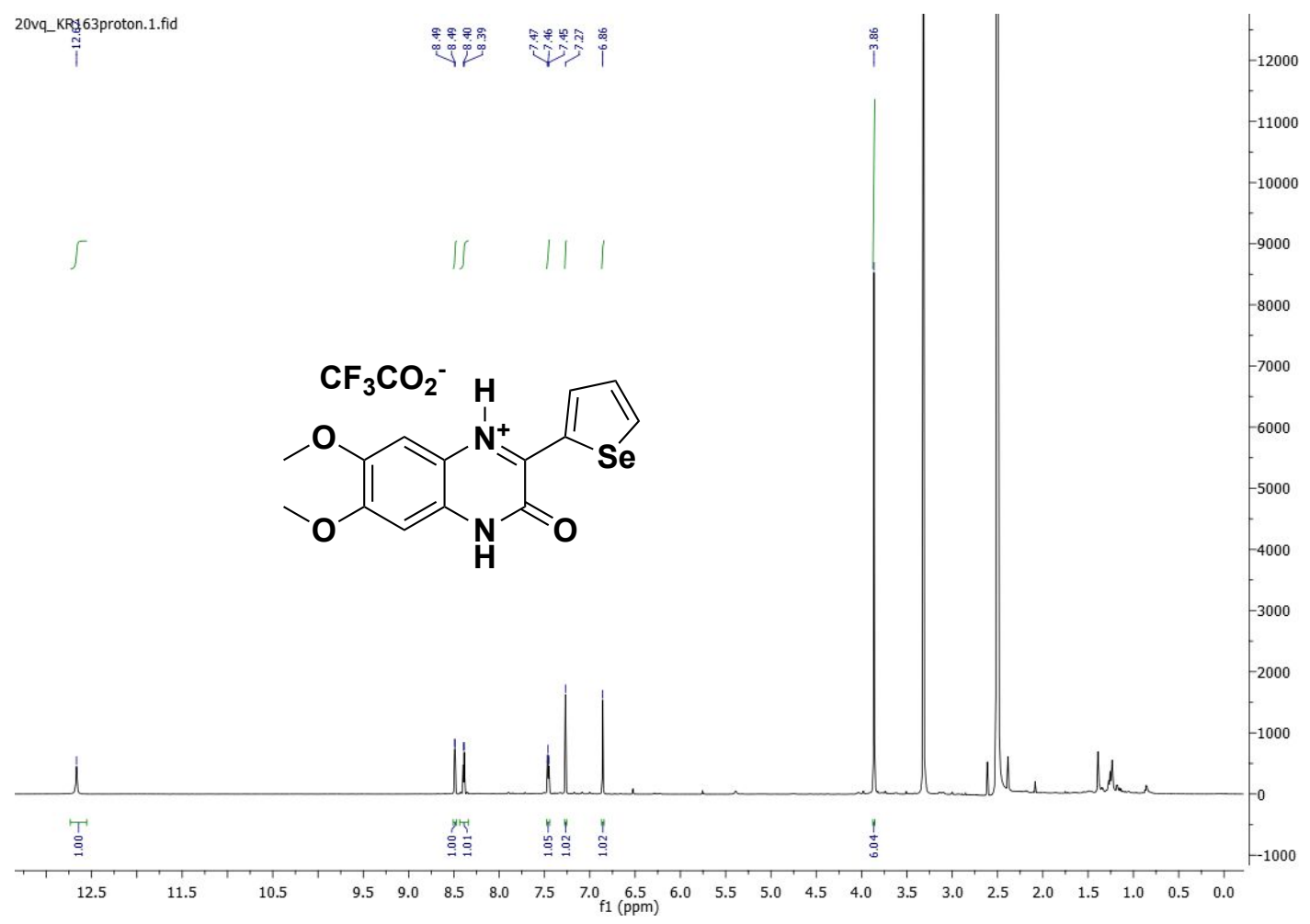

Fig. S56 $-{ }^{13} \mathrm{C}$ NMR spectrum of quinoxalin-2(1H)-one 7 (TFA salt) in DMSO- $d_{6}$ (151 MHz)

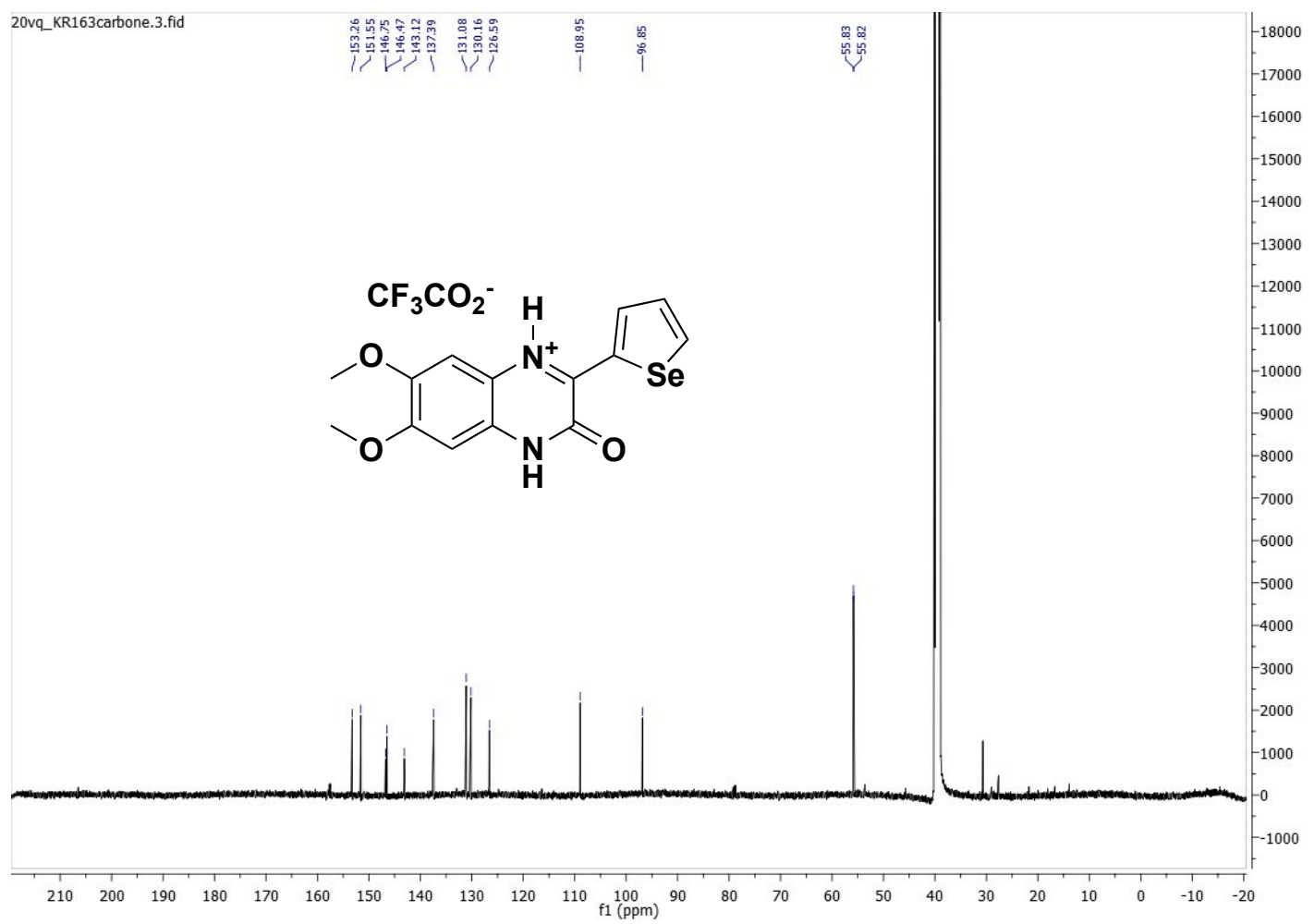

please note: signal of one quaternary carbon is missing (probably, the carbon carrying 2-selenothienyl substituent) even after an extended acquisition time. 
Fig. S57 - ${ }^{19}$ F NMR spectrum of quinoxalin-2(1H)-one 7 (TFA salt) in DMSO- $d_{6}$ (565 MHz)

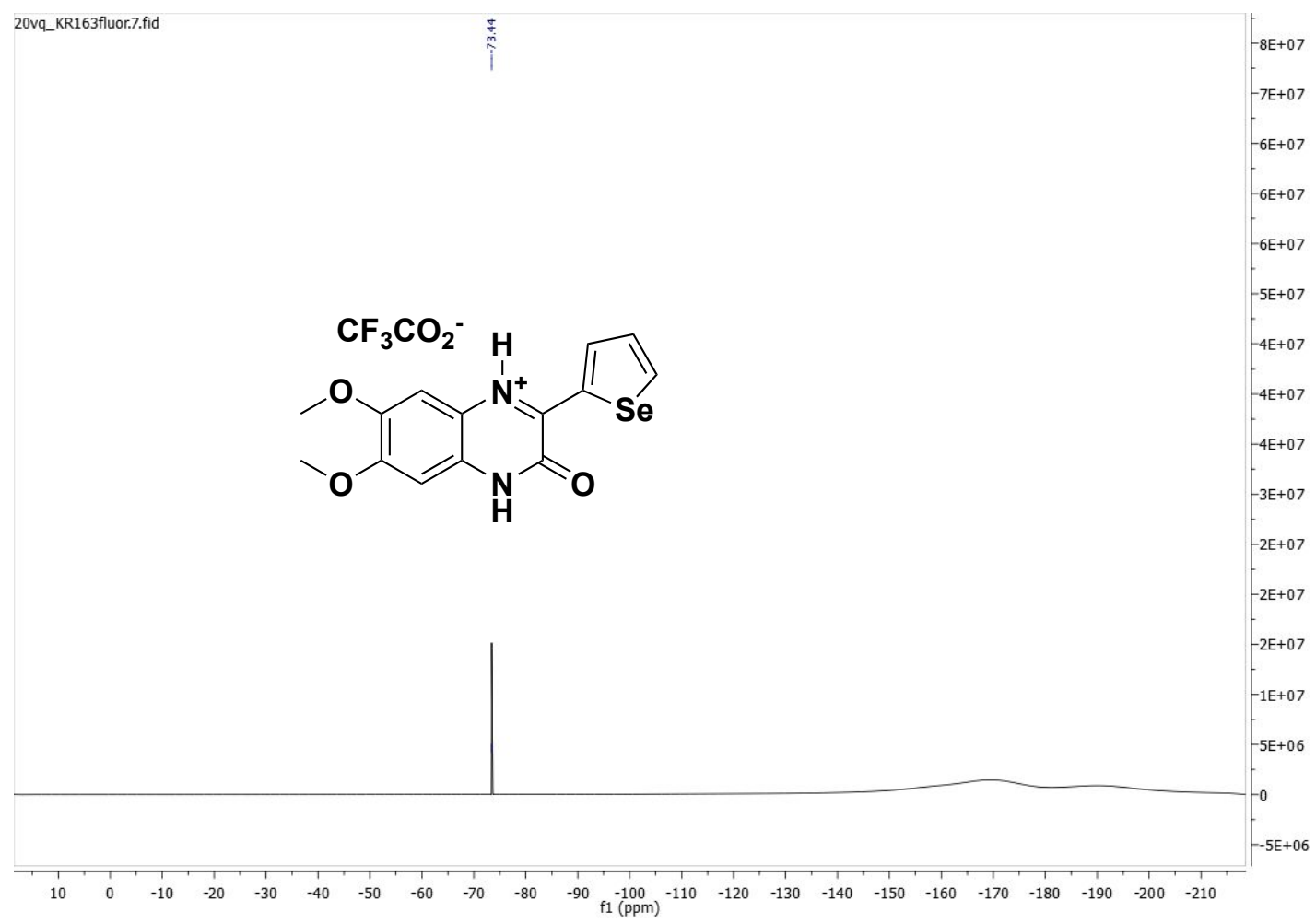

Fig. S58 - ${ }^{77}$ Se NMR spectrum of quinoxalin-2(1H)-one 7 (TFA salt) in DMSO- $d_{6}$ (114.5 MHz)<smiles>COc1cc2[nH]c(=O)c(-c3ccc[se]3)[nH+]c2cc1OC(F)(F)F</smiles>

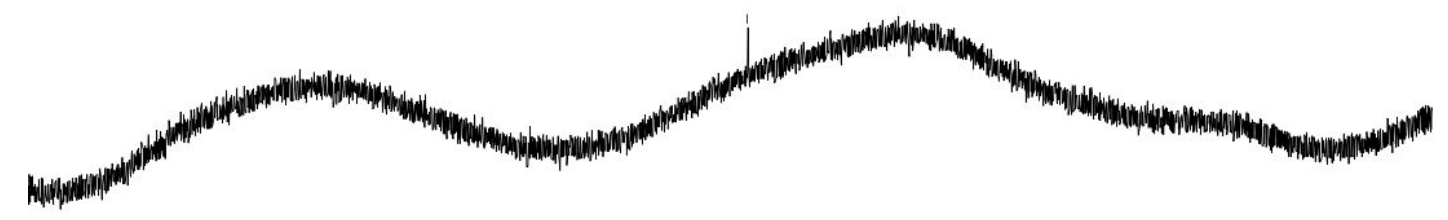

\begin{tabular}{|llllllllllllllllllllllllllllllll}
900 & 880 & 860 & 840 & 820 & 800 & 780 & 760 & 740 & 720 & 700 & 680 & $\underset{\mathrm{f}}{6}(\mathrm{ppm})$ & 620 & 600 & 680 & 560 & 540 & 520 & 500 & 480 & 460 & 440 & 420 & 400
\end{tabular} 
Fig. S59 - TFA determination by IC - results for sample of quinoxalin-2(1H)-one 7

\begin{tabular}{|c|c|c|}
\hline Concentration & \multicolumn{2}{|c|}{$1.0 \mathrm{mg} / \mathrm{mL}$ in DMSO } \\
\hline Sample dilution factor & 100 & 50 \\
\hline Raw data ppm & 1.709 & 3.518 \\
\hline Content in wt \% & 17.09 & 17.59 \\
\hline Average content in wt \% & \multicolumn{2}{|c|}{17.34} \\
\hline
\end{tabular}

Fig. S60 - ESI+ mass spectrum (high resolution) of quinoxalin-2(1H)-one 8

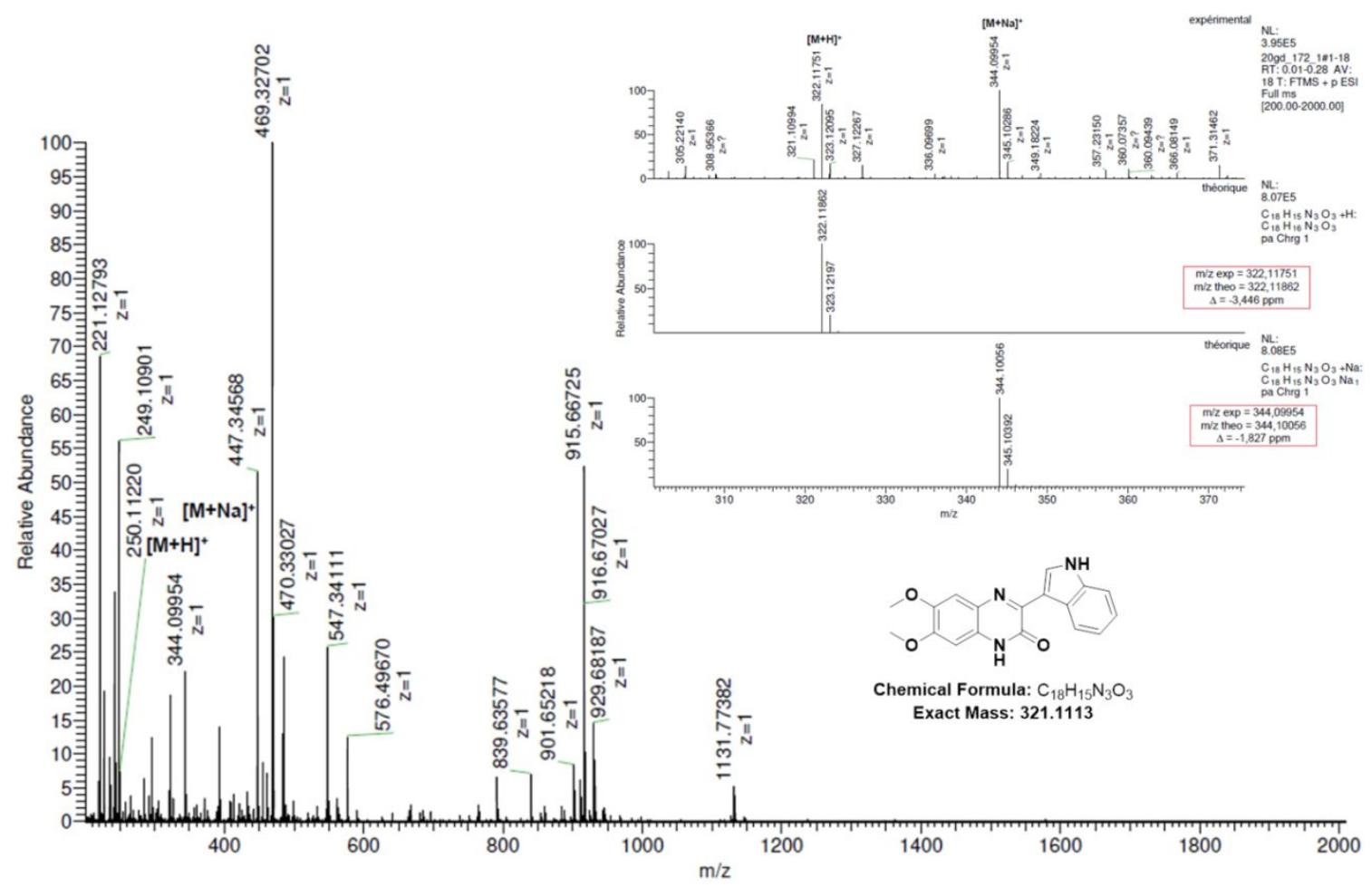


Fig. S61 - ESI- mass spectrum (high resolution) of quinoxalin-2(1H)-one 8

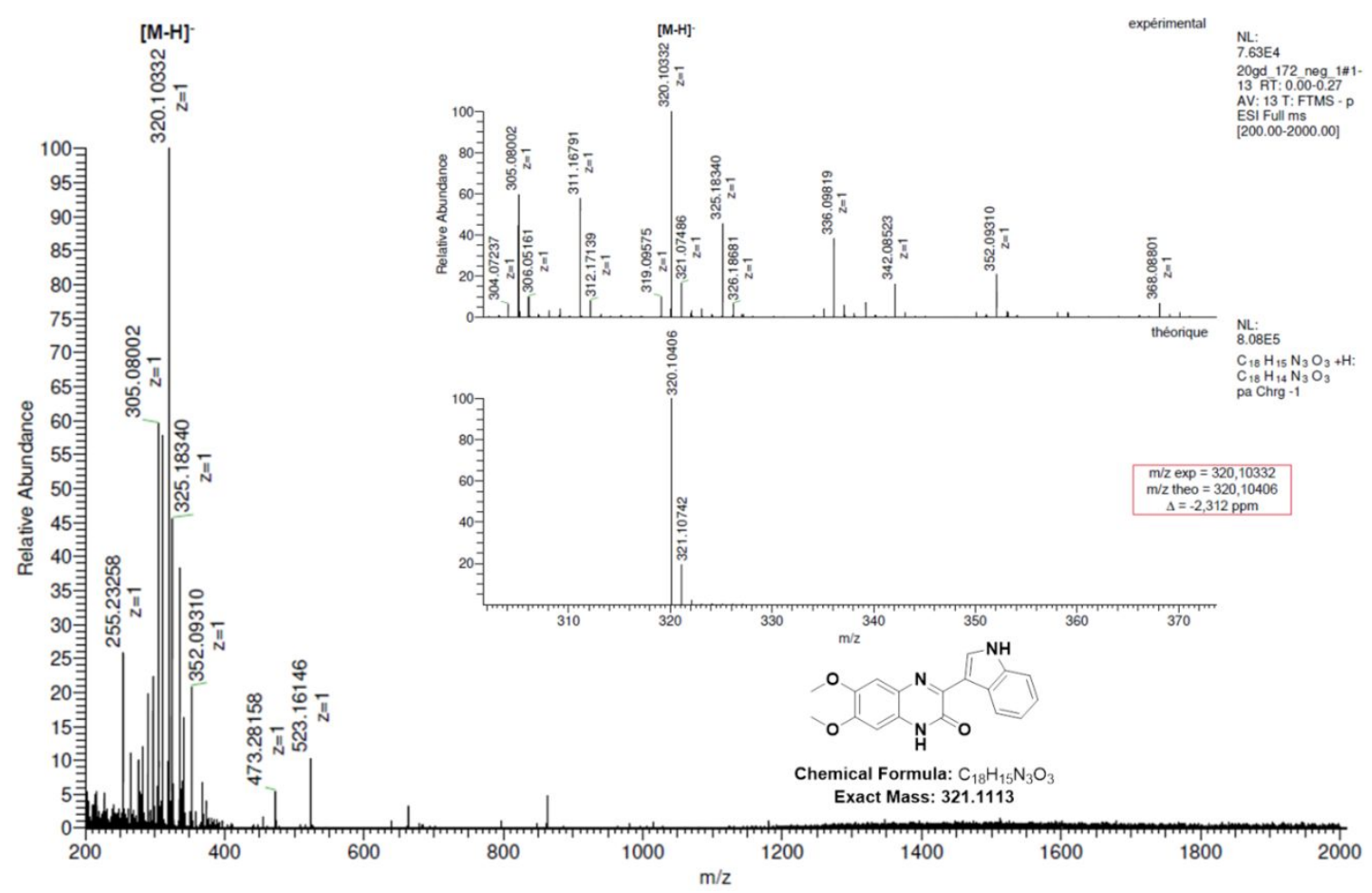

Fig. S62 - ESI+ (left) / ESI- (right) mass spectra (low resolution) of quinoxalin2(1H)-one 8
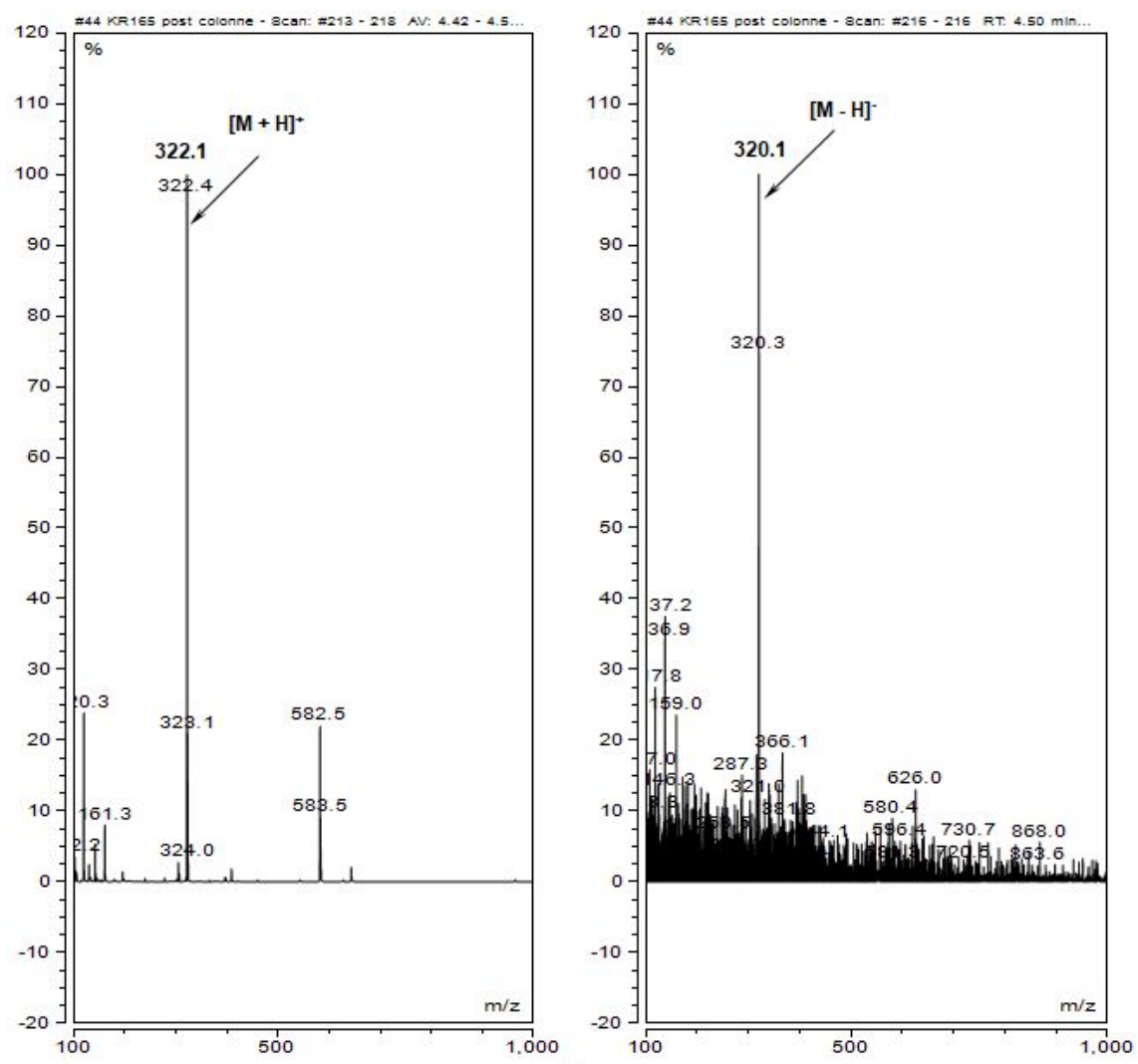
Fig. S63 - RP-HPLC elution profile of quinoxalin-2(1H)-one 8 (system A, detection at $260 \mathrm{~nm}$ )

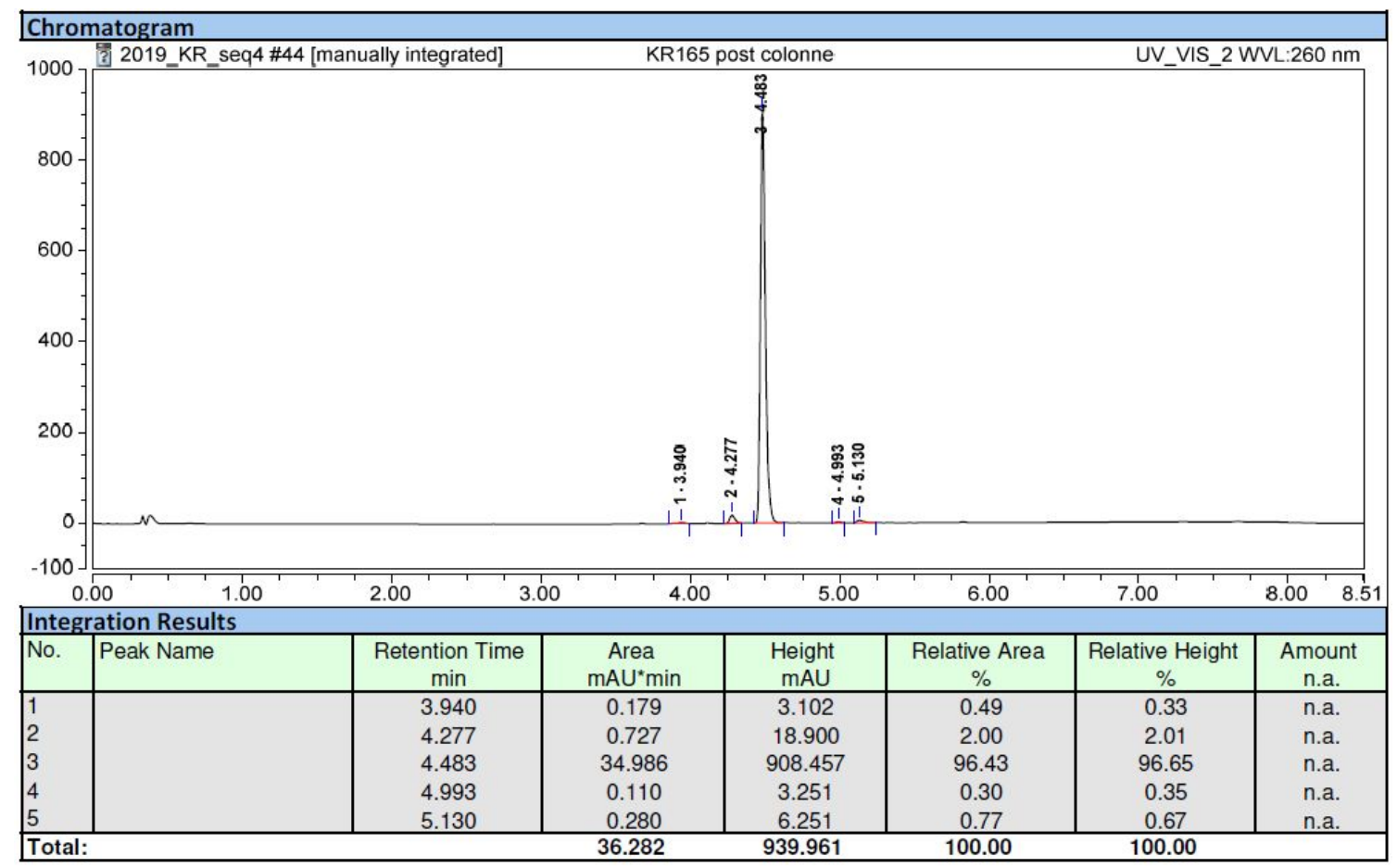

Fig. S64 - RP-HPLC elution profile of quinoxalin-2(1H)-one 8 (system A, detection at $450 \mathrm{~nm}$ )

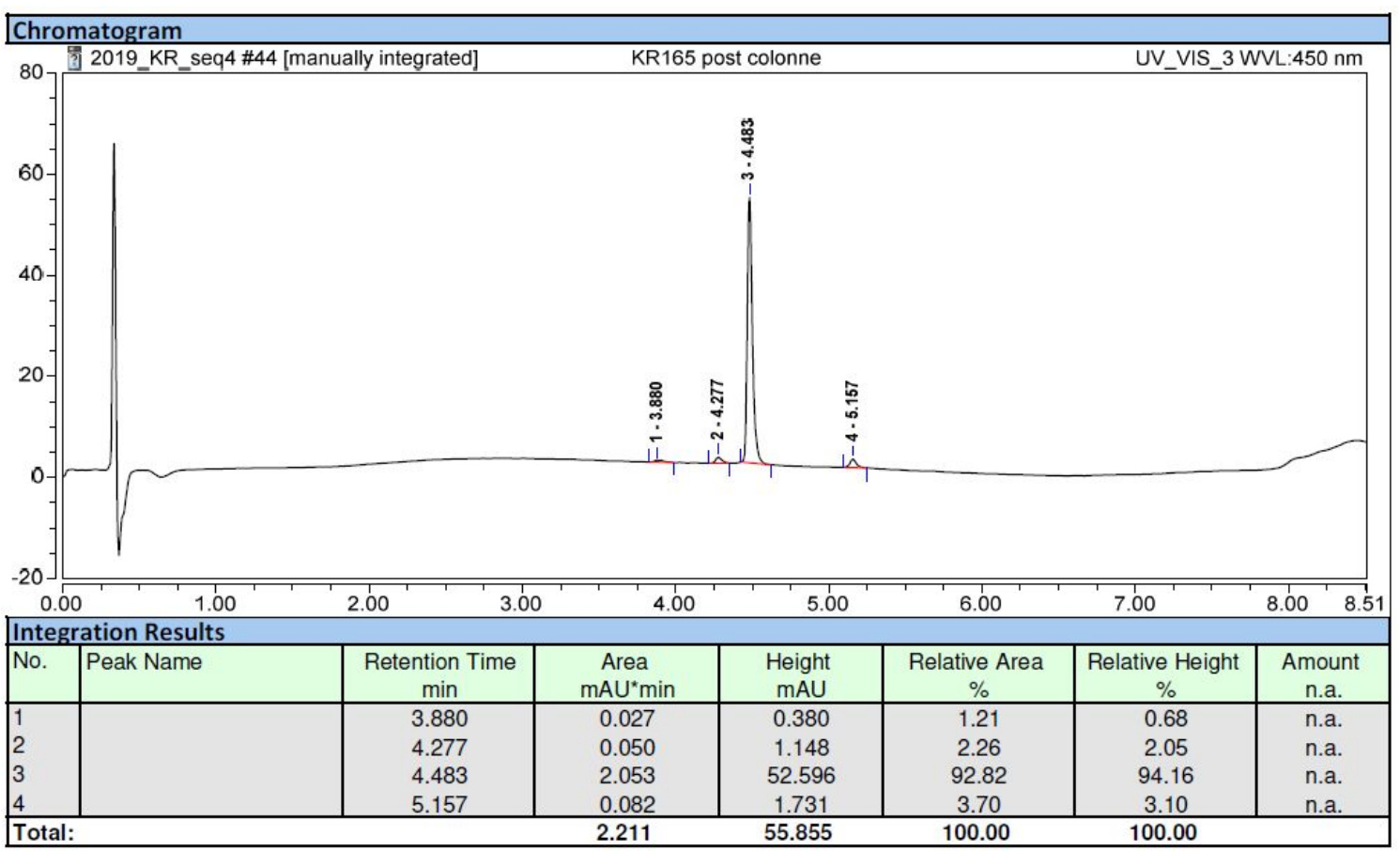


Fig. S65 - IR-ATR spectrum of quinoxalin-2(1H)-one 8

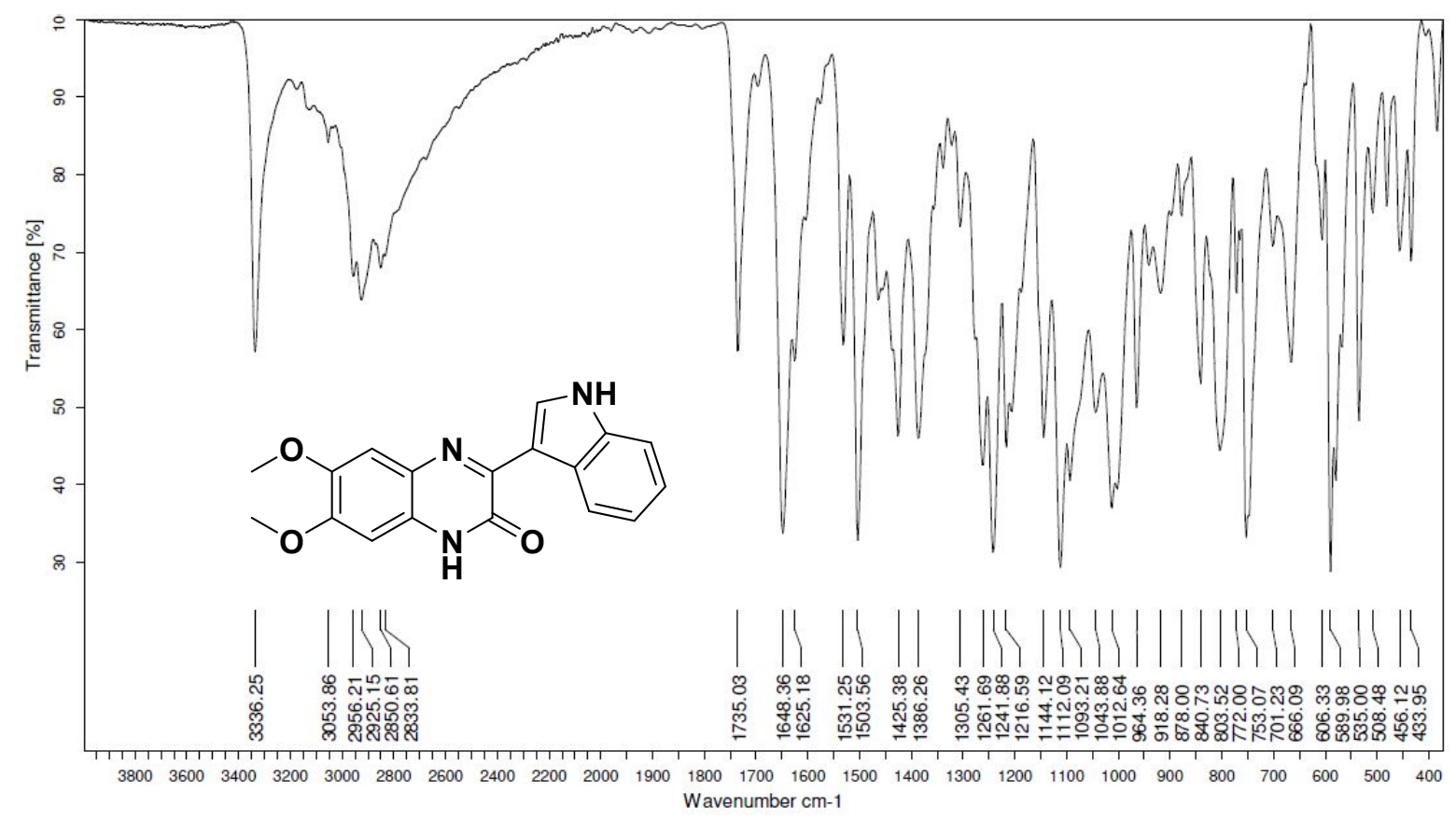

Fig. S66 - ${ }^{1} \mathrm{H}$ NMR spectrum of quinoxalin-2(1H)-one 8 in DMSO- $d_{6}(500 \mathrm{MHz})$

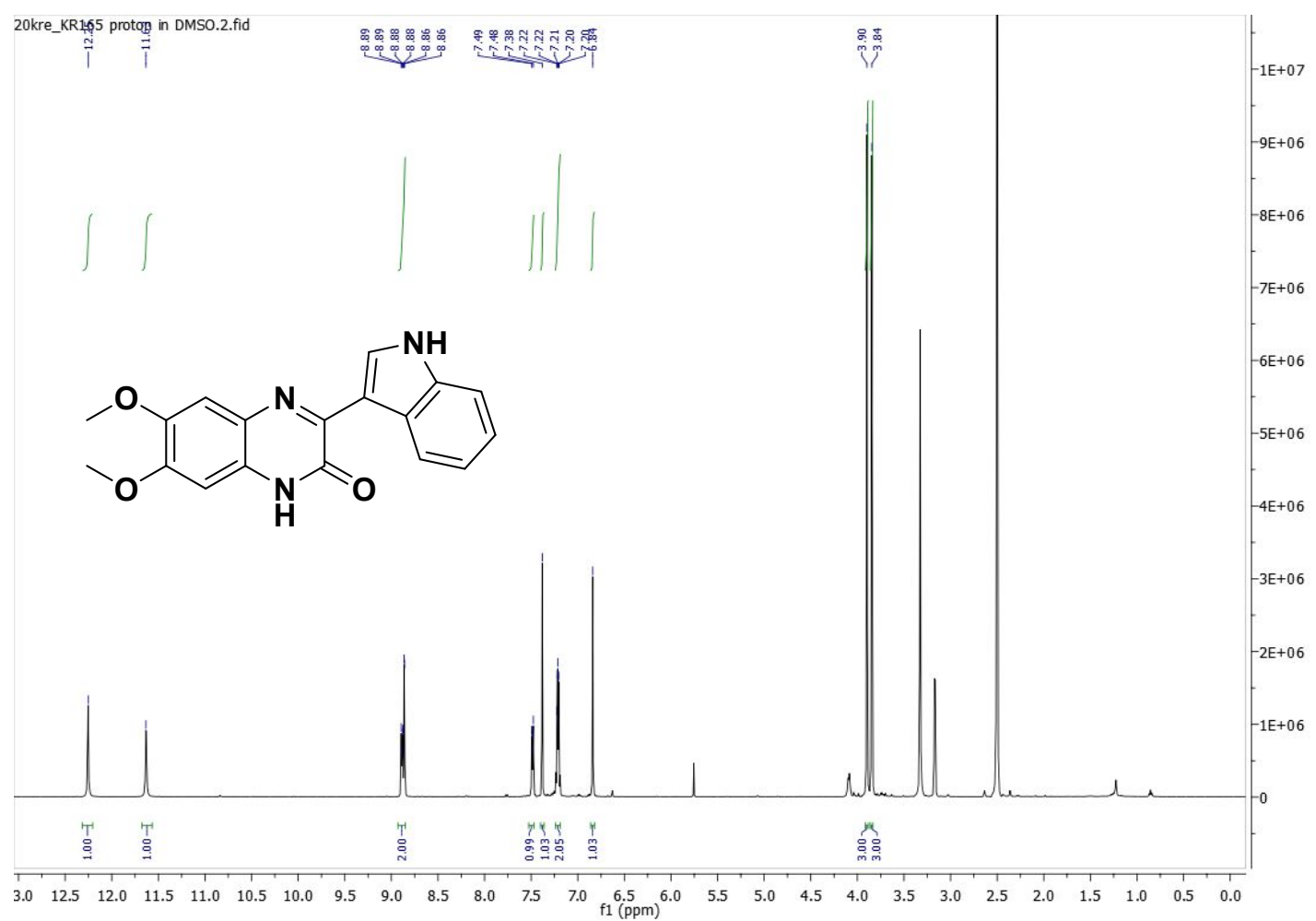


Fig. S67 - ${ }^{13} \mathrm{C}$ NMR spectrum of quinoxalin-2(1H)-one 8 in DMSO- $d_{6}(126 \mathrm{MHz})$

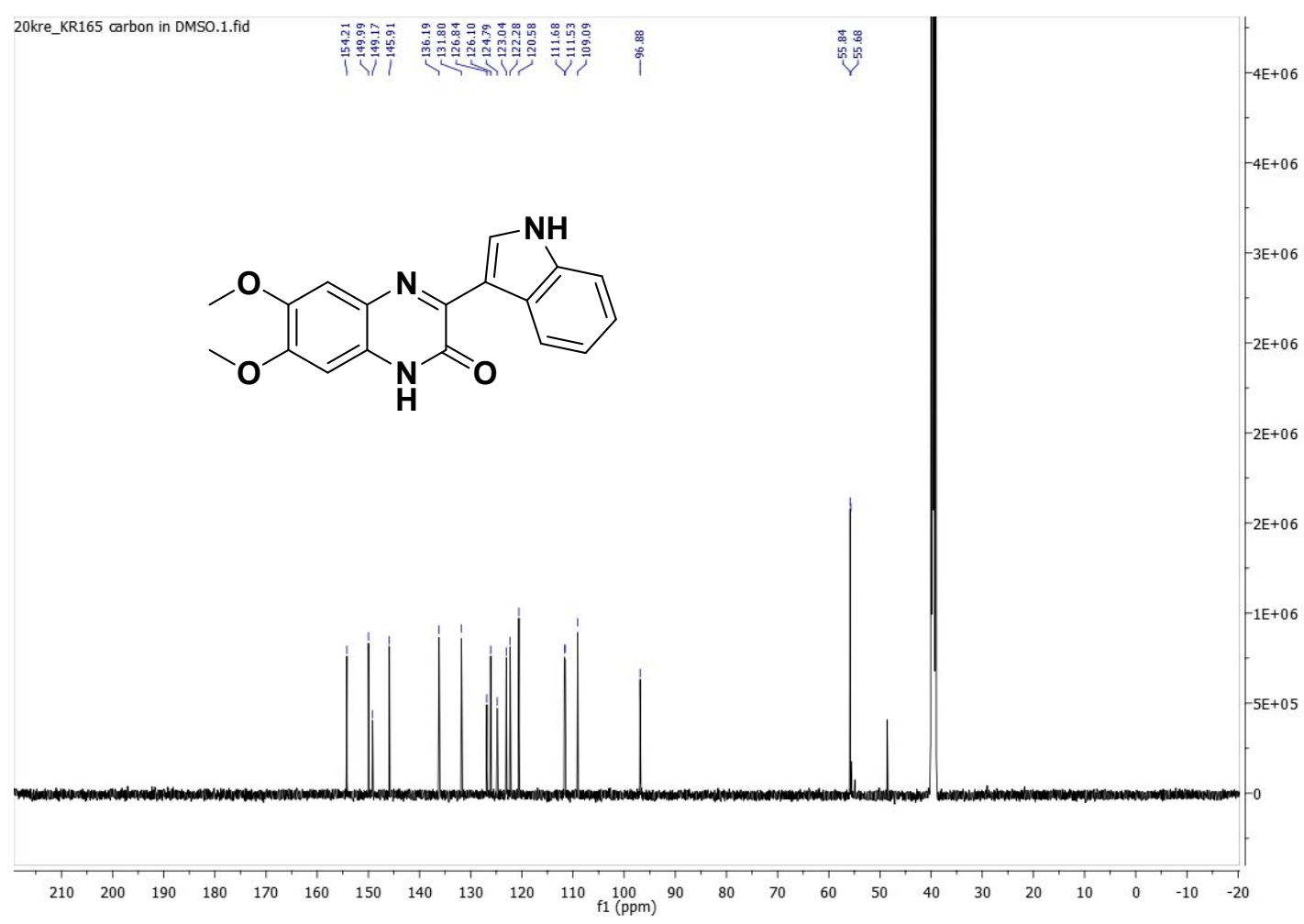

Fig. S68 - Confocal fluorescence images (left for full image and right for zoom) of fixed A549 cells incubated with quinoxalin-2(1H)-one 8 (concentration: $5.0 \mu \mathrm{M}$ ) for 2 h. Ex. 405 nm / Em. 430-600 nm
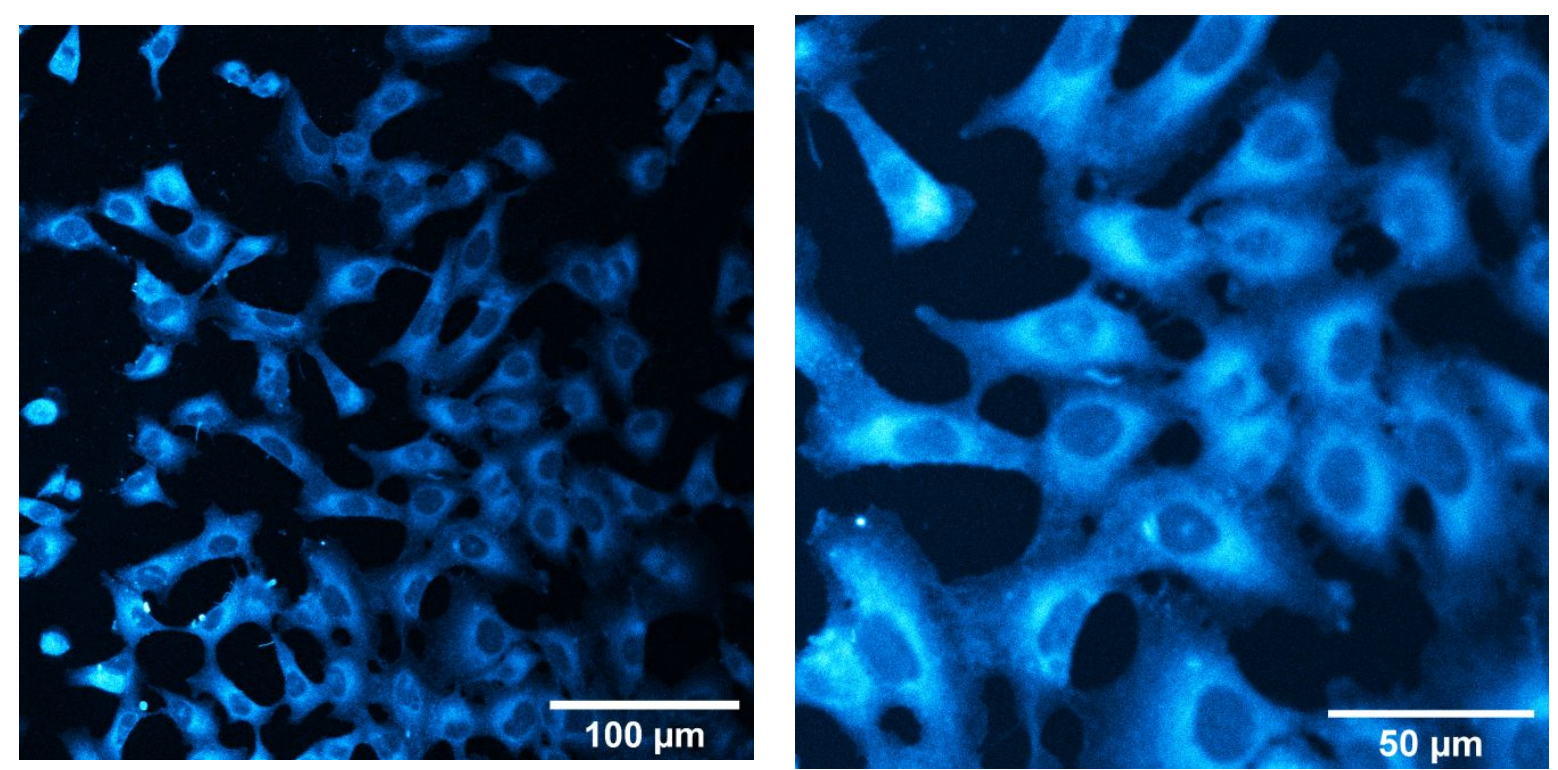

please note: living cells A549 first incubated with fluorophore 8 for 2 h and subsequently fixed with PFA. 
Fig. S69 - Confocal fluorescence image of fixed A549 cells incubated with quinoxalin-2(1H)-one 2 (concentration: $5.0 \mu \mathrm{M}$ ) for $2 \mathrm{~h}$. Ex. $405 \mathrm{~nm} / \mathrm{Em}$. 430-600 nm

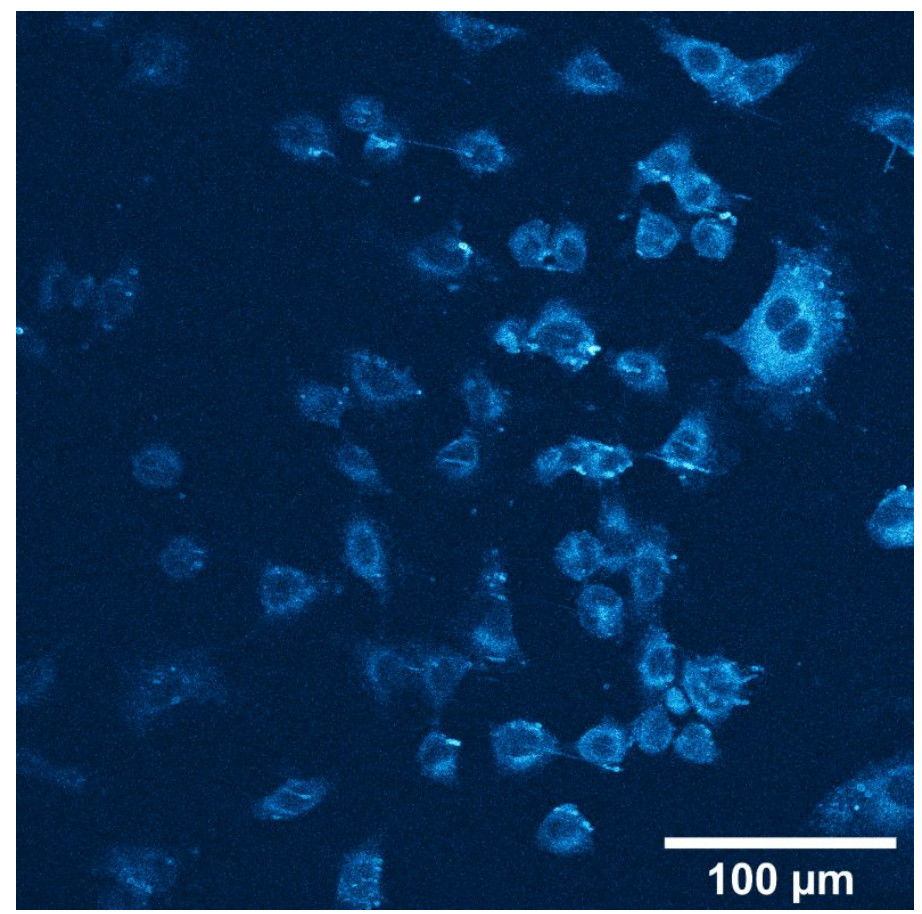

please note: living cells A549 first incubated with fluorophore 2 for $2 \mathrm{~h}$ and subsequently fixed with PFA.

Fig. S70 - ESI+ mass spectrum (high resolution) of mono- $N$-acyl 1,2phenylenediamine 11

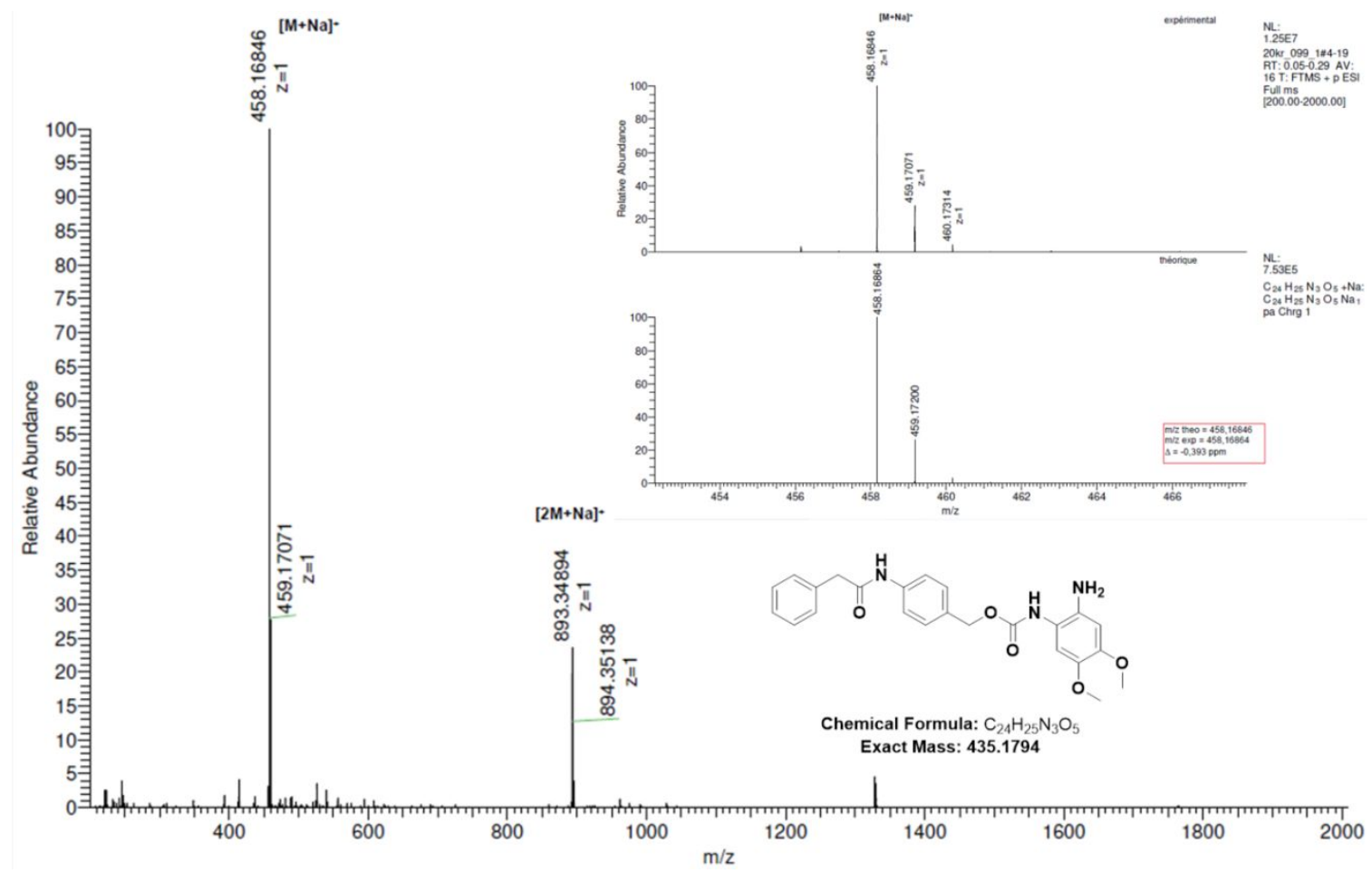


Fig. S71 - ESI+ (left) / ESI- (right) mass spectra (low resolution) of mono- $N$-acyl 1,2-phenylenediamine 11
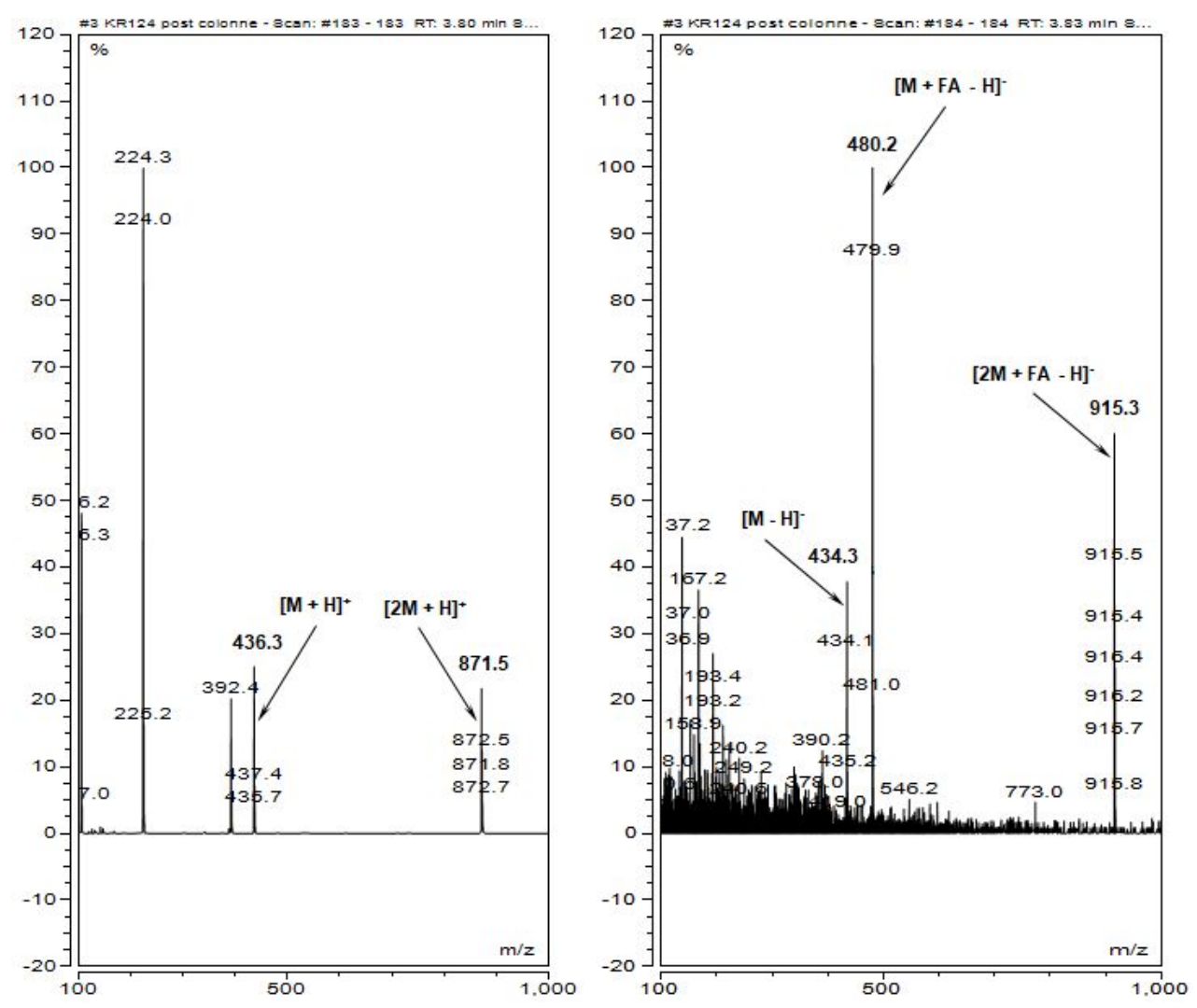

Fig. S72 - RP-HPLC elution profile of mono- $N$-acyl 1,2-phenylenediamine 11 (system A, detection at $260 \mathrm{~nm}$ )

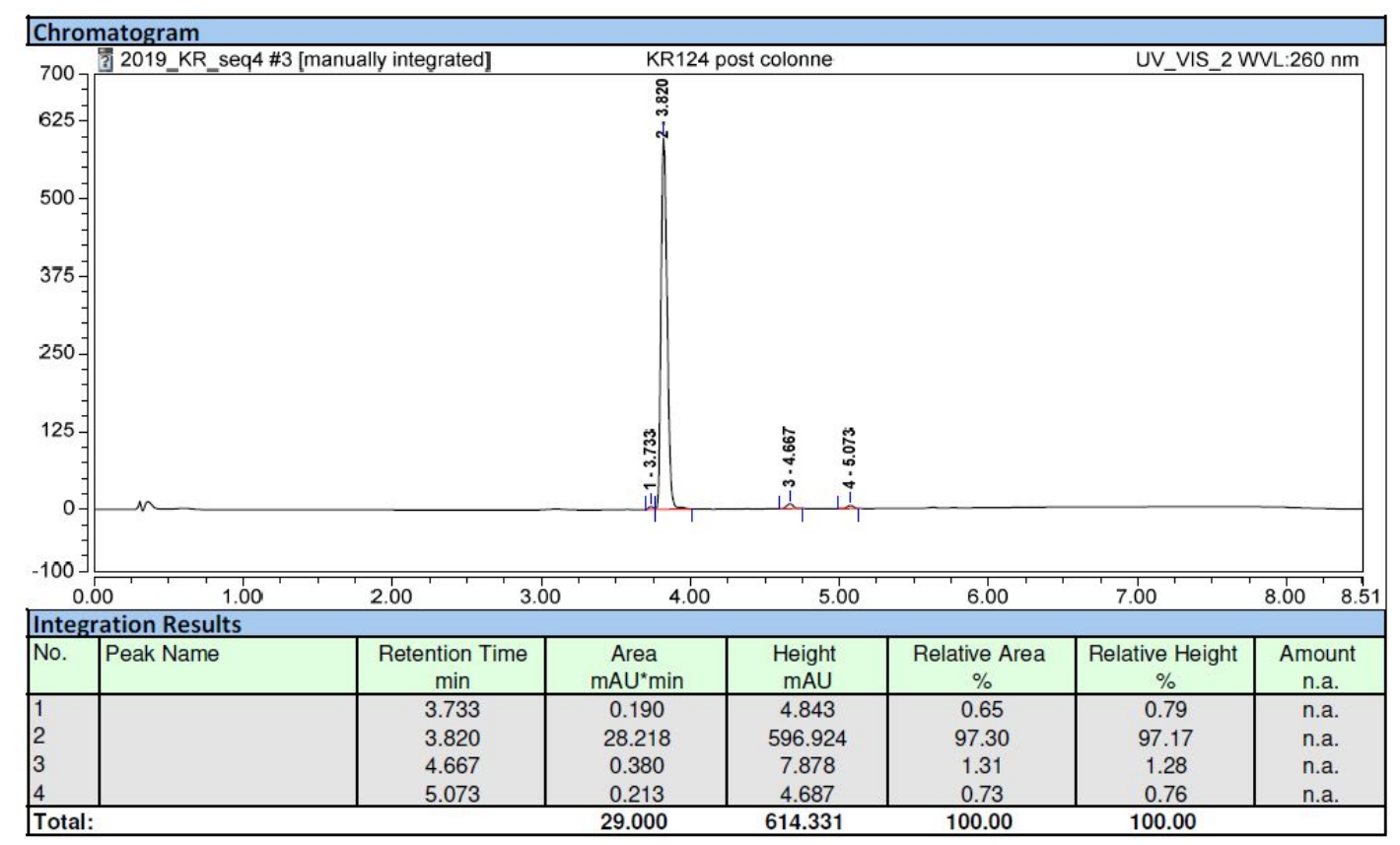


Fig. S73 - IR-ATR spectrum of mono- $N$-acyl 1,2-phenylenediamine 11

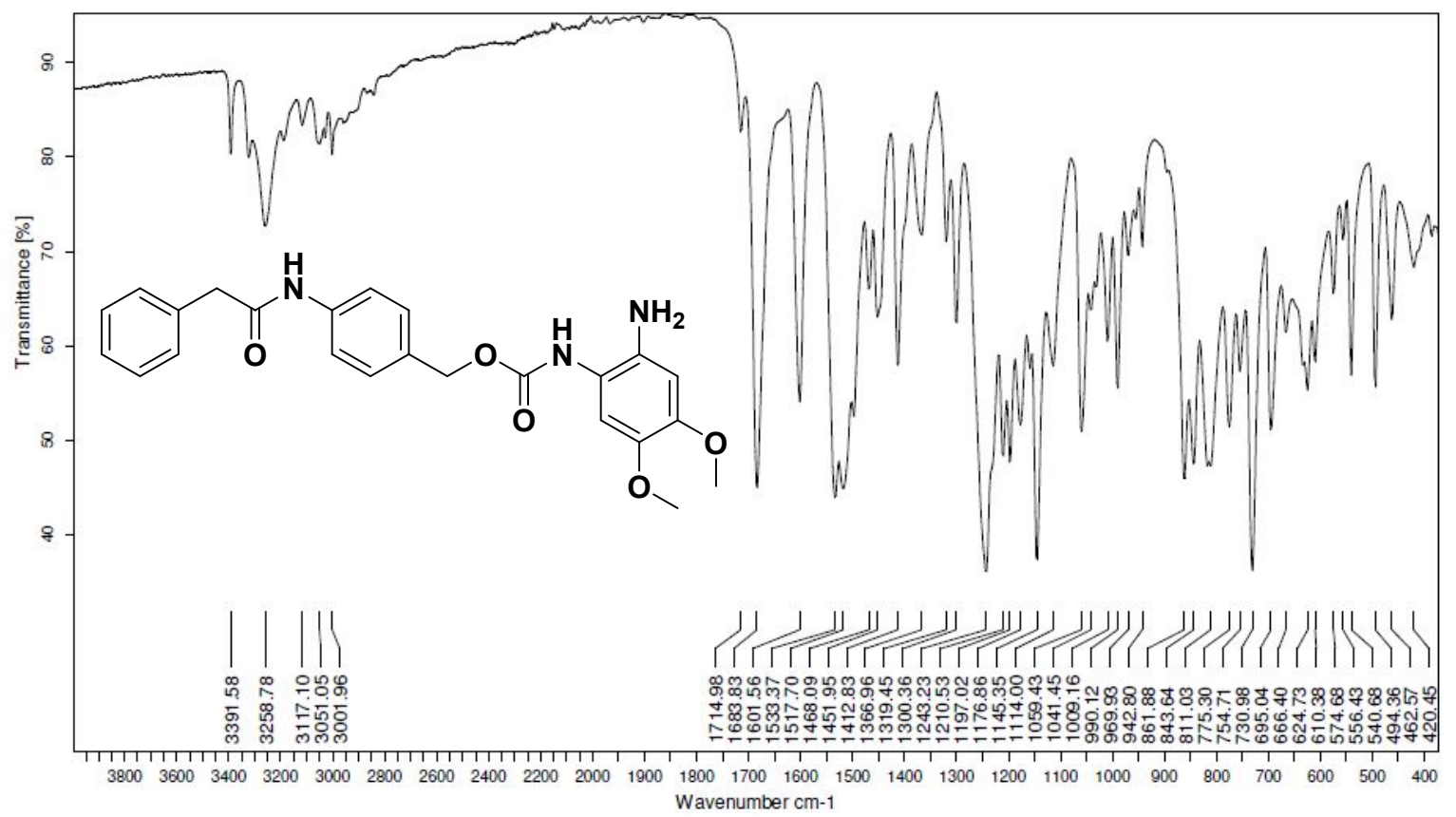

Fig. S74 - ${ }^{1} \mathrm{H}$ NMR spectrum of mono- $N$-acyl 1,2-phenylenediamine 11 in DMSO$d_{6}(500 \mathrm{MHz})$

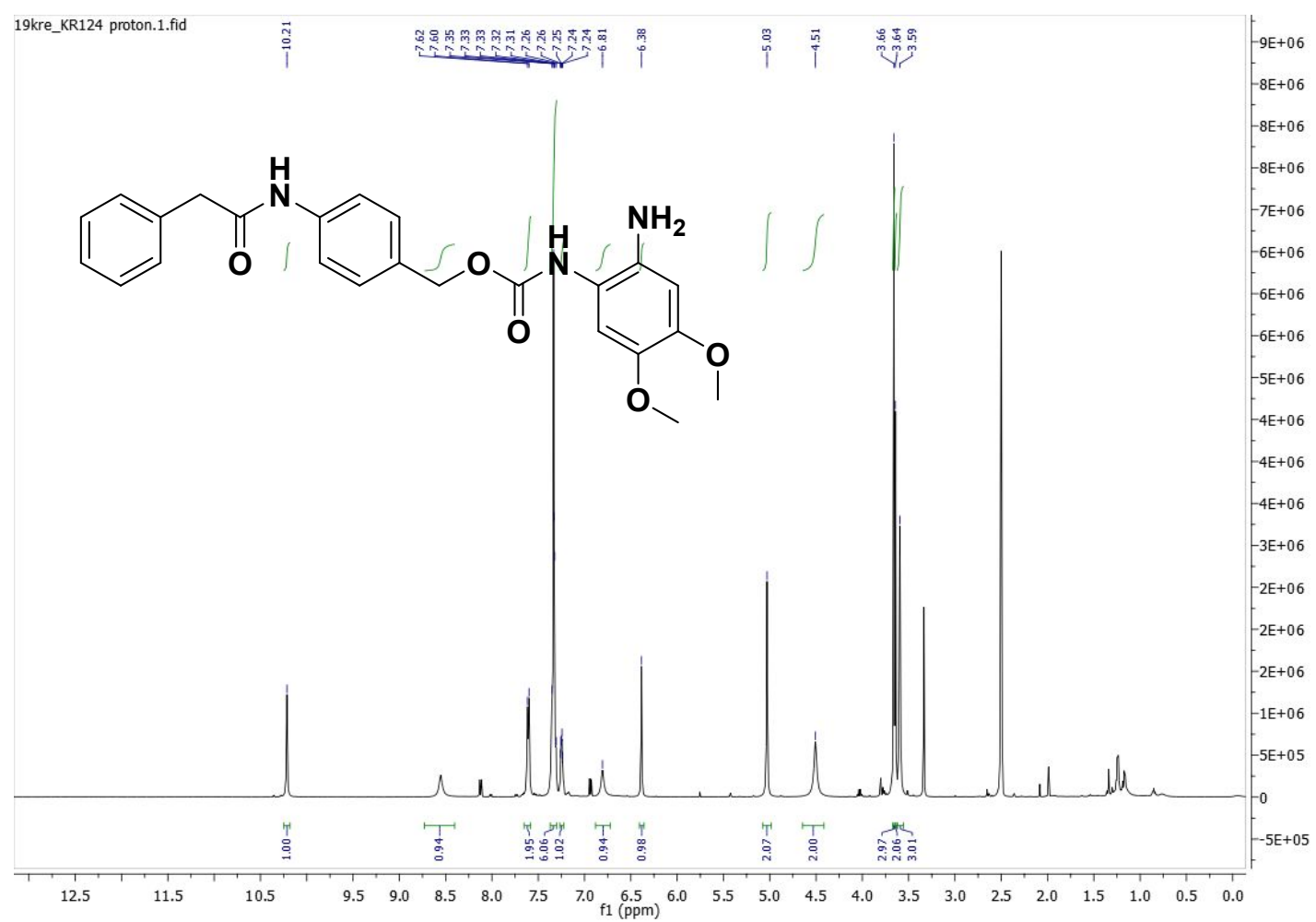


Fig. S75 - ${ }^{13} \mathrm{C}$ NMR spectrum of mono-N-acyl 1,2-phenylenediamine 11 in DMSO$d_{6}(126 \mathrm{MHz})$

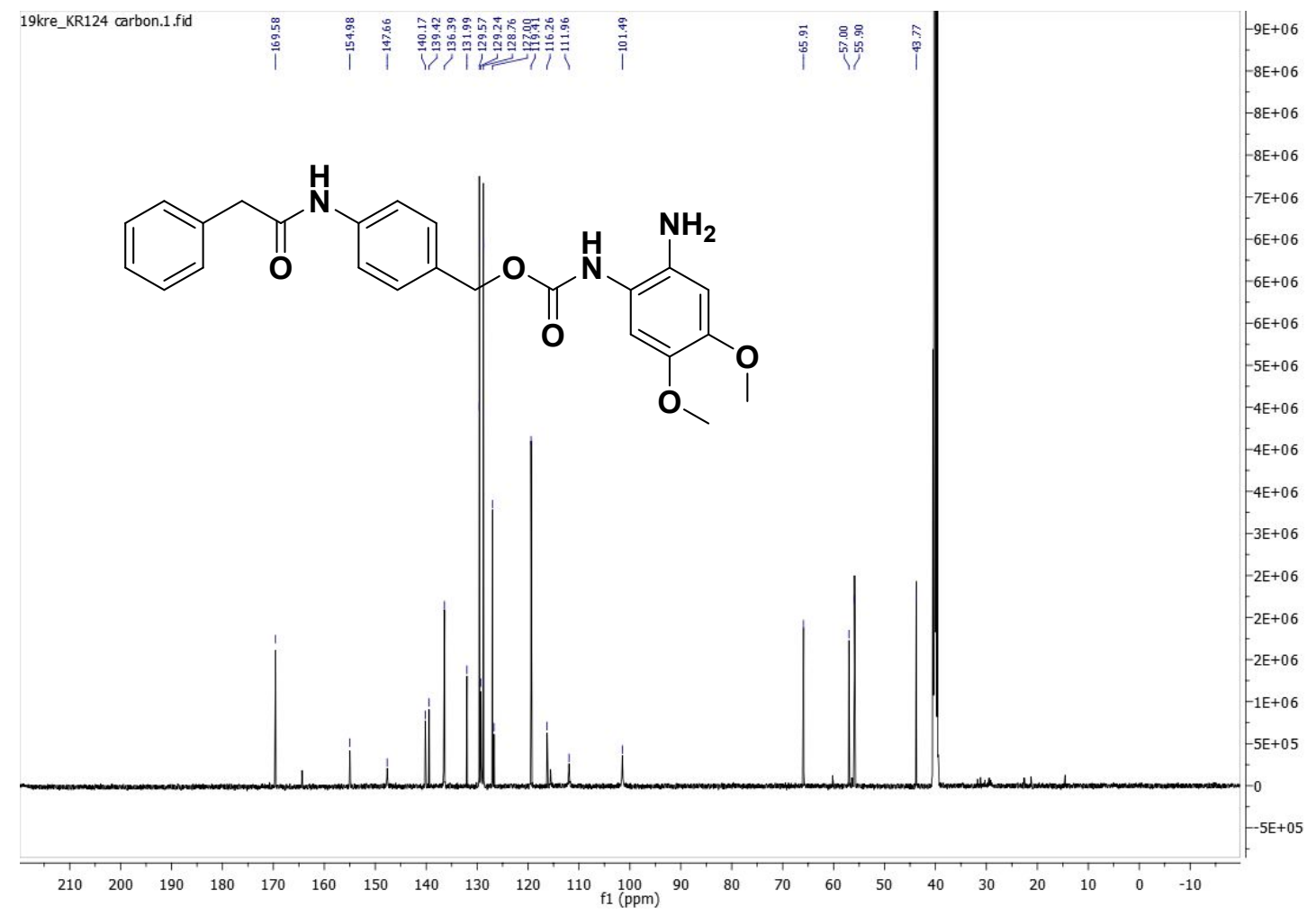

Fig. S76 - ESI+ mass spectrum (high resolution) of probe 12

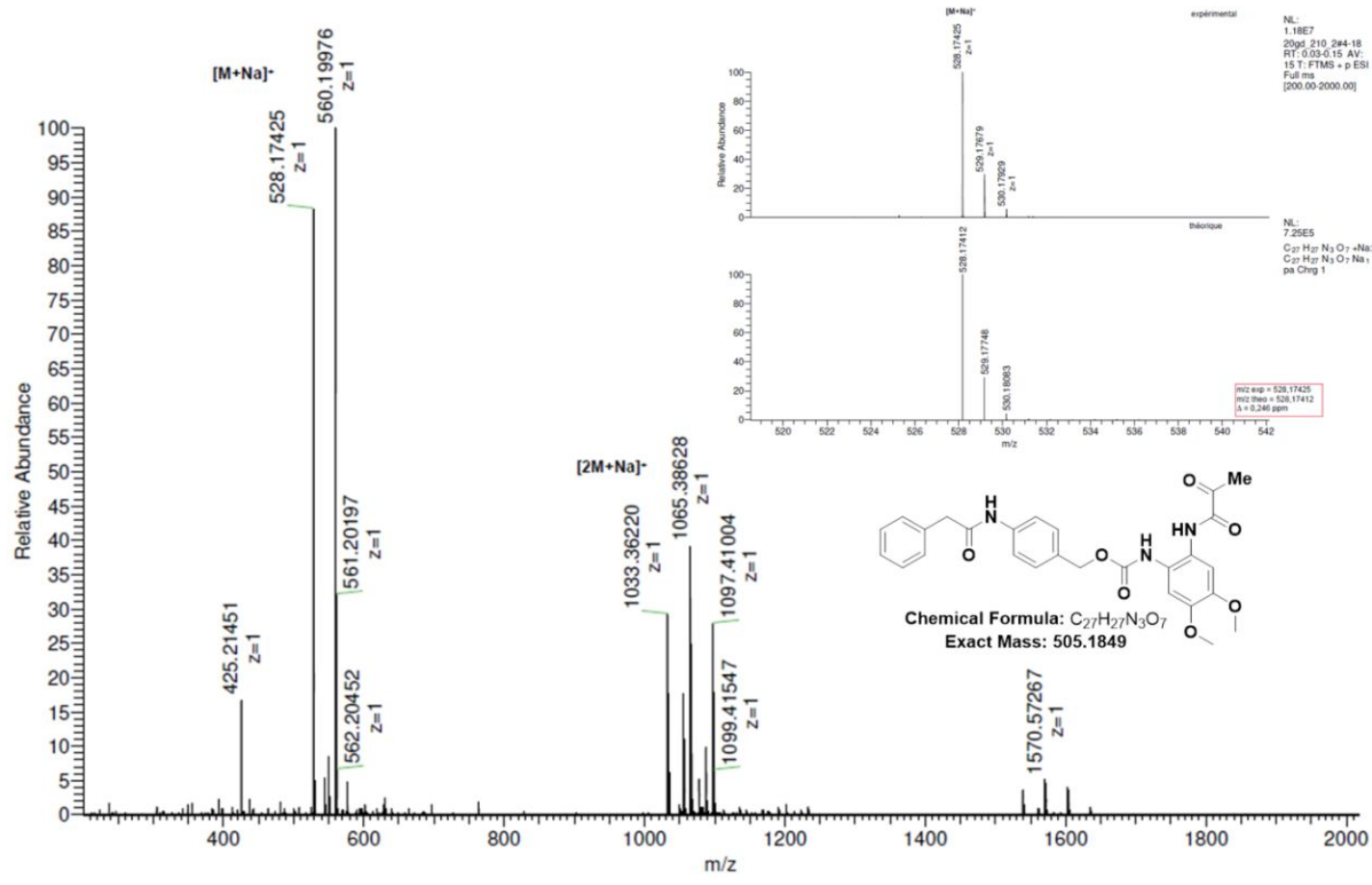


Fig. S77 - ESI- mass spectrum (low resolution) of probe 12

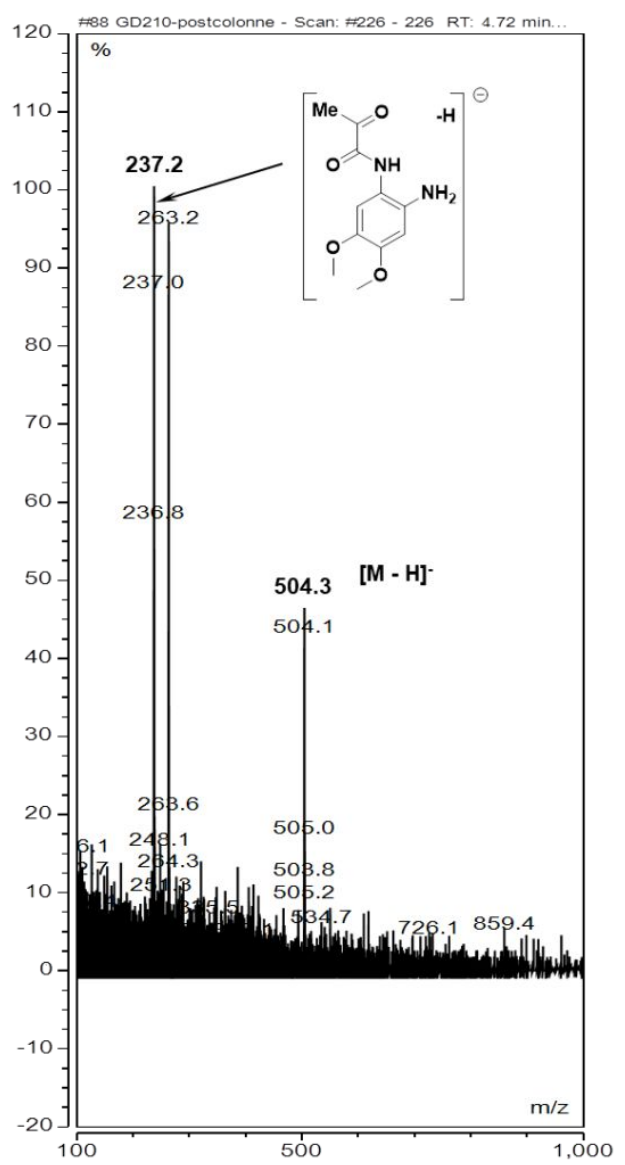

Fig. S78 - RP-HPLC elution profile of probe 12 (system A, detection at $260 \mathrm{~nm}$ )

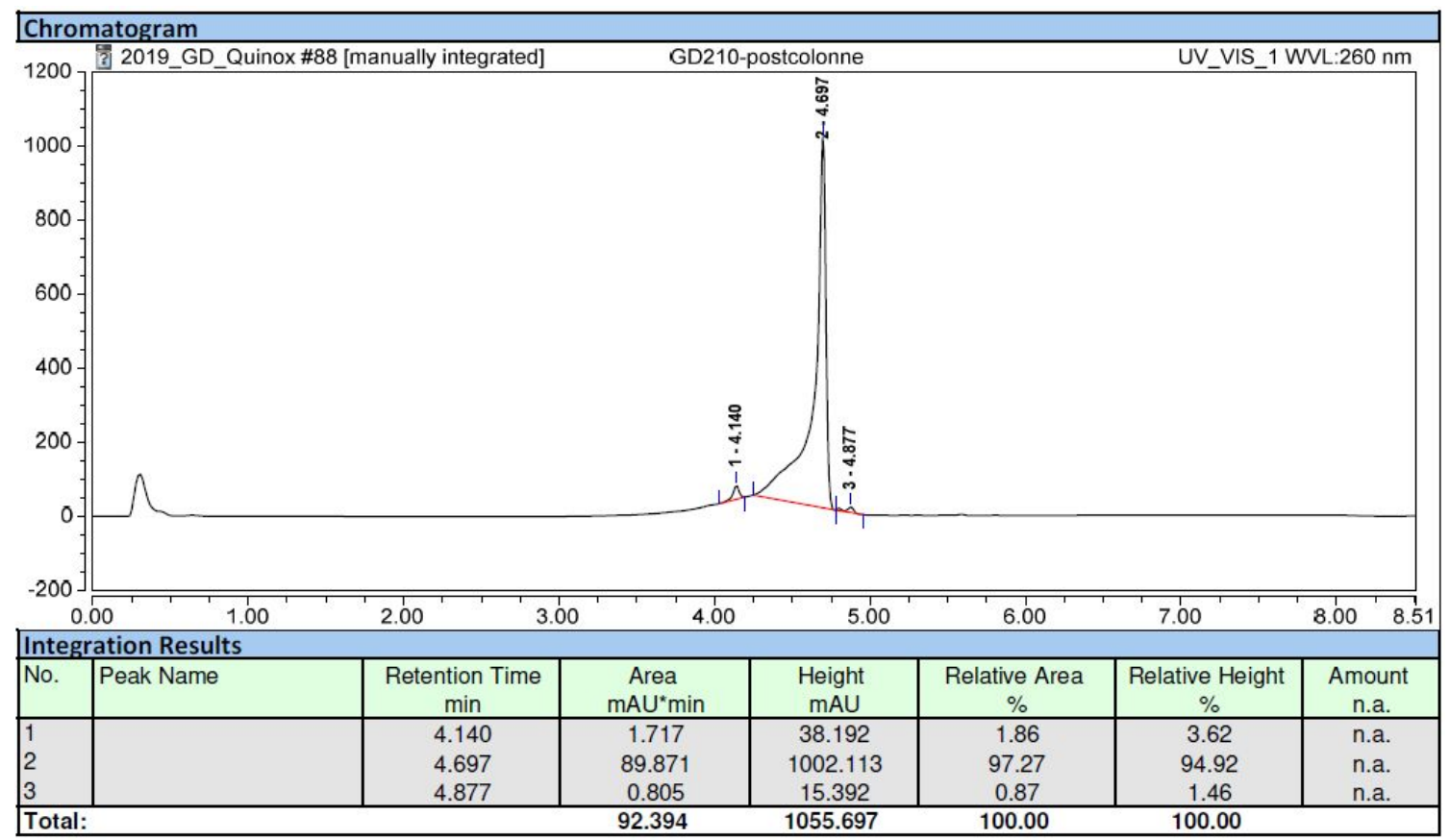


Fig. S79 - IR-ATR spectrum of probe 12

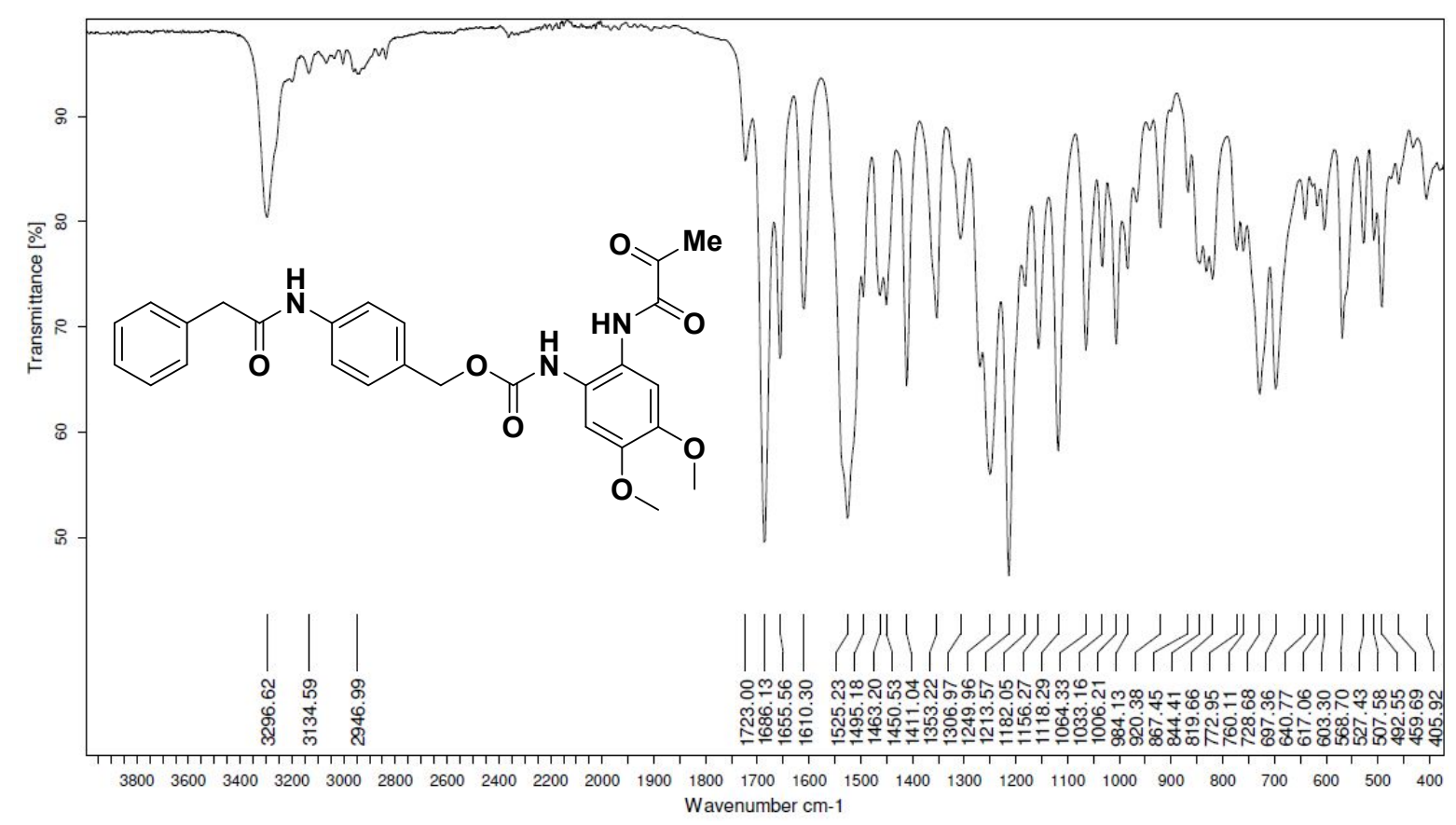

Fig. S80 - ${ }^{1} \mathrm{H}$ NMR spectrum of probe 12 in $\mathrm{CDCl}_{3}(400 \mathrm{MHz})$

20gde_GD210-Cdd3.2.fid
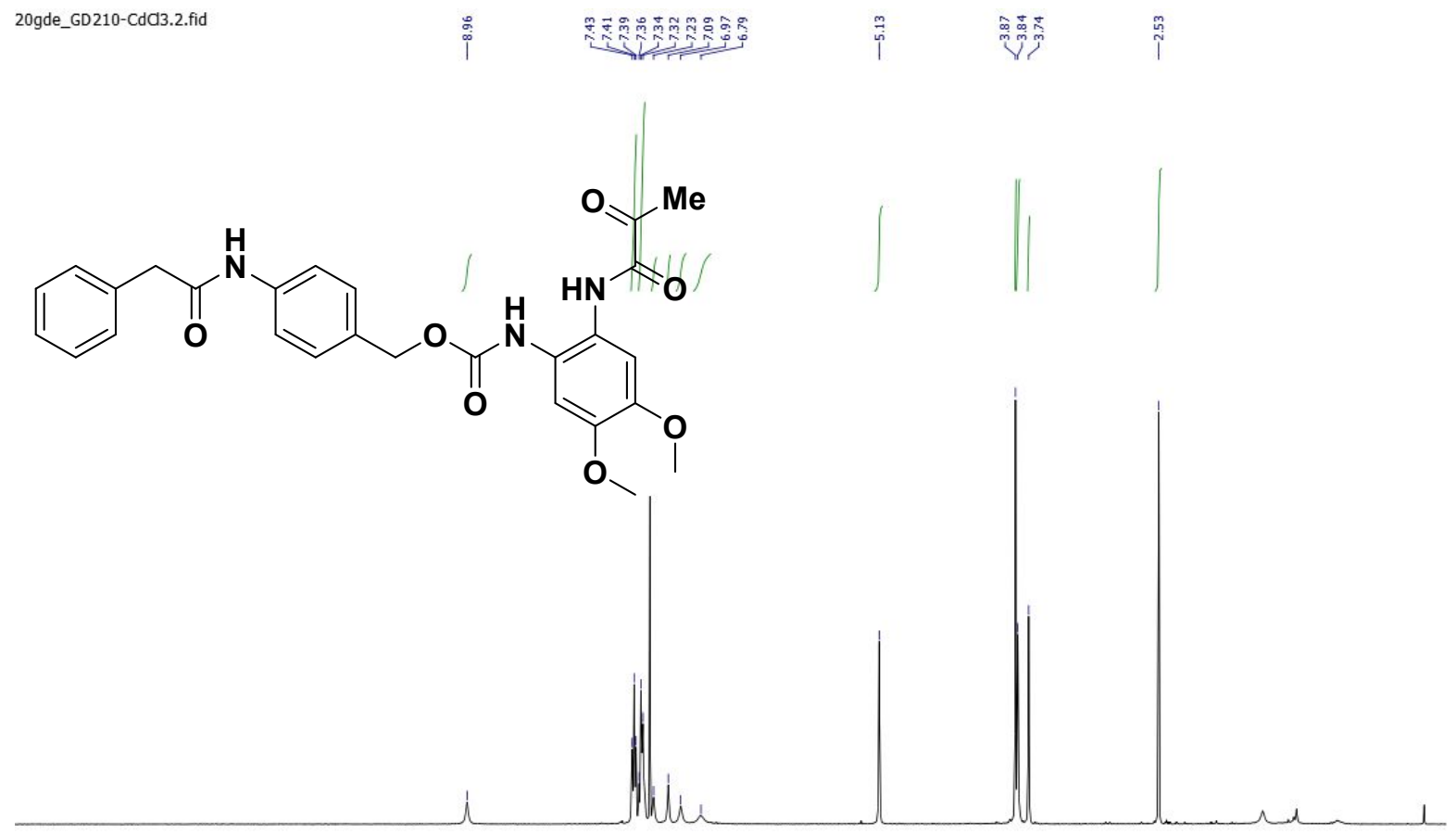

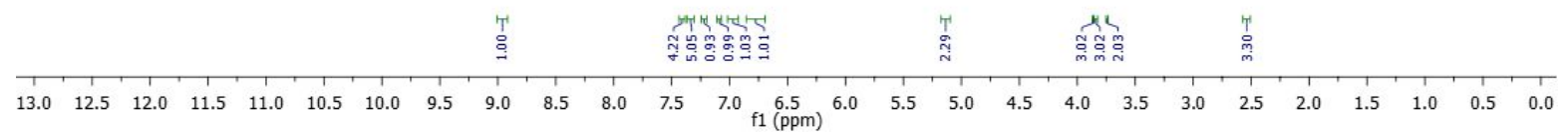


Fig. S81 - ${ }^{13} \mathrm{C}$ NMR spectrum of probe 12 in $\mathrm{CDCl}_{3}(101 \mathrm{MHz})$

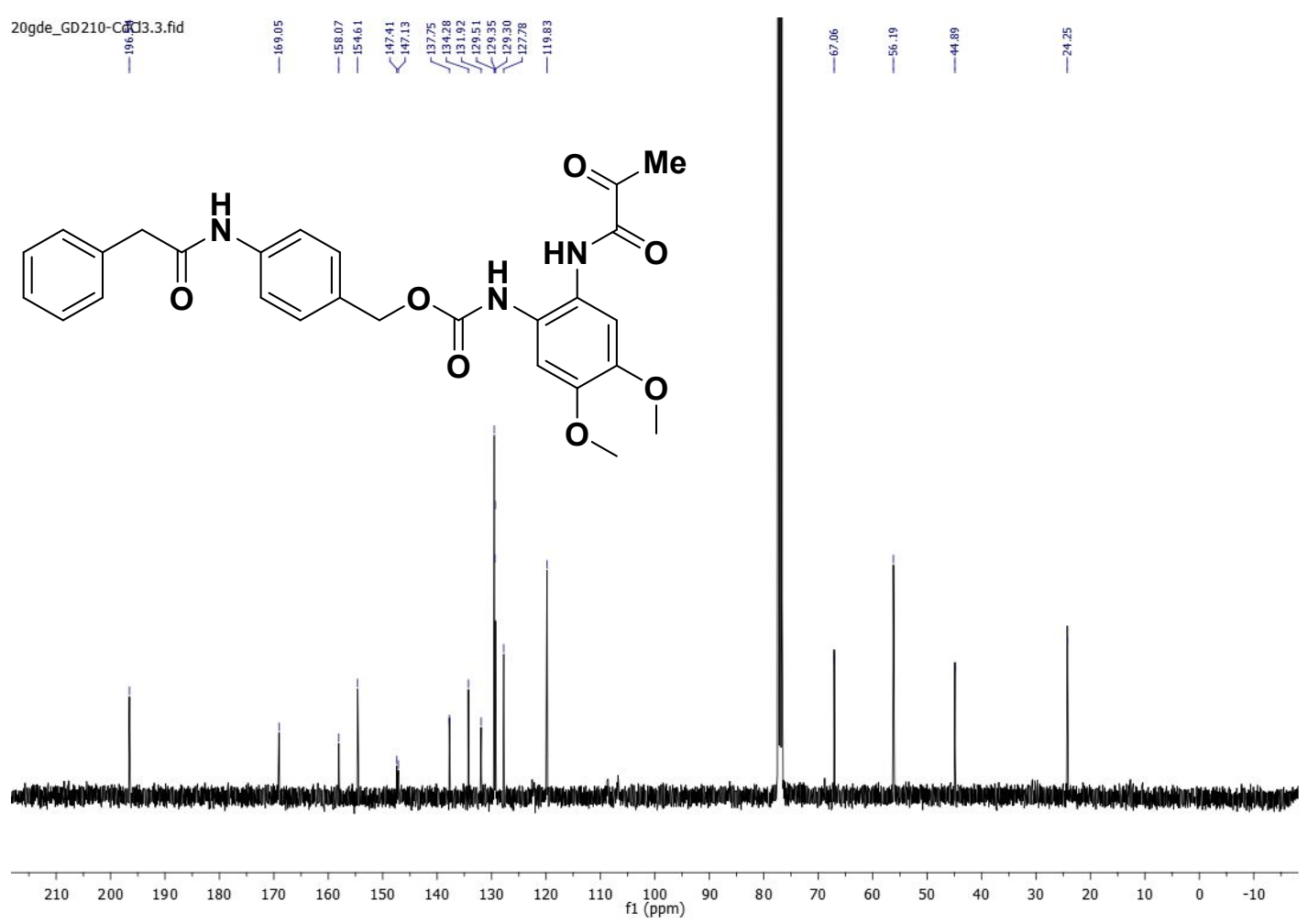

Fig. S82 - ESI+ mass spectrum (high resolution) of probe 13

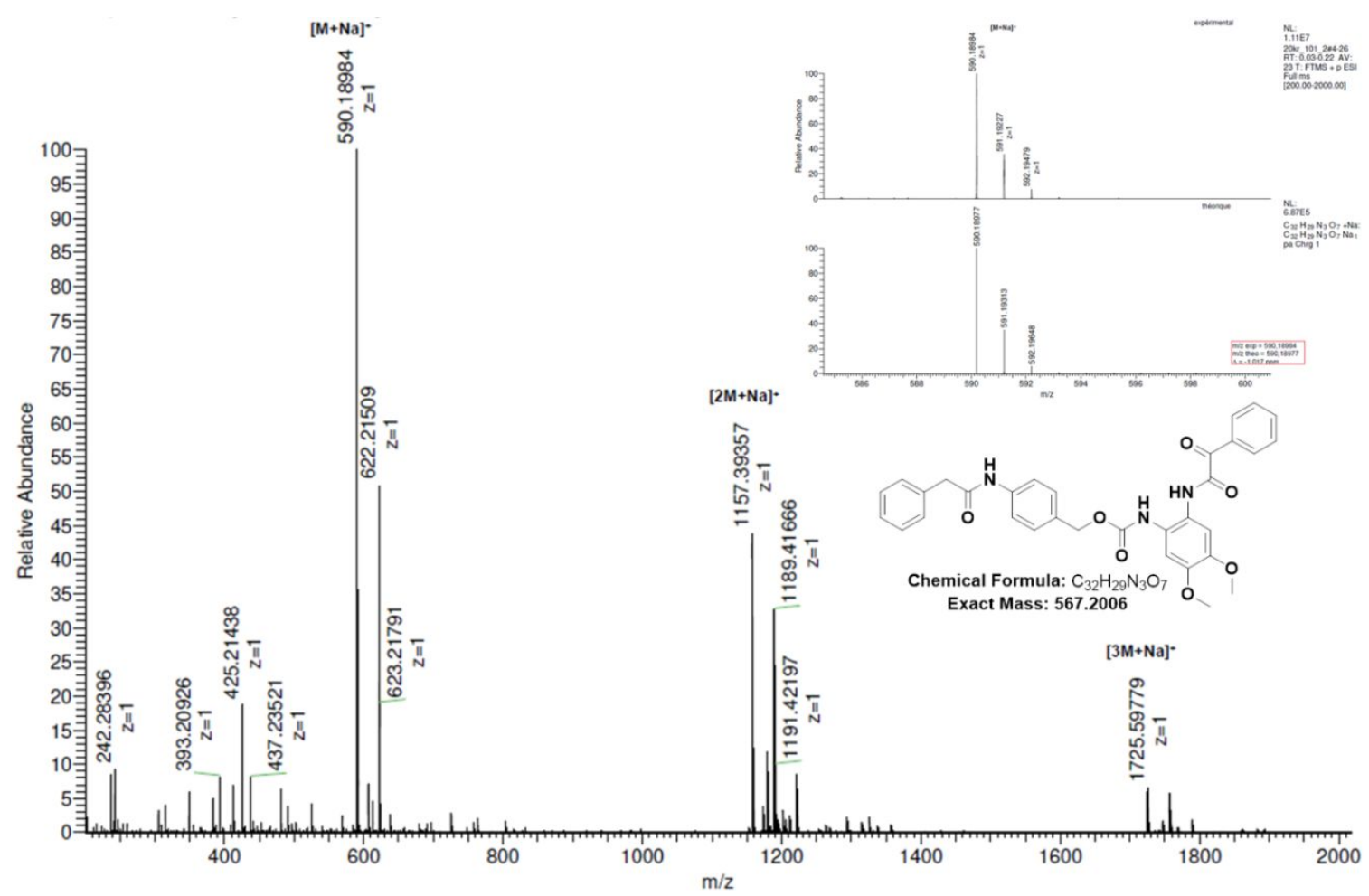


Fig. S83 - ESI+ (left) / ESI- (right) mass spectra (low resolution) of probe 13

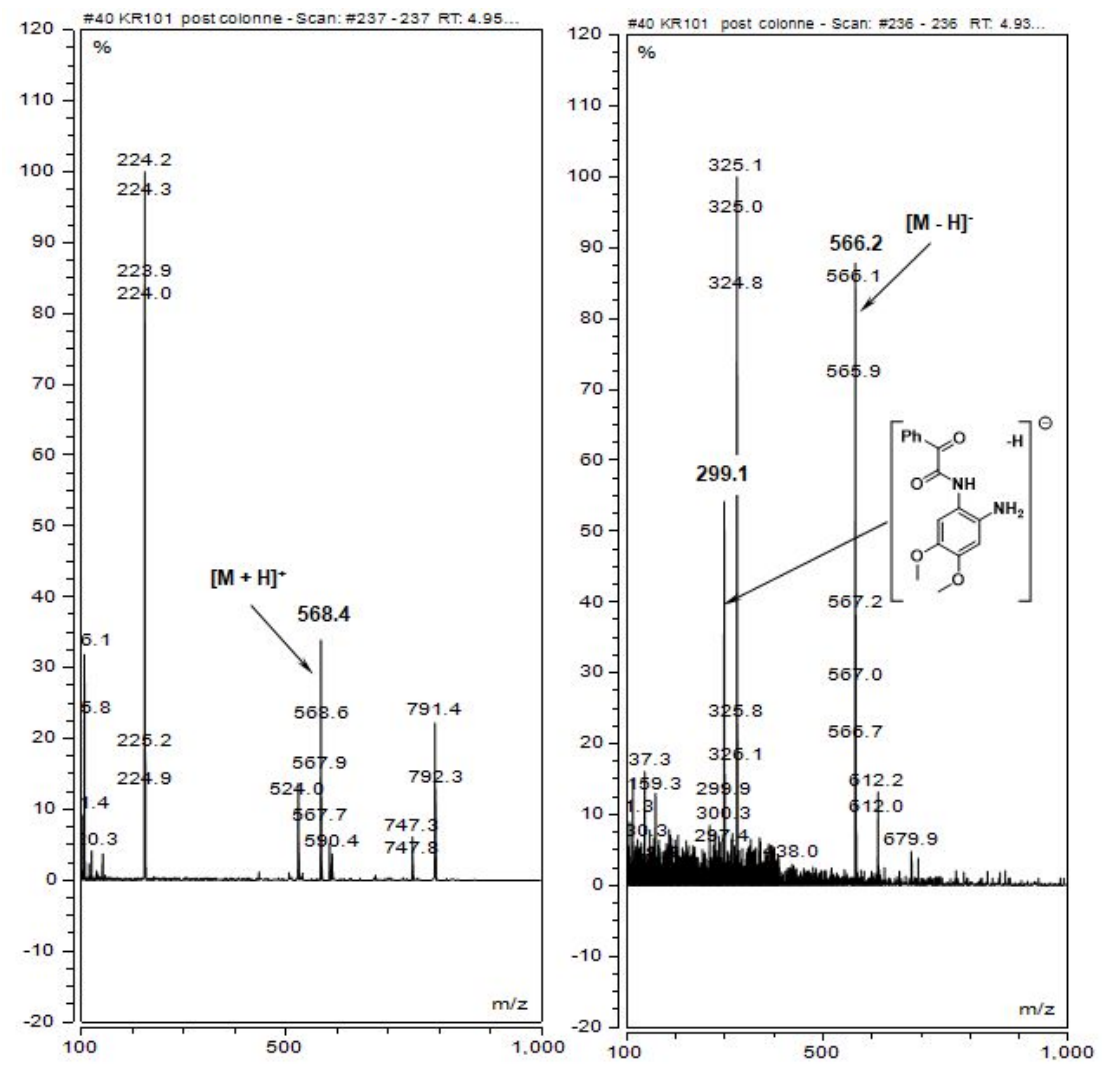

Fig. S84 - RP-HPLC elution profile of probe 13 (system A, detection at $260 \mathrm{~nm}$ )

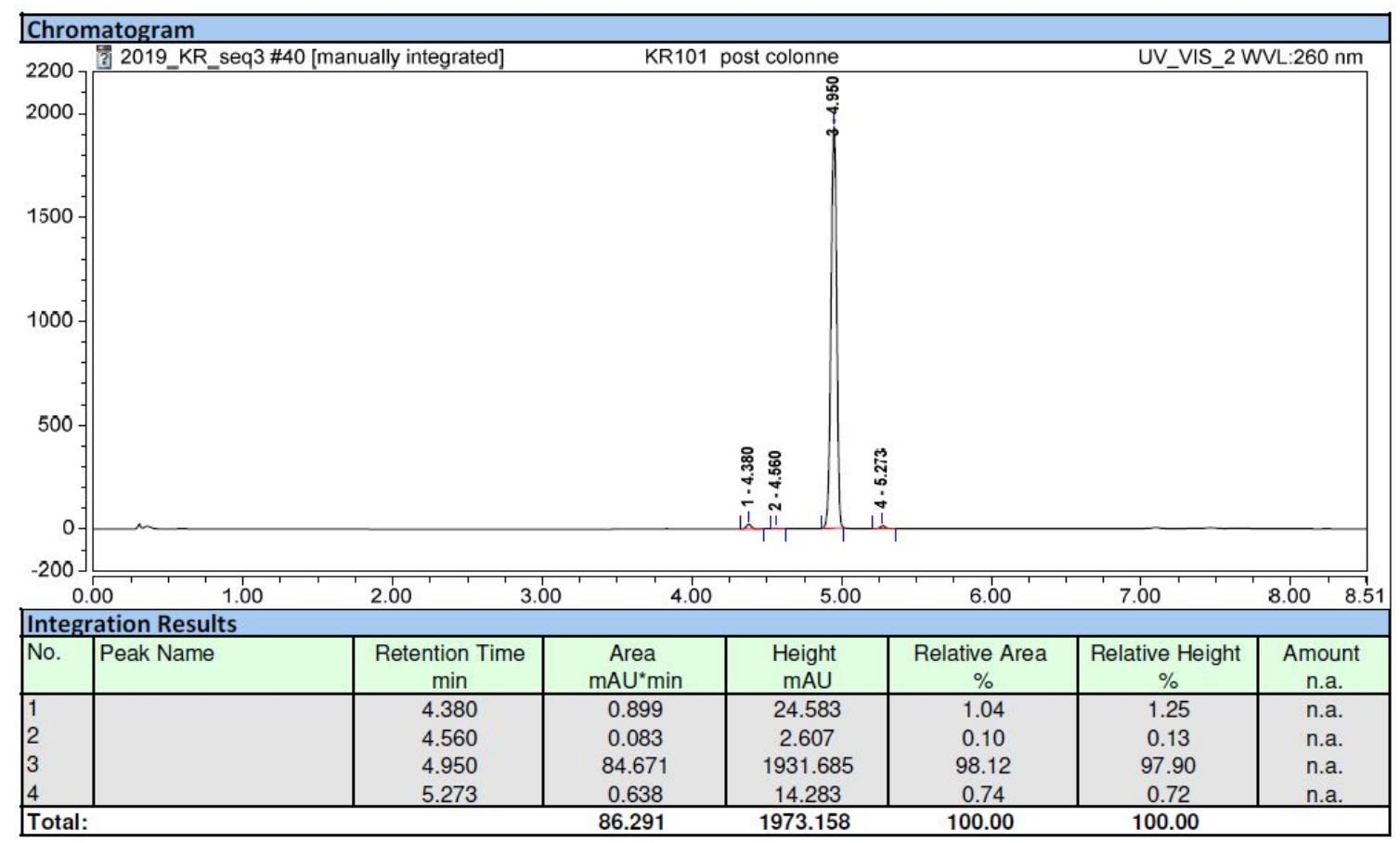


Fig. S85 - IR-ATR spectrum of probe 13

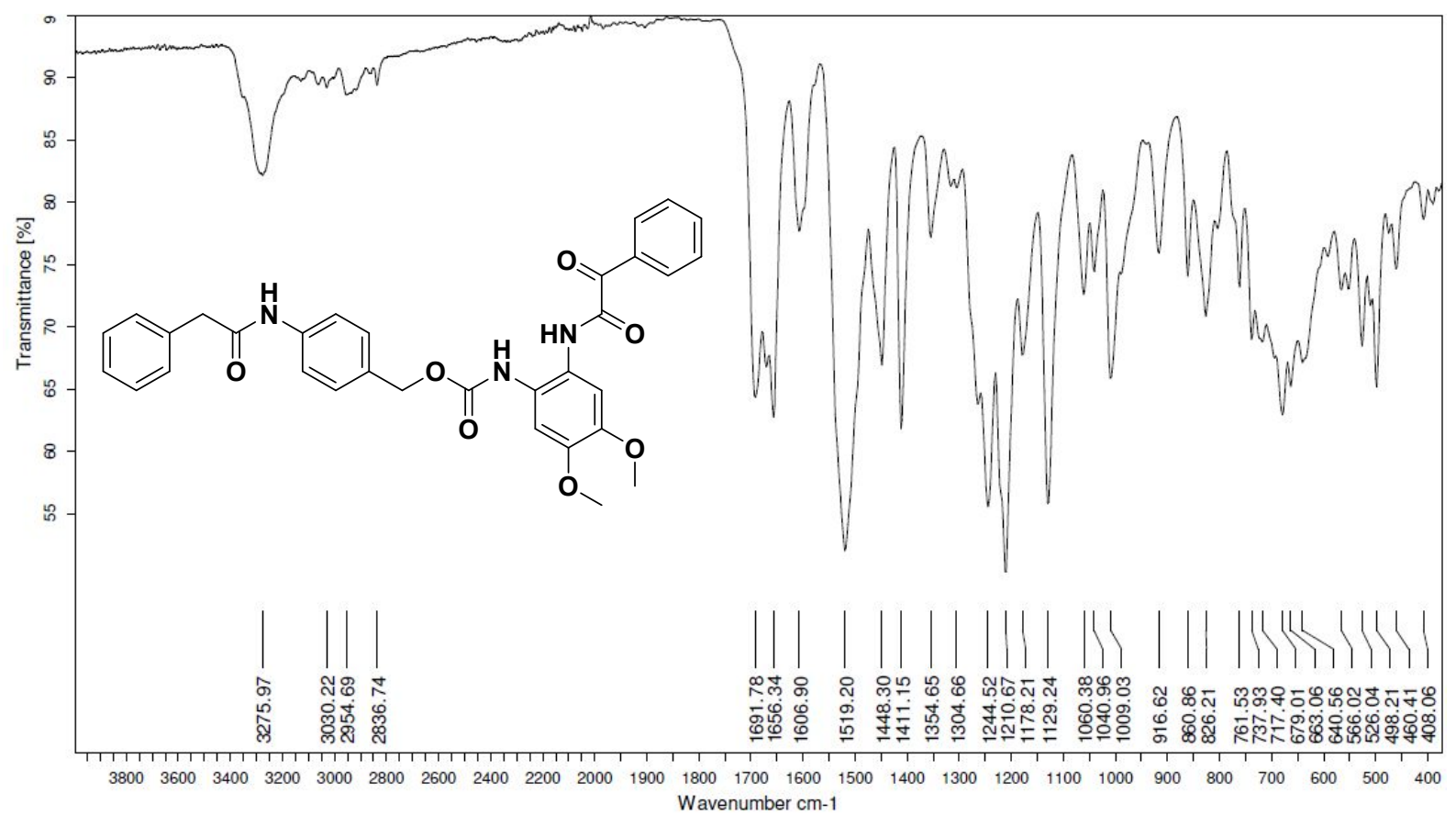

Fig. S86 - ${ }^{1} \mathrm{H}$ NMR spectrum of probe 13 in $\mathrm{CDCl}_{3}(600 \mathrm{MHz})$

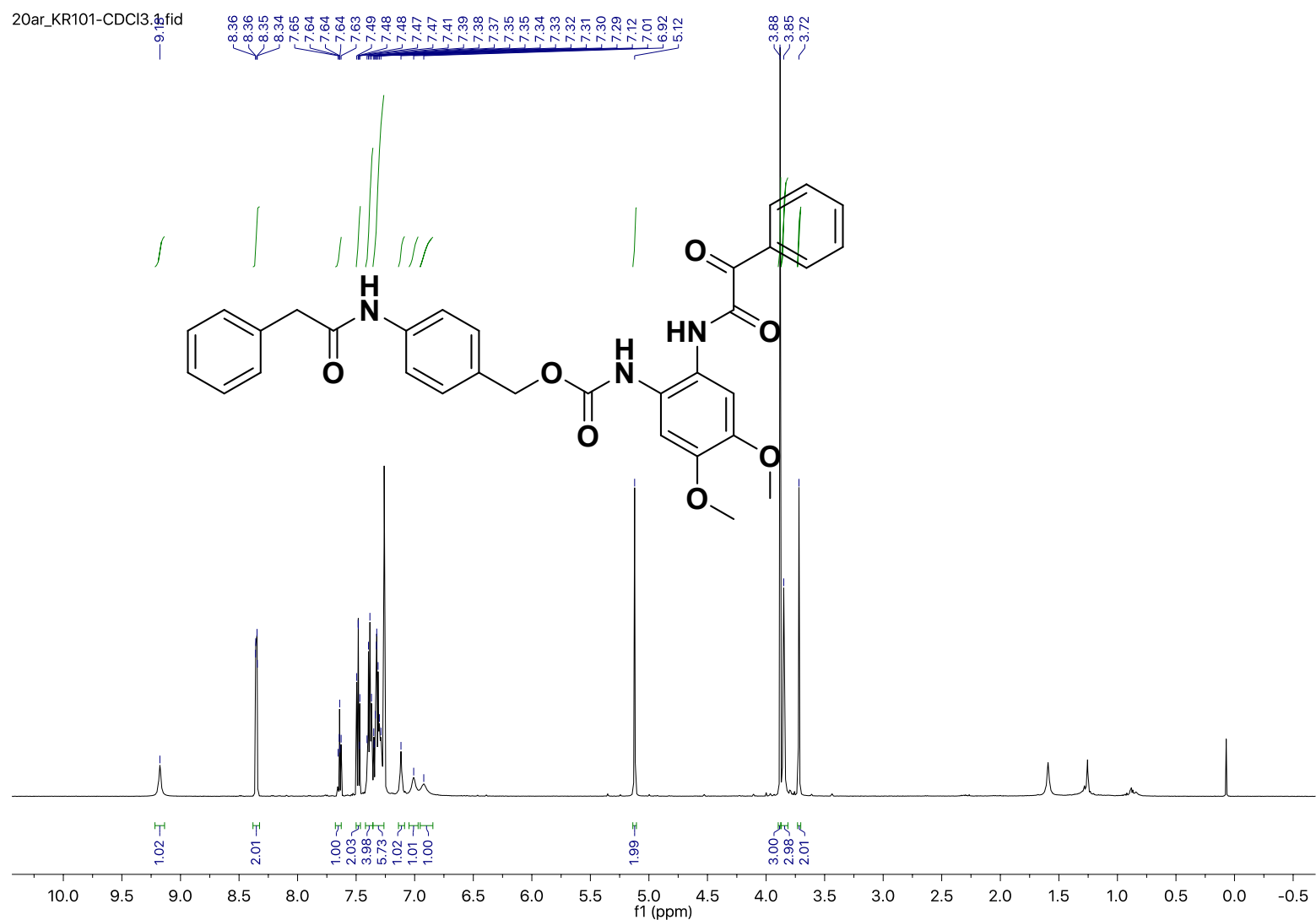


Fig. $\mathrm{S87}-{ }^{13} \mathrm{C}$ NMR spectrum of probe 13 in $\mathrm{CDCl}_{3}(151 \mathrm{MHz})$

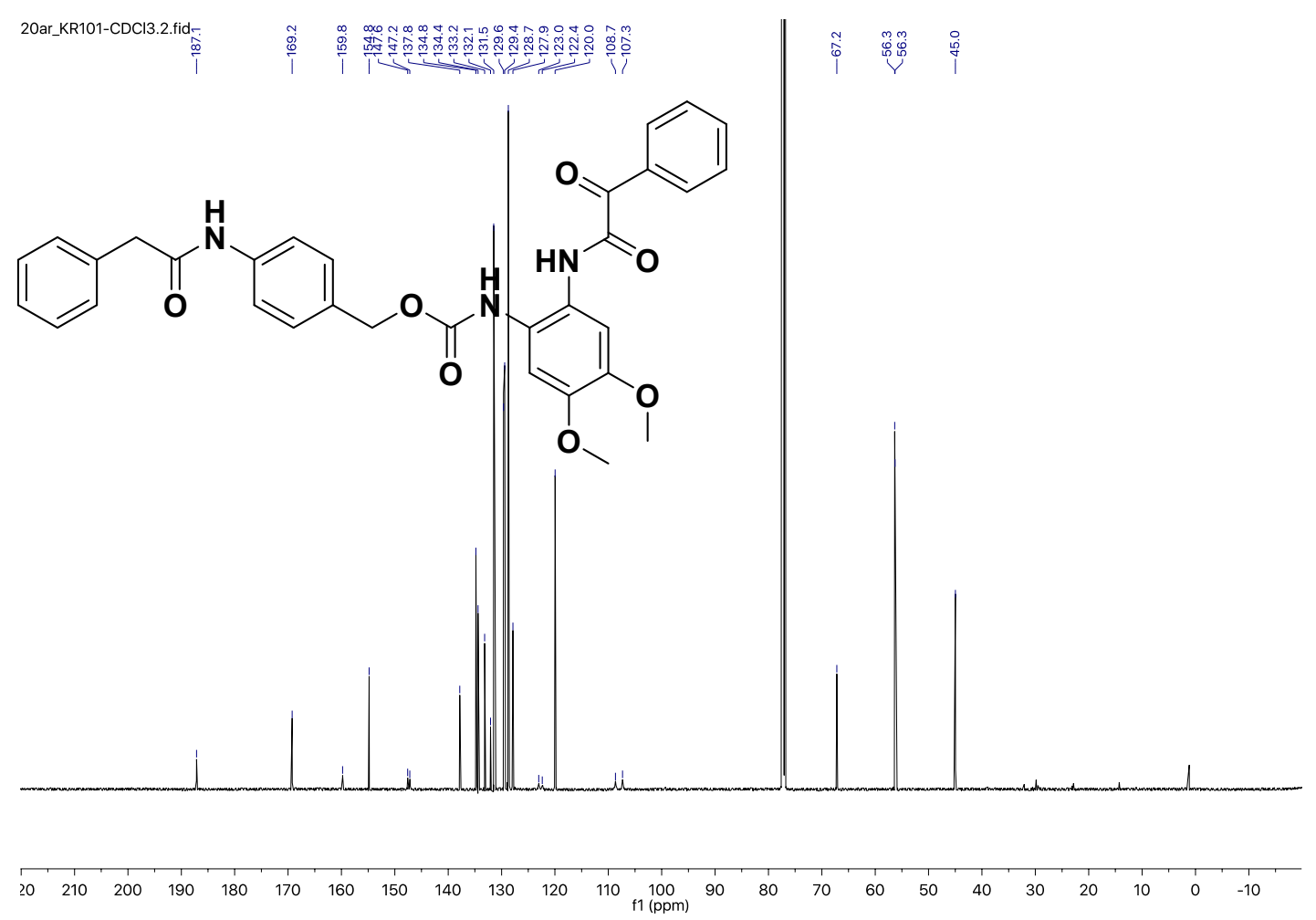

Fig. S88 - ESI+ mass spectrum (high resolution) of probe 14

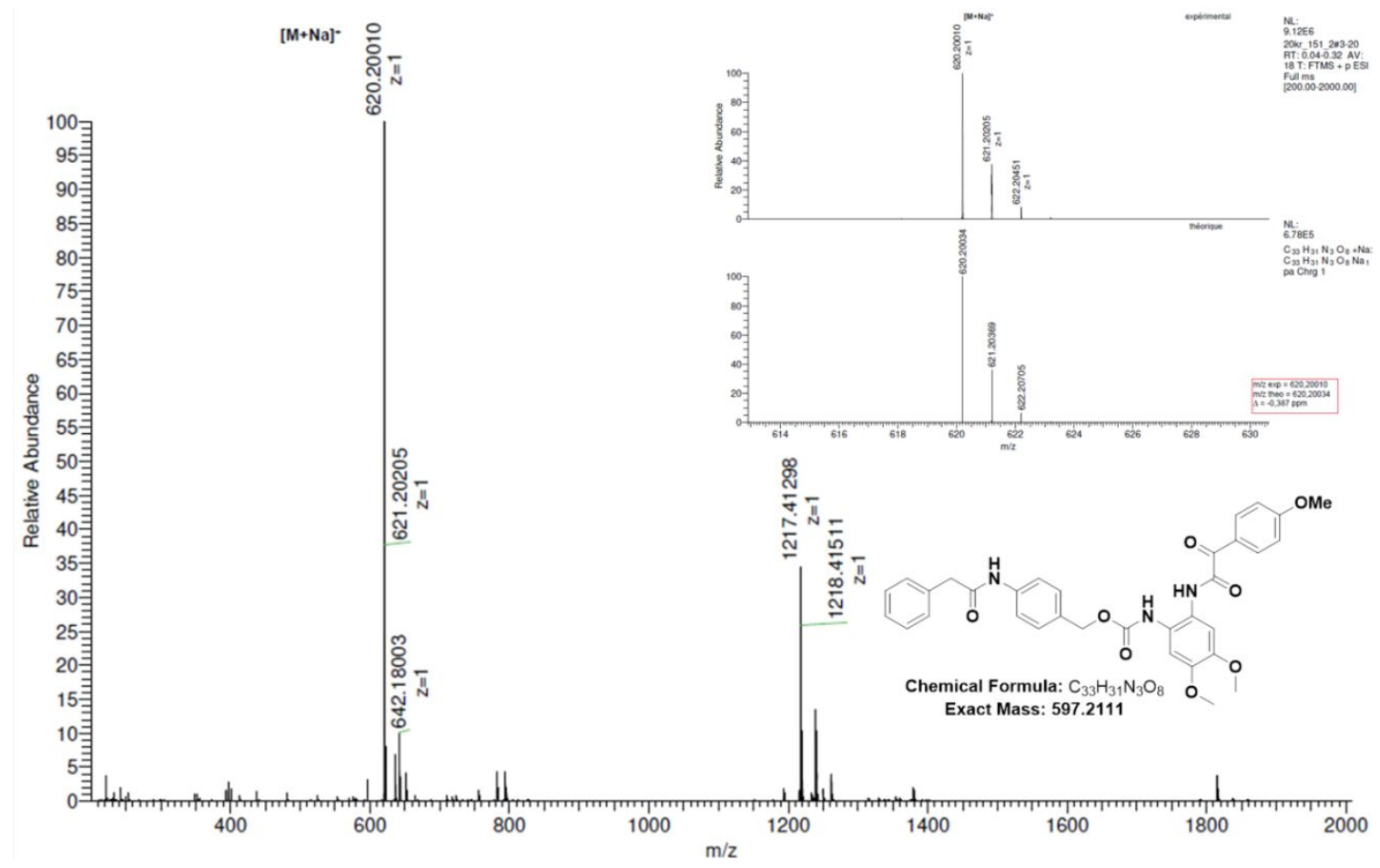


Fig. S89 - ESI+ (left) / ESI- (right) mass spectra (low resolution) of probe 14
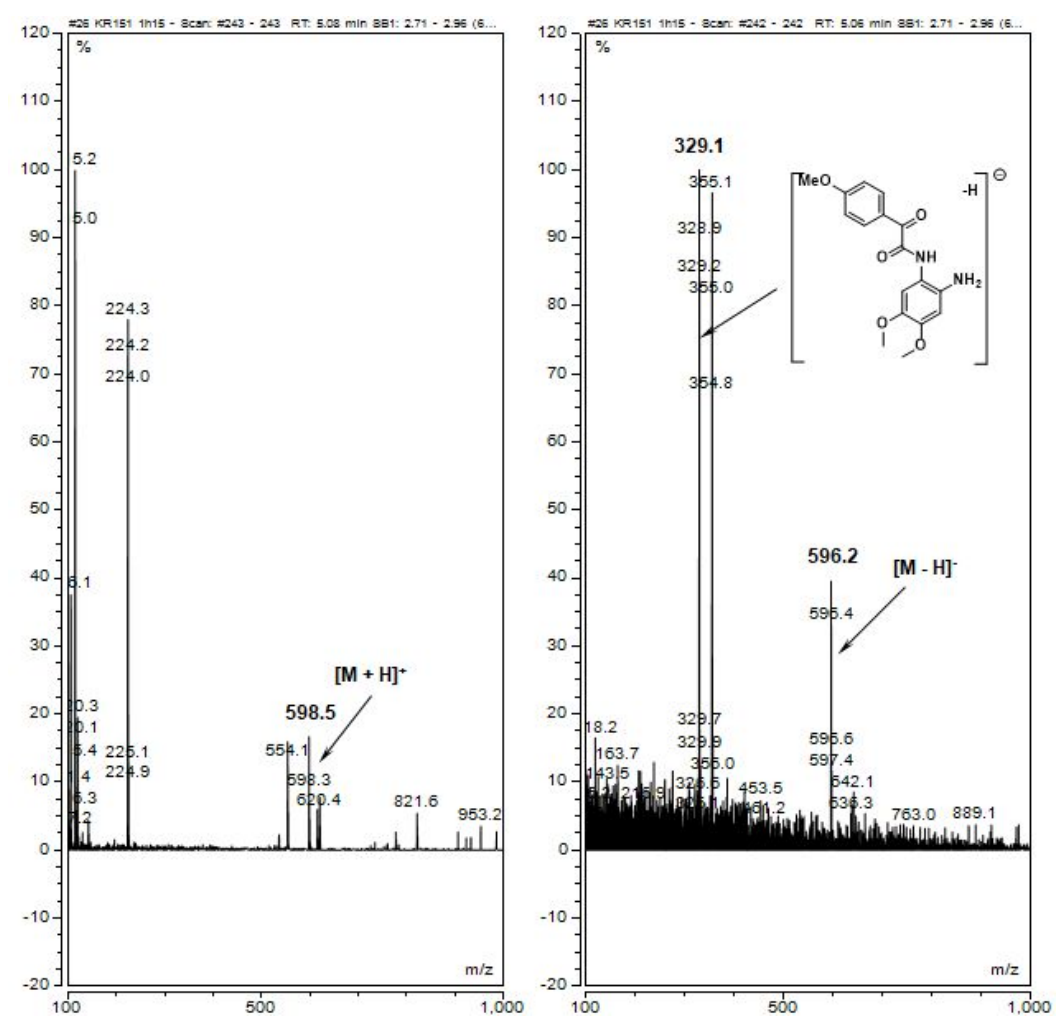

Fig. S90 - RP-HPLC elution profile of probe 14 (system A, detection at 260 nm)

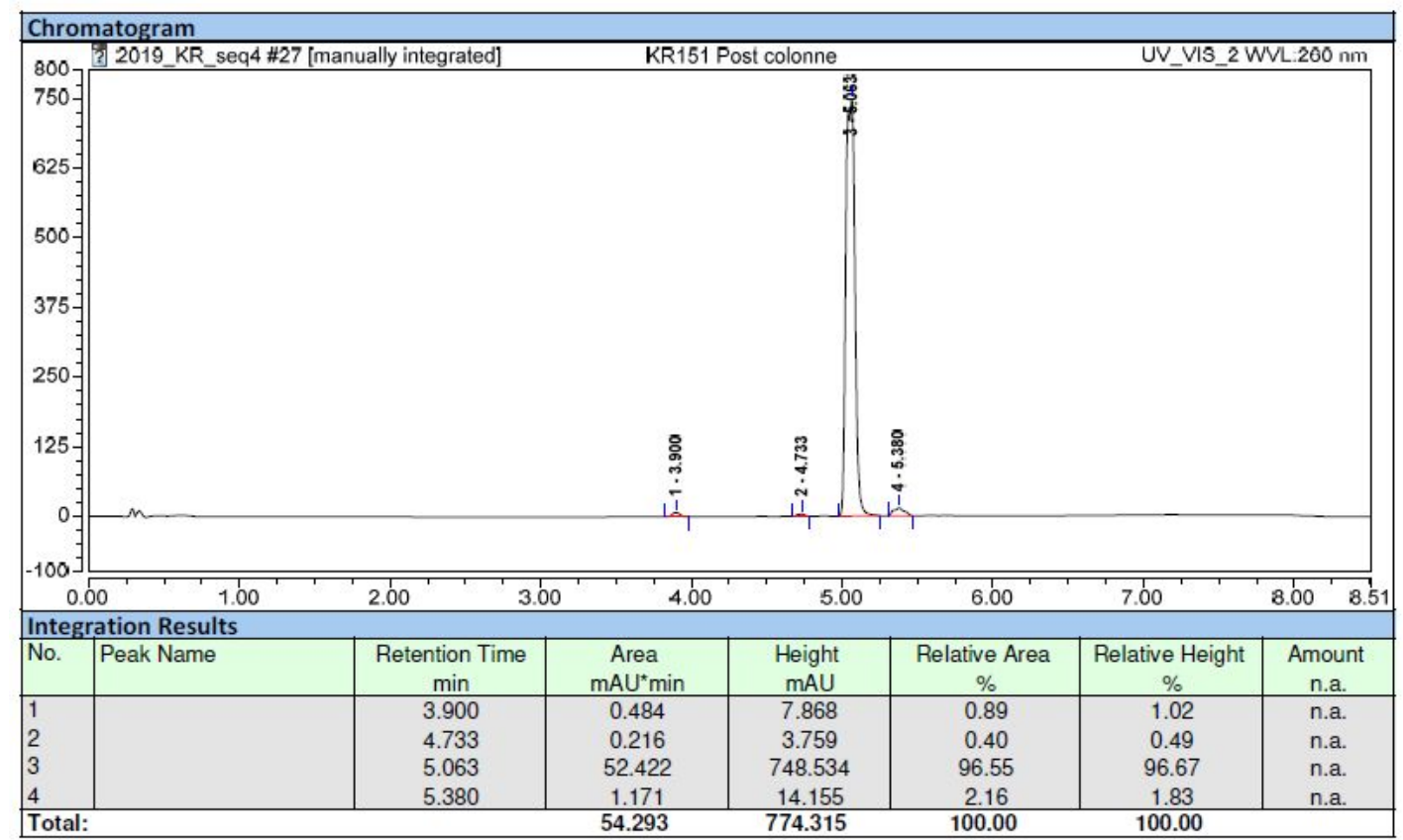


Fig. S91 - IR-ATR spectrum of probe 14

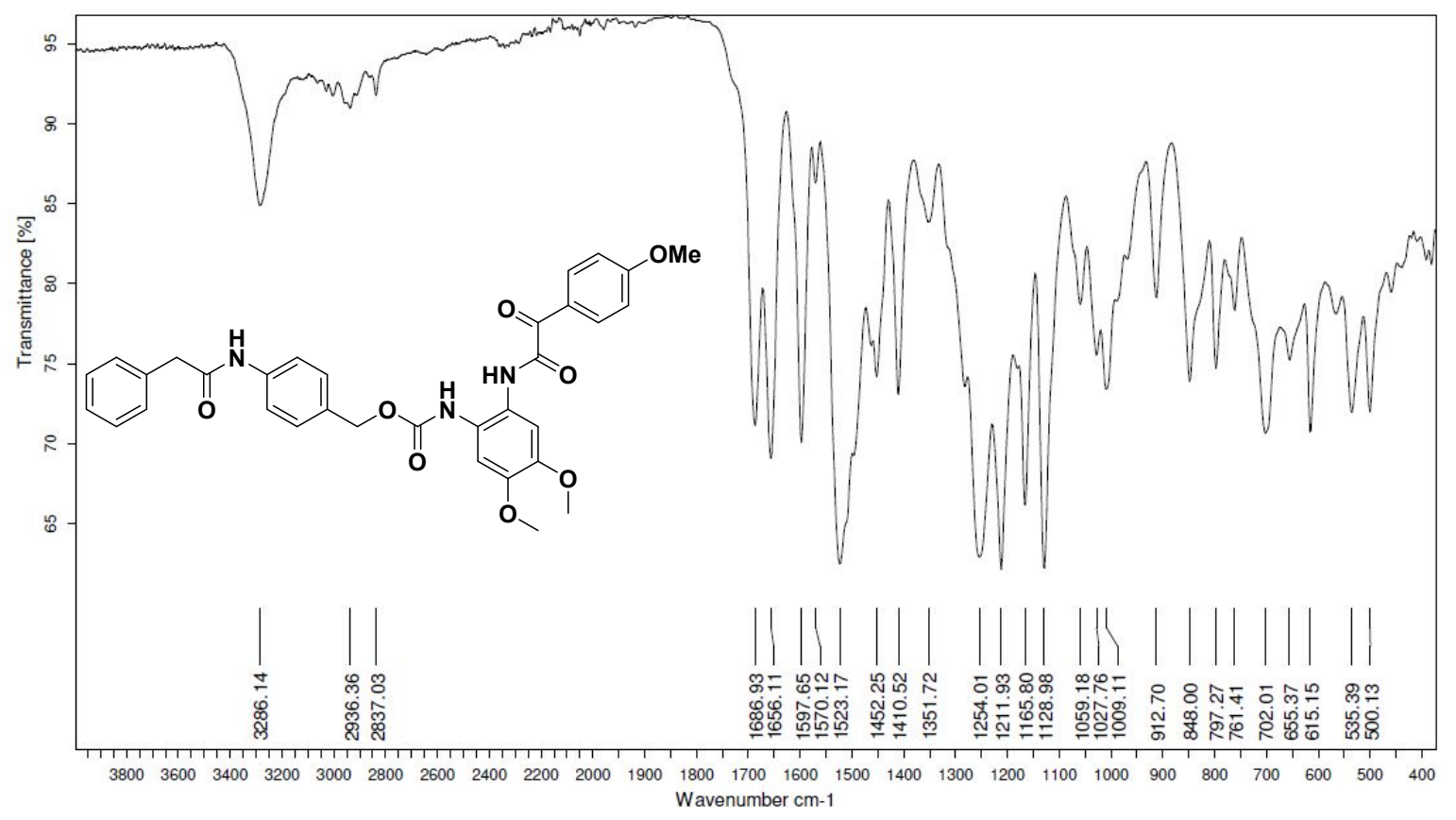

Fig. S92 - ${ }^{1} \mathrm{H}$ NMR spectrum of probe 14 in DMSO-d D $_{6}(500 \mathrm{MHz})$

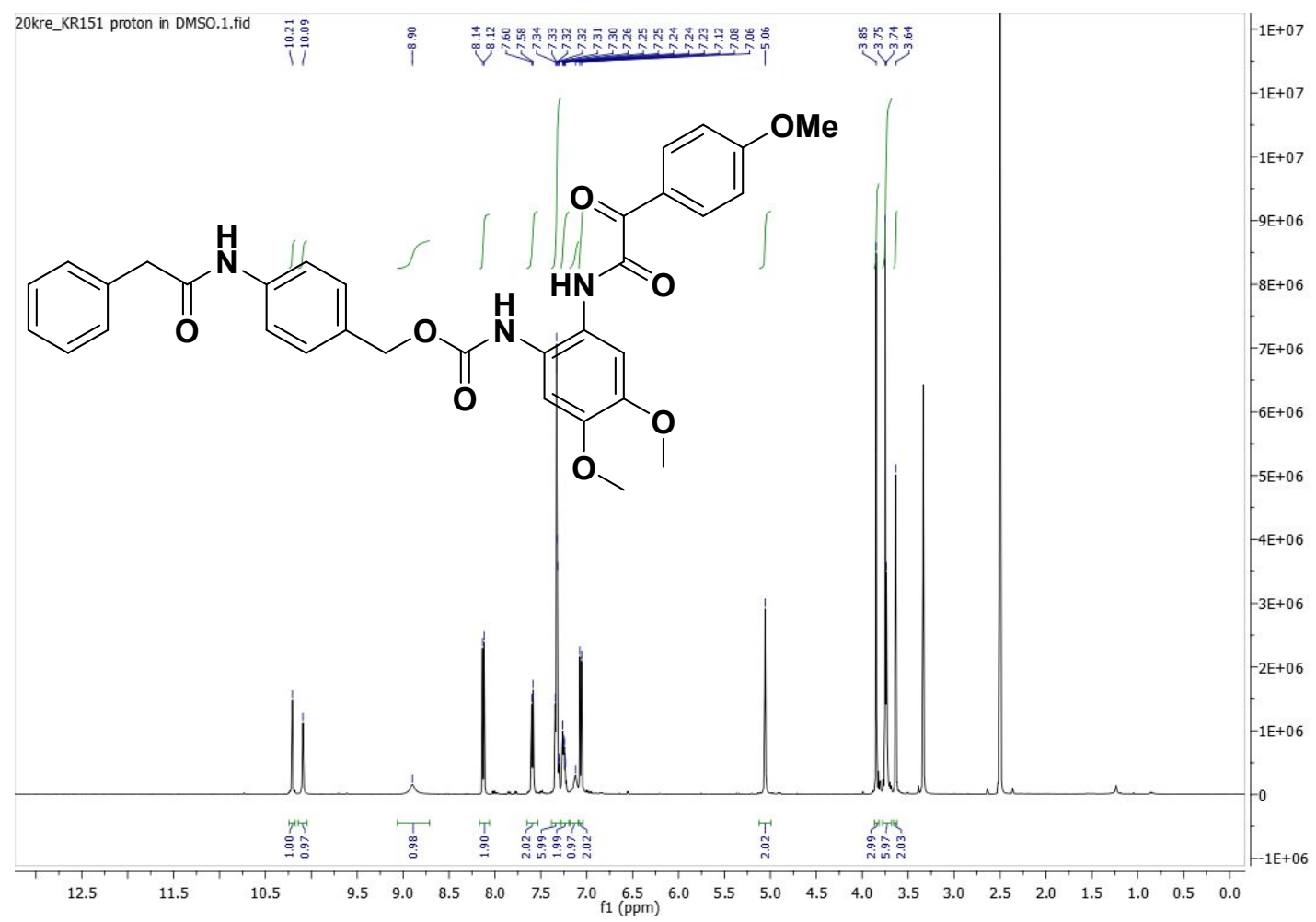


Fig. S93 - ${ }^{13}$ C NMR spectrum of probe 14 in DMSO- $d_{6}(126 \mathrm{MHz})$

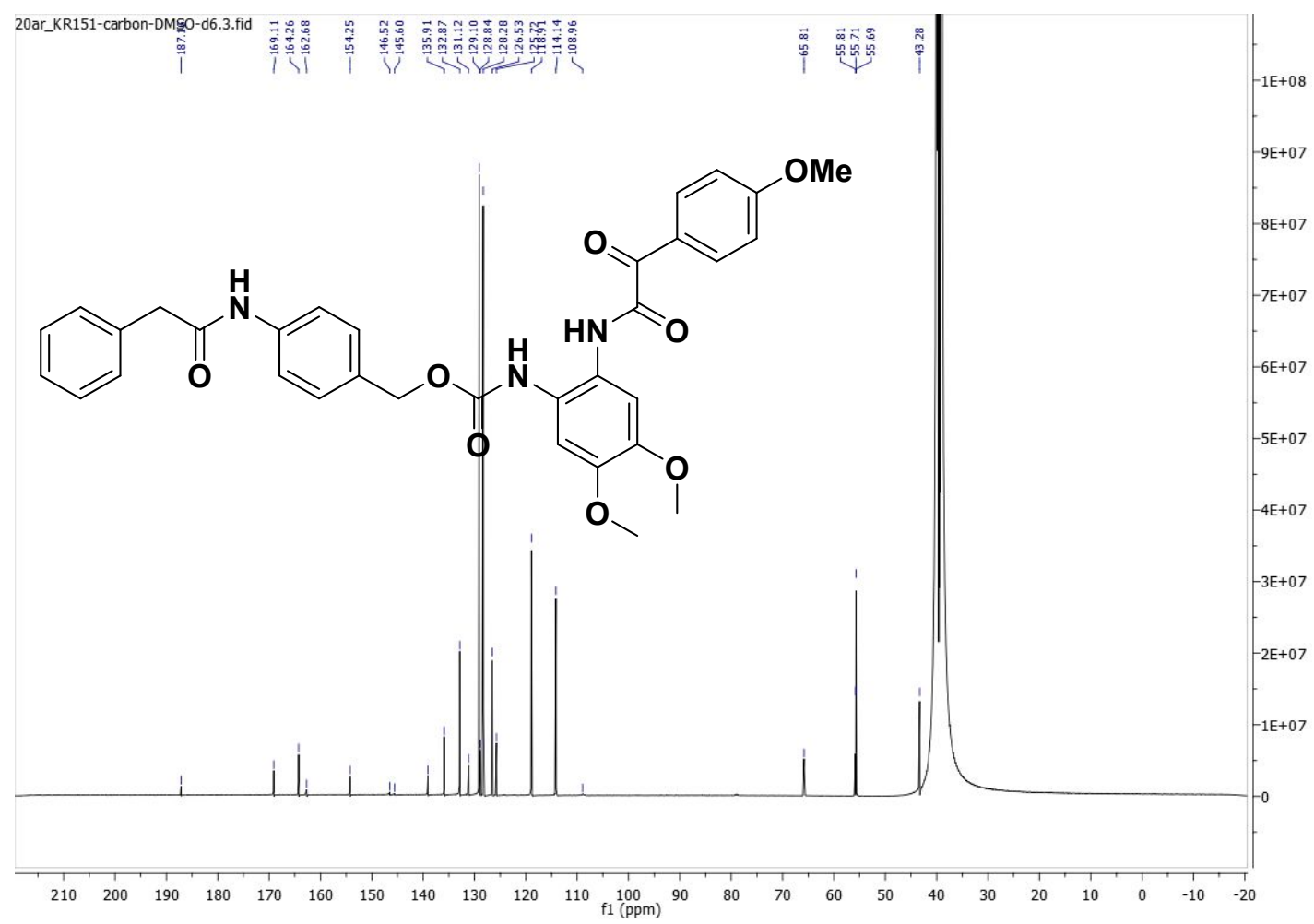

Fig. S94 - ESI+ mass spectrum (high resolution) of probe 15

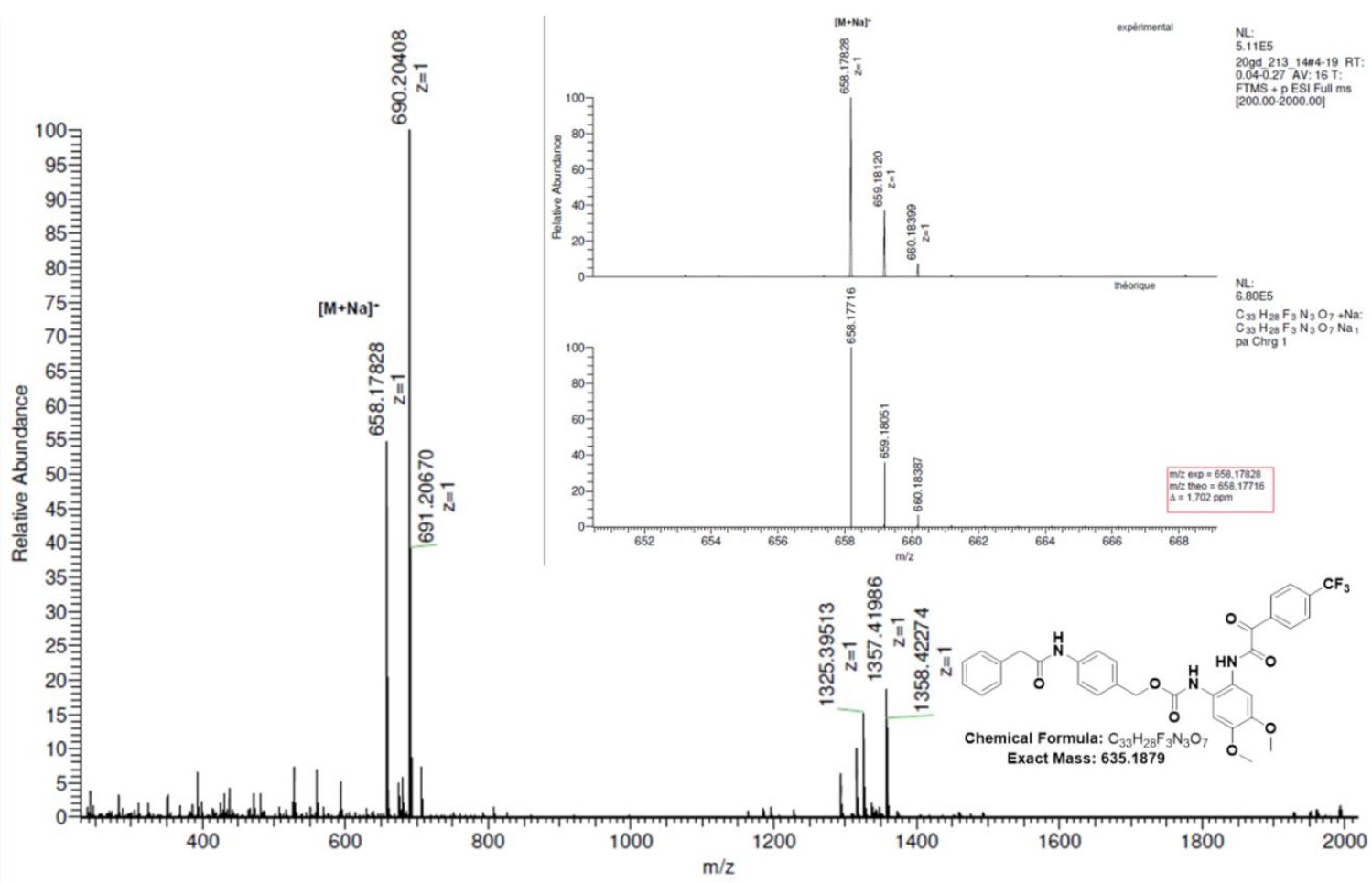


Fig. S95 - ESI+ (left) / ESI- (right) mass spectra (low resolution) of probe 15

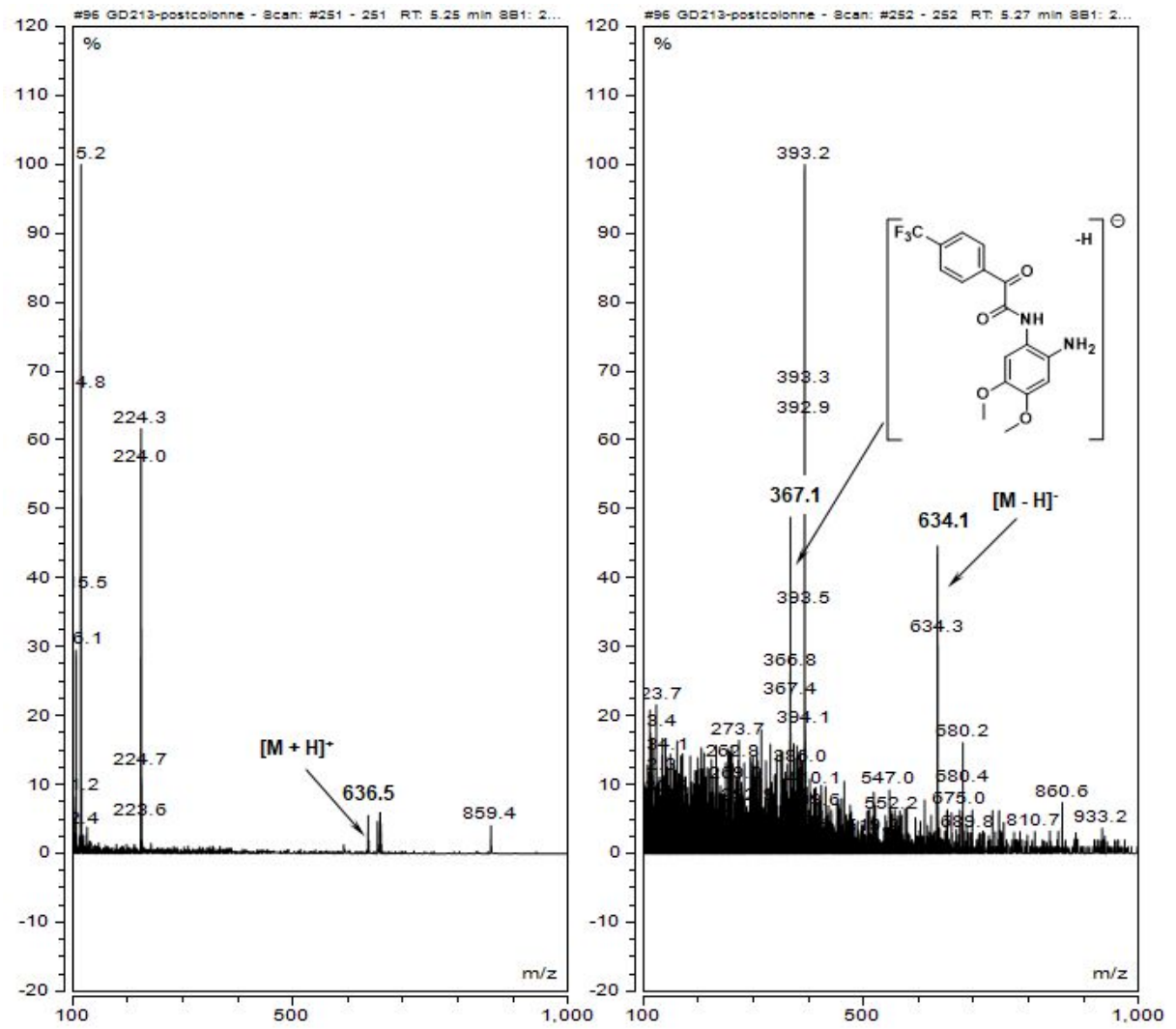

Fig. S96 - RP-HPLC elution profile of probe 15 (system A, detection at $260 \mathrm{~nm}$ )

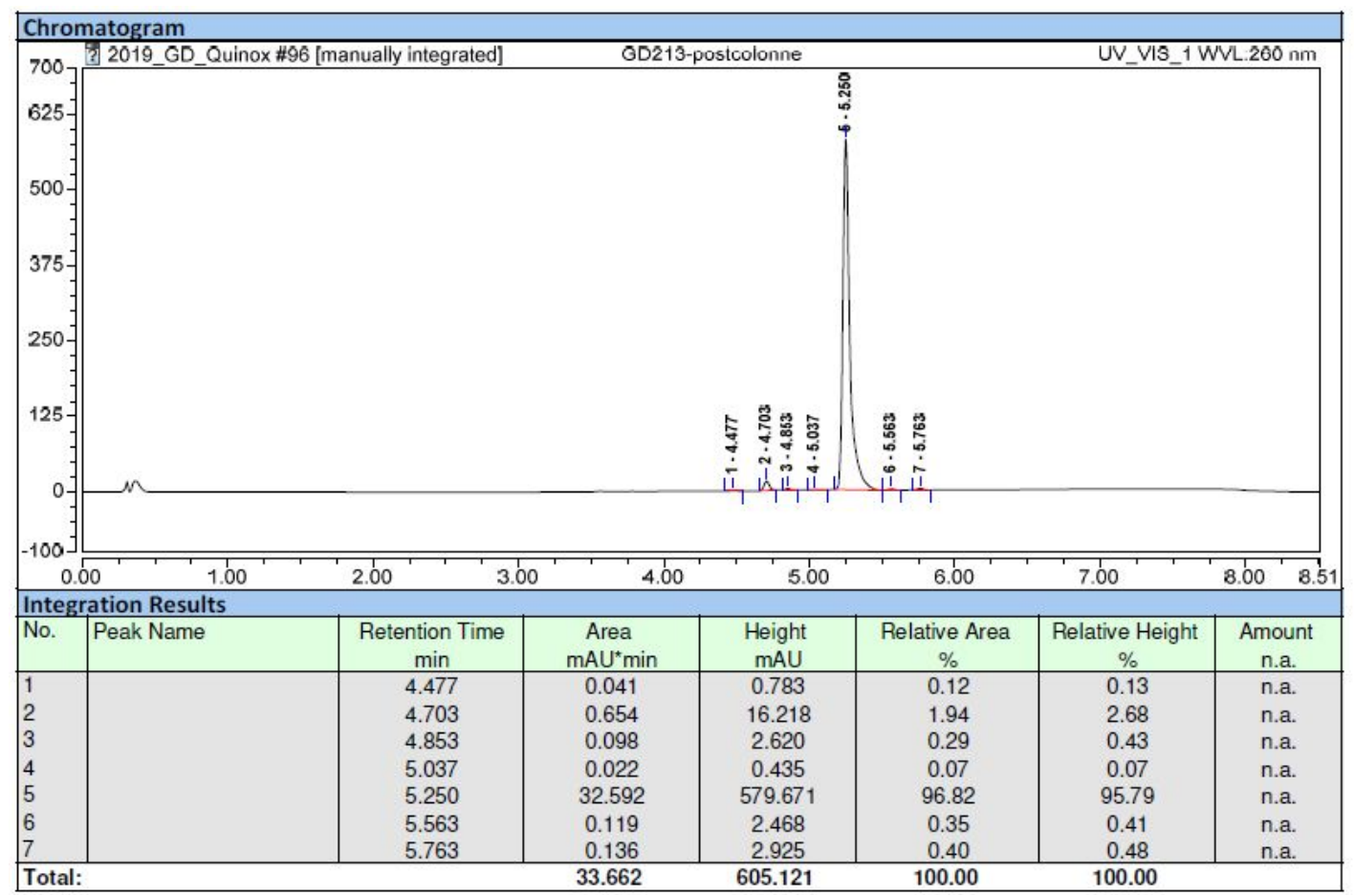


Fig. S97 - IR-ATR spectrum of probe 15

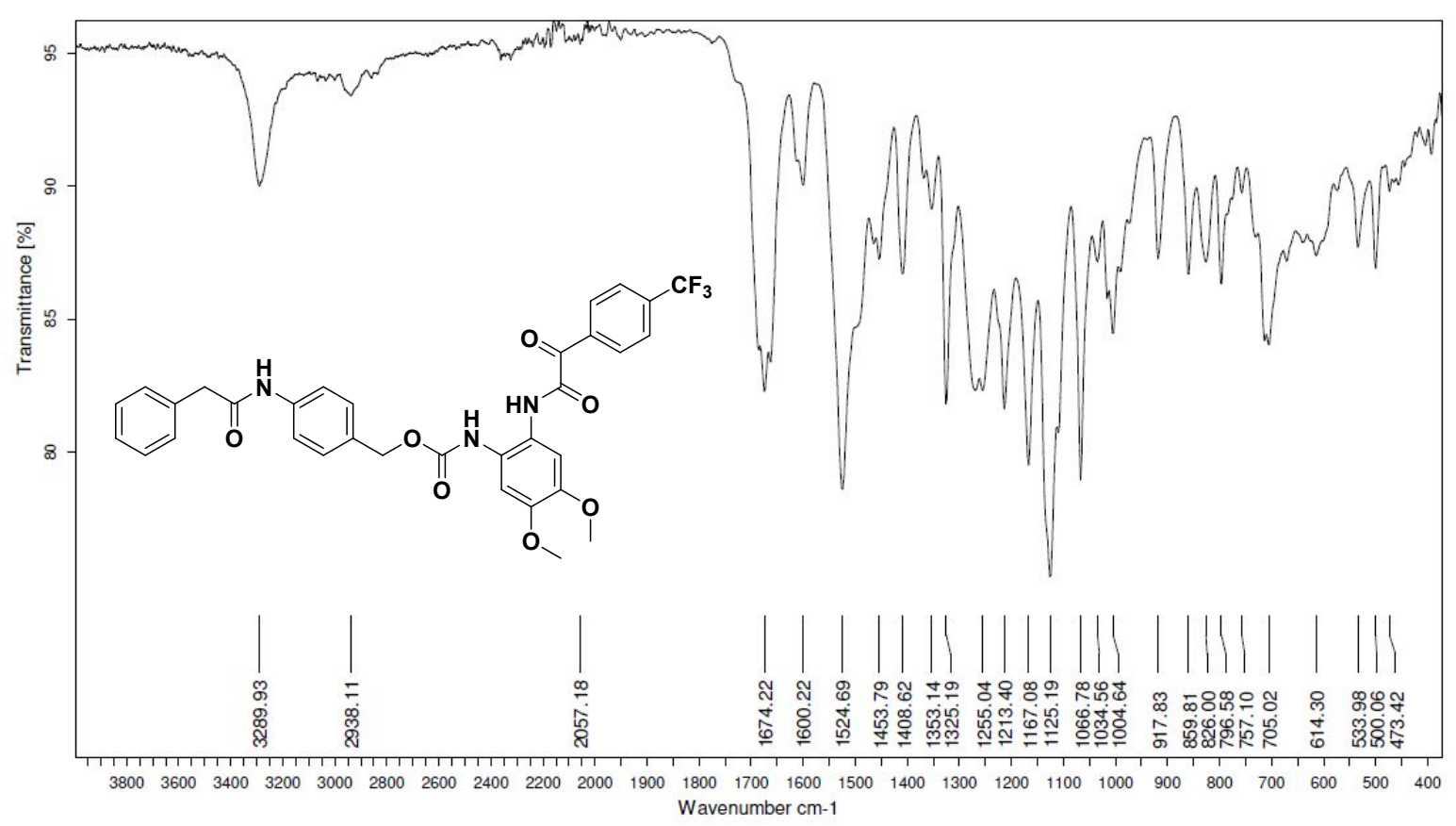

Fig. S98 - ${ }^{1} \mathrm{H}$ NMR spectrum of probe 15 in $\mathrm{CDCl}_{3}(400 \mathrm{MHz})$

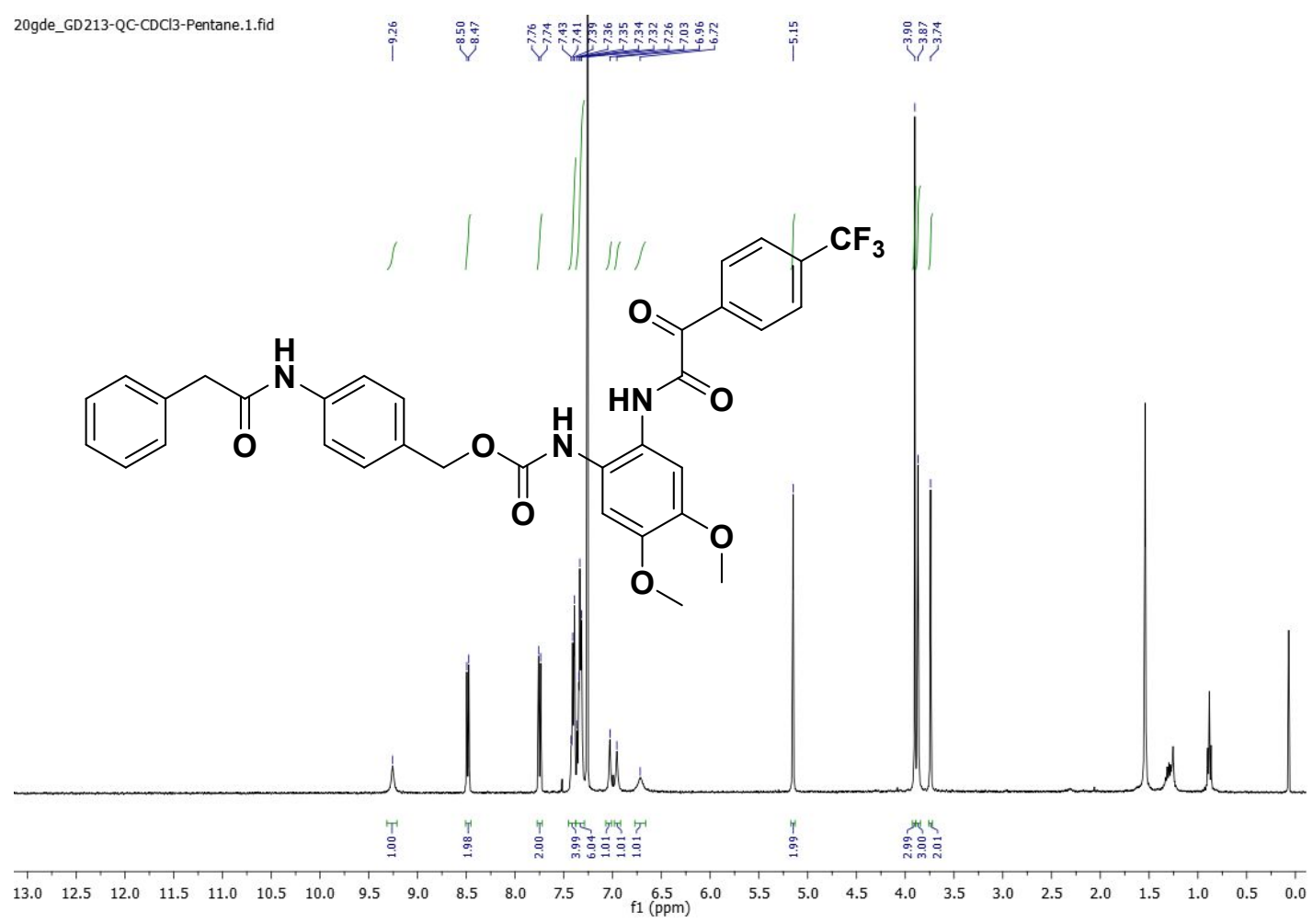


Fig. S99 - ${ }^{13} \mathrm{C}$ NMR spectrum of probe 15 in $\mathrm{CDCl}_{3}(126 \mathrm{MHz})$

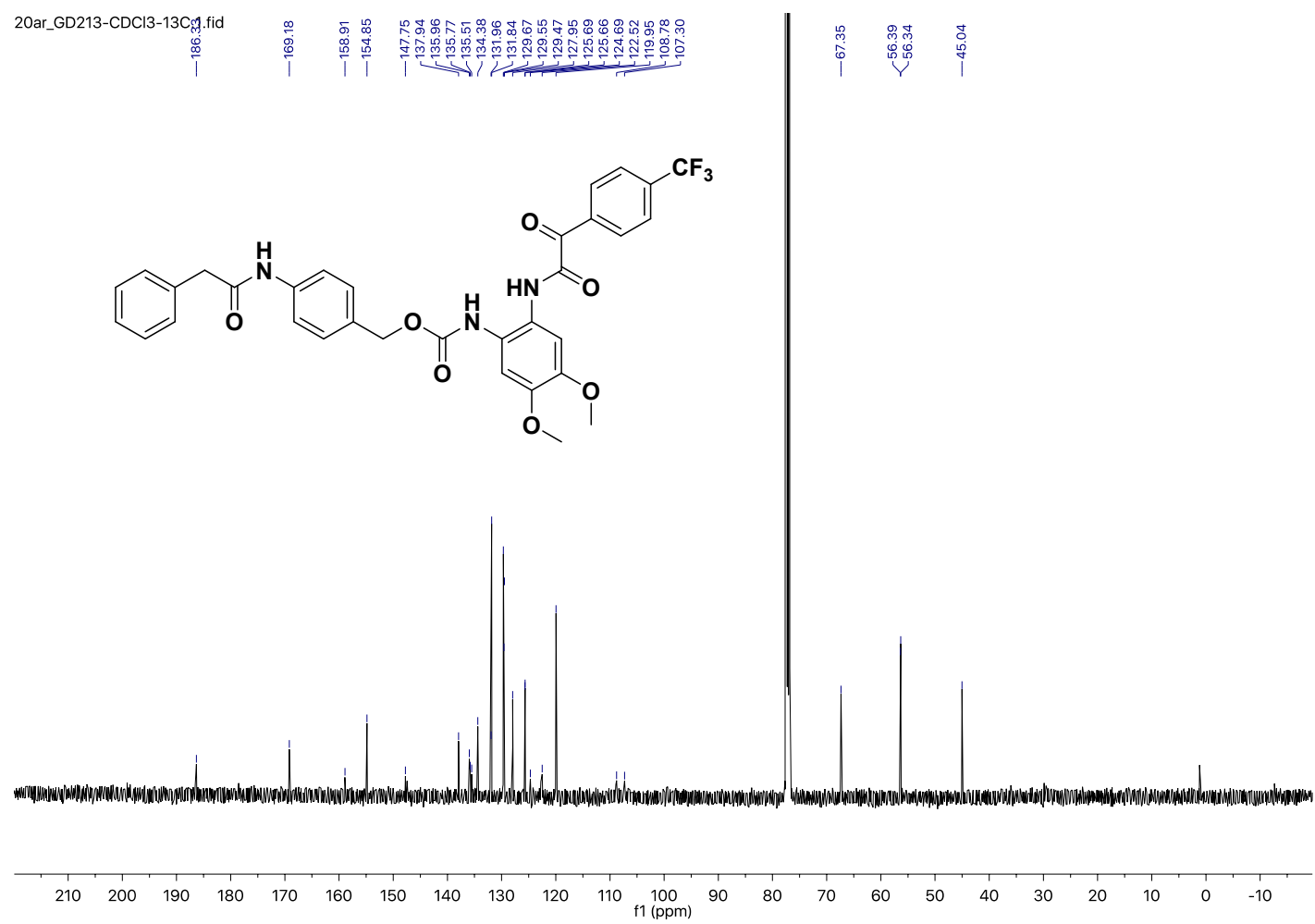

Fig. S100 - ${ }^{19} \mathrm{~F}$ NMR spectrum of probe 15 in $\mathrm{CDCl}_{3}(470 \mathrm{MHz})$

20gde_GD213-QC-CDC13.5.fid

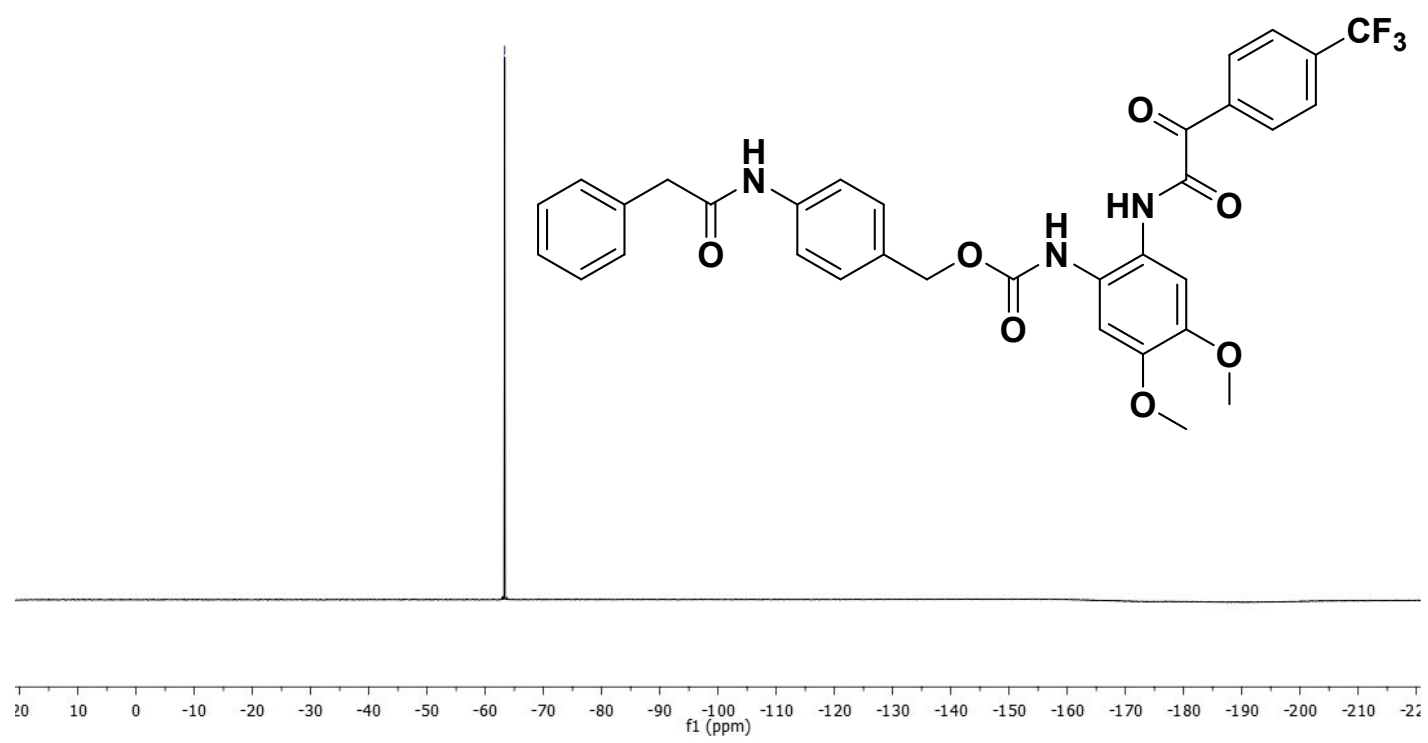


Fig. S101 - ESI+ mass spectrum (high resolution) of probe 16

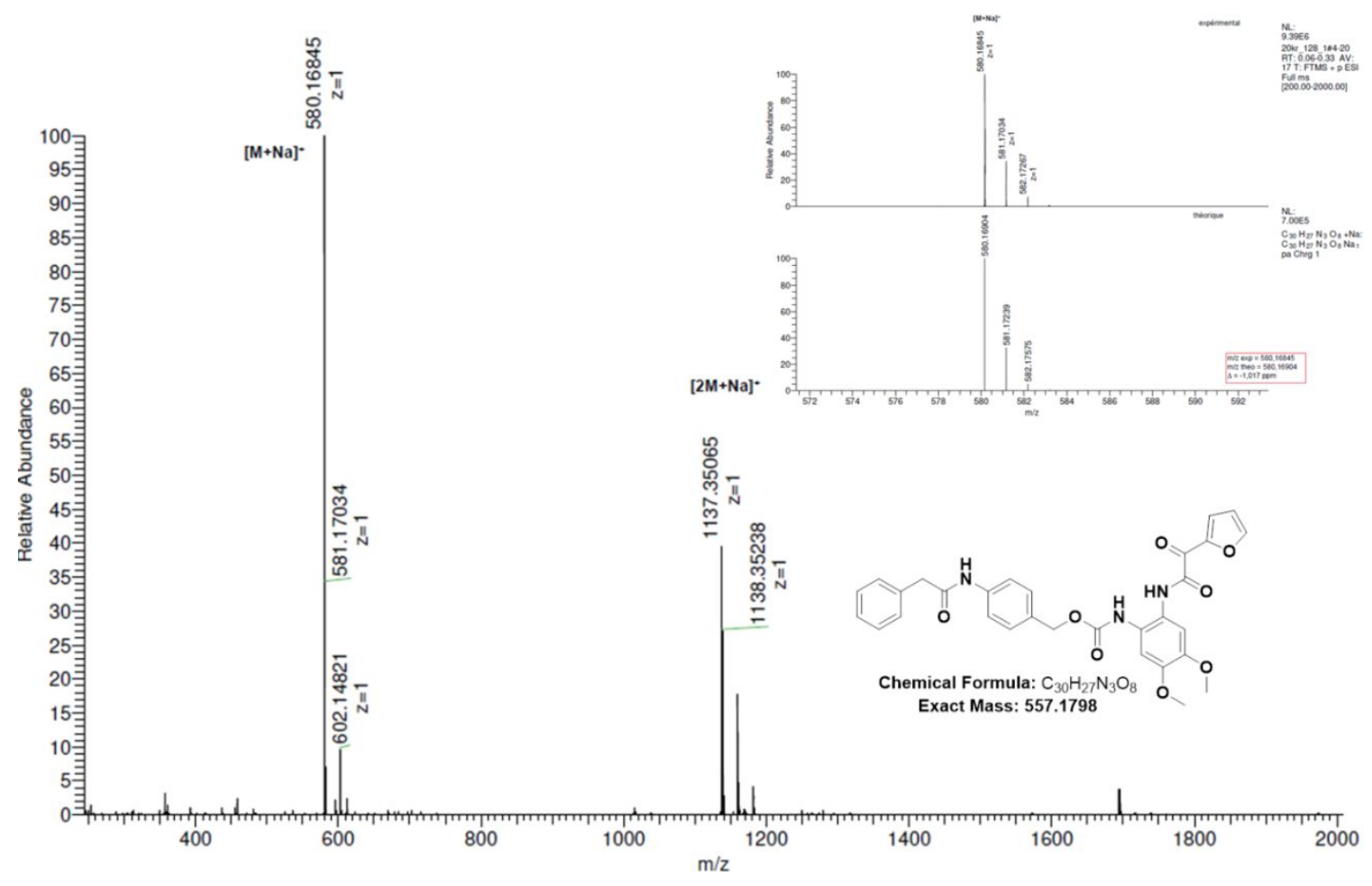

Fig. S102 - ESI+ (left) / ESI- (right) mass spectra (low resolution) of probe 16
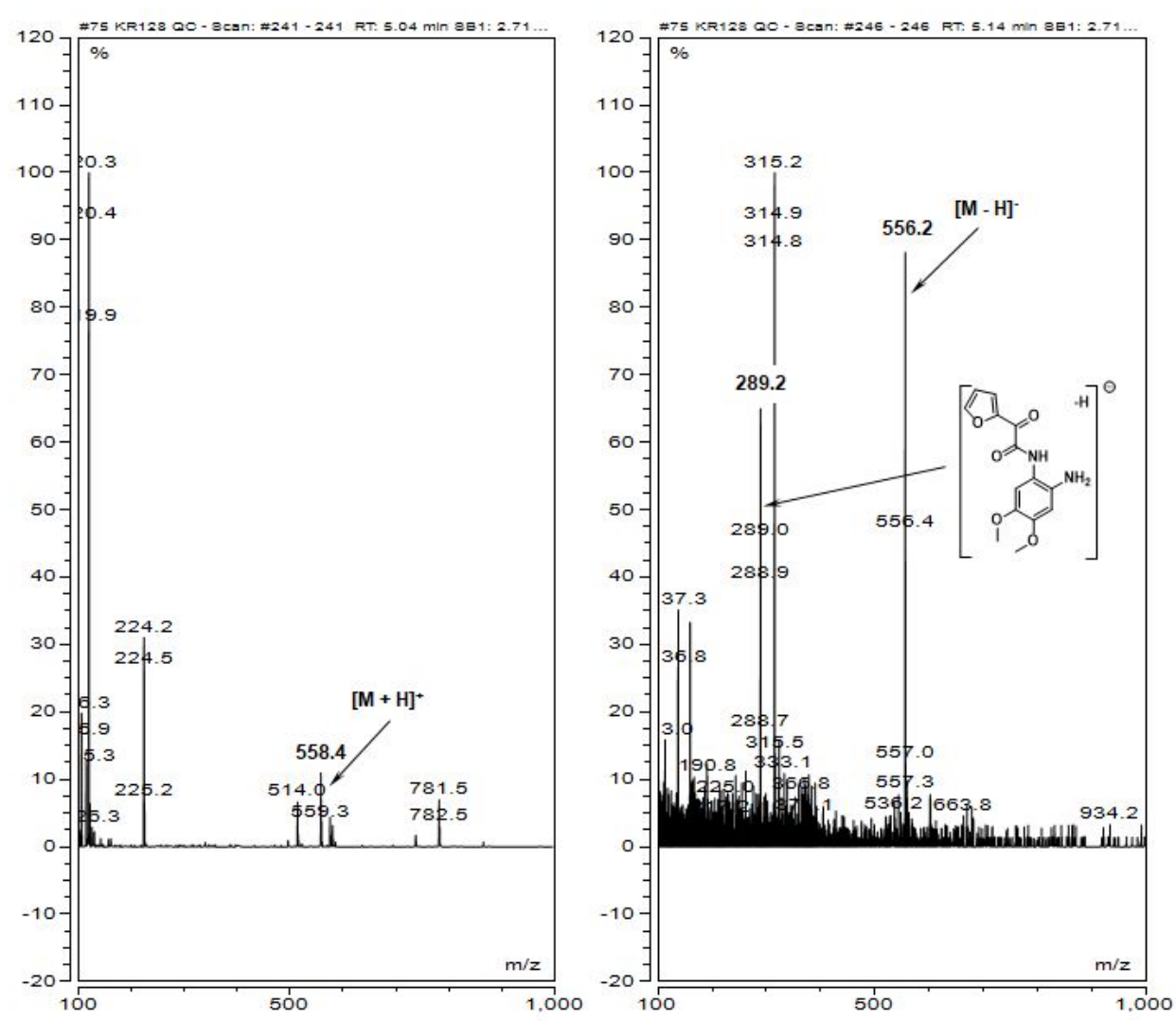
Fig. S103 - RP-HPLC elution profile of probe 16 (system A, detection at 260 nm)

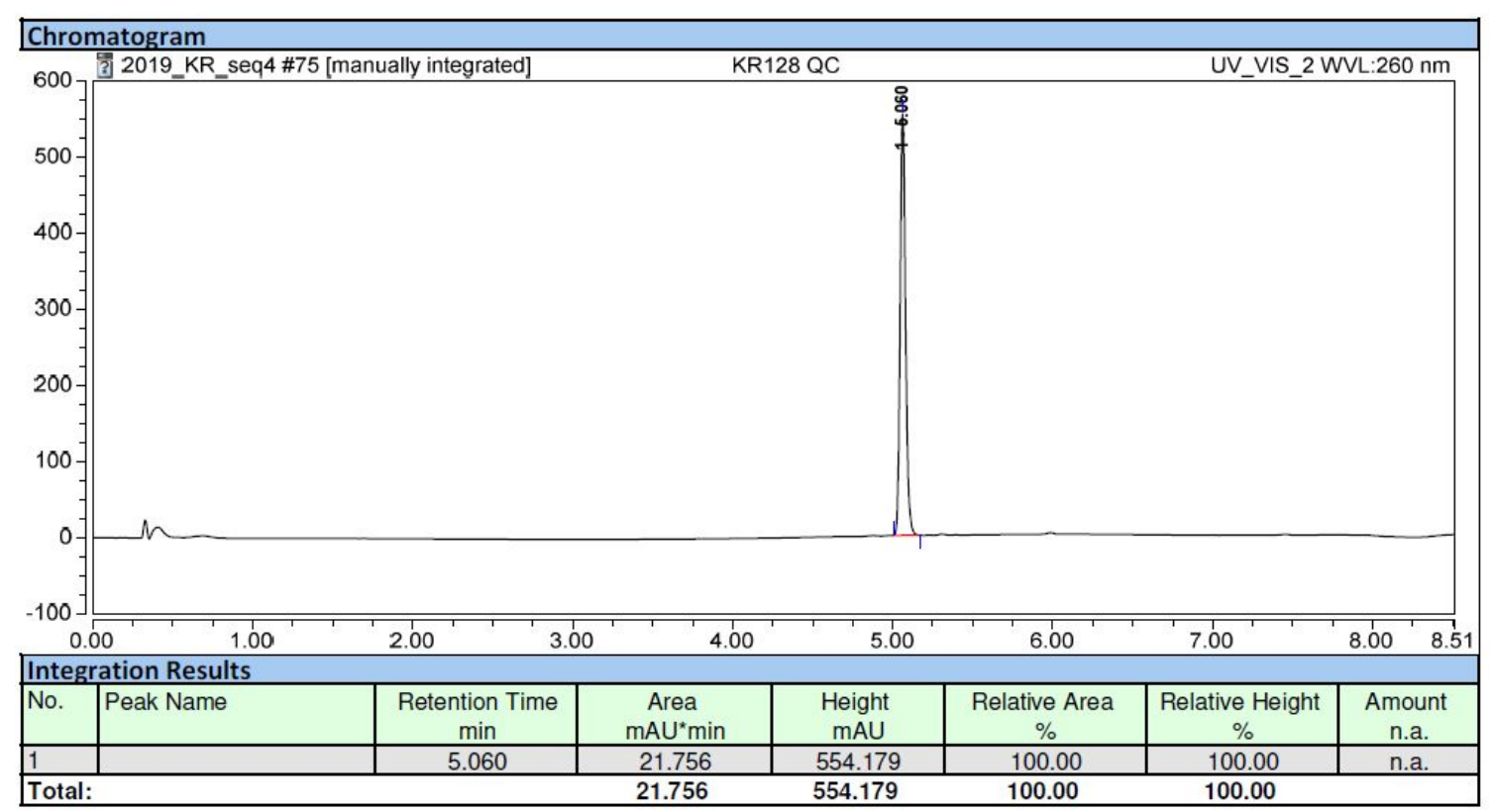

Fig. S104 - IR-ATR spectrum of probe 16

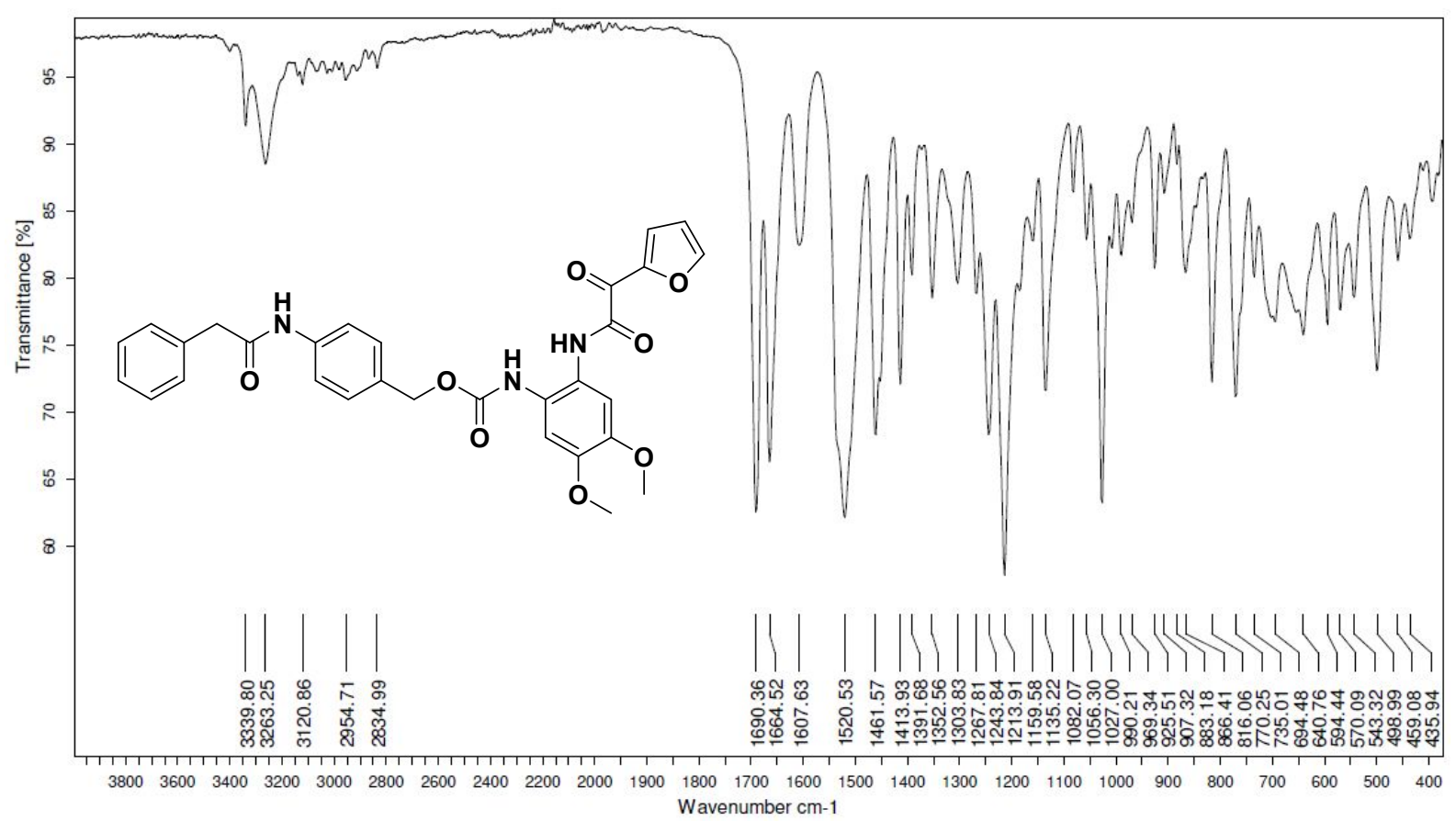


Fig. S105 - ${ }^{1} \mathrm{H}$ NMR spectrum of probe 16 in DMSO- $d_{6}(600 \mathrm{MHz})$

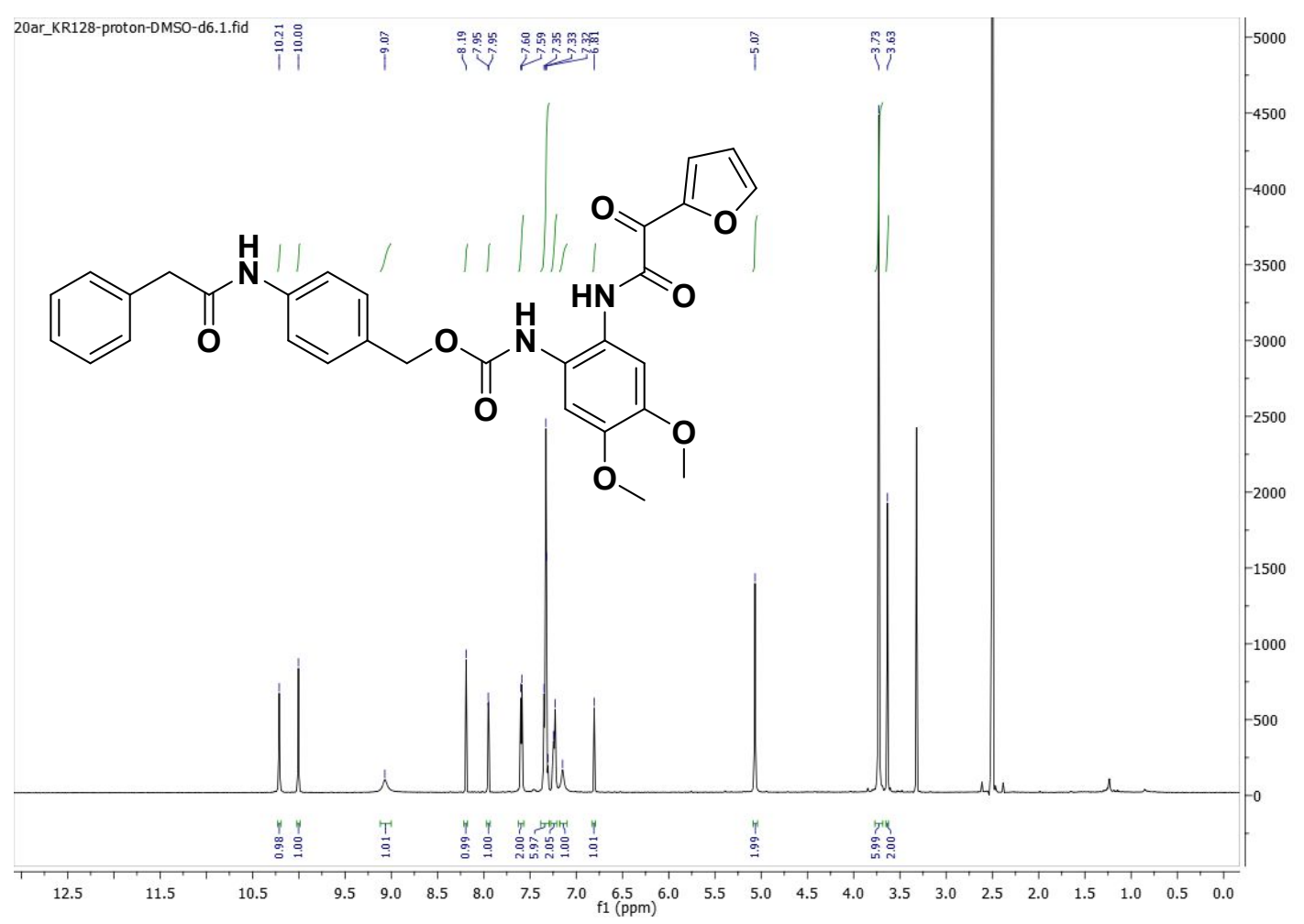

Fig. S106 $-{ }^{13} \mathrm{C}$ NMR spectrum of probe 16 in DMSO- $d_{6}(151 \mathrm{MHz})$

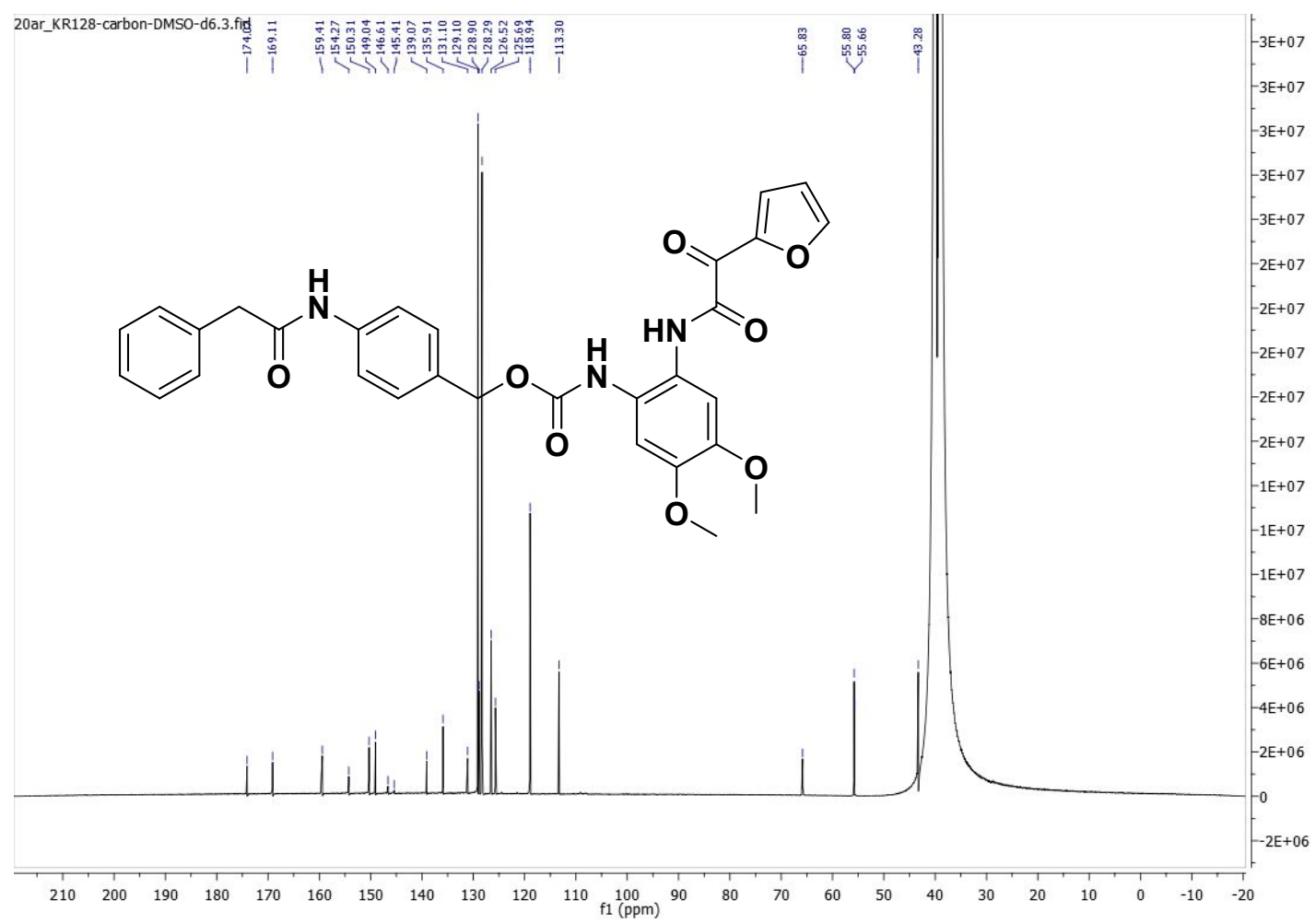


Fig. S107 - ESI+ mass spectrum (high resolution) of probe 17

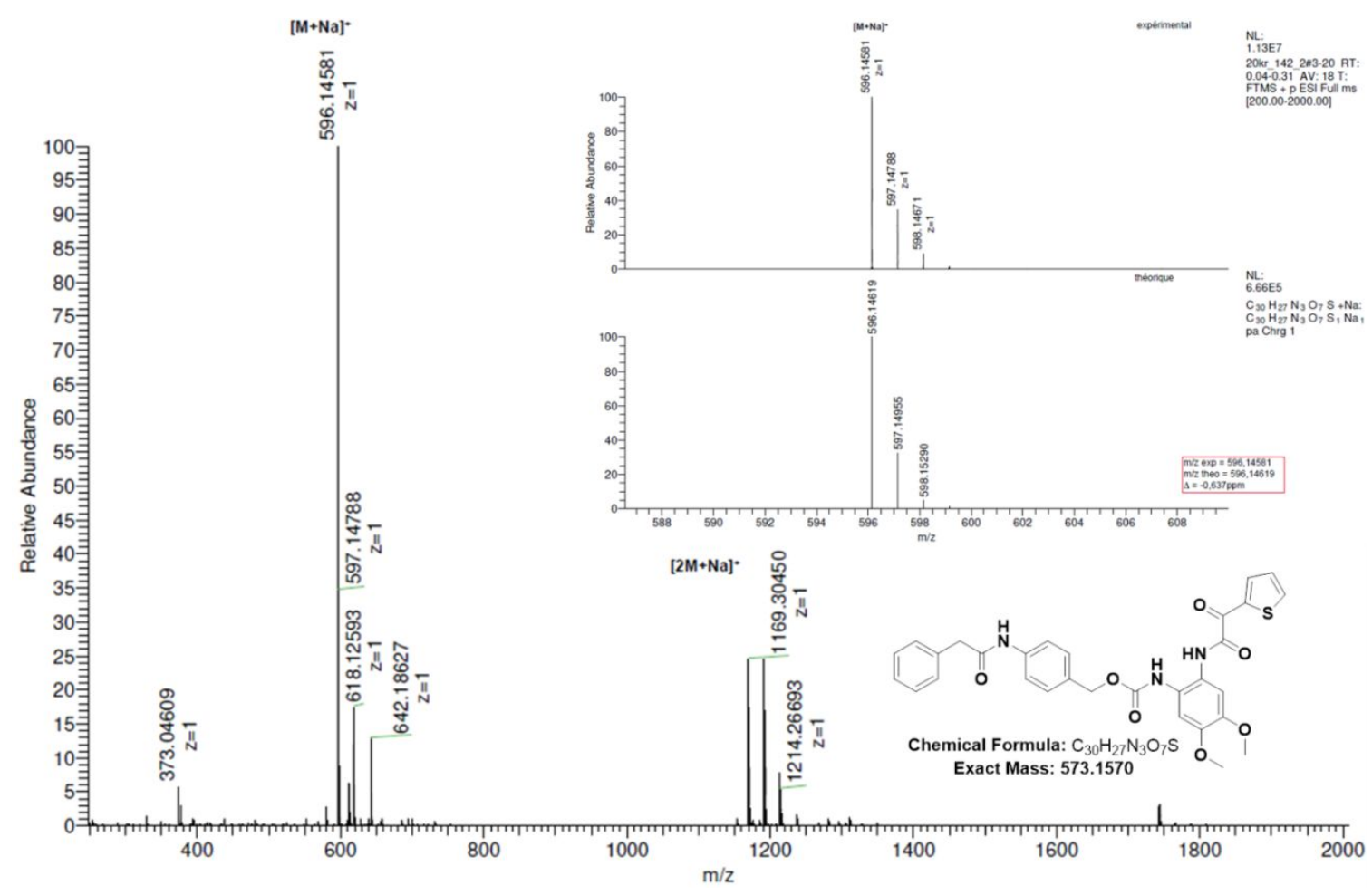

Fig. S108 - ESI- mass spectrum (low resolution) of probe 17

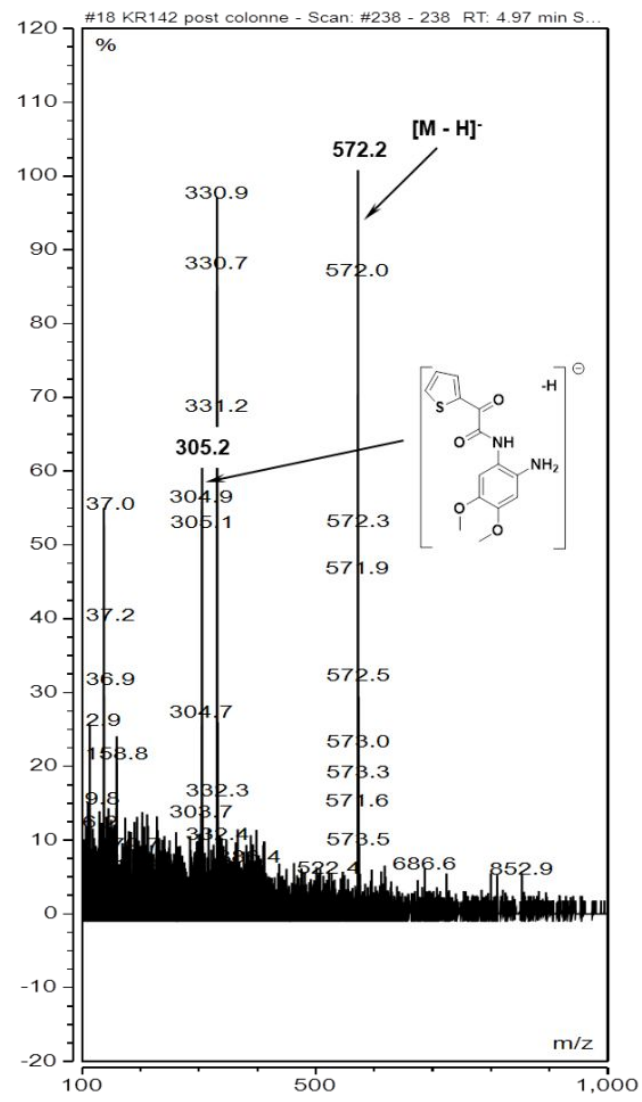


Fig. S109 - RP-HPLC elution profile of probe 17 (system A, detection at 260 nm)

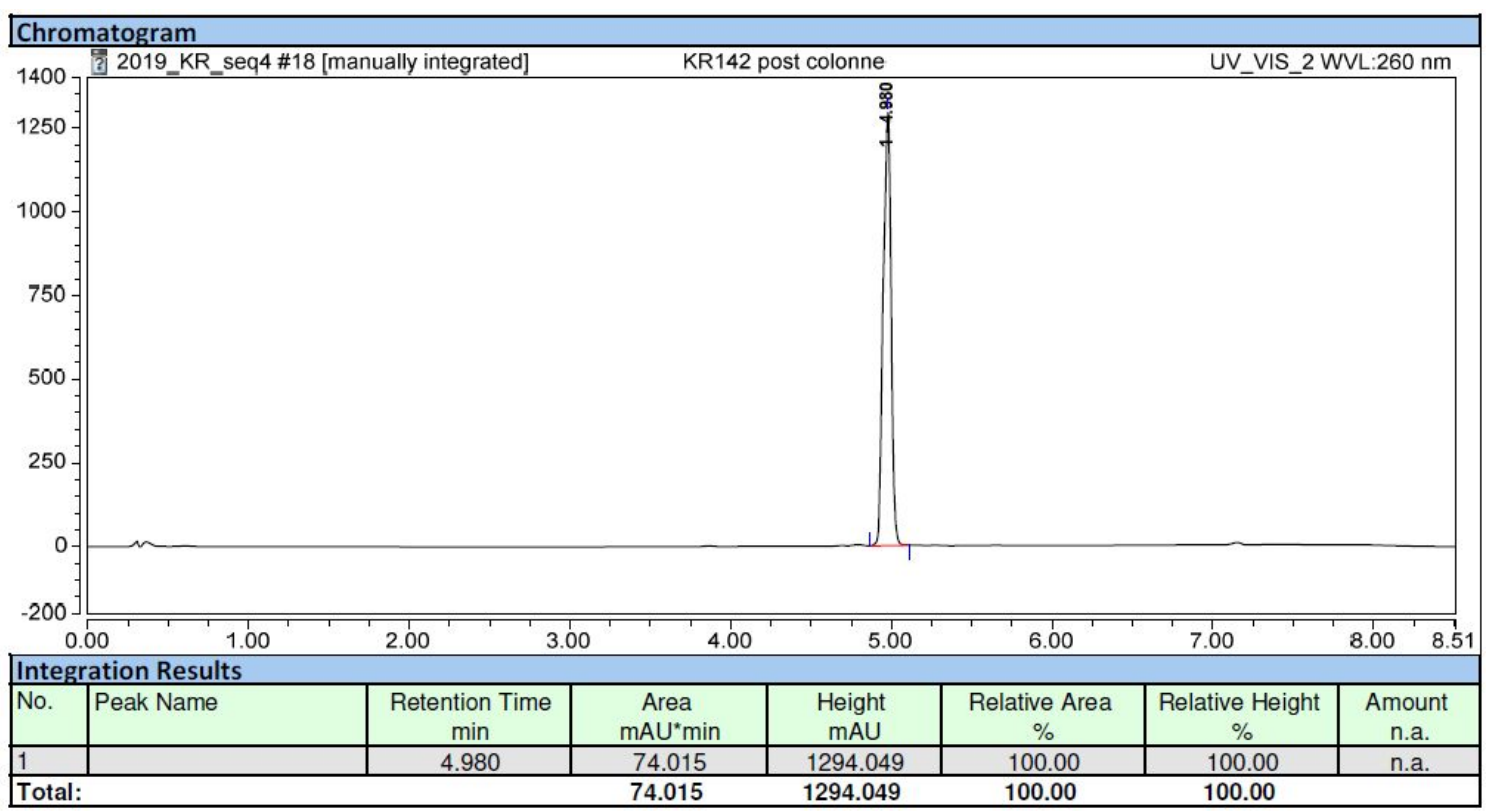

Fig. S110 - IR-ATR spectrum of probe 17

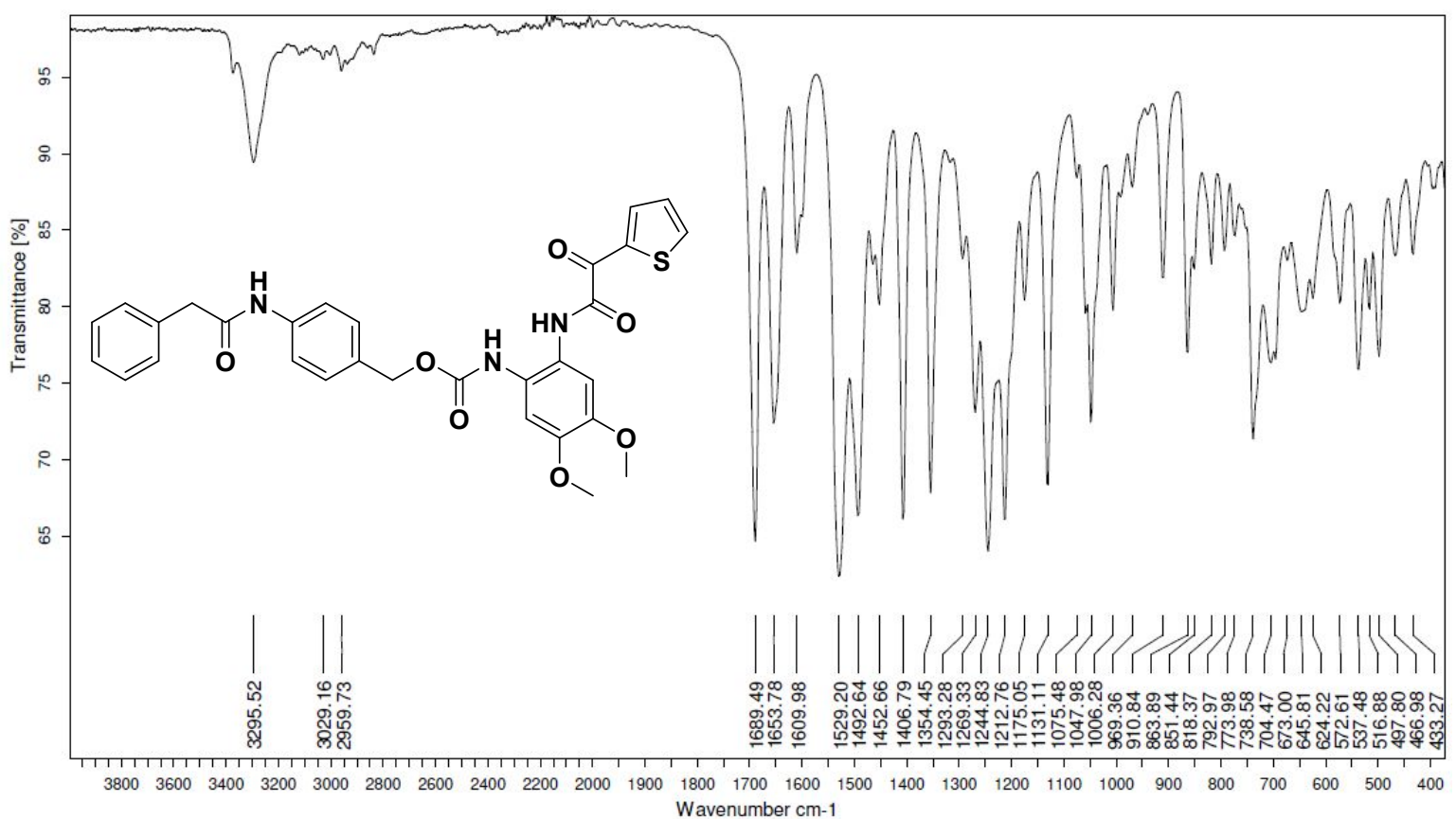


Fig. S111 - ${ }^{1} \mathrm{H}$ NMR spectrum of probe 17 in DMSO- $d_{6}(500 \mathrm{MHz})$

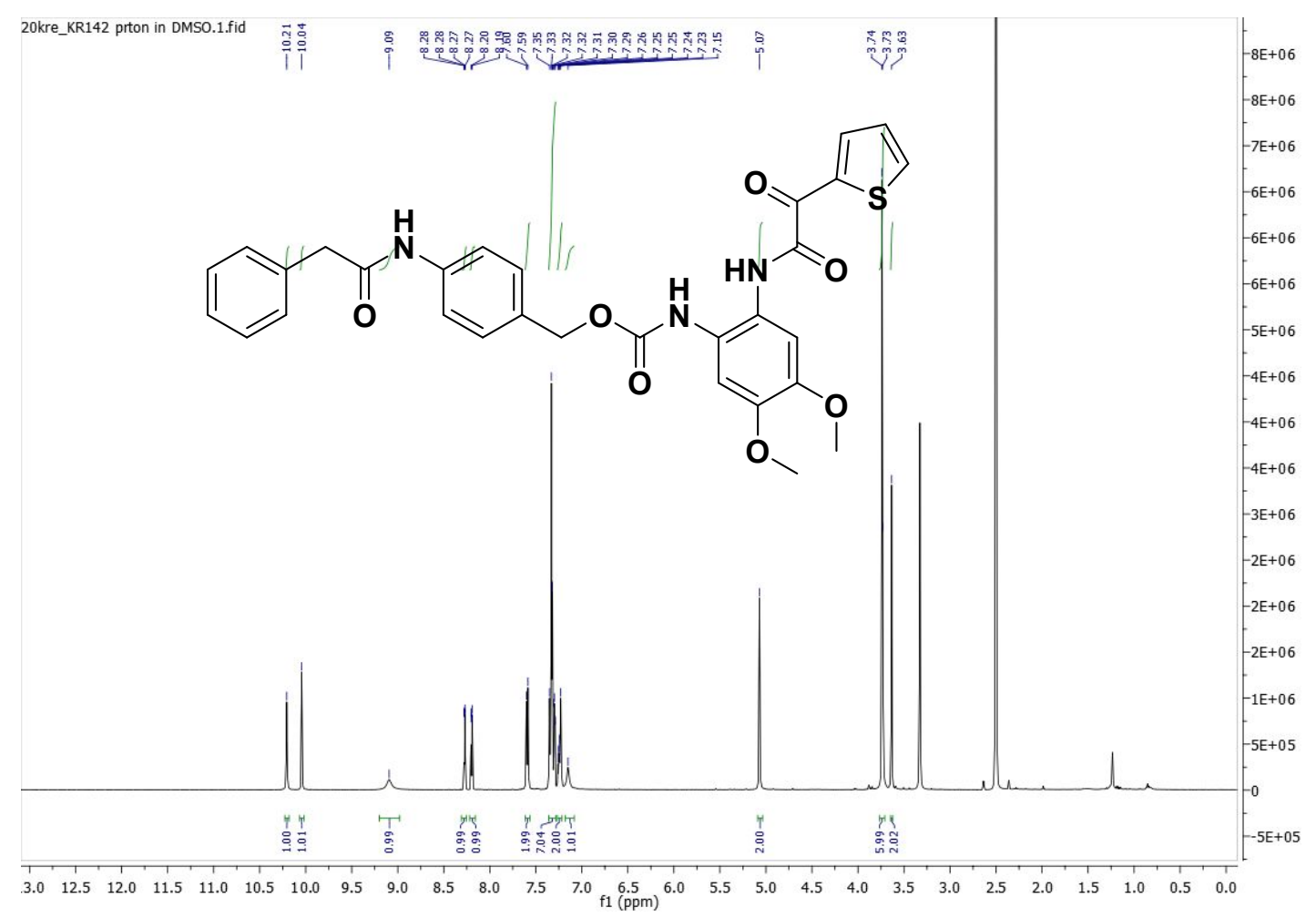

Fig. S112 $-{ }^{13} \mathrm{C}$ NMR spectrum of probes 17 in DMSO- $d_{6}(151 \mathrm{MHz})$

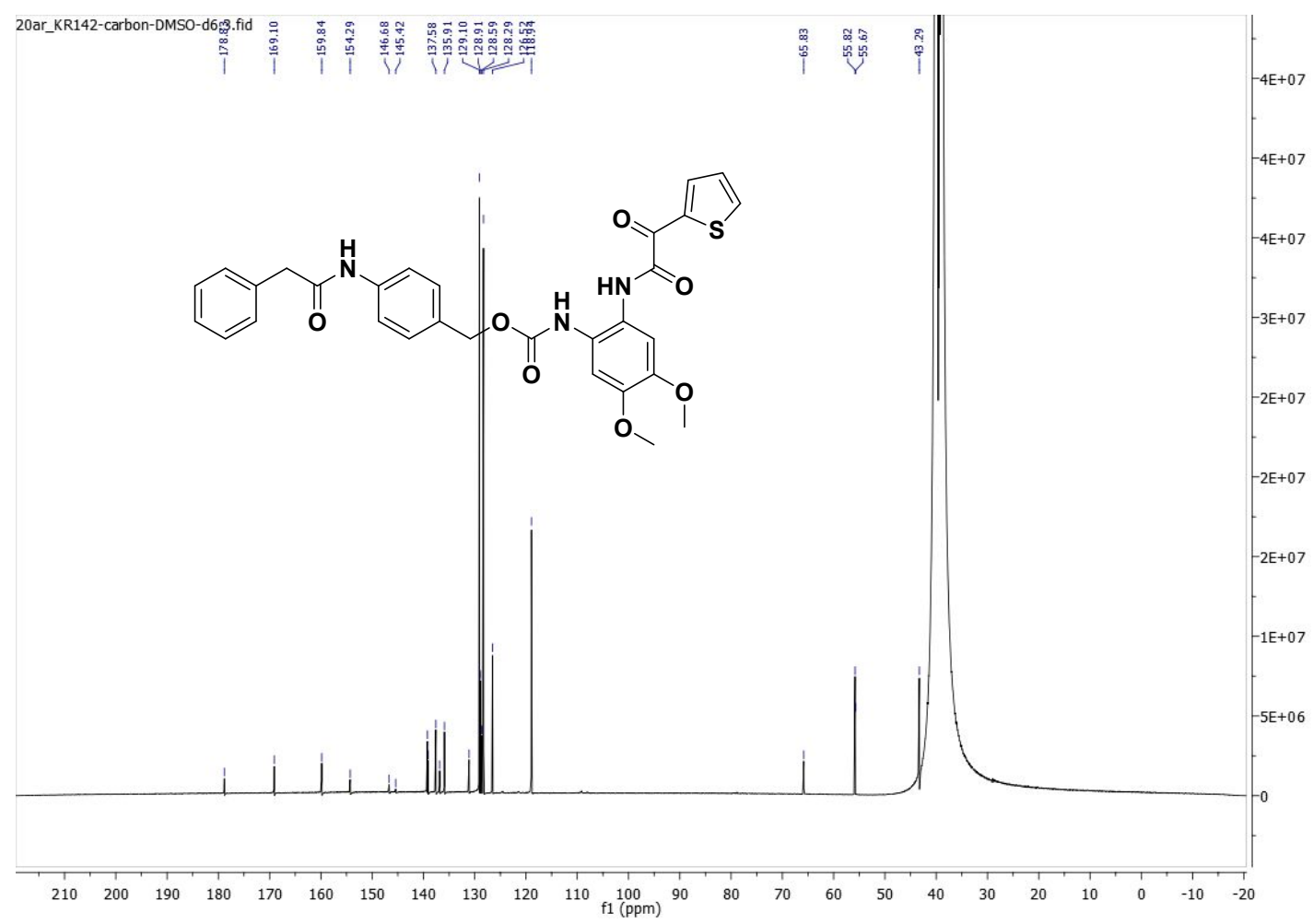


Fig. S113 - ESI+ mass spectrum (high resolution) of probe 18
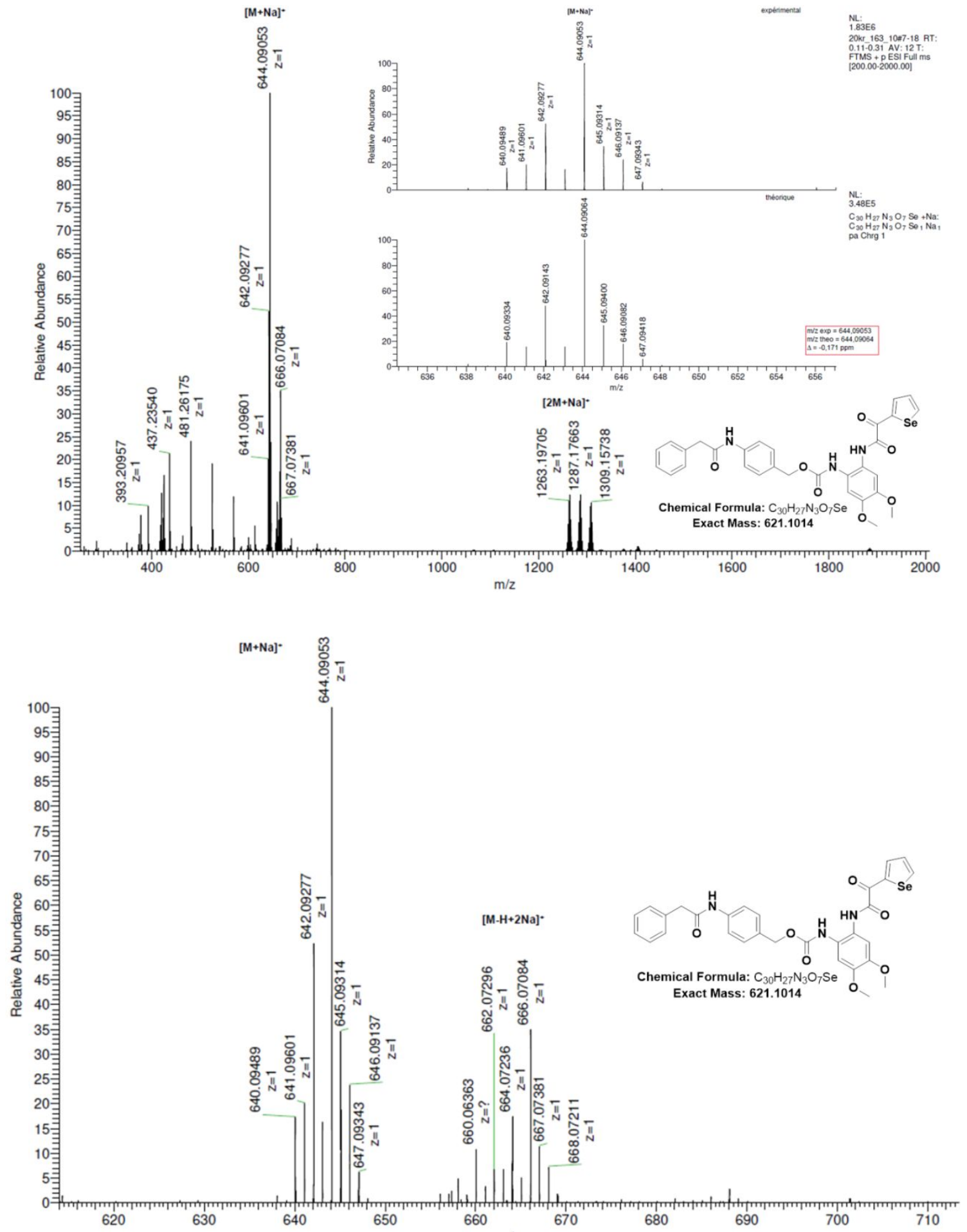
Fig. S114 - ESI+ (left) / ESI- (right) mass spectra (low resolution) of probe 18

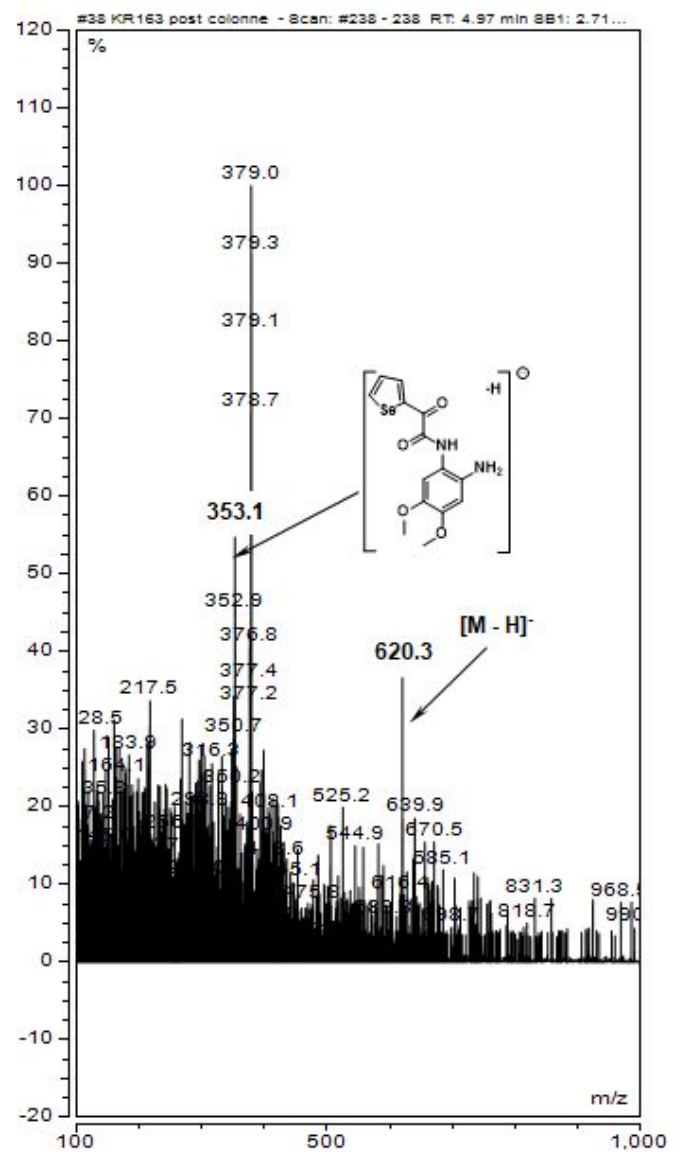

Fig. S115 - RP-HPLC elution profile of probe 18 (system A, detection at $260 \mathrm{~nm}$ )

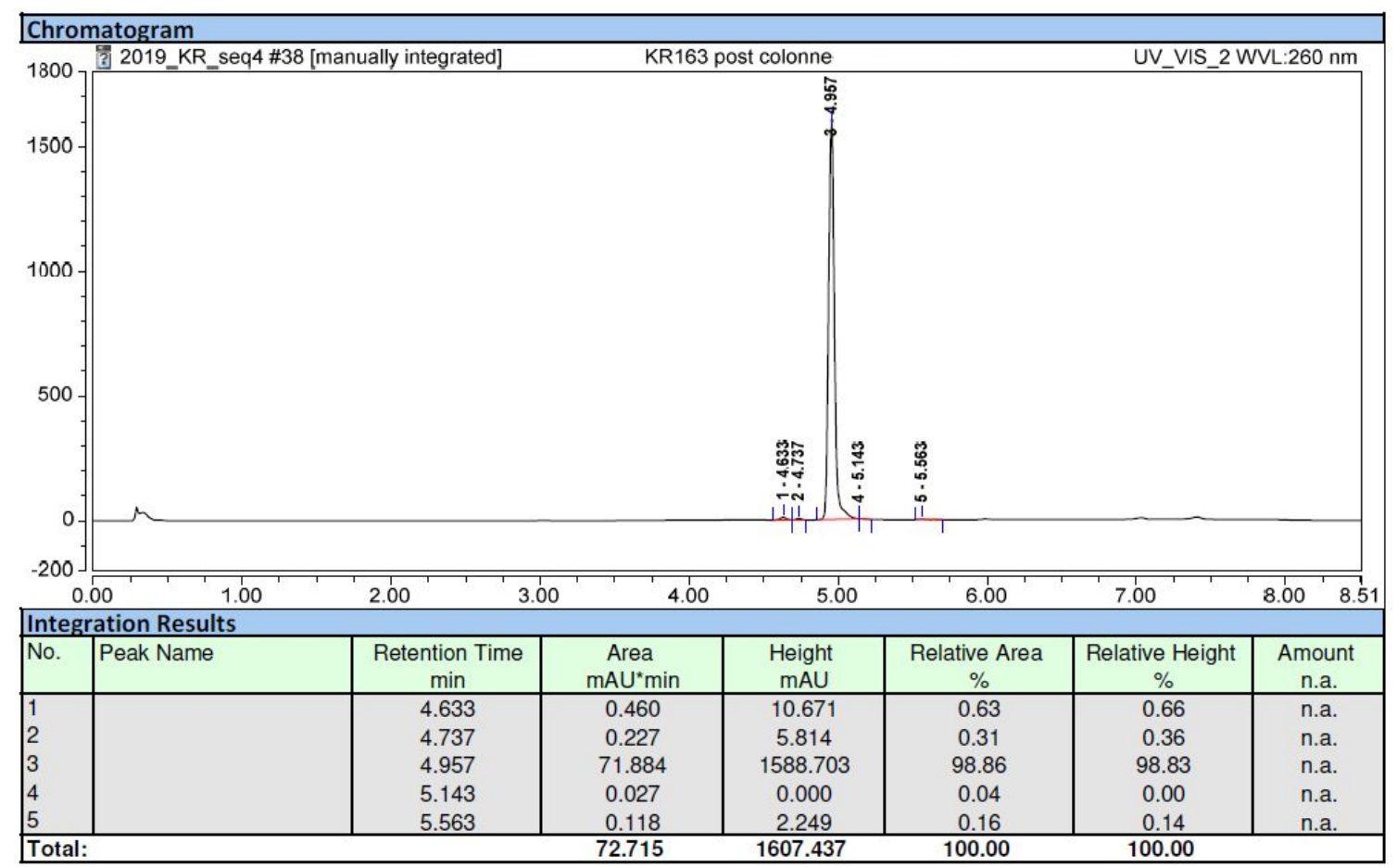


Fig. S116 - IR-ATR spectrum of probe 18

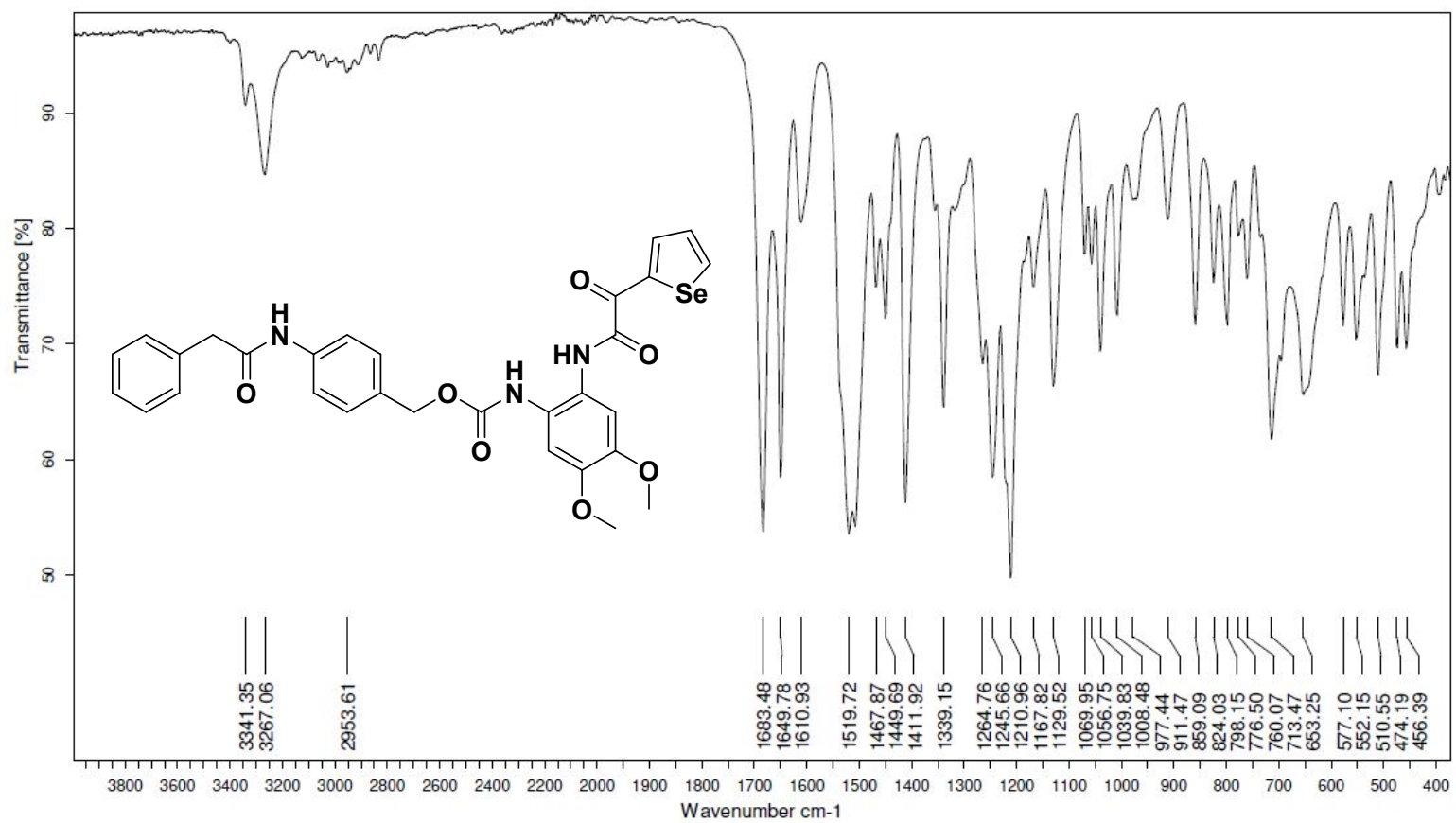

Fig. S117 - ${ }^{1} \mathrm{H}$ NMR spectrum of probe 18 in DMSO-d ${ }_{6}(500 \mathrm{MHz})$

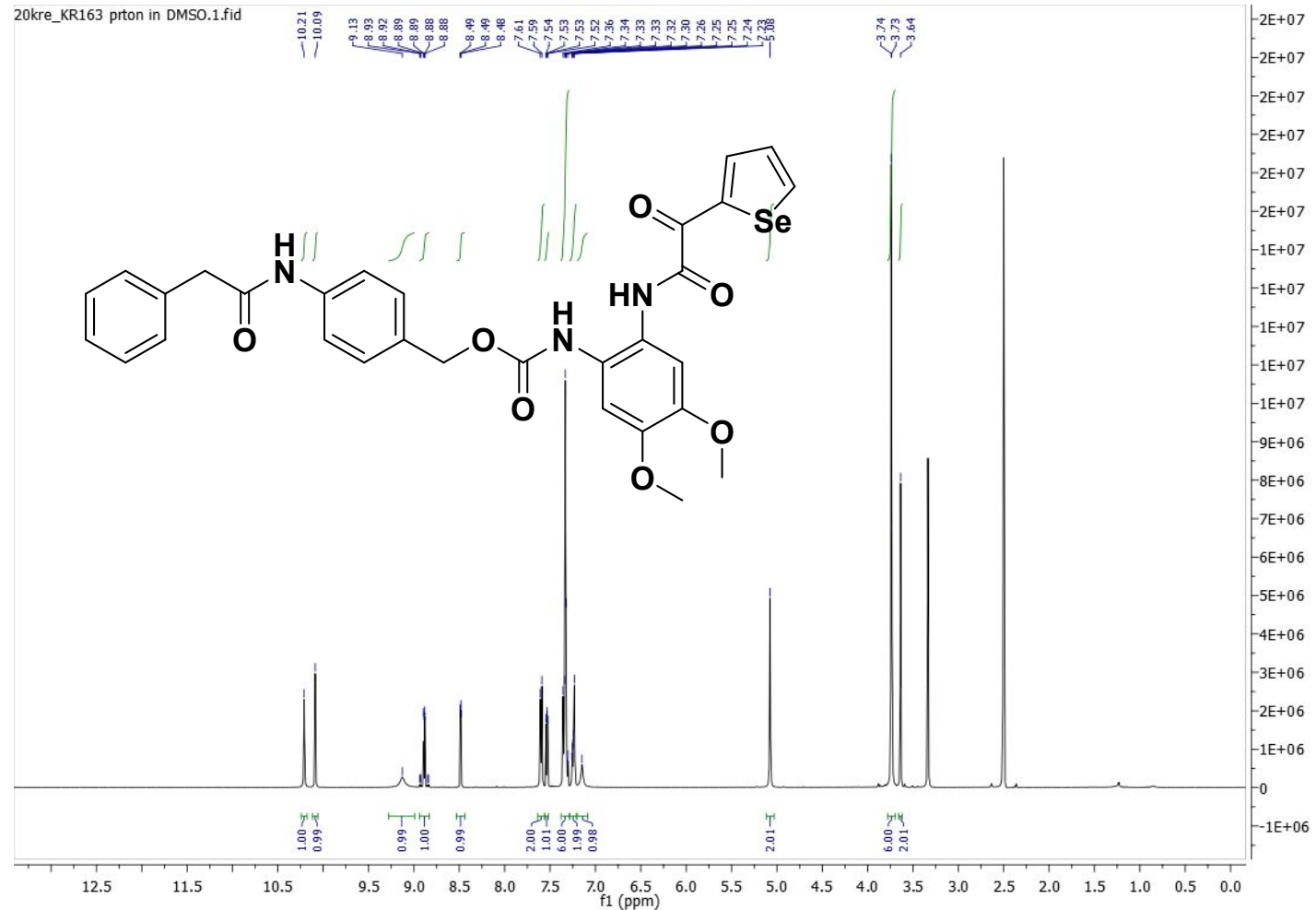


Fig. S118 $-{ }^{13} \mathrm{C}$ NMR spectrum of probe 18 in DMSO- $d_{6}(151 \mathrm{MHz})$

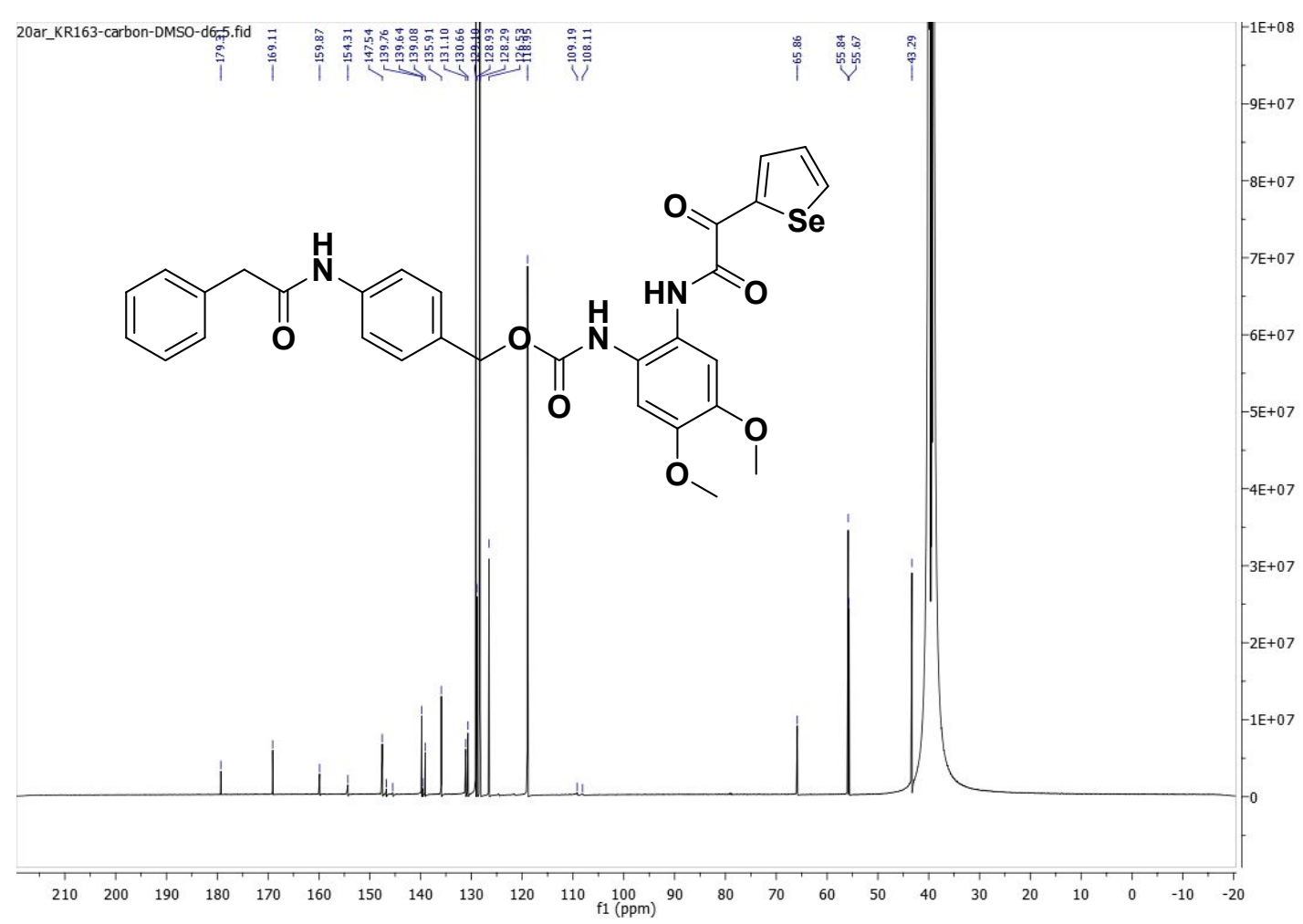

Fig. S119 - ${ }^{77}$ Se NMR spectrum of probe 18 in DMSO-d $d_{6}(114.5 \mathrm{MHz})$

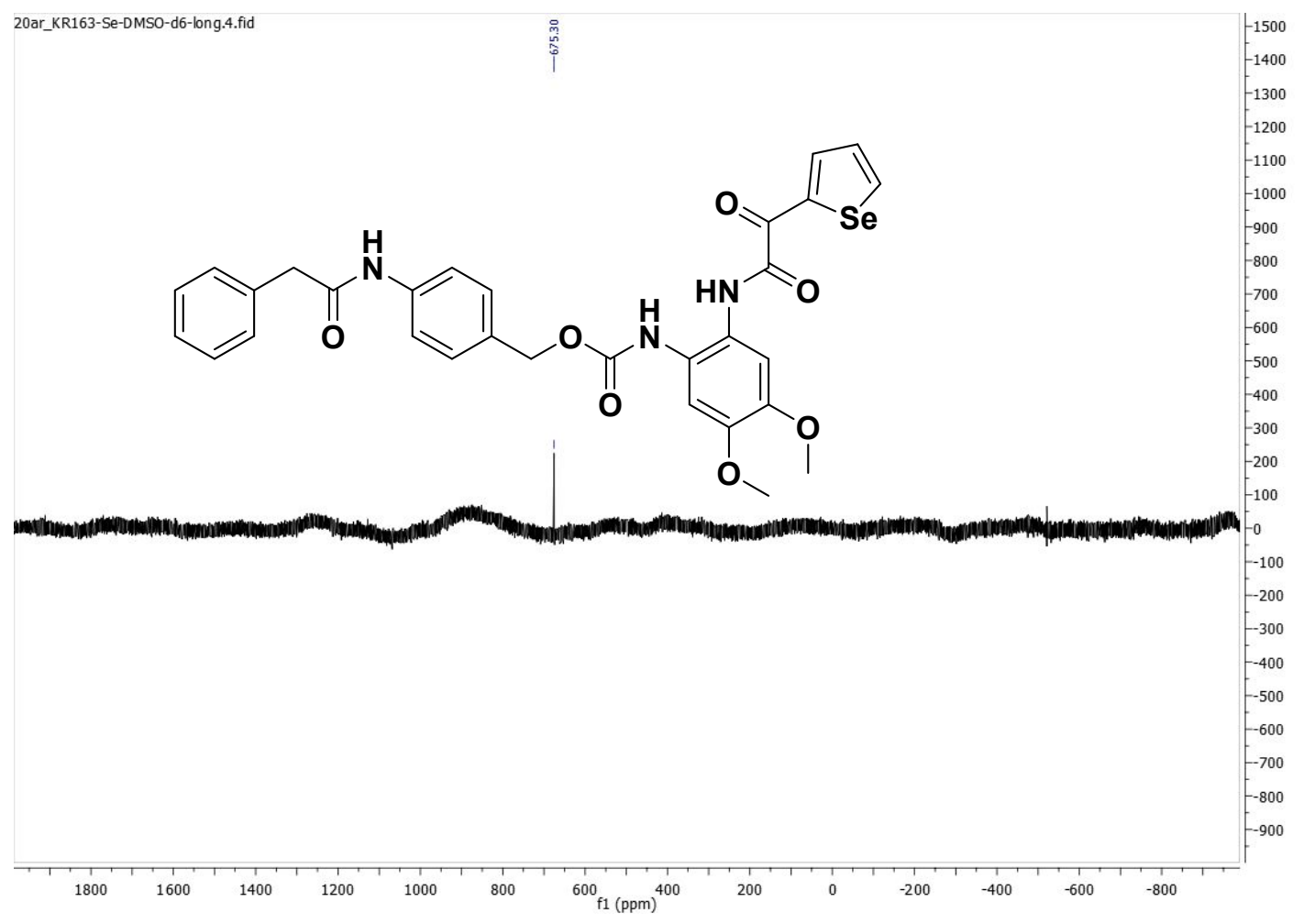


Please note: in some Em. spectra displayed below, peak assigned to Raman scattering by water molecules (centered at $417 \mathrm{~nm}$ ) is observed.

Fig. S120 - Normalized UV-vis absorption, excitation (Em. 500 nm, slit 5 nm), emission (Ex. $366 \mathrm{~nm}$, slit $5 \mathrm{~nm}$ ) spectra of quinoxalin-2(1H)-one 1 in DMSO at 25 ${ }^{\circ} \mathrm{C}$

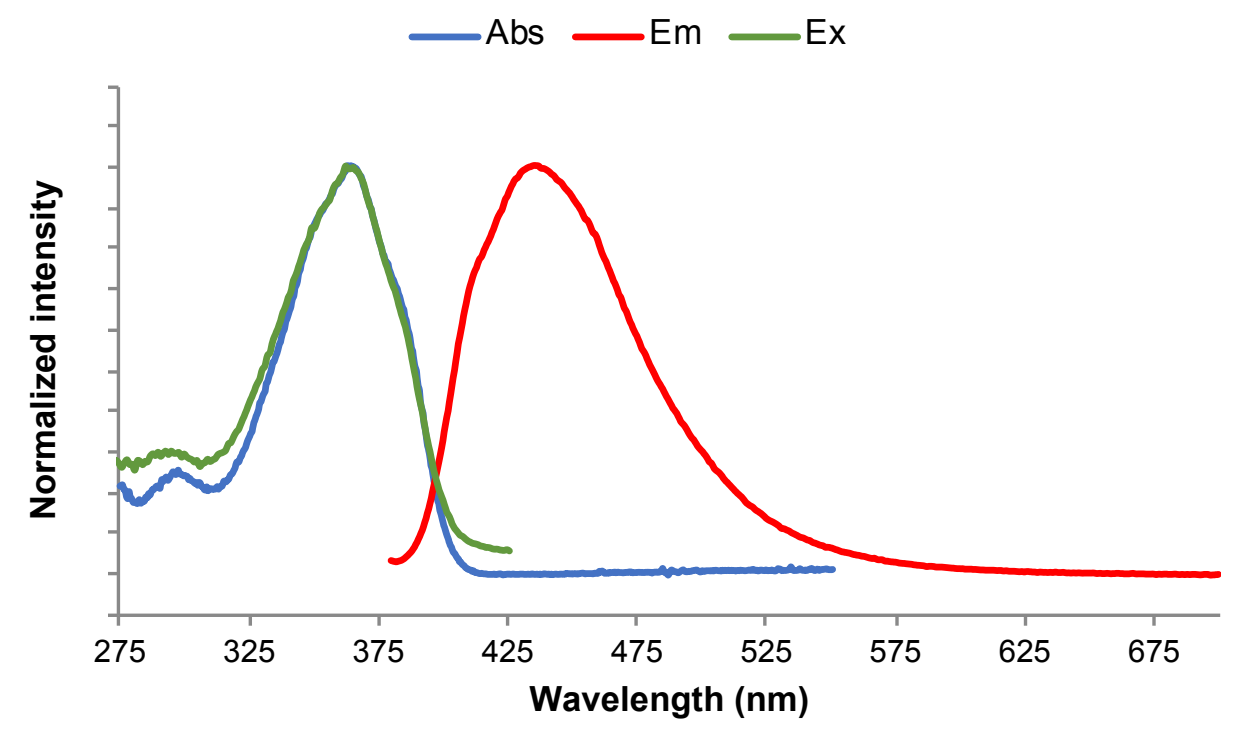

Fig. S121 - Normalized UV-vis absorption, excitation (Em. 500 nm, slit 5 nm), emission (Ex. $366 \mathrm{~nm}$, slit $5 \mathrm{~nm}$ ) spectra of quinoxalin-2(1H)-one 1 in $\mathrm{PB}$ at $25^{\circ} \mathrm{C}$

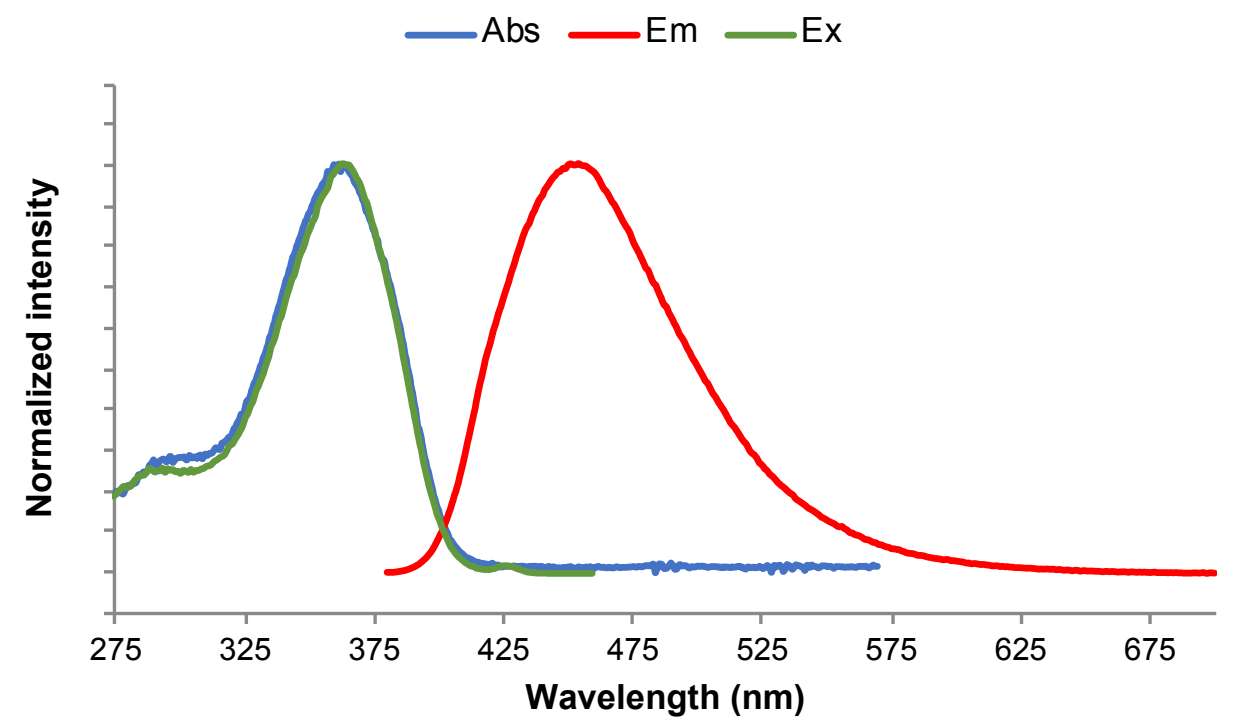


Fig. S122 - Normalized UV-vis absorption, excitation (Em. 500 nm, slit 5 nm), emission (Ex. $366 \mathrm{~nm}$, slit $5 \mathrm{~nm}$ ) spectra of quinoxalin-2(1H)-one 2 in DMSO at 25 ${ }^{\circ} \mathrm{C}$

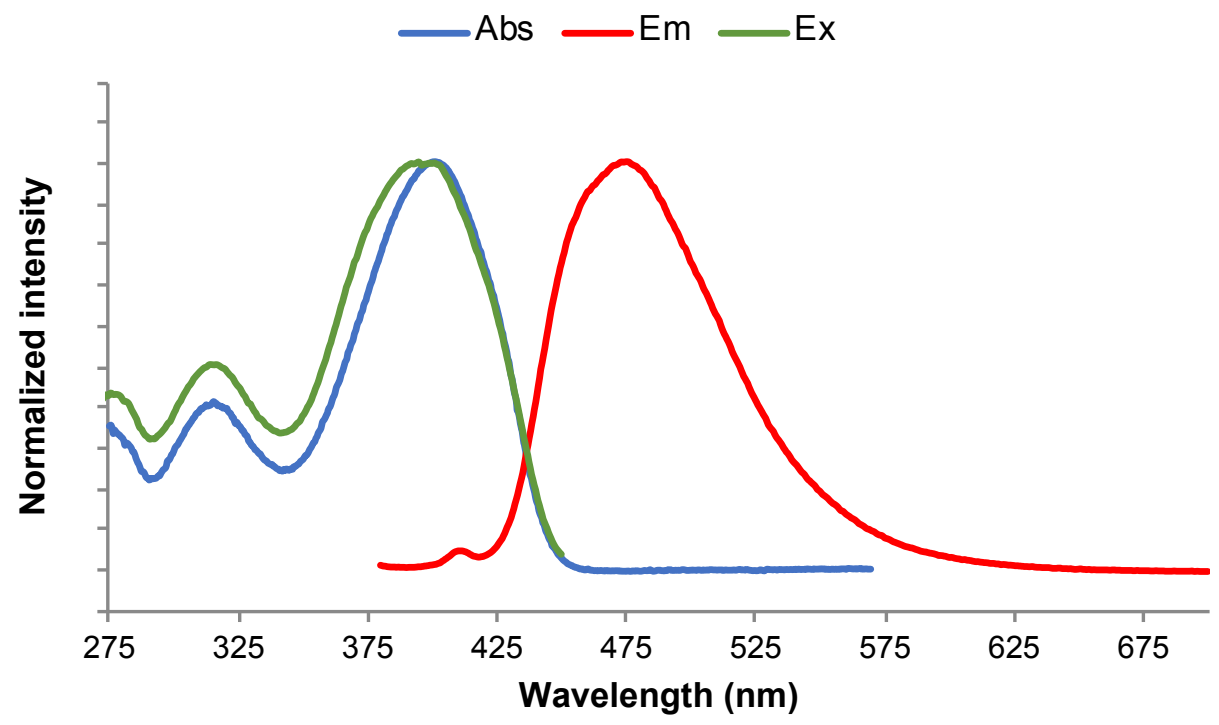

Fig. S123 - Normalized UV-vis absorption, excitation (Em. $500 \mathrm{~nm}$, slit $5 \mathrm{~nm}$ ), emission (Ex. $366 \mathrm{~nm}$, slit $5 \mathrm{~nm}$ ) spectra of quinoxalin-2(1H)-one 2 in PB at $25^{\circ} \mathrm{C}$

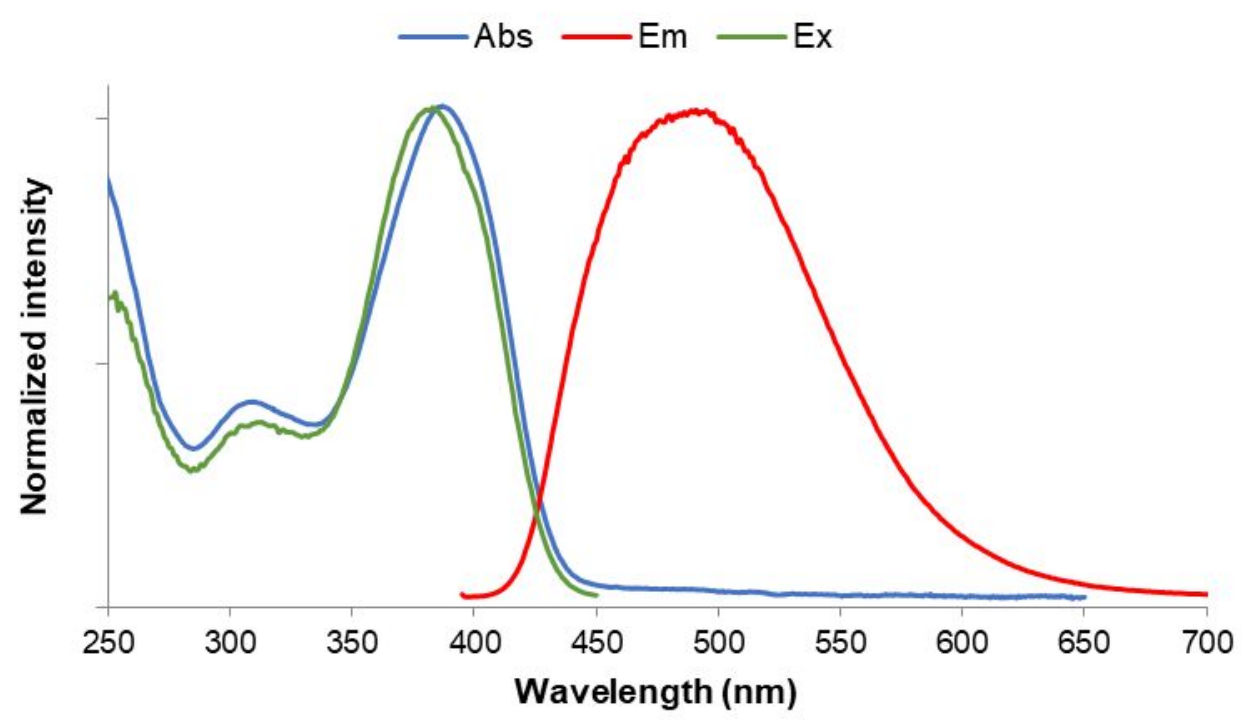


Fig. S124 - Normalized UV-vis absorption, excitation (Em. $500 \mathrm{~nm}$, slit $5 \mathrm{~nm}$ ), emission (Ex. $366 \mathrm{~nm}$, slit $5 \mathrm{~nm}$ ) spectra of quinoxalin-2(1H)-one 3 in DMSO at 25 ${ }^{\circ} \mathrm{C}$

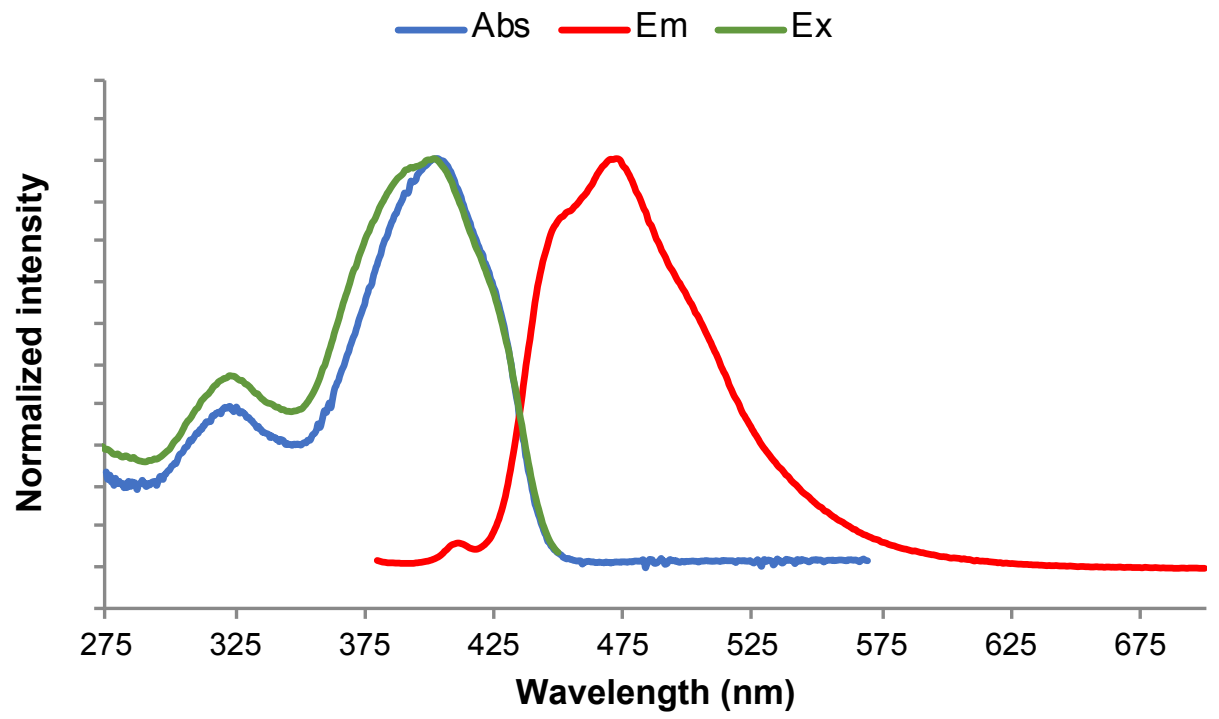

Fig. S125 - Normalized UV-vis absorption, excitation (Em. $500 \mathrm{~nm}$, slit $5 \mathrm{~nm}$ ), emission (Ex. $366 \mathrm{~nm}$, slit $5 \mathrm{~nm}$ ) spectra of quinoxalin-2(1H)-one 3 in PB at $25^{\circ} \mathrm{C}$

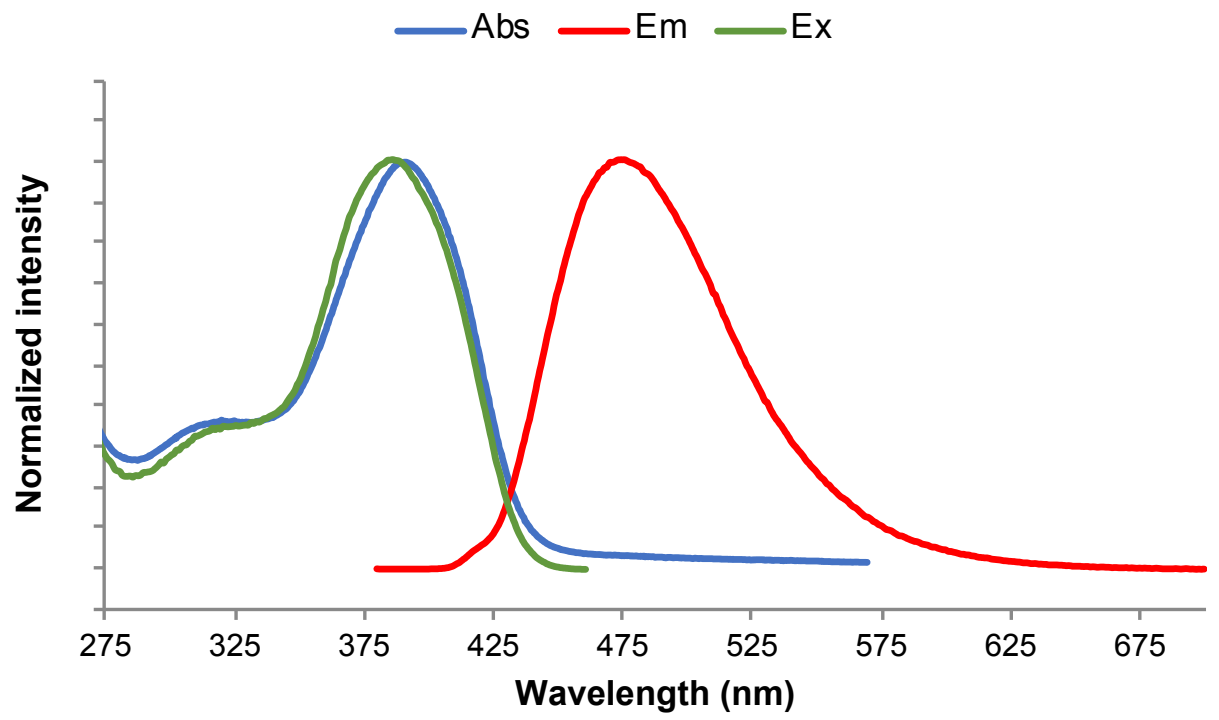


Fig. S126 - Normalized UV-vis absorption, excitation (Em. $500 \mathrm{~nm}$, slit $5 \mathrm{~nm}$ ), emission (Ex. $421 \mathrm{~nm}$, slit $5 \mathrm{~nm}$ ) spectra of quinoxalin-2(1H)-one 4 in DMSO at 25 ${ }^{\circ} \mathrm{C}$

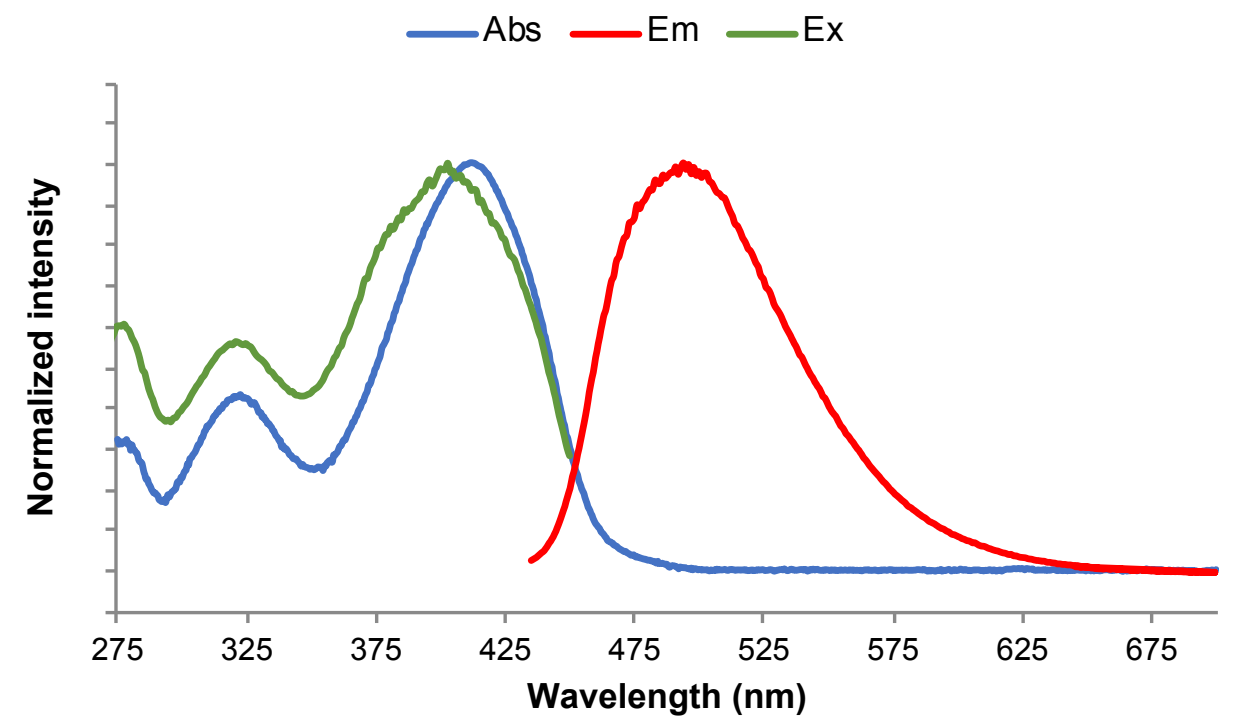

Fig. S127 - Normalized UV-vis absorption, excitation (Em. $500 \mathrm{~nm}$, slit $5 \mathrm{~nm}$ ), emission (Ex. $366 \mathrm{~nm}$, slit $5 \mathrm{~nm}$ ) spectra of quinoxalin-2(1H)-one 4 in PB at $25{ }^{\circ} \mathrm{C}$

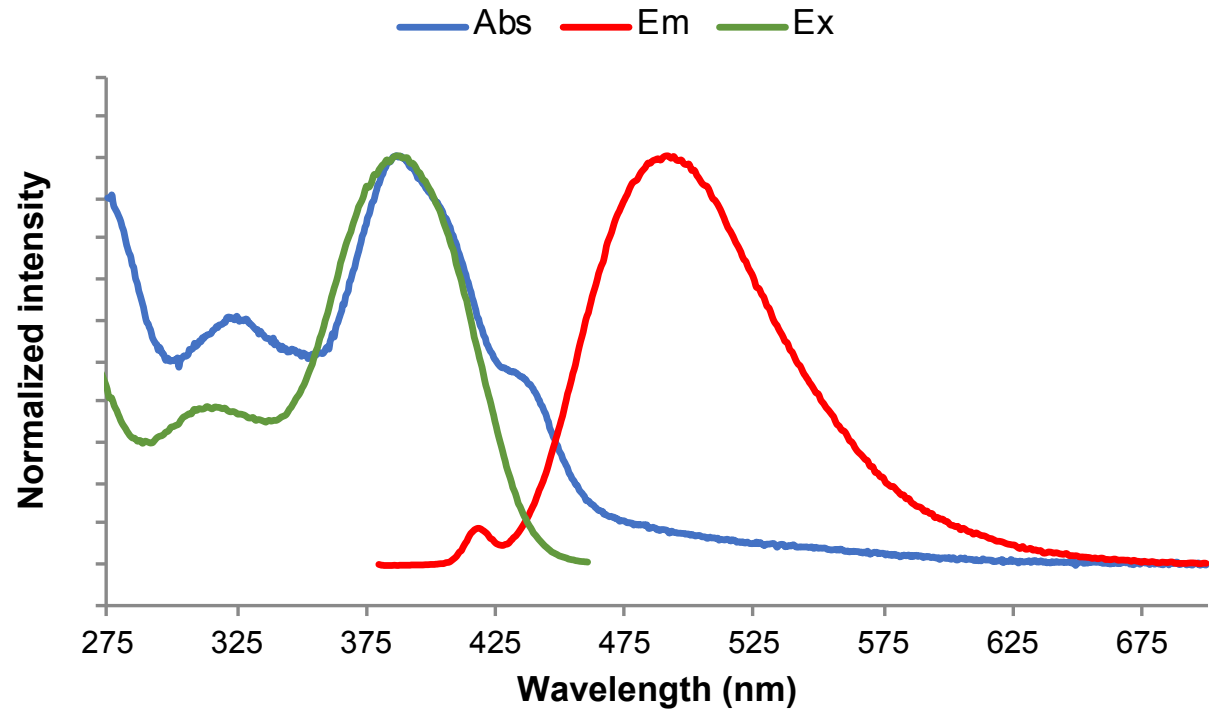

please note: formation of aggregates in PB may explain the non-perfect matching between Abs and Ex. spectra. 
Fig. S128 - Normalized UV-vis absorption, excitation (Em. $500 \mathrm{~nm}$, slit $5 \mathrm{~nm}$ ), emission (Ex. $366 \mathrm{~nm}$, slit $5 \mathrm{~nm}$ ) spectra of quinoxalin-2(1H)-one 5 in DMSO at 25 ${ }^{\circ} \mathrm{C}$

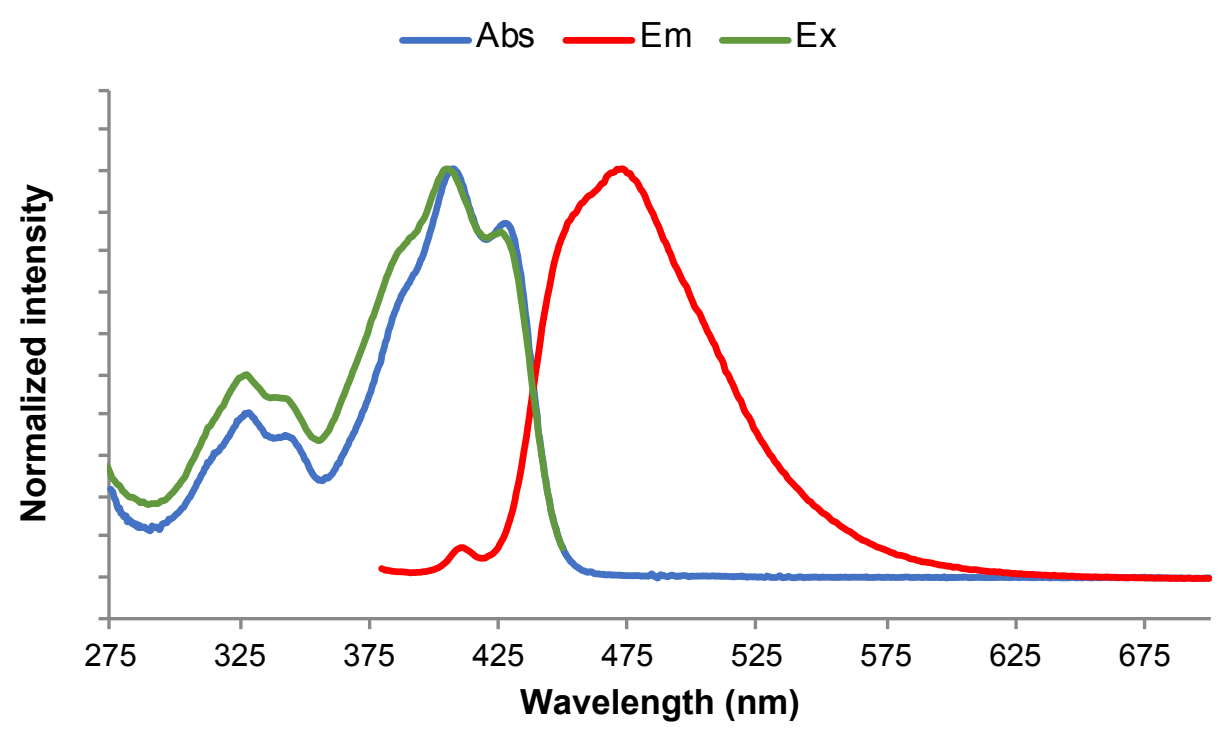

Fig. S129 - Normalized UV-vis absorption, excitation (Em. $500 \mathrm{~nm}$, slit $5 \mathrm{~nm}$ ), emission (Ex. $366 \mathrm{~nm}$, slit $5 \mathrm{~nm}$ ) spectra of quinoxalin-2(1H)-one 5 in PB at $25^{\circ} \mathrm{C}$

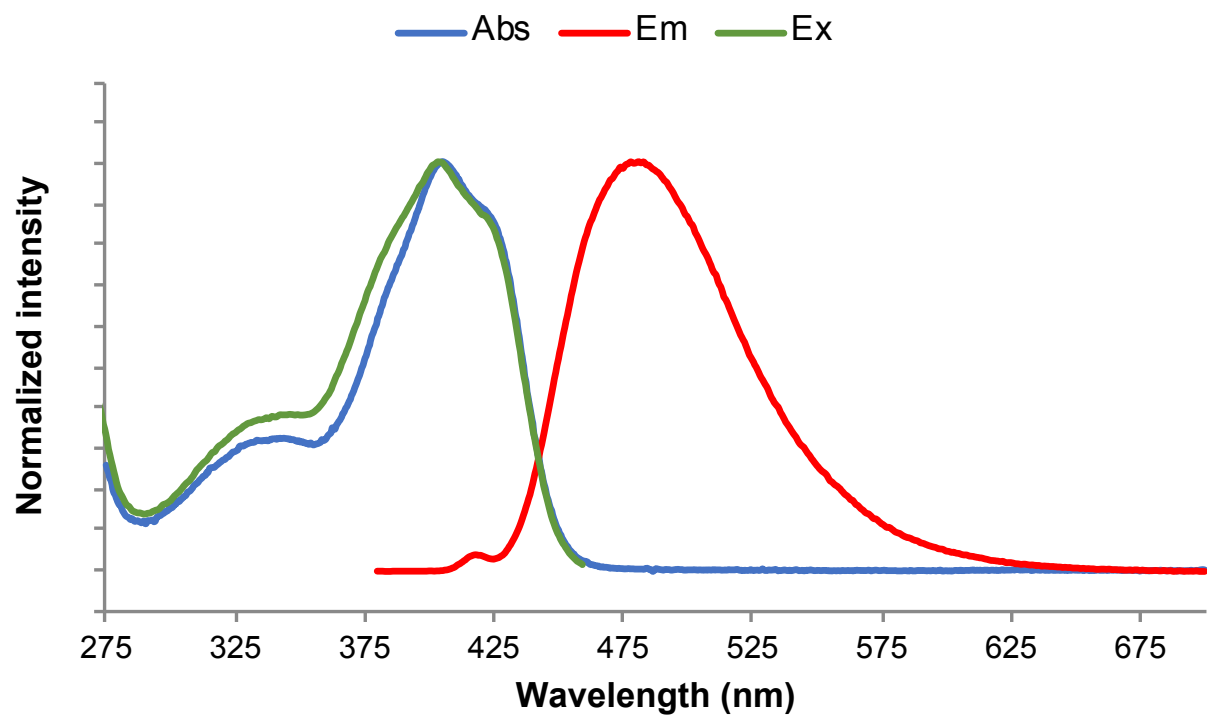


Fig. S130 - Normalized UV-vis absorption, excitation (Em. $500 \mathrm{~nm}$, slit $5 \mathrm{~nm}$ ), emission (Ex. $421 \mathrm{~nm}$, slit $5 \mathrm{~nm}$ ) spectra of quinoxalin-2(1H)-one 6 in DMSO at 25 ${ }^{\circ} \mathrm{C}$

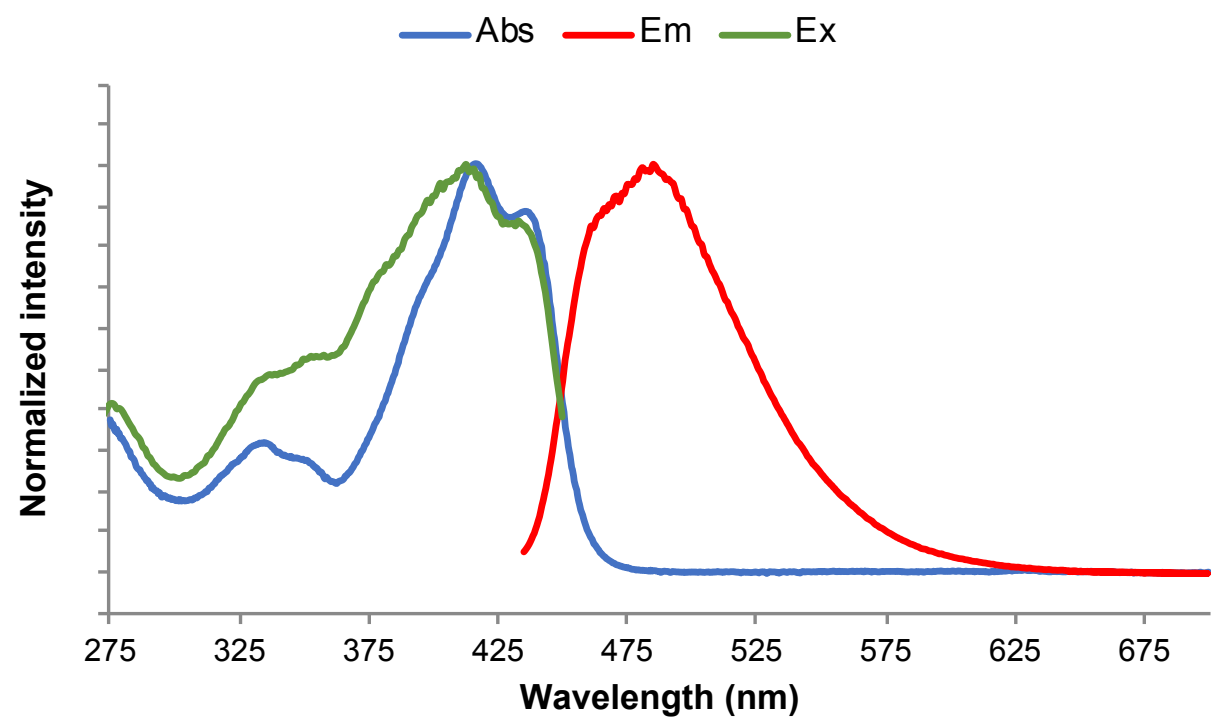

Fig. S131 - Normalized UV-vis absorption, excitation (Em. $500 \mathrm{~nm}$, slit $5 \mathrm{~nm}$ ), emission (Ex. $366 \mathrm{~nm}$, slit $5 \mathrm{~nm}$ ) spectra of quinoxalin-2(1H)-one 6 in PB at $25^{\circ} \mathrm{C}$

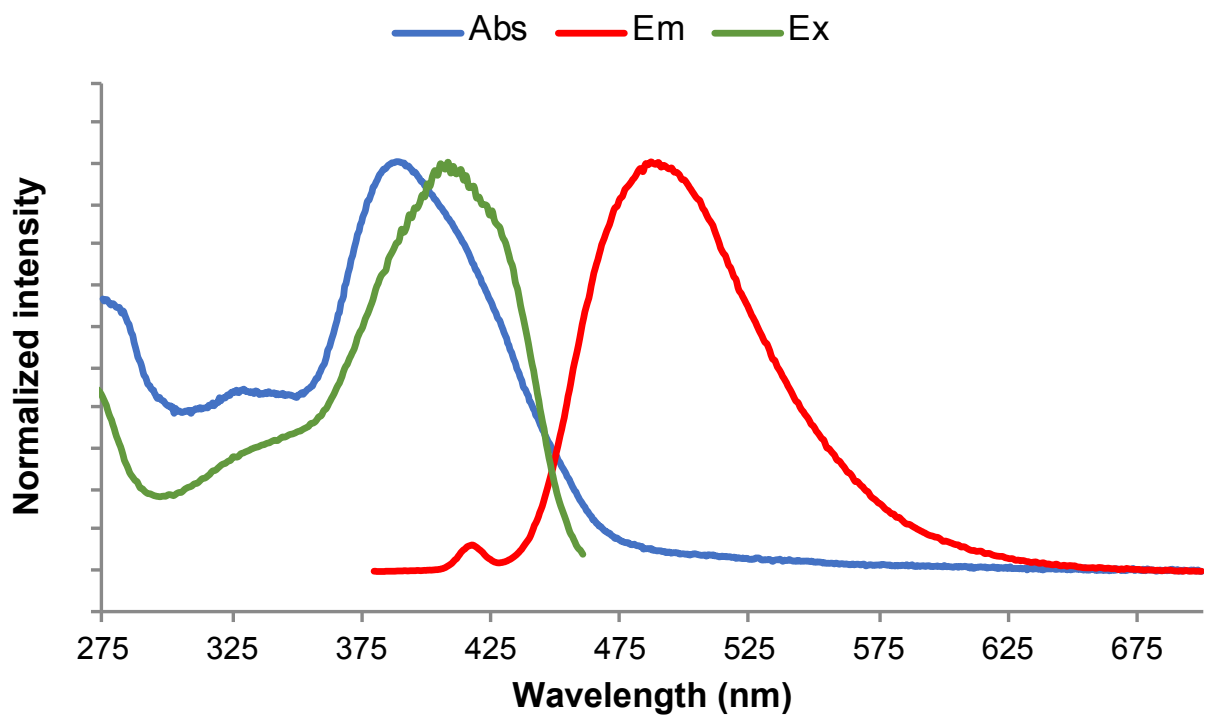

please note: formation of aggregates in PB may explain the non-perfect matching between Abs and Ex. spectra. 
Fig. S132 - Normalized UV-vis absorption, excitation (Em. $500 \mathrm{~nm}$, slit $5 \mathrm{~nm}$ ), emission (Ex. $366 \mathrm{~nm}$, slit $5 \mathrm{~nm}$ ) spectra of quinoxalin-2(1H)-one 7 in DMSO at 25 ${ }^{\circ} \mathrm{C}$

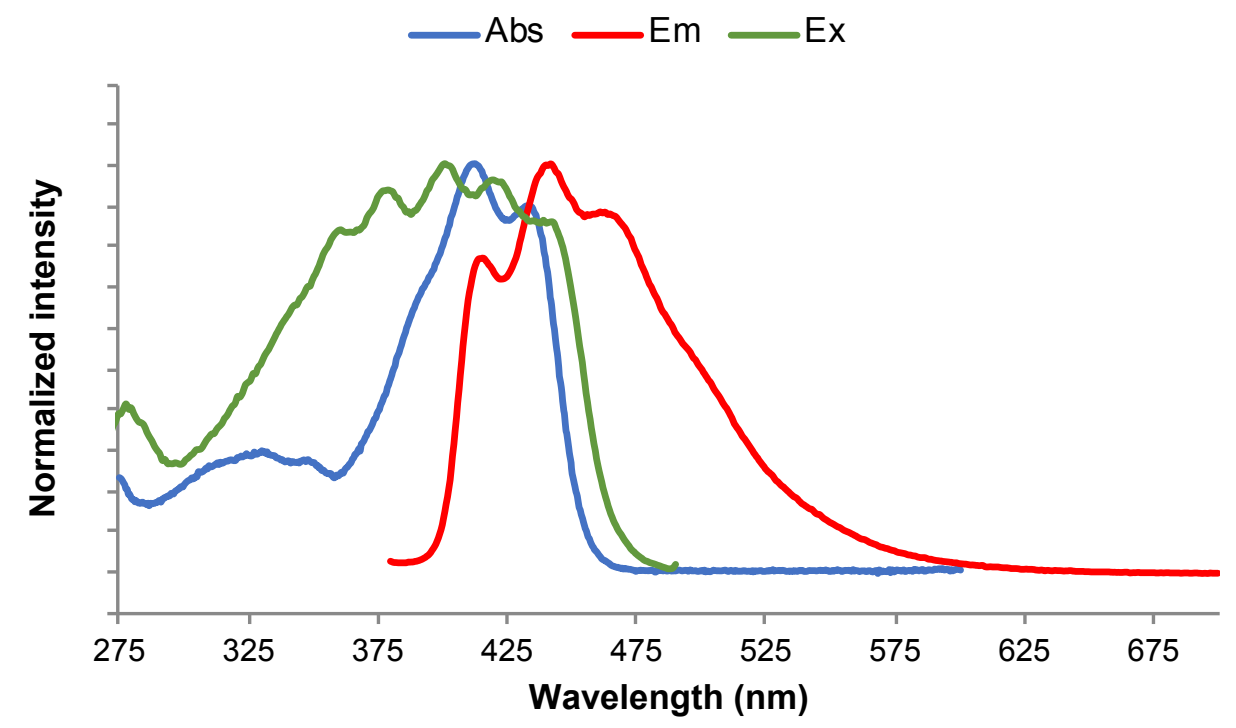

Fig. S133 - Normalized UV-vis absorption, excitation (Em. $500 \mathrm{~nm}$, slit $5 \mathrm{~nm}$ ), emission (Ex. $366 \mathrm{~nm}$, slit $5 \mathrm{~nm}$ ) spectra of quinoxalin-2(1H)-one 7 in $\mathrm{PB}$ at $25^{\circ} \mathrm{C}$

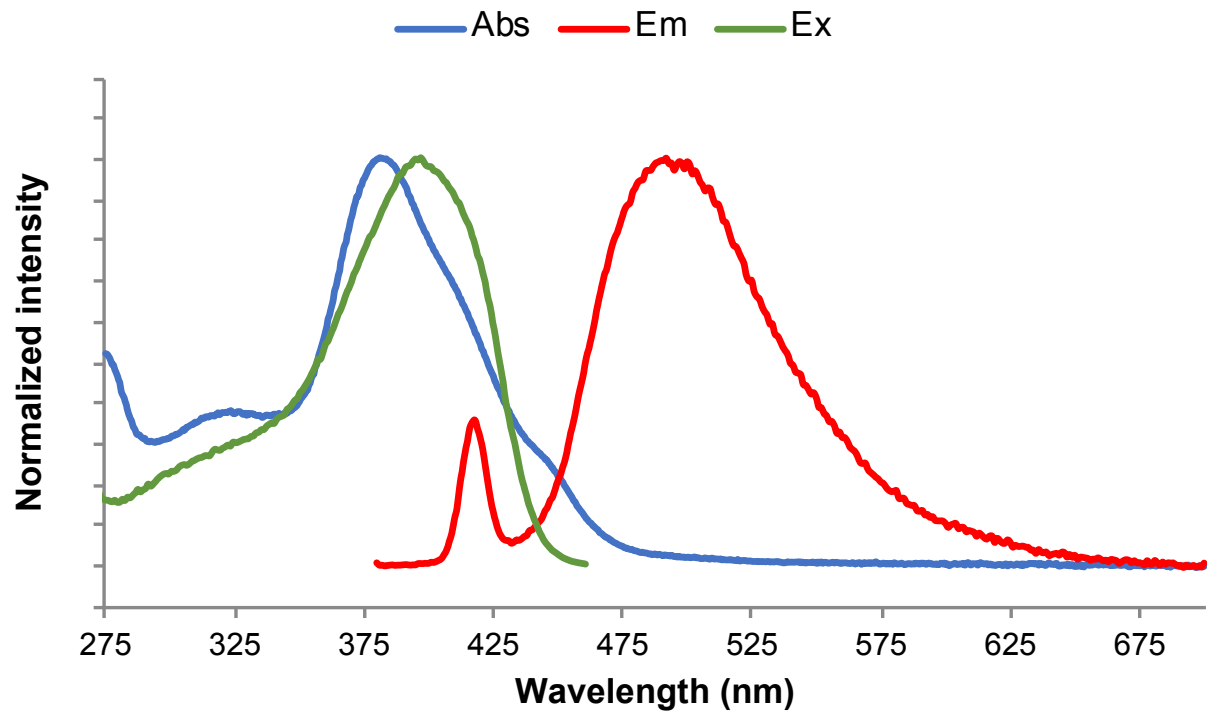

please note: formation of aggregates in PB may explain the non-perfect matching between Abs and Ex. spectra. 
Fig. S134 - Normalized UV-vis absorption, excitation (Em. 500 nm, slit 5 nm), emission (Ex. $366 \mathrm{~nm}$, slit $5 \mathrm{~nm}$ ) spectra of quinoxalin-2(1H)-one 8 in DMSO at 25 ${ }^{\circ} \mathrm{C}$

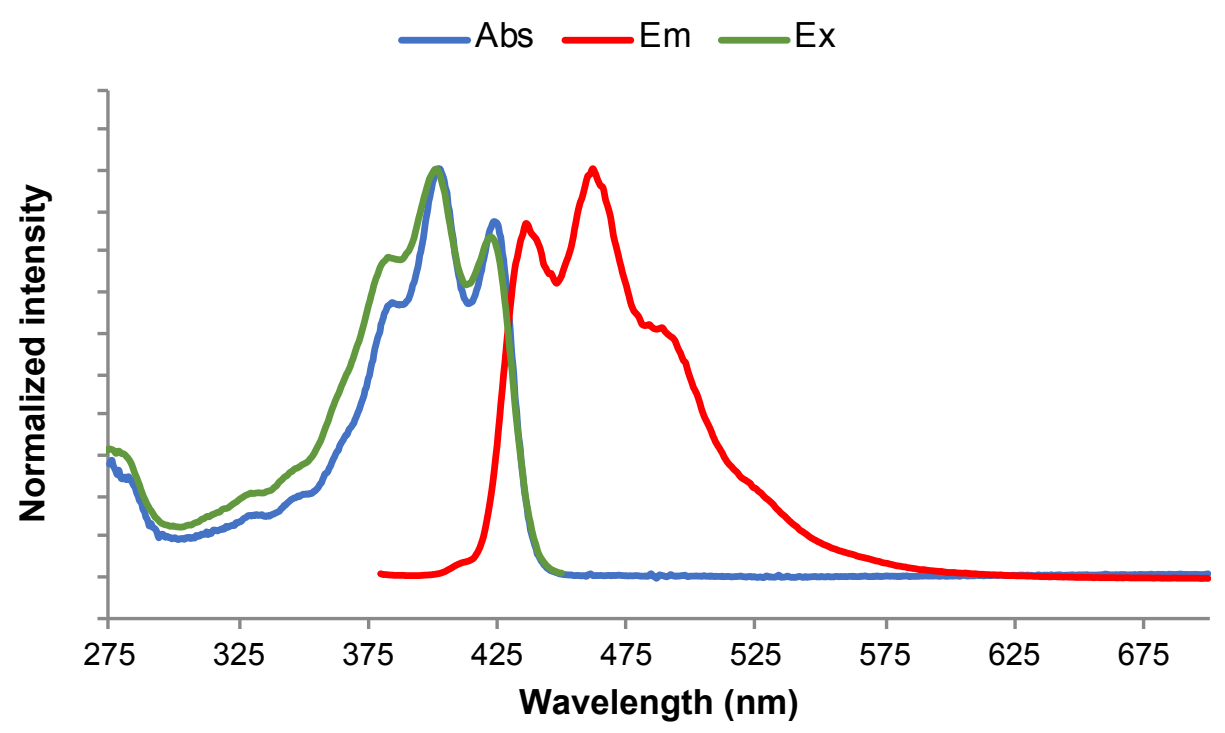

Fig. S135 - Normalized UV-vis absorption, excitation (Em. $500 \mathrm{~nm}$, slit $5 \mathrm{~nm}$ ), emission (Ex. $366 \mathrm{~nm}$, slit $5 \mathrm{~nm}$ ) spectra of quinoxalin-2(1H)-one 8 in PB at $25^{\circ} \mathrm{C}$

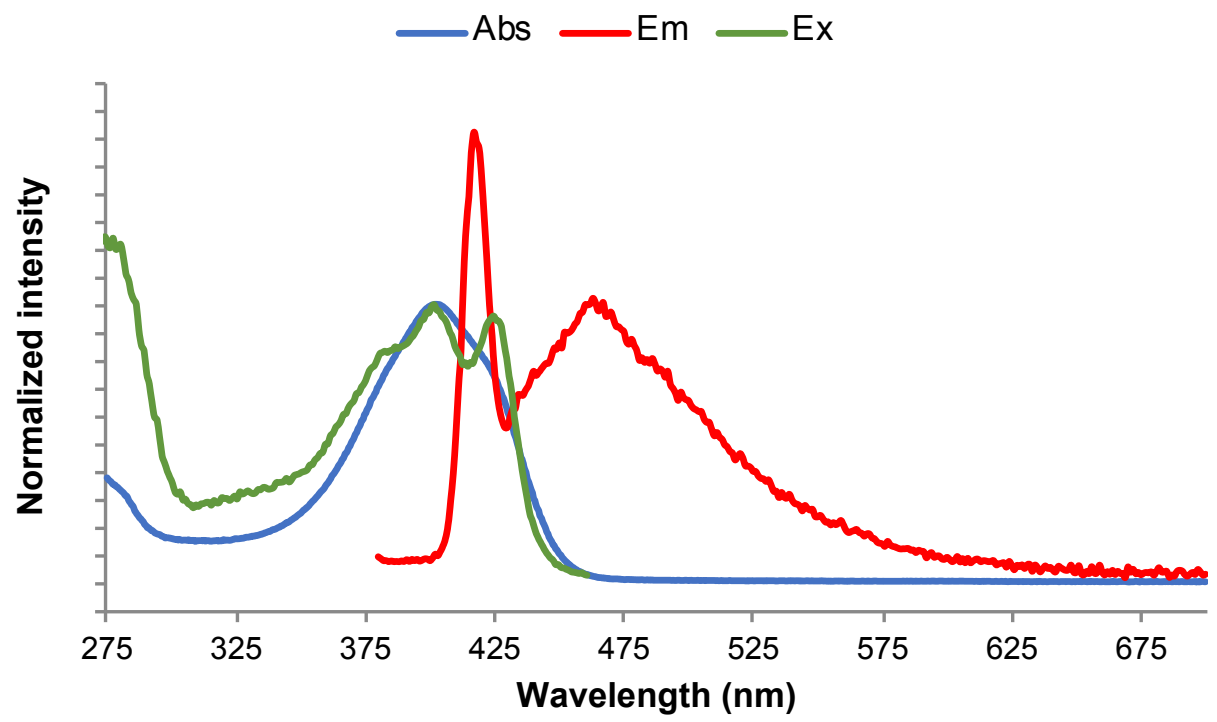

please note: this compound was found to be almost non-fluorescent in PB. 
Fig. S136 - UV-vis spectrum of probe 12 (recorded during RP-HPLC analysis)

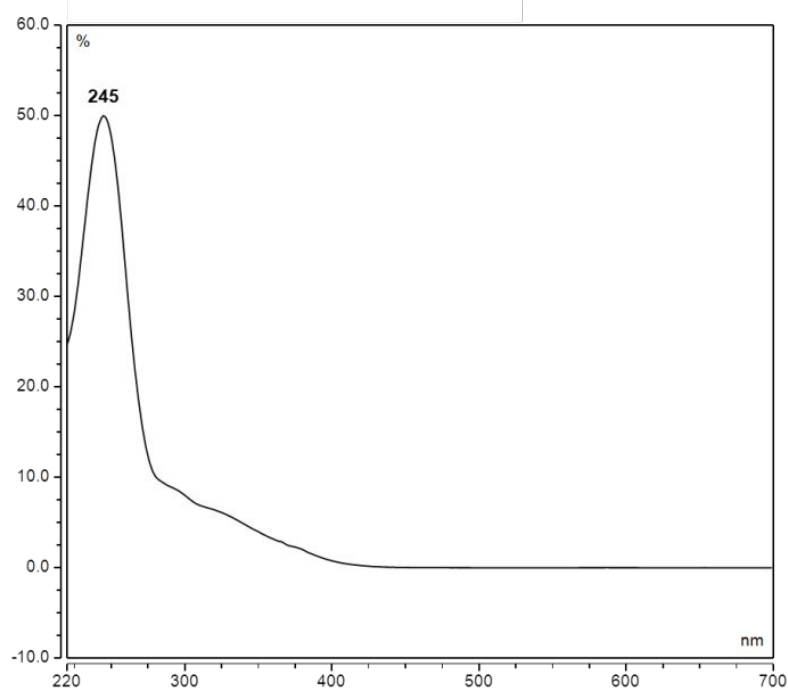

Fig. S137 - UV-vis spectrum of probe 13 (recorded during RP-HPLC analysis)

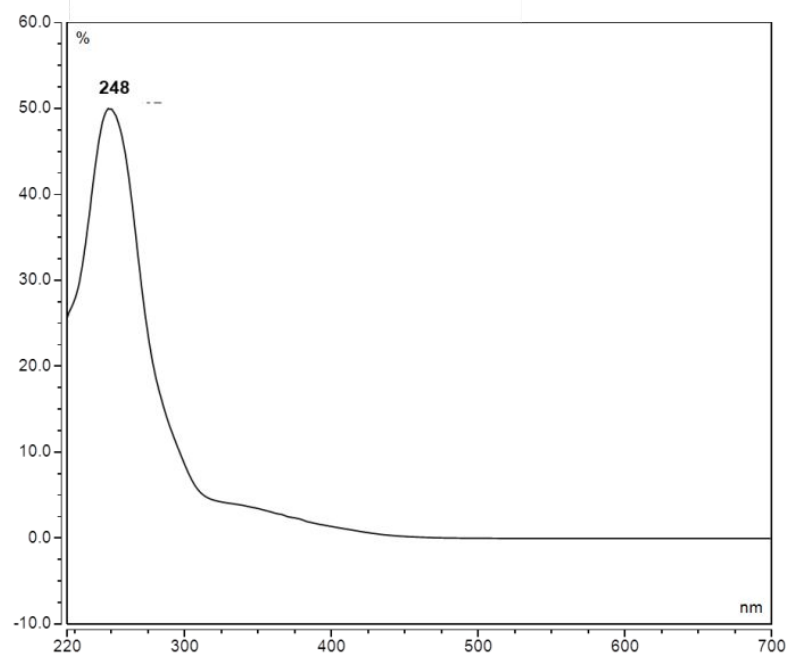

Fig. S138 - UV-vis spectrum of probe 14 (recorded during RP-HPLC analysis)

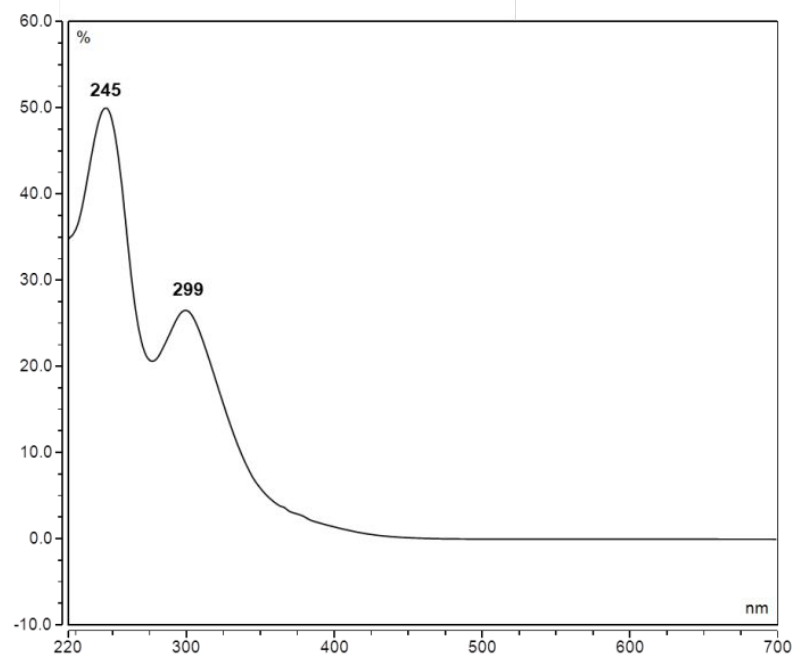


Fig. S139 - UV-vis spectrum of probe 15 (recorded during RP-HPLC analysis)

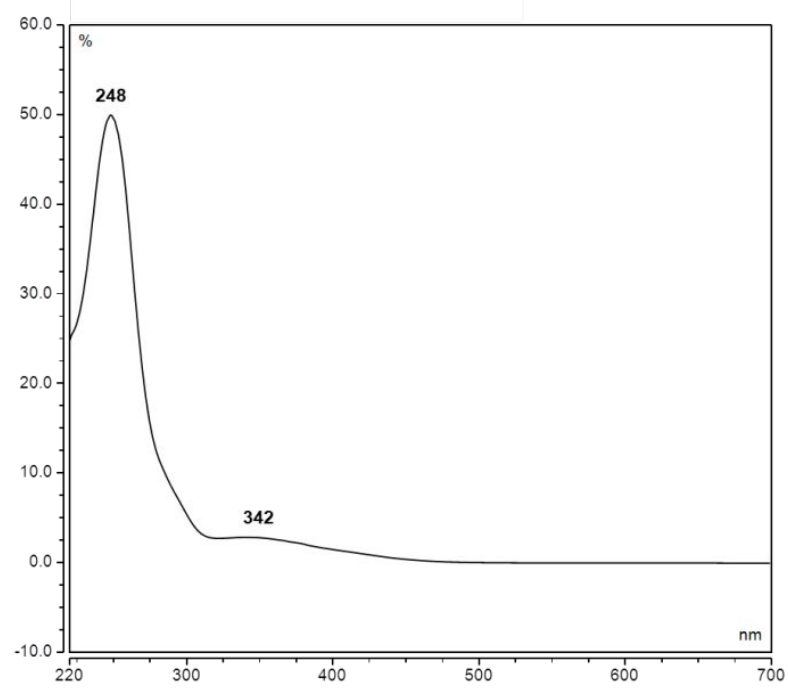

Fig. S140 - UV-vis spectrum of probe 16 (recorded during RP-HPLC analysis)

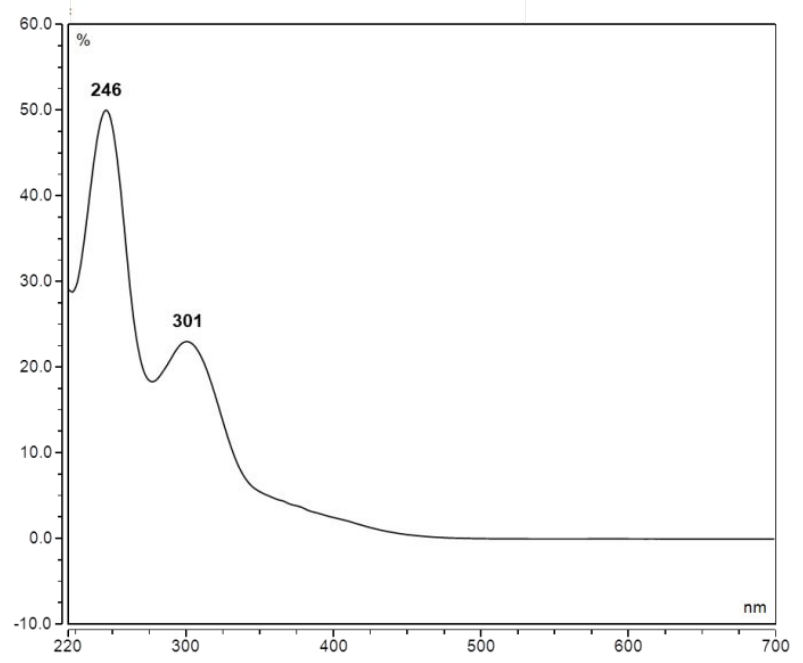

Fig. S141 - UV-vis spectrum of probe 17 (recorded during RP-HPLC analysis)

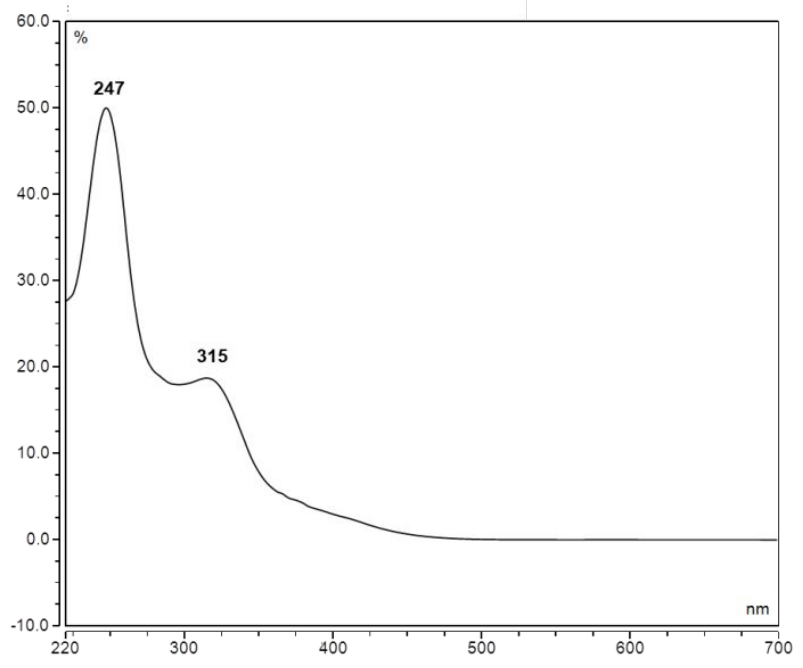


Fig. S142 - UV-vis spectrum of probe 18 (recorded during RP-HPLC analysis)

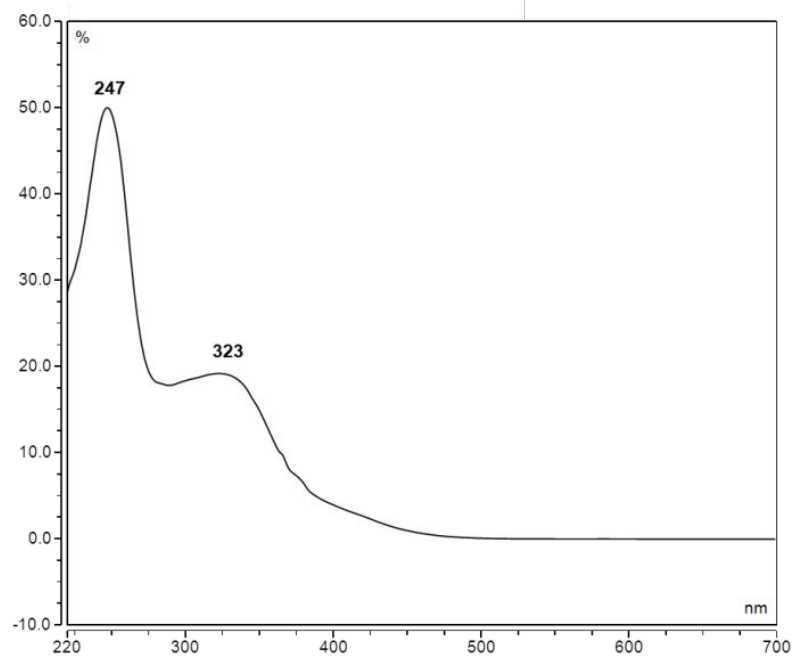

Fig. S143 - Time-dependent changes in the blue-cyan fluorescence intensity $($ Ex./Em. 365/455 nm, slit $2 \mathrm{~nm}$ ) of fluorogenic probe 12 (concentration: $1.0 \mu \mathrm{M}$ ) in the presence of PGA $(1 \mathrm{U})$ in $\mathrm{PB}$ at $37^{\circ} \mathrm{C}$

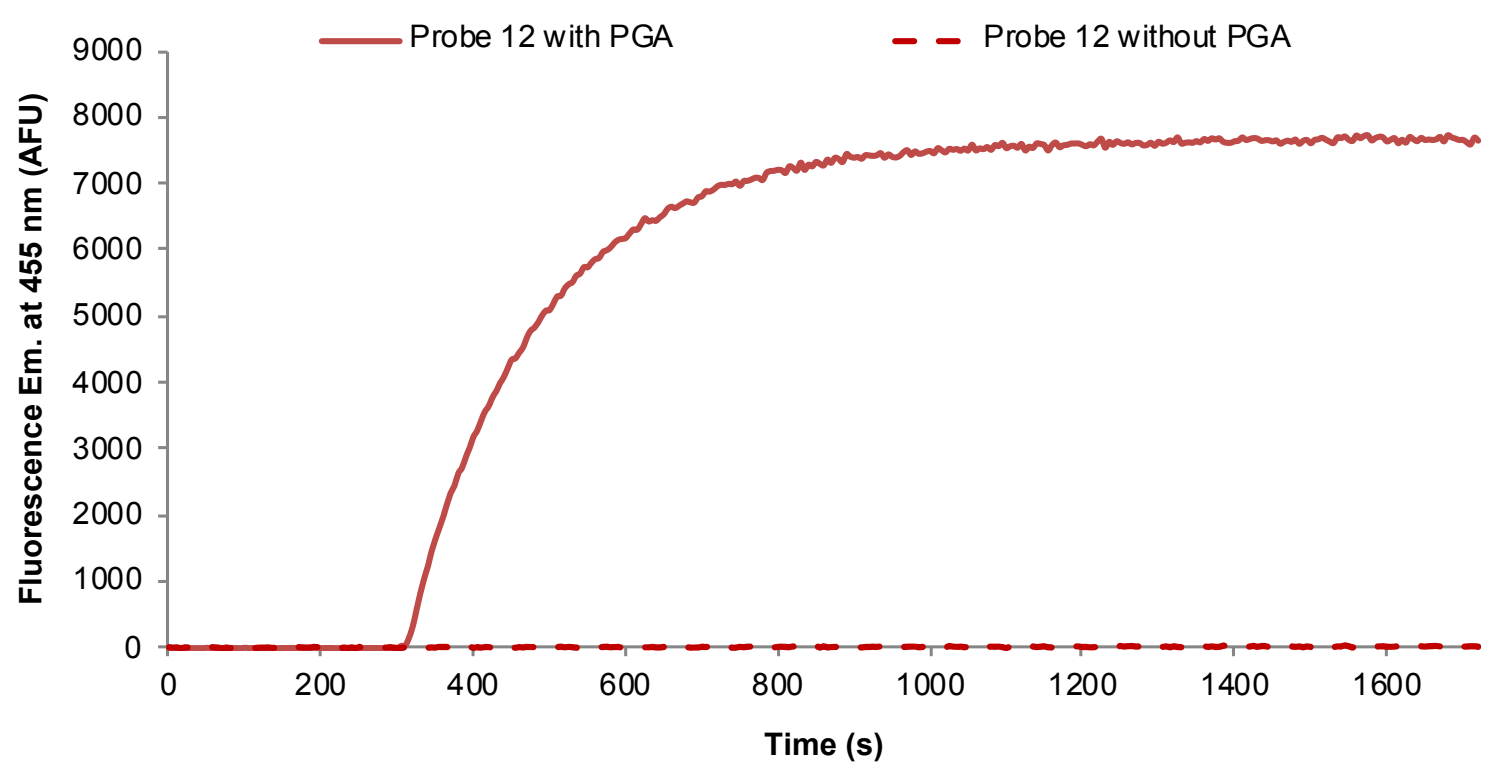


Fig. S144 - Over-layed fluorescence emission spectra (Ex. $365 \mathrm{~nm}$, slit $5 \mathrm{~nm})$ of fluorogenic probe 12 before and after incubation with PGA

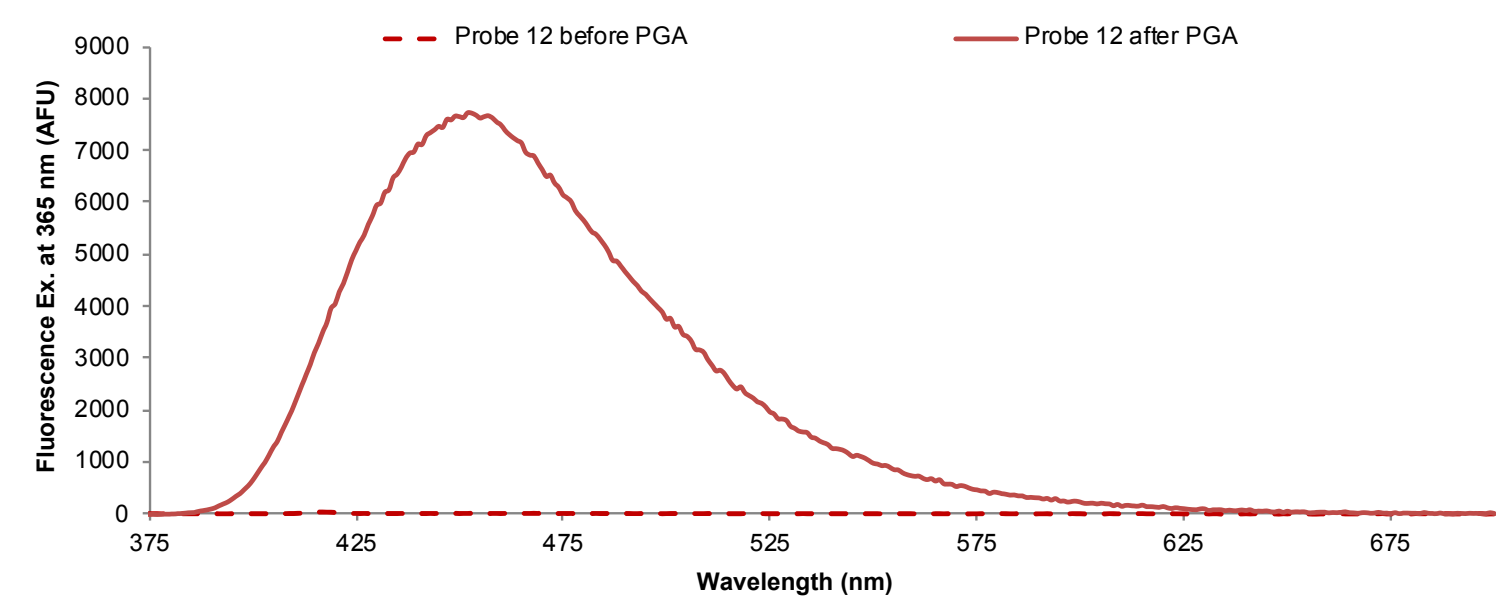

Fig. S145 - Time-dependent changes in the blue-cyan fluorescence intensity $(E x . / E m .380 / 480 \mathrm{~nm}$, slit $2 \mathrm{~nm}$ ) of fluorogenic probe 13 (concentration: $1.0 \mu \mathrm{M}$ ) in the presence of PGA (1 U) in PB at $37^{\circ} \mathrm{C}$

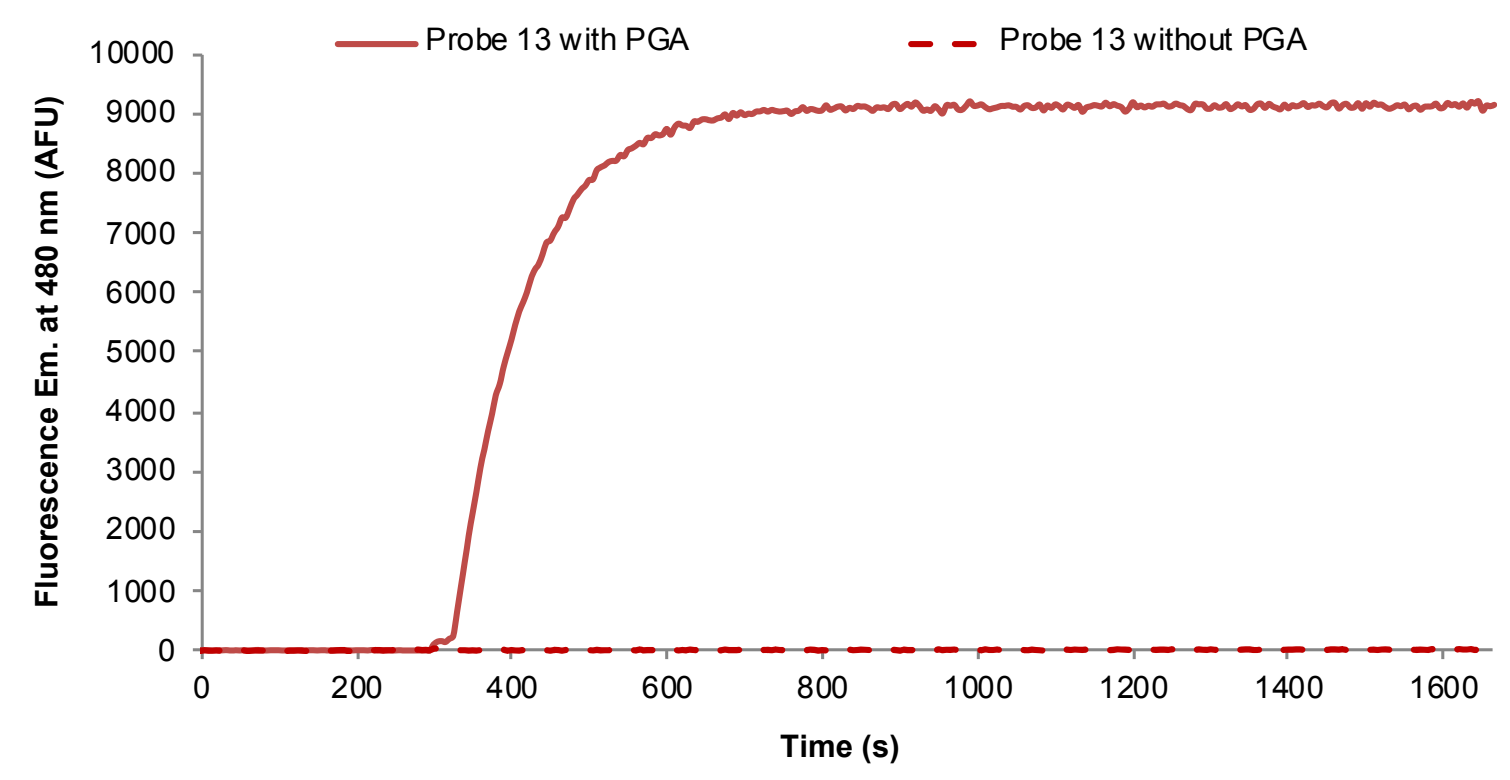


Fig. S146 - Over-layed fluorescence emission spectra (Ex. $380 \mathrm{~nm}$, slit $5 \mathrm{~nm})$ of fluorogenic probe 13 before and after incubation with PGA

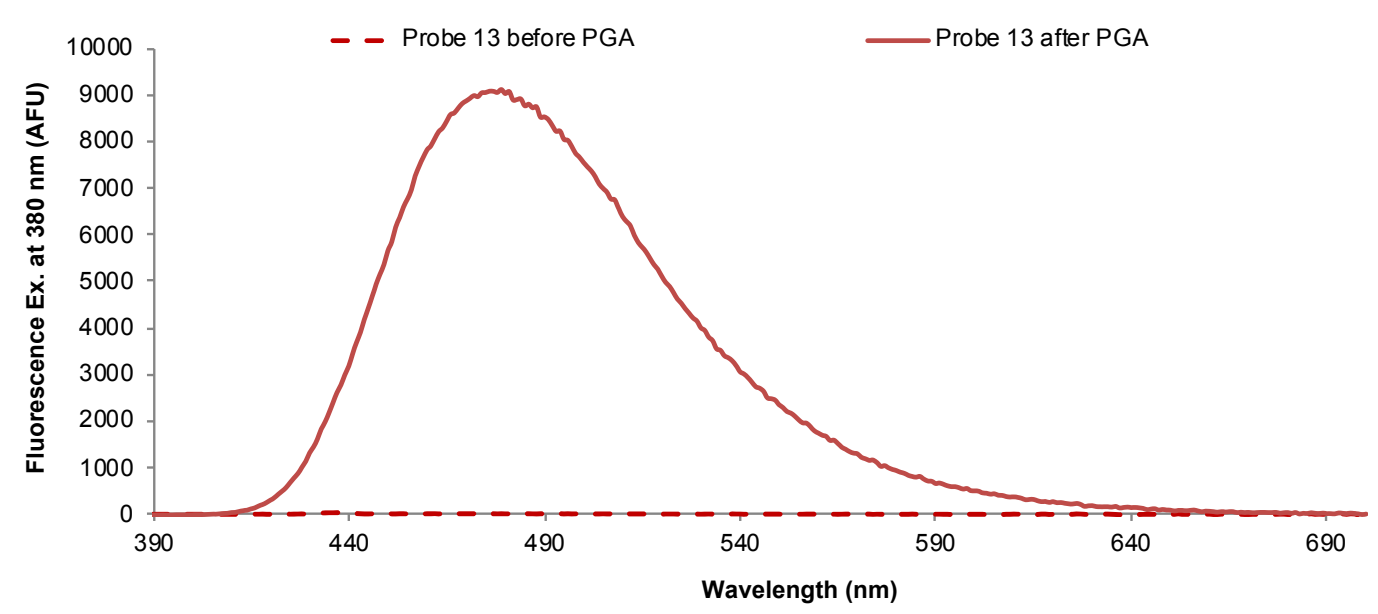

Fig. S147 - Time-dependent changes in the blue-cyan fluorescence intensity (Ex./Em. 390/475 nm, slit $2 \mathrm{~nm}$ ) of fluorogenic probe 14 (concentration: $1.0 \mu \mathrm{M}$ ) in the presence of PGA (1 U) in $\mathrm{PB}$ at $37^{\circ} \mathrm{C}$

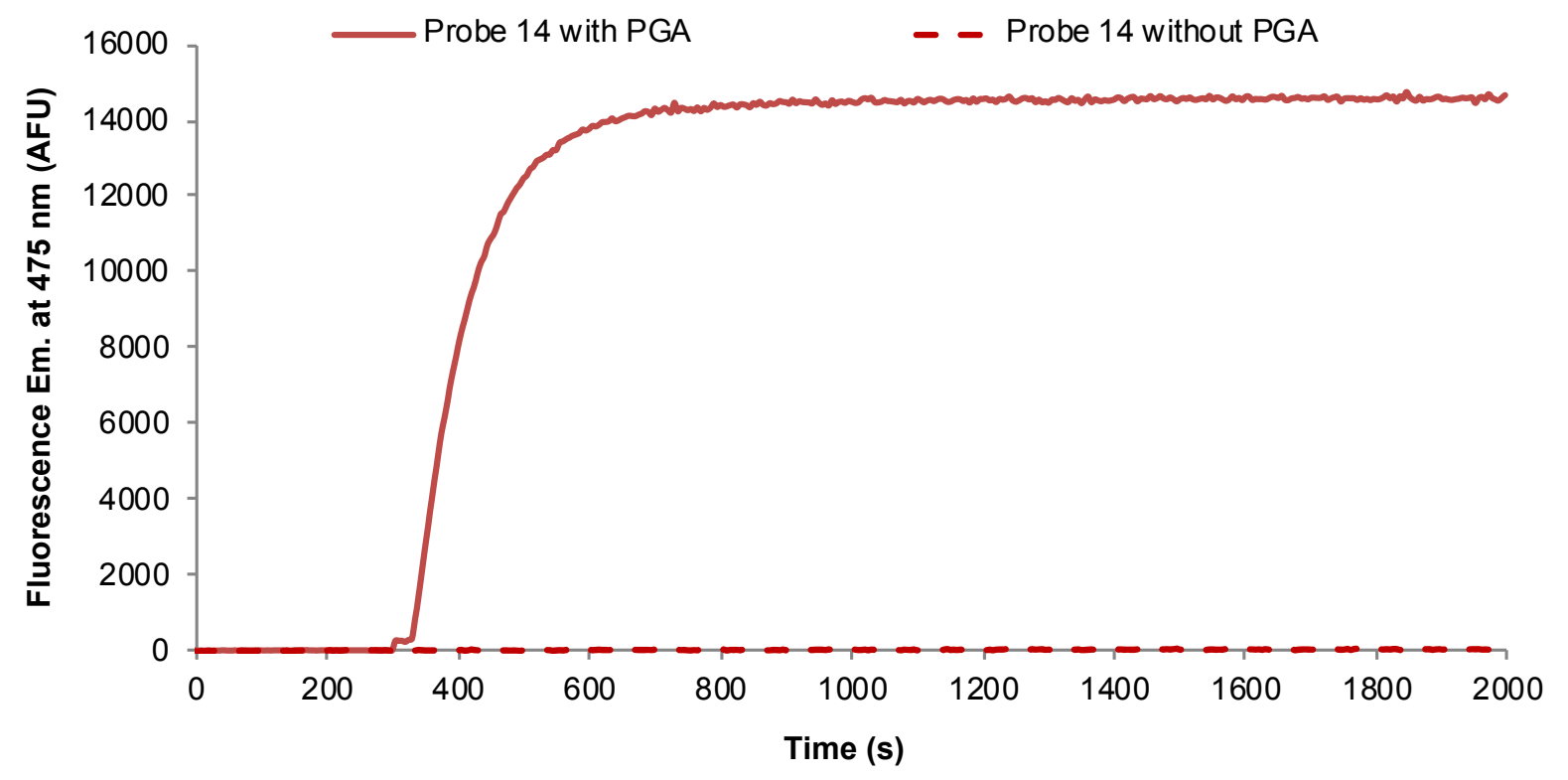


Fig. S148 - Over-layed fluorescence emission spectra (Ex. $390 \mathrm{~nm}$, slit $5 \mathrm{~nm})$ of fluorogenic probe 14 before and after incubation with PGA

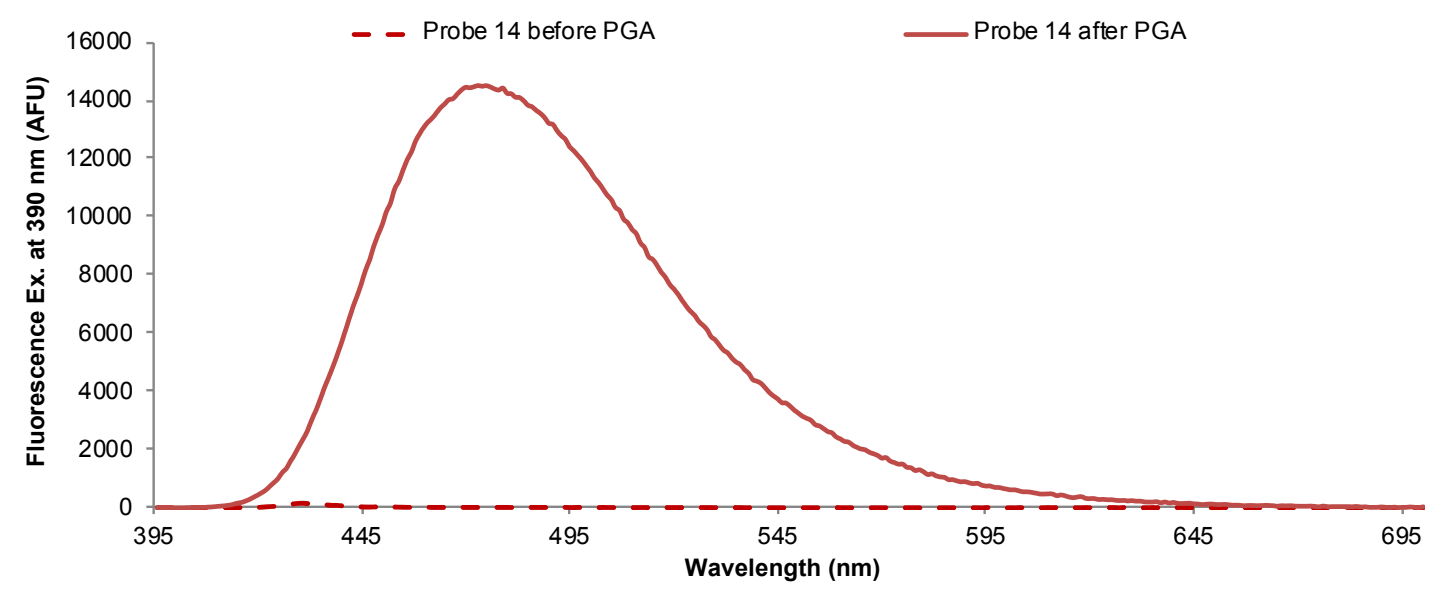

Fig. S149 - Time-dependent changes in the blue-cyan fluorescence intensity (Ex./Em. $385 / 490 \mathrm{~nm}$, slit $2 \mathrm{~nm}$ ) of fluorogenic probe 15 (concentration: $1.0 \mu \mathrm{M}$ ) in the presence of $\mathrm{PGA}(1 \mathrm{U})$ in $\mathrm{PB}$ at $37^{\circ} \mathrm{C}$

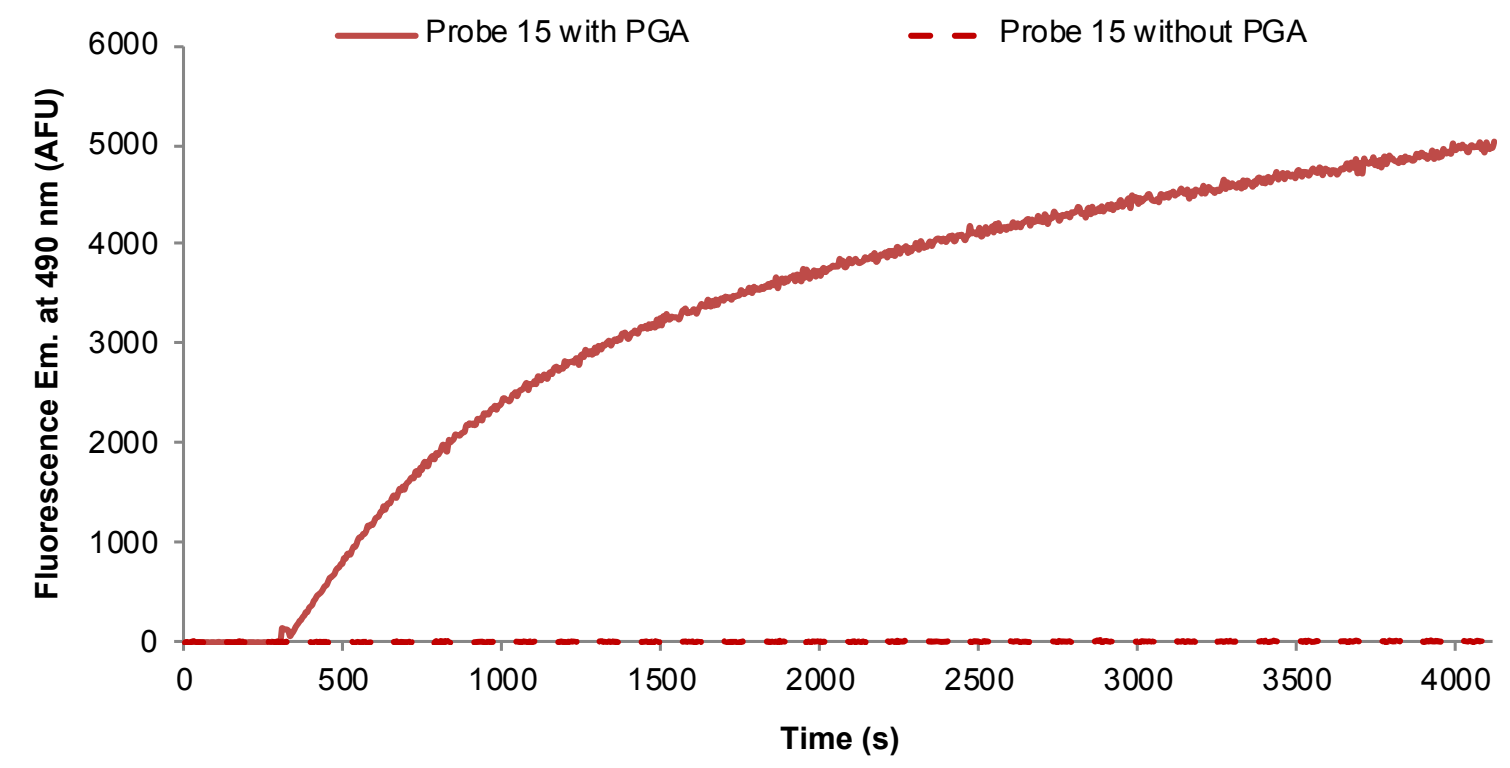


Fig. S150 - Over-layed fluorescence emission spectra (Ex. $385 \mathrm{~nm}$, slit $5 \mathrm{~nm}$ ) of fluorogenic probe 15 before and after incubation with PGA

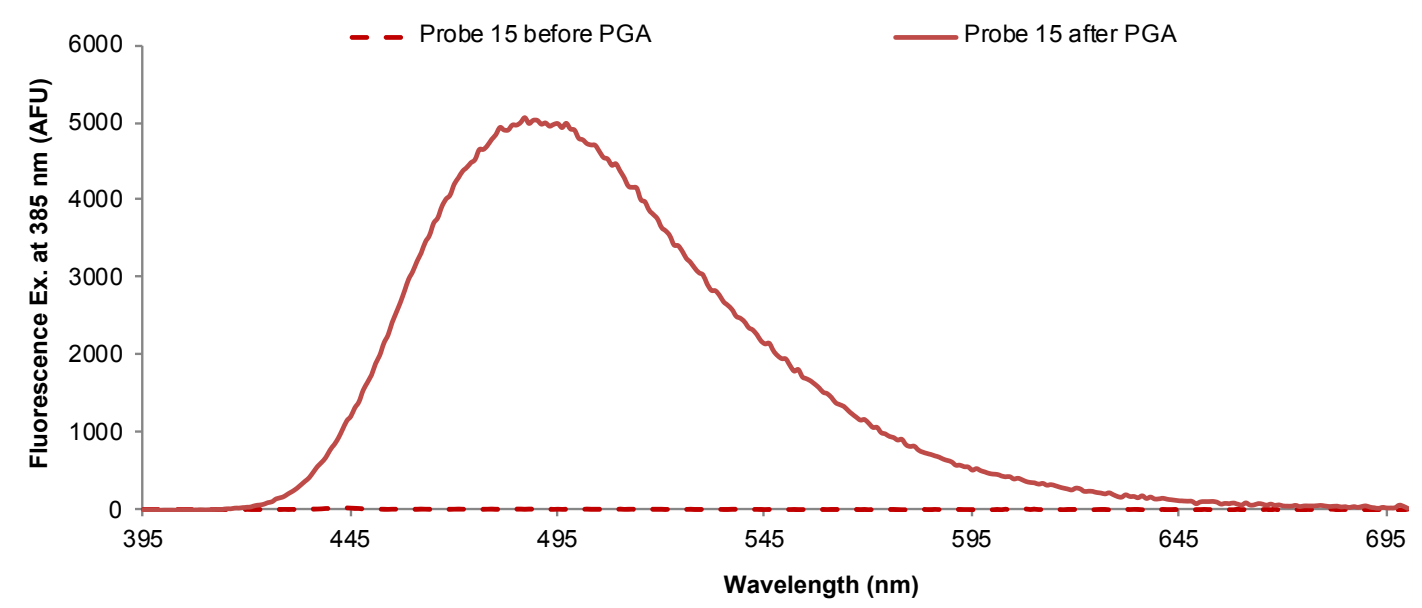

Fig. S151 - Time-dependent changes in the blue-cyan fluorescence intensity (Ex./Em. 405/480 nm, slit $2 \mathrm{~nm}$ ) of fluorogenic probe 16 (concentration: $1.0 \mu \mathrm{M}$ ) in the presence of PGA (1 U) in $\mathrm{PB}$ at $37^{\circ} \mathrm{C}$

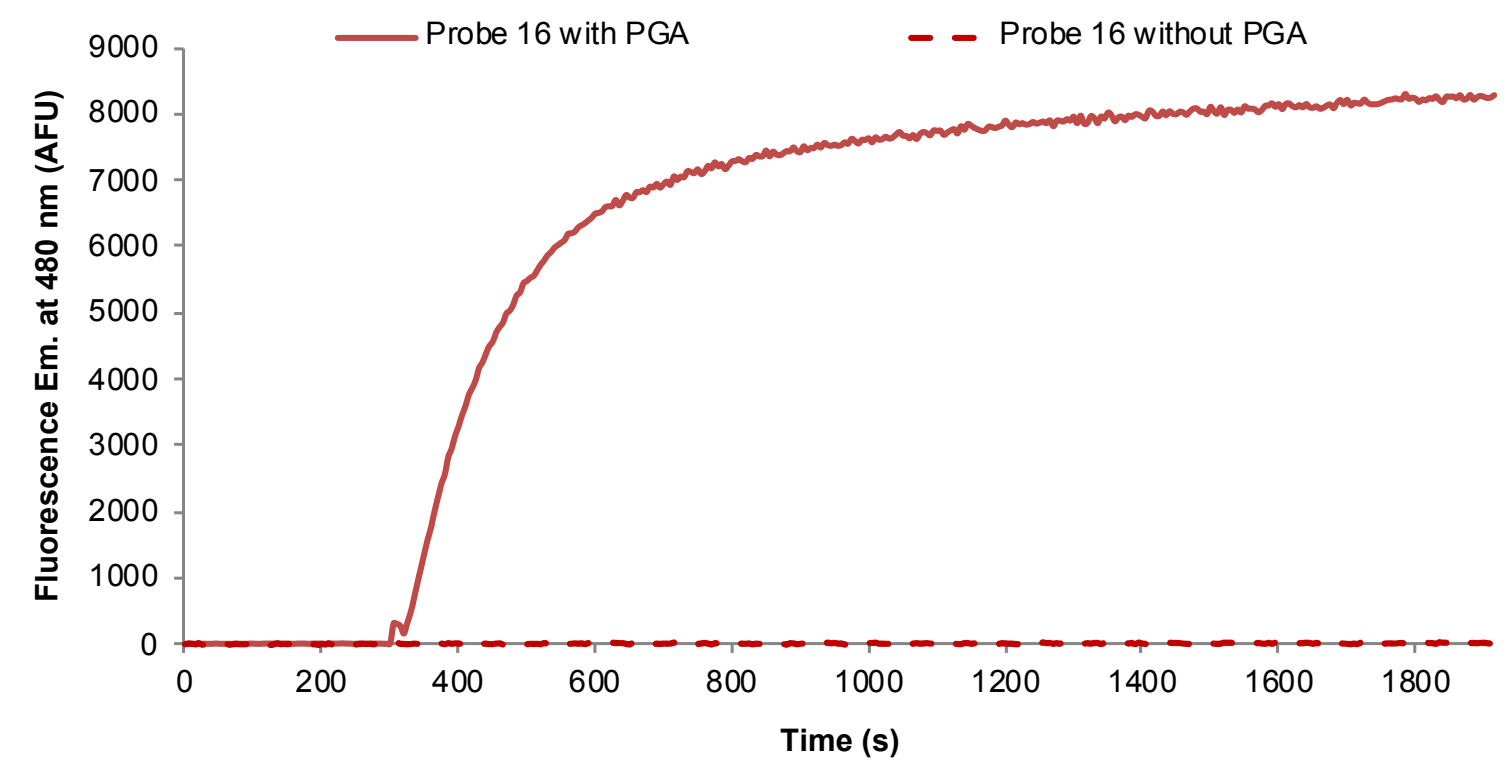


Fig. S152 - Over-layed fluorescence emission spectra (Ex. 405 nm, slit 5 nm) of fluorogenic probe 16 before and after incubation with PGA

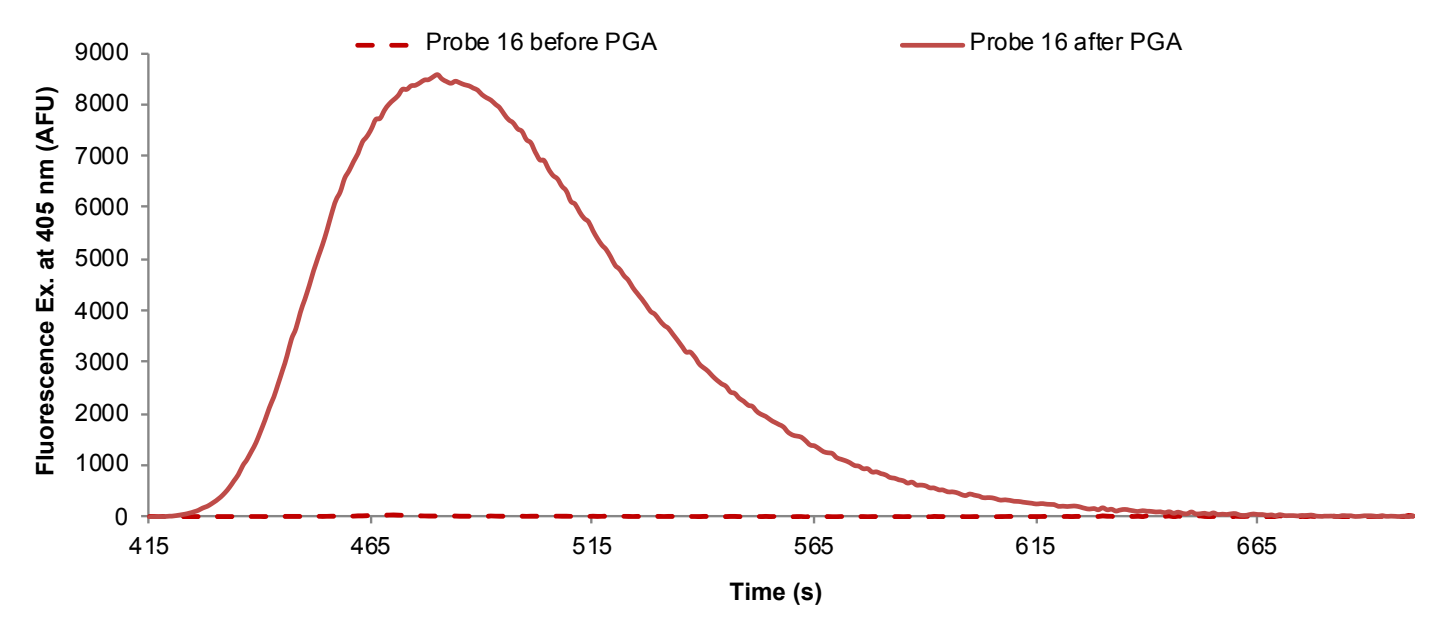

Fig. S153 - Time-dependent changes in the blue-cyan fluorescence intensity $(E x . / E m .390 / 480 \mathrm{~nm}$, slit $2 \mathrm{~nm}$ ) of fluorogenic probe 17 (concentration: $1.0 \mu \mathrm{M}$ ) in the presence of PGA (1 U) in PB at $37^{\circ} \mathrm{C}$

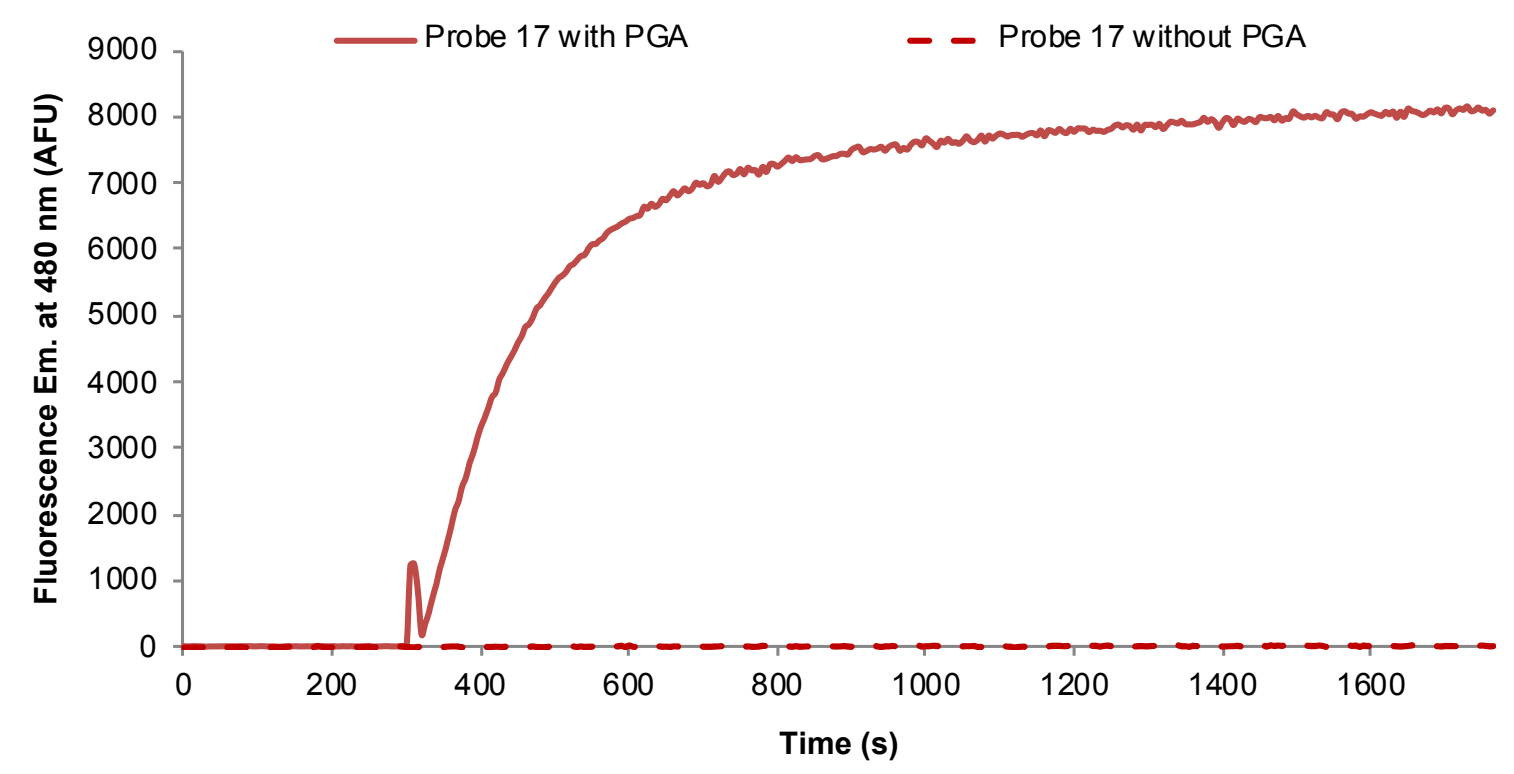


Fig. S154 - Over-layed fluorescence emission spectra (Ex. $390 \mathrm{~nm}$, slit $5 \mathrm{~nm})$ of fluorogenic probe 17 before and after incubation with PGA

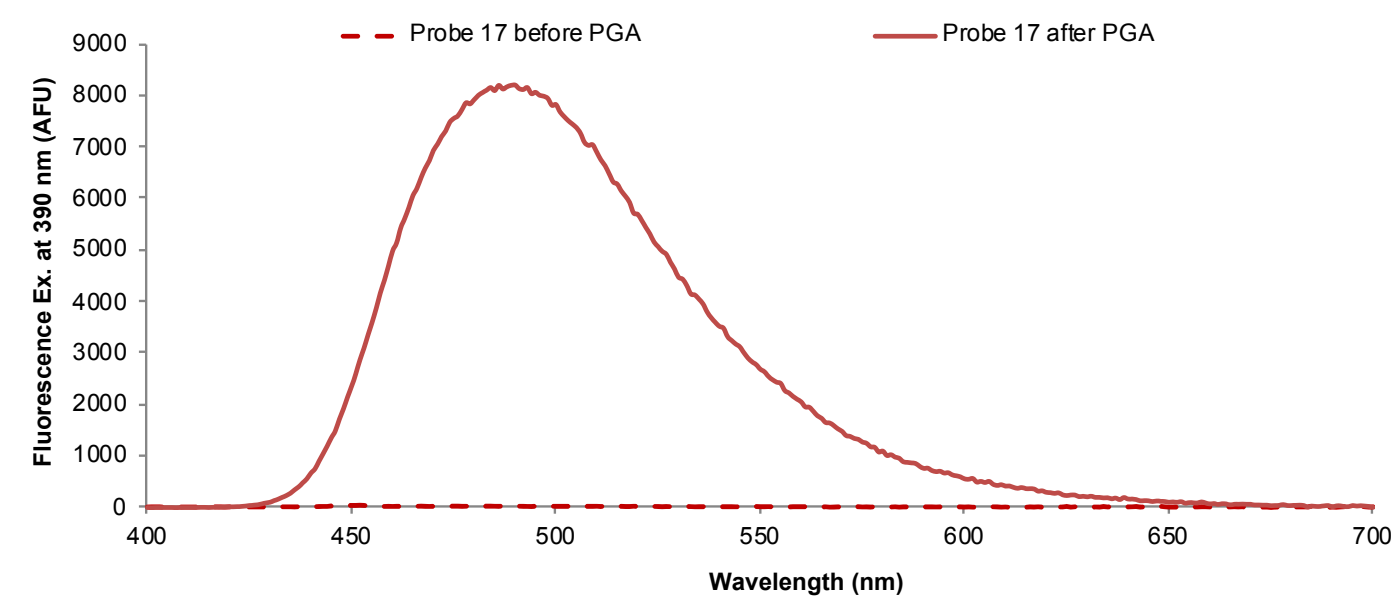

Fig. S155 - Time-dependent changes in the blue-cyan fluorescence intensity (Ex./Em. 380/490 nm, slit $2 \mathrm{~nm}$ ) of fluorogenic probe 18 (concentration: $1.0 \mu \mathrm{M}$ ) in the presence of $\mathrm{PGA}(1 \mathrm{U})$ in $\mathrm{PB}$ at $37^{\circ} \mathrm{C}$

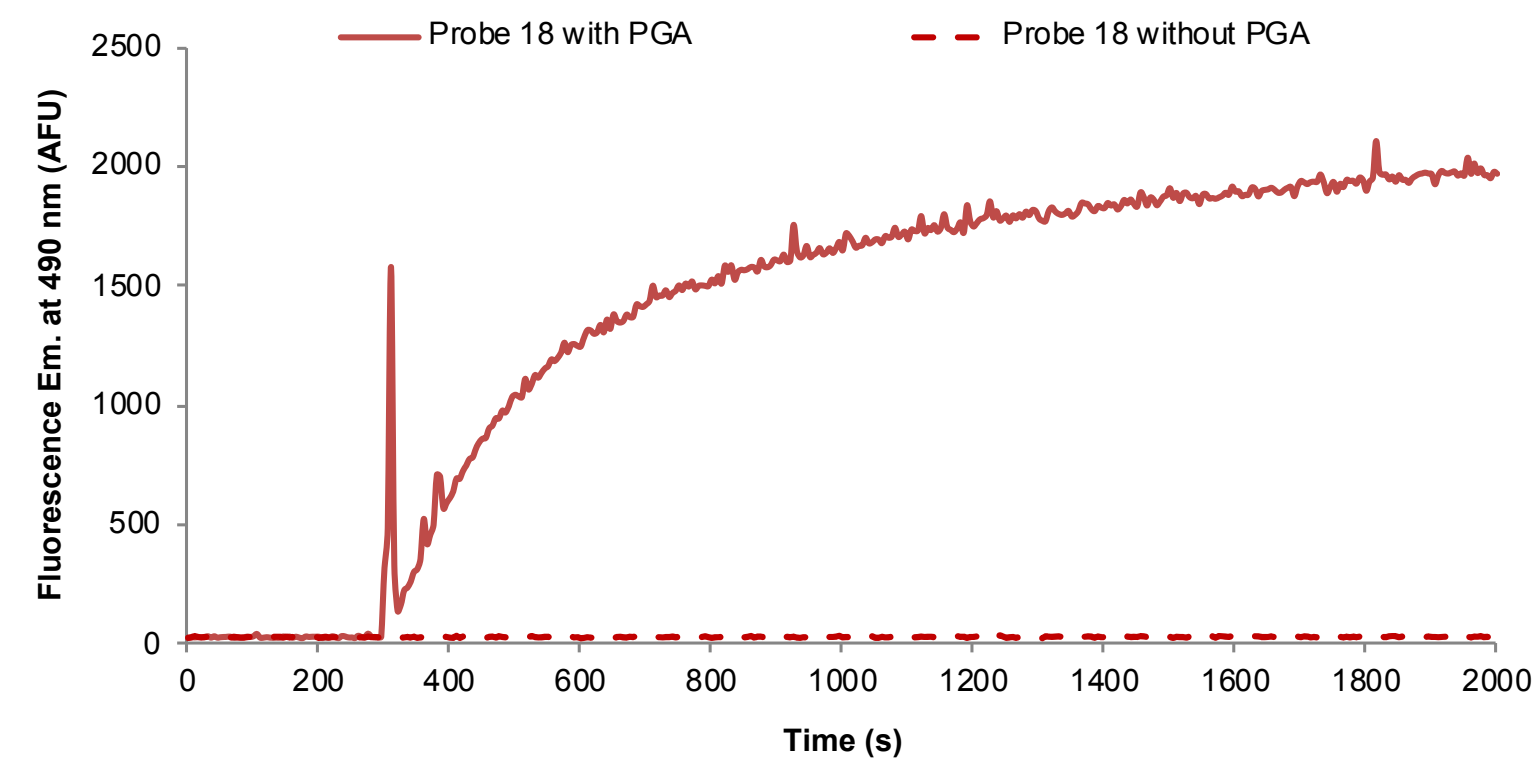


Fig. S156 - Over-layed fluorescence emission spectra (Ex. $380 \mathrm{~nm}$, slit $5 \mathrm{~nm})$ of fluorogenic probe 18 before and after incubation with PGA

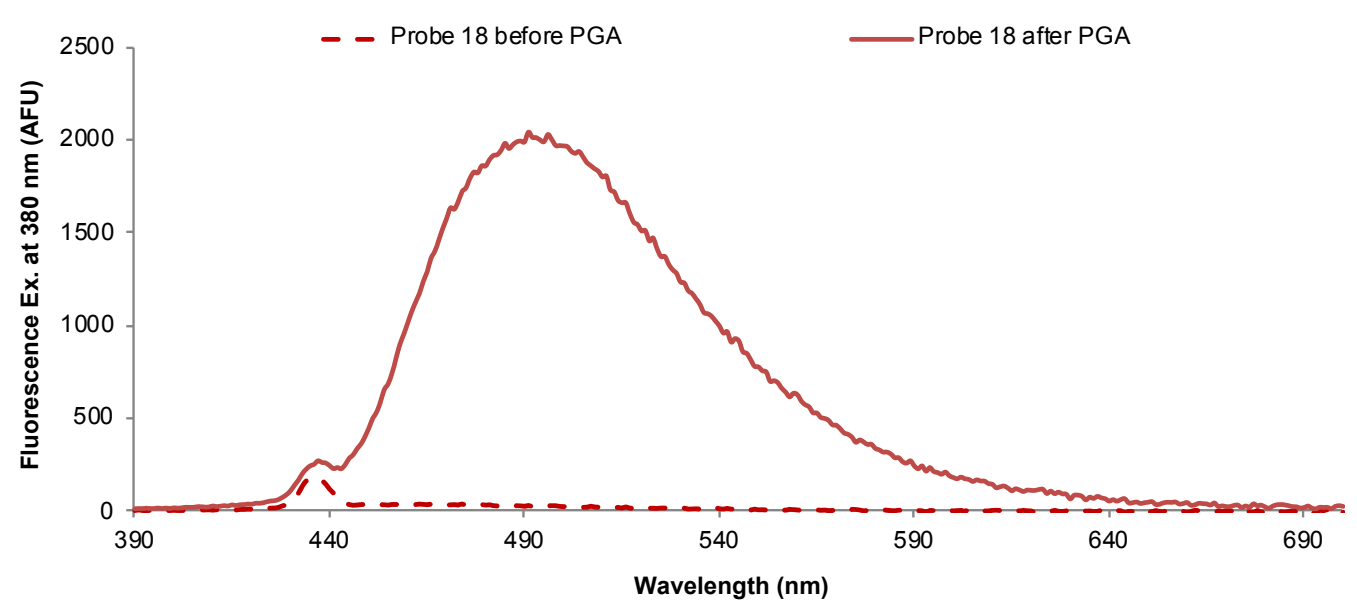

Fig. S157 - Time-dependent changes in the blue-cyan fluorescence intensity (Ex./Em. 365/455 nm, slit $2 \mathrm{~nm}$ ) of fluorogenic probe 12 (concentration: $1.0 \mu \mathrm{M}$ ) in the presence of PGA (1 $\mathrm{U}$ ) with or without GSH (50 equiv.), in PB at $37^{\circ} \mathrm{C}$

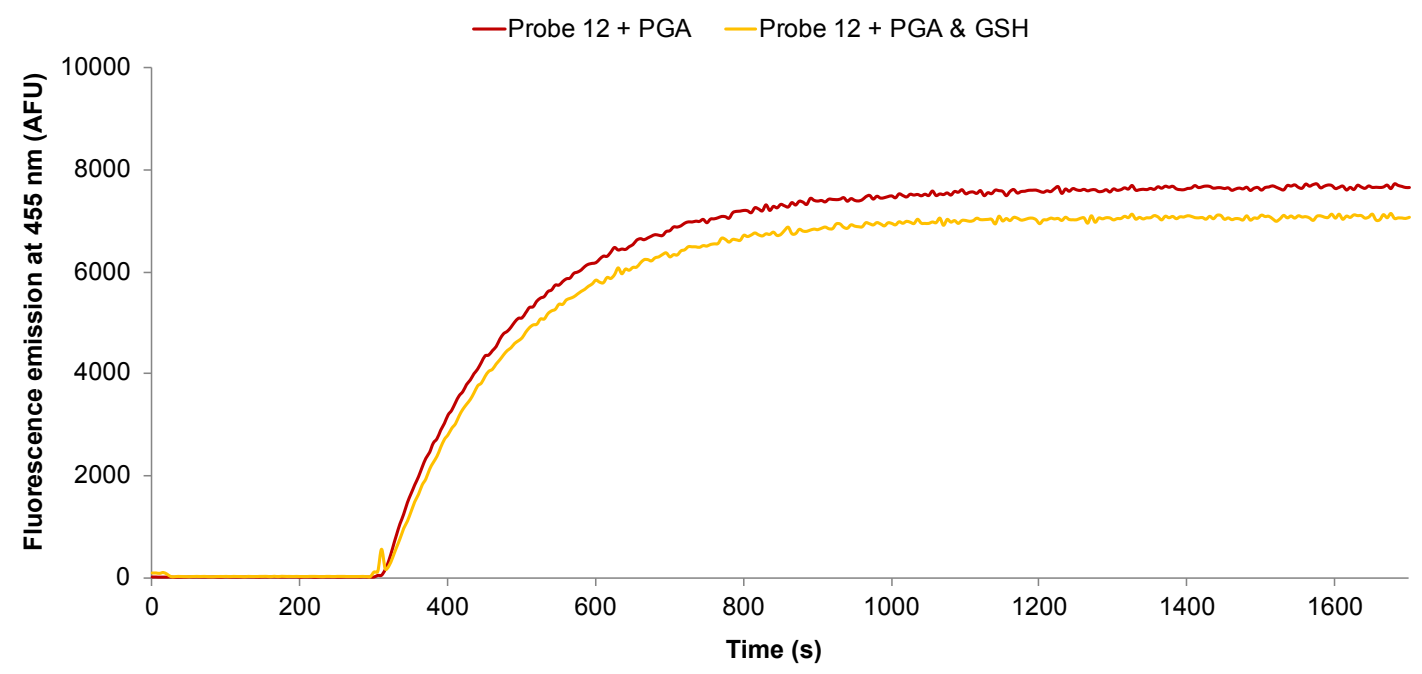


Fig. S158 - Time-dependent changes in the blue-cyan fluorescence intensity $(E x . / E m .380 / 480 \mathrm{~nm}$, slit $2 \mathrm{~nm}$ ) of fluorogenic probe 13 (concentration: $1.0 \mu \mathrm{M}$ ) in the presence of PGA ( $1 \mathrm{U}$ ) with or without GSH (50 equiv.), in PB at $37^{\circ} \mathrm{C}$

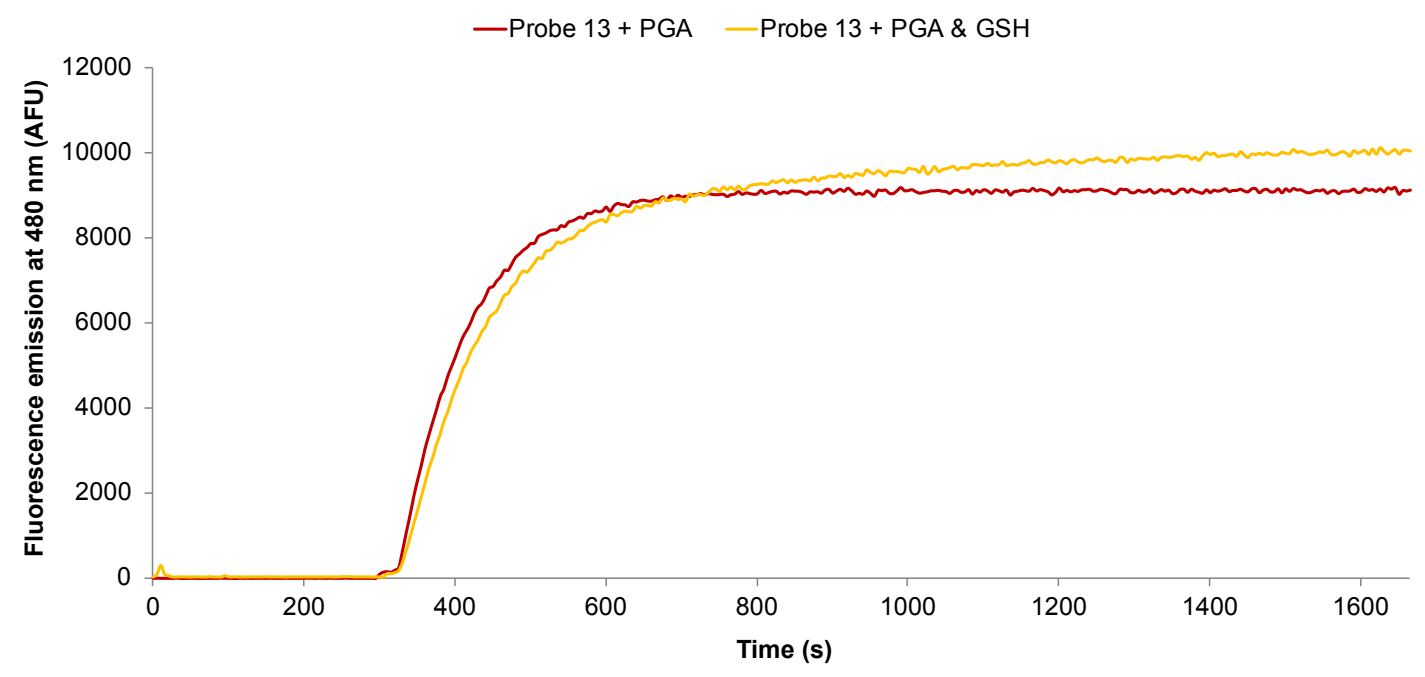

Fig. S159 - Time-dependent changes in the blue-cyan fluorescence intensity $(E x . / E m .390 / 475 \mathrm{~nm}$, slit $2 \mathrm{~nm}$ ) of fluorogenic probe 14 (concentration: $1.0 \mu \mathrm{M})$ in the presence of PGA ( $1 \mathrm{U}$ ) with or without GSH (50 equiv.), in PB at $37^{\circ} \mathrm{C}$

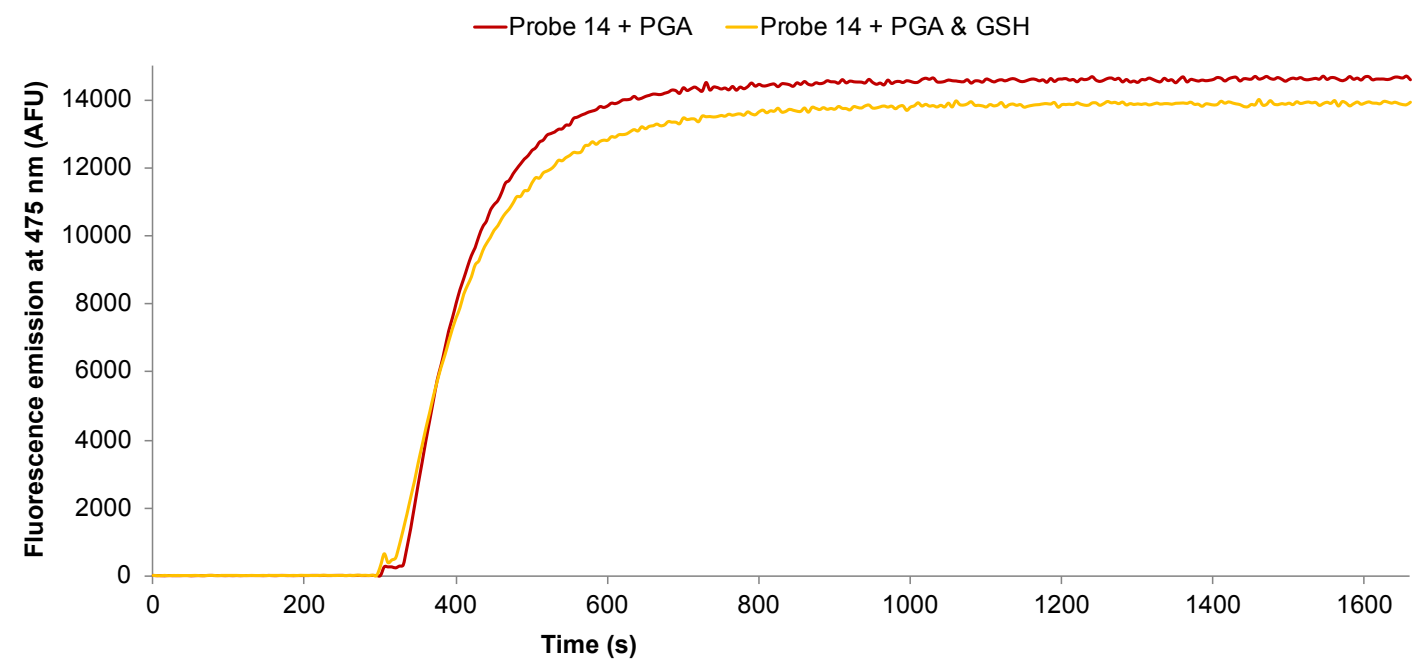


Fig. S160 - Time-dependent changes in the blue-cyan fluorescence intensity $(E x . / E m .385 / 490 \mathrm{~nm}$, slit $2 \mathrm{~nm}$ ) of fluorogenic probe 15 (concentration: $1.0 \mu \mathrm{M})$ in the presence of PGA ( $1 \mathrm{U}$ ) with or without GSH (50 equiv.), in PB at $37^{\circ} \mathrm{C}$

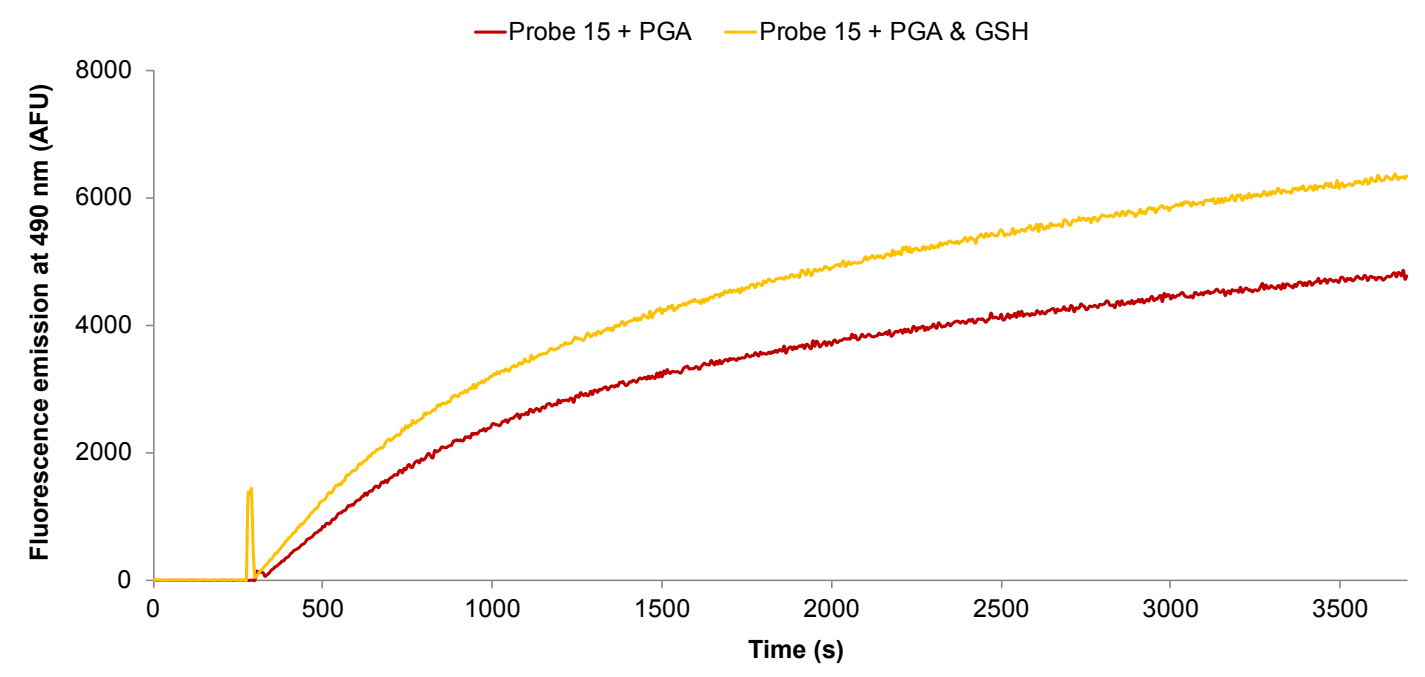

Fig. S161 - Time-dependent changes in the blue-cyan fluorescence intensity $(E x . / E m .405 / 480 \mathrm{~nm}$, slit $2 \mathrm{~nm}$ ) of fluorogenic probe 16 (concentration: $1.0 \mu \mathrm{M}$ ) in the presence of PGA ( $1 \mathrm{U}$ ) with or without GSH (50 equiv.), in $\mathrm{PB}$ at $37^{\circ} \mathrm{C}$

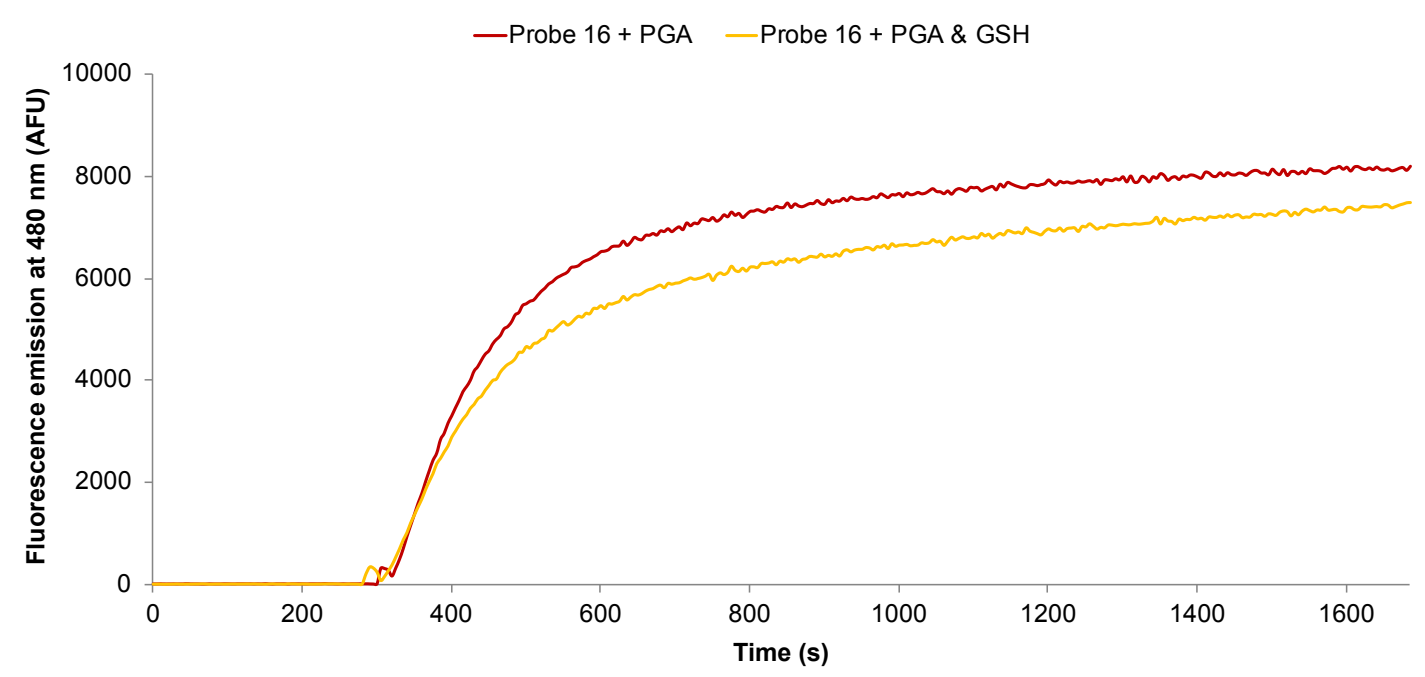


Fig. S162 - Time-dependent changes in the blue-cyan fluorescence intensity $(E x . / E m .390 / 480 \mathrm{~nm}$, slit $2 \mathrm{~nm}$ ) of fluorogenic probe 17 (concentration: $1.0 \mu \mathrm{M}$ ) in the presence of PGA ( $1 \mathrm{U}$ ) with or without GSH (50 equiv.), in PB at $37^{\circ} \mathrm{C}$

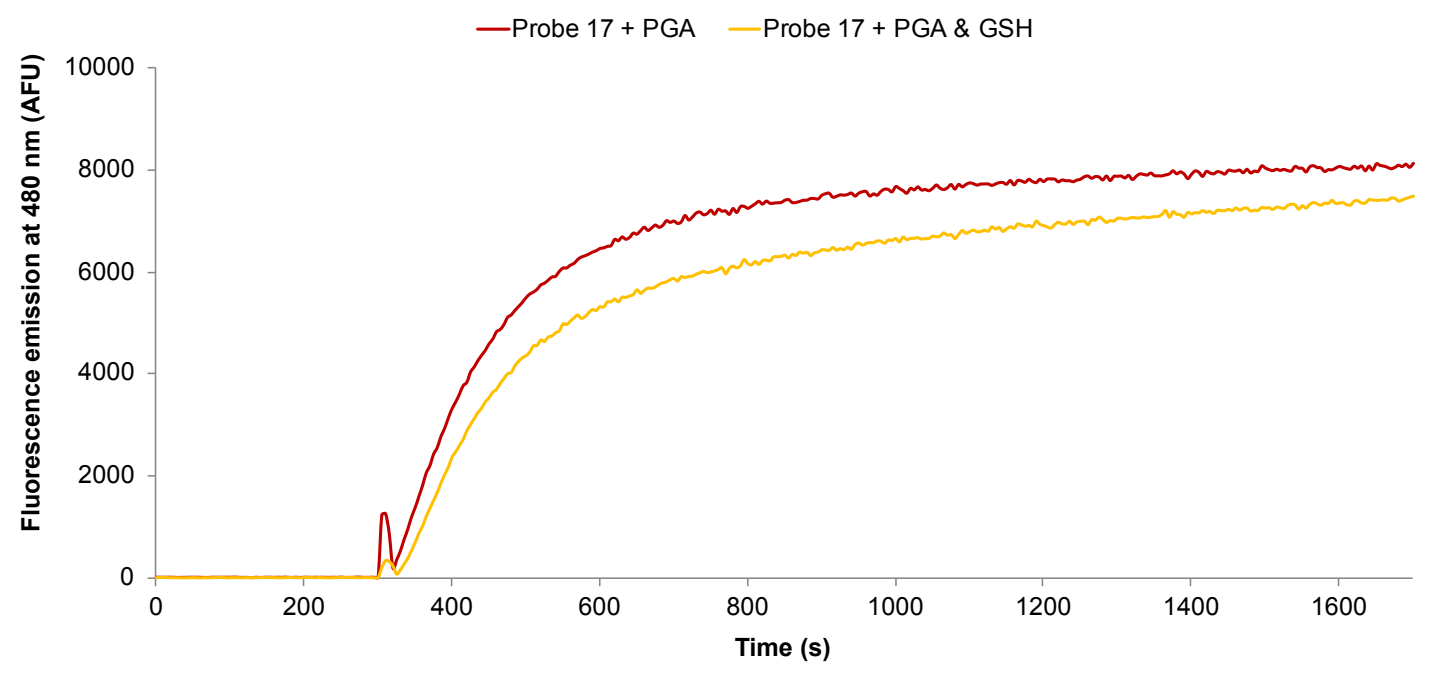

Fig. S163 - Time-dependent changes in the blue-cyan fluorescence intensity $(E x . / E m .380 / 490 \mathrm{~nm}$, slit $2 \mathrm{~nm}$ ) of fluorogenic probe 18 (concentration: $1.0 \mu \mathrm{M}$ ) in the presence of PGA (1 U) with or without GSH (50 equiv.), in PB at $37^{\circ} \mathrm{C}$

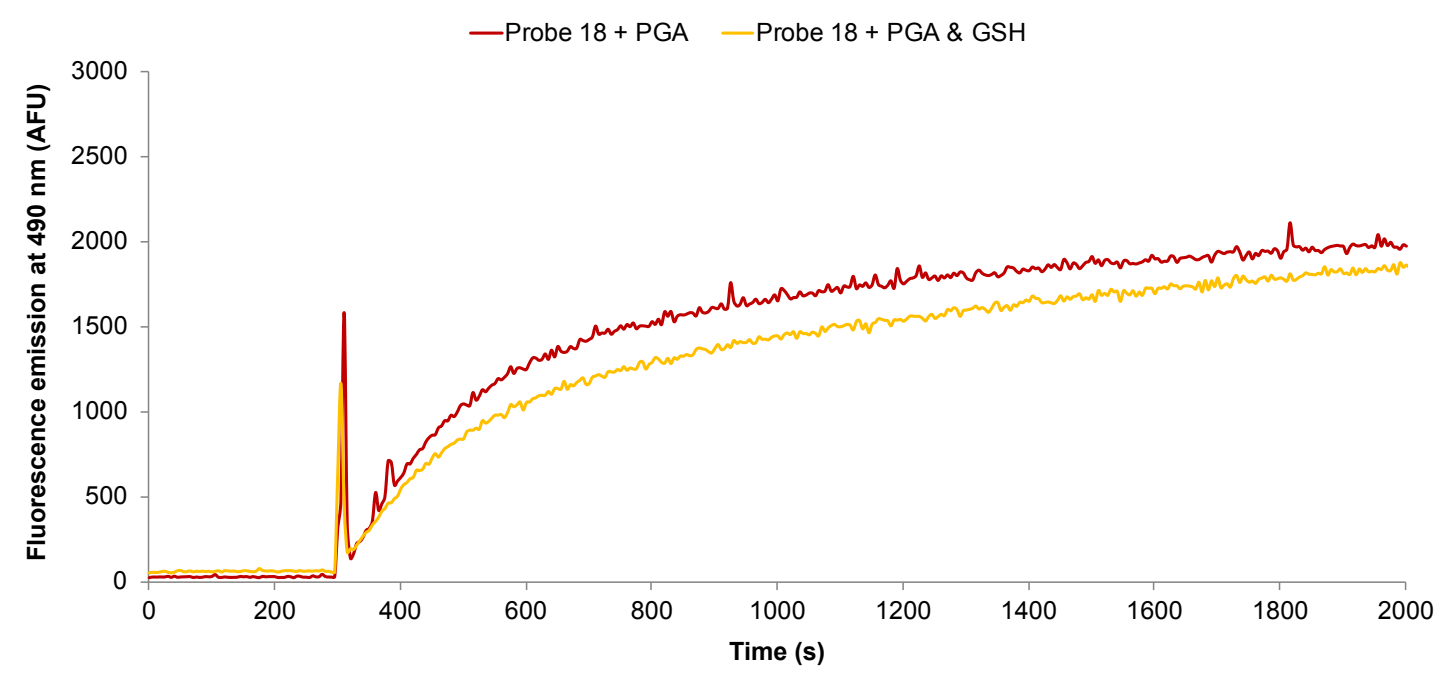


Fig. S164 - RP-HPLC elution profile (system E, fluorescence detection Ex./Em. $365 / 455 \mathrm{~nm}$ ) of $\mathrm{PB}$

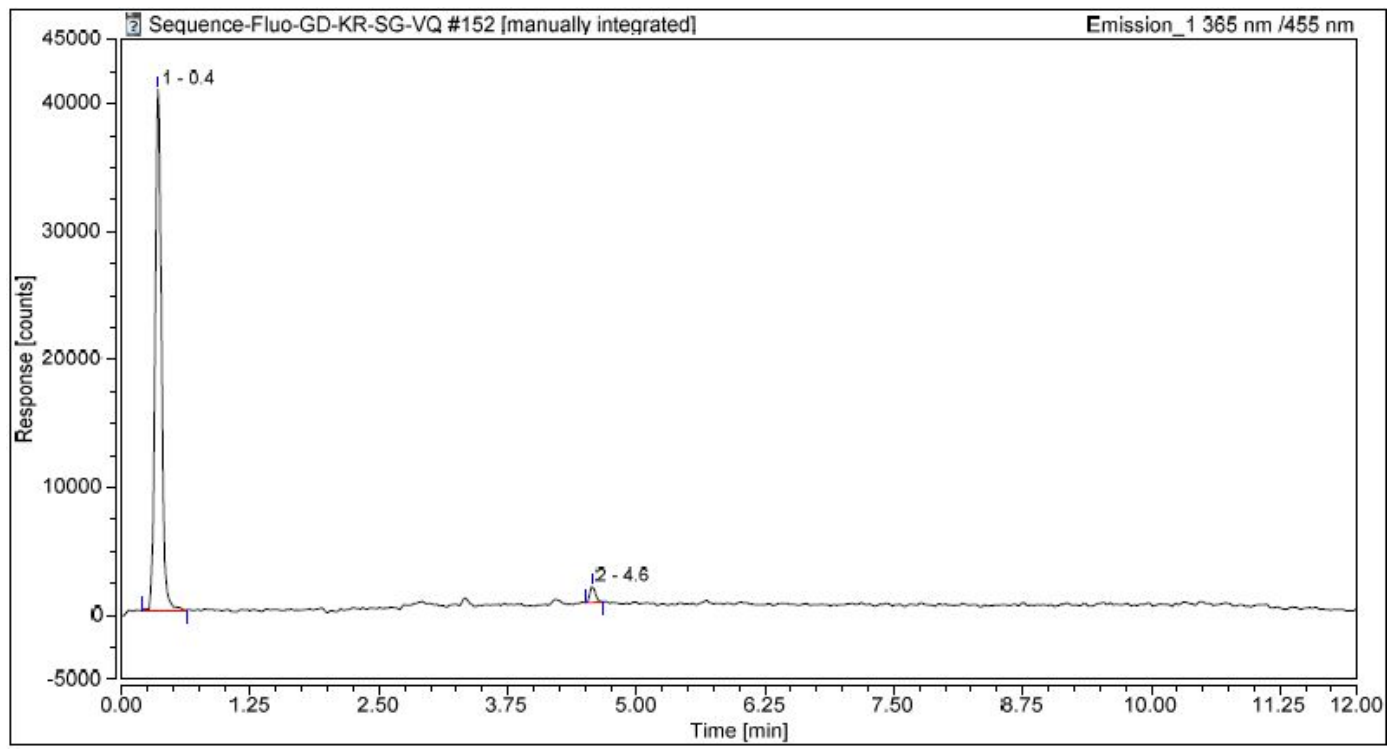

Fig. S165 - RP-HPLC elution profile (system E, fluorescence detection Ex./Em. $365 / 455 \mathrm{~nm}$ ) of quinoxalin-2(1H)-one 1 (concentration: $1.0 \mu \mathrm{M}$ in PB)

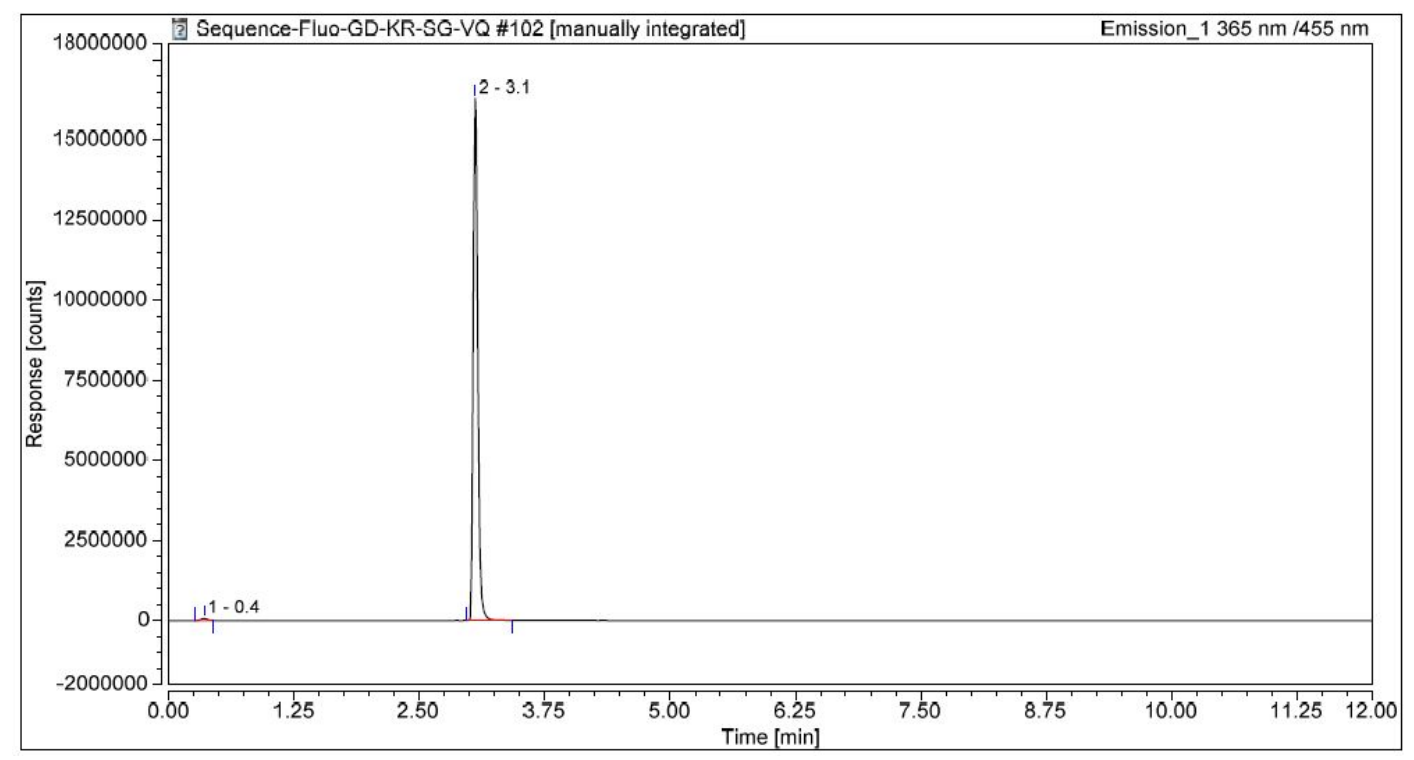


Fig. S166 - RP-HPLC elution profile (system E, fluorescence detection Ex./Em. $365 / 455 \mathrm{~nm}$ ) of fluorogenic probe 12 without PGA (concentration: $1.0 \mu \mathrm{M}$ in PB, $30 \mathrm{~min}, 37^{\circ} \mathrm{C}$ )

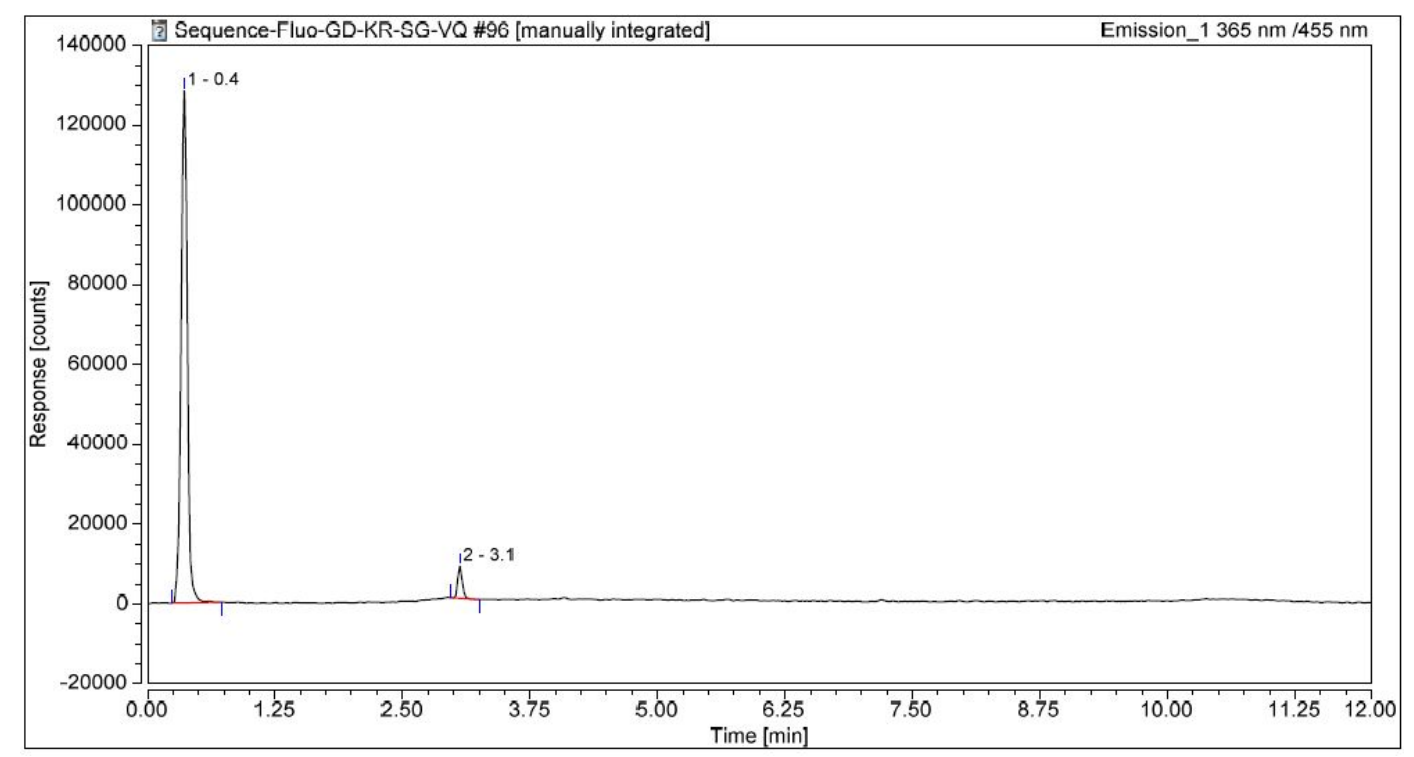

Fig. S167 - RP-HPLC elution profile (system E, fluorescence detection Ex./Em. $365 / 455 \mathrm{~nm}$ ) of fluorogenic probe 12 (concentration: 1.0 $\mu \mathrm{M}$ in PB) with PGA (1 U, $30 \mathrm{~min}, 37^{\circ} \mathrm{C}$ )

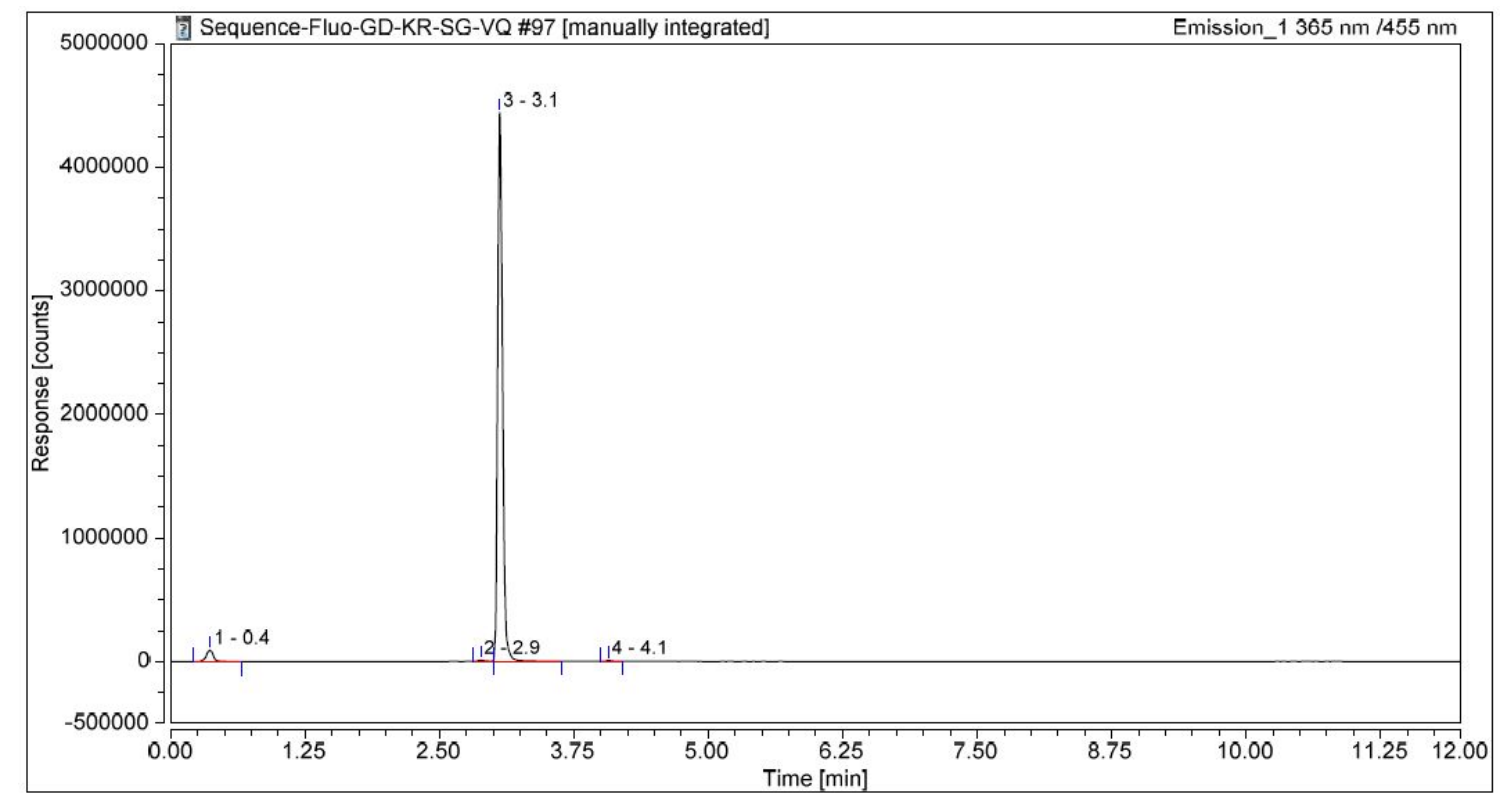


Fig. S168 - RP-HPLC elution profile (system E, fluorescence detection Ex./Em. $365 / 455 \mathrm{~nm}$ ) of co-injection of fluorogenic probe 12 (concentration: $0.5 \mu \mathrm{M}$ in PB) with PGA (1 $\left.\mathrm{U}, 30 \mathrm{~min}, 37^{\circ} \mathrm{C}\right)$ and quinoxalin-2(1H)-one 1 (concentration: $0.5 \mu \mathrm{M}$ in PB)

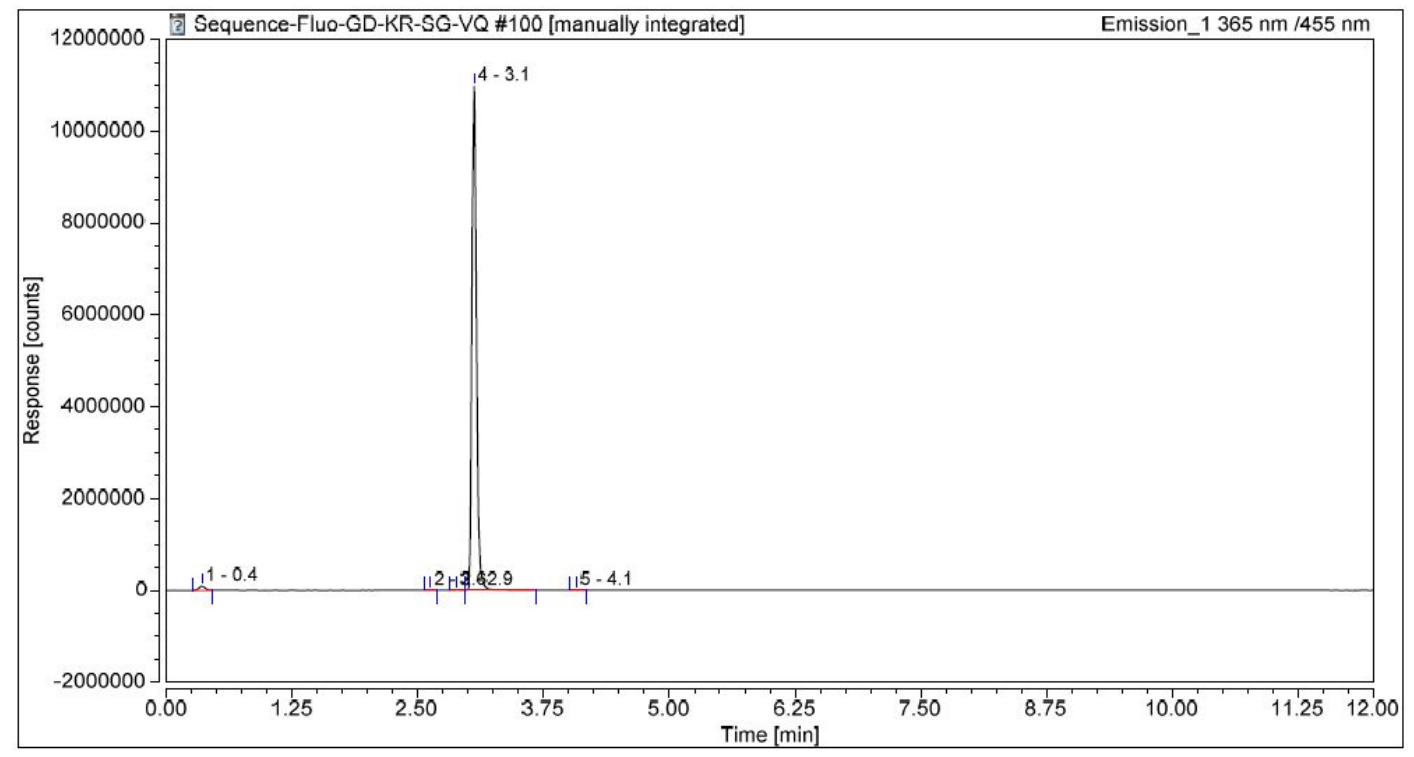

Fig. S169 - RP-HPLC elution profile (system E, fluorescence detection Ex./Em. 365/455 nm) of fluorogenic probe 12 (concentration: $1.0 \mu \mathrm{M}$ in PB) with PGA (1 U, $30 \mathrm{~min}, 37^{\circ} \mathrm{C}$ ) and GSH (50 equiv.)

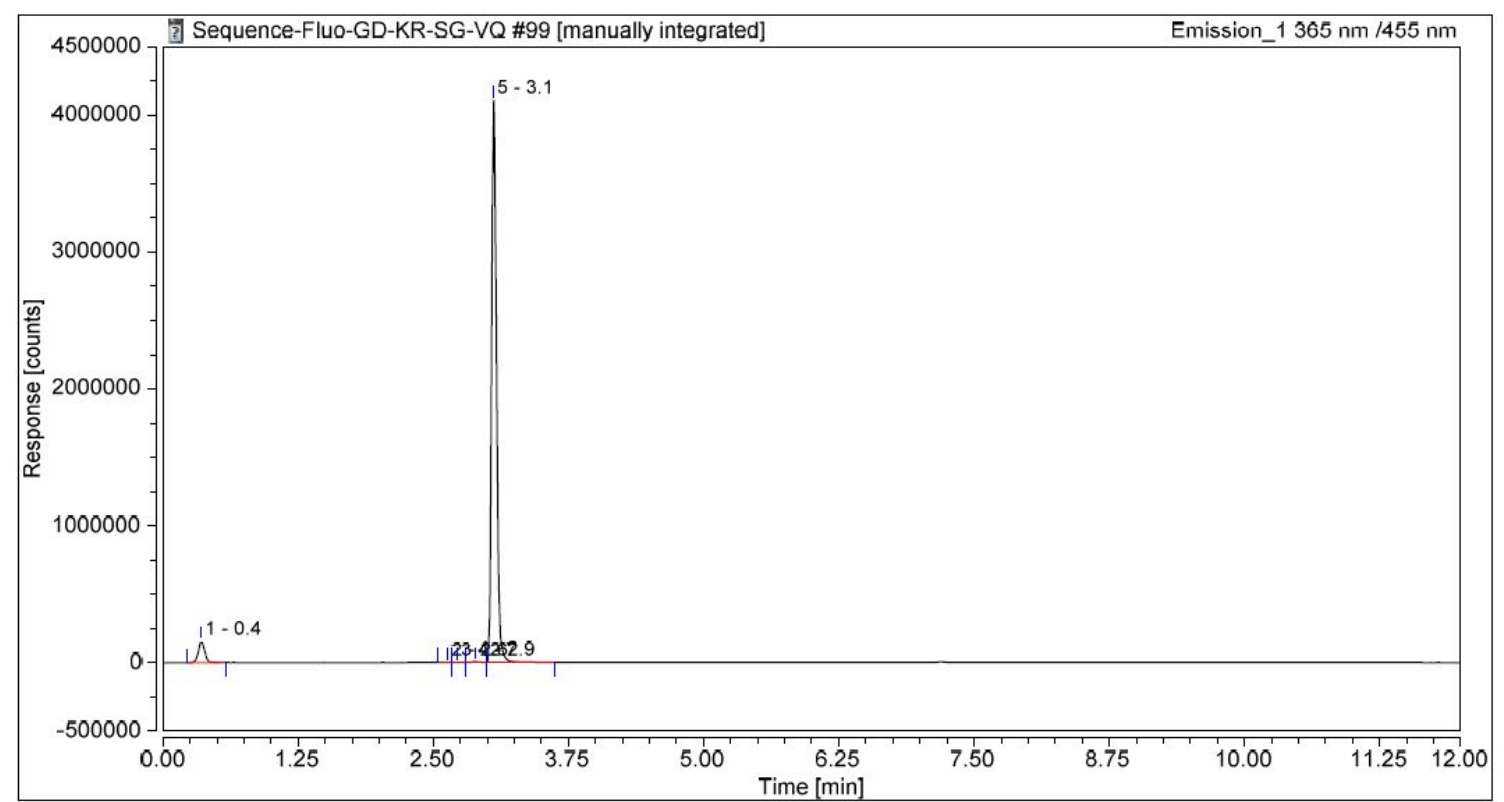


Fig. S170 - RP-HPLC elution profile (system E, fluorescence detection Ex./Em. $365 / 455 \mathrm{~nm}$ ) of co-injection of fluorogenic probe 12 (concentration: $0.5 \mu \mathrm{M}$ in PB) with PGA (1 U, $30 \mathrm{~min}, 37^{\circ} \mathrm{C}$ ) and GSH (50 equiv.), and quinoxalin-2(1H)-one 1 (concentration: $0.5 \mu \mathrm{M}$ in $\mathrm{PB}$ )

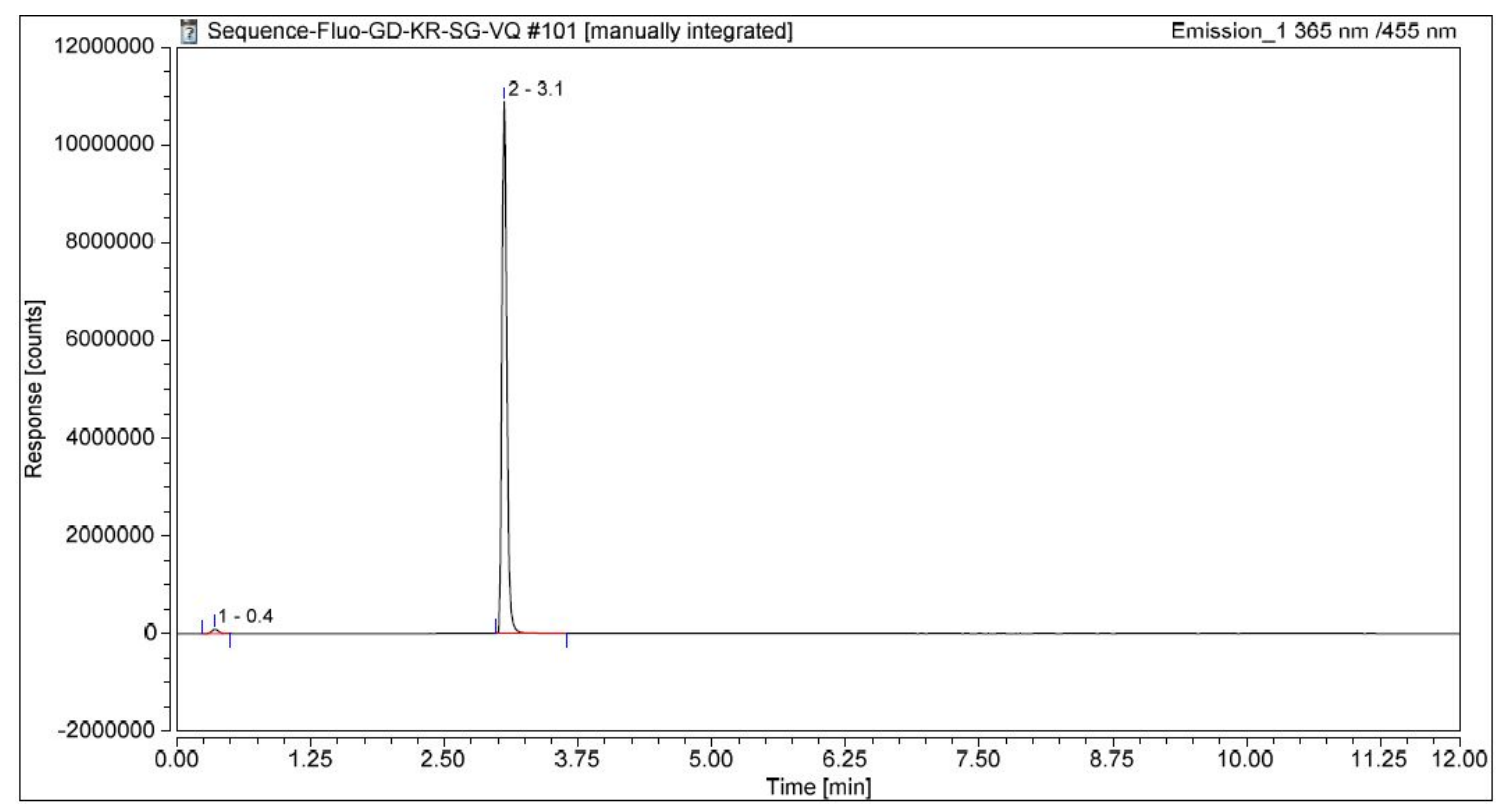

Fig. S171 - RP-HPLC elution profile (system E, fluorescence detection Ex./Em. $380 / 480 \mathrm{~nm}$ ) of $P B$

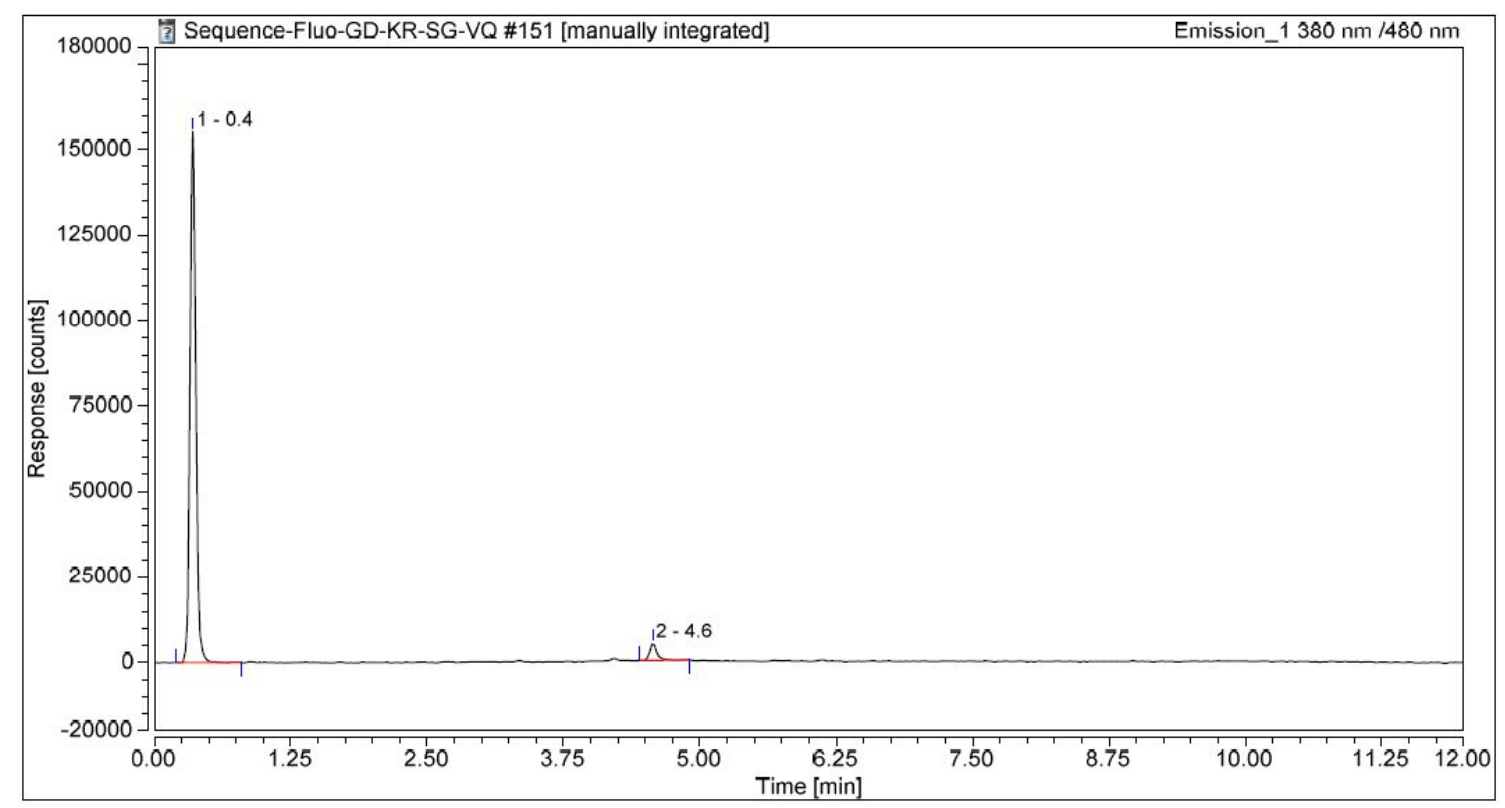


Fig. S172 - RP-HPLC elution profile (system E, fluorescence detection Ex./Em. $380 / 480 \mathrm{~nm}$ ) of quinoxalin- $2(1 \mathrm{H})$-one 2 (concentration: $1.0 \mu \mathrm{M}$ in PB)

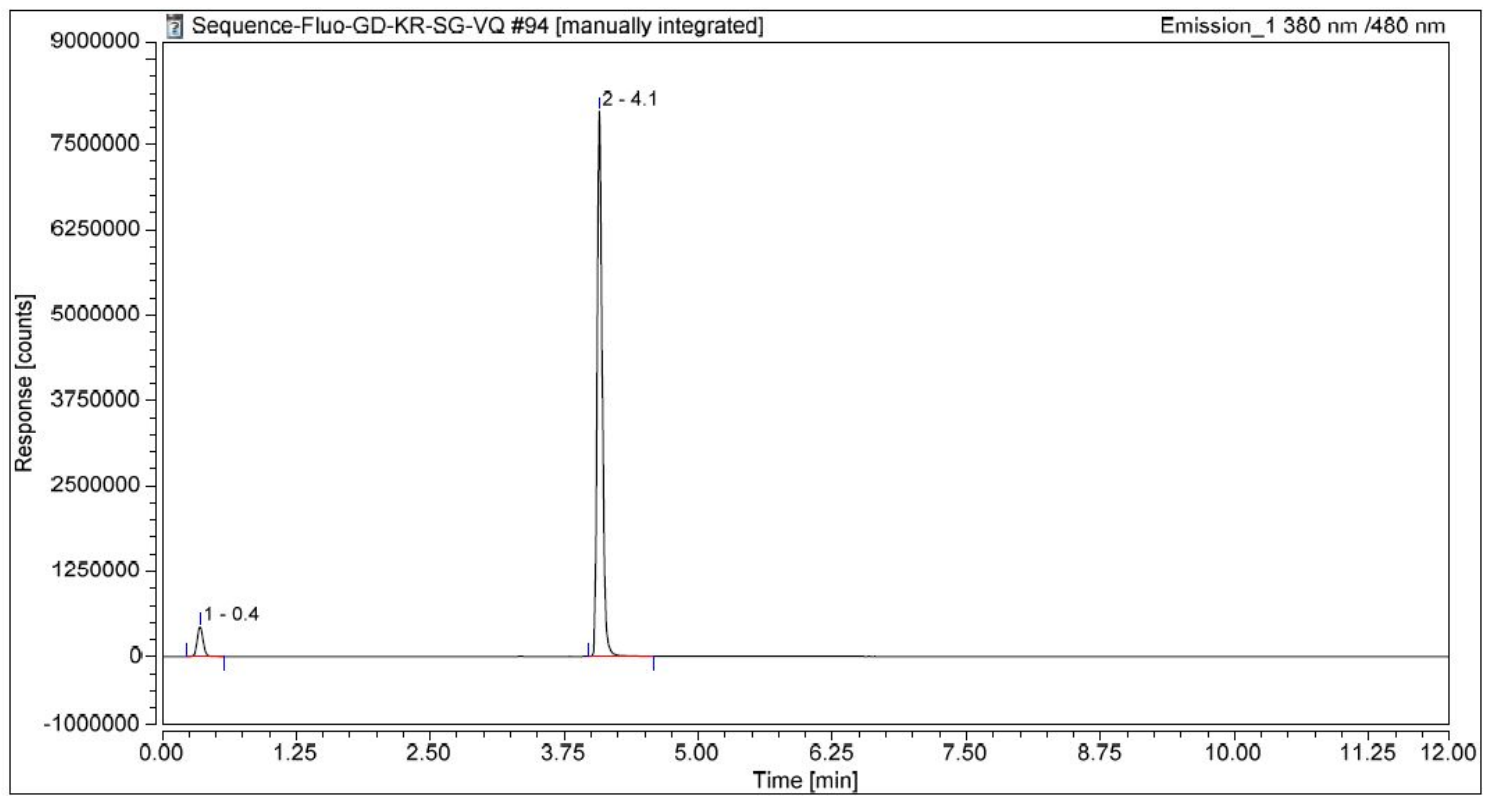

Fig. S173 - RP-HPLC elution profile (system E, fluorescence detection Ex./Em. $380 / 480 \mathrm{~nm}$ ) of fluorogenic probe 13 without PGA (concentration: $1.0 \mu \mathrm{M}$ in PB, $30 \mathrm{~min}, 37^{\circ} \mathrm{C}$ )

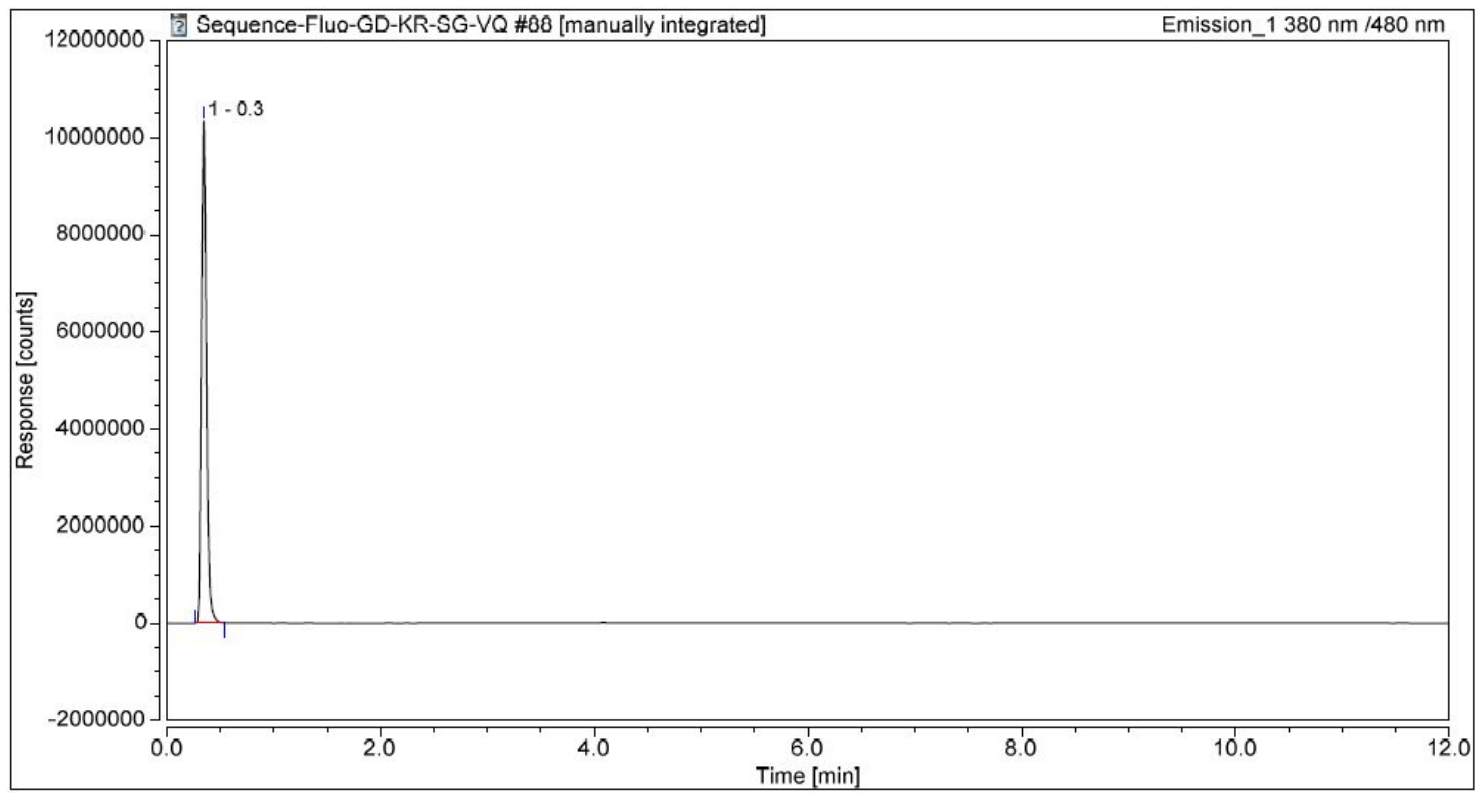


Fig. S174 - RP-HPLC elution profile (system E, fluorescence detection Ex./Em. $380 / 480 \mathrm{~nm}$ ) of fluorogenic probe 13 (concentration: $1.0 \mu \mathrm{M}$ in PB) with PGA (1 U, $30 \min , 37^{\circ} \mathrm{C}$ )

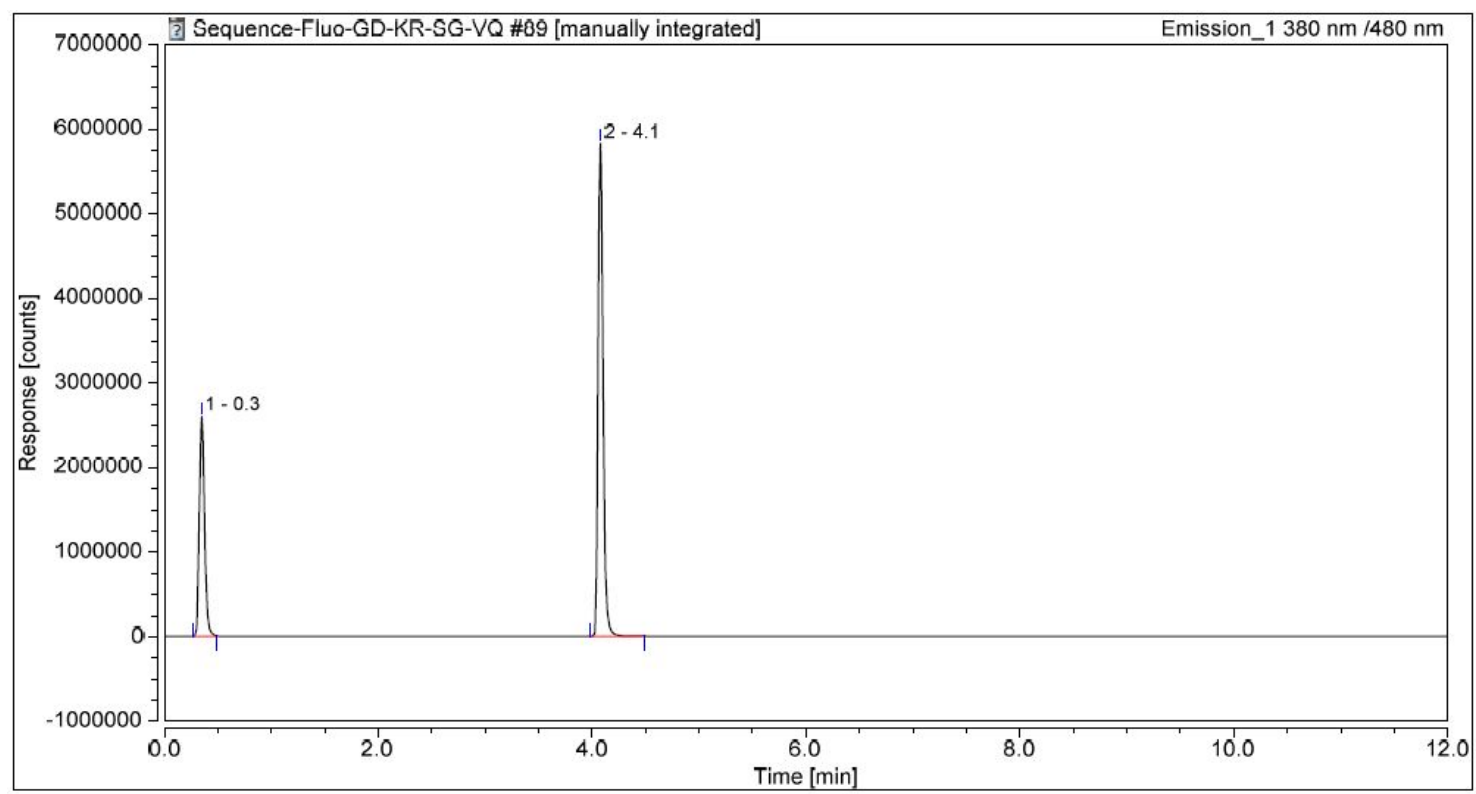

Fig. S175 - RP-HPLC elution profile (system E, fluorescence detection Ex./Em. $380 / 480 \mathrm{~nm}$ ) of co-injection of fluorogenic probe 13 (concentration: $0.5 \mu \mathrm{M}$ in PB) with PGA (1 U, $30 \mathrm{~min}, 37^{\circ} \mathrm{C}$ ) and quinoxalin-2(1H)-one 2 (concentration: $0.5 \mu \mathrm{M}$ in $\mathrm{PB}$ )

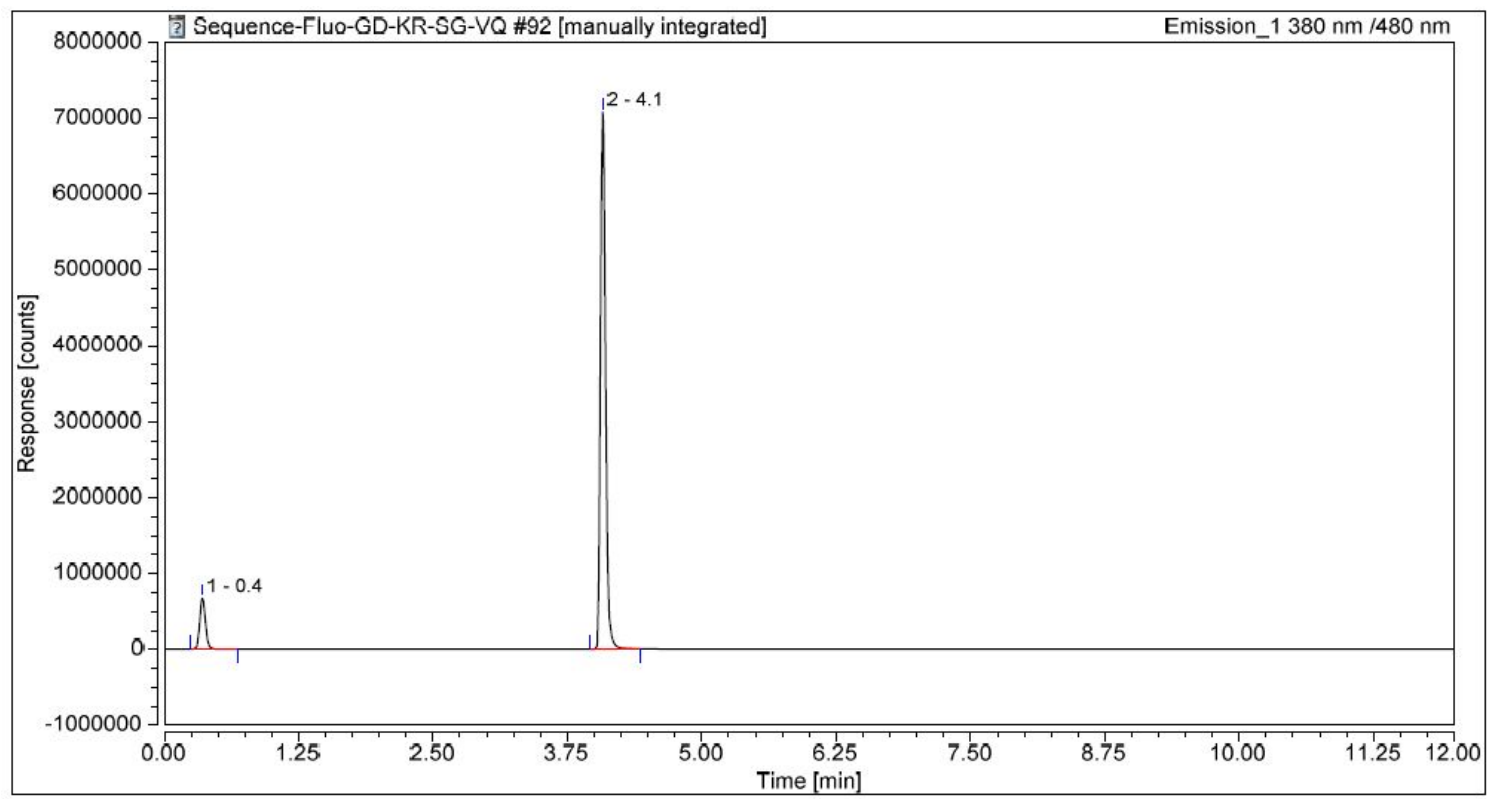


Fig. S176 - RP-HPLC elution profile (system E, fluorescence detection Ex./Em. $380 / 480 \mathrm{~nm}$ ) of fluorogenic probe 13 (concentration: $1.0 \mu \mathrm{M}$ in PB) with PGA (1 U, $30 \mathrm{~min}, 37^{\circ} \mathrm{C}$ ) and GSH (50 equiv.)

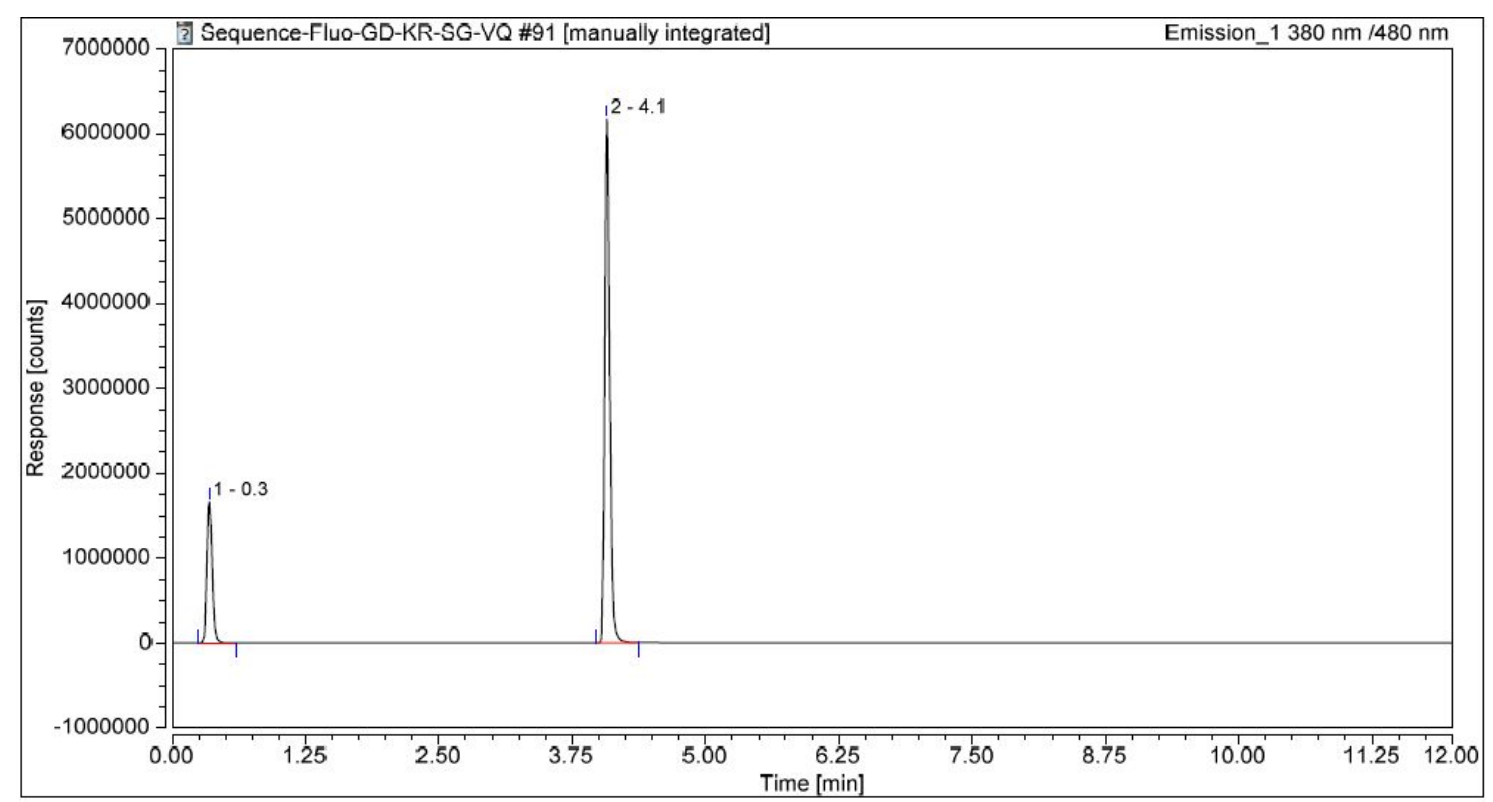

Fig. S177 - RP-HPLC elution profile (system E, fluorescence detection Ex./Em. $380 / 480 \mathrm{~nm}$ ) of co-injection of fluorogenic probe 13 (concentration: $0.5 \mu \mathrm{M}$ in PB) with PGA (1 U, $30 \mathrm{~min}, 37^{\circ} \mathrm{C}$ ) and GSH (50 equiv.), and quinoxalin-2(1H)-one 2 (concentration: $0.5 \mu \mathrm{M}$ in PB)

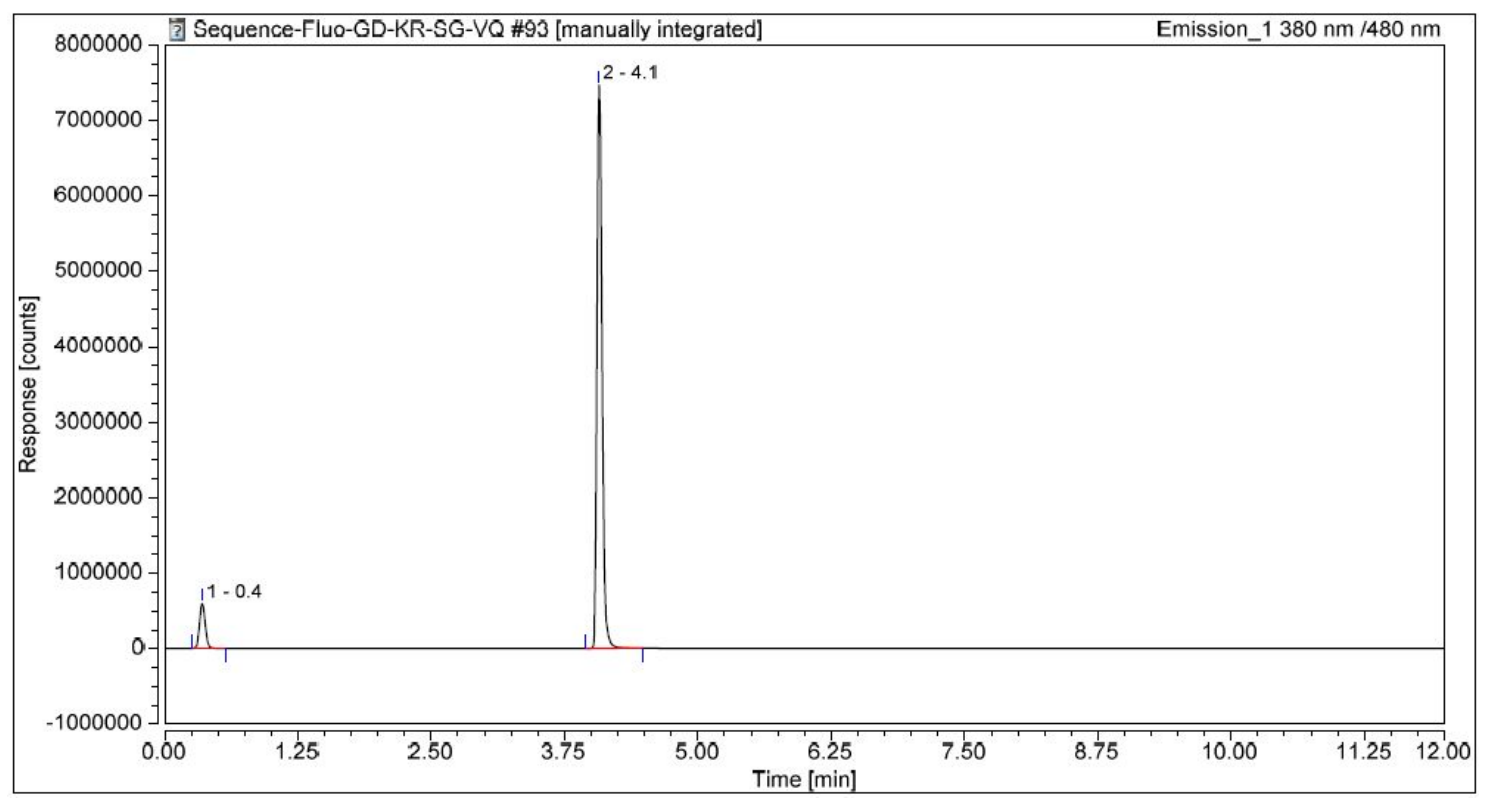


Fig. S178 - RP-HPLC elution profile (system E, fluorescence detection Ex./Em. $390 / 475 \mathrm{~nm}$ ) of $\mathrm{PB}$

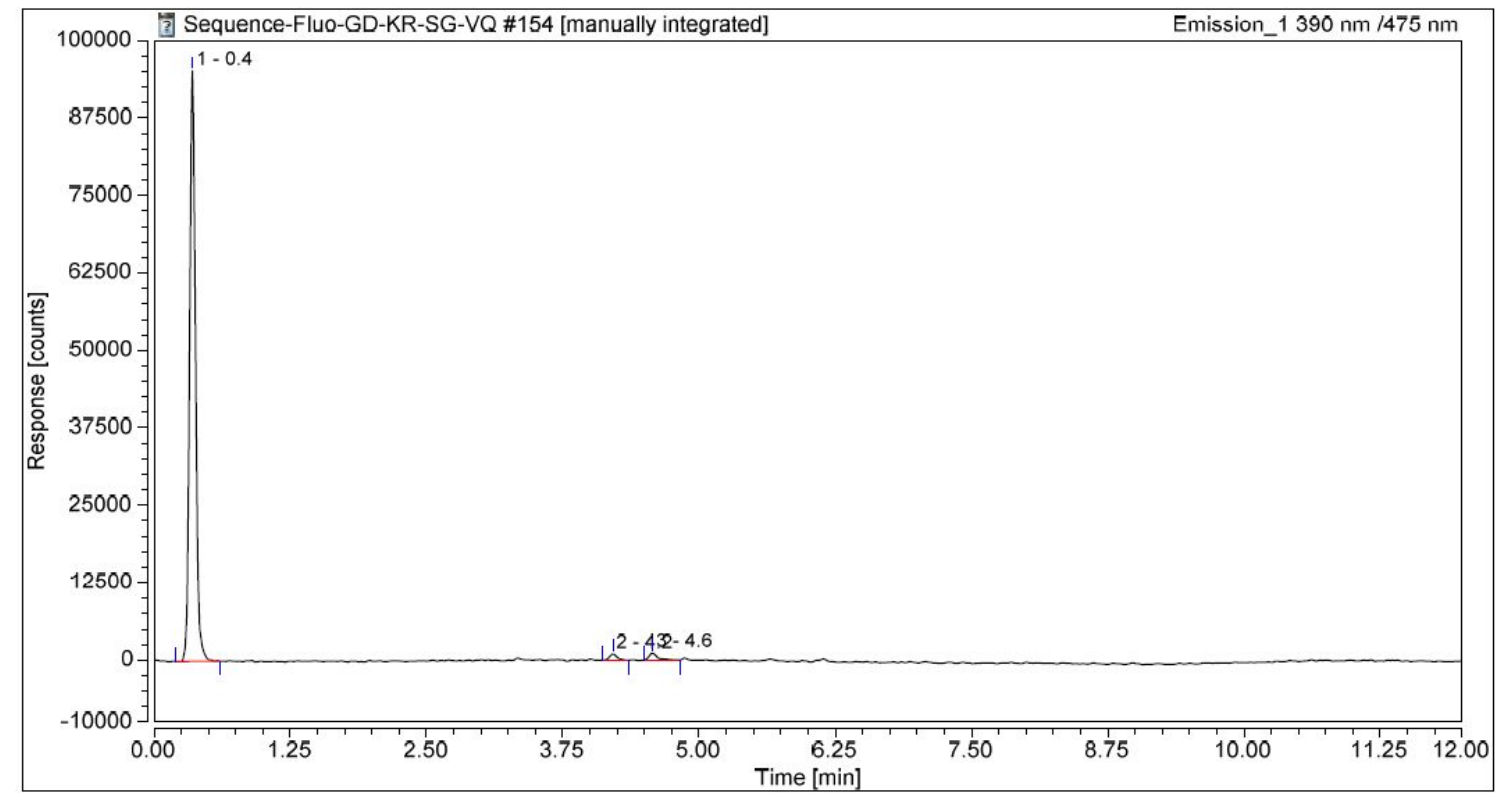

Fig. S179 - RP-HPLC elution profile (system E, fluorescence detection Ex./Em. 390/475 nm) of quinoxalin-2(1H)-one 3 (concentration: $1.0 \mu \mathrm{M}$ in $\mathrm{PB}$ )

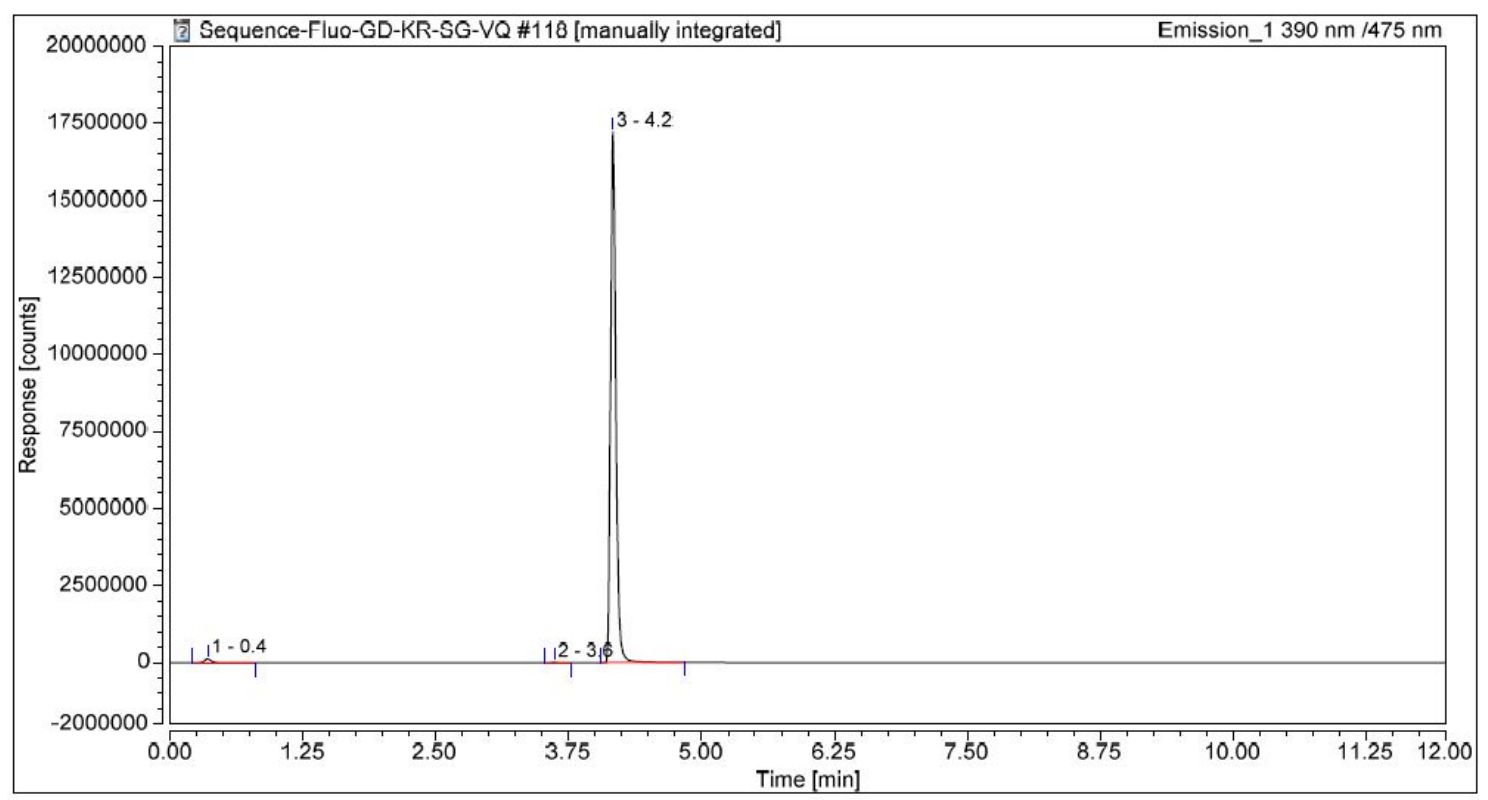


Fig. S180 - RP-HPLC elution profile (system E, fluorescence detection Ex./Em. 390/475 nm) of fluorogenic probe 14 without PGA (concentration: $1.0 \mu \mathrm{M}$ in PB, $30 \min , 37^{\circ} \mathrm{C}$ )

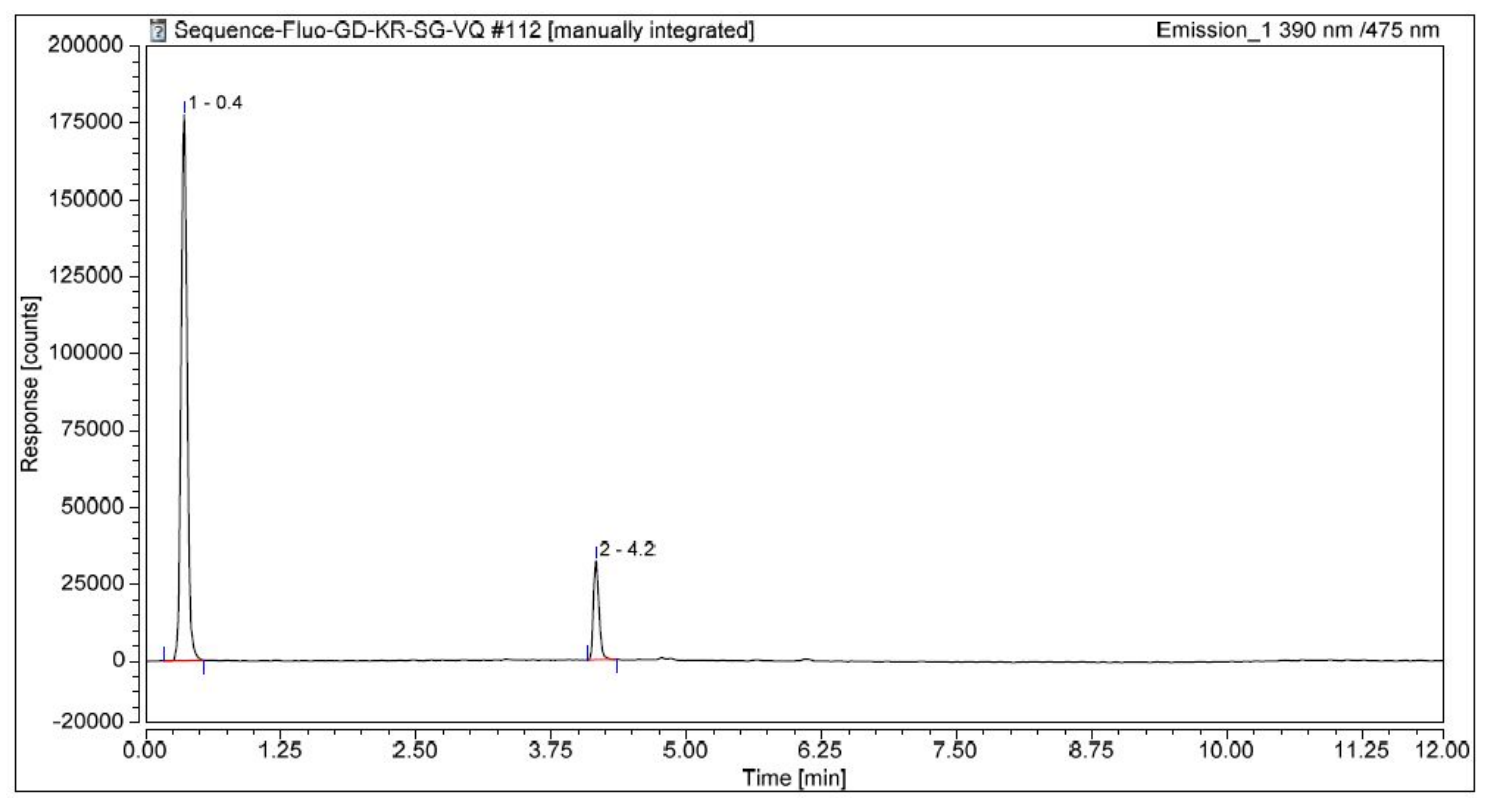

Fig. S181 - RP-HPLC elution profile (system E, fluorescence detection Ex./Em. 390/475 nm) of fluorogenic probe 14 (concentration: 1.0 $\mu$ M in PB) with PGA (1 U, $30 \mathrm{~min}, 37^{\circ} \mathrm{C}$ )

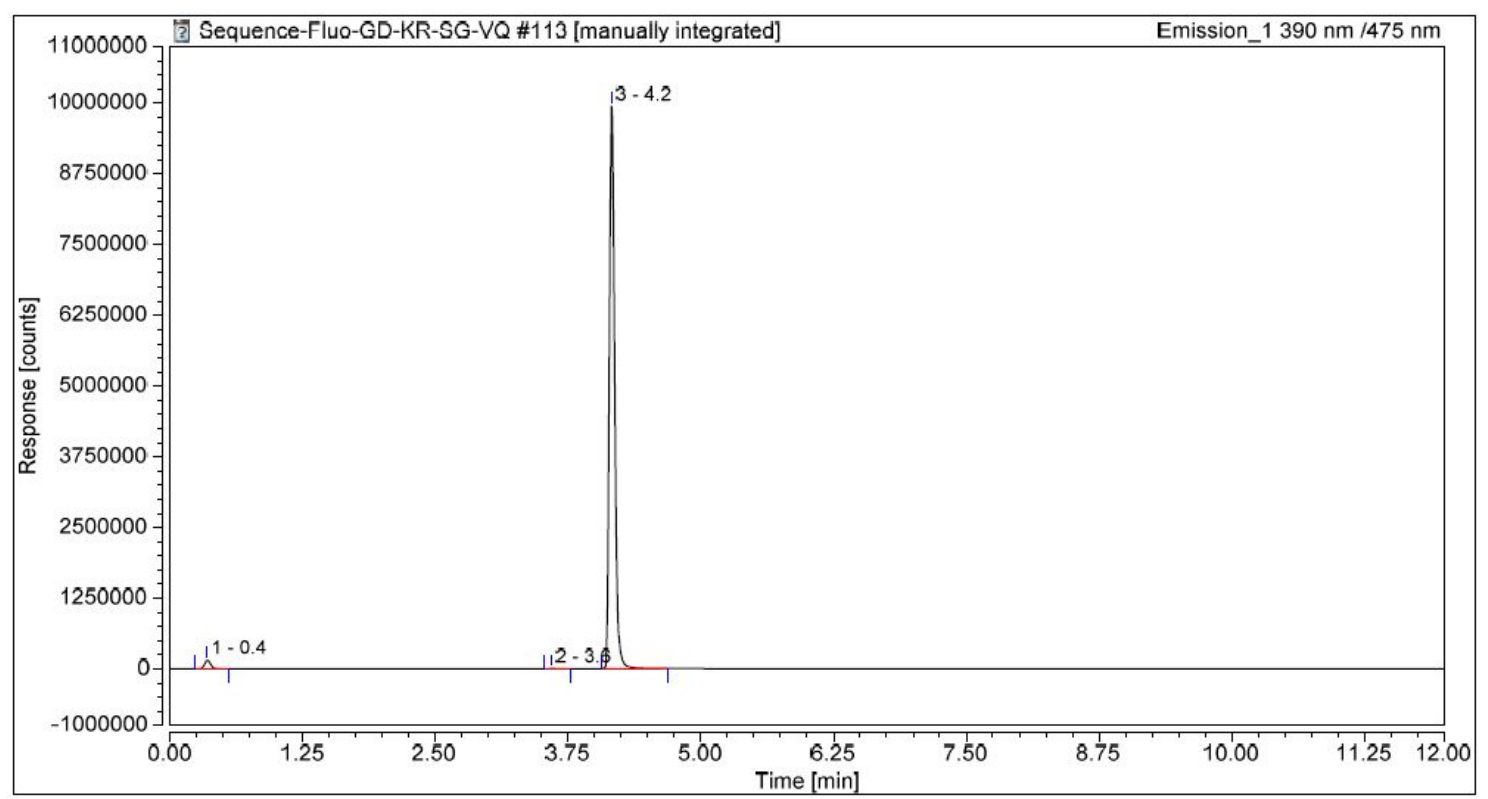


Fig. S182 - RP-HPLC elution profile (system E, fluorescence detection Ex./Em. $390 / 475 \mathrm{~nm}$ ) of co-injection of fluorogenic probe 14 (concentration: $0.5 \mu \mathrm{M}$ in PB) with PGA (1 $\mathrm{U}, 30 \mathrm{~min}, 37^{\circ} \mathrm{C}$ ) and quinoxalin-2(1H)-one 3 (concentration: $0.5 \mu \mathrm{M}$ in PB)

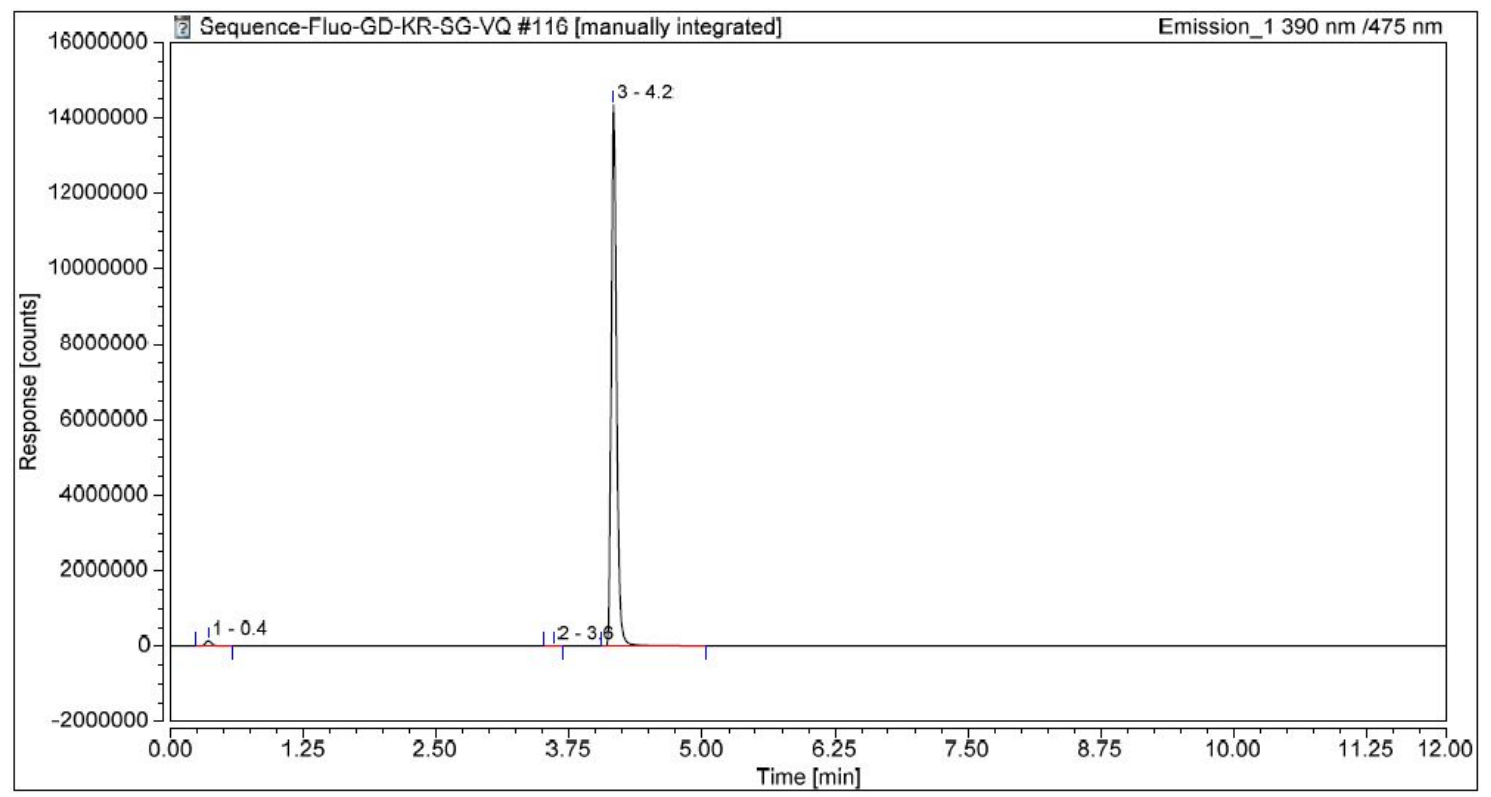

Fig. S183 - RP-HPLC elution profile (system E, fluorescence detection Ex./Em. 390/475 nm) of fluorogenic probe 14 (concentration: 1.0 $\mu$ M in PB) with PGA (1 U, $30 \mathrm{~min}, 37^{\circ} \mathrm{C}$ ) and GSH (50 equiv.)

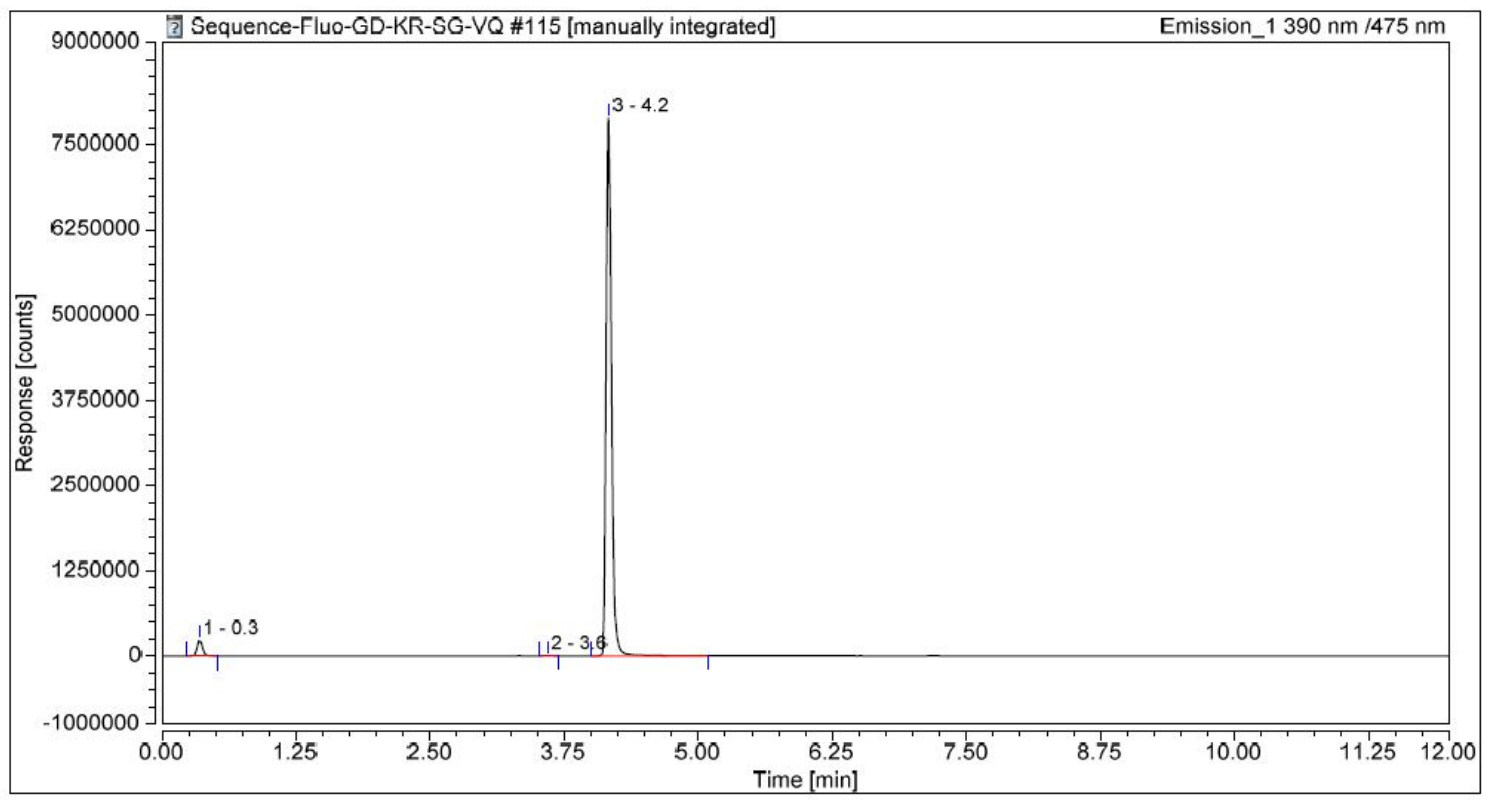


Fig. S184 - RP-HPLC elution profile (system E, fluorescence detection Ex./Em. $390 / 475 \mathrm{~nm}$ ) of co-injection of fluorogenic probe 14 (concentration: $0.5 \mu \mathrm{M}$ in PB) with PGA (1 U, $30 \mathrm{~min}, 37^{\circ} \mathrm{C}$ ) and GSH (50 equiv.), and quinoxalin-2(1H)-one 3 (concentration: $0.5 \mu \mathrm{M}$ in $\mathrm{PB}$ )

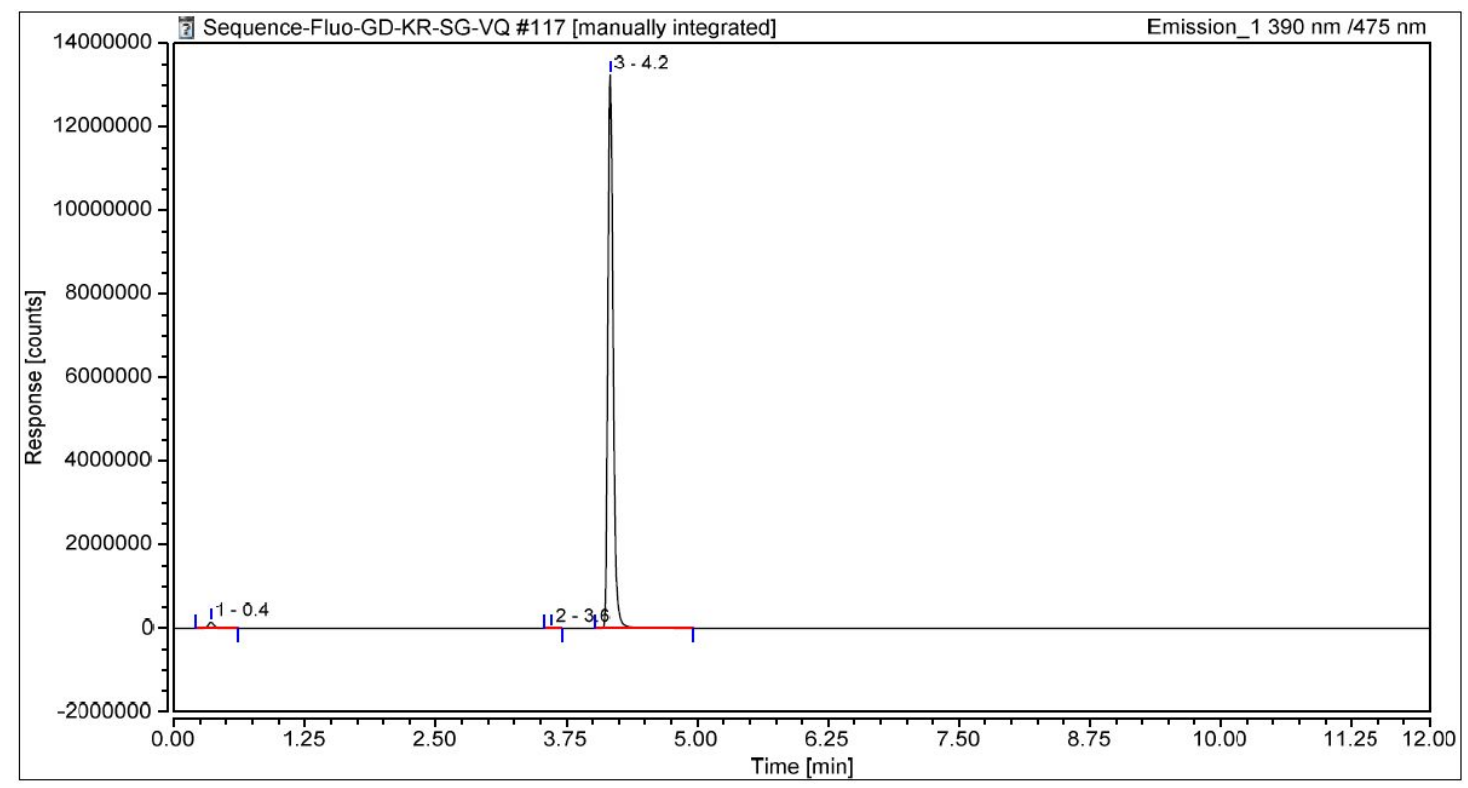

Fig. S185 - RP-HPLC elution profile (system E, fluorescence detection Ex./Em. $385 / 490 \mathrm{~nm})$ of $\mathrm{PB}$

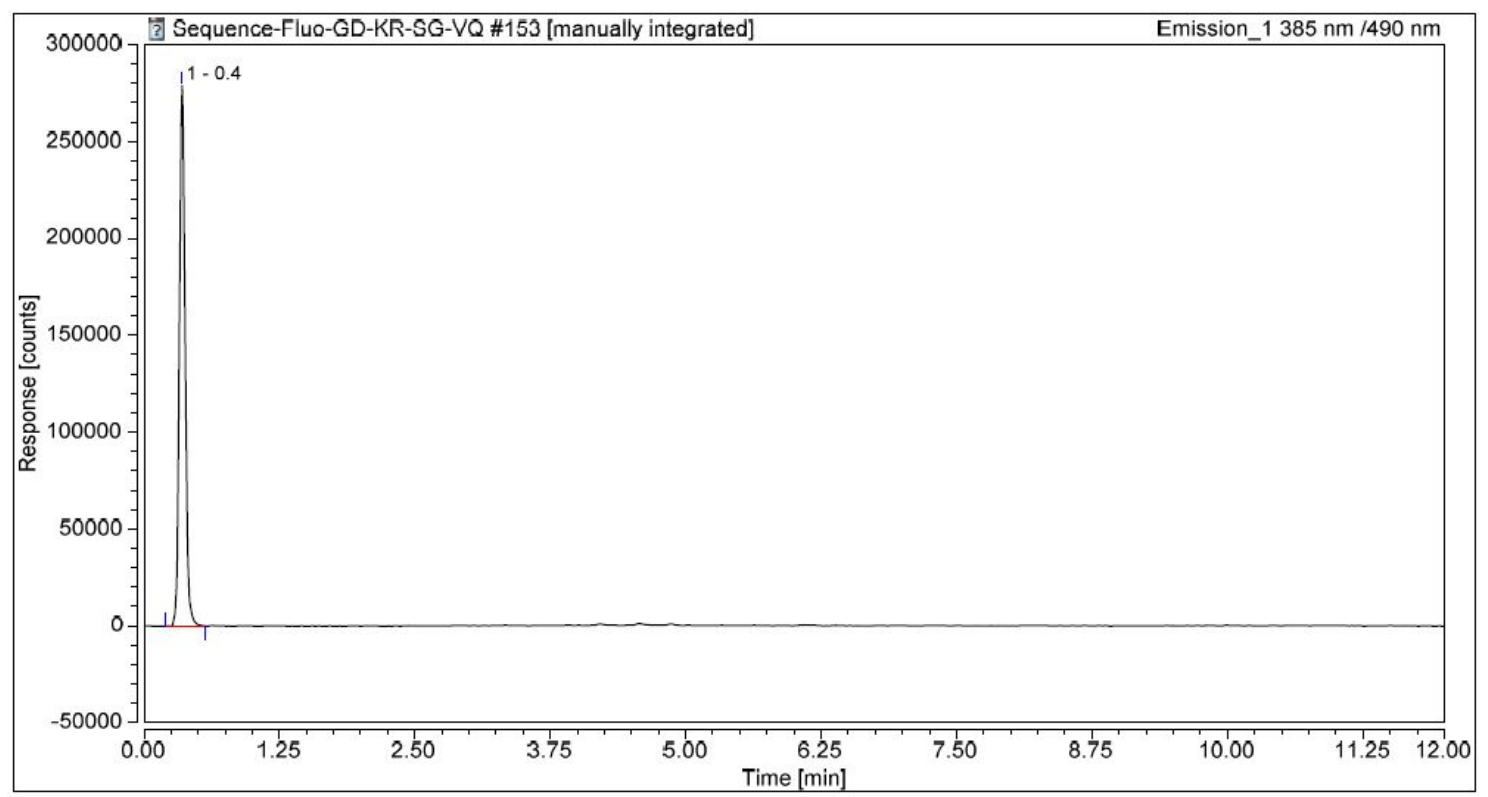


Fig. S186 - RP-HPLC elution profile (system E, fluorescence detection Ex./Em. $385 / 490 \mathrm{~nm}$ ) of quinoxalin-2(1H)-one 4 (concentration: $1.0 \mu \mathrm{M}$ in PB)

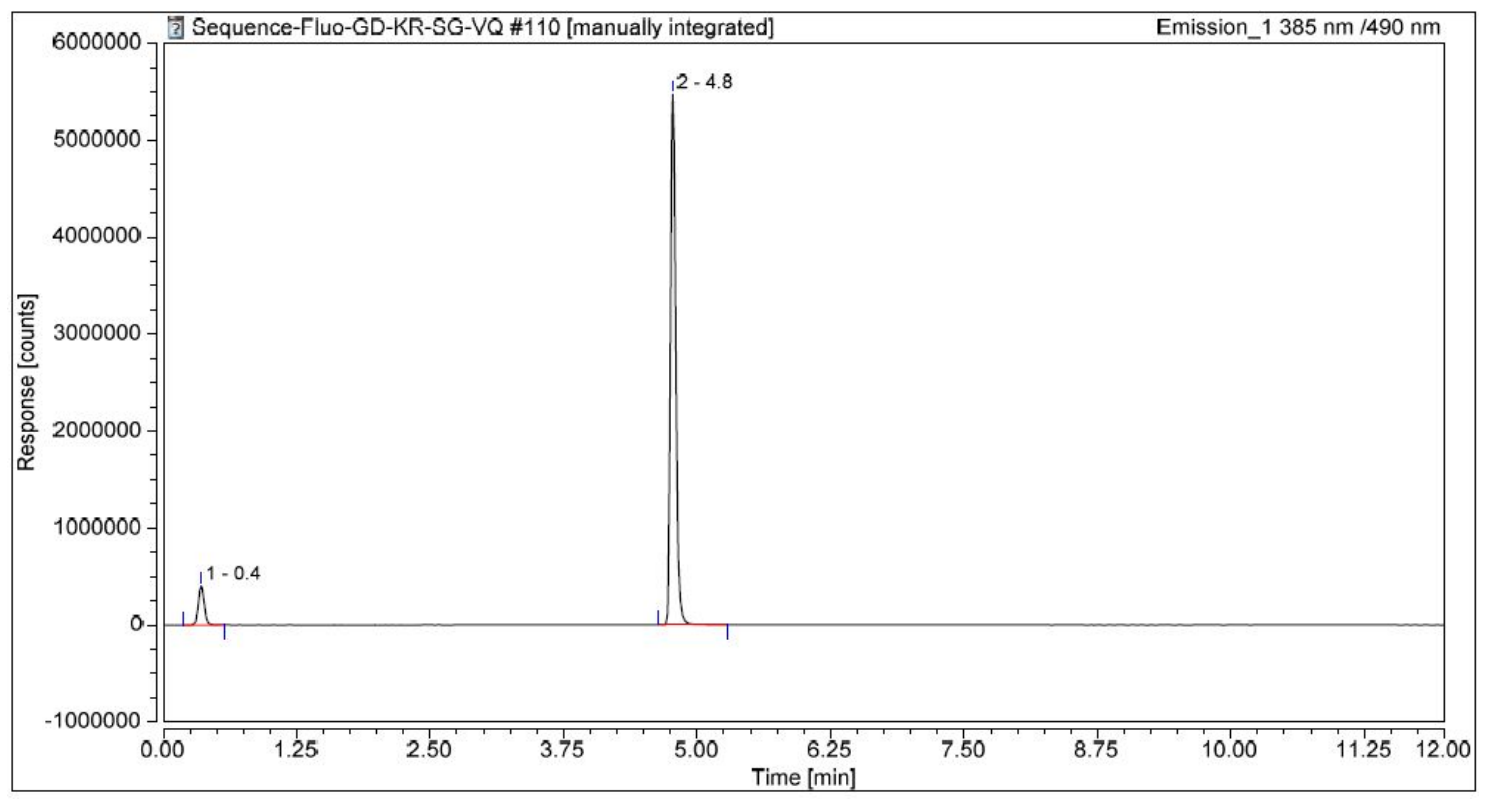

Fig. S187 - RP-HPLC elution profile (system E, fluorescence detection Ex./Em. $385 / 490 \mathrm{~nm}$ ) of fluorogenic probe 15 without PGA (concentration: $1.0 \mu \mathrm{M}$ in PB, $90 \mathrm{~min}, 37^{\circ} \mathrm{C}$ )

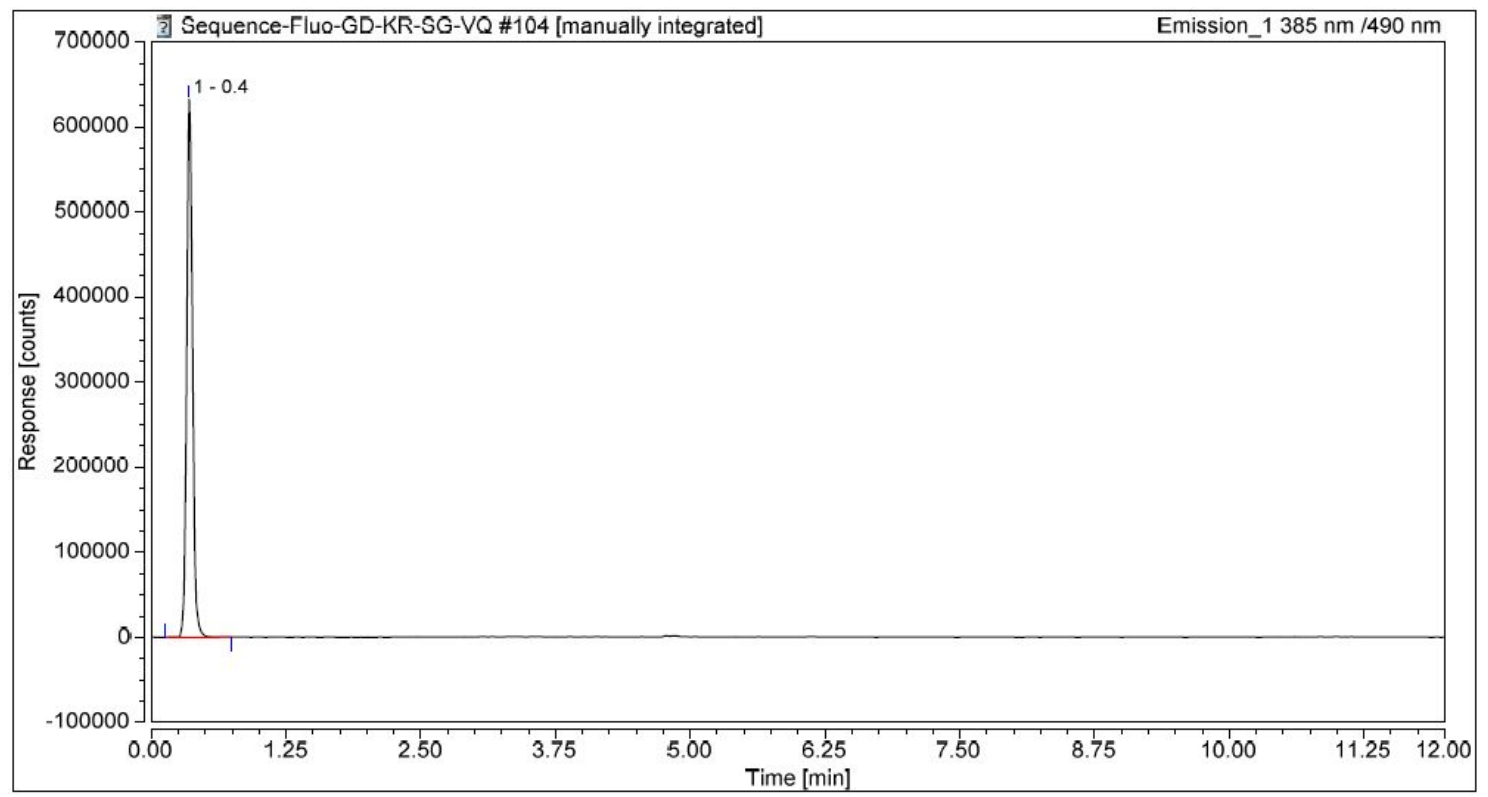


Fig. S188 - RP-HPLC elution profile (system E, fluorescence detection Ex./Em. $385 / 490 \mathrm{~nm}$ ) of fluorogenic probe 15 (concentration: 1.0 $\mu \mathrm{M}$ in PB) with PGA (1 U, $90 \mathrm{~min}, 37^{\circ} \mathrm{C}$ )

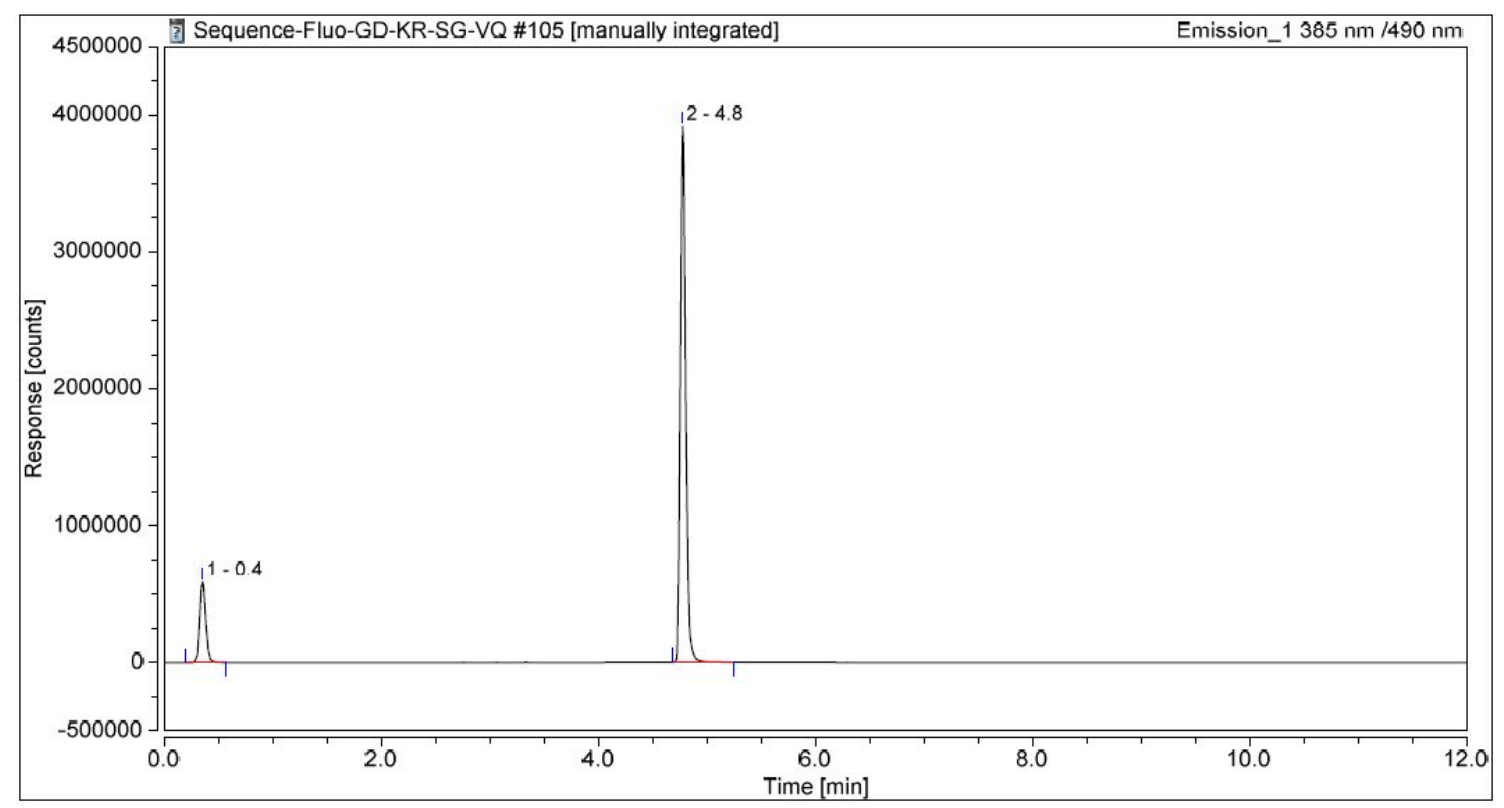

Fig. S189 - RP-HPLC elution profile (system E, fluorescence detection Ex./Em. $385 / 490 \mathrm{~nm}$ ) of co-injection of fluorogenic probe 15 (concentration: $0.5 \mu \mathrm{M}$ in PB) with PGA (1 U, $90 \mathrm{~min}, 37^{\circ} \mathrm{C}$ ) and quinoxalin-2(1H)-one 4 (concentration: $0.5 \mu \mathrm{M}$ in $\mathrm{PB})$

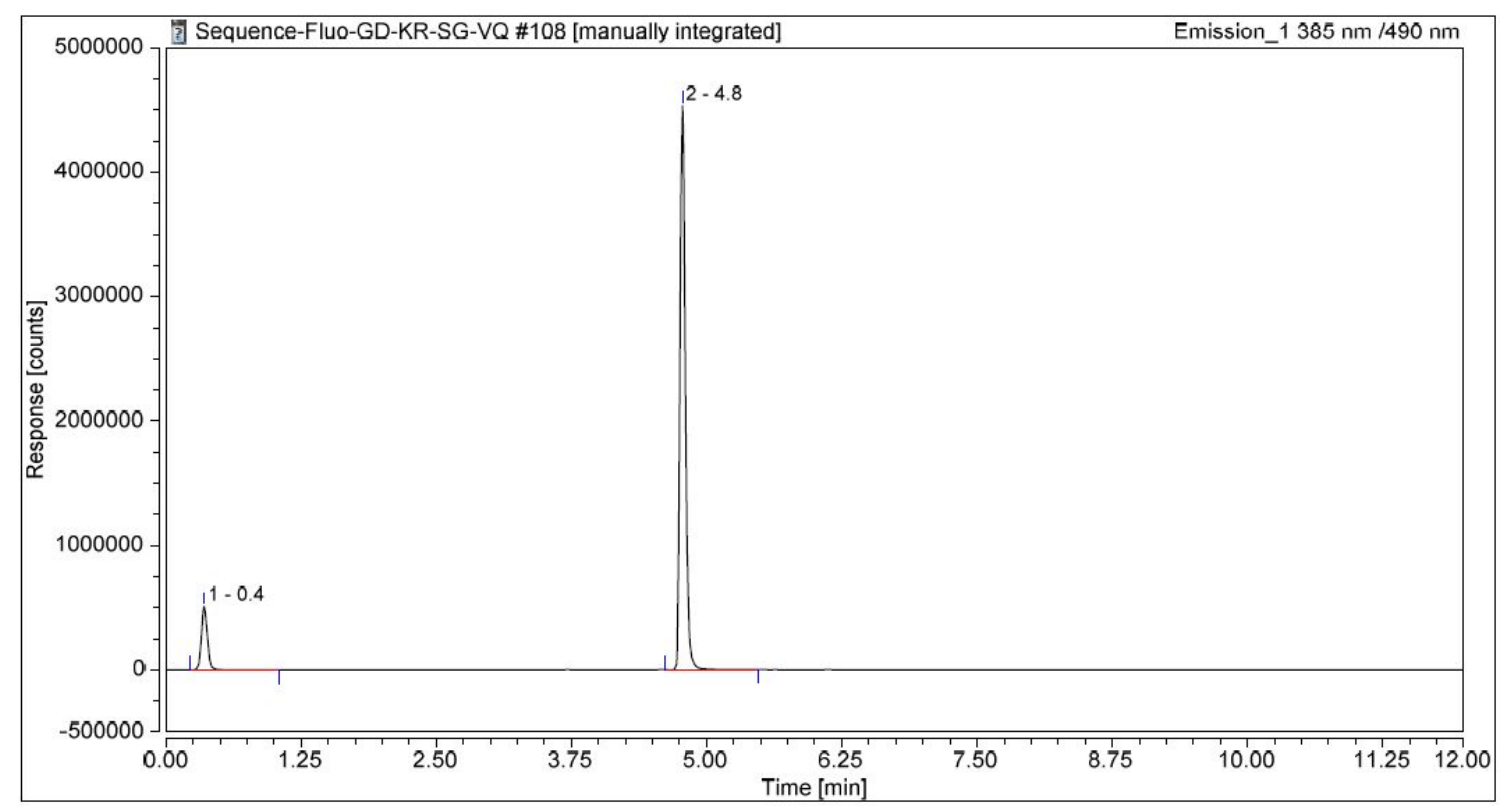


Fig. S190 - RP-HPLC elution profile (system E, fluorescence detection Ex./Em. $385 / 490 \mathrm{~nm}$ ) of fluorogenic probe 15 (concentration: $1.0 \mu \mathrm{M}$ in PB) with PGA (1 U, $90 \mathrm{~min}, 37^{\circ} \mathrm{C}$ ) and GSH (50 equiv.)

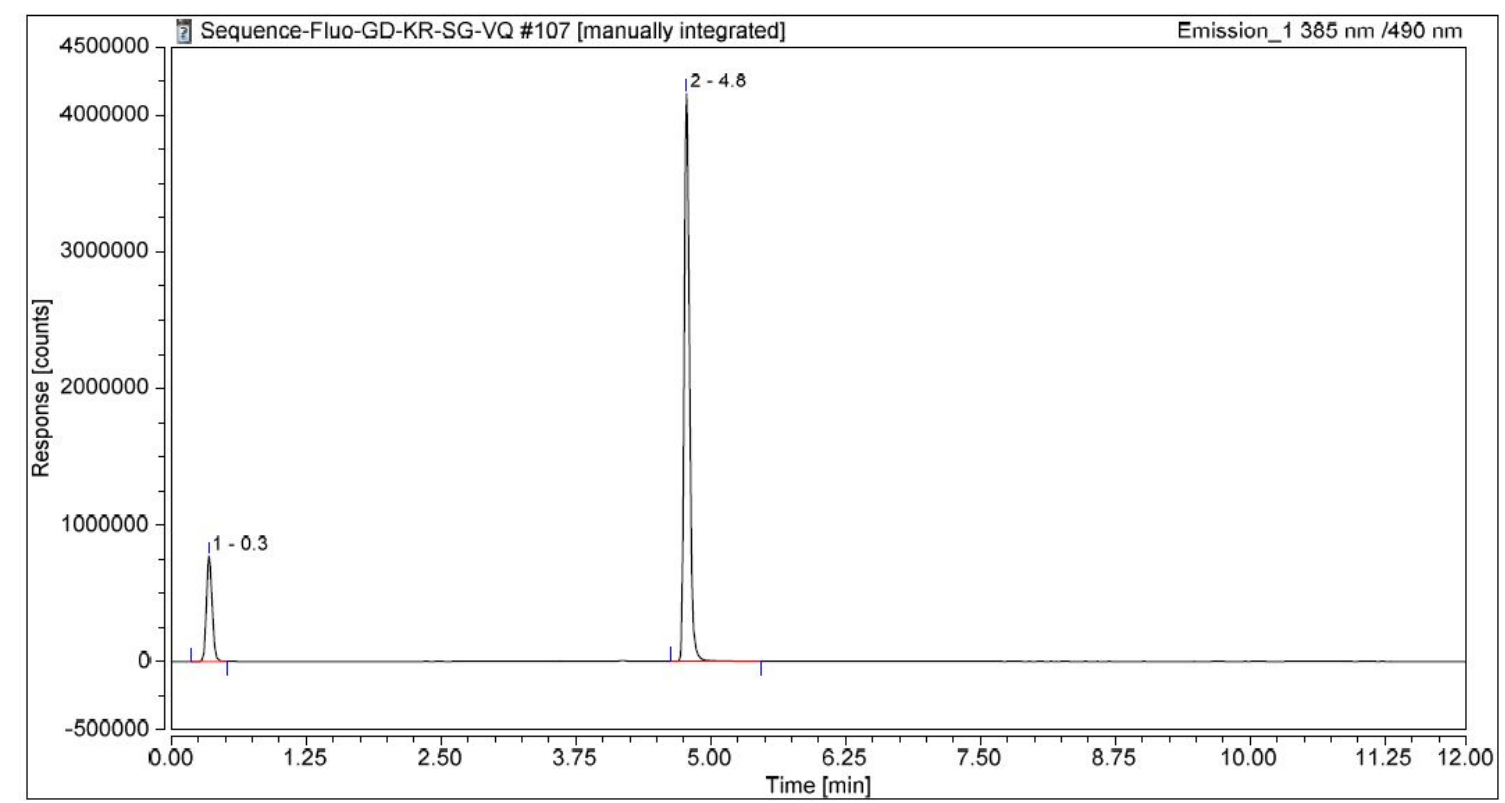

Fig. S191 - RP-HPLC elution profile (system E, fluorescence detection Ex./Em. $385 / 490 \mathrm{~nm}$ ) of co-injection of fluorogenic probe 15 (concentration: $0.5 \mu \mathrm{M}$ in PB) with PGA (1 U, $\left.90 \mathrm{~min}, 37^{\circ} \mathrm{C}\right)$ and GSH (50 equiv.), and quinoxalin-2(1H)-one 4 (concentration: $0.5 \mu \mathrm{M}$ in $\mathrm{PB}$ )

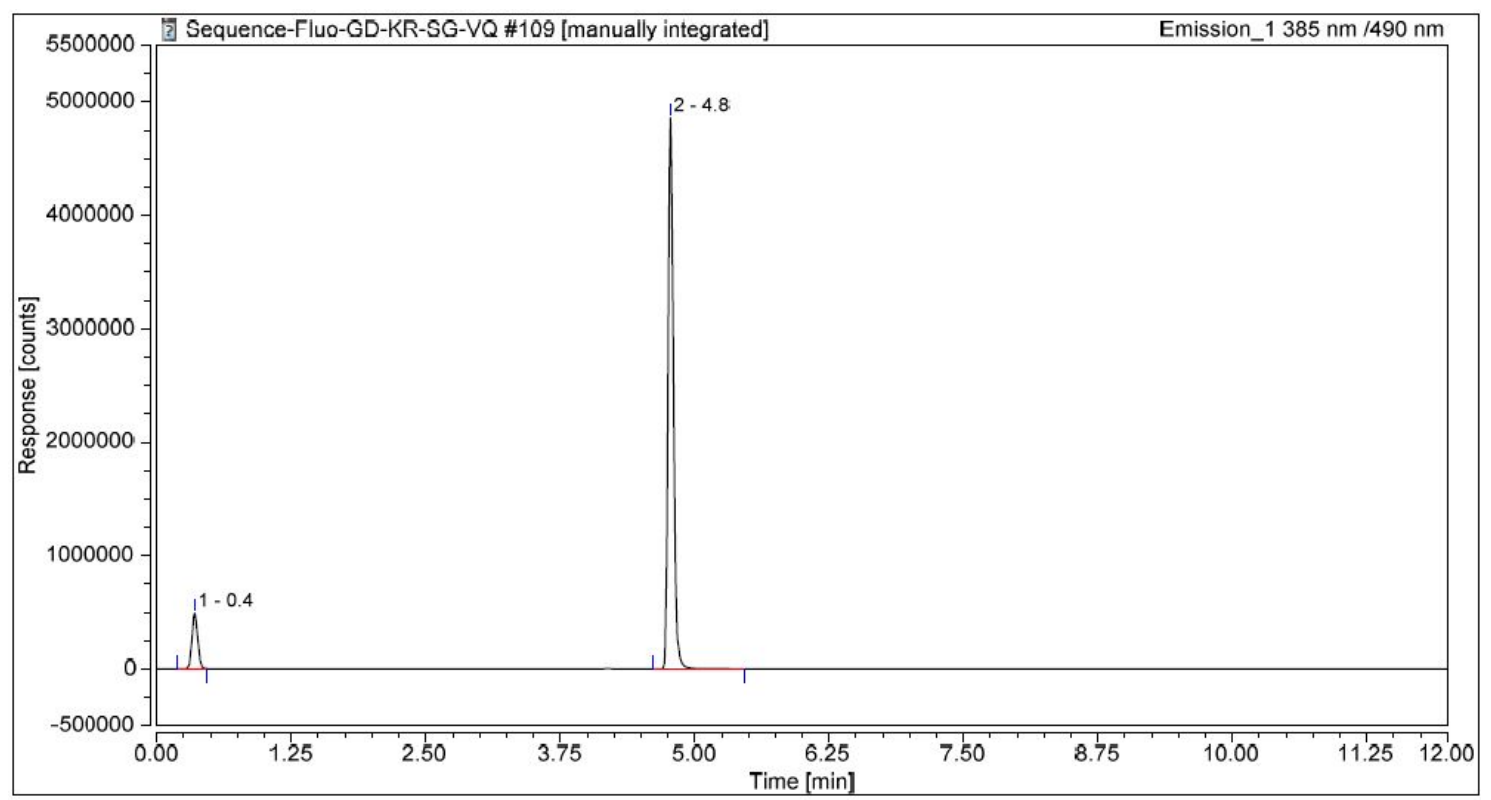


Fig. S192 - RP-HPLC elution profile (system E, fluorescence detection Ex./Em. $405 / 480 \mathrm{~nm}$ ) of $\mathrm{PB}$

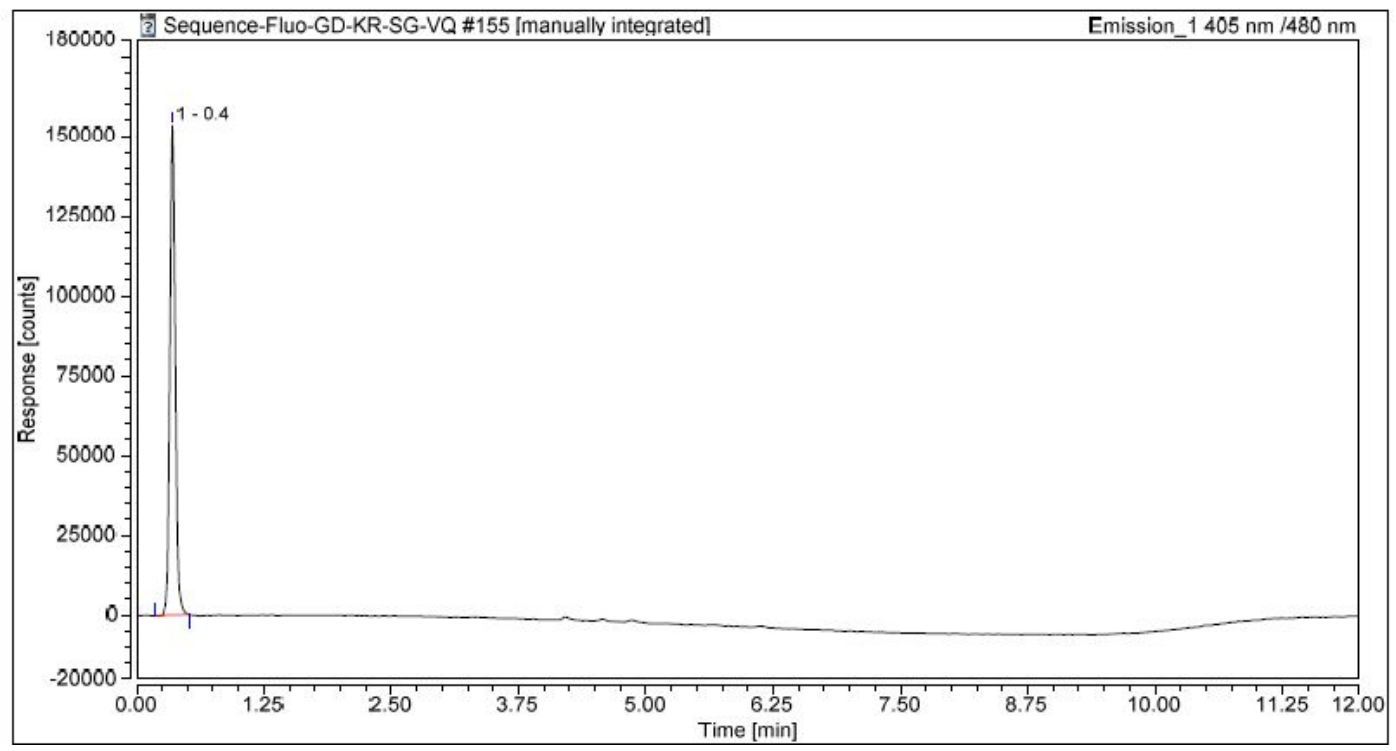

Fig. S193 - RP-HPLC elution profile (system E, fluorescence detection Ex./Em. $405 / 480 \mathrm{~nm}$ ) of quinoxalin-2(1H)-one 5 (concentration: $1.0 \mu \mathrm{M}$ in $\mathrm{PB}$ )

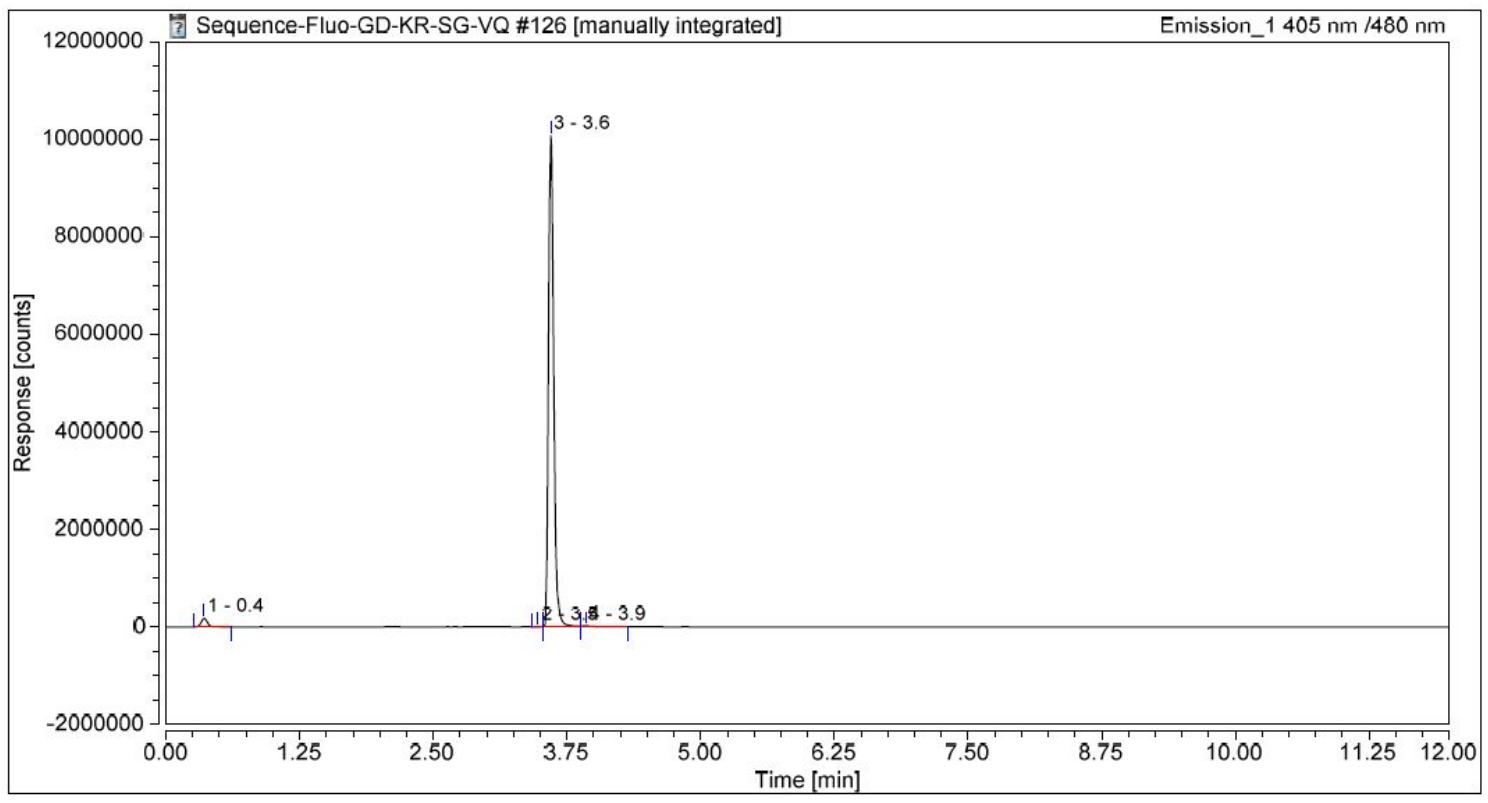


Fig. S194 - RP-HPLC elution profile (system E, fluorescence detection Ex./Em. $405 / 480 \mathrm{~nm}$ ) of fluorogenic probe 16 without PGA (concentration: $1.0 \mu \mathrm{M}$ in PB, $30 \min , 37^{\circ} \mathrm{C}$ )

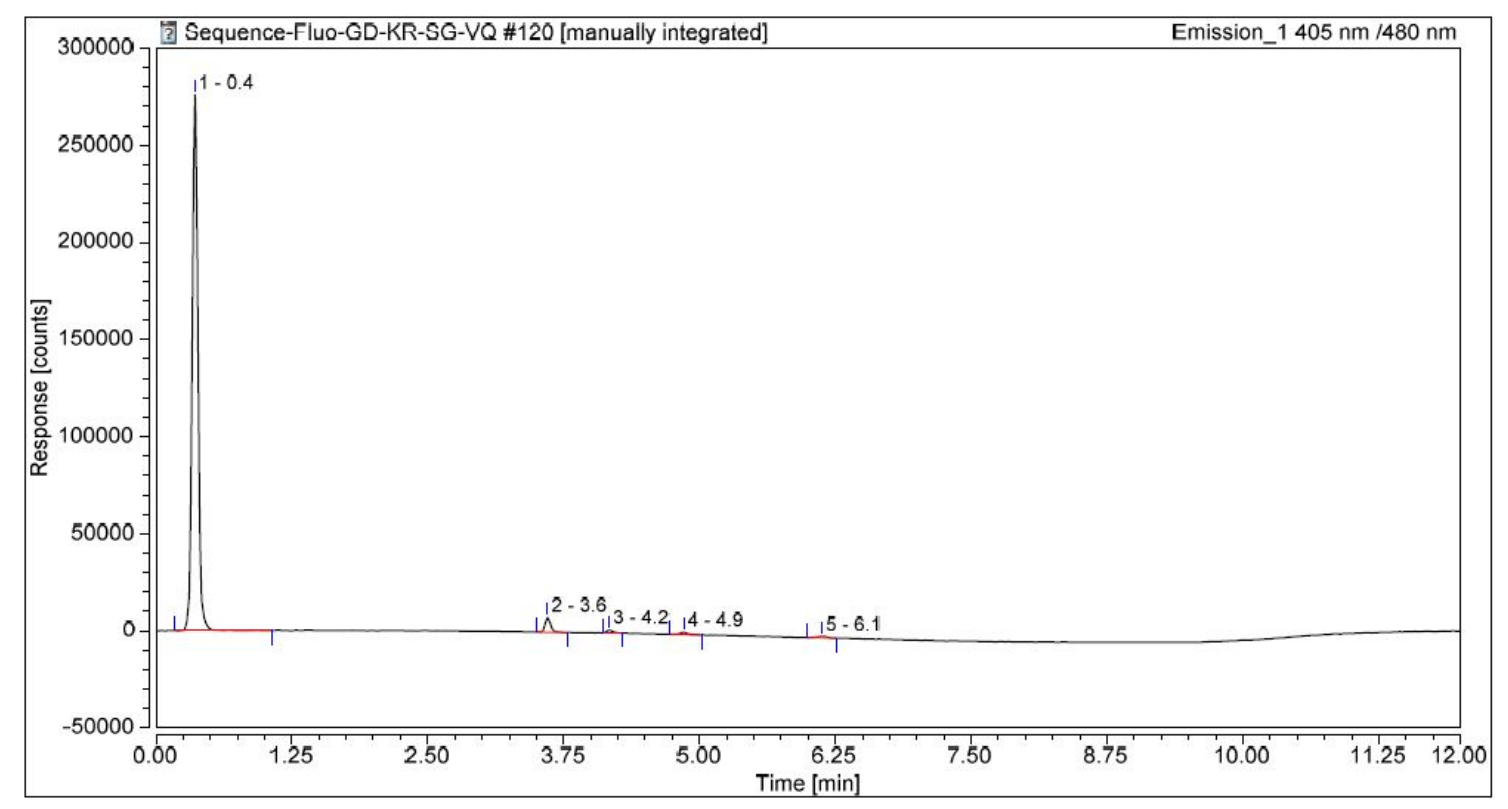

Fig. S195 - RP-HPLC elution profile (system E, fluorescence detection Ex./Em. 405/480 nm) of fluorogenic probe 16 (concentration: $1.0 \mu \mathrm{M}$ in PB) with PGA (1 U, $30 \mathrm{~min}, 37^{\circ} \mathrm{C}$ )

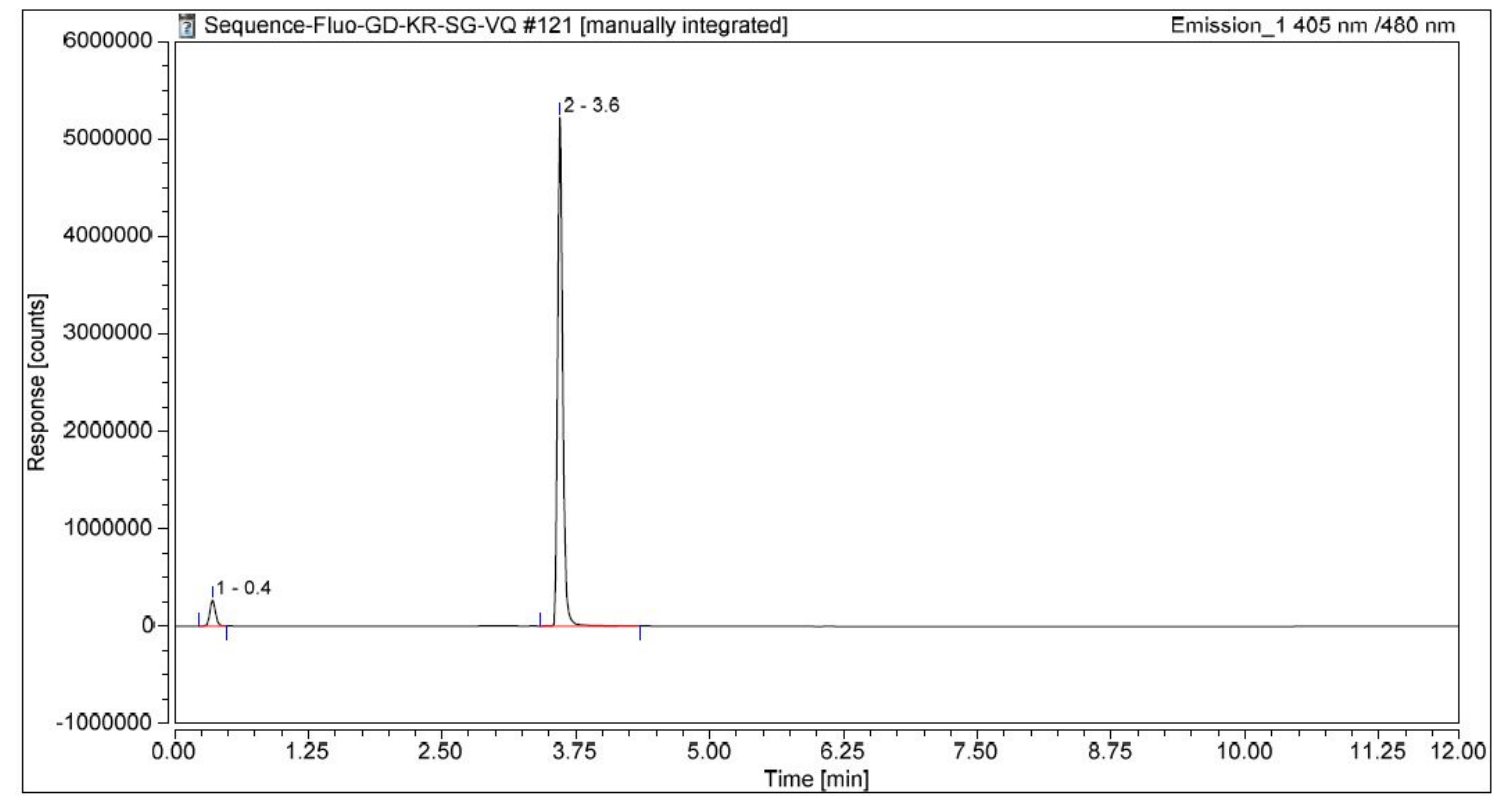


Fig. S196 - RP-HPLC elution profile (system E, fluorescence detection Ex./Em. $405 / 480 \mathrm{~nm}$ ) of co-injection of fluorogenic probe 16 (concentration: $0.5 \mu \mathrm{M}$ in PB) with PGA (1 $\mathrm{U}, 30 \mathrm{~min}, 37^{\circ} \mathrm{C}$ ) and quinoxalin-2(1H)-one 5 (concentration: $0.5 \mu \mathrm{M}$ in $\mathrm{PB})$.

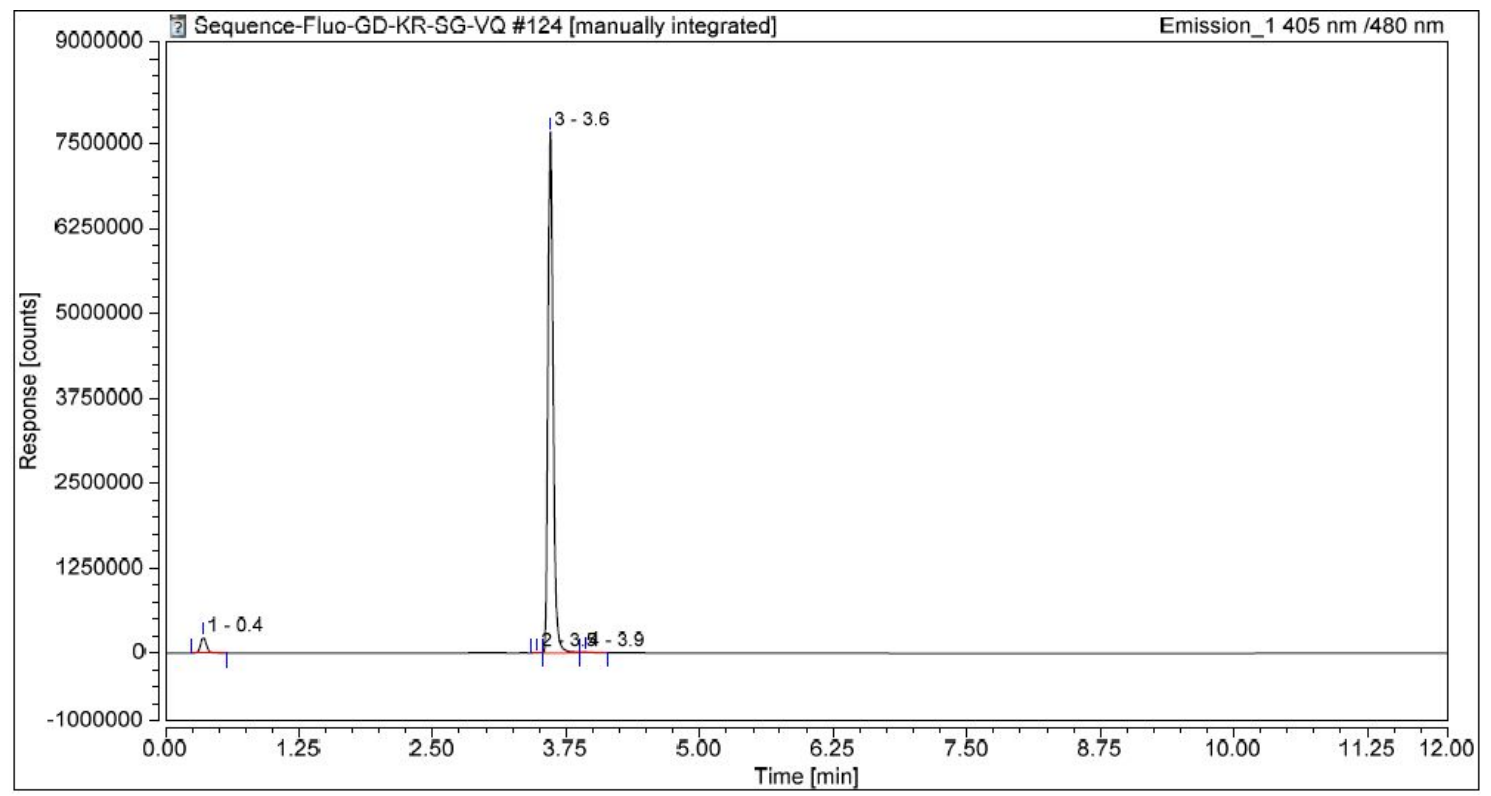

Fig. S197 - RP-HPLC elution profile (system E, fluorescence detection Ex./Em. 405/480 nm) of fluorogenic probe 16 (concentration: 1.0 $\mu \mathrm{M}$ in PB) with PGA (1 U, $30 \mathrm{~min}, 37^{\circ} \mathrm{C}$ ) and GSH (50 equiv.)

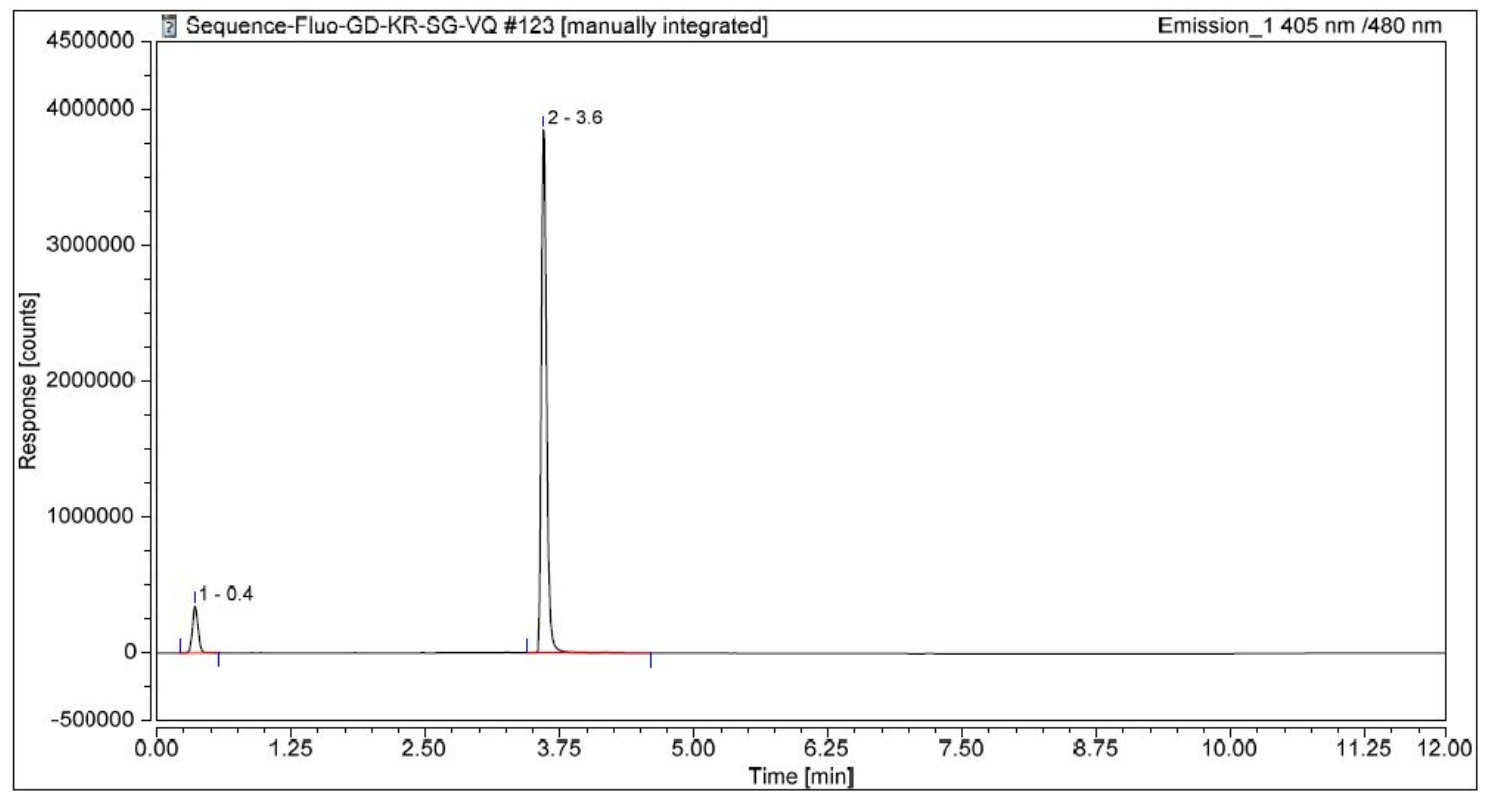


Fig. S198 - RP-HPLC elution profile (system E, fluorescence detection Ex./Em. $405 / 480 \mathrm{~nm}$ ) of co-injection of fluorogenic probe 16 (concentration: $0.5 \mu \mathrm{M}$ in PB) with PGA (1 $\mathrm{U}, 30 \mathrm{~min}, 37^{\circ} \mathrm{C}$ ) and GSH (50 equiv.), and quinoxalin-2(1H)-one 5 (concentration: $0.5 \mu \mathrm{M}$ in $\mathrm{PB}$ )

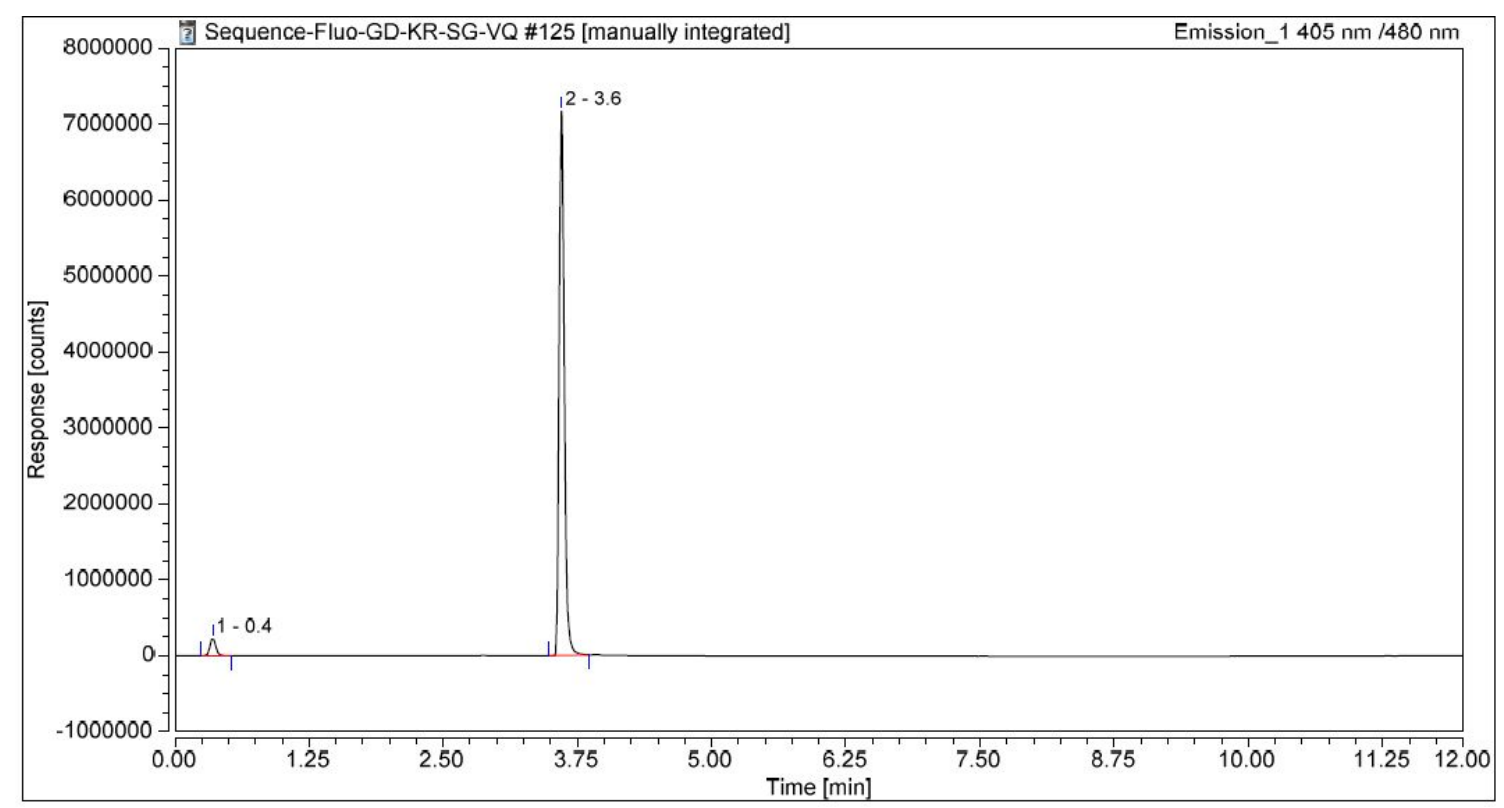

Fig. S199 - RP-HPLC elution profile (system E, fluorescence detection Ex./Em. $390 / 480 \mathrm{~nm})$ of PB (0.1 M, pH 7.6)

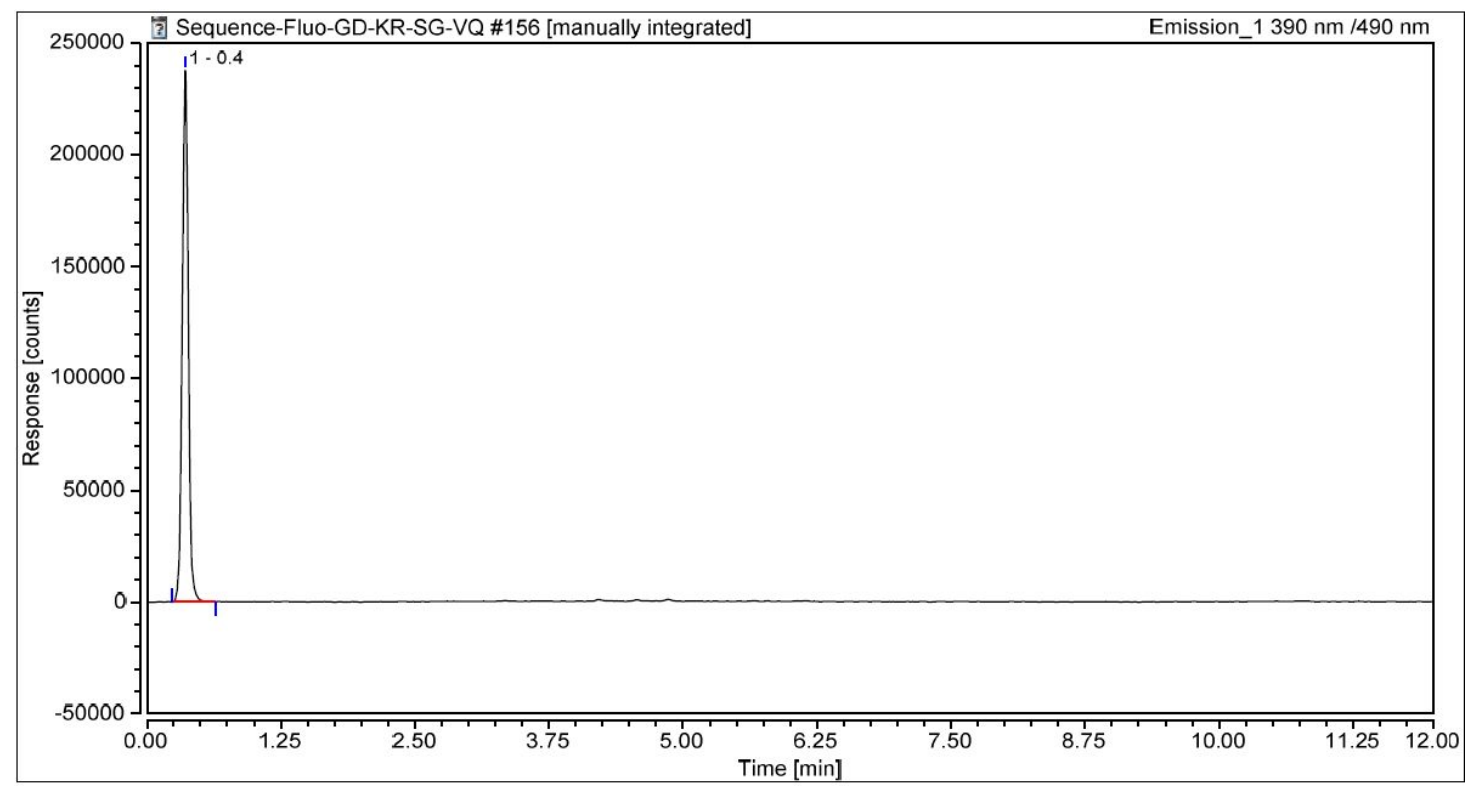


Fig. S200 - RP-HPLC elution profile (system E, fluorescence detection Ex./Em. 390/480 nm) of quinoxalin-2(1H)-one 6 (concentration: 1.0 $\mu \mathrm{M}$ in PB)

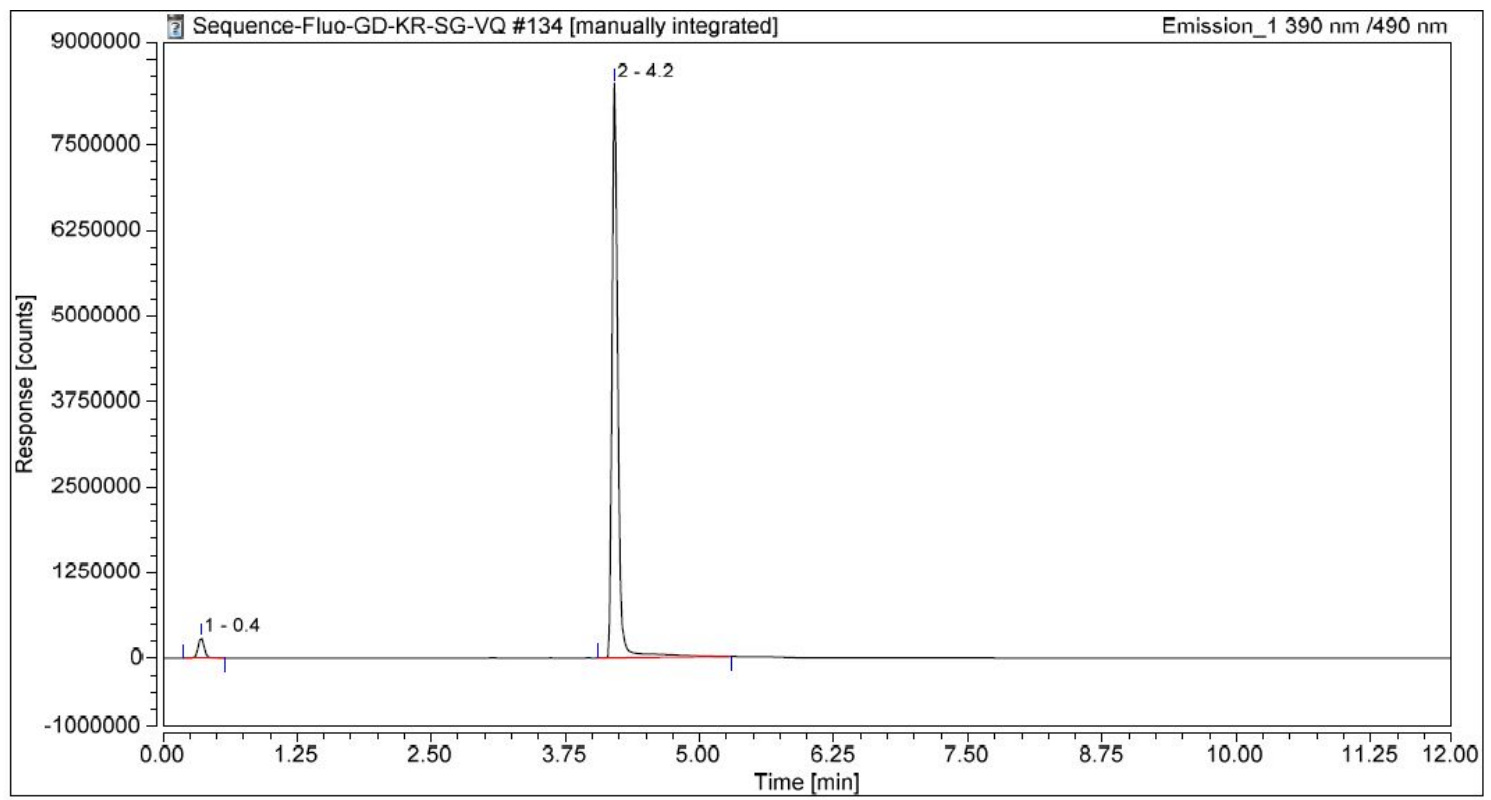

Fig. S201 - RP-HPLC elution profile (system E, fluorescence detection Ex./Em. 390/480 nm) of fluorogenic probe 17 without PGA (concentration: $1.0 \mu \mathrm{M}$ in PB, $30 \mathrm{~min}, 37^{\circ} \mathrm{C}$ )

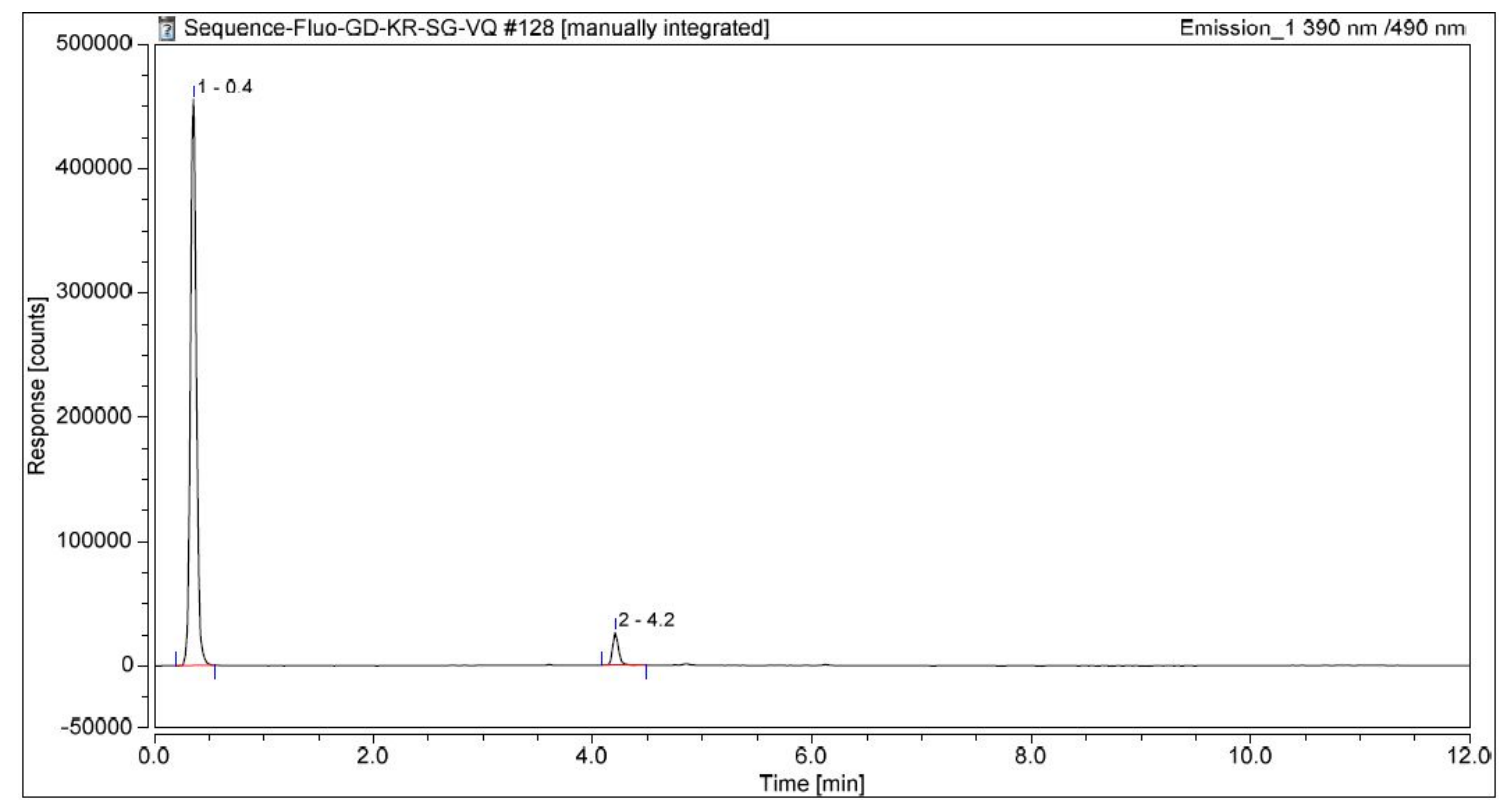


Fig. S202 - RP-HPLC elution profile (system E, fluorescence detection Ex./Em. 390/480 nm) of fluorogenic probe 17 (concentration: 1.0 $\mu \mathrm{M}$ in PB) with PGA (1 U, $30 \mathrm{~min}, 37^{\circ} \mathrm{C}$ )

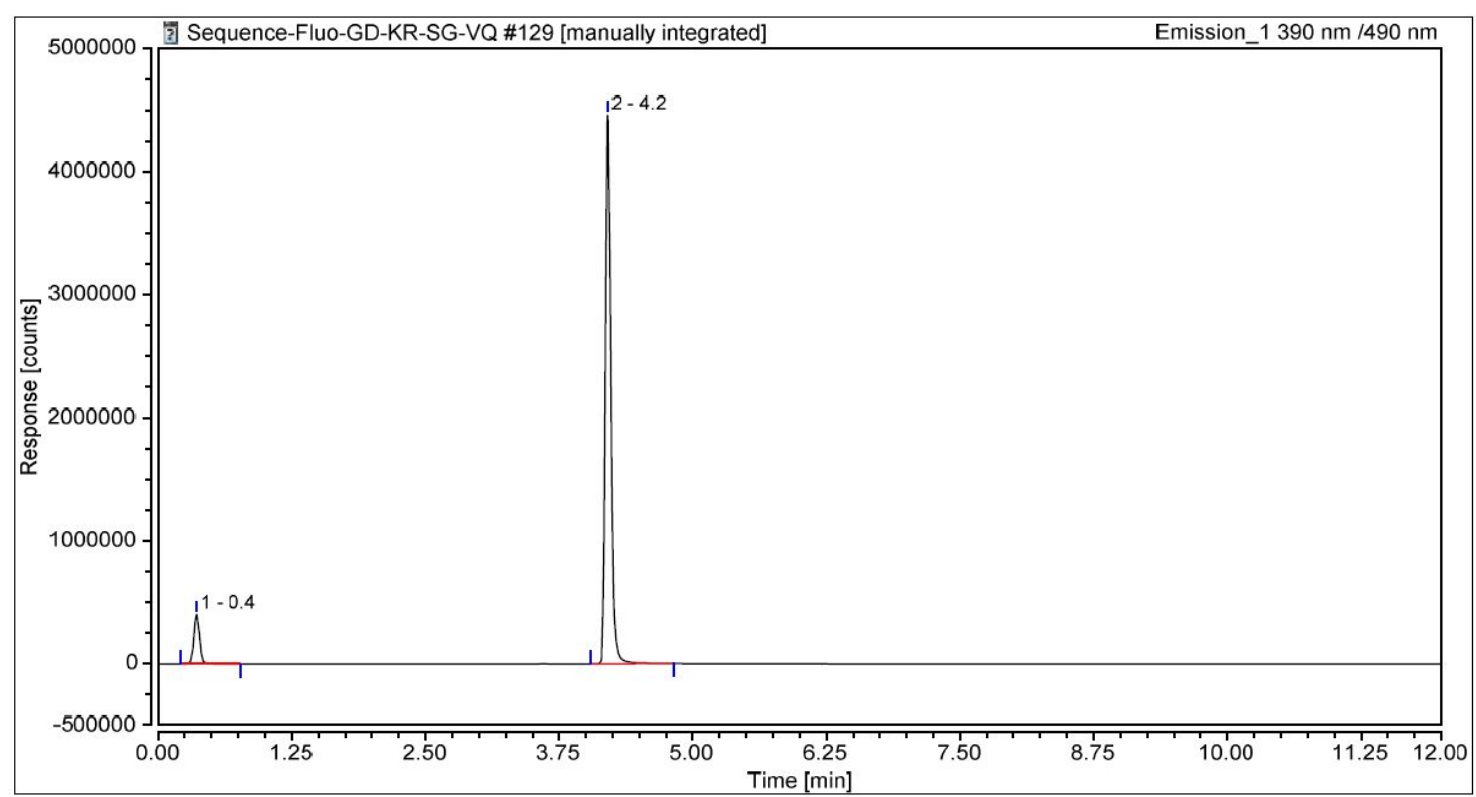

Fig. S203 - RP-HPLC elution profile (system E, fluorescence detection Ex./Em. $390 / 480 \mathrm{~nm}$ ) of co-injection of fluorogenic probe 17 (concentration: $0.5 \mu \mathrm{M}$ in PB) with PGA (1 U, $30 \mathrm{~min}, 37^{\circ} \mathrm{C}$ ) and quinoxalin-2(1H)-one 6 (concentration: $0.5 \mu \mathrm{M}$ in $\mathrm{PB}$ )

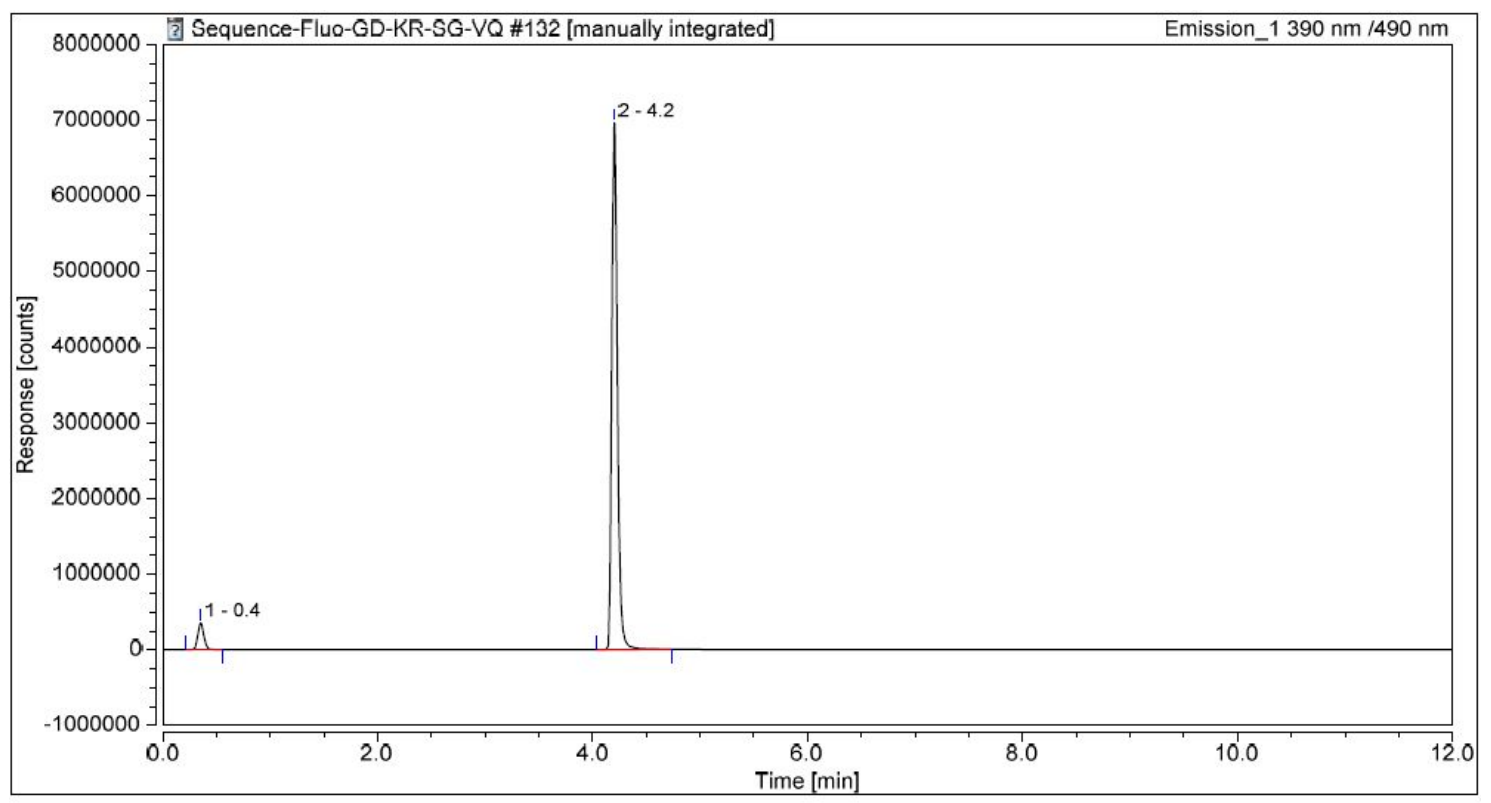


Fig. S204 - RP-HPLC elution profile (system E, fluorescence detection Ex./Em. 390/480 nm) of fluorogenic probe 17 (concentration: $1.0 \mu \mathrm{M}$ in PB) with PGA (1 U, $30 \mathrm{~min}, 37^{\circ} \mathrm{C}$ ) and GSH (50 equiv.)

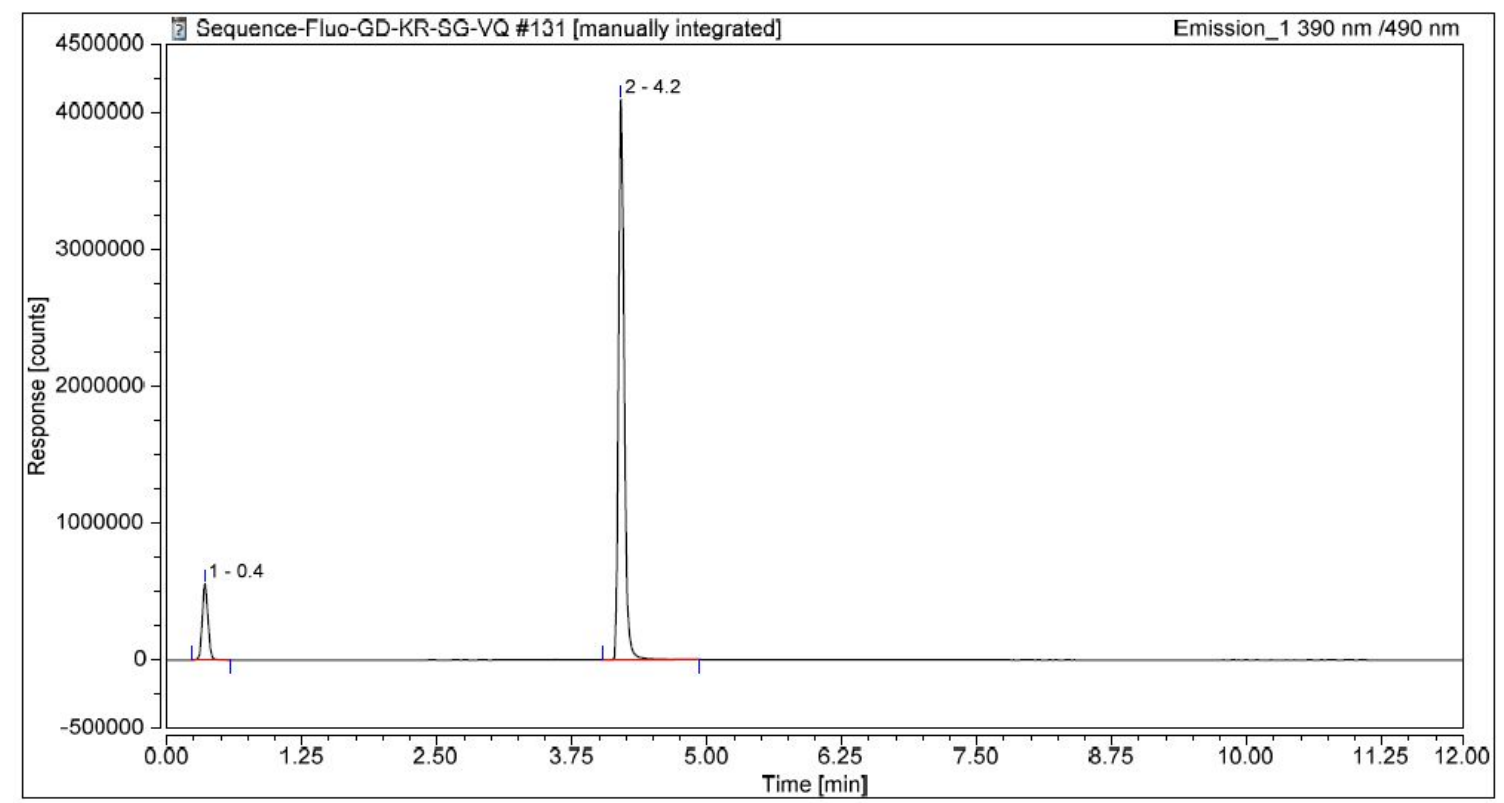

Fig. S205 - RP-HPLC elution profile (system E, fluorescence detection Ex./Em. $390 / 480 \mathrm{~nm}$ ) of co-injection of fluorogenic probe 17 (concentration: $0.5 \mu \mathrm{M}$ in PB) with PGA (1 U, $30 \mathrm{~min}, 37^{\circ} \mathrm{C}$ ) and GSH (50 equiv.), and quinoxalin-2(1H)-one 6 (concentration: $0.5 \mu \mathrm{M}$ in $\mathrm{PB}$ )

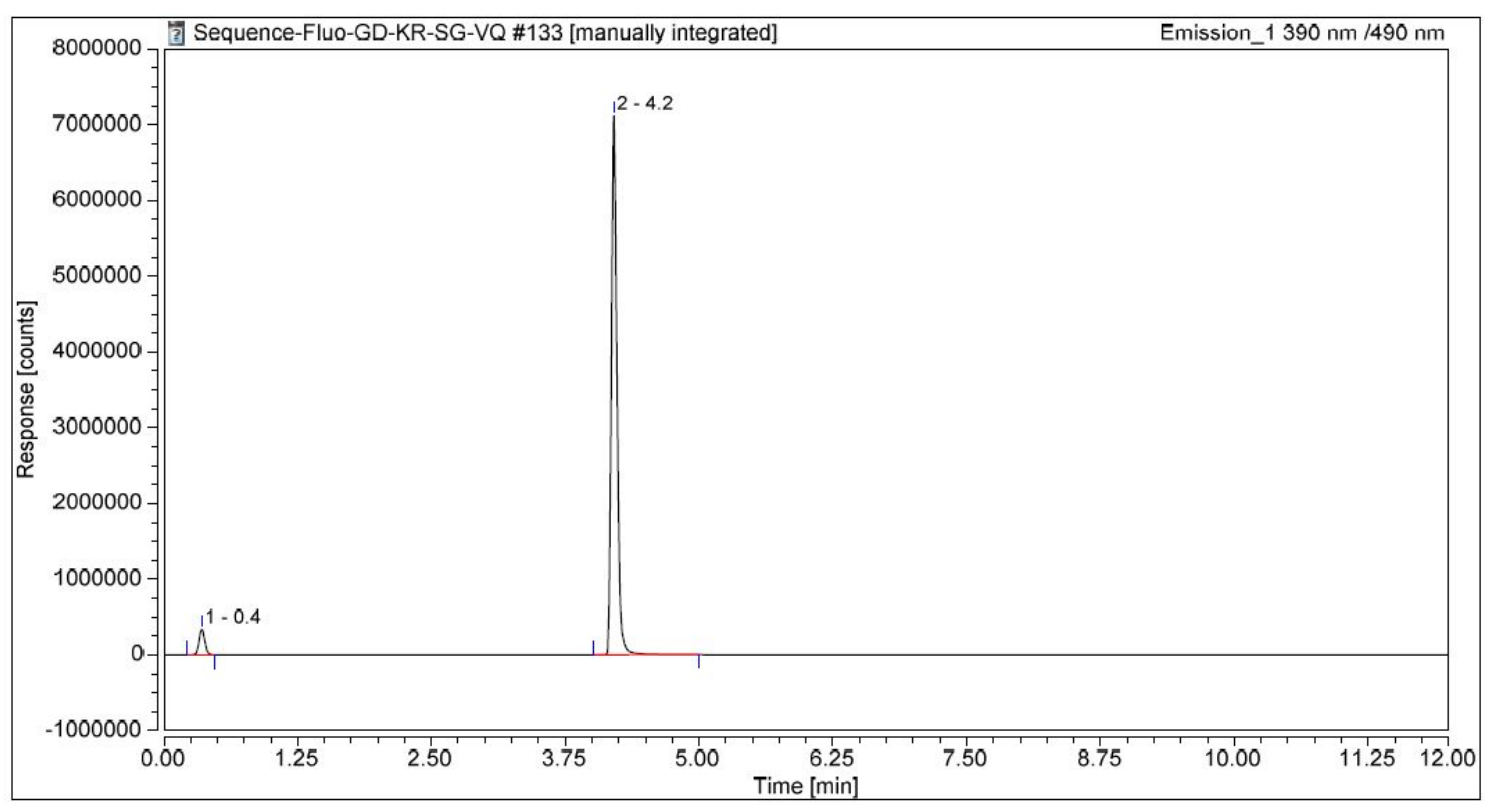


Fig. S206 - RP-HPLC elution profile (system E, fluorescence detection Ex./Em. $380 / 490 \mathrm{~nm}$ ) of $\mathrm{PB}$

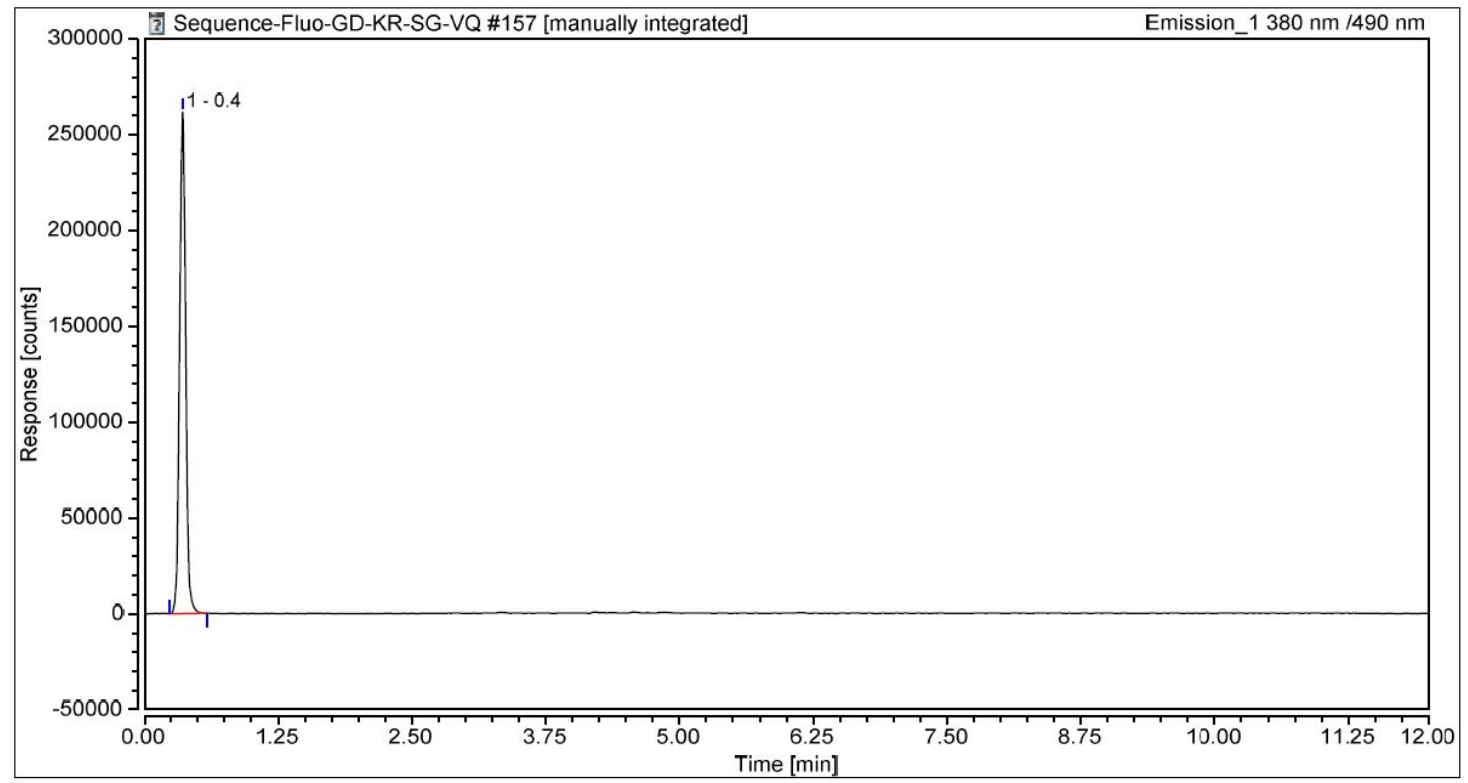

Fig. S207 - RP-HPLC elution profile (system E, fluorescence detection Ex./Em. $380 / 490 \mathrm{~nm}$ ) of quinoxalin-2(1H)-one 7 (concentration: $1.0 \mu \mathrm{M}$ in PB)

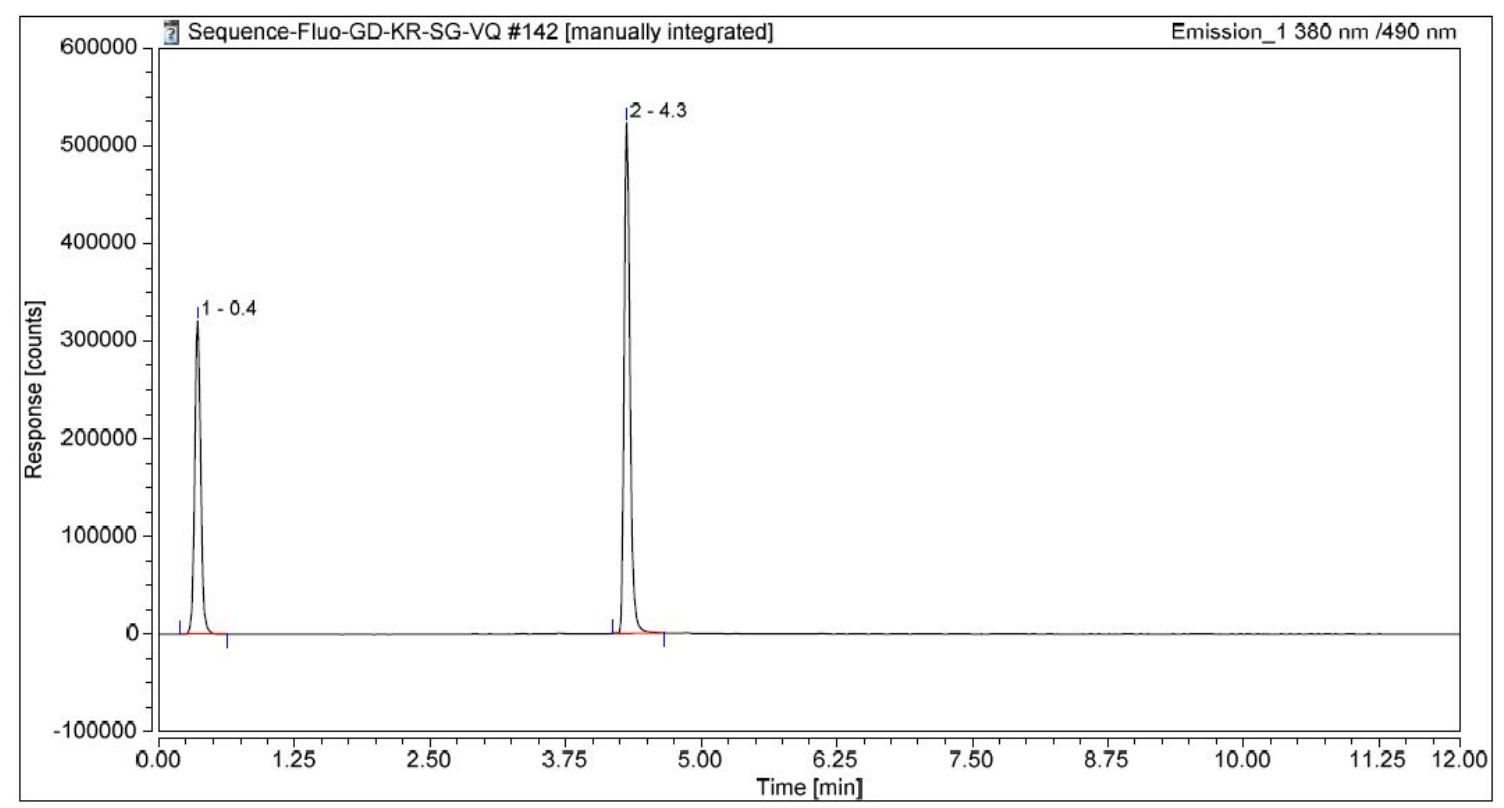


Fig. S208 - RP-HPLC elution profile (system E, fluorescence detection Ex./Em. $380 / 490 \mathrm{~nm}$ ) of fluorogenic probe 18 without PGA (concentration: $1.0 \mu \mathrm{M}$ in PB, $30 \min , 37^{\circ} \mathrm{C}$ )

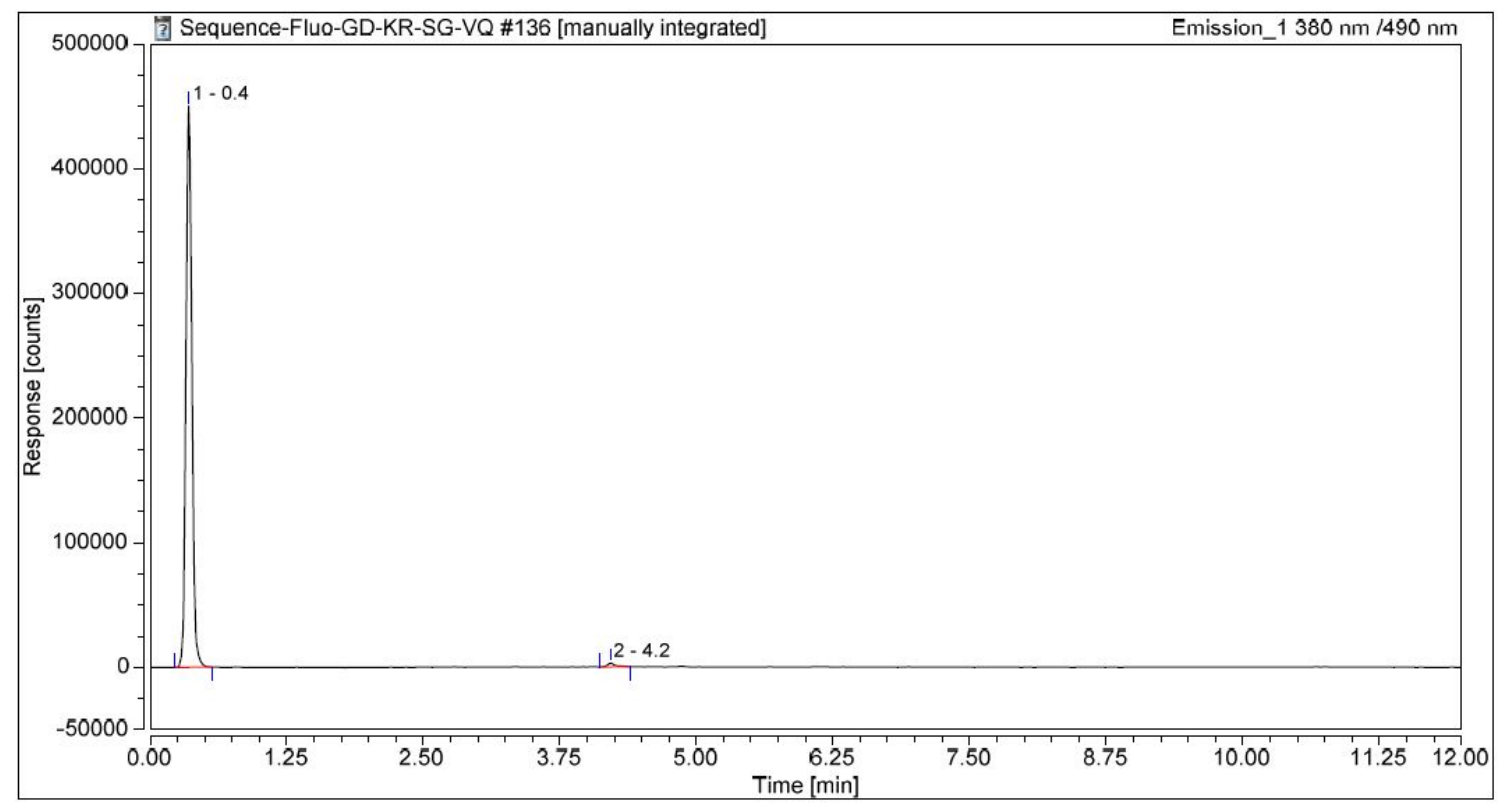

Fig. S209 - RP-HPLC elution profile (system E, fluorescence detection Ex./Em. $380 / 490 \mathrm{~nm}$ ) of fluorogenic probe 18 (concentration: 1.0 $\mu \mathrm{M}$ in PB) with PGA (1 U, $30 \mathrm{~min}, 37^{\circ} \mathrm{C}$ )

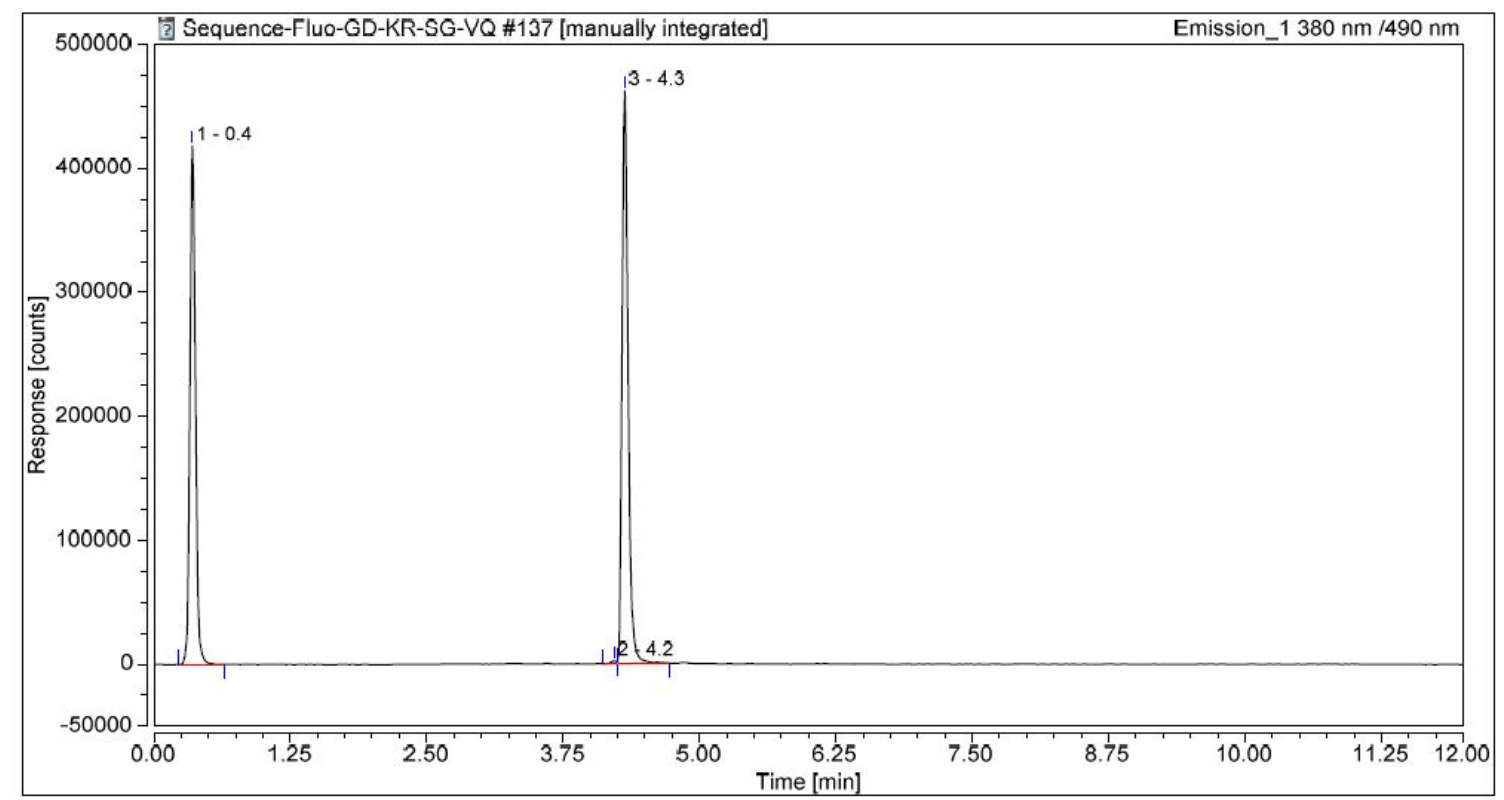


Fig. S210 - RP-HPLC elution profile (system E, fluorescence detection Ex./Em. $380 / 490 \mathrm{~nm}$ ) of co-injection of fluorogenic probe 18 (concentration: $0.5 \mu \mathrm{M}$ in PB) with PGA (1 $\mathrm{U}, 30 \mathrm{~min}, 37^{\circ} \mathrm{C}$ ) and quinoxalin-2(1H)-one 7 (concentration: $0.5 \mu \mathrm{M}$ in PB)

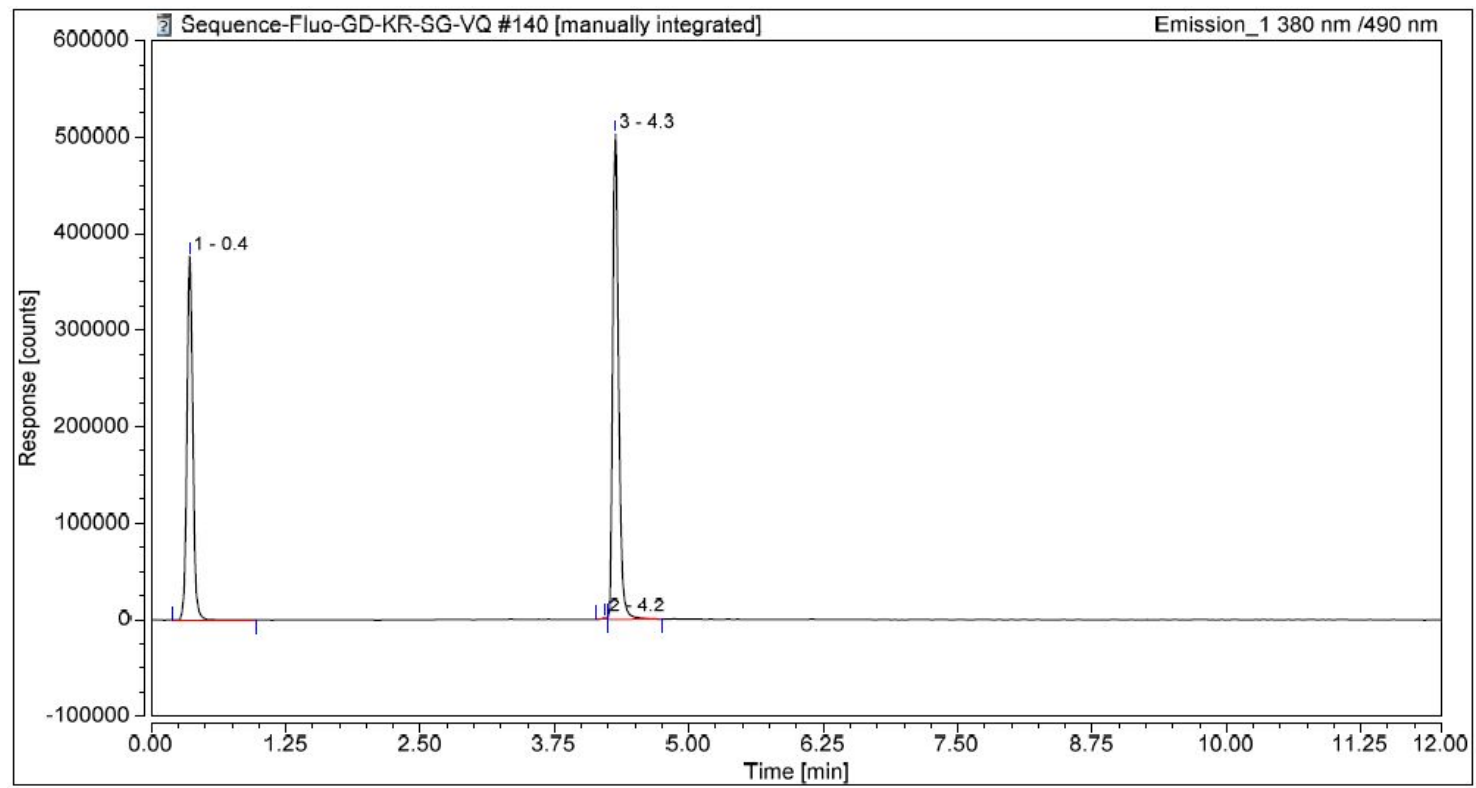

Fig. S211 - RP-HPLC elution profile (system E, fluorescence detection Ex./Em. $380 / 490 \mathrm{~nm}$ ) of fluorogenic probe 18 (concentration: 1.0 $\mu \mathrm{M}$ in PB) with PGA (1 U, $30 \mathrm{~min}, 37^{\circ} \mathrm{C}$ ) and GSH (50 equiv.)

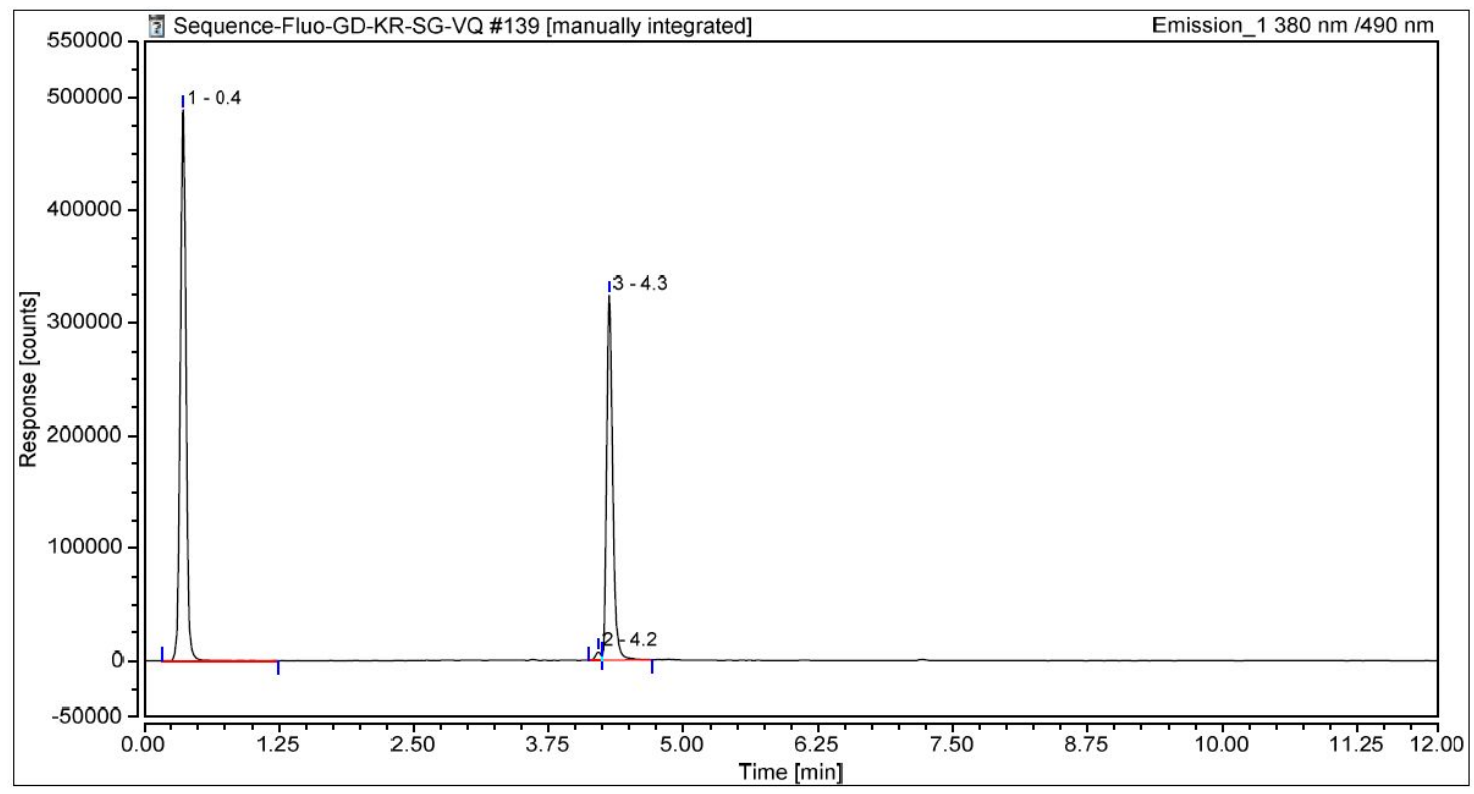


Fig. S212 - RP-HPLC elution profile (system E, fluorescence detection Ex./Em. $380 / 490 \mathrm{~nm}$ ) of co-injection of fluorogenic probe 18 (concentration: $0.5 \mu \mathrm{M}$ in PB) with PGA (1 $\mathrm{U}, 30 \mathrm{~min}, 37^{\circ} \mathrm{C}$ ) and GSH (50 equiv.), and quinoxalin-2(1H)-one 7 (concentration: $0.5 \mu \mathrm{M}$ in $\mathrm{PB}$ )

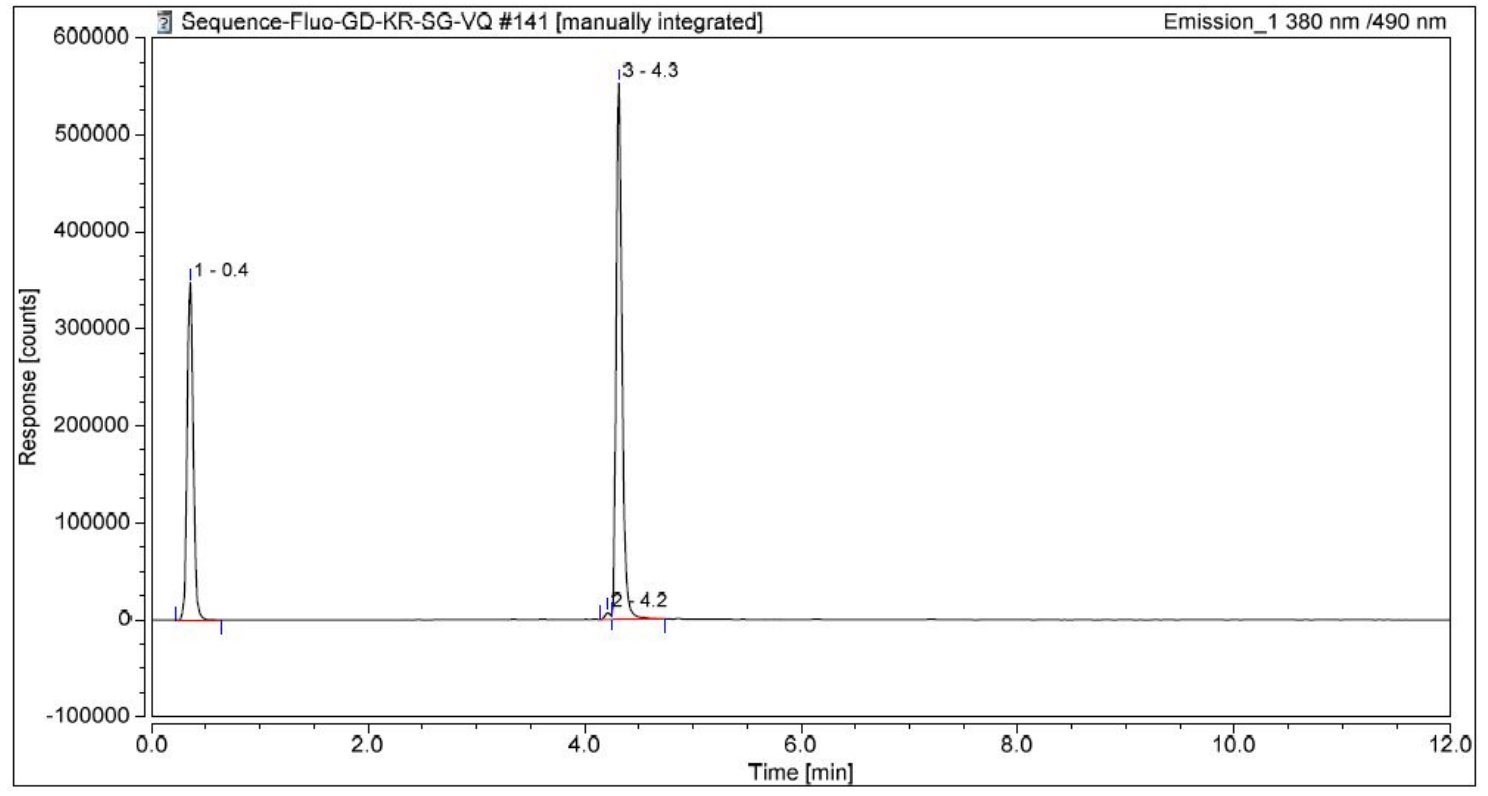

Fig. S213 - RP-HPLC elution profile (system B) of blank (injection of PB alone). UV detection at $260 \mathrm{~nm}$; UV detection at $365 \mathrm{~nm}$; ESI+ mass detection (SIM mode at $m / z, 221.1 \pm 0.5$ ); ESI+/ESI- mass detection (SIM mode at $m / z, 506.2 \pm 0.5$ and $504.2 \pm 0.5)$ (top-down)

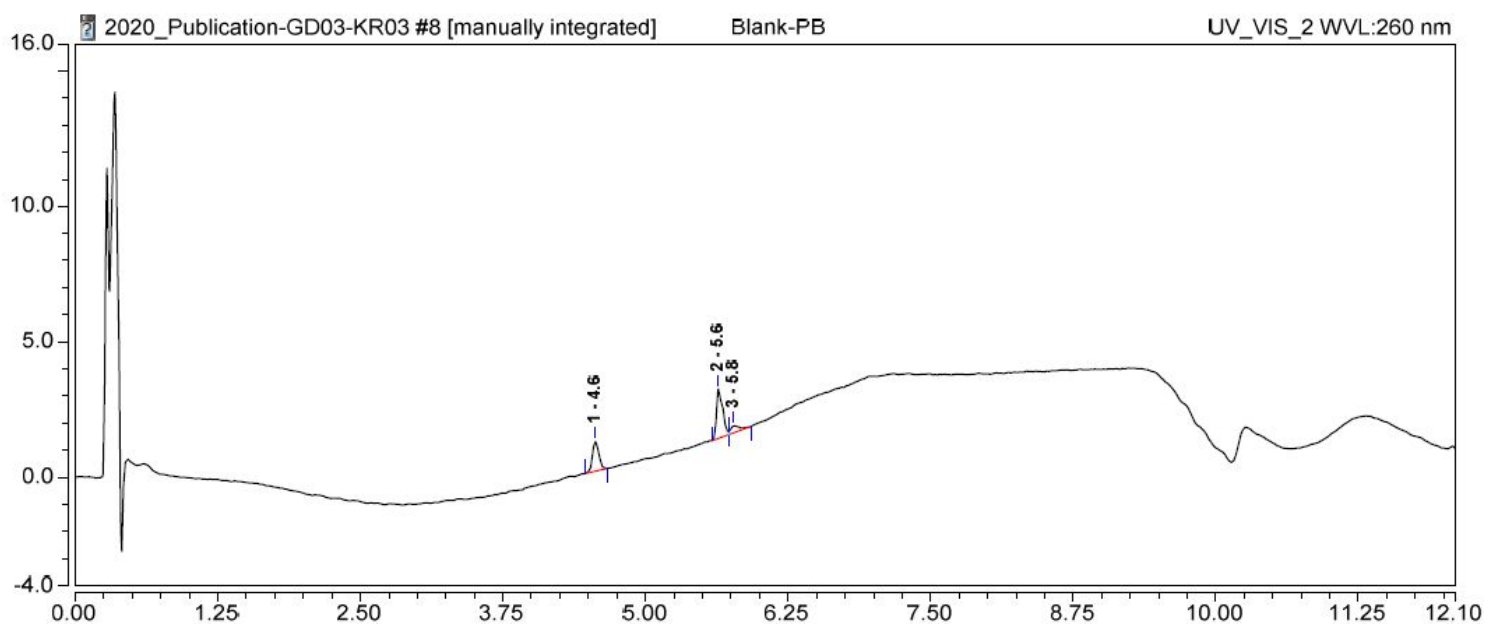




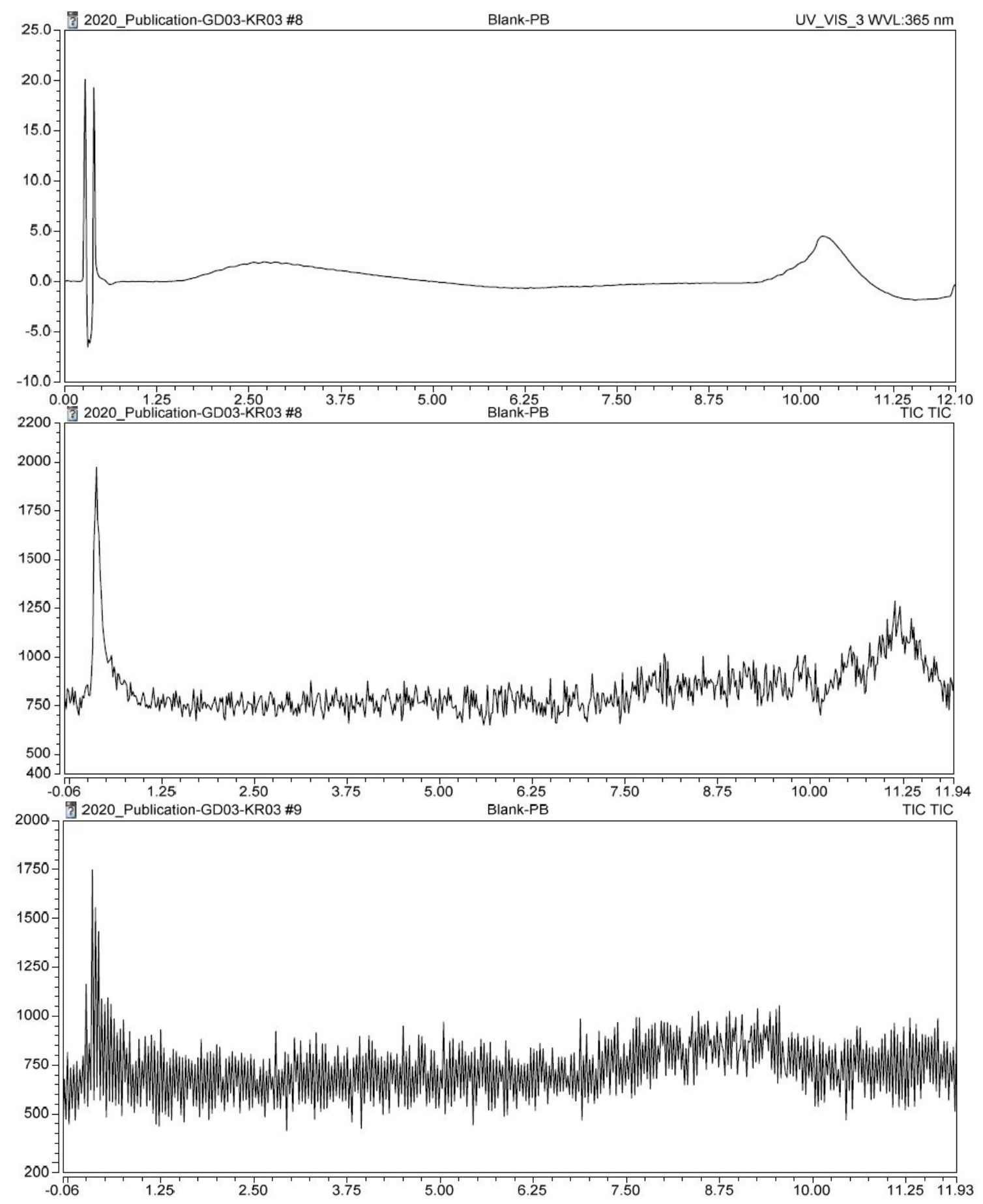


Fig. S214 - RP-HPLC elution profile (system B) of probe 12 without PGA (concentration: $1.0 \mu \mathrm{M}$ in $\mathrm{PB}, 30 \mathrm{~min}, 37^{\circ} \mathrm{C}$ ). $\mathrm{UV}$ detection at $260 \mathrm{~nm}$; $\mathrm{UV}$ detection at $365 \mathrm{~nm}$; ESI+ mass detection (SIM mode at $\mathrm{m} / z 221.1 \pm 0.5$ ); ESI+/ESI- mass detection (SIM mode at $m / z, 506.2 \pm 0.5$ and $504.2 \pm 0.5$ ) (top-down)

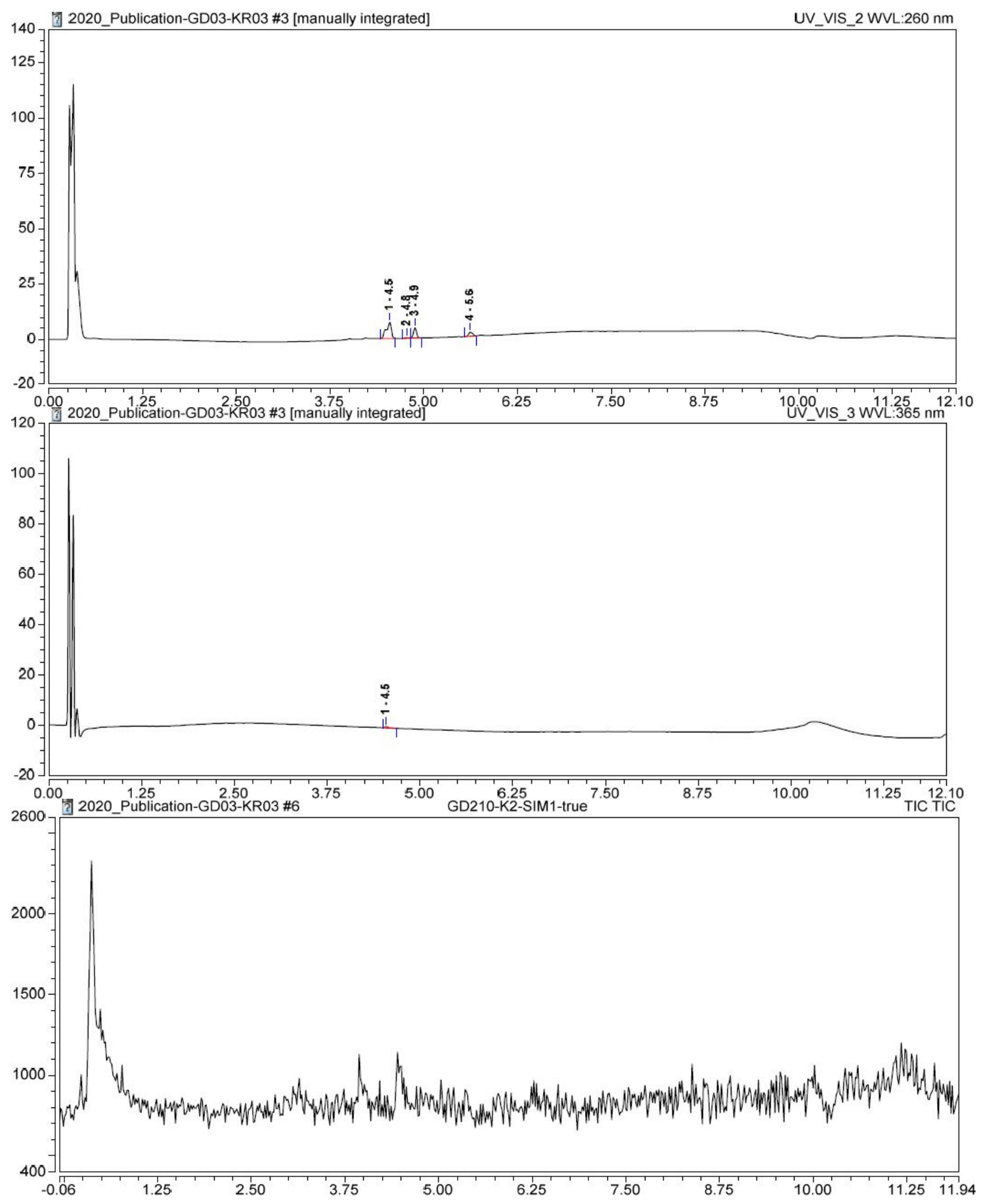




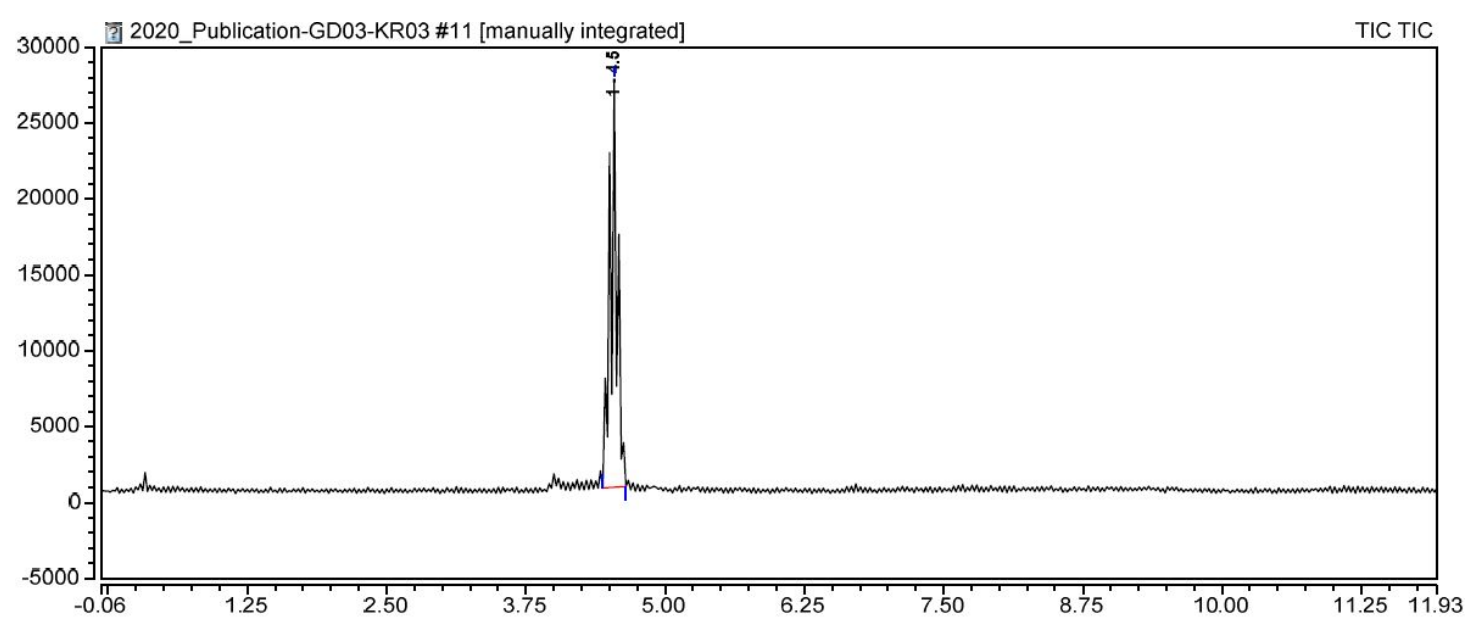

Fig. S215 - RP-HPLC elution profile (system B) of probe 12 (concentration: $1.0 \mu \mathrm{M}$ in PB) with PGA (1 $\left.\mathrm{U}, 30 \mathrm{~min}, 37^{\circ} \mathrm{C}\right)$. $\mathrm{UV}$ detection at $260 \mathrm{~nm}$; $\mathrm{UV}$ detection at 365 $\mathrm{nm}$; ESI+ mass detection (SIM mode at $m / z 221.1 \pm 0.5$ ); ESI+/ESI- mass detection (SIM mode at $m / z 506.2 \pm 0.5$ and $504.2 \pm 0.5)$ (top-down)

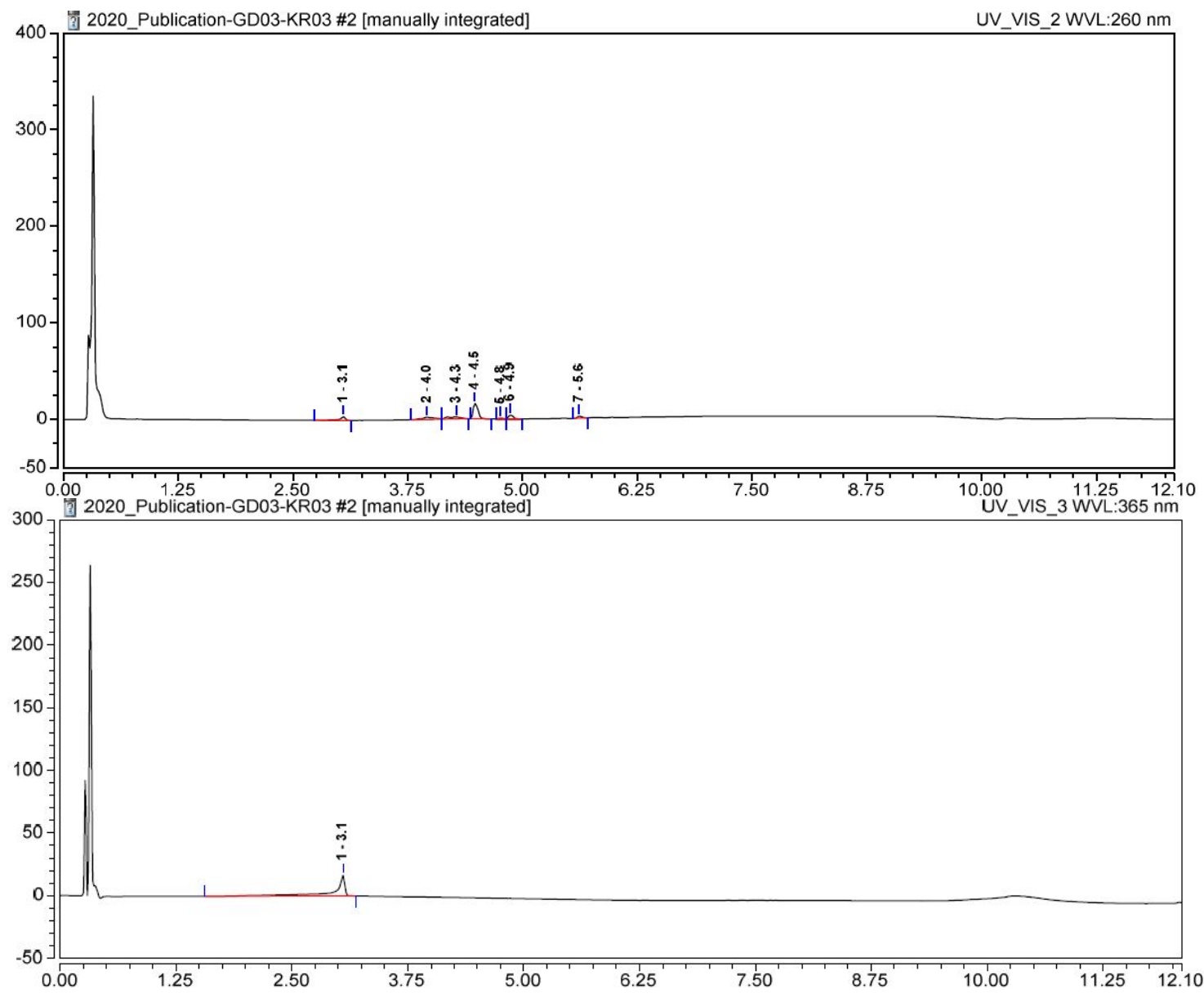




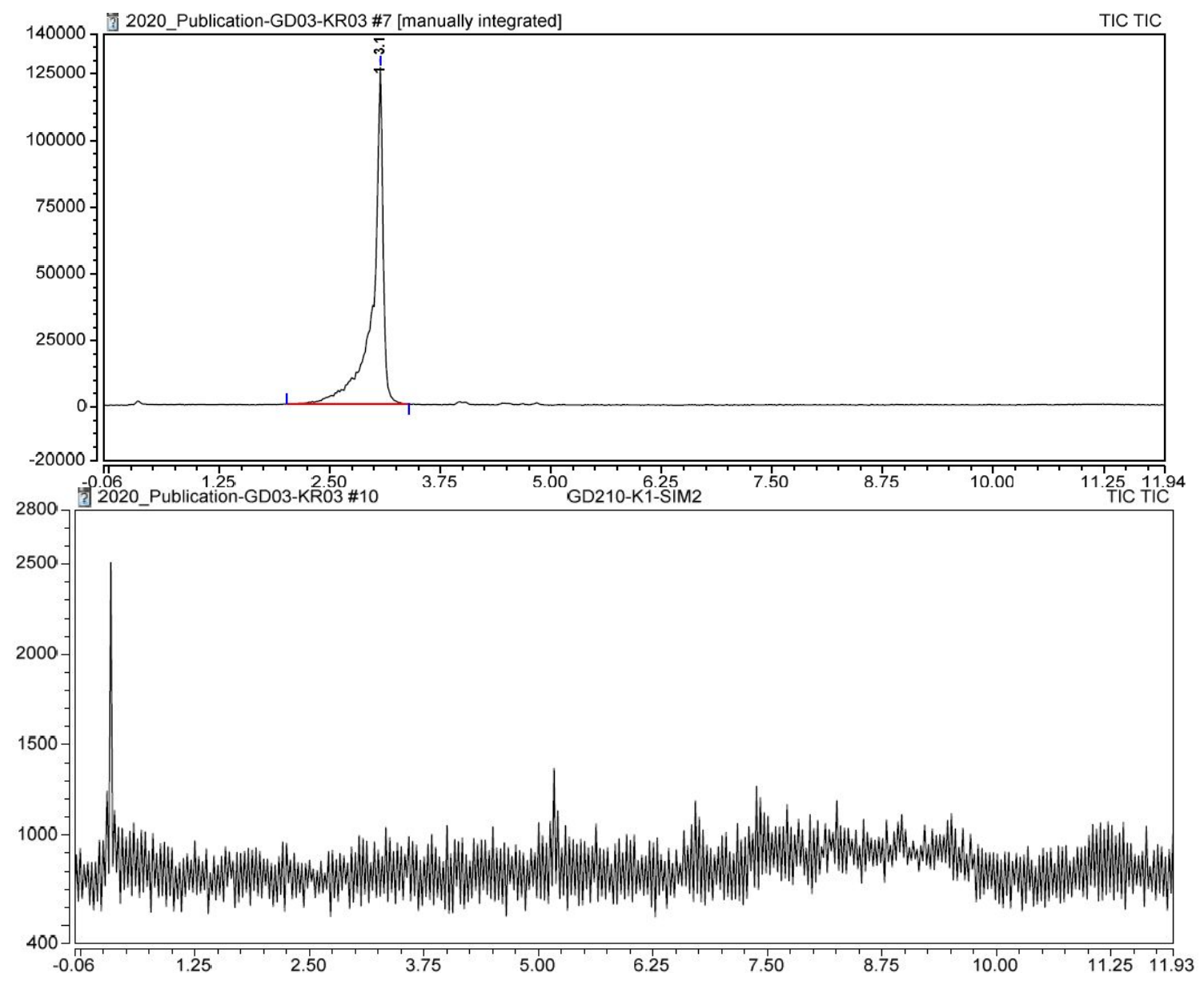

Fig. S216 - RP-HPLC elution profile (system B) of probe 12 (concentration: $1.0 \mu \mathrm{M}$ in PB) with PGA ( $1 \mathrm{U}, 30 \mathrm{~min}, 37^{\circ} \mathrm{C}$ ) and GSH (50 equiv.). UV detection at 260 $\mathrm{nm}$; UV detection at $365 \mathrm{~nm}$; ESI+ mass detection (SIM mode at $m / z, 221.1 \pm 0.5$ ); ESI+/ESI- mass detection (SIM mode at $m / z, 506.2 \pm 0.5$ and $504.2 \pm 0.5$ ) (top-down)

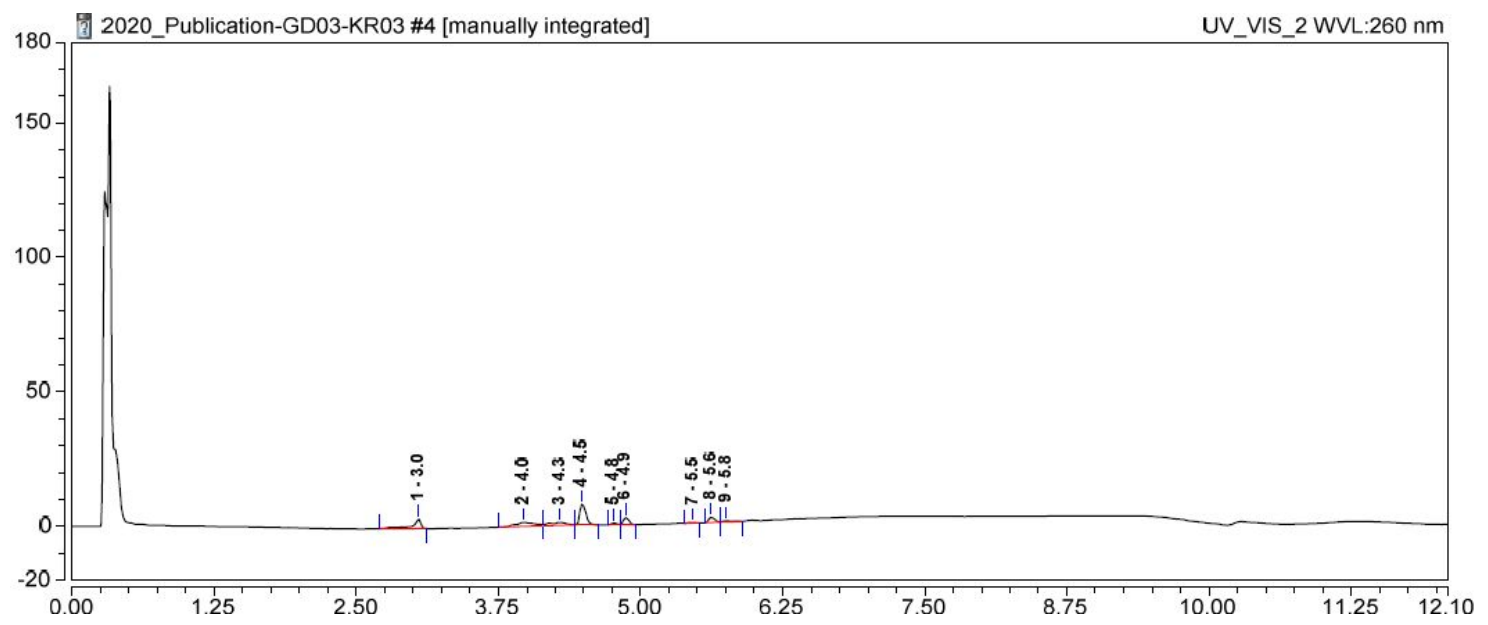




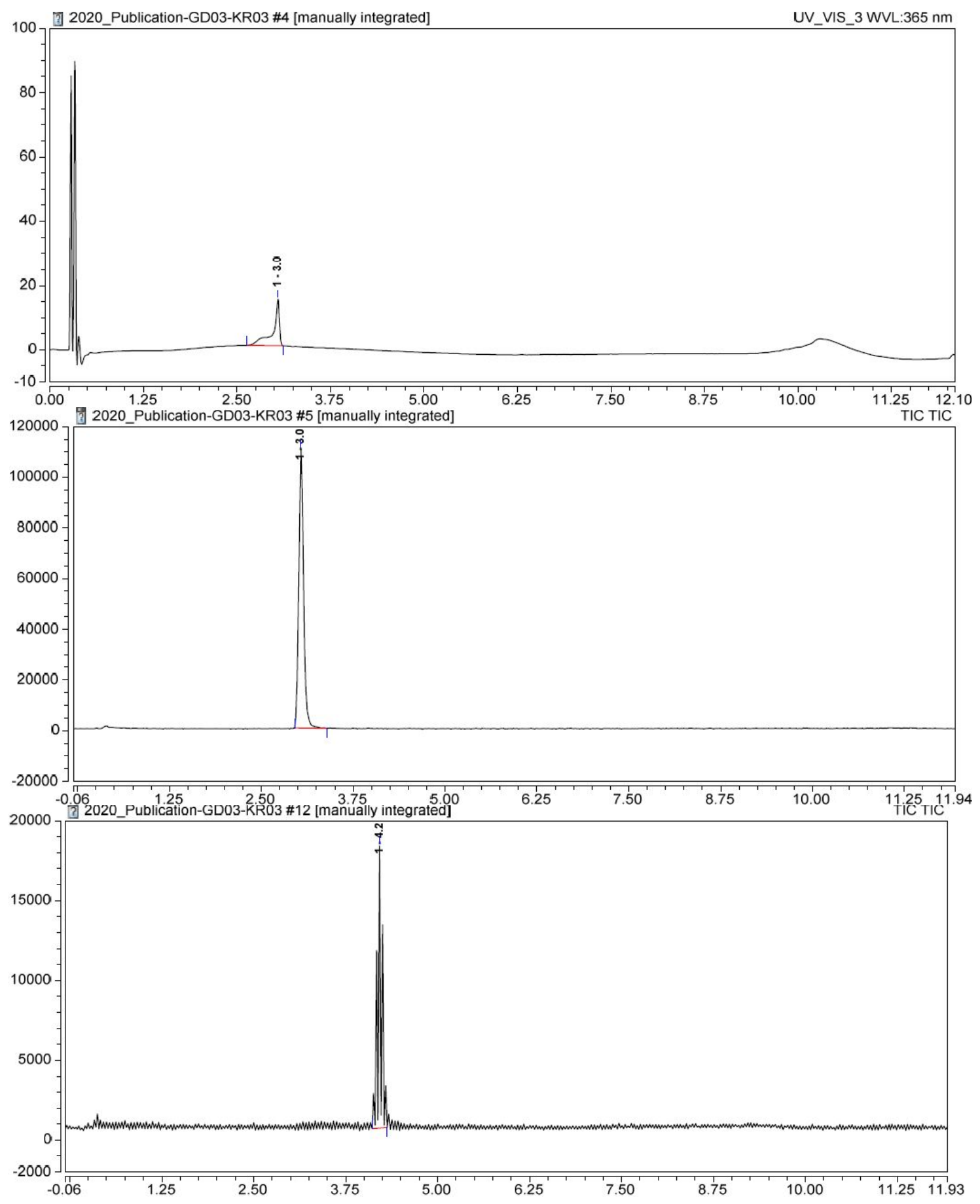


Fig. S217 - RP-HPLC elution profile (system B) of blank (injection of PB alone). UV detection at $260 \mathrm{~nm}$; $\mathrm{UV}$ detection at $400 \mathrm{~nm}$; ESI+ mass detection (SIM mode at $m / z, 283.1 \pm 0.5$ ); ESI+/ESI- mass detection (SIM mode at $m / z, 568.2 \pm 0.5$ and $566.2 \pm 0.5)$ (top-down)

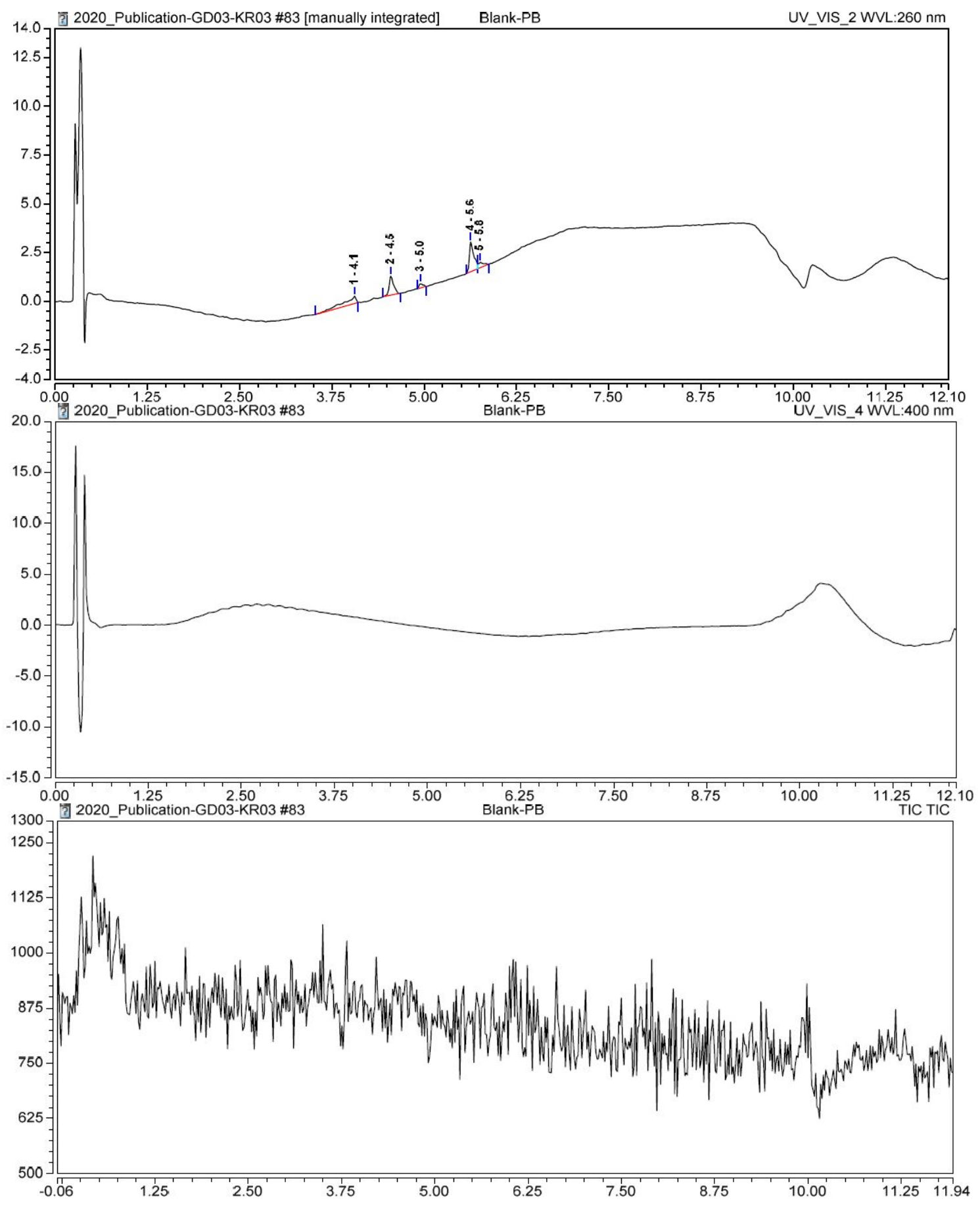




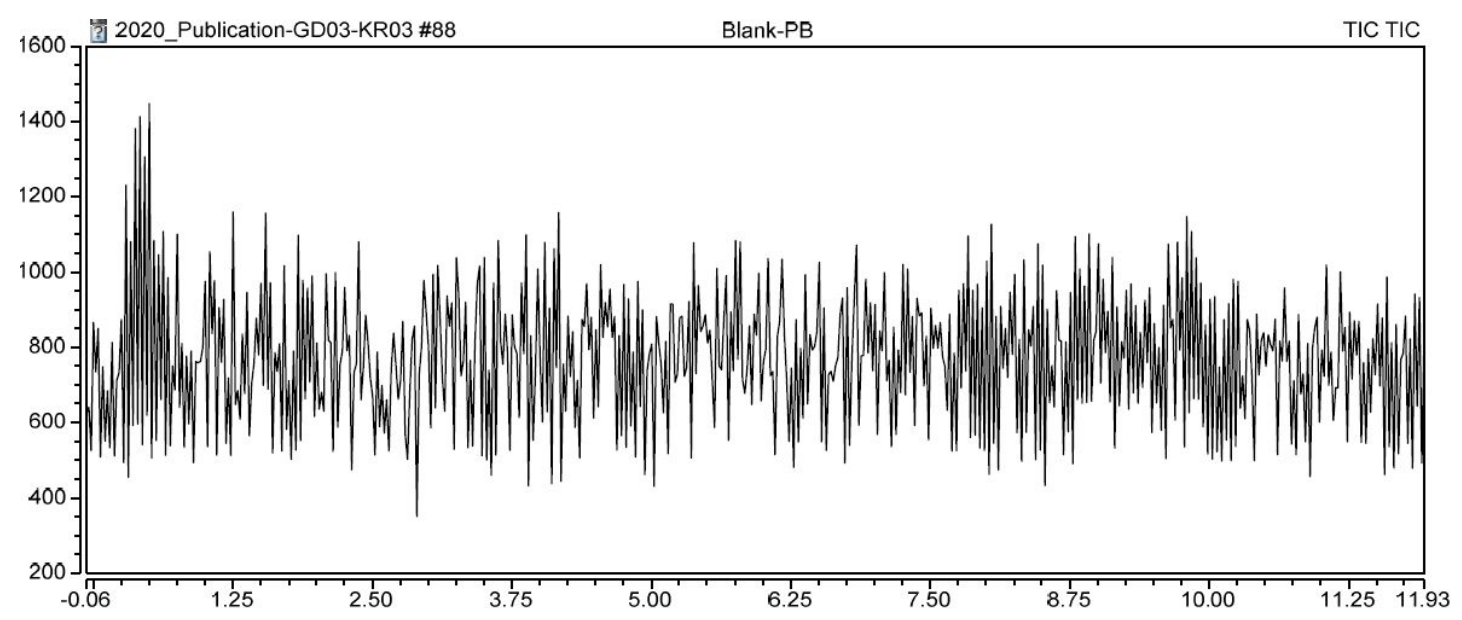

Fig. S218 - RP-HPLC elution profile (system B) of probe 13 without PGA (concentration: $1.0 \mu \mathrm{M}$ in $\mathrm{PB}, 30 \mathrm{~min}, 37^{\circ} \mathrm{C}$ ). $\mathrm{UV}$ detection at $260 \mathrm{~nm}$; $\mathrm{UV}$ detection at $400 \mathrm{~nm}$; ESI+ mass detection (SIM mode at $m / z 283.1 \pm 0.5$ ); ESI+/ESI- mass detection (SIM mode at $m / z 568.2 \pm 0.5$ and $566.2 \pm 0.5$ ) (top-down).

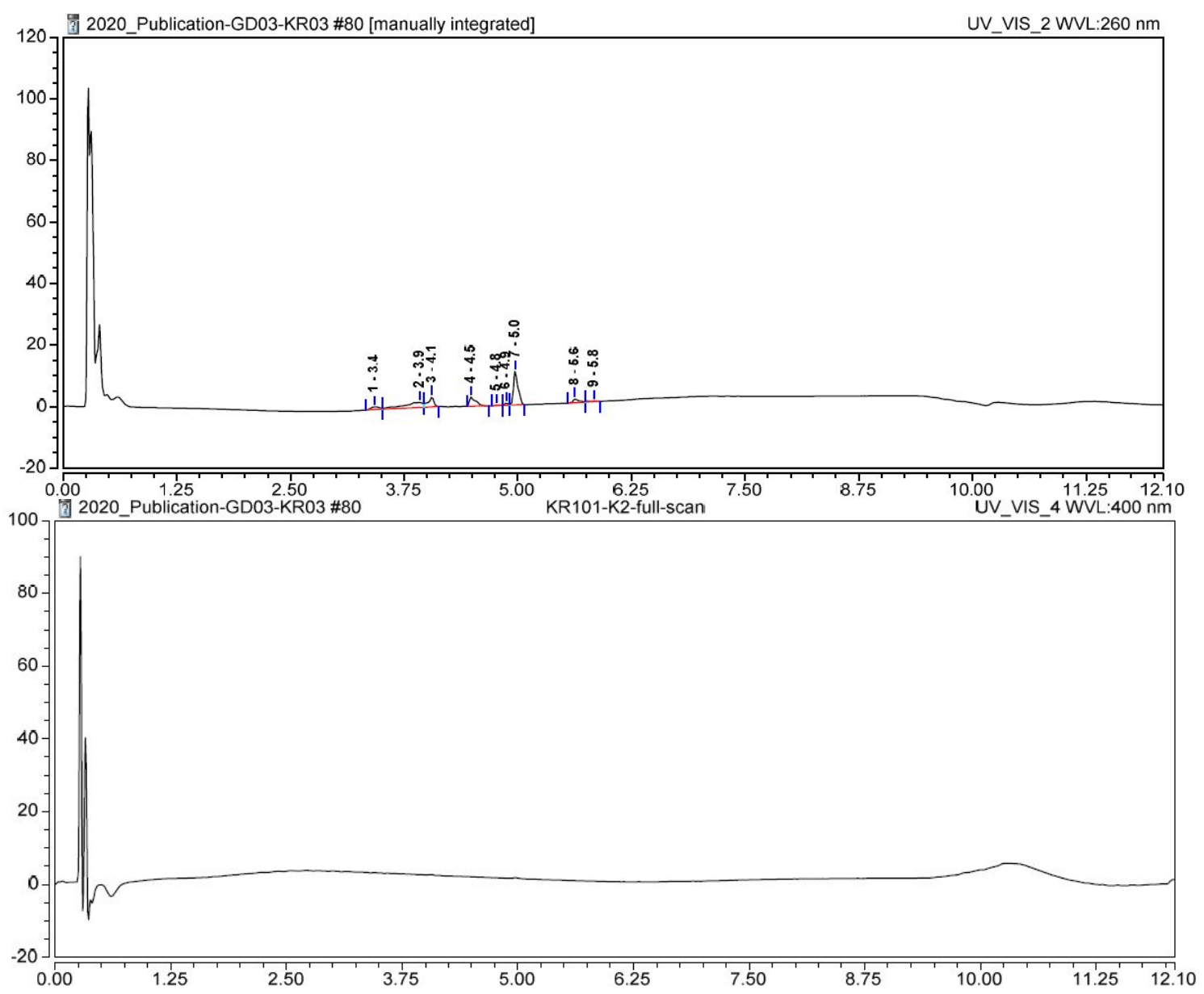




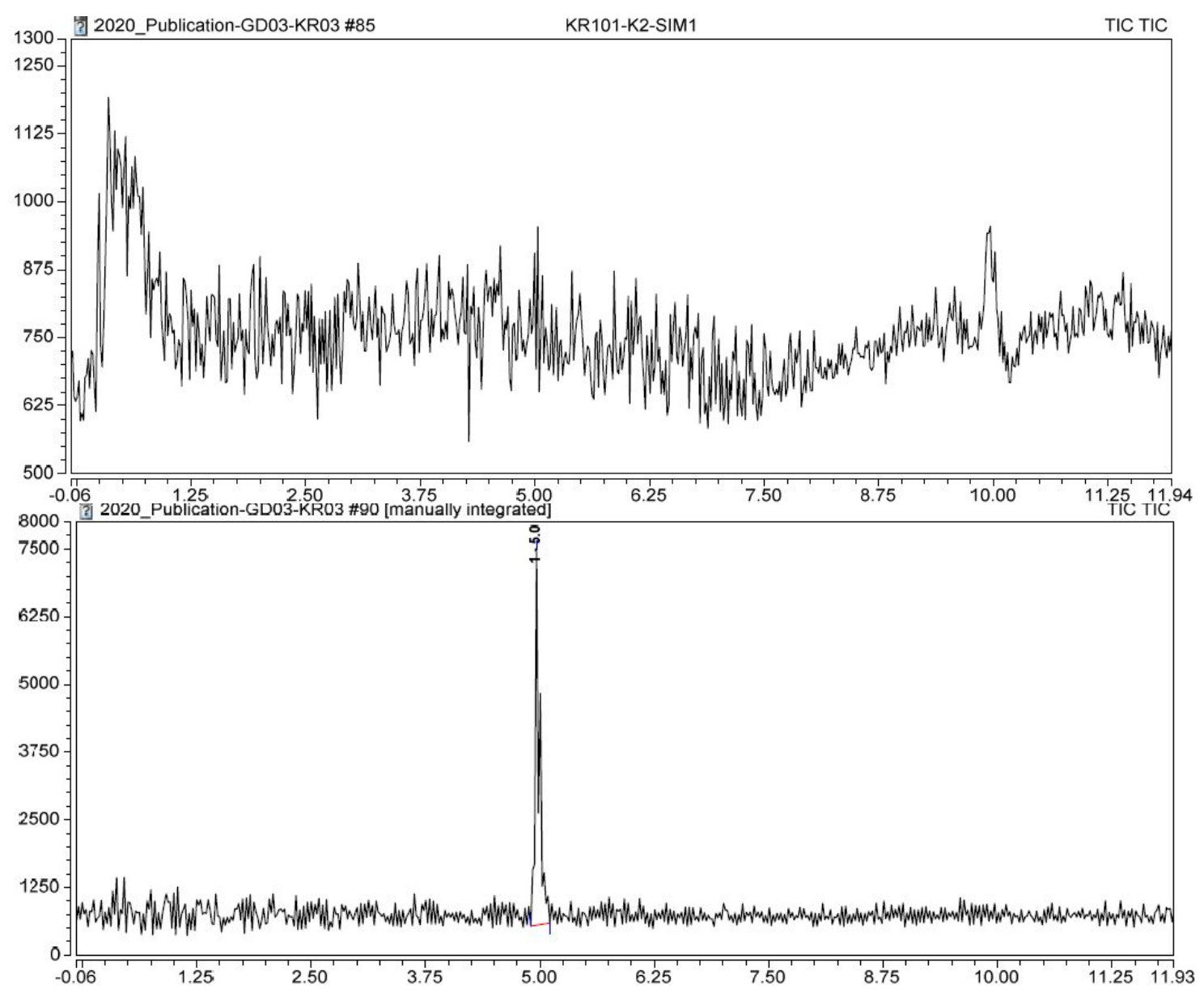

Fig. S219 - RP-HPLC elution profile (system B) of probe 13 (concentration: $1.0 \mu \mathrm{M}$ in PB) with PGA (1 $\left.\mathrm{U}, 30 \mathrm{~min}, 37^{\circ} \mathrm{C}\right)$. $\mathrm{UV}$ detection at $260 \mathrm{~nm}$; $\mathrm{UV}$ detection at 400 $\mathrm{nm}$; ESI+ mass detection (SIM mode at $m / z, 283.1 \pm 0.5$ ); ESI+/ESI- mass detection (SIM mode at $m / z 568.2 \pm 0.5$ and $566.2 \pm 0.5$ ) (top-down)

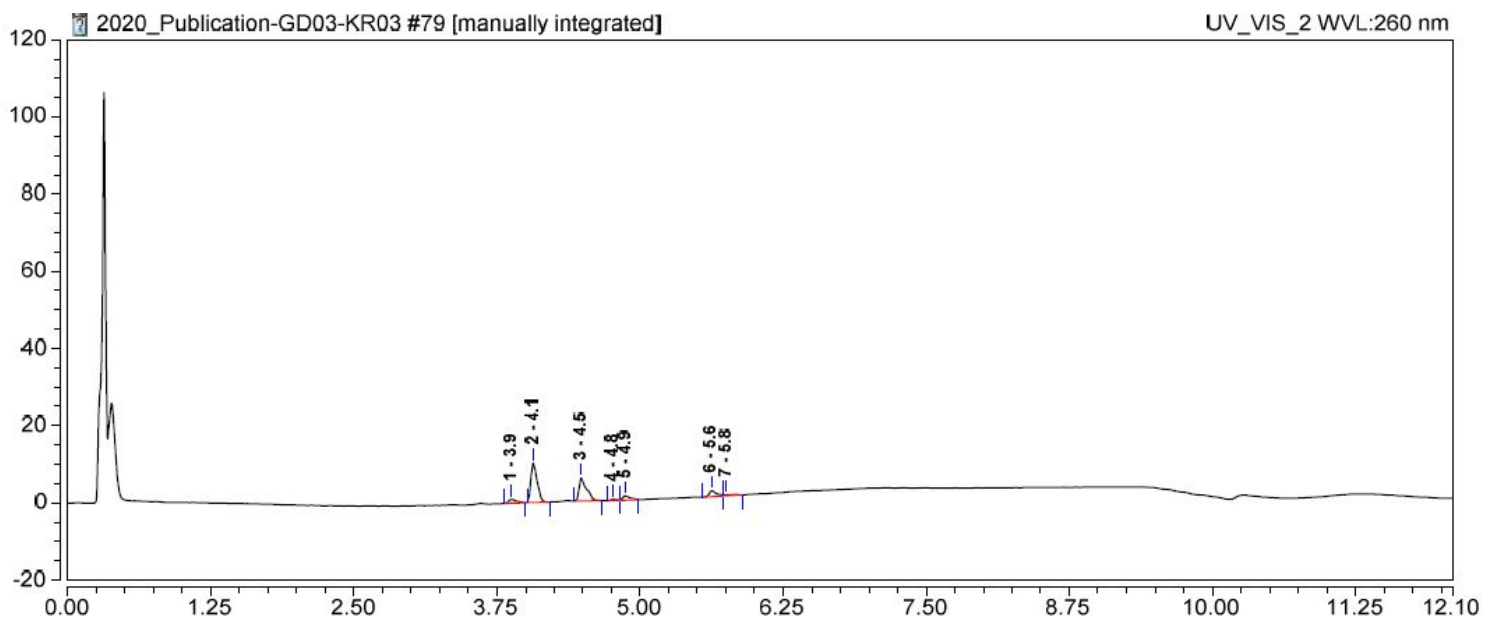



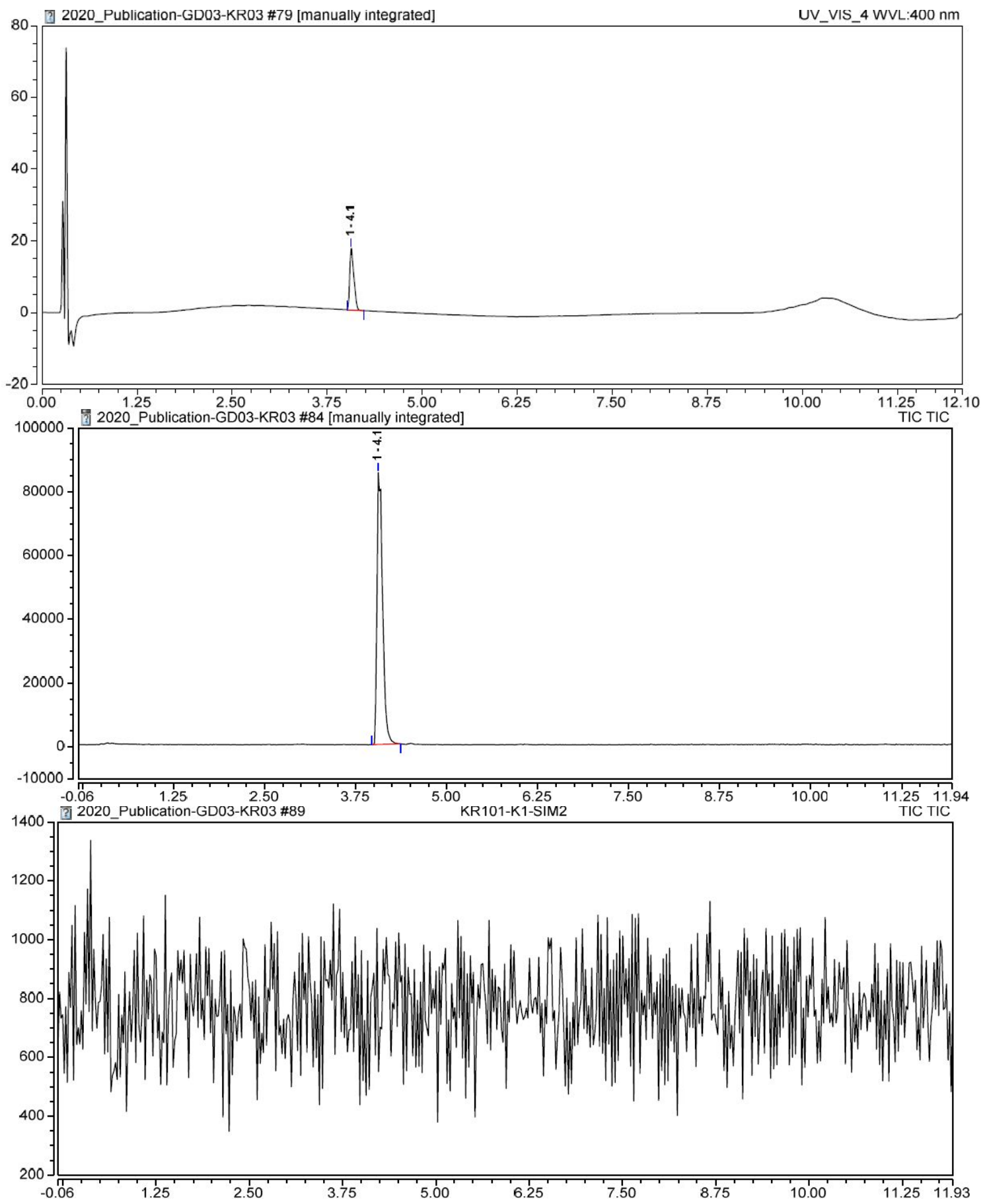
Fig. S220 - RP-HPLC elution profile (system B) of probe 13 (concentration: $1.0 \mu \mathrm{M}$ in PB) with PGA (1 $\mathrm{U}, 30 \mathrm{~min}, 37^{\circ} \mathrm{C}$ ) and GSH (50 equiv.). UV detection at 260 $\mathrm{nm}$; UV detection at $400 \mathrm{~nm}$; ESI+ mass detection (SIM mode at $\mathrm{m} / \mathrm{z}, 283.1 \pm 0.5$ ); ESI+/ESI- mass detection (SIM mode at $m / z, 568.2 \pm 0.5$ and $566.2 \pm 0.5$ ) (top-down)

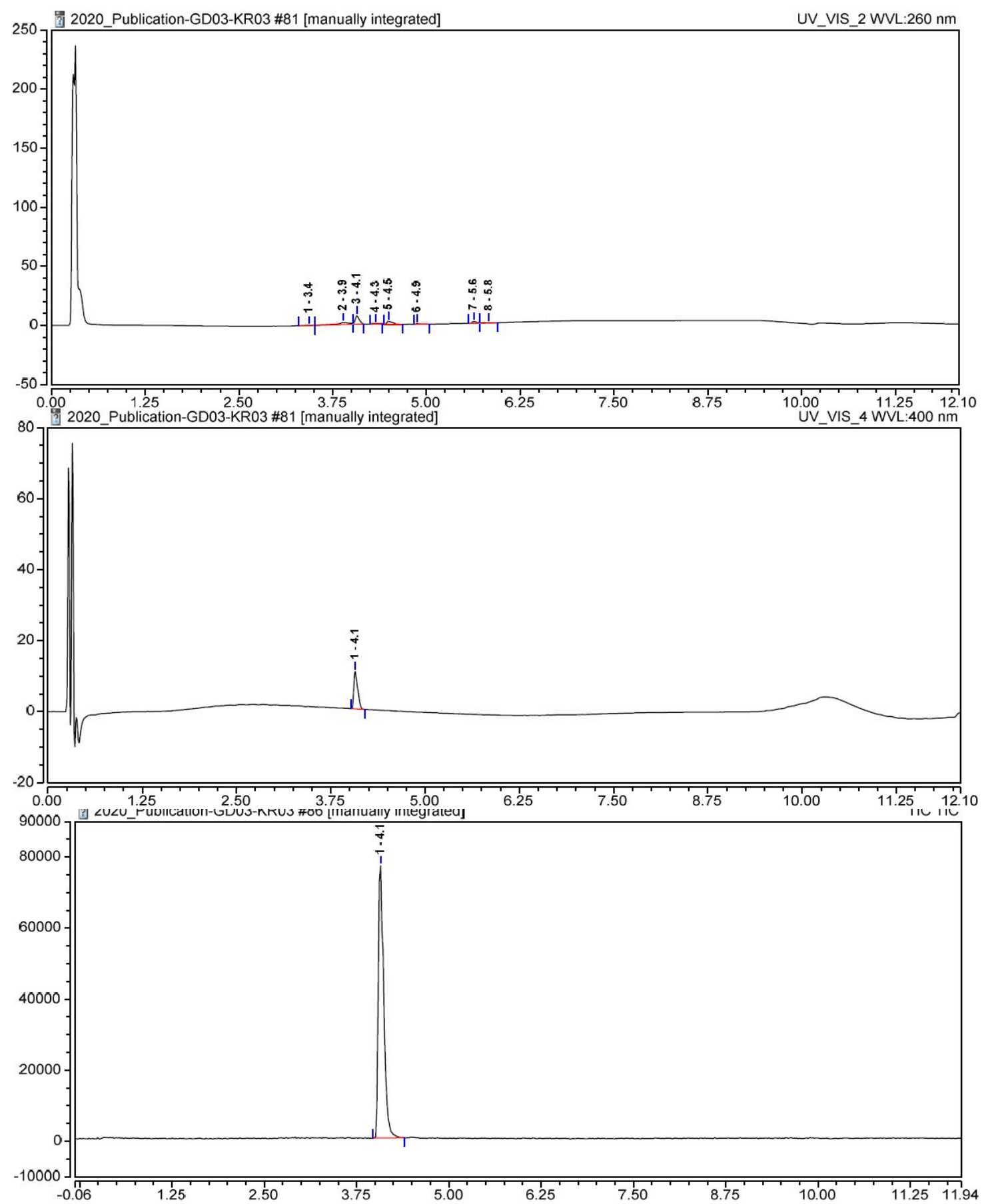




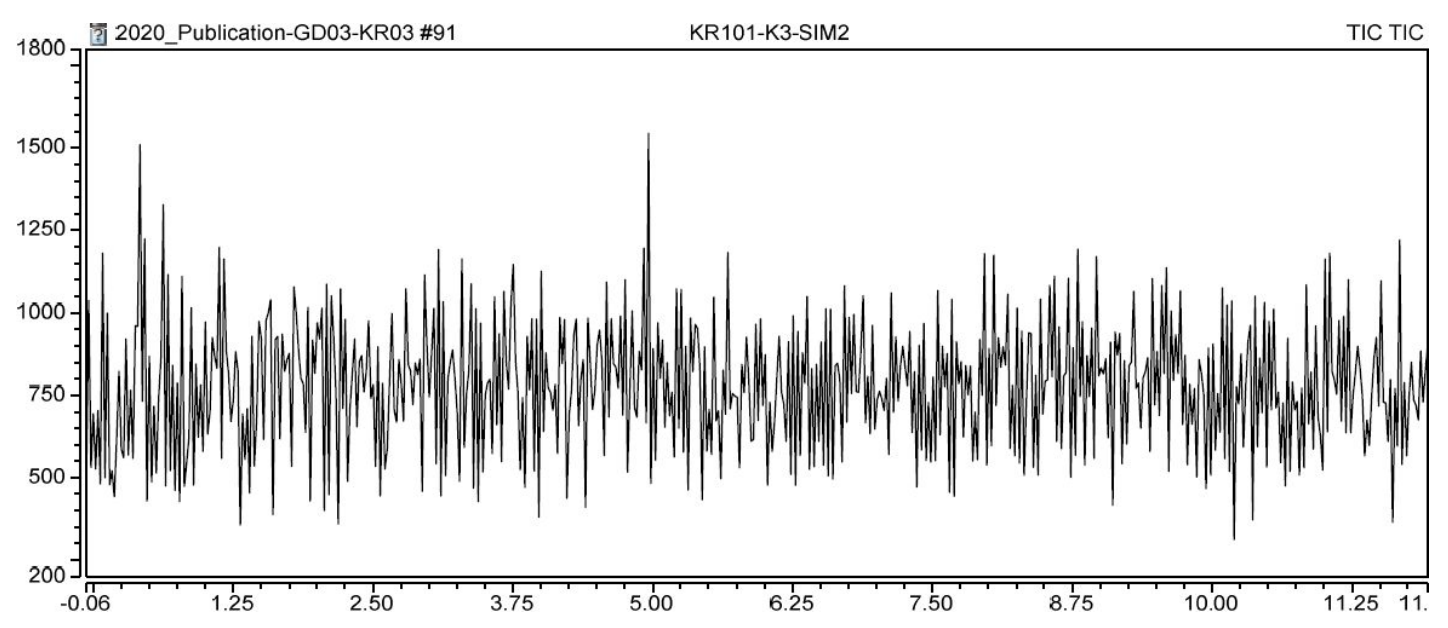

Fig. S221 - RP-HPLC elution profile (system B) of blank (injection of PB alone). $\mathrm{UV}$ detection at $260 \mathrm{~nm}$; $\mathrm{UV}$ detection at $400 \mathrm{~nm}$; ESI+ mass detection (SIM mode at $m / z, 313.1 \pm 0.5$ ); ESI+/ESI- mass detection (SIM mode at $m / z 598.2 \pm 0.5$ and $596.2 \pm 0.5)$ (top-down).

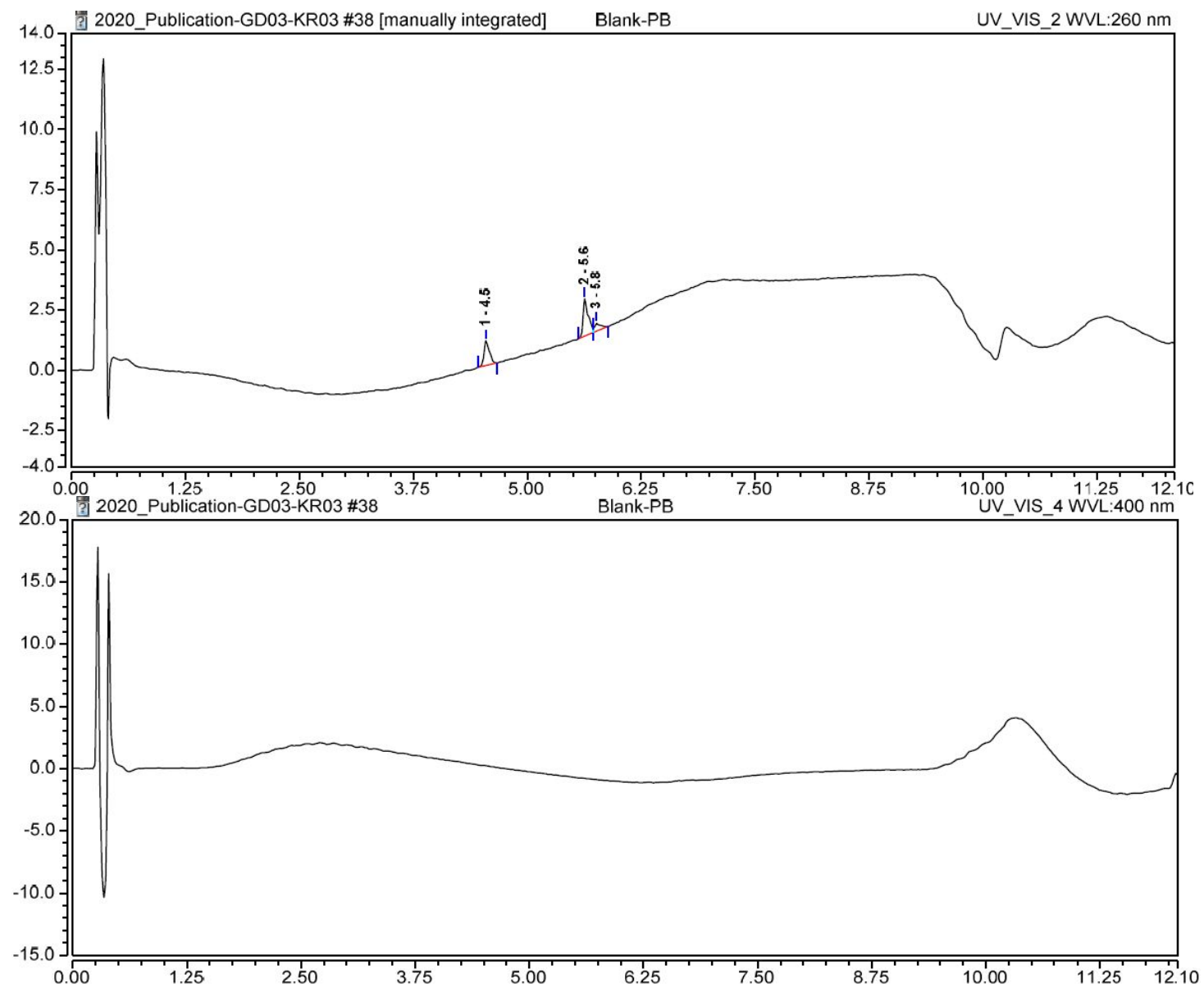




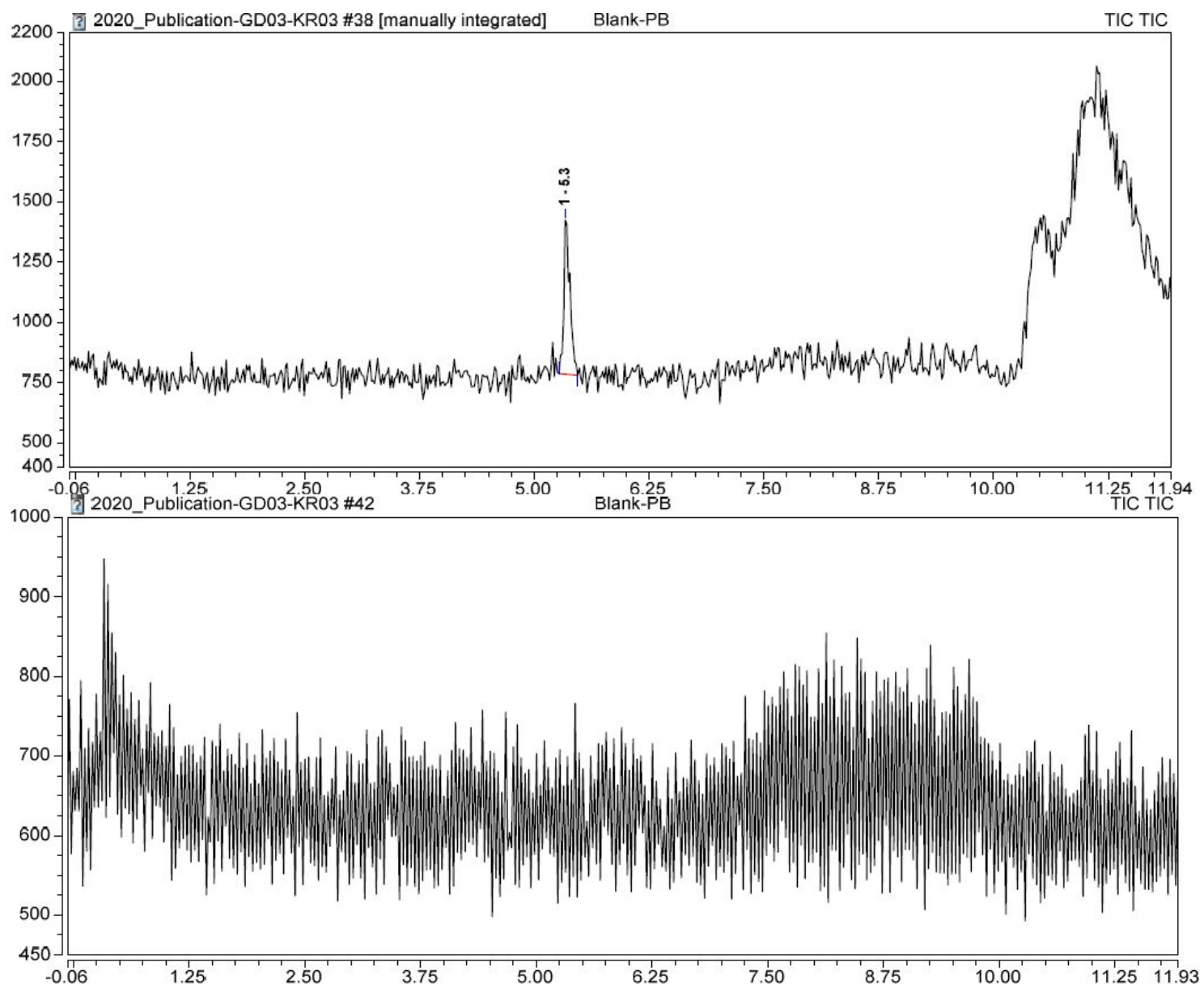

Fig. S222 - RP-HPLC elution profile (system B) of probe 14 without PGA (concentration: $1.0 \mu \mathrm{M}$ in $\mathrm{PB}, 30 \mathrm{~min}, 37^{\circ} \mathrm{C}$ ). $\mathrm{UV}$ detection at $260 \mathrm{~nm}$; $\mathrm{UV}$ detection at $400 \mathrm{~nm}$; ESI+ mass detection (SIM mode at $\mathrm{m} / z 313.1 \pm 0.5$ ); ESI+/ESI- mass detection (SIM mode at $m / z 598.2 \pm 0.5$ and $596.2 \pm 0.5$ ) (top-down)

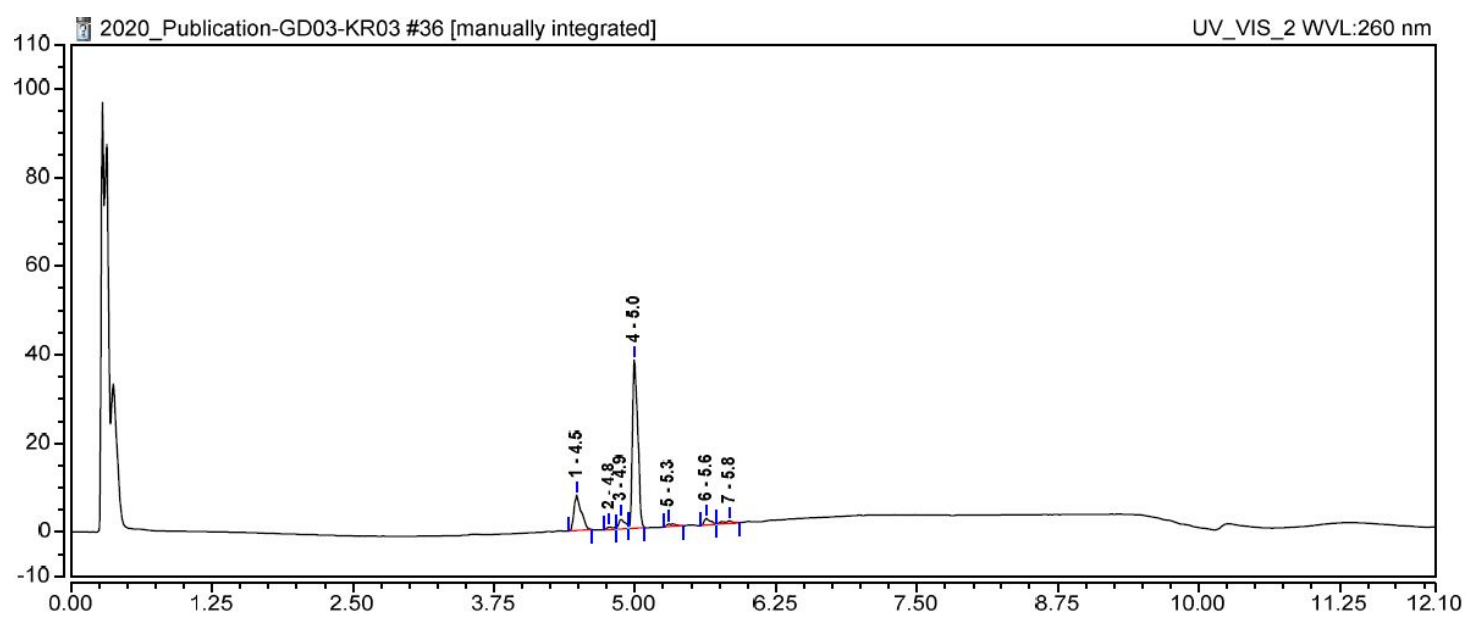



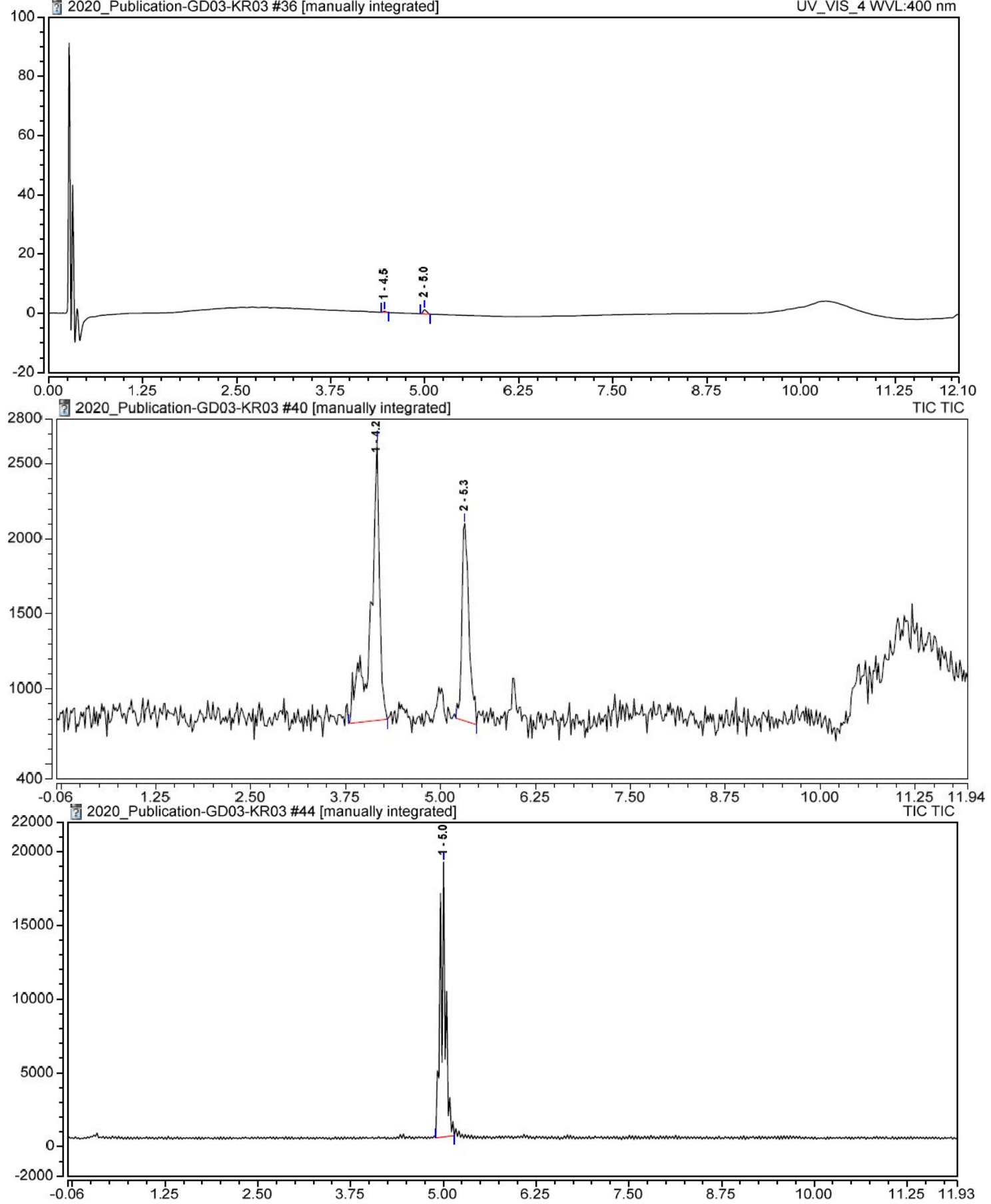
Fig. S223 - RP-HPLC elution profile (system B) of probe 14 (concentration: $1.0 \mu \mathrm{M}$ in PB) with PGA (1 $\left.\mathrm{U}, 30 \mathrm{~min}, 37^{\circ} \mathrm{C}\right)$. $\mathrm{UV}$ detection at $260 \mathrm{~nm}$; $\mathrm{UV}$ detection at 400 $\mathrm{nm}$; ESI+ mass detection (SIM mode at $m / z 313.1 \pm 0.5$ ); ESI+/ESI- mass detection (SIM mode at $m / z 598.2 \pm 0.5$ and $596.2 \pm 0.5$ ) (top-down)

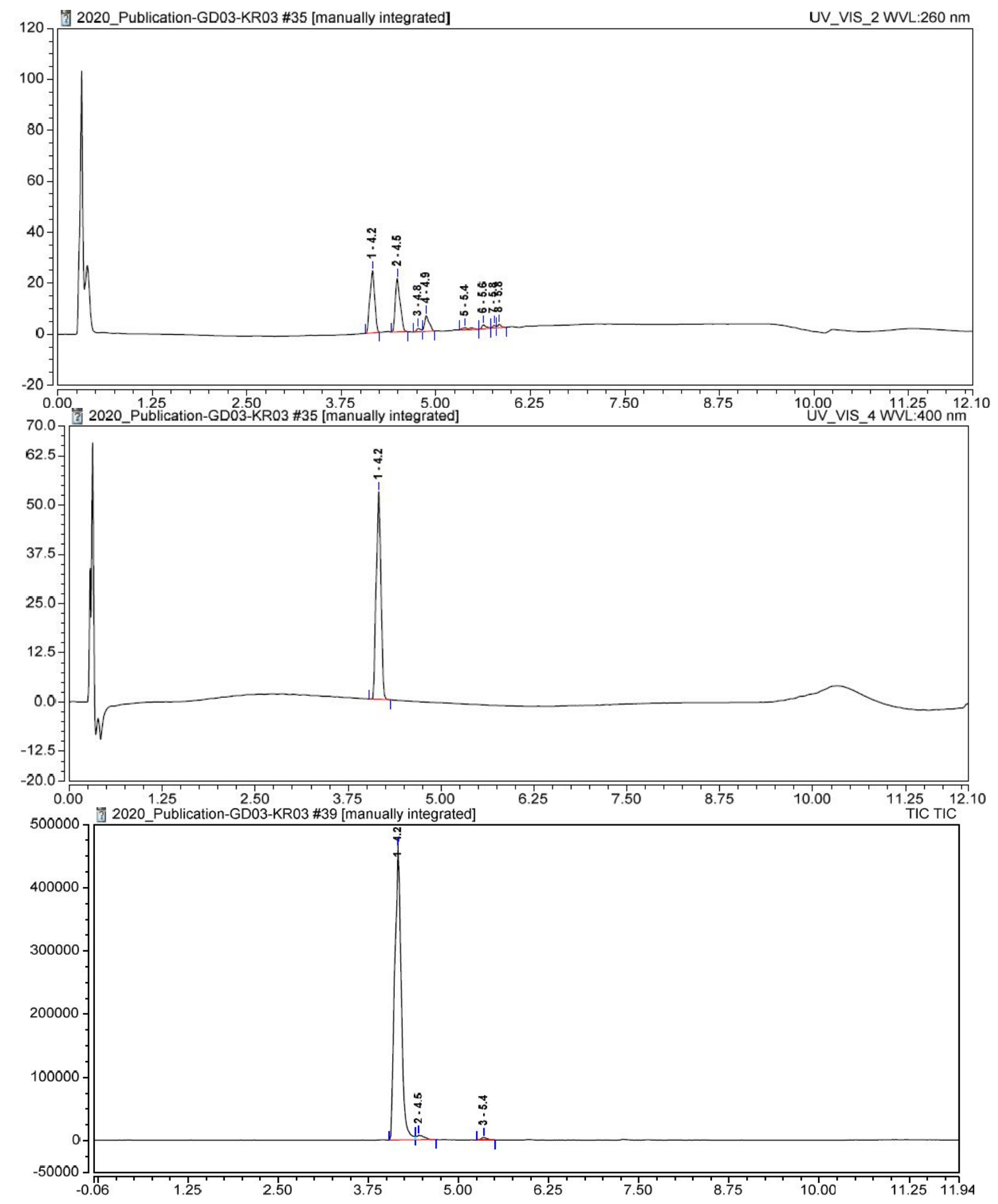




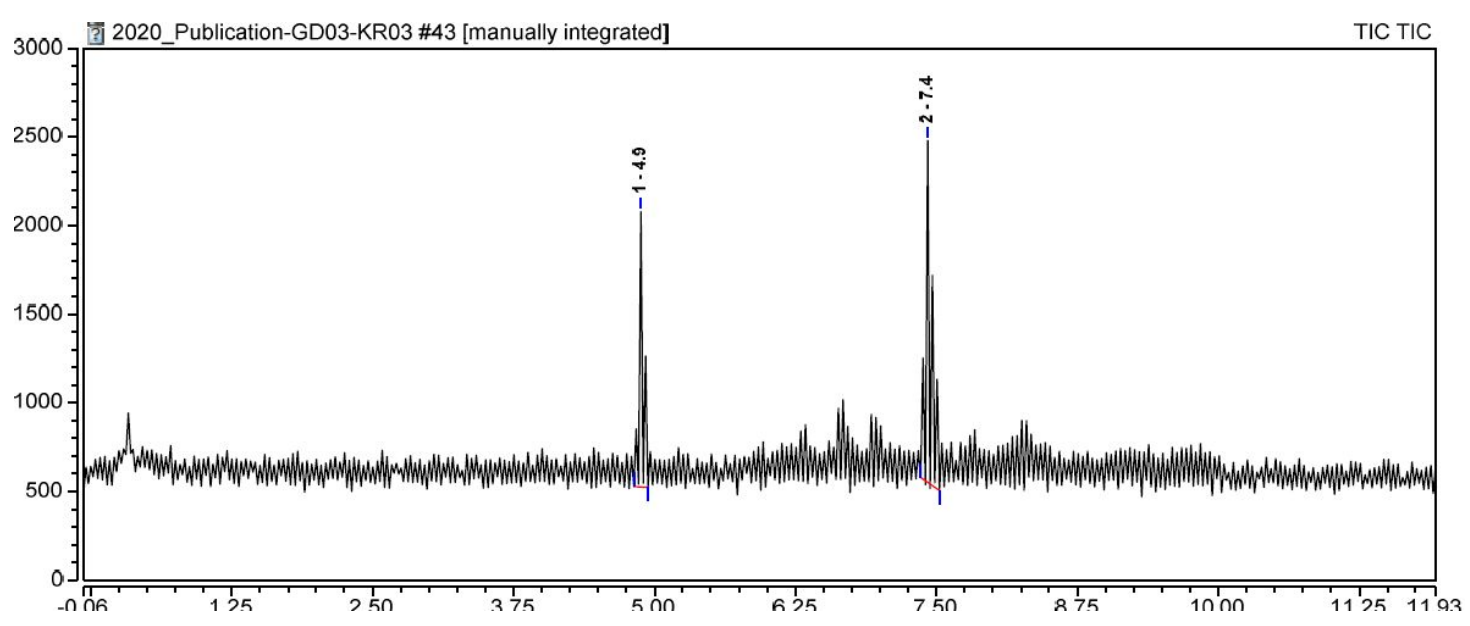

Fig. S224 - RP-HPLC elution profile (system B) of probe 14 (concentration: 1.0 $\mu \mathrm{M}$ in PB) with PGA ( $1 \mathrm{U}, 30 \mathrm{~min}, 37^{\circ} \mathrm{C}$ ) and GSH (50 equiv.). UV detection at 260 $\mathrm{nm}$; UV detection at $400 \mathrm{~nm}$; ESI+ mass detection (SIM mode at $\mathrm{m} / z .313 .1 \pm 0.5$ ); ESI+/ESI- mass detection (SIM mode at $m / z, 598.2 \pm 0.5$ and $596.2 \pm 0.5$ ) (top-down)

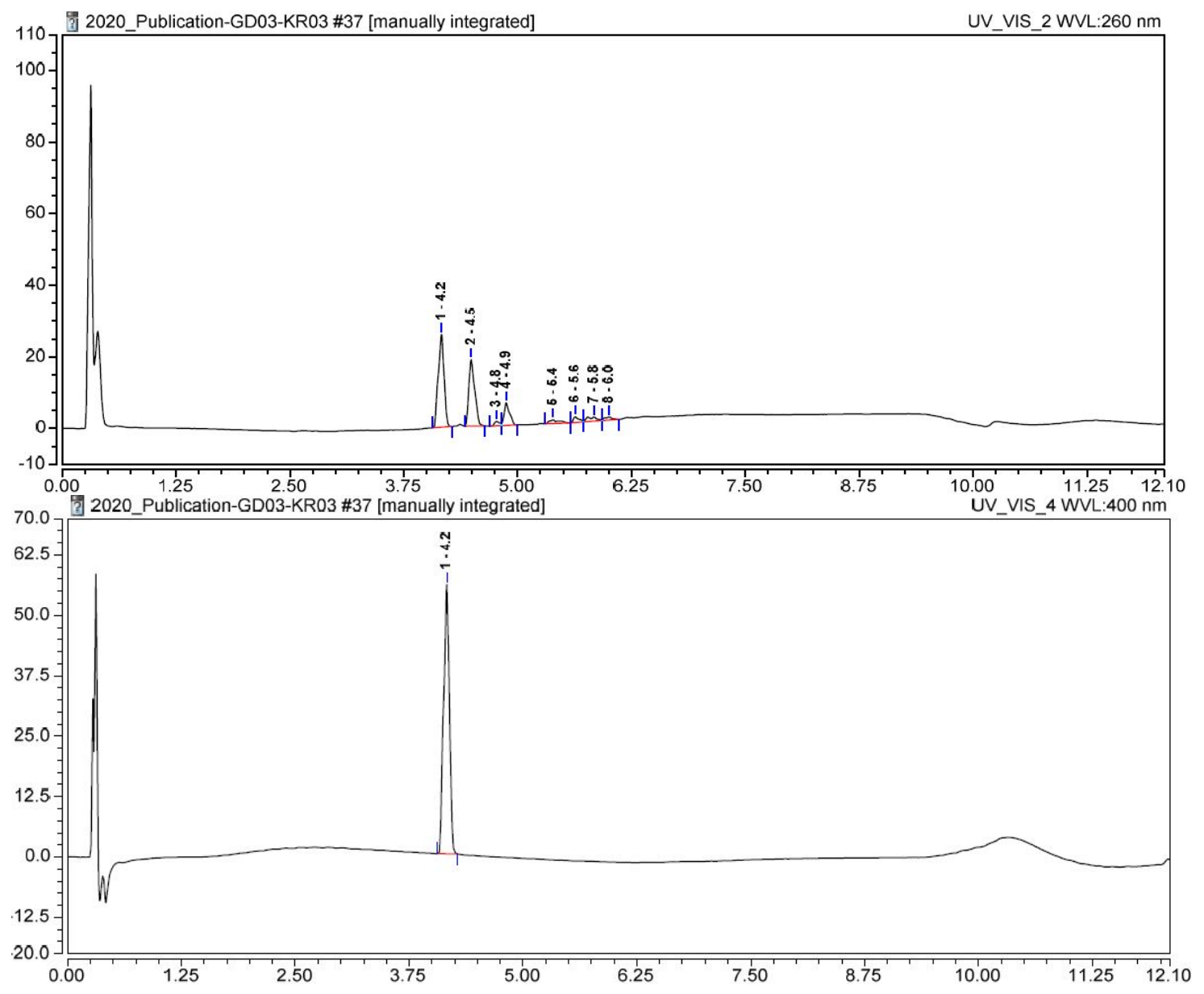



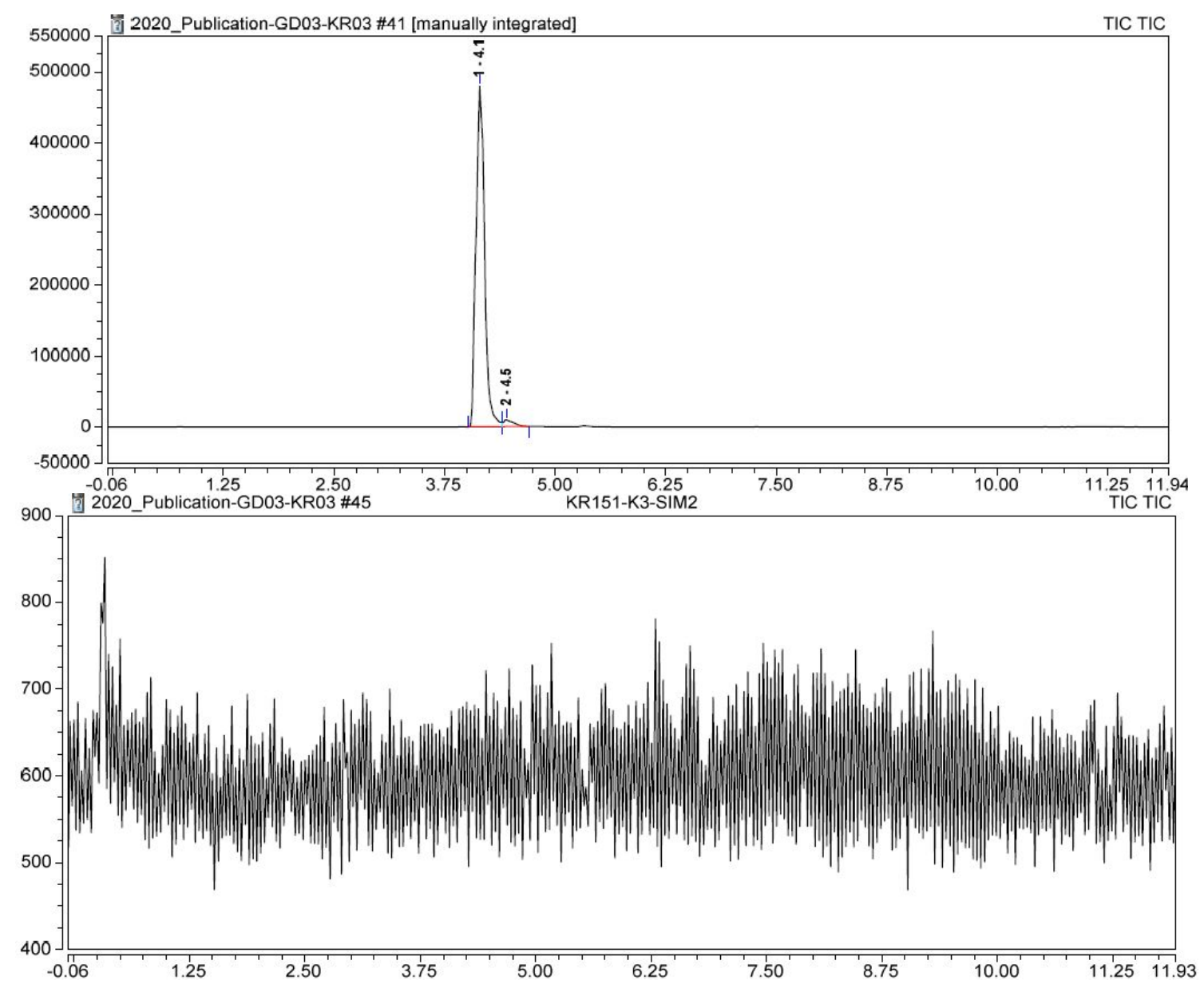

Fig. S225 - RP-HPLC elution profile (system B) of blank (injection of PB alone). UV detection at $260 \mathrm{~nm}$; UV detection at $400 \mathrm{~nm}$; ESI+ mass detection (SIM mode at $m / z, 351.1$ \pm 0.5 ); ESI+/ESI- mass detection (SIM mode at $m / z, 636.2 \pm 0.5$ and $634.2 \pm 0.5$ ) (top-down)

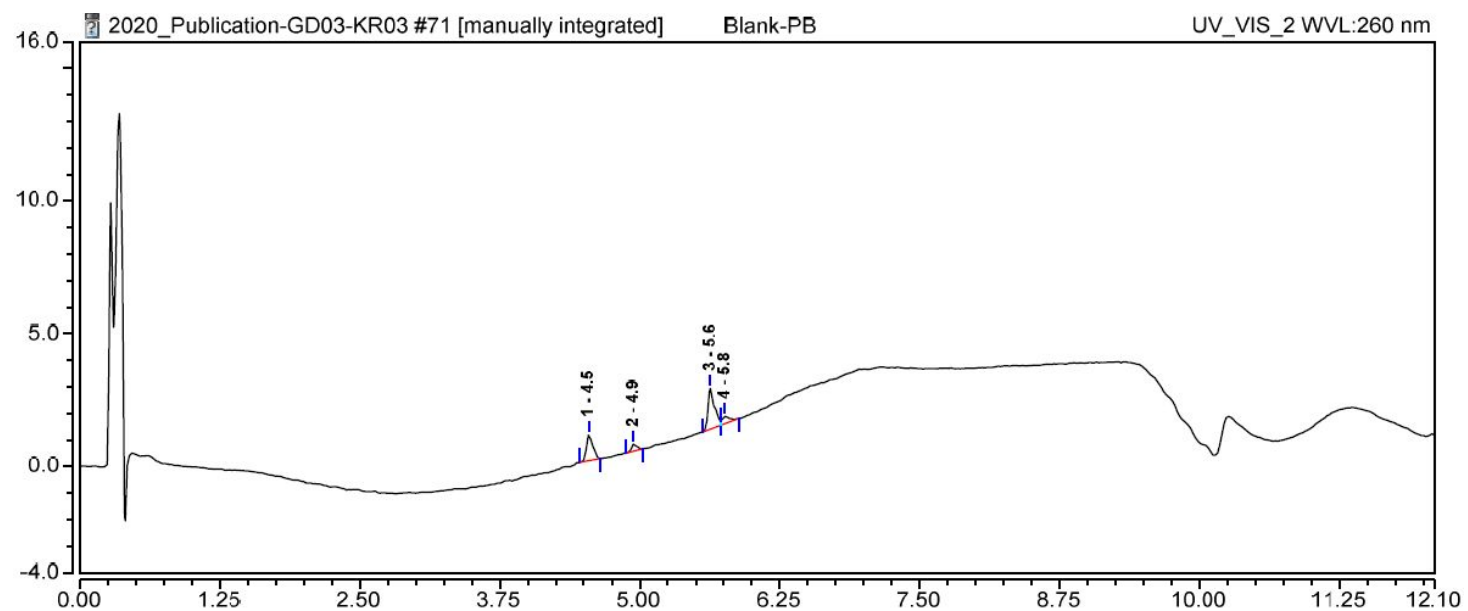




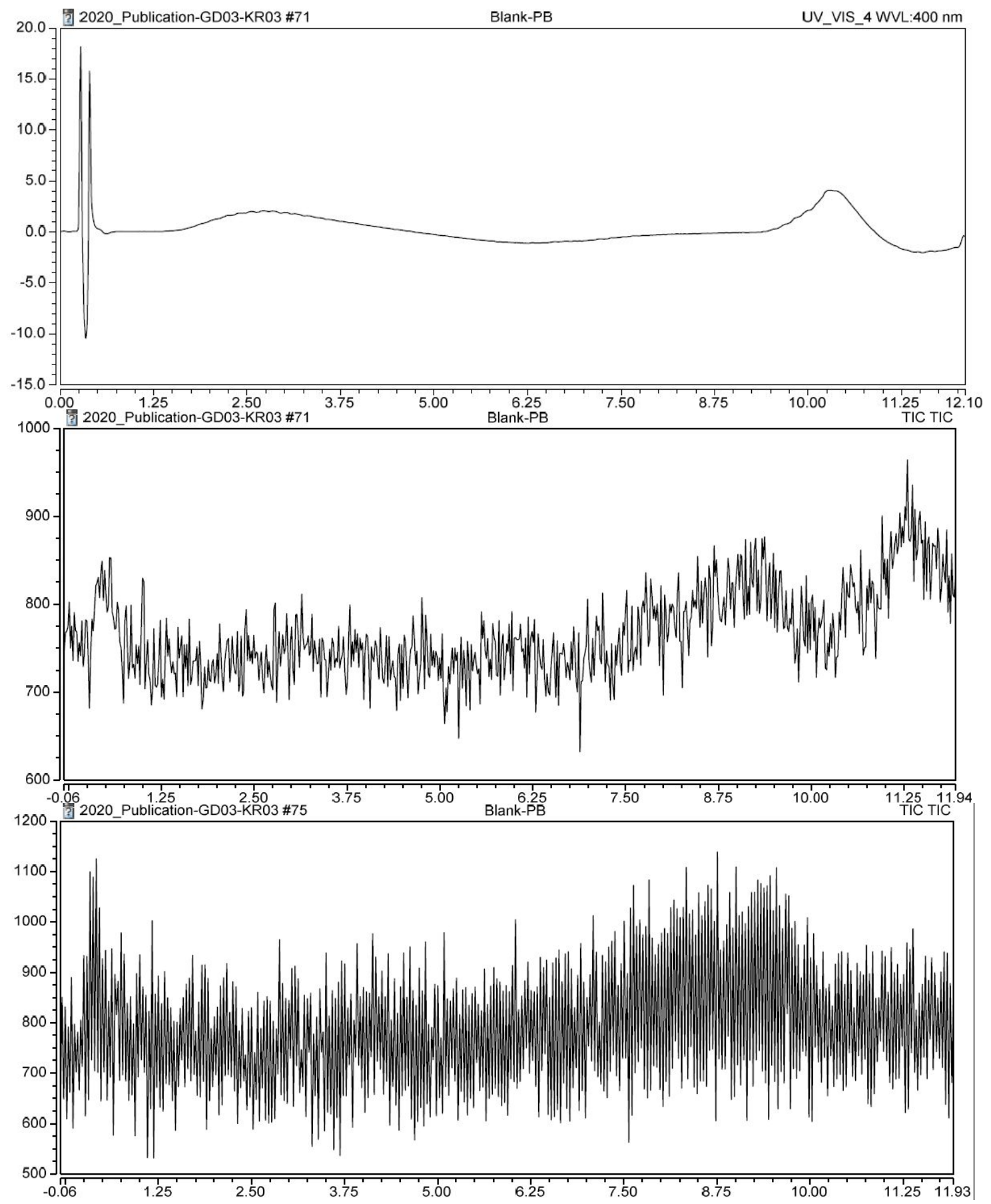


Fig. S226 - RP-HPLC elution profile (system B) of probe 15 without PGA (concentration: $1.0 \mu \mathrm{M}$ in $\mathrm{PB}, 90 \mathrm{~min}, 37^{\circ} \mathrm{C}$ ). $\mathrm{UV}$ detection at $260 \mathrm{~nm}$; $\mathrm{UV}$ detection at $400 \mathrm{~nm}$; ESI+ mass detection (SIM mode at $\mathrm{m} / z 351.1 \pm 0.5$ ); ESI+/ESI- mass detection (SIM mode at $m / z 636.2 \pm 0.5$ and $634.2 \pm 0.5$ ) (top-down)

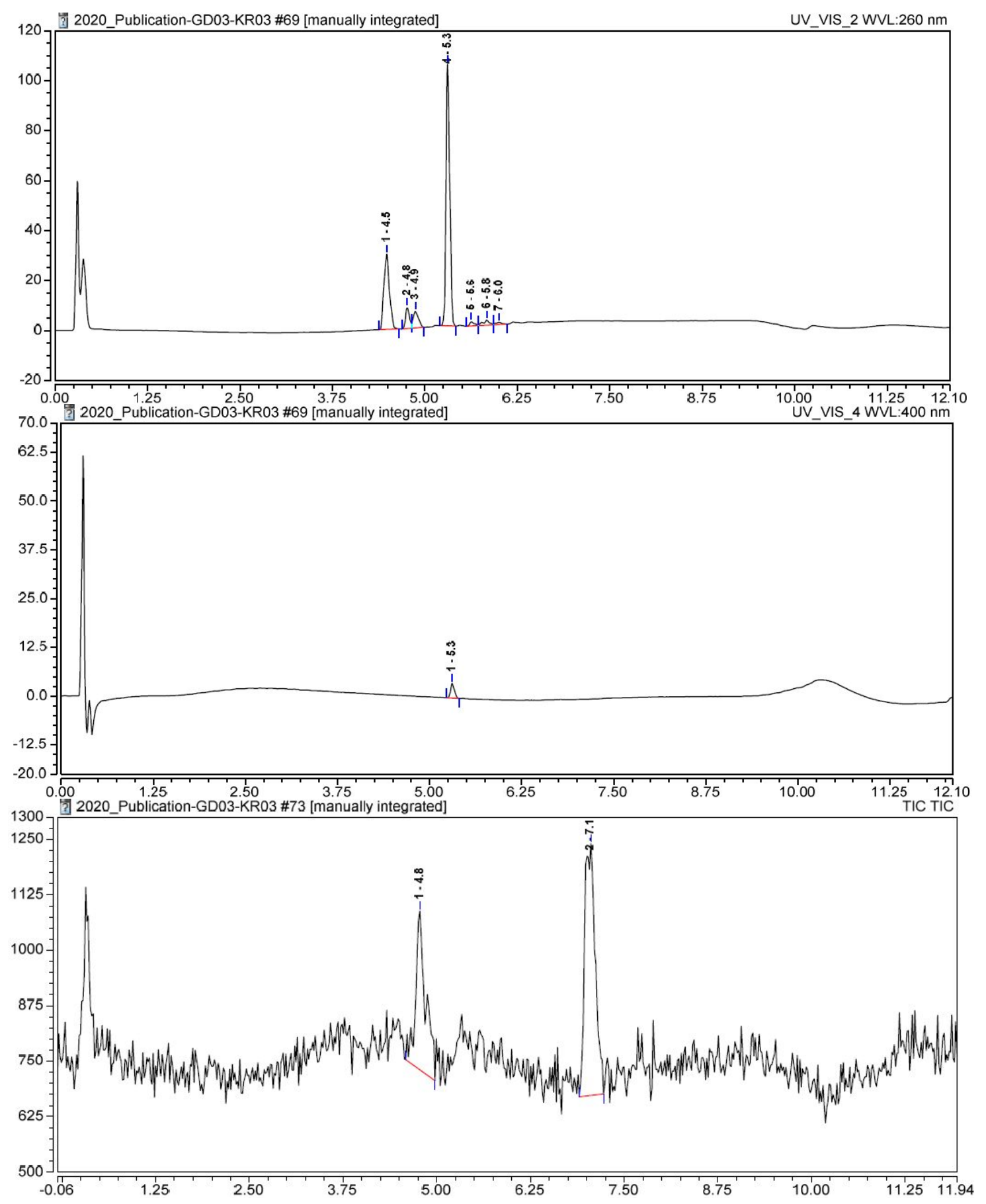




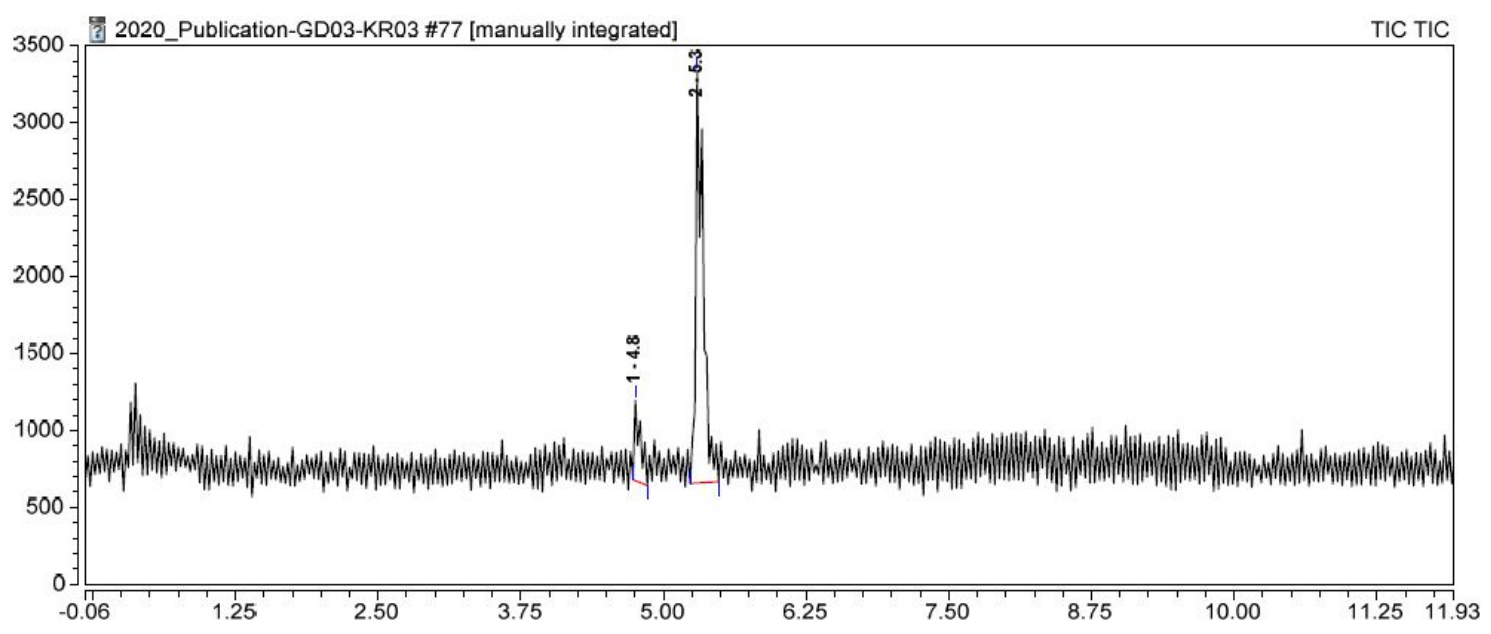

Fig. S227 - RP-HPLC elution profile (system B) of probe 15 (concentration: $1.0 \mu \mathrm{M}$ in PB) with PGA (1 $\left.\mathrm{U}, 90 \mathrm{~min}, 37^{\circ} \mathrm{C}\right)$. $\mathrm{UV}$ detection at $260 \mathrm{~nm}$; $\mathrm{UV}$ detection at 400 $\mathrm{nm}$; ESI+ mass detection (SIM mode at $\mathrm{m} / \mathrm{z} 351.1 \pm 0.5$ ); ESI+/ESI- mass detection (SIM mode at $m / z 636.2 \pm 0.5$ and $634.2 \pm 0.5$ ) (top-down)

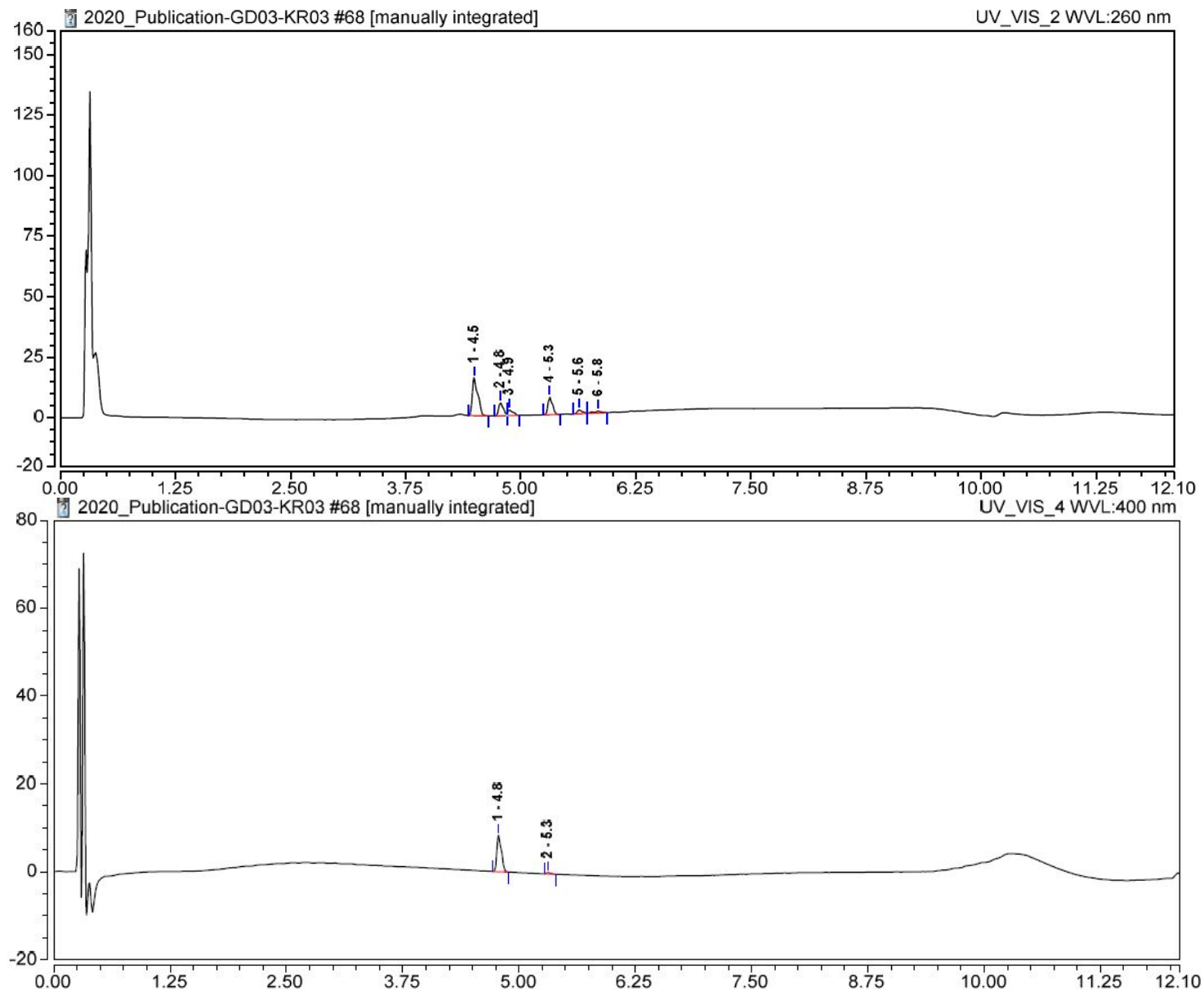




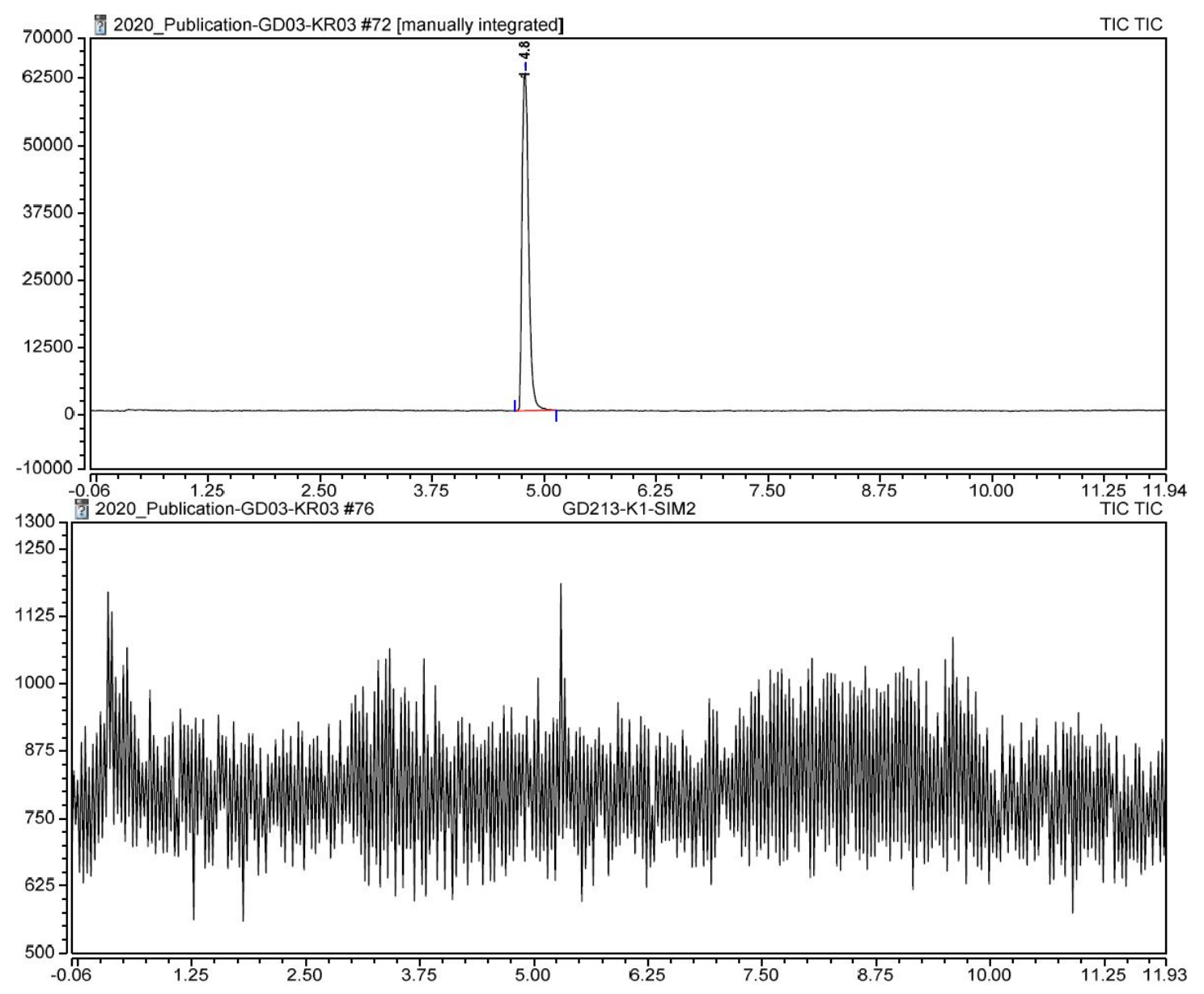

Fig. S228 - RP-HPLC elution profile (system B) of probe 15 (concentration: $1.0 \mu \mathrm{M}$ in PB) with PGA (1 $\mathrm{U}, 90 \mathrm{~min}, 37^{\circ} \mathrm{C}$ ) and GSH (50 equiv.). UV detection at 260 $\mathrm{nm}$; UV detection at $400 \mathrm{~nm}$; ESI+ mass detection (SIM mode at $\mathrm{m} / z \mathbf{z} 351.1 \pm 0.5$ ); ESI+/ESI- mass detection (SIM mode at $m / z 636.2 \pm 0.5$ and $634.2 \pm 0.5$ ) (top-down)

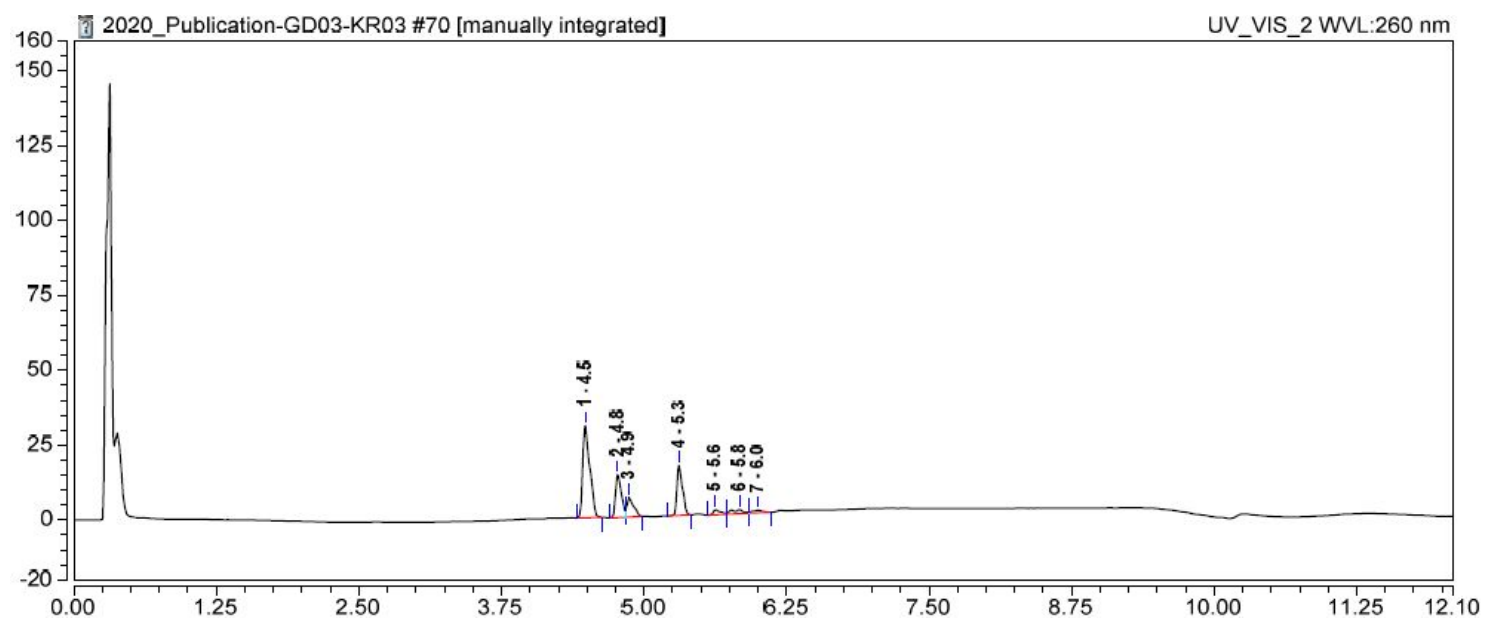




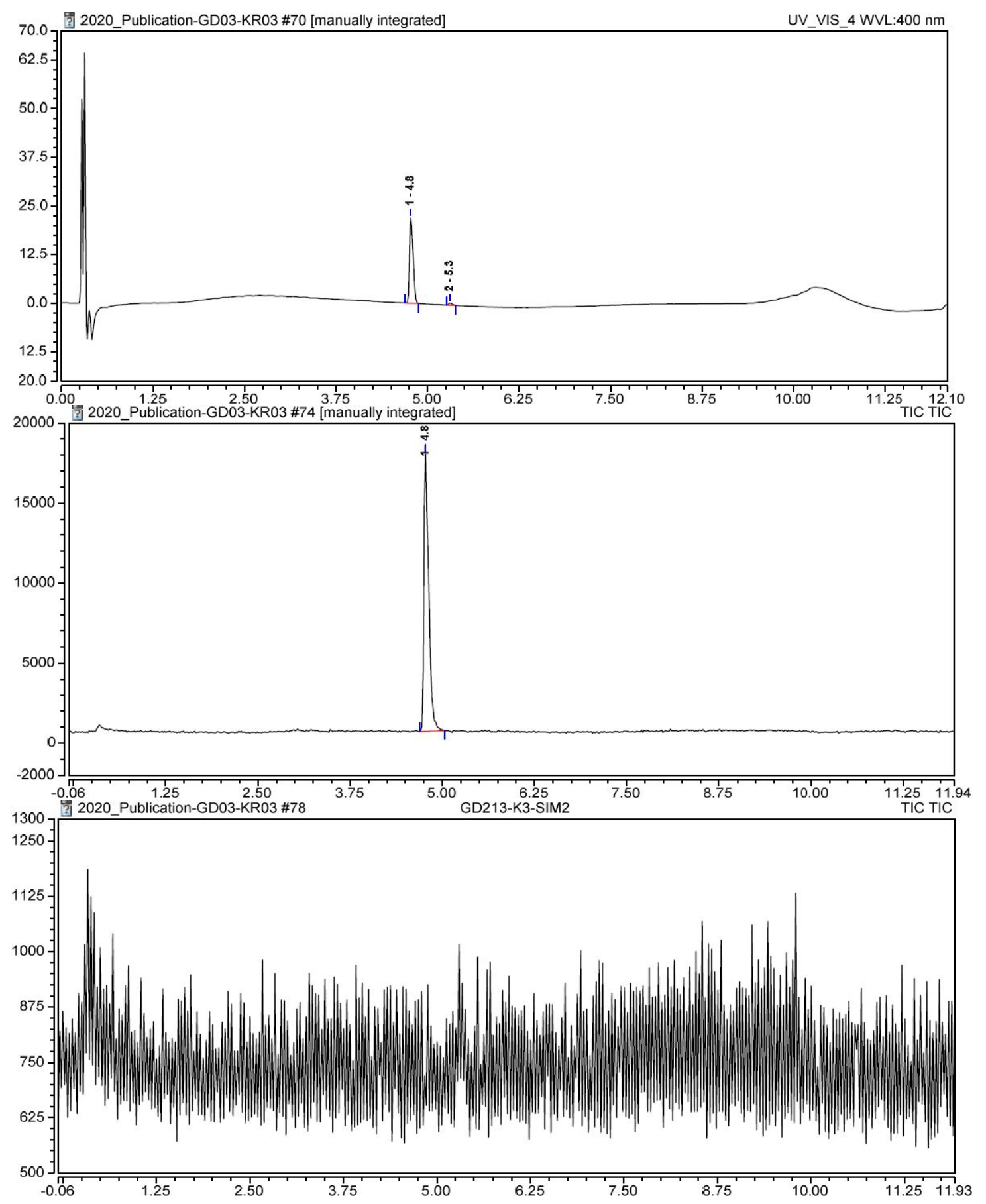


Fig. S229 - RP-HPLC elution profile (system B) of blank (injection of PB alone). $\mathrm{UV}$ detection at $260 \mathrm{~nm}$; $\mathrm{UV}$ detection at $400 \mathrm{~nm}$; ESI+ mass detection (SIM mode at $m / z, 273.1 \pm 0.5$ ); ESI+/ESI- mass detection (SIM mode at $m / z 558.2 \pm 0.5$ and $556.2 \pm 0.5)($ top-down)

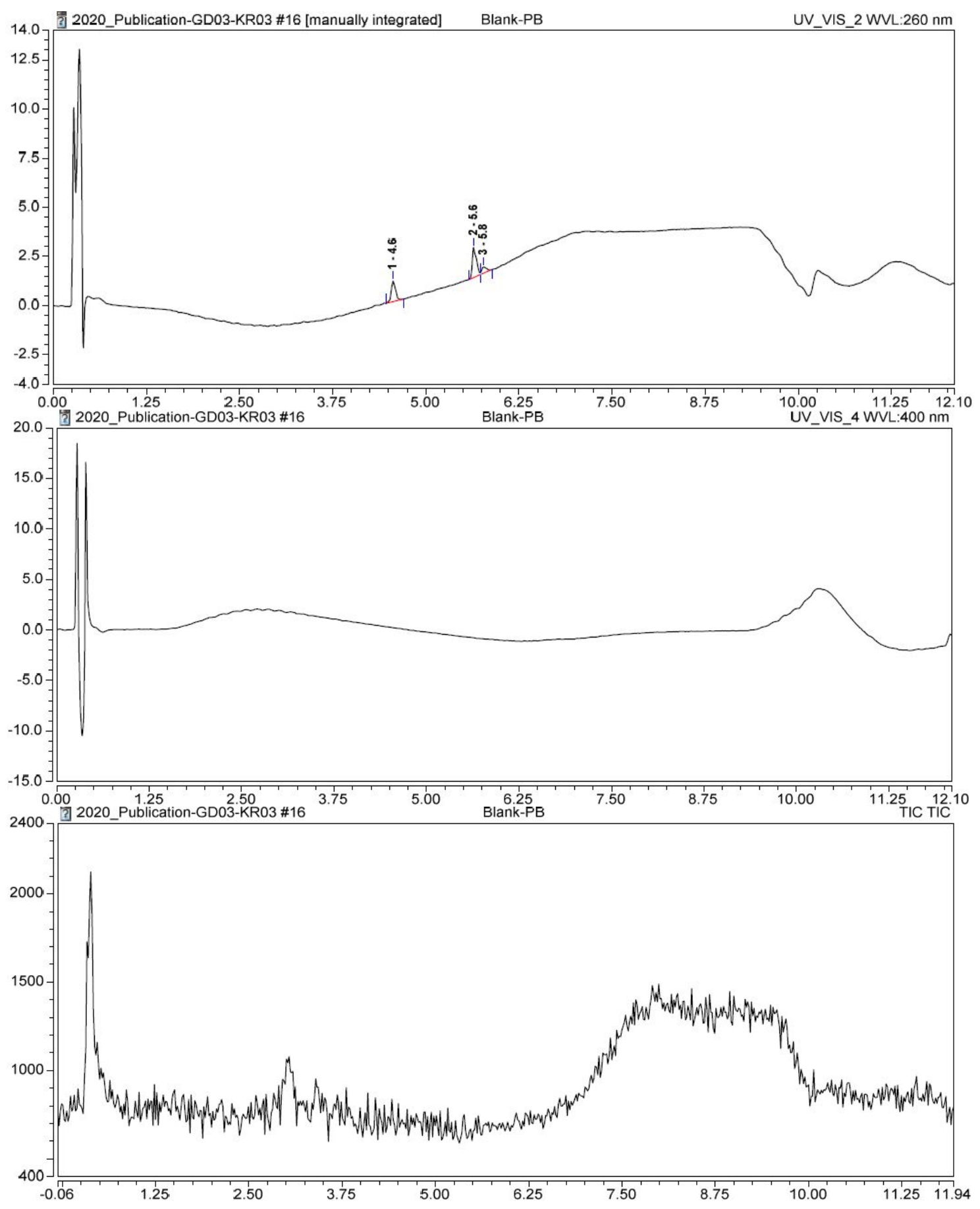




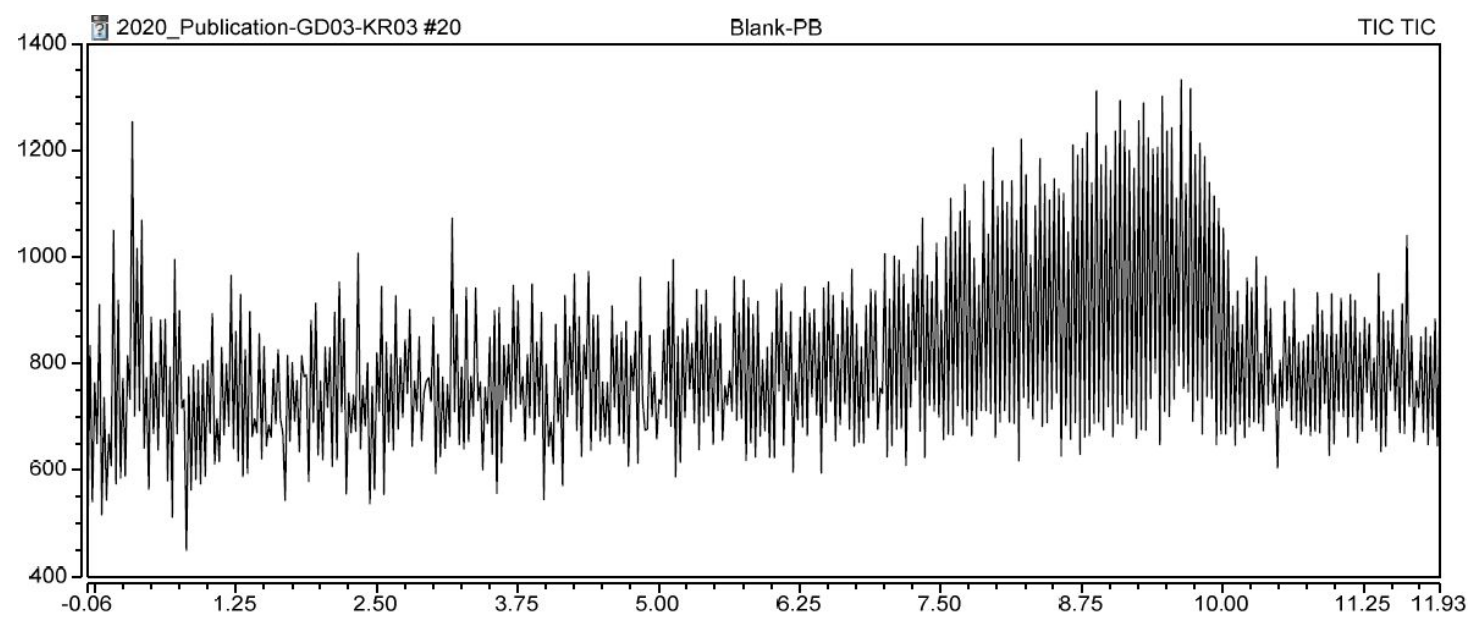

Fig. S230 - RP-HPLC elution profile (system B) of probe 16 without PGA (concentration: $1.0 \mu \mathrm{M}$ in $\mathrm{PB}, 30 \mathrm{~min}, 37^{\circ} \mathrm{C}$ ). $\mathrm{UV}$ detection at $260 \mathrm{~nm}$; $\mathrm{UV}$ detection at $400 \mathrm{~nm}$; ESI+ mass detection (SIM mode at $m / z, 273.1 \pm 0.5$ ); ESI+/ESI- mass detection (SIM mode at $m / z 558.2 \pm 0.5$ and $556.2 \pm 0.5$ ) (top-down)

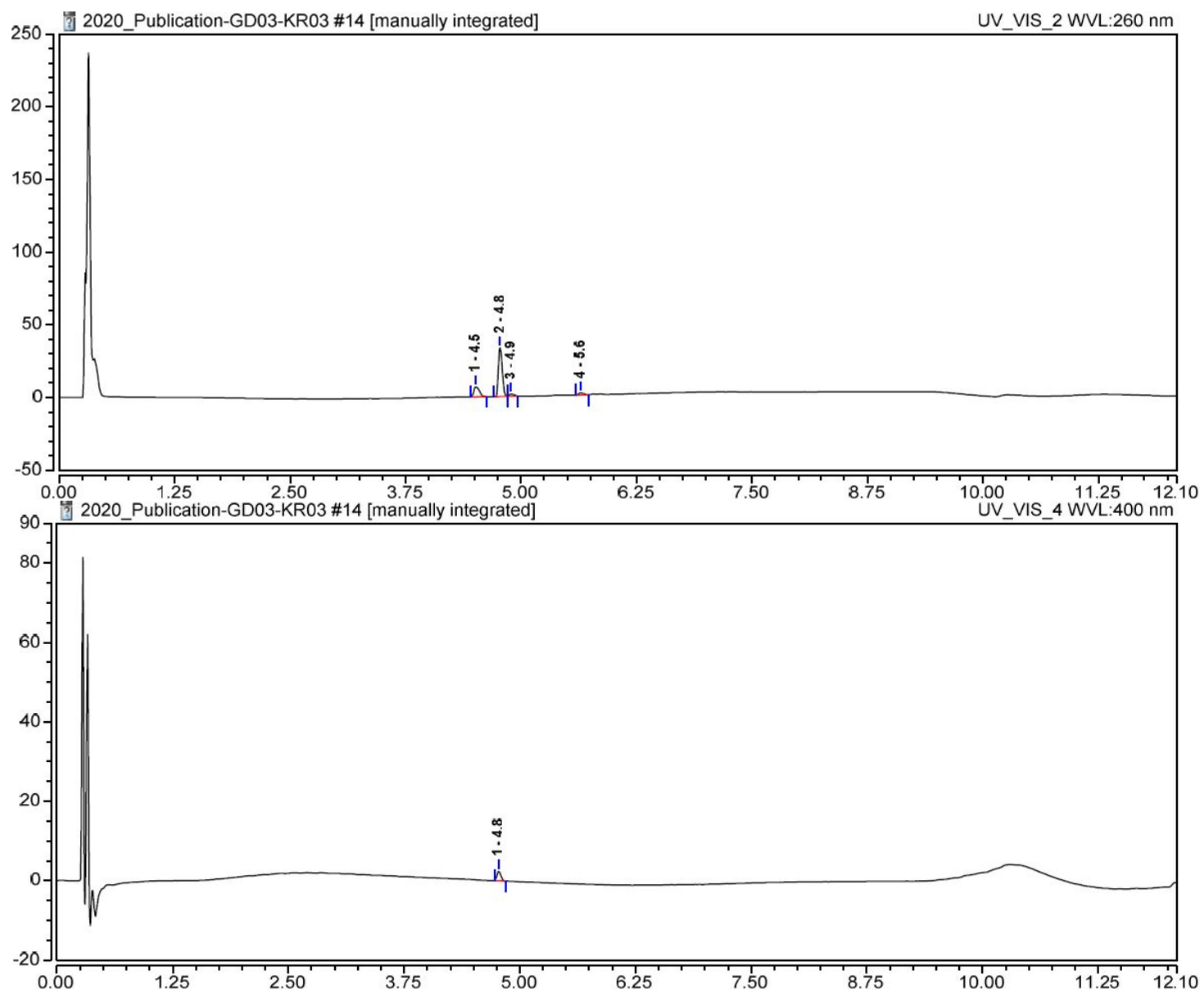



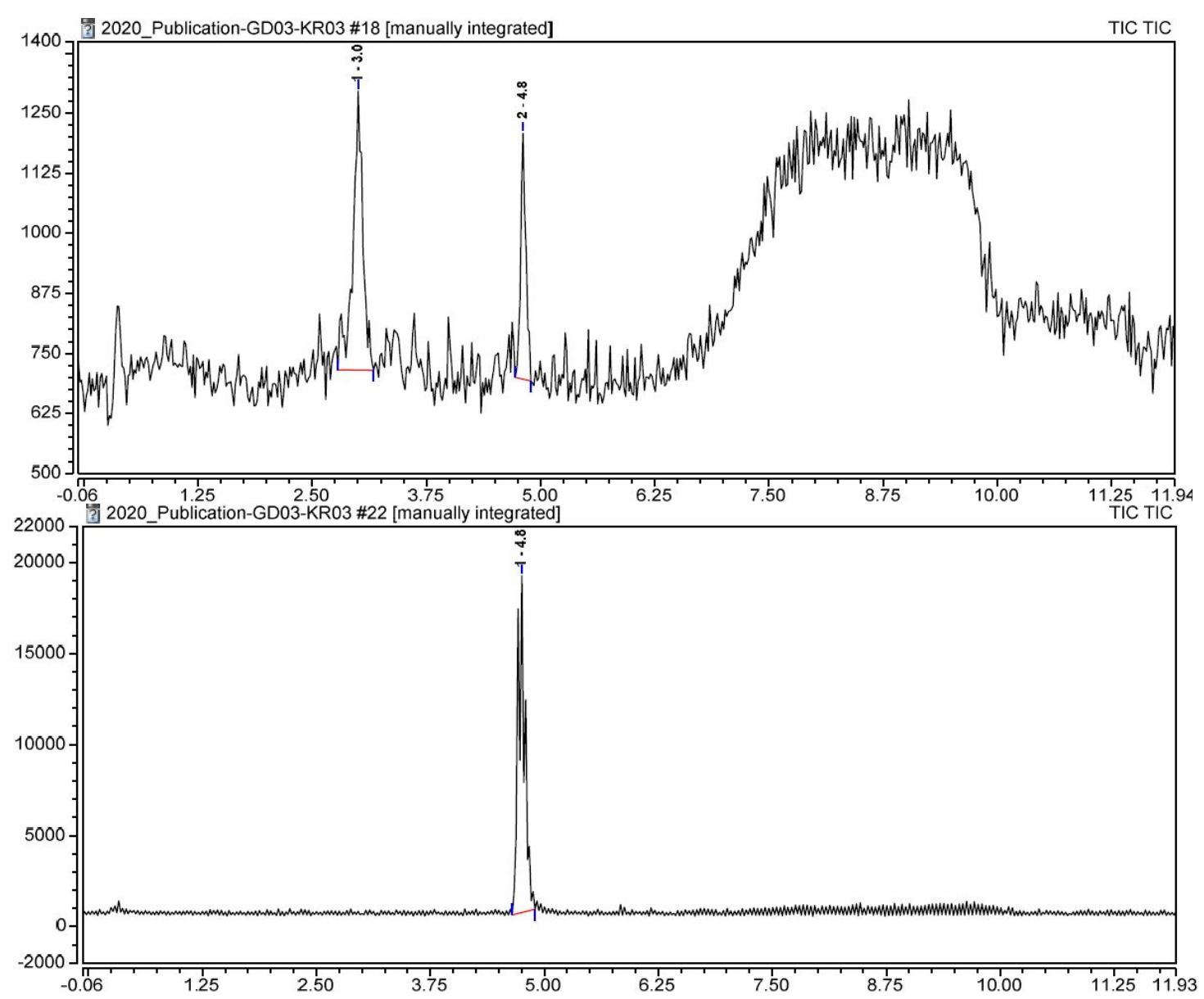

Fig. S231 - RP-HPLC elution profile (system B) of probe 16 (concentration: $1.0 \mu \mathrm{M}$ in PB) with PGA $\left(1 \mathrm{U}, 30 \mathrm{~min}, 37^{\circ} \mathrm{C}\right)$. $\mathrm{UV}$ detection at $260 \mathrm{~nm}$; $\mathrm{UV}$ detection at 400 $\mathrm{nm}$; ESI+ mass detection (SIM mode at $m / z 273.1 \pm 0.5$ ); ESI+/ESI- mass detection (SIM mode at $m / z 558.2 \pm 0.5$ and $556.2 \pm 0.5$ ) (top-down)

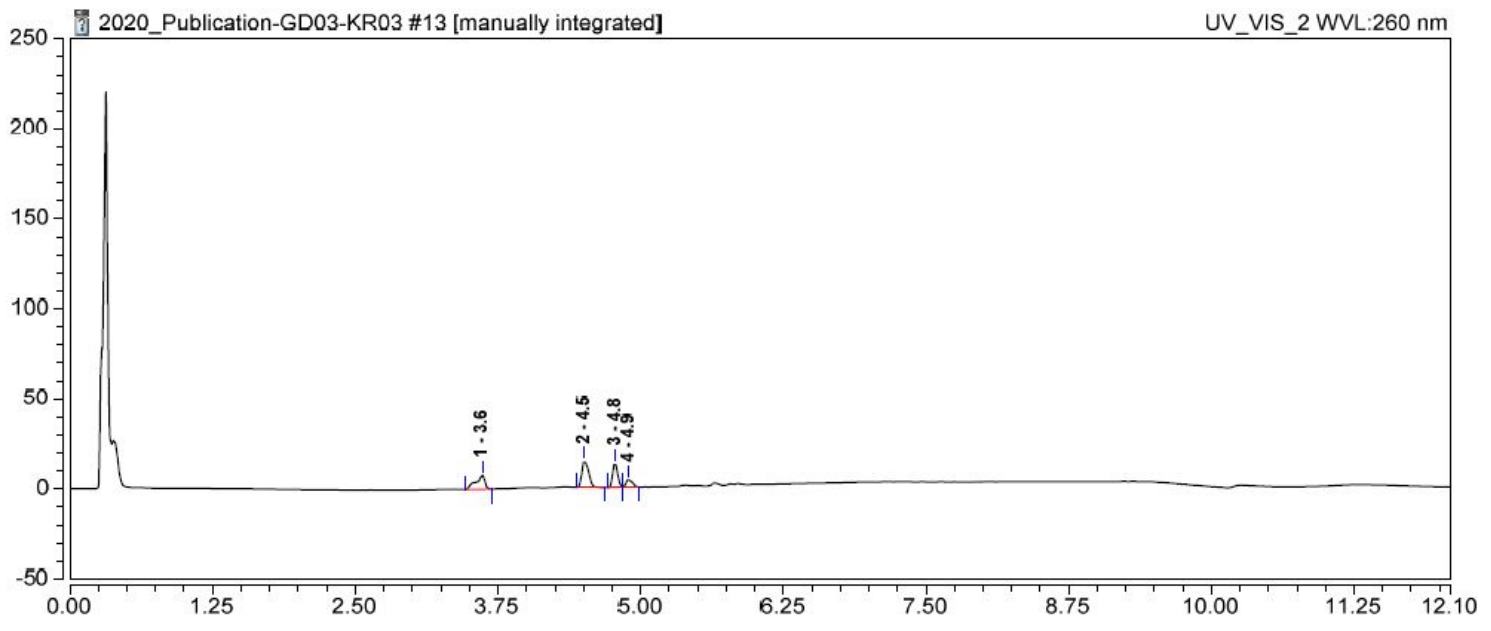




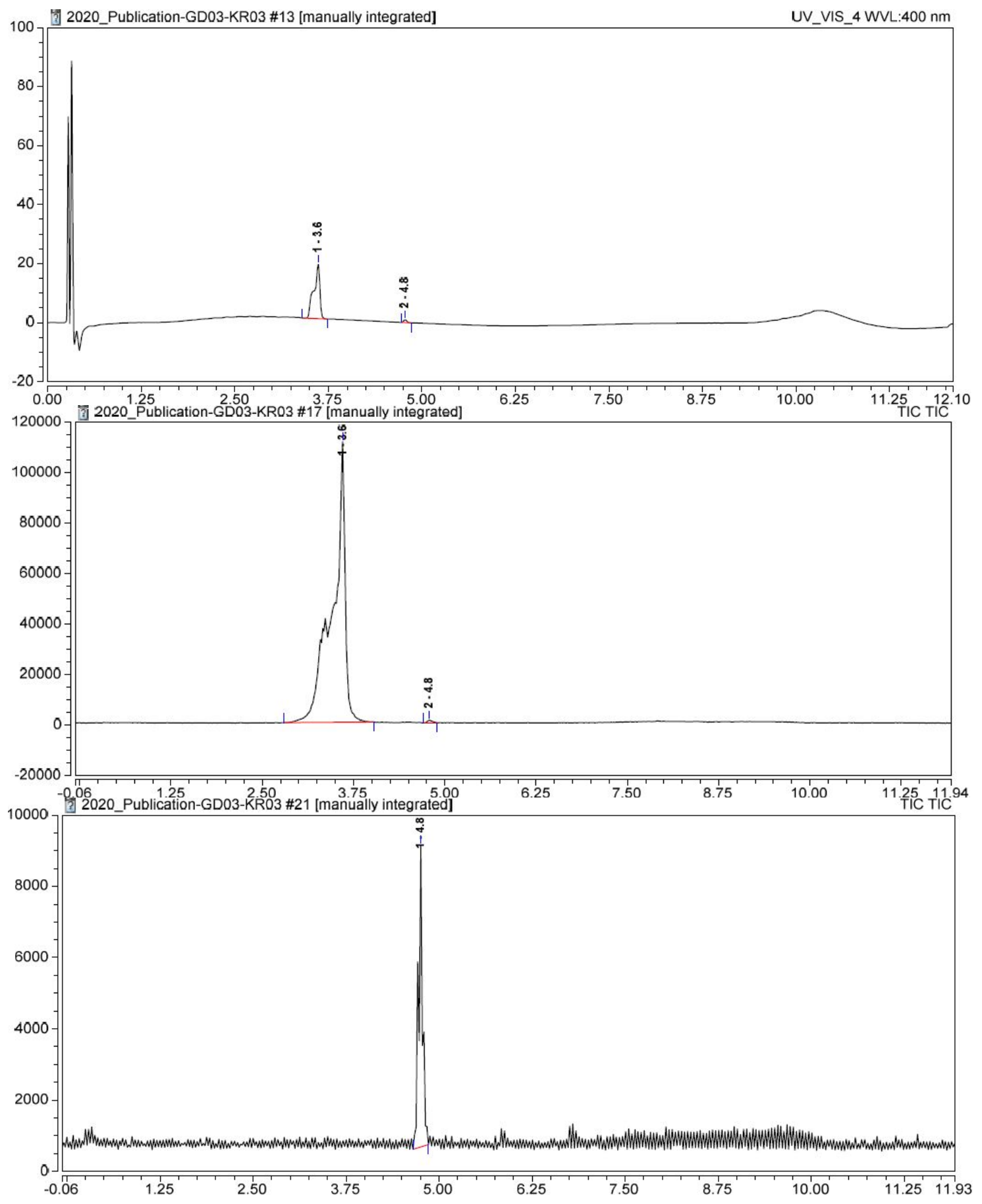


Fig. S232 - RP-HPLC elution profile (system B) of probe 16 (concentration: $1.0 \mu \mathrm{M}$ in PB) with PGA (1 $\mathrm{U}, 30 \mathrm{~min}, 37^{\circ} \mathrm{C}$ ) and GSH (50 equiv.). UV detection at 260 $\mathrm{nm}$; UV detection at $400 \mathrm{~nm}$; ESI+ mass detection (SIM mode at $m / z, 273.1 \pm 0.5$ ); ESI+/ESI- mass detection (SIM mode at $m / z, 558.2 \pm 0.5$ and $556.2 \pm 0.5$ ) (top-down)

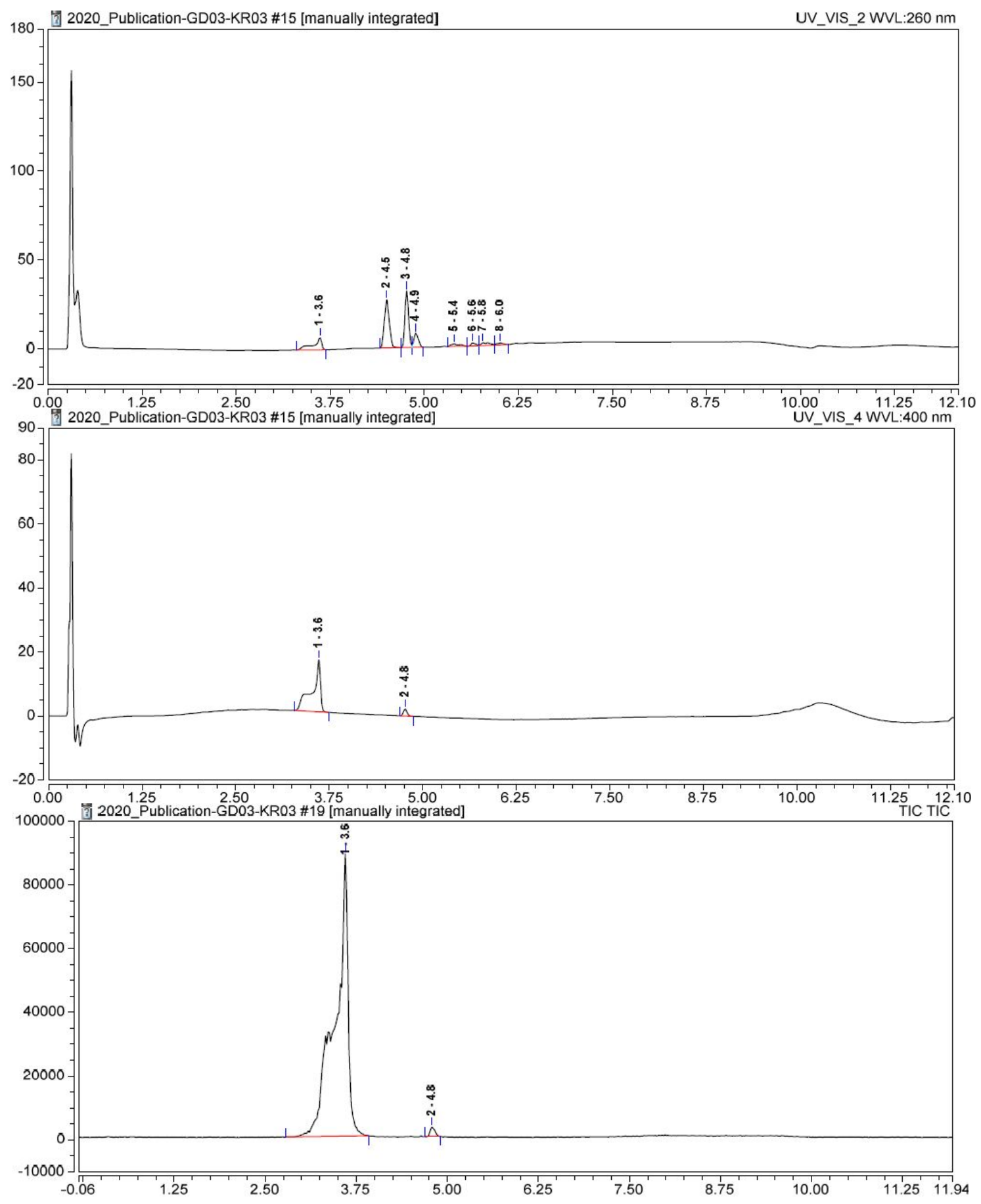




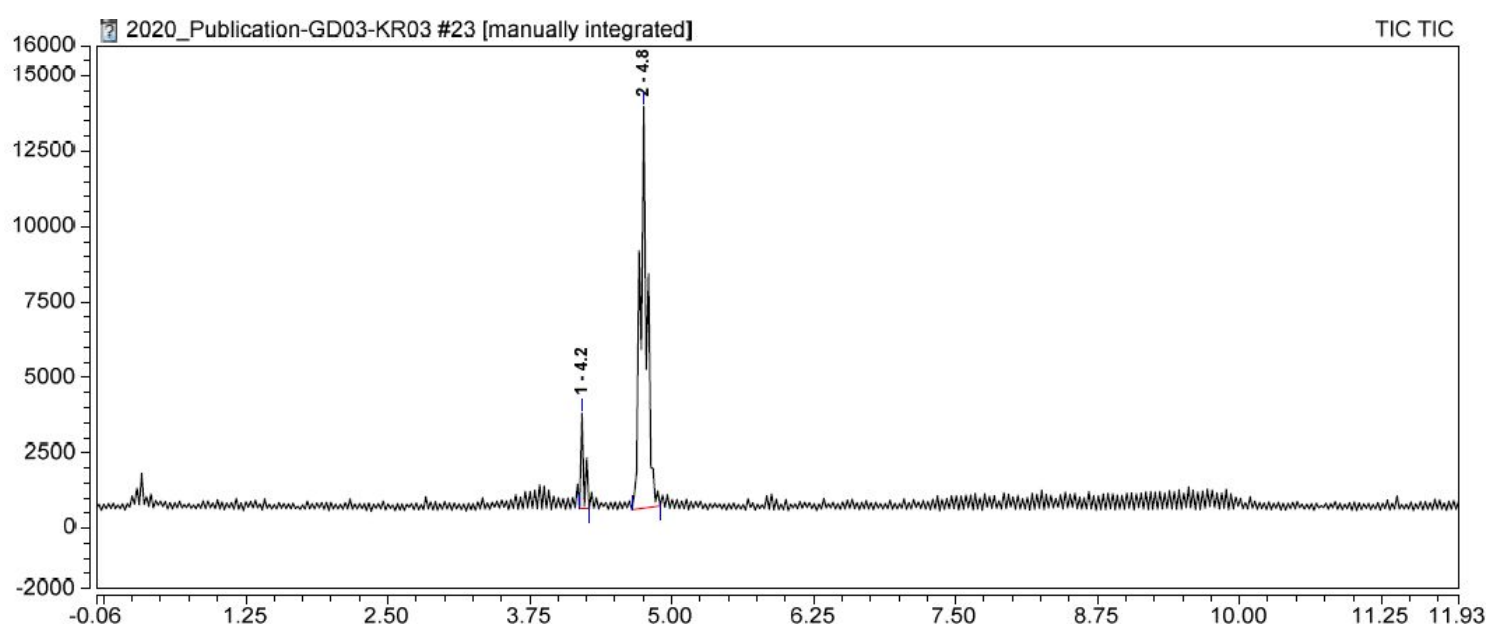

Fig. S233 - RP-HPLC elution profile (system B) of blank (injection of PB alone). UV detection at $260 \mathrm{~nm}$; $\mathrm{UV}$ detection at $400 \mathrm{~nm}$; ESI+ mass detection (SIM mode at $\mathrm{m} / \mathrm{z} 289.1 \pm 0.5$ ) ESI+/ESI- mass detection (SIM mode at $\mathrm{m} / \mathrm{z} 574.2 \pm 0.5$ and $572.2 \pm 0.5)($ top-down)

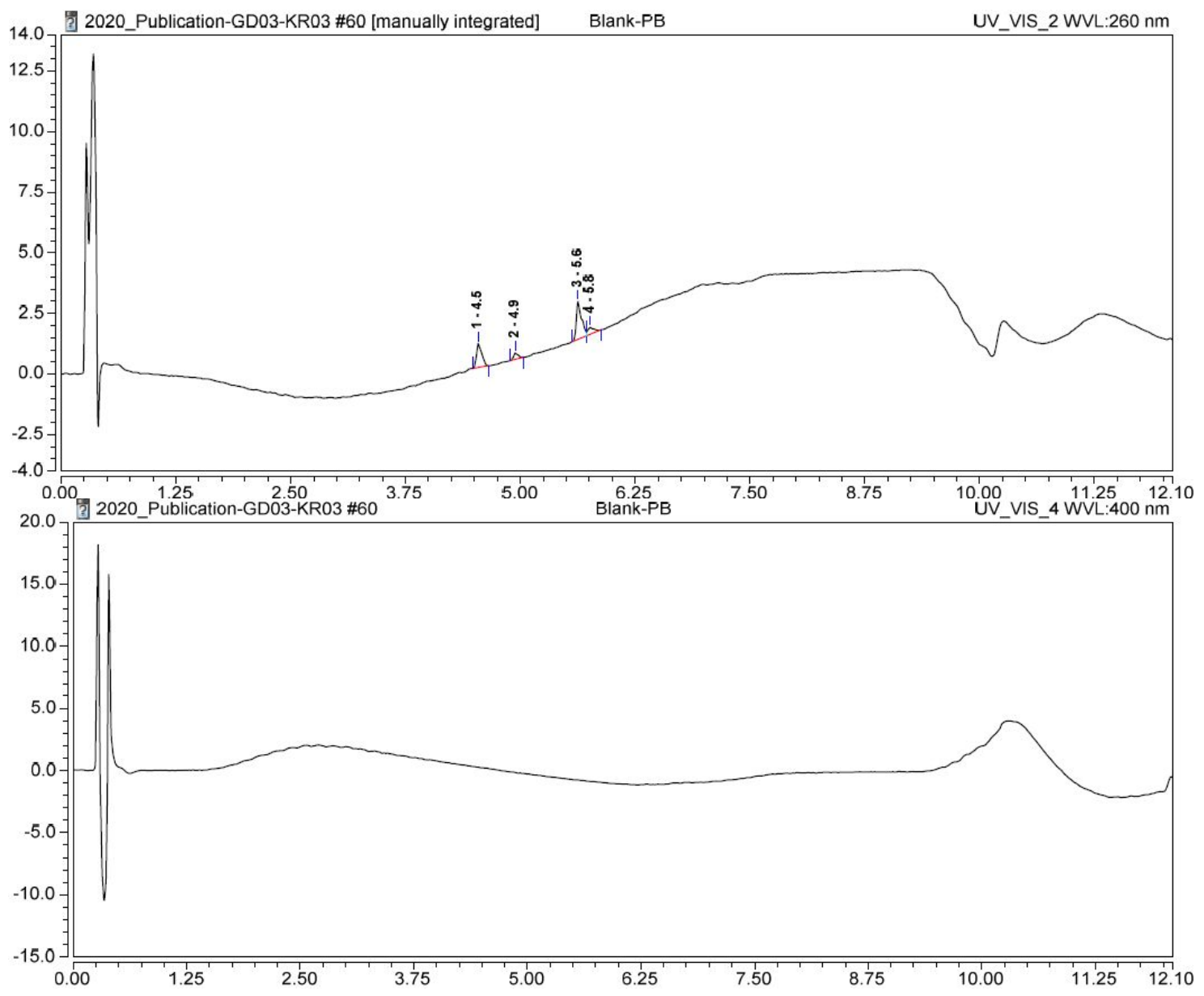




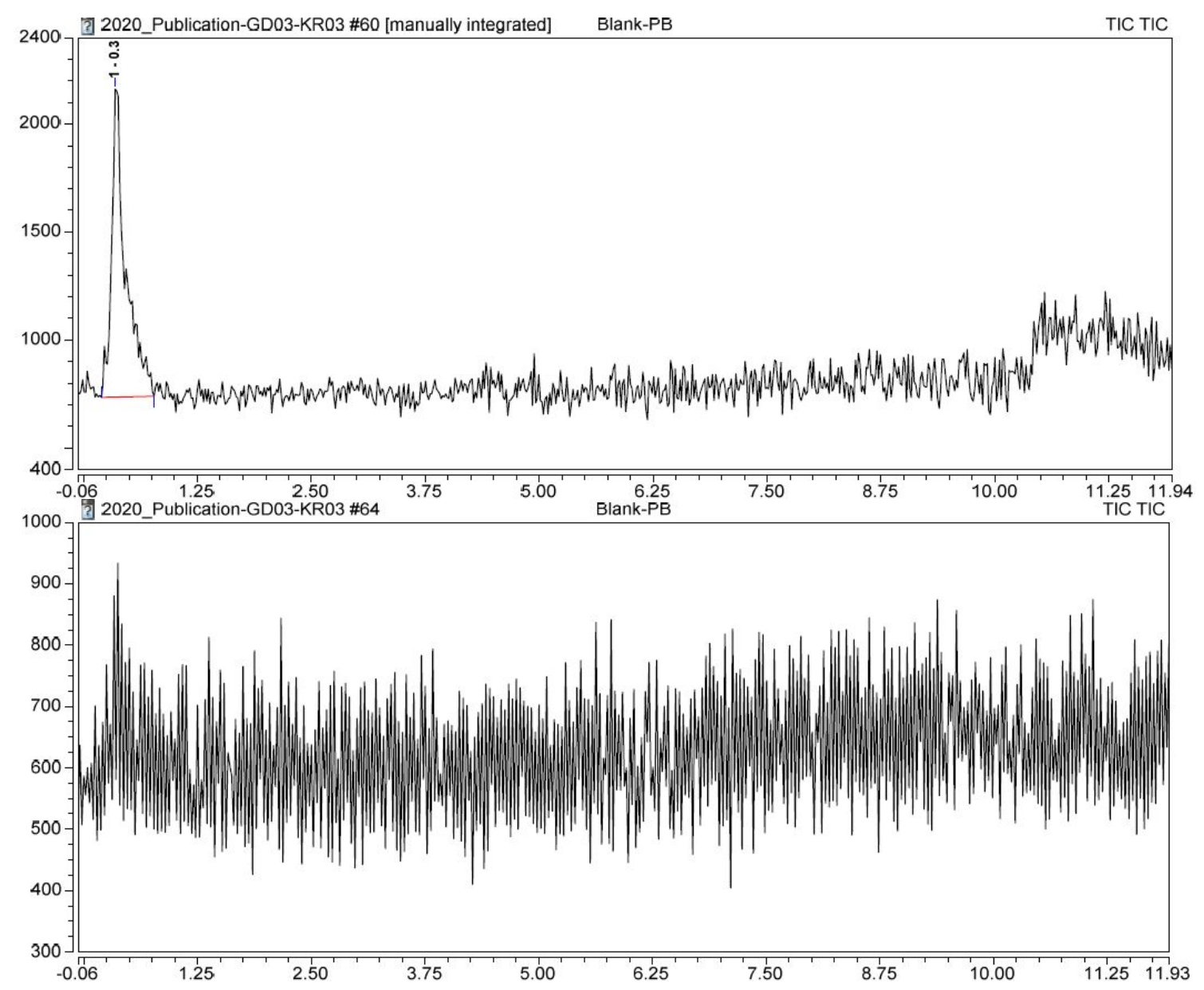

Fig. S234 - RP-HPLC elution profile (system B) of probe 17 without PGA (concentration: $1.0 \mu \mathrm{M}$ in $\mathrm{PB}, 30 \mathrm{~min}, 37^{\circ} \mathrm{C}$ ). $\mathrm{UV}$ detection at $260 \mathrm{~nm}$; $\mathrm{UV}$ detection at $400 \mathrm{~nm}$; ESI+ mass detection (SIM mode at $\mathrm{m} / z$ 289.1 \pm 0.5 ); ESI+/ESI- mass detection (SIM mode at $m / z, 574.2 \pm 0.5$ and $572.2 \pm 0.5)$ (top-down)

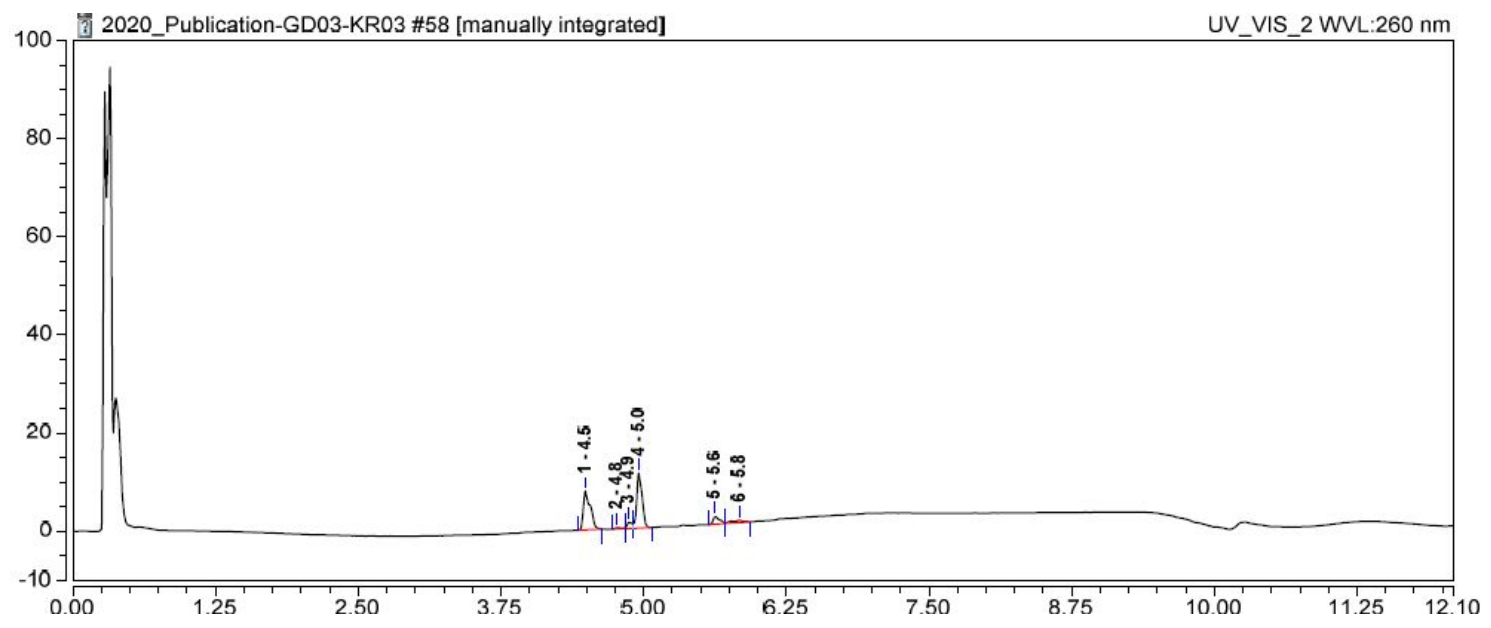



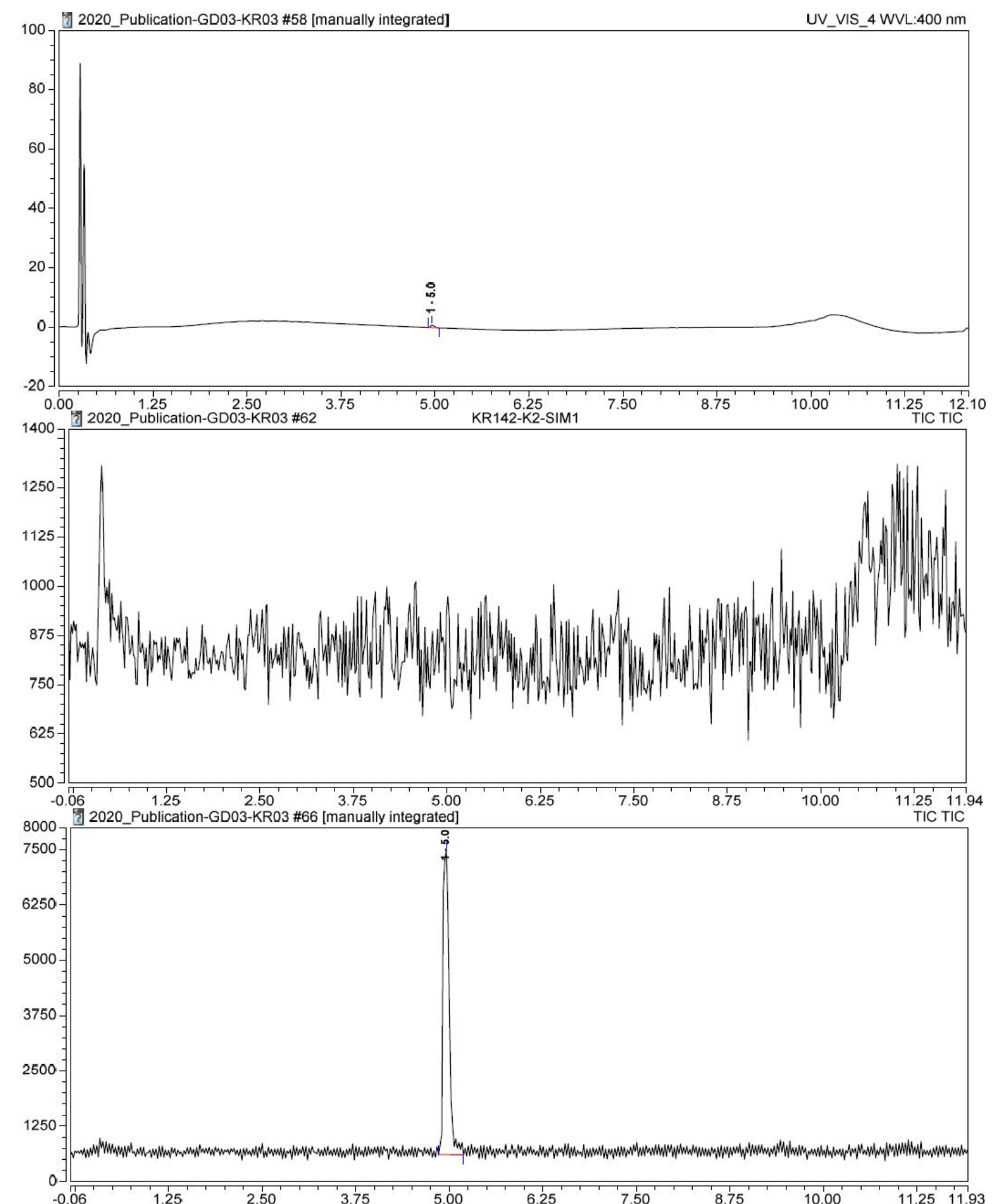
Fig. S235 - RP-HPLC elution profile (system B) of probe 17 (concentration: $1.0 \mu \mathrm{M}$ in PB) with PGA (1 $\left.\mathrm{U}, 30 \mathrm{~min}, 37^{\circ} \mathrm{C}\right)$. $\mathrm{UV}$ detection at $260 \mathrm{~nm}$; $\mathrm{UV}$ detection at 400 $\mathrm{nm}$; ESI+ mass detection (SIM mode at $m / z 289.1 \pm 0.5$ ); ESI+/ESI- mass detection (SIM mode at $m / z 574.2 \pm 0.5$ and $572.2 \pm 0.5$ ) (top-down)

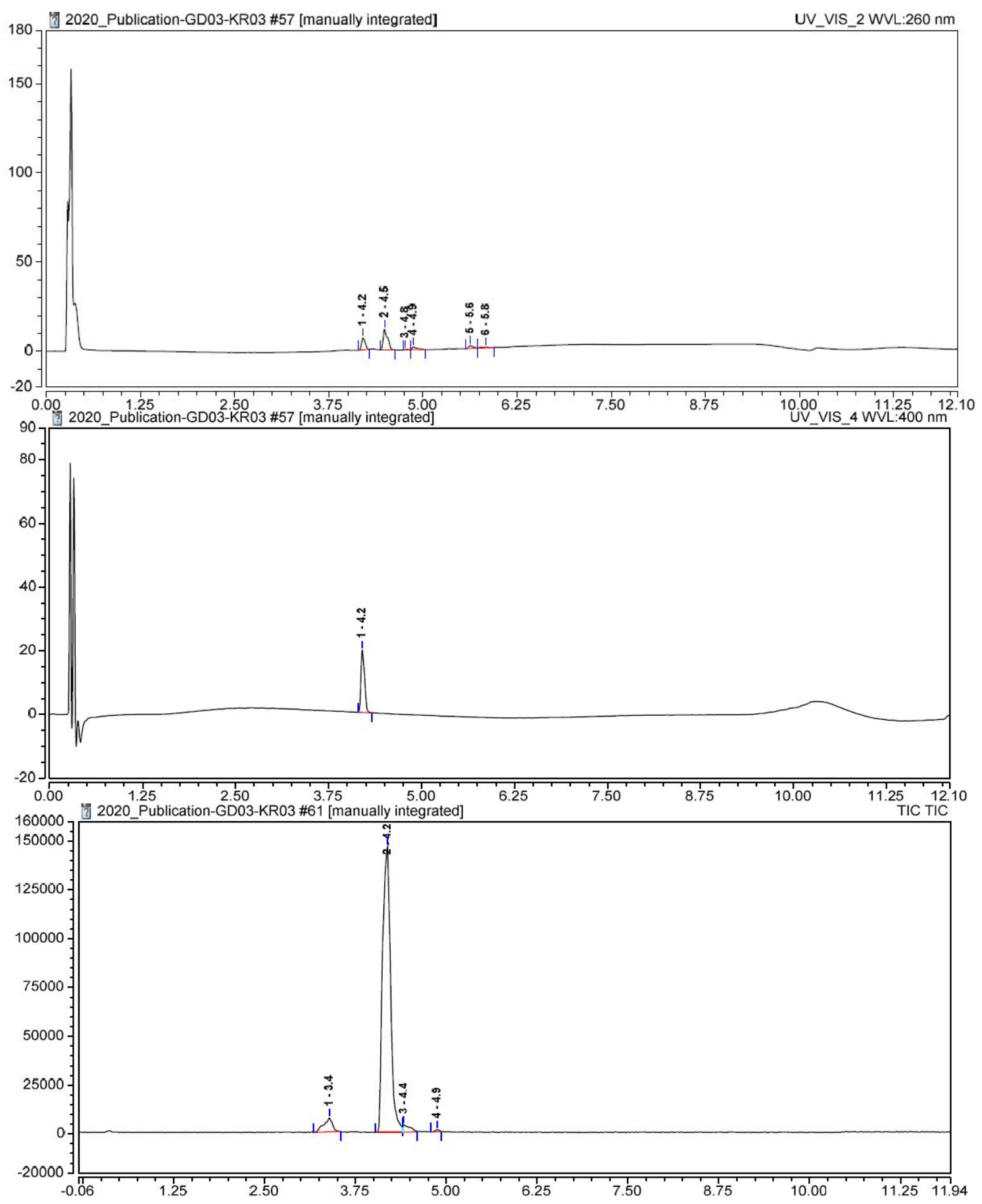




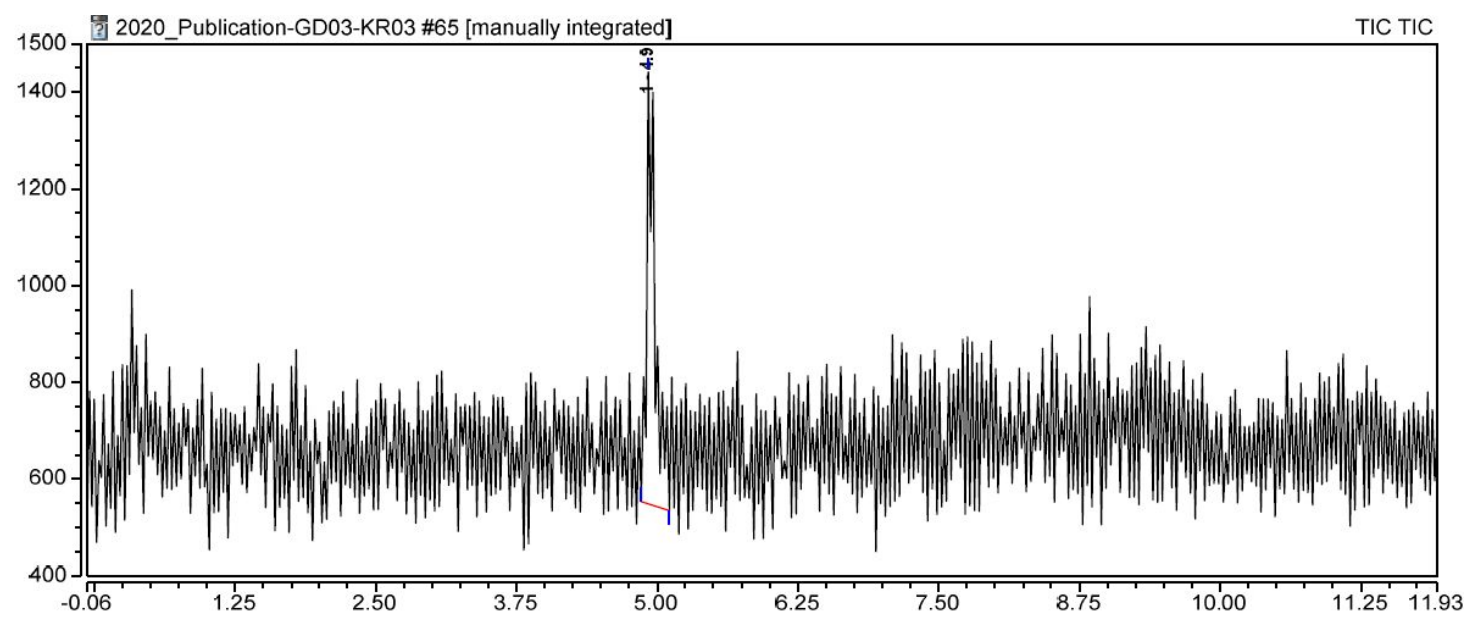

Fig. S236 - RP-HPLC elution profile (system B) of probe 17 (concentration: $1.0 \mu \mathrm{M}$ in PB) with PGA (1 $\mathrm{U}, 30 \mathrm{~min}, 37^{\circ} \mathrm{C}$ ) and GSH (50 equiv.). $\mathrm{UV}$ detection at 260 $\mathrm{nm}$; UV detection at $400 \mathrm{~nm}$; ESI+ mass detection (SIM mode at $\mathrm{m} / \mathrm{z} 289.1 \pm 0.5$ ); ESI+/ESI- mass detection (SIM mode at $m / z, 574.2 \pm 0.5$ and $572.2 \pm 0.5$ ) (top-down)

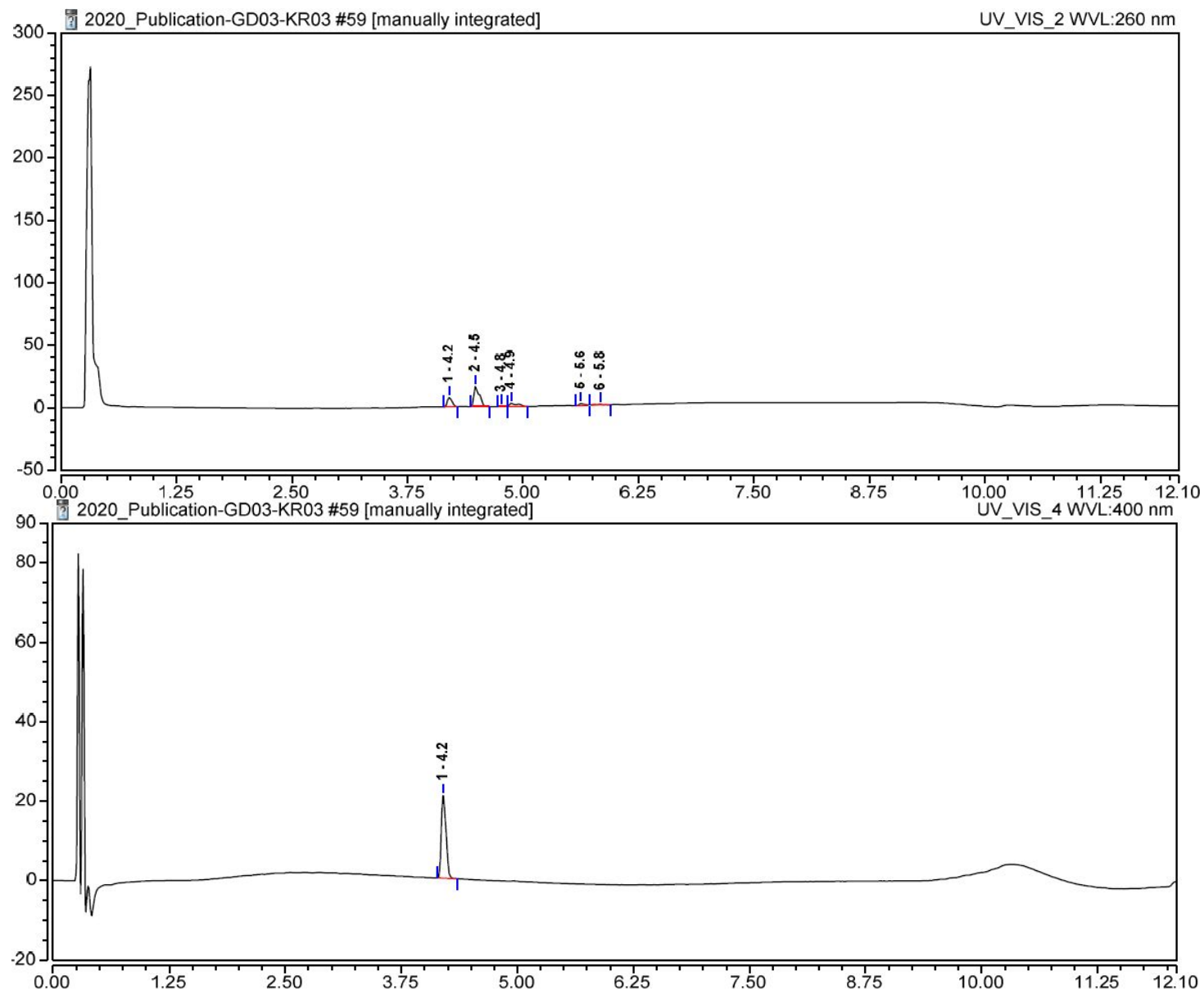




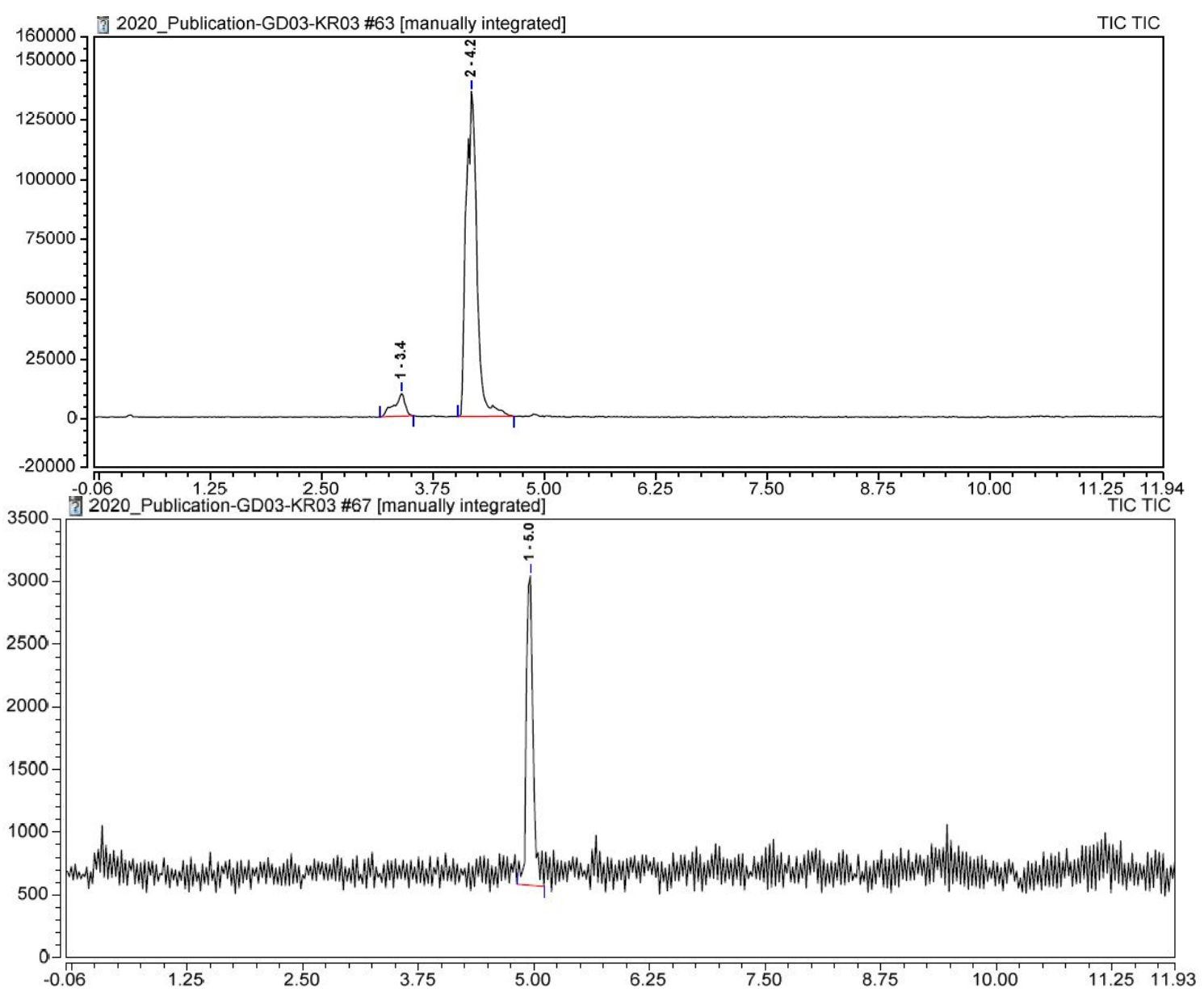

Fig. S237 - RP-HPLC elution profile (system B) of blank (injection of PB alone). UV detection at $260 \mathrm{~nm}$; UV detection at $400 \mathrm{~nm}$; ESI+ mass detection (SIM mode at $m / z 337.0 \pm 0.5$ ); ESI+/ESI- mass detection (SIM mode at $m / z, 622.1 \pm 0.5$ and $620.1 \pm 0.5)($ top-down)

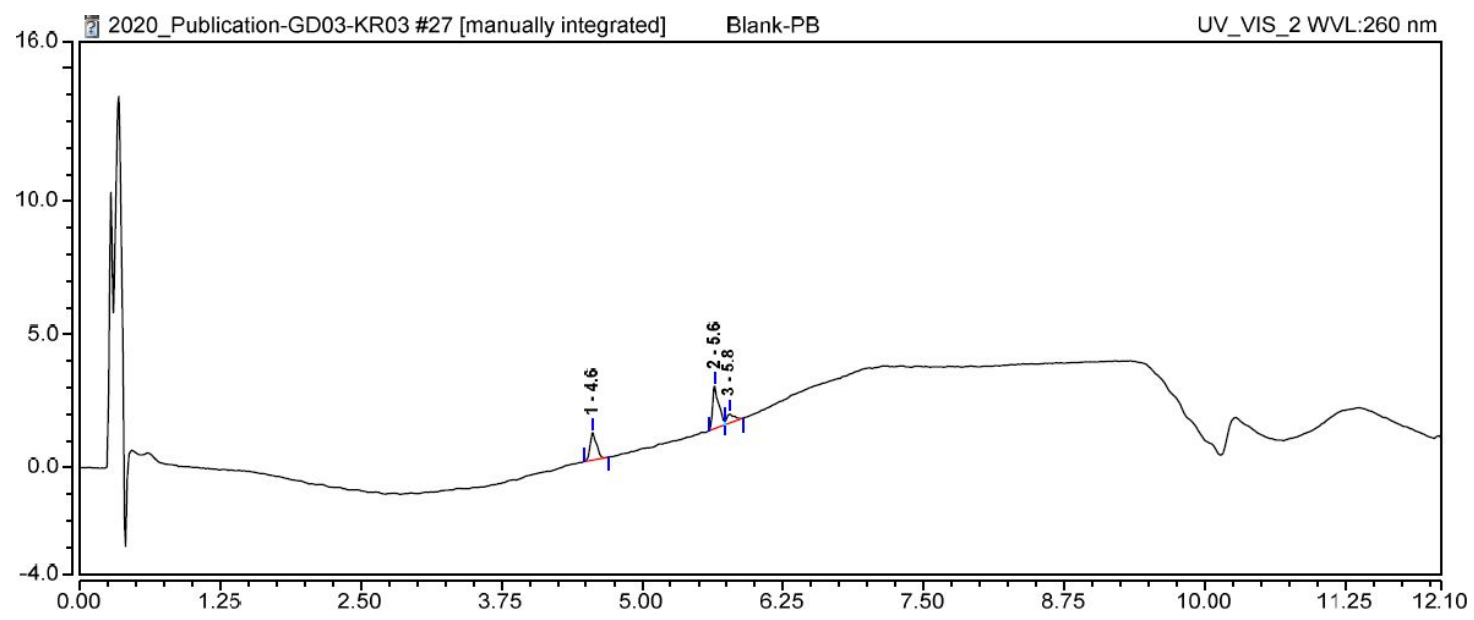




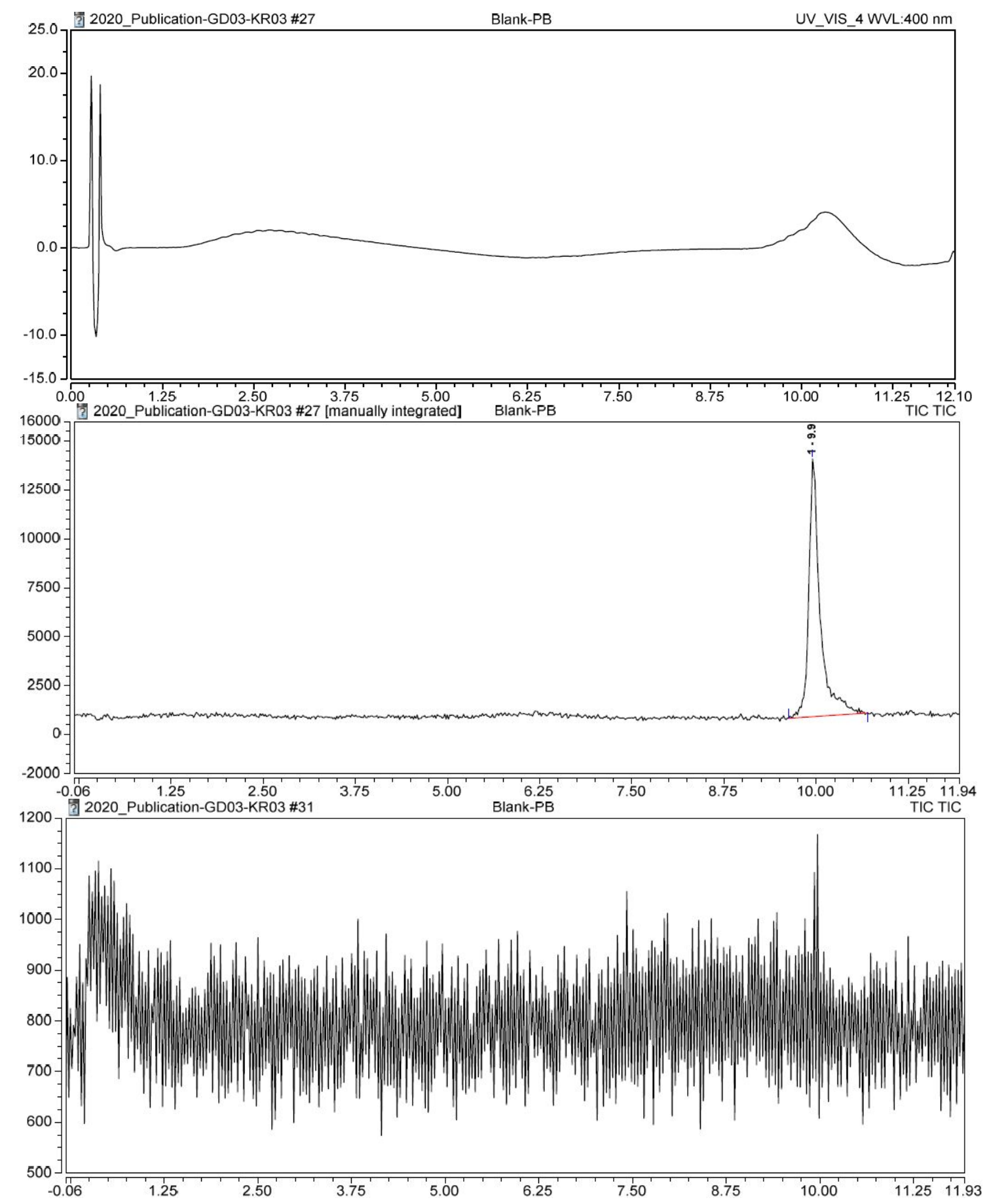


Fig. S238 - RP-HPLC elution profile (system B) of probe 18 without PGA (concentration: $1.0 \mu \mathrm{M}$ in $\mathrm{PB}, 30 \mathrm{~min}, 37^{\circ} \mathrm{C}$ ). $\mathrm{UV}$ detection at $260 \mathrm{~nm}$; $\mathrm{UV}$ detection at $400 \mathrm{~nm}$; ESI+ mass detection (SIM mode at $m / z 337.0 \pm 0.5$ ); ESI+/ESI- mass detection (SIM mode at $m / z, 622.1 \pm 0.5$ and $620.1 \pm 0.5$ ) (top-down)

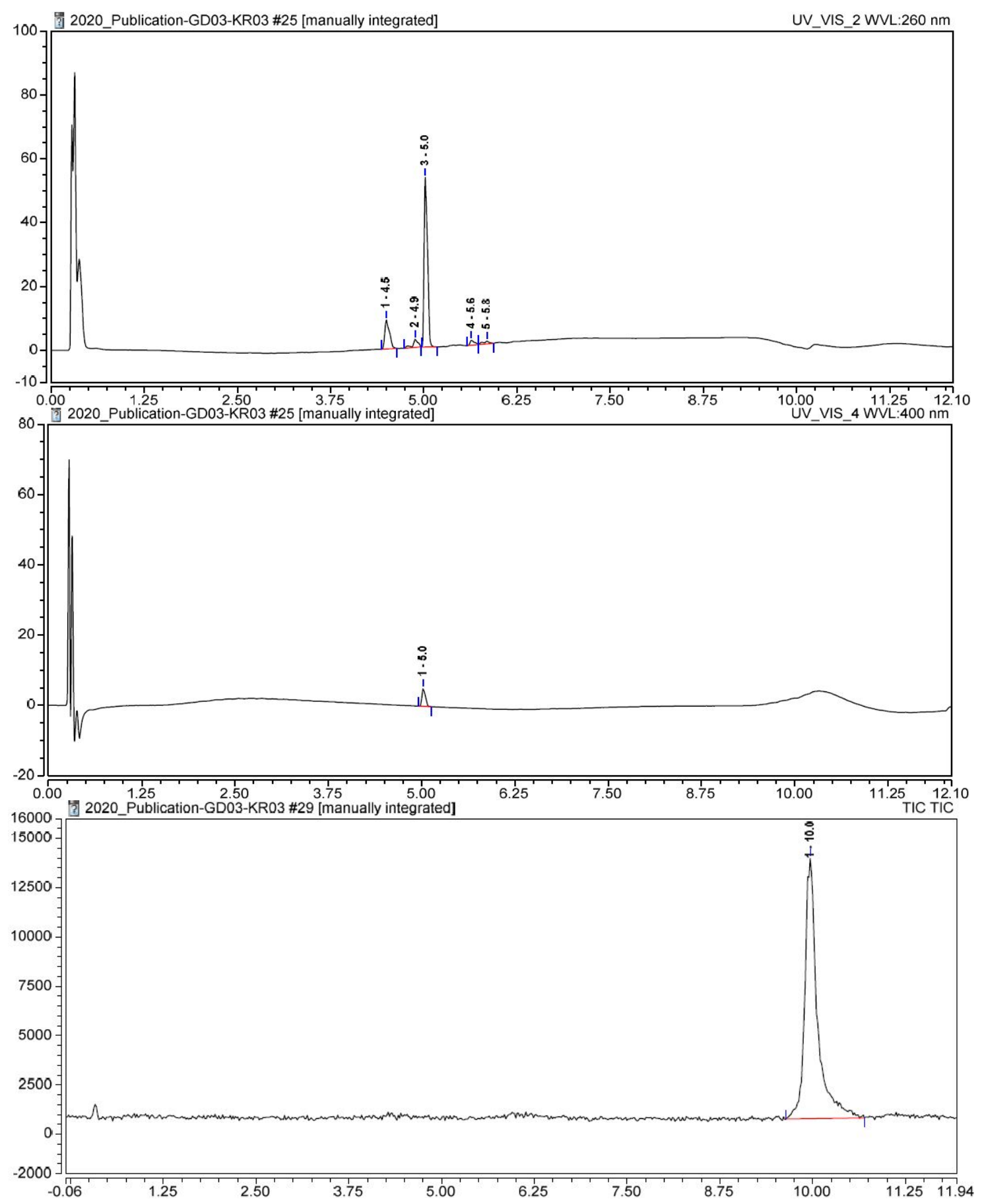




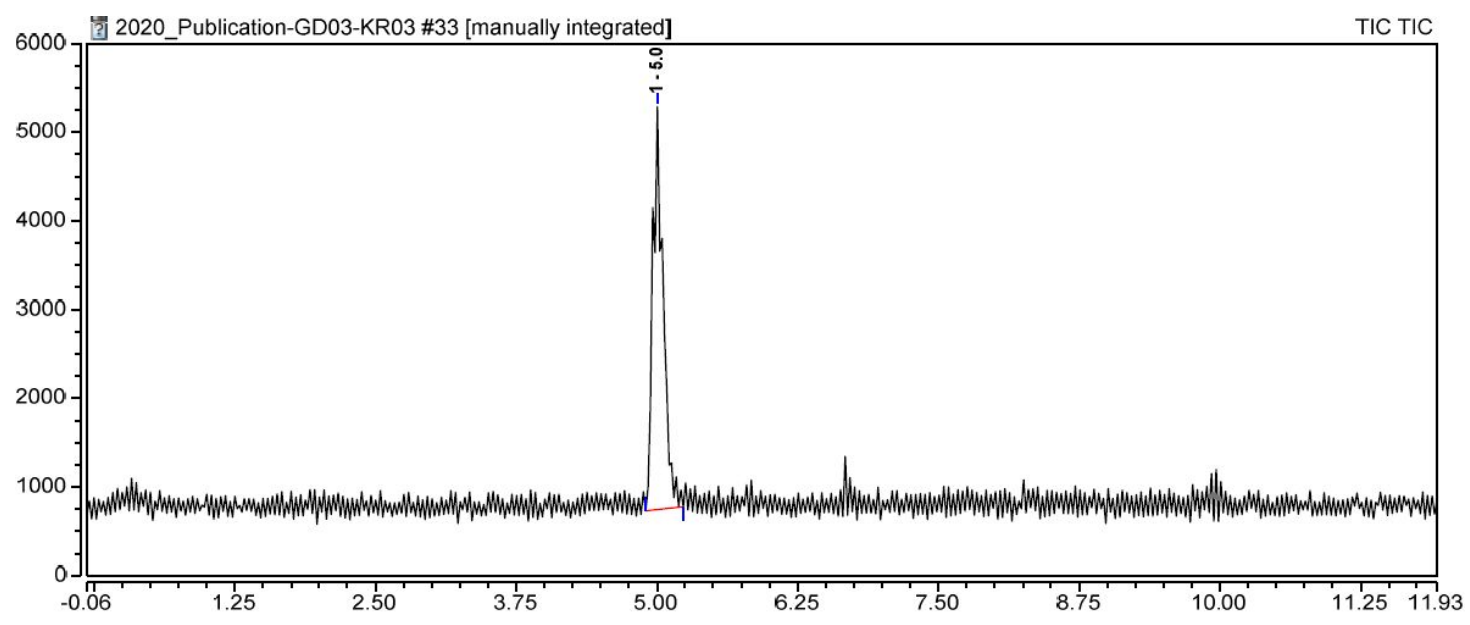

Fig. S239 - RP-HPLC elution profile (system B) of probe 18 (concentration: $1.0 \mu \mathrm{M}$ in PB) with PGA $\left(1 \mathrm{U}, 30 \mathrm{~min}, 37^{\circ} \mathrm{C}\right)$. $\mathrm{UV}$ detection at $260 \mathrm{~nm}$; $\mathrm{UV}$ detection at 400 $\mathrm{nm}$; ESI+ mass detection (SIM mode at $\mathrm{m} / z \mathbf{z 3 7 . 0} \pm \mathbf{0 . 5}$ ); ESI+/ESI- mass detection (SIM mode at $m / z 622.1 \pm 0.5$ and $620.1 \pm 0.5$ ) (top-down)

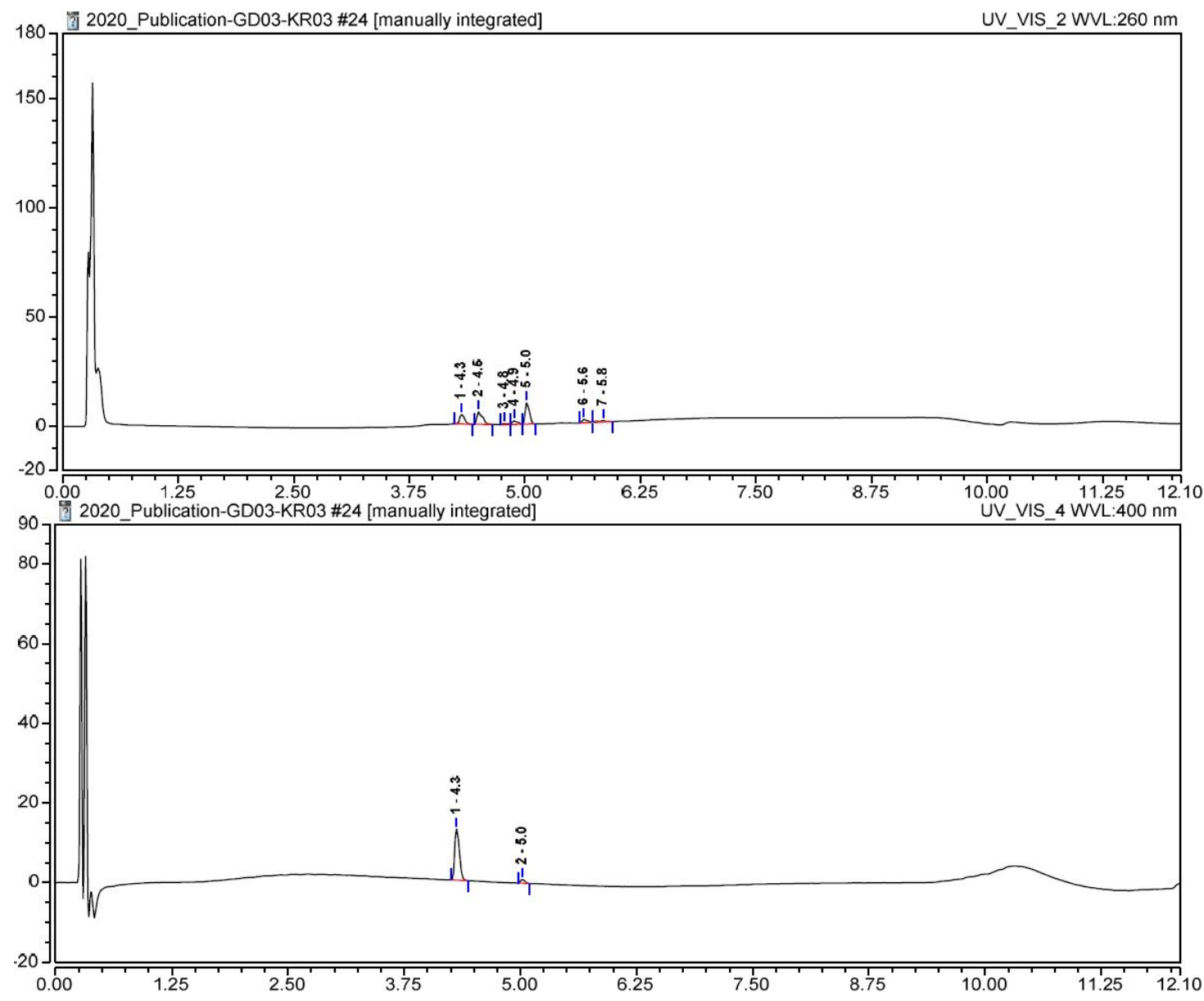



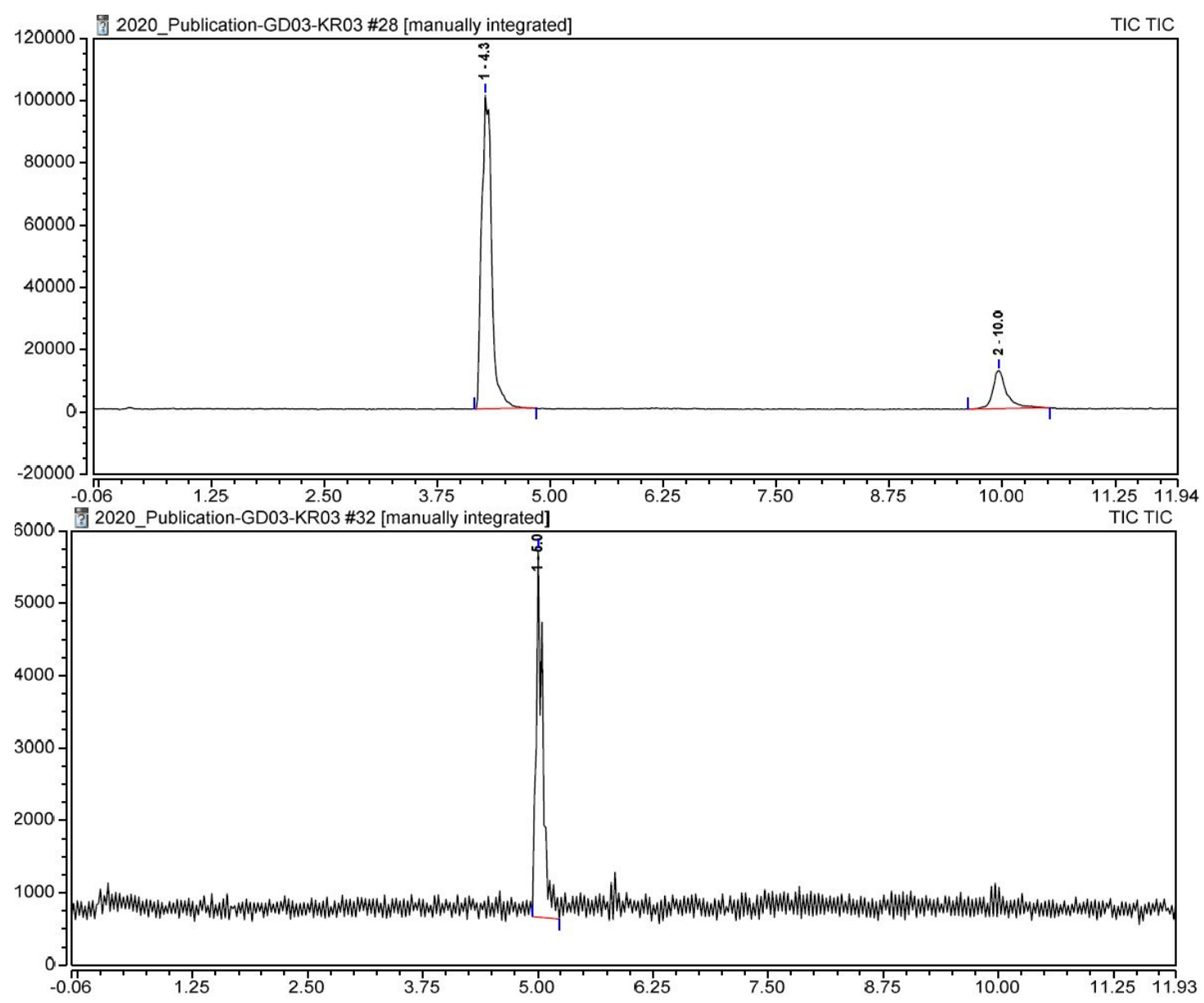

Fig. S240 - RP-HPLC elution profile (system B) of probe 18 (concentration: $1.0 \mu \mathrm{M}$ in PB) with PGA ( $1 \mathrm{U}, 30 \mathrm{~min}, 37^{\circ} \mathrm{C}$ ) and GSH (50 equiv.). UV detection at 260 $\mathrm{nm}$; UV detection at $400 \mathrm{~nm}$; ESI+ mass detection (SIM mode at $m / z, 337.0 \pm 0.5$ ); ESI+/ESI- mass detection (SIM mode at $m / z 622.1 \pm 0.5$ and $620.1 \pm 0.5$ ) (top-down)

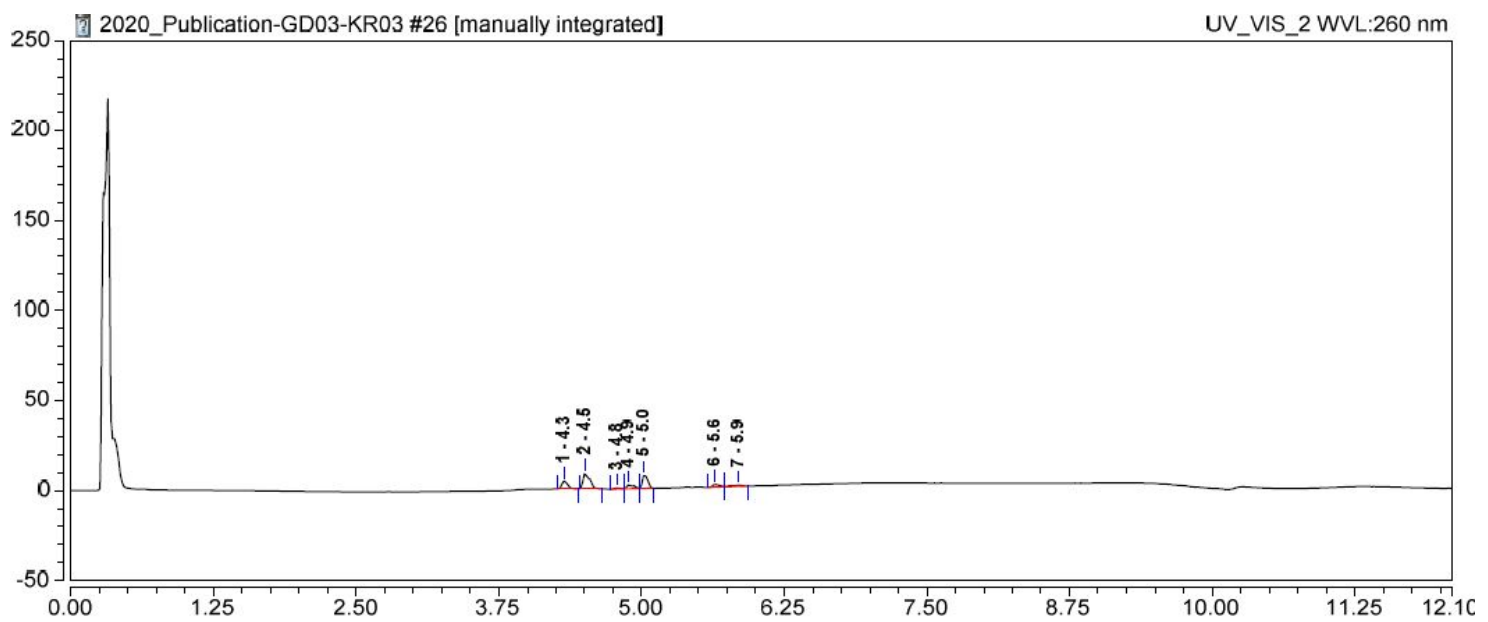




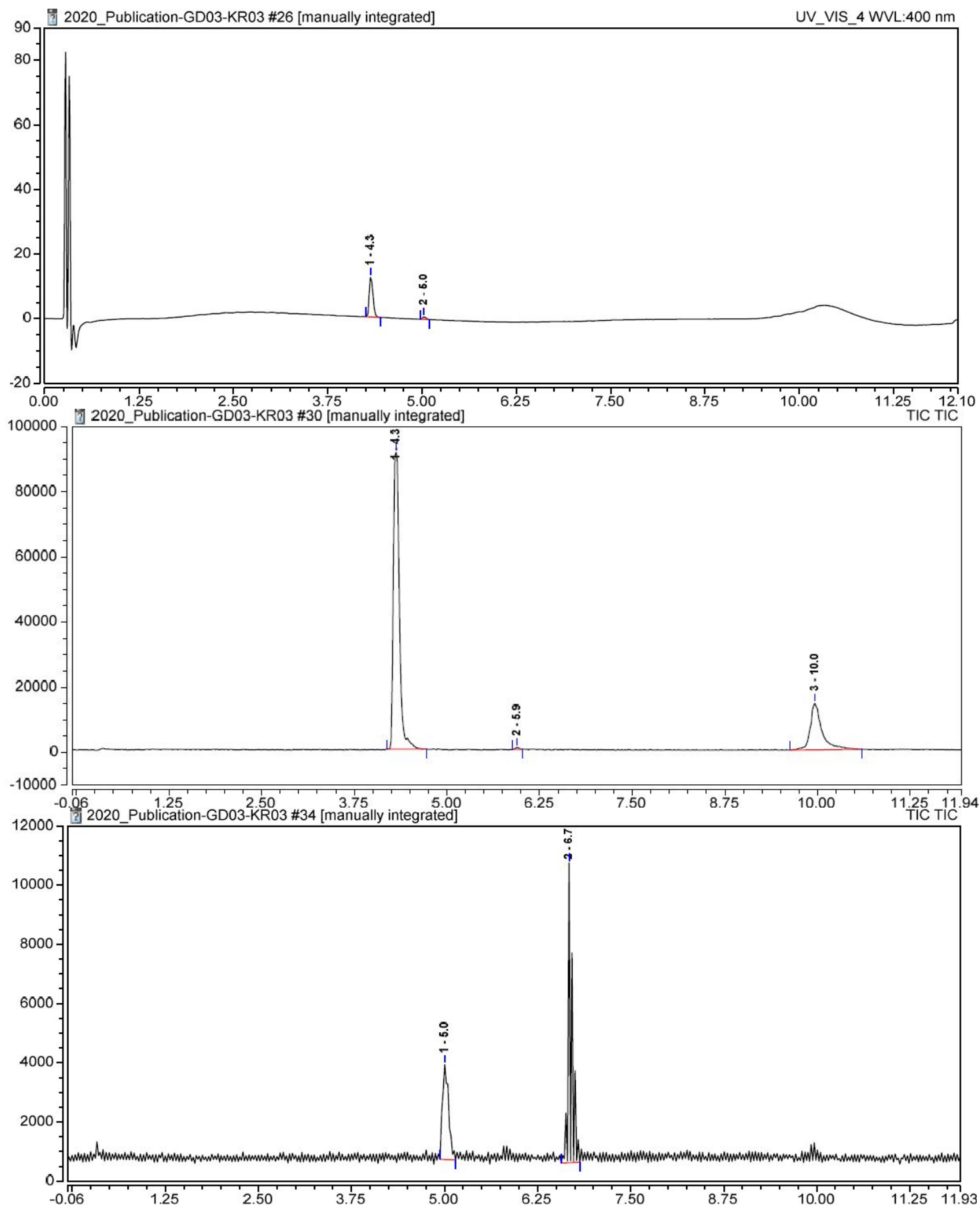

\section{References}

(1) Fulmer, G. R.; Miller, A. J. M.; Sherden, N. H.; Gottlieb, H. E.; Nudelman, A.; Stoltz, B. M.; Bercaw, J. E.; Goldberg, K. I. NMR Chemical Shifts of Trace Impurities: Common Laboratory Solvents, Organics, and Gases in Deuterated Solvents Relevant to the Organometallic Chemist. Organometallics 2010, 29, 2176-2179.

(2) Dejouy, G.; Laly, M.; Valverde, I. E.; Romieu, A. Synthesis, stability and spectral behavior of fluorogenic sulfone-pyronin and sulfone-rosamine dyes. Dyes Pigm. 2018, 159, 262-274.

(3) Brouwer, A. M. Standards for photoluminescence quantum yield measurements in solution. Pure Appl. Chem. 2011, 83, 2213-2228. 
(4) Setsukinai, K.-I.; Urano, Y.; Kikuchi, K.; Higuchi, T.; Nagano, T. Fluorescence switching by O-dearylation of 7-aryloxycoumarins. Development of novel fluorescence probes to detect reactive oxygen species with high selectivity. J. Chem. Soc., Perkin Trans. 2 2000, 2453-2457. (5) (a) Chen, J.; Li, F.; Wang, F.; Hu, Y.; Zhang, Z.; Zhao, M.; Zhang, W. Pd(OAc)2-Catalyzed Asymmetric Hydrogenation of $\alpha$-Iminoesters. Org. Lett. 2019, 21, 9060-9065. (b) Yang, N.; Zhang, H.; Yuan, G. KI-catalyzed reactions of aryl hydrazines with $\alpha$-oxocarboxylic acids in the presence of $\mathrm{CO}_{2}$ : access to 1,3,4-oxadiazol-2(3H)-ones. Org. Chem. Front. 2019, 6, 532536.

(6) Vogl, M.; Kratzer, R.; Nidetzky, B.; Brecker, L. Candida tenuis xylose reductase catalyzed reduction of acetophenones: the effect of ring-substituents on catalytic efficiency. Org. Biomol. Chem. 2011, 9, 5863-5870.

(7) (a) Ottenwaelder, X.; Ruiz-Garcia, R.; Blondin, G.; Carasco, R.; Cano, J.; Lexa, D.; Journaux, Y.; Aukauloo, A. From metal to ligand electroactivity in nickel(II) oxamato complexes. Chem. Commun. 2004, 504-505. (b) Pessah, N.; Reznik, M.; Shamis, M.; Yantiri, F.; Xin, H.; Bowdish, K.; Shomron, N.; Ast, G.; Shabat, D. Bioactivation of carbamate-based 20(S)-camptothecin prodrugs. Bioorg. Med. Chem. 2004, 12, 1859-1866.

(8) Trofimov, B. A.; Schmidt, E. Y.; Mikhaleva, A. I.; Pozo-Gonzalo, C.; Pomposo, J. A.; Salsamendi, M.; Protzuk, N. I.; Zorina, N. V.; Afonin, A. V.; Vashchenko, A. V.; Levanova, E. P.; Levkovskaya, G. G. Synthesis of 2-(Selenophen-2-yl)pyrroles and Their Electropolymerization to Electrochromic Nanofilms. Chem. - Eur. J. 2009, 15, 6435-6445. 